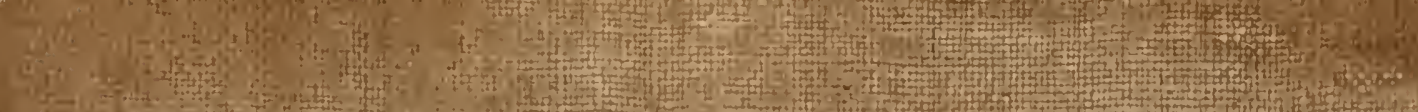

(1)

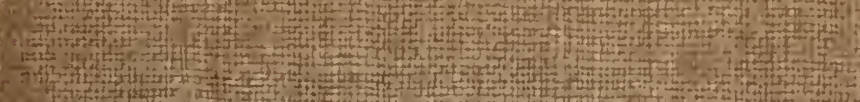

(2)

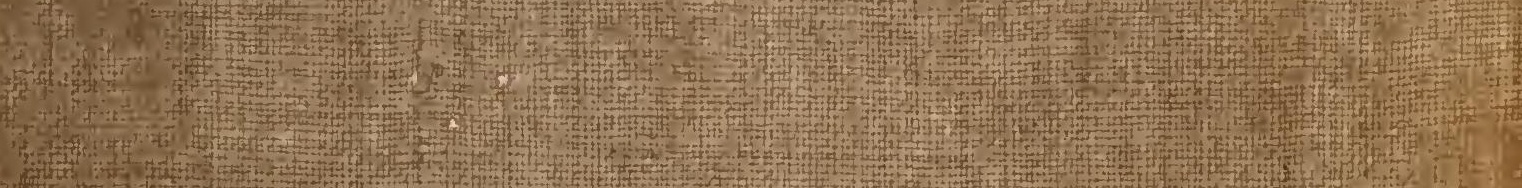

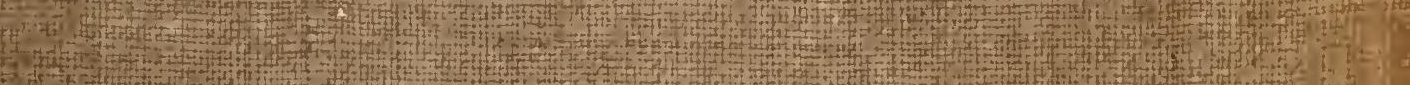
The

(4)

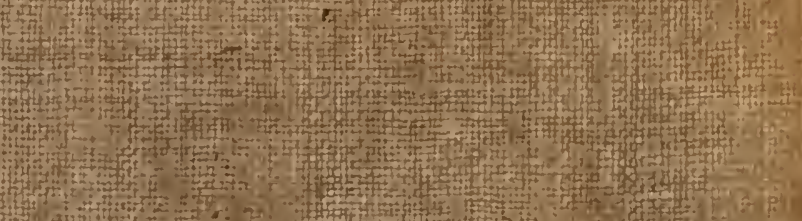

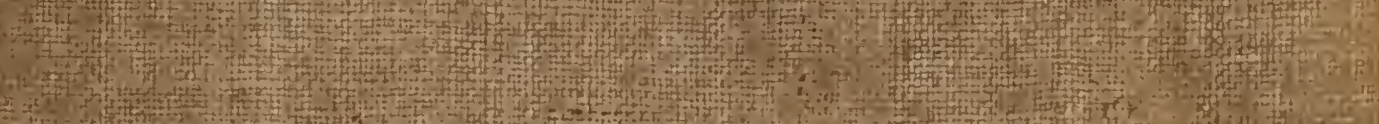
(5) (1) 159. (1) (A) A (1)

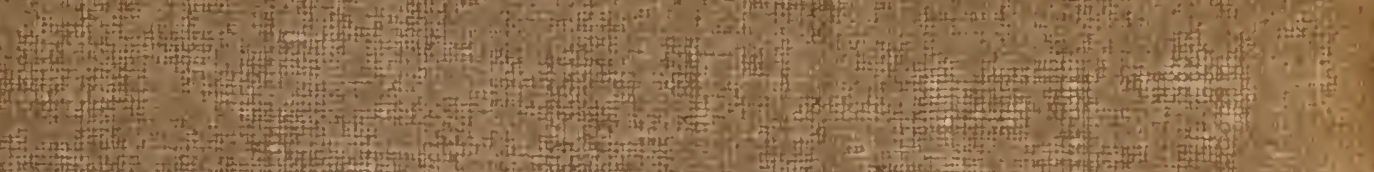
frat

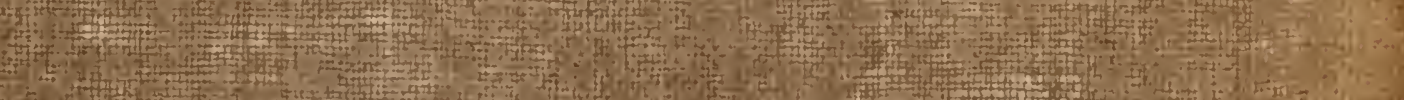
(1) int (1)

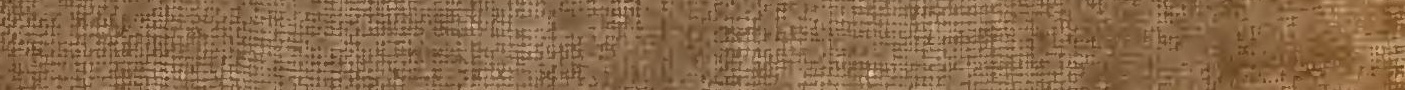
4 . (1) 



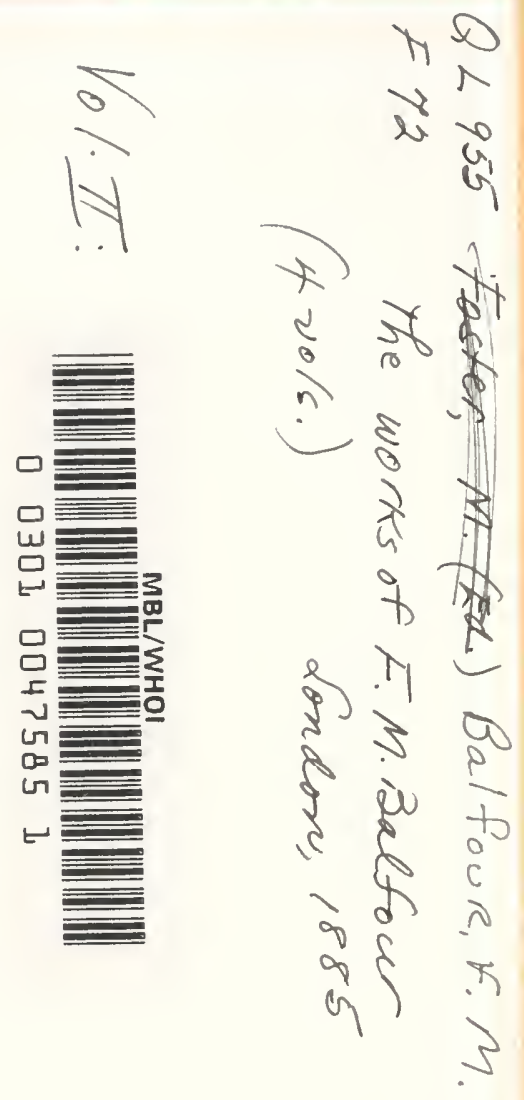





\title{
THE WORKS
}

OF

\section{FRANCIS MAITLAND BALFOUR.}

\author{
VOL. II.
}

Atrmorial extítion. 


\section{Cambrioge:}

PRINTED BY C. J. CLAY, M.A. AND SON, AT THE UNIVERSITY PRESS. 


\title{
Atrmorial Exítion.
}

\section{THE WORKS}

OF

\section{FRANCIS MAITLAND BALFOUR, \\ M.A., LL.D., F.R.S., \\ FELLOW OF TRINITY COLLEGE, \\ AND PROFESSOR OF ANIMAL MORPHOLOGY IN THE UNIVERSITY OF CAMBRIDGE.}

\begin{abstract}
EDITED BY
M. FOSTER, F.R.S.,

PROFESSOR OF PHYSIOLOGY IN THE UNIVERSITY OF CAMBRIDGE;

AND

ADAM SEDGWICK, M.A.,

FELLOW AND LECTURER OF TRINITY COLLEGE, CAMBRIDGE.
\end{abstract}

VOL. II.

A TREATISE ON COMPARATIVE EMBRYOLOGY.

Vol. I. Invertebrata.

\section{Ilonton:}

MACMILLAN AND CO.

I 885 
[The Right of Translation is reserved.] 


\section{PREFACE.}

My aim in writing this work has been to give such an account of the development of animal forms as may prove useful both to students and to those engaged in embryological research. The present volume, save in the introductory chapters, is limited to a description of the development of the Invertebrata: the second and concluding volume will deal with the Vertebrata, and with the special histories of the several organs.

Since the work is, I believe, with the exception of a small but useful volume by Packard, the first attempt to deal in a complete manner with the whole science of Embryology in its recent aspects, and since a large portion of the matter contained in it is not to be found in the ordinary text books, it appeared desirable to give unusually ample references to original sources. I have accordingly placed at the end of each chapter, or in some cases of each section of a chapter, a list of the more important papers referring to the subject dealt with. The papers in each list are numbered continuously, and are referred to in the text by their numbers. These lists are reprinted as an appendix at the end of each volume. It will of course be understood that they do not profess to form a complete bibliography of the subject. 
In order to facilitate the use of the work by students I have employed two types. The more general parts of the work are printed in large type; while a smaller type is used for much of the theoretical matter, for the details of various special modes of development, for the histories of the less important forms, and for controversial matter generally. The student, especially when commencing his studies in Embryology, may advantageously confine his attention to the matter in the larger type; it is of course assumed that he already possesses a competent knowledge of Comparative Anatomy.

Since the theory of evolution became accepted as an established doctrine, the important bearings of Embryology on all morphological views have been universally recognised; but the very vigour with which this department of science has been pursued during the last few years has led to the appearance of a large number of incomplete and contradictory observations and theories: and to arrange these into anything like an orderly and systematic exposition has been no easy task. Many Embryologists will indeed probably hold that any attempt to do so at the present time is premature, and therefore doomed to failure. I must leave it to others to decide how far my effort has been justified. That what I have written contains errors and shortcomings is I fear only too certain, but I trust that those who are most capable of detecting them will also be most charitable in excusing them.

The work is fully illustrated, and most of the figures have been especially engraved from original memoirs or from my own papers or drawings by Mr Collings, who has spared no pains to render the woodcuts as clear and 
intelligible as possible. I trust my readers will not be disappointed with the results. The sources from which the woodcuts are taken have been in all cases acknowledged, and in the cases where no source is given the illustrations are my own.

I take this opportunity of acknowledging my great obligations to Professors Agassiz, Huxley, Gegenbaur, Lankester, Turner, Kölliker, and Claus, to Sir John Lubbock, Mr Moseley, and Mr P. H. Carpenter, for the use of electrotypes of woodcuts from their works.

I am also under great obligations to numerous friends who have helped me in various ways in the course of my labour. Professor Kleinenberg, of Messina, has read through the whole of the proofs, and has made numerous valuable criticisms. My friend and former pupil, Mr Adam Sedgwick, has been of the greatest assistance to me in correcting the proofs. I have had the benefit of many useful suggestions by Professor Lankester especially in the chapter on the Mollusca, and Mr P. H. Carpenter has kindly revised the chapter on the Echinodermata.

I am also much indebted to Dr Michael Foster, Mr Moseley, and Mr Dew-Smith for aid and advice. 



\title{
CONTENTS OF VOLUME I.
}

\author{
Introduction. Pp. I-I 6.
}

\section{Chapter I. The Ovum and Spermatozoon.}

General history of the Ovum, pp. 17-25. Special history of the Ovum in different types, pp. $26-65$. The Spermatozoon, pp. $65-67$.

Chapter II. 'The Maturation and Impregnation of the Ovum.

Maturation of the Ovum, and formation of the polar bodies, pp. 68-79, Impregnation of the Ovum, pp. 79-86. Summary, pp. 86.

Chapter III. The Segmentation of the Ovum.

Internal phenomena of Segmentation, pp. 88-92. External features of Segmentation, pp. 92-I 22.

Introduction to Systematic Embryology. Pp. i25-izo.

Chapter IV. Dicyemide and Orthonectide. Pp. i3 I-i37.

Chapter V. Porifera. Pp. i 38 - I5I.

Chapter Vi. Cellenterata.

Hydrozoa, pp. 152-167. Actinozoa, pp. 167-173. Ctenophora, pp. 173 - I 78 . Summary, etc., pp. $178-182$. Alternations of generations, pp. $182-$ 187 .

Chapter Vil. Platyelminthes.

Turbellaria, pp. I89-196. Nemertea, pp. 196-20.4. Trematoda, pp. 205 -210. Cestoda, pp. 210-218.

Chapter VIII. Rotifera. Pp. 22 I-224. 


\section{Chapter IX. Mollusca.}

Formation of the layers and larval characters, pp. 225-273. Gasteropola and Pteropola, pp. 225-2+2. Cephalopola, pp. 2+2-25+. Polyplacophora, pp. 25t-257. Scaphopoda, pp. 257, 258. Lamillibranchiatu, pp. 258-269 General review of Molluscan Larva, pp. 27o-273. Development of organs, pp. $273-288$.

\section{Chapter X. Polyzon.}

Entoprocta, pp. 292-297. Ectoprocta, pp. 297-305. Summary and general considerations, pp. $305^{--}-308$.

\section{Chapter XI. Brachiopoda.}

Development of the layers, pp. $3^{I} I_{-} 3^{I} 3$. The history of the larva, pp. $3^{1} 3-$ 317. Development of organs, p. $3 \mathbf{I} 7$. General observations on the affinities of the Brachiopoda, pp. $317,318$.

\section{Chapter XII. Cheitopoda.}

Formation of the germinal layers, $\mathrm{pl} \cdot 319-325$. The larval form, $\mathrm{pp} \cdot 3^{25-}$ 338. Formation of organs, pp. $33^{8}-3 t^{2}$. Alternations of generations, pp. $34^{2}, 343$.

\section{Chapter XiII. Discophora.}

Formation of layers, pp. $3+7-350$. History of larva, P1. $35^{1-354}$.

\section{Ch.ppter XIV. Gephyrea.}

Gephyrea nuda, pp. 355-361. Gephyrea tubicola, pp. 361--36+. General considerations, $3^{6}+$.

\section{Chapter XV.}

Chætognatha, pp. 366-369. Myzostomea, pp. 369, 37o. Gastrotricha, p. 370 .

\section{Chapter XVI.}

Nematelminthes, 1p. 370-379. Acanthocephala, pp. 379-381.

\section{Chapter XVII. Tracheata.}

Prototracheata, pp. $3^{82}-3^{8} 7$. Myriapoda, pp. 387-395. Insecta, pp. 395429. Embryonic membranes and the formation of the layers, pp. 400-406. Formation of the organs, pp. $+06-+17$. Stecial types of larva, pp. $+17-+19$. Metamorphosis and heterogamy, pp. $+20-429$. Arachnida, pp. $+31-455$. Formation of the layers and general development, pp. $+3 \mathrm{I}-++6$. Formation of the organs, pp. $+46-455$. Formation of the layers and embryonic envelopes in the Tracheata, pp. $+56-458$. 


\section{Chapter XVIII. Crustacea.}

History of larval forms, pp. 459-511. Branchiopoda, pp. $459-465$. Malacostraca, pp. $4^{65-487}$. Copepoda, pp. $487-492$. Cirripedia, pp. 492-500. Ostracoda, pp. 500-502. Phylogenzy of the Crustacea, pp. 502-5I I. The formation of the germinal layers, PP. 5II-52I. Comparative development of organs, Pp. $52 \mathrm{I}-529$.

\section{Chapter XIX.}

Poecilopoda, pp. 534-538. Pycnogonida, pp. 538, 539. Pentastomida, pp. 539-54I. Tardigrada, p. 54I. Summary of Arthropodan Development, pp. $5+\mathrm{I}-5+3$.

\section{Chapter XX. Echinodermata.}

Development of the germinal layers, pp. 544-553. Development of the larval appendages and metamorphosis, pp. 553-573. Summary and general considerations, pp. $573-576$.

Chapter XXI. Enteropneusta. Pp. $579-583$.

INDEX. Pp. $5{ }^{8} 4-590$.

Appendix. 



\section{EM BRYOLOGY.}

\section{INTRODUCTION.}

EMBRYology forms a large and important department of Biology. Strictly interpreted according to the meaning of the word, it ought to deal with the growth and structure of organisms during their development within the egg membranes, before they are capable of leading an independent existence. Modern investigations have however shewn that such a limitation of the science would have a purely artificial character, and the term Embryology is now employed to cover the anatomy and physiology of the organism during the whole period included between its first coming into being and its attainment of the adult state.

The subject-matter of the science of Embryology admits of a twofold classification. It may be placed under a series of heads, each dealing either with a special group of organisms, or with a special department of the whole science. If classified in the first of these ways the science will naturally be divided into an Embryology of Plants, and an Embryology of Animals; each of which admits of further subdivision. In the second way the subject falls under two primary heads; viz. Physiological Embryology and Anatomical Embryology.

The present treatise deals only with the Embryology of Animals, and is further confined to those animals known as Metazoa. The science is moreover treated from the morphological or anatomical, rather than from the physiological side.

B. II. 
The marvellous phenomenon of the evolution of a highly complicated living being from a simple undifferentiated germ in which it needs the aid of the most modern microscopical appliances to detect any visible signs of life, has not unnaturally attracted the attention of biologists from the very earliest periods. Before the establishment of the cell theory the origin of the organism from the germ was not known to be an occurrence of the same nature as the growth of the fully formed individual, and Embryological investigations were mixed up with irrelevant speculations on the origin of life ${ }^{1}$.

The difficulties of understanding the formation of the individual from the structureless germ led anatomists at one time to accept the view "according to which the embryo preexisted, "even though invisible, in the ovum, and the changes which "took place during incubation consisted not in a formation of " parts, but in a growth, i.e. in an expansion with concomitant "changes of the already existing germ."

Great as is the interest attaching to the simple and isolated life histories of individual organisms, this interest has been increased tenfold by the generalizations of Mr Charles Darwin.

It has long been recognized that the embryos and larvæ of the higher forms of each group pass, in the course of their development, through a series of stages in which they more or less completely resemble the lower forms of the group ${ }^{2}$. This remarkable phenomenon receives its explanation on $\mathrm{Mr}$ Darwin's theory of descent. There are, according to this theory, two guiding, and in a certain sense antagonistic principles which have rendered possible the present order of the organic world. These are known as the laws of heredity and variation. The first of these laws asserts that the characters of an organism

1 To this general statement Wolff forms a remarkable exception, for though without any clear knowledge of what we call cells he had very distinct notions on the relations of growth and development.

${ }^{2}$ Von Baer who is often stated to have established the above generalization really maintained a somewhat different view. He held (Ueber Entwickelungsgeschichted. Thicre, p. 224) that the embryos of higher forms never resembled the adult stages of lower forms but merely the embryos of such forms. Von Baer was mistaken in thus absolutely limiting the generalization, but his statement is much more nearly true than a definite statement of the exact similarity of the embryos of higher forms to the adults of lower ones. 
at all stages of its existence are reproduced in its descendants at corresponding stages. The second of these laws asserts that offspring never exactly resemble their parents. By the common action of these two principles continuous variation from a parent type becomes a possibility, since every acquired variation has a tendency to be inherited.

The remarkable law of development enunciated above, which has been extended, especially by the researches of Huxley ${ }^{1}$ and Kowalevsky, beyond the limits of the more or less artificial groups created by naturalists, to the whole animal kingdom, is a special case of the law of heredity. This law, interpreted in accordance with the theory of descent, asserts that each organism in the course of its individual ontogeny repeats the history of its ancestral development. It may be stated in another way so as to bring out its intimate connection with the laws of inheritance and variation. Each organism reproduces the variations inherited from all its ancestors at successive stages in its individual ontogeny which correspond with those at which the variations appeared in its ancestors. This mode of stating the law shews that it is a necessary consequence of the law of inheritance. The above considerations clearly bring out the fact that Comparative Embryology has important bearings on Phylogeny, or the history of the race or group, which constitutes one of the most important branches of Zoology.

Were it indeed the case that each organism contained in its development a full record of its origin, the problems of Phylogeny would be in a fair way towards solution. As it is, however, the law above enunciated is, like all physical laws, the statement of what would occur without interfering conditions. Such a state of things is not found in nature, but development as it actually occurs is the resultant of a series of influences of which that of heredity is only one. As a consequence of this, the embryological record, as it is usually presented to us, is both imperfect and misleading. It may be compared to an ancient manuscript with many of the sheets lost, others displaced, and with spurious passages interpolated by a later hand. The embryological

1 Huxley was the first to shew that the body of the Colenterata was formed of two layers, and to identify these with the two primary germinal layers of the Vertebrata. 
record is almost always abbreviated in accordance with the tendency of nature (to be explained on the principle of survival of the fittest) to attain her ends by the easiest means. The time and sequence of the development of parts is often modified, and finally, secondary structural features make their appearance to fit the embryo or larva for special conditions of existence. When the life history of a form is fully known, the most difficult part of his task is still before the scientific embryologist. Like the scholar with his manuscript, the embryologist has by a process of careful and critical examination to determine where the gaps are present, to detect the later insertions, and to place in order what has been misplaced.

The aims of Comparative Embryology as restricted in the present work are two-fold: (I) to form a basis for Phylogeny, and (2) to form a basis for Organogeny or the origin and evolution of organs. The justification for employing the results of Comparative Embryology in the solution of the problems in these two departments of science is to be found in the law above enunciated, but the results have to be employed with the qualifications already hinted at; and in both cases a knowledge of Comparative Anatomy is a necessary prelude to their application.

In accordance with the above objects Comparative Embryology may be divided into two departments.

The scientific method employed in both of these departments is that of comparison, and is in fact fundamentally the same as the method of Comparative Anatomy. By this method it becomes possible with greater or less certainty to distinguish the secondary from the primary or ancestral embryonic characters, to determine the relative value to be attached to the results of isolated observations, and generally to construct a science out of the rough mass of collected facts. It moreover enables each observer to know to what points it is important to direct his attention, and so prevents that simple accumulation of disconnected facts which is too apt to clog and hinder the advance of the science it is intended to promote.

In the department of Phylogeny the following are the more important points aimed at.

(I) To test how far Comparative Embryology brings to light ancestral forms common to the whole of the Metazoa. 
Examples of such forms have been identified by various embryologists in the ovum itself, supposed to represent the unicellular ancestral form of the Metazoa : in the ovum at the close of segmentation regarded as the polycellular Protozoon parent form: in the two-layered gastrula, etc., regarded by Haeckel as the ancestral form of all the Metazoa ${ }^{1}$.

(2) How far some special embryonic larval form is constantly reproduced in the ontogeny of the members of one or more groups of the animal kingdom; and how far such larval forms may be interpreted as the ancestral type for those groups.

As examples of such forms may be cited the six-limbed Nauplius supposed by Fritz Müller to be the ancestral form of the Crustacea ; the trochosphere larva of Lankester, which he considers to be common to the Mollusca, Vermes, and Echinodermata: the planula of the Cœlenterata, etc.

(3) How far such forms agree with living or fossil forms in the adult state; such an agreement being held to imply that the living or fossil form in question is closely related to the parent stock of the group in which the larval form occurs. It is not easy to cite examples of a very close agreement of this kind between the larval forms of one group and the existing or fossil forms of another. The larvæ of some of the Chætopoda with long? provisional setæ resemble fossil Chætopods. The Rotifers have many points of resemblance to the trochosphere, especially to that form of trochosphere characteristic of the Mollusca. The Turbellarians have some features in common with the Cœlenterate planula. Some of the Gephyrea in the presence of a præoral lobe resemble certain trochosphere types. The larva of the Tunicata has the characters of a simple type of the Chordata.

Within the limits of a single group agreements of this kind are fairly numerous. In the Craniata the tadpole of the Anura has its living representative in the Pisces and perhaps especially in the Myxinoids. The larval forms of the Insecta approach Peripatus. The stalked larva of Comatula is reproduced by the living Pentacrinus and Rhizocrinus etc.

1 The value of these identifications as well as of those below is discussed in its appropriate place in the body of the work. Their citation here is not to be regarded as necessarily implying my acceptance of them. 
Numerous examples of the same phenomenon are found amongst the Crustacea.

(4) How far organs appear in the embryo or larva which either atrophy or become functionless in the adult state, and which persist permanently in members of some other group or in lower members of the same group. Cases of this kind are of the most constant occurrence, and it is only necessary to cite such examples as the gill-slits and Wolffian body in the embryos of higher Craniata to illustrate the kind of instance alluded to. The same conclusions may be drawn from them as from the cases under the previous heading.

(5) How far organs pass in the course of their development through a condition permanent in some lower form. Phylogenetic conclusions may be drawn from instances of this character, though they have a more important bearing on Oiganology than on Phylogeny.

The considerations which were used to shew that the ancestral history is reproduced in the ontogeny of the individual apply with equal force to the evolution of organs. The special questions in Organology, on which Comparative Embryology throws light, may be classified under the following heads.

(I) The origin and homologies of what are known as the germinal layers; or the layers into which the embryo becomes divided immediately after the segmentation.

(2) The origin of primary tissues, epithelial, nervous, muscular, connective, etc., and their relation to the germinal layers.

(3) The origin of organs. The origin of the primitive organs is intimately connected with that of the germinal layers. The first differentiation of the segmented ovum results in the cells of the embryo becoming arranged as two layers, an outer one known as the epiblast and an inner one as the hypoblast. The outer of these forms a primitive sensory organ, and the inner a primitive digestive organ.

(4) The gradual evolution of the more complicated organs and systems of organs.

This part of the subject, even more than that dealing with questions of Phylogeny, is intimately bound up with Comparative Anatomy; without which indeed it becomes quite meaningless. 


\section{REPRODUCTION.}

A study of reproduction logically precedes that of Embryology. Reproduction essentially consists in the separation of a portion of an organism which has the capacity of developing into a form similar to that which gave it origin. The simplest modes of reproduction are those which occur amongst the Protozoa.

In this group, reproduction may take place in-a great variety of ways. These may be classified in three groups: (I) fission, (2) budding or gemmation, (3) spore formation.

Reproduction in all these ways may take place either subsequently to and apparently in consequence of a very important process known as conjugation, which consists in the temporary or permanent fusion of two or more individuals, or spontaneously, i.e. independently of any such previous conjugation.

Reproduction by fission consists simply in the division of the organism into two similar parts, the nucleus when present becoming divided simultaneously with the cell body. This mode of reproduction is the simplest conceivable, and is not followed by a development, since the two organisms produced are exactly similar, except in size, to the parent form. Besides single fission, a process of multiple fission may take place, as amongst the Flagellata, where Drysdale and Dallinger have shewn that an individual enclosed within a structureless cyst may divide first into two, then into four, and so on.

The process of budding differs mainly from that of simple fission in the fact that the two organisms produced are dissimilar in size, and also that the separation of the smaller organism from the larger is preceded by a process of growth in the latter, so that in the separation of the bud no essential part of the parent form is removed. This mode of reproduction is found amongst the Infusoria, Acineta, \&c. An interesting variation in it is the internal gemmation of many of the Acineta, where a portion of the internal protoplasm with part of the nucleus is separated off to form a fresh individual. This mode of gemmation is connected by a series of gradations with the normal 
external gemmation. The organisms produced by gemmation are not always similar at birth to the parent; e.g. Acineta.

Both fission and gemmation when incomplete lead to the formation of colonies.

The third mode of reproduction, by spore formation, does not essentially differ from that by multiple fission. It consists in the breaking up of the organisms into a number (usually very considerable) of portions; each of which eventually developes into an organism like the parent form. All gradations between a simultaneous division of the organism into such spores and simple multiple fission are to be found, but this process of reproduction may be sometimes distinguished from that by such fission by the fact that the two processes may coexist in a single form, e.g. the biflagellate monad of Drysdale and Dallinger. In the majority of cases the spores produced differ at first from the parent organism not only in size but in other points, such as the possession of a flagellum, etc. They may even be without a nucleus when the parent organism is nucleated, as in the Gregarinidæ.

The encystment, which in many cases precedes reproduction by any of the above processes, and more especially by spores, is not an essential condition of their occurrence; and is probably in the first instance a protective arrangement which has become secondarily adapted to and connected with reproduction.

As has been already stated, all the above modes of reproduction take place in some of the Protozoa without any anterior process which can be regarded as of a sexual nature; but very often they are preceded by the temporary or permanent fusion of two or more individuals, such fusion being known as conjugation.

In most cases reproduction by spores is the consequence of conjugation, but in the Infusoria etc. where the fusion at conjugation is temporary (except Vorticella), there is probably merely a renewed activity - a rejuvenescence-which most likely results in active fission or budding. In the Gregarinidæ reproduction by spores usually follows conjugation, but may also take place without it. In some Flagellata reproduction by spores follows the conjugation of two individuals in a different stage of de- 
velopment. Thus in the springing Monad, described by Drysdale and Dallinger, a form produced by the fission of a monad in an amøboid condition fuses with an ordinary monad to produce an individual, which then breaks up into spores. Another instance of the fusion of dissimilar individuals is afforded by Vorticella, where a free-swimming individual conjugates and is permanently united with a fixed one (Engelmann, Buitschli). Conjugation often consists in the fusion of more than two individuals. In conjugation where the fusion is permanent, the nuclei of the conjugating forms usually unite before the product breaks up into spores; and where temporary fusion occurs in the Infusoria a division of the paranuclei and often of the nuclei takes place, followed by the ejection of parts of them, and a reproduction of new paranuclei and nuclei from the remainder of the original structures.

In order to understand the meaning of conjugation in connection with reproduction, it is important to understand how the two became in the first instance related. For the solution of this question the fact that many Protozoa have the capacity of temporarily or permanently fusing together without an immediate act of reproduction is of great importance. A good example of such fusion is supplied by Actinophrys. We must suppose in fact that the simple coalescence of two or more individuals gives a sufficient amount of extra vigour to their product, to compensate the race for the loss in number of individuals so caused. This extra vigour probably first exhibited itself especially by increased activity in reproduction, till finally the two processes, viz. that of conjugation and that of reproduction, came to be inseparably connected together.

The reproduction of the forms above the Protozoa, which are known as the Metazoa, takes place by two methods, viz. a sexual and an asexual one. The sexual process, which occurs in every known Metazoon ${ }^{1}$, consists essentially, as is shewn in the second chapter of this work, in the fusion of two cells budded off from the parent organism, viz. the female cell or ovum, and the male cell or spermatozoon, and of the subsequent division of the compound cell so produced into a number of parts which build

${ }_{1}$ Dicyema, if it is a true Metazoon, would seem to form an exception to this rule. 
themselves up into an organism resembling one of the parents. The sexual process has obviously at first sight a very close resemblance to the process of conjugation. Since it is a question of fundamental importance to determine how sexual reproduction originated, it becomes necessary to examine how far this apparent resemblance is a real one, and how far sexual reproduction can be derived from reproduction following upon conjugation.

In spite of the general similarity between the two processes there is an obvious difficulty in comparing them, in that the result of conjugation is usually the breaking up of the individual formed by the fusion of two other individuals into a number of new organisms, while the result of the fusion which takes place in sexual reproduction is the formation of a single new organism. This difference between the two processes, great as it is, is perhaps apparent rather than real. It must be remembered that a single individual Metazoon is equivalent to a number of Protozoa coalesced to form a single organism in a higher state of aggregation. It results from this that the segmentation of the ovum which follows the sexual act may be compared to the breaking up of the product of conjugation into spores, the difference between the two processes consisting in the fact that in the one case the spores separate each to form an independent organism, while in the other they remain united and give rise to a single compound organism.

If the above considerations are well founded it seems permissible to accept the general view according to which sexual reproduction is derived from conjugation. It is necessary to suppose that, in a colony of Protozoa in the course of becoming a Metazoon, the capacity of reproduction by spores became localized in certain definite cells, and although the formation of spores from these cells may have been possible without previous conjugation, yet that conjugation gradually became established as the rule. The differentiation of primitively similar conjugating cells into male and female cells was probably a very early occurrence, since indications of an analogous differentiation, as has already been mentioned, are found in certain existing Protozoa (Monads, Vorticella, etc.). I have attempted to shew in the second chapter that the breaking up of the cell into spores 
without previous conjugation is perhaps provided against in the extrusion of the so-called 'directive body'.

With the differentiation of special germinal cells, to take the place of the whole individual in the act of conjugation, the possibility of each act of conjugation resulting in the production of only a single organism became introduced. Germinal cells can be indefinitely produced, and the reproductive capacity of a single individual is therefore unlimited; while if two whole individuals conjugated and only produced one from the process, the result would be a diminution instead of an increase in the race $^{1}$.

It must be admitted that, in the present state of our knowledge, the passage from reproduction by spores following conjugation, to true sexual reproduction, can only be traced in a very speculative manner, and that a further advance in our knowledge may prove that the steps which I have attempted to sketch out are far from representing the true origin of sexual differentiation. The peculiar conjugation and fusion of two individuals to form Diplozoon paradoxum may be alluded to in this connection. This fusion merely results in the attainment of sexual maturity by the two conjugating individuals. It does not appear to me probable that this conjugation is in any way connected with the conjugation of the Protozoa, but the reverse must be borne in mind as a possibility.

It is not easy to decide whether the hermaphrodite or the

1 In the vegetable kingdom there are numerous types of Thallophytes, which throw a considerable amount of light on the relation between sexual reproduction and conjugation. Subjoined are a few of the more striking cases. In Pandorina at the time of sexual reproduction the cells which constitute a colony divide each into sixteen, and the products of their division are set free. Pairs of them then conjugate and permanently fuse. After a resting stage the protoplasm is set free from its envelope after division into two or four parts. Each of these then divides into sixteen coherent cells and constitutes a new Pandorina colony. In (Edogonium the fertilization is effected by a spermatozoon fusing with an oosphere (ovum). The fertilized oosphere (oospore) then undergoes segmentation like the ovum of an animal; but the segments, instead of uniting to form a single organism, separate from each other, and each of them gives rise to a fresh individual (swarm-spore) which grows into a perfect (Edogonium. In Coleochrete the impregnation and segmentation take place nearly as in Edogonium, but the segments remain united together, acquire definite cell walls, and form a single embryo. There is in fact in Coleochrte a true sexual reproduction of the ordinary type. (Vide S. H. Vines "On alternation of generation in the Thallophytes." Fournal of Botany, Nov., i 879.) 
diœcious state is the primitive one, or in other words whether the two conjugating cells, from which I have supposed the sexual products to originate, were derived in the first instance from one or from two colonies of Protozoa. On purely à priori grounds it seems probable that they were originally formed in one colony, and that their derivation from two colonies or individuals was inaugurated when the spermatozoon became motile. There can be no doubt that the diœecious state is a very early one, and that the majority of existing cases of hermaphroditism are secondary.

The above considerations with reference to the male and female cells appear to indicate that they were primitively homodynamous; a conclusion which is on the whole borne out by the history of their development.

Although the modes of reproduction amongst the Metazoa have been divided into the classes sexual and asexual, there is nevertheless one mode of asexual reproduction which ought to be classified with the sexual rather than with the asexual modes. I mean parthenogenesis, which consists essentially in the development of the ovum into a fresh individual without previous coalescence with the male element. This mode of reproduction, which has a very limited range in the animal kingdom, being confined to the Arthropoda and Rotifera, is undoubtedly secondarily derived from sexual reproduction. The conditions of its occurrence are discussed in the second chapter.

It is remarkable that in certain cases the absence of fertilization causes the production of males (Bees, a Saw-fly, Nematus ventricosus, etc.); more usually it results in the production of females only, and there are very often in the Arthropoda a series of successive generations of females all producing ova which develope parthenogenetically into females; eventually however, usually in direct or indirect connection with a change of food or temperature, or other conditions, ova are formed which give rise without fertilization both to males and females.

The true asexual modes of reproduction amongst the Metazoa consist of fission and gemmation. Gemmation is by far the most widely disseminated of the two. Various as are the methods in which it takes place, it seems nevertheless that cells derived from all the germinal layers, and very frequently from all the im- 
portant organs of the adult, assist in forming the bud. Into the details of the process, which require in many points a fuller elucidation, it is not my purpose to enter.

Gemmation is a far commoner occurrence amongst the simpler than amongst the more highly organised forms. It appears to have been superadded to the sexual mode of reproduction quite independently in a number of different instances.

While there is no difficulty in understanding how gemmation may have started in such simple types as the Colenterata, the manner in which it first originated in certain highly organised forms, as for instance the Ascidians, is somewhat obscure, but it seems probable that it began with the division of the developing germ into two or more embryos, at a very early stage of growth.

Such a division of the germ is, as has been shewn by Kleinenberg, normal in Lumbricus trapezoides ${ }^{1}$ and Haeckel has shewn that an artificial division of the germ in the Siphonophora leads to the development of two individuals. It has been pointed out by various naturalists that the production of double monsters is often a phenomenon of the same nature. While it is next to impossible to understand how production of a bud could commence for the first time in the adult of a highly organised form, it is not difficult to form a picture of the steps by which the fission of the germ might eventually lead to the formation of buds in the adult state.

The coexistence of sexual reproduction with normal asexual multiplication, or with parthenogenesis, has led to a remarkable phenomenon in the animal kingdom known as alternations of generations ${ }^{2}$.

For the details of the various types of alternations of generations, and their origin, the reader is referred to the body of the work; but a few general remarks on the nature and origin of the process, and on its nomenclature, may conveniently be introduced in this place. The simplest cases are those in which

1 The case of Pyrosoma, which might be cited in this connection, is probably secondary.

${ }^{2}$ For an excellent account of this subject, vide Allen Thompson's article Ovum in Todd's Cyclopadia. The metamorphosis of the Echinoderms included under this head in Thompson's article is now known not to be a proper case of alternations of generations. 
an individual which produces by sexual means gives origin to asexual individuals differently organised to itself, which produce by budding the original sexual form, and so complete a cycle. Instances of this kind are supplied by the Hydrozoa, Annelida and Tunicata. In the case of the Tunicata (Doliolum) two different asexual generations may be interpolated between the sexual generations. In all these cases the origin of the phenomenon is easily understood. It appears, as is most clearly shewn in the case of the Annelida, that the ancestors of the species which now exhibit alternations of generations originally reproduced themselves at the same time both sexually and by budding, though probably the two modes of reproduction did not take place at the same season. Gradually a differentiation became established, by which sexual reproduction was confined to certain individuals, which in most instances did not also reproduce asexually. After the two modes of reproduction became confired to separate individuals, the dissimilarity in habits of life necessitated by their diverse functions caused a difference in their organization; and thus a complete alternation of generations became established. The above is no merely speculative history, since all gradations between complete alternations of generations and simple budding combined with sexual reproduction can be traced in actually existing forms.

The alternation of generations as it is found amongst the Entoparasitic Trematodes and most Cestodes, is to be explained in a slightly different way.

It appears that in these parasitic forms a complicated metamorphosis first arose from the parasite having to accommodate itself to the different hosts it was compelled to inhabit, owing to the liability of its primitive and subsequent hosts to be devoured ${ }^{1}$. A capacity for asexual multiplication-obviously of immense advantage to a parasite-appears to have been acquired in some of the stages of this metamorphosis, and an alternation of generations thus established.

1 The appearance of Vertebrata on the globe as the forms which most frequently preyed on Invertebrate forms, and were themselves not so liable to be devoured, has no doubt had a great influence on the metamorphosis of internal parasites, and has amongst other things resulted in these parasites usually reaching their sexual state in a vertebrate host. 
A nearly parallel series to that exhibiting alternations of sexual generations with generations which produce by budding is supplied by the cases where sexual generations alternate with parthenogenetic ones, or in some instances even with larvæ which reproduce sexually or else parthenogenetically.

The best known examples of this form of alternations of generations are found amongst the Insecta ${ }^{1}$. A simple case is that of the Aphides. The ova deposited by impregnated females give rise to forms differently organised to the parents but provided with an ovary ${ }^{2}$. The eggs from the ovary develope parthenogenetically within the oviduct, and so long as there is plenty of food and warmth the generations produced are always parthenogenetic forms. The failure of warmth and nutriment causes the production of true males and females, and so the cycle is completed. We must suppose that the capacity possessed by so many female insects of producing eggs capable of developing without the influence of the male element, has been, so to speak, taken hold of by natural selection, and has led to the production of viviparous parthenogenetic forms, by which, so long as food is abundant, a clear economy in reproduction is effected. The continuance of the species during winter is secured by the production of males and females, the females laying eggs in autumn which are hatched in the spring.

In Chermes there is less modification of the primitive condition in that the parthenogenetic generations lay their eggs like the impregnated females. In the gall-flies (Cynipidæ), there is frequently an alternation of generations of the same kind as in Chermes; there being no viviparous forms. The individuals of the different generations differ from each other to some extent in all these cases.

A second type of alternations of parthenogenetic and sexual generations is exemplified by the cases of Chironomus and Cecidomyia, where the larve which develope from the eggs of the fertilized female produce parthenogenetically, by means of true ova, forms which eventually after several generations (Cecidomyia) of larval reproduction give rise to sexual forms. The

1 For details vide Chapter on Insecta.

2 The distinction drawn by Huxley between ova and pseudova does not appear to me a convenient one in practice. 
explanation is here practically the same as in the case of Aphis, and is paralleled in the gemmiparous series by the production of buds in the lavval forms of Trematodes, etc. A very similar occurrence takes place in Ascaris nigrovenosa (vide chapter on Nematoidea), except that larval forms, which carry on reproduction and then perish without developing farther, do so by a true sexual process. Thus there is an alternation of generations of adult and larval sexual forms. The Axolotl is an intermittent example of the same phenomenon.

As might be anticipated from the mode in which alternations of generations have become established, incomplete approximations to it are not uncommon. Such approximations are especially found in the Arthropoda, where alternations of sexual and parthenogenetic generations frequently take place, in which the individuals of different generations are similarly organised (Psychidæ, Apus, \&c.). Another approximation is afforded by the parthenogenetic winter eggs of Leptodora amongst the Phyllopods, which give rise to Nauplius larvæ, while the young hatched from the summer eggs do not pass through a metamorphosis. Numerous transitional cases are also found amongst the forms in which there is an alternation of sexual and gemmiparous generations.

The whole of the cases to which allusion has been made in this section may be conveniently classed under the term alternations of generations, but the cases of alternation of two sexual generations, and of sexual and parthenogenetic generations, are classified by Leuckart, Claus, etc. as cases of heterogeny, which they oppose to the other form of alternation of generations. If special terms are to be adopted for the two kinds of alternation of generations, it would be perhaps convenient to classify the cases of alternations of sexual and gemmiparous generations under the term metagenesis, and to employ the term heterogamy for the cases of alternation of sexual and parthenogenetic generations.

The term Nurse (German Amme), employed for the asexual generations in metagenesis, may advantageously be dropped altogether. 


\section{CHAPTER I.}

\section{THE OVUM AND SPERMATOZOON.}

\section{The Ovum.}

THE complete developmental history of any being constitutes a cycle. It is therefore permissible in treating of this history to begin at any point. As a matter of convenience the ovum appears to be the most suitable point of departure. The question as to the germinal layer from which it is ultimately derived is dealt with in a subsequent part of the work; the present chapter deals with its origin and growth.

\section{General History of the Ovun.}

Every young ovum (fig. I) has the character of a simple cell. It is formed of a mass of naked protoplasm $(a)$, containing in its interior a nucleus (b), within which there is a nucleolus $(c)$. The nucleus and nucleolus are usually known as the germinal vesicle and germinal spot.

The ovum so constituted is developed either (I) from one cell out of an aggregation or layer of cells all of which have the capacity of becoming ova; or (2) from one out of a number of cells segmented off

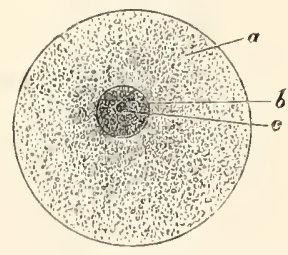

Fig, i. Diagram of THE OVum. (From Gegenbaur.)

a. Granular protoplasm. b. Nucleus (germinal vesicle). c. Nucleolus (germinal spot). from a polynuclear mass of protoplasm, not divided into separate cells. In both cases the cells which have the capacity of becoming ova may be spoken of as germinal cells, and in the case where the ova are ultimately developed from a polyB. II. 
nuclear mass of protoplasm the latter structure may be called a germogen.

In some cases the whole of the germinal cells eventually become ova, but as a rule only a small proportion of them have this fate, the remainder undergoing various changes to be spoken of in the sequel.

Extended investigations have shewn that the distinction between germinal cells which are independent cells from the first, or derived from a germogen in which the nucleated protoplasm is not divided into cells, is an unimportant one; and closely allied forms may differ in this respect. It is moreover probable that a germogen of nucleated protoplasm is less common than is often supposed: it being a matter of great difficulty to determine the structure of the organs usually so described. A germogen is stated to be found in most Platyelminthes, Nematoidea, Discophora, Insecta, and Crustacea.

A more important distinction in the origin of the germinal cells is that afforded by their position. In this respect three groups may be distinguished. (I) The germinal cells may form the lining of a sack or tube, having the form of a syncytium or of an epithelium of separate cells (Platyelminthes, Mollusca, Rotifera, Echinodermata, Nematoidea, Arthropoda). (2) Or they may form a specialized part of the epithelium lining the general body cavity (Chetopoda, Gephyrea, Vertebrata). (3) Or they may form a mass placed between the two elsewhere contiguous primitive germinal layers (Colenterata ${ }^{1}$ ).

Types of transition between the first and second group are not uncommon. Such types, properly belonging to the second group, originate by a special membranous sack continuous with the oviduct being formed round the primitively free patch of germinal cells. Examples of this are afforded by the Discophora, the Teleostei, etc. It is very probable that all the cases which fall under the first heading may have been derived from types which belonged to the second group.

The mode of conversion of the germinal cells into ova is somewhat diverse. Before the change takes place the germinal

1 In all the Metazoa the generative organs are placed between the primitive germinal layers; and the peculiarity of their position in the Coelenterata depends on the absence of a body cavity and of a distinct mesoblast. 
cells frequently multiply by division. The change itself usually involves a considerable enlargement of the germinal cell, and generally a change in the character of the germinal vesicle, which in most young ova (fig. 2) is very large as compared to the body of the ovum. The most complicated history of this kind is that of the ovum of the Craniata. (Vide pp. 56, 57.)

The ovum in its young condition is obviously nothing but a simple cell; and such it remains till the period when it attains maturity.

Nevertheless the changes which it undergoes in the course of its growth are of a very peculiar kind, and, consisting as they do in many instances of the absorption of other cells, have led various biologists to hold that the ovum is a compound structure. It becomes therefore necessary to consider the processes by which the growth and nutrition of the ovum is effected before dealing with the structure of the ovum at all periods of its history.

The ovum is of course nourished like every other cell by the nutritive fluids in which it is surrounded, and special provisions are made for this, in that the ovary is very frequently placed in contiguity with vascular channels. But in addition to such nutrition a further nutrition, the details of which are given in the special part of this chapter, is provided for in the germinal cells which do not become ova.

In the simplest case, as in many $\mathrm{Hy}$ drozoa (fig. 3), the germinal cells which do not become ova are assimilated by the ovum much in the manner of an Amœba.

In other cases the ovum becomes invested by a special layer of cells, which then constitutes what is known as a follicle. The cells which form the follicle are

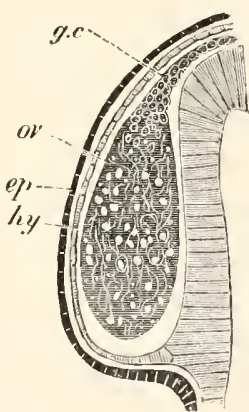

Fig. 3. FEMALE GONOPHORE OF TUBULARIA MESEMBRYANTHEMUM. Containing ONE LARGE OVUM (ov) AND A NUMBER OF GERMINAL CELLS (g.c.).

$c p$. Epiblast (Ectoderm). hy. Hypoblast (Entoderm). ov. Ovum. g.c. Germinal cells. often germinal cells, e.g. Holothuria, Insecta (fig. I 7), Vertebrata 
(fig. I9). In other cases they seem rather to be adjoining connective-tissue or epithelioid cells, though it is sometimes difficult to draw the line between such cells and germinal cells. Examples of follicles formed of ordinary connective-tissue cells, are supplied by Asterias, Bonellia (fig. I6), Cephalopoda (fig. I4), etc.

A membrane enclosing the ovum without a lining of cells, as in many Arachnida, vide p. 5I, has no true analogy with a follicle and does not deserve the same name.

The function of the follicle cells appears to be, to elaborate nutriment for the growth of the ovum. The follicle cells are not as a rule directly absorbed into the body of the ovum, though in some instances, as in Sepia (vide p. 40), they are eventually assimilated in this way.

In many cases some of the germinal cells form a follicle, while other germinal cells form a mass within the follicle destined eventually to be used as pabulum. Insects supply the best known examples of this, but Piscicola, Bonellia (?) may also be cited as examples of the same character. In the Craniata (pp. 56-58) some of the germinal cells which advance a certain distance on the road towards becoming ova, are eventually used as pabulum, before the formation of the follicle; while other germinal cells form at a later period the follicular epithelium. A peculiar case is that of the Platyelminthes (fig. 9), where a kind of follicle is constituted by the cells of a specially differentiated part of the ovary, known as the yolk-gland. The cells of this follicle may either remain distinct, and continue to surround the ovum after its development has commenced, and so be used as food by the embryo; or they may secrete yolk particles, which enter directly into the protoplasm of the ovum.

For further variations in the mode of nutrition the reader is referred to the special part of this chapter. Suffice it to say that none of the known modes of nutrition indicate that the ovum becomes a compound body any more than the fact of an Amœba feeding on another Amoba would imply that the first Amœba ceased thereby to be a unicellular organism.

The constitution of the ovum may be considered under three heads :- 
(I) The body of the ovum.

(2) The nucleus or germinal vesicle.

(3) The investing membranes.

The body of the ovum. The essential constituent of the body of the ovum is an active living protoplasm. As a rule there are present certain extraneous matters in addition, which have not the vital properties of protoplasm. The most important of these is known as food-yolk, which appears to be generally composed of an albuminoid matter.

The body of the ovum is at first very small compared with the germinal vesicle, but continually increases as the ovum approaches towards maturity. It is at first comparatively free from food-yolk; but, except in the rare instances where it is almost absent, food-yolk becomes deposited in the form of granules, or highly refracting spheres, by the inherent activity of the protoplasm during the later stages in the ripening of the ovum. In many instances the protoplasm of the ovum assumes a sponge-like or reticulate arrangement, a fluid yolk substance being placed in the meshes of the reticulum. The character of the food-yolk varies greatly. Many of its chief modifications are described below. There is not unfrequently present in the vitellus a peculiar body known as the yolk

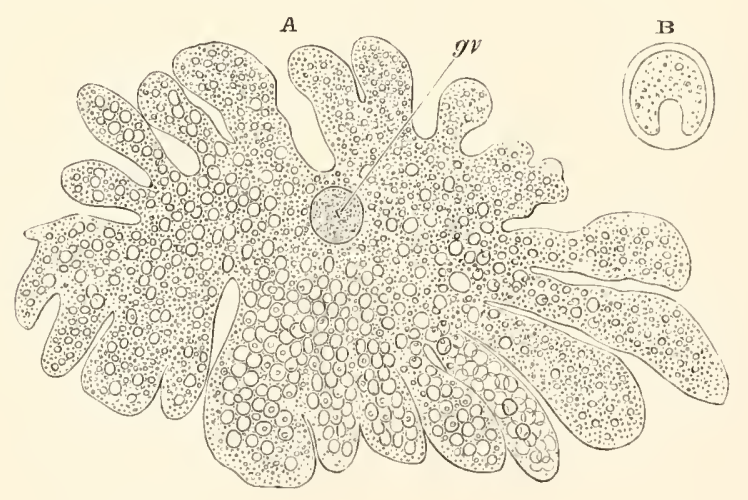

Fig. 4. $A$. Ovum OF Hydra in the ameboid state, Witi yolk SPHERUles (PSEUdocells) and Chlorophyll Granules. (After Kleinenberg.) g\%. Germinal vesicle.

B. SiNGLE PSEUDOCELL OF HYdRA. 
nucleus, which is very possibly connected with the formation of the food-yolk. It is found in many Arachnida, Myriapoda, Amphibia, etc. ${ }^{1}$

More important for the subsequent development than the variation in the character of the food-yolk is its amount and distribution. In a large number of forms it is distributed unsymmetrically, the yolk being especially concentrated at one pole of the ovum, the germinal vesicle, surrounded by a special layer of protoplasm comparatively free from food-yolk, being placed at the opposite pole. In the Arthropoda it has in most instances a symmetrical distribution. Further details on this subject are given in connection with the segmentation; the character of which is greatly influenced by the distribution of food-yolk.

The body of the ovum is usually spherical, but during a period in its development it not unfrequently exhibits a very irregular amœboid form, e.g. Hydra (fig. 4), Halisarca.

The germinal vesicle. The germinal vesicle exhibits all the essential characters of a nucleus. It has a more or less spherical shape, and is enveloped by a distinct membrane which seems, however, in the living state to be very often of a viscous semi-fluid nature and only to be hardened into a membrane by the action of reagents (Fol). The contents of the germinal vesicle are for the most part fluid, but may be more or less

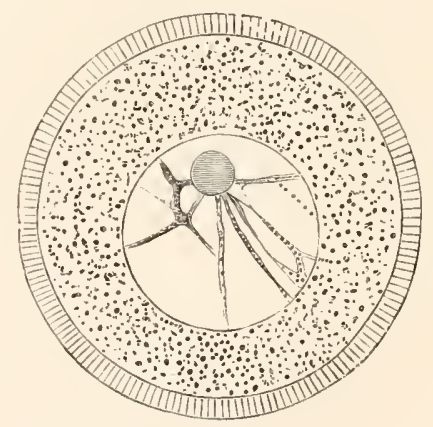

FIG. 5. UNRIPE OVUM OF ToxopNeustes LIVIDUs. (Copied from Hertwig.) granular. Their most characteristic components are, however, a protoplasmic network and the germinal spots ${ }^{2}$. The protoplasmic network stretches from the germinal spots to the investing membrane, but is especially concentrated round the former. (Fig. 5.) The germinal spot

1 For details on the yolk nucleus vide Balbiani, Leçons s. l. Génération d. Vertébrés. Paris, 1879 . In this work the anthor maintains very peculiar views on the nature and function of the yolk nucleus, which do not appear to me well founded.

${ }^{2}$ In the germinal vesicles of very young ova the reticulum is often absent. 
forms a nearly homogeneous body, with frequently one or more vacuoles. It often occupies an eccentric position within the germinal vesicle, and is usually rendered very conspicuous by its high refrangibility. In many instances it has been shewn to be capable of amceboid movements (Hertwig, Eimer), and is moreover more solid and more strongly tinged by colouring reagents than the remaining constituents of the germinal vesicle.

In many instances there is only one germinal spot, or else one main spot and two or three accessory smaller spots. In other cases, e.g. Osseous Fishes, Echinaster fallax, Eucope polystyla, there are a large number of nearly equal germinal spots which appear to result from the division or endogenous proliferation of the original spot. Sometimes the germinal spots are placed immediately within the membrane of the germinal vesicle (Elasmobranchii and Sagitta). In many Lamellibranchiata, in the earth-worm, and in many Chretopoda the components of the germinal spot become separated into two nearly spherical masses (fig. I2), which remain in contiguity along a small part of their circumference, and are firmly united together. The smaller of the two parts is more highly refractive than the larger. Hertwig has shewn that the germinal spot is often composed of two constituents as in the above cases, but that the more highly refractive material is generally completely enclosed by the less dense substance. By Fol the germinal spot is stated to be absent in a species of Sagitta, but this must be regarded as doubtful. In young ova the relative size of the germinal vesicle is very considerable. It occupies in the first instance a central position in the ovum, but at maturity is almost always found in close proximity to the surface. Its change of position in a large number of instances is accomplished during the growth of the ovum in the ovary, but in other cases does not take place till the ovum has been laid.

As the ovum attains maturity, important changes take place in the constitution of the germinal vesicle, which are described in the next chapter.

The egg-membranes. A certain number of ova when ready to be fertilized are naked cells devoid of any form of protecting covering, but as a rule the ovum is invested by some form of membrane. Such coverings present great variety in 
their character and origin, and may be conveniently (Ludwig, No. 4) divided into two great groups, viz. (I) those derived from the protoplasm of the ovum itself or from its follicle, which may be called primary egg-membranes; and (2) those formed by the wall of the oviduct or otherwise, such as the egg-shell of a bird, which may be called secondary egg-membranes.

The primary egg-membranes may again be divided into two groups (Ed. van Beneden, No. 1), viz., (I) those formed by the protoplasm of the ovum, to which the name vitelline membranes will be applied; and (2) those formed by the cells of the follicle, to which the name chorion will be applied.

The secondary egg-membranes will be dealt with in connection with the systematic account of the development of the various groups. They

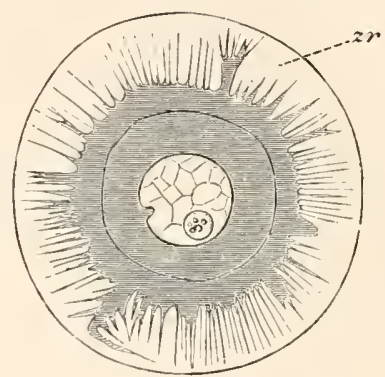

Fig. 6. Ovum of ToxoPNEUSTES VARIEGATUS WITH THE PSEUDOPODIA-LIKE PROCESSES OF THE PROTOPLASM PENETRATING THE ZONA RADIATA $(z r) . \quad$ (After Selenka.) coexist as a rule with primary membranes, though in some types (Cephalophorous Mollusca, many Platyelminthes, etc.), they constitute the only protecting coverings of the ovum.

The vitelline membranes are either simple structureless membranes or present numerous radial pores. Membranes with the latter structure are very widely distributed, Echinodermata, Gephyrea, Vertebrata, etc. (Vide figs. 5 and 7.) The function of the pores appears to be a nutritive one. They either serve for the emission of pseudopodia-like processes of the protoplasm of the ovum, as has been very beautifully shewn in the case of Toxopneustes by Selenka (fig. 6), or they admit (?) processes of the follicular epithelial cells (Vertebrata). Their presence is in fact probably caused by the existence of such processes, which prevent the continuous deposition of the membrane. The term zona radiata will be applied to perforated membranes of this kind. Two vitelline membranes, one perforated and the other homogeneous, may coexist at the same time, e.g. Sipunculida, Vertebrata. (Fig. 7.)

The chorion is often ornamented with various processes, etc. 
It is in many cases doubtful whether a particular membrane is a chorion or a vitelline membrane.

All the membranes which surround the ovum may be provided with a special aperture known as the micropyle. A micropyle is by no means found in the majority of types, and there is no homology between the various apertures so named. Micropyles have two functions, either (I) to assist in the nutrition of the ovum during its development, or (2) to permit the entrance of the spermatozoa. The two functions may in some cases coexist. Micropyles of the first class are developed at the point of attach-

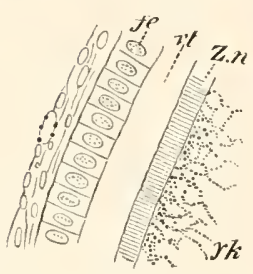

Fig. 7. SECTION THROUGH A SMALL PART OF THE SURFACE OF AN OVUM OF AN IMMATURE FEMALE OF SCyllium CANicula.

fe. Follicular epithelium. vt. Vitelline membrane. $Z n$. Zona radiata. $y k$. Yolk with protoplasmic network. ment of the ovum to the wall of the ovary or to its follicle. Good examples of this kind of micropyle are afforded by the Lamellibranchiata (fig. I2), Holothuria, and many Annelida (Polynoe, etc.). The micropyle of the Lamellibranchiata (p. 37) probably serves also to admit the spermatozoa. The second type of micropyle is found in many Insecta, Teleostei, etc.

\section{General Bibliography of the Ovum.}

(1) Ed. van Beneden. "Recherches sur la composition et la signification de l'œuf," etc. Mém. cour. d. l'Acad. roy. dés Sciences de Belgique, Vol. xxxiv. 1870.

(2) R. Leuckart. Artikel "Zeugung," R. Wagner's Handzwörterbuch d. Physiologie, Vol. IV. I 853 .

(3) Fr. Leydig. "Die Dotterfurchung nach ihrem Vorkommen in d. Thierwelt u. n. ihrer Bedeutung." Okcn. Isis, I 848 .

(4) Ludwig. "Ueber d. Eibildung im Thierreiche." Arbeiten a. d. zool.-zoot. Institut Wiürourg, Vol. I. 1874.

(5) Allen Thomson. Article "Ovum" in Todd's Cyclopadia of Anatomy and Physiology", Vol. v. I859.

(6) W. Waldeyer. Eirrstock u. Ei. Leipzig, i 87o.

1 A very complete and critical account of the literature is contained in this paper. 


\section{Special History of the Ovum an different types.}

\section{Colenterata.}

(7) Ed. van Beneden. "De la distinction originelle d. testicule et de l'ovaire." Bull. Acal. roy. Belgique, $3^{\mathrm{e}}$ série, Vol. xxxvir. i874.

(8) R. and O. Hertwig. Der Organismus d. Melusen. Jena, r878.

(9) N. Kleinenberg. Hydra. Leipzig, 1872.

Amongst the Cœelenterata the ova are developed in imperfectly specialized organs, which are situated in various parts of the body, for the most part in the space between the epiblast and the hypoblast.

In Hydra the locality where the ova are developed only becomes specialized at the time when an ovum is about to be formed. At one or more points the interstitial cells of the epiblast increase in number and form a protuberance of germinal cells, which may be called the ovary. In this ovary a single ovum is formed by the special growth of one cell. (Kleinenberg, No. 9.) In the free and attached gonophores of Hydrozoa, the ova appear either around the walls of the stomach, or the radial canals, or around other parts of the gastro-vascular canals.

Their close relations to the gastrovascular canals are probably determined by the greater nutritive facilities thereby afforded. (Hertwig, No. 8.)

In the permanent Medusa-forms the ova have similar relations to the gastro-vascular system. Amongst the Actinozoa the ova are usually developed between the epiblast and the hypoblast in the walls of the gastric mesenteries. Amongst the Ctenophora the ova are situated in close relation with the peripheral canals of the gastro-vascular system, which run along the bases of the ciliated bands. There are many ex-

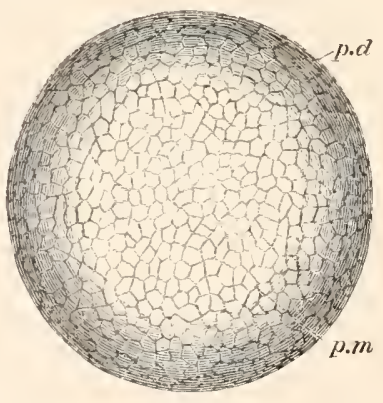

Fig. 8. Ripe Ovum of Epibulia aurantiaca. The GerMiNAL VESICLE has BeCOME INVISIBLE. WITHOUT REAGENTS.

Copied from Metschnikoff, "Entwicklung der Siphonophoren." Zitschrift f. wiss. Zool., Vol. Xxiv. I 874 .

$p . d$. Peripheral layer of denser protoplasm. p.m. Central area consisting of a protoplasmic meshwork. 
amples amongst the Cœlenterata of ova which retain in their mature state the very simple constitution which has been described as characteristic of all young ova; and which are, when laid, absolutely without any trace of a vitelline membrane or chorion. In many other cases both amongst the Medusæ, the Siphonophora, and the Ctenophora, the ripe egg exhibits a distinction into two parts. The outer part is composed of a dense protoplasm, while the interior is composed of a network or more properly a spongework of protoplasm enclosing in its meshes a more fluid substance. (Fig. 8.)

In some cases the ovum while still retaining the constitution last described becomes invested by a very delicate membrane. Such is the constitution of the ripe ovum of Hippopodius gleba amongst the Siphonophora $^{1}$ and of the eggs of Geryonia amongst the permanent Medusæ ${ }^{2}$. The ripe eggs of the Ctenophora usually present a similar structure ${ }^{3}$. After being laid they are found to be invested by a delicate membrane separated by a space filled with fluid from the body of the ovum. The latter is composed of two layers, an outer one of finely granular protoplasm and an inner layer consisting of a protoplasmic spongework containing in its meshes irregular spheres. These latter are stated by Agassiz to be of a fatty nature, and it is probable that in most cases where a protoplasmic network is present, this alone constitutes the active protoplasm; and that the substance which fills up its meshes is to be looked on as a form of food-yolk or deutoplasm, though it appears sometimes to have the power of assimilating the firmer yolk particles.

The membrane which invests the ovum of many of the Cœlenterata is probably a vitelline membrane.

The ova of the Hydrozoa take their origin, in most groups at any rate ${ }^{4}$, from the deeper layer of the epiblast (interstitial layer of Kleinenberg). The interstitial cells in the ovarian region form primary germinal cells, and by an excess of nutrition certain of them outstrip their fellows and become young ova. Such ova differ from the full-grown ova already

1 Metschnikoff. Zeitschrift f. wiss. Zoologie, Vol. xxIv. I874.

2 Herman Fol. Jenaische Zeitschrift, Vol. vir.

${ }^{3}$ Kowalevsky. "Entwicklungsgeschichte d. Rippenquallen." Nímoire de l'Acad. Pítersbourg, I\$866. And Alex. Agassiz. "Embryology of the Ctenophore." Amer. Acad. of Science and Arts, Vol. x. No. II I.

4 The view of van Beneden, according to which the ova have an endodermal (hypoblastic) origin, has been shewn to be at any rate confined to certain groups. The whole question of the origin of the generative products from the germinal layers in the Colenterata is still involved in great obscurity. 
described, mainly in the fact that they have a proportionately smaller amount of protoplasm round the germinal vesicle. They grow to a considerable extent at the expense of germinal cells which do not become converted into ova.

The ova of many Cœlenterata undergo changes of a more complicated kind before attaining their full development. Of these ova that of Hydra may be taken as the type. The ovary of Hydra (Kleinenberg, No. 9) is constituted of angular flattish germinal cells of which no single one can be at first distinguished from the remainder. As growth proceeds one of the cells occupying a central position becomes distinguished from the remaining cells by its greater size, and wedge-like shape. It constitutes the single ovum of the ovary. After it has become prominent it grows rapidly in size, and throws out irregular processes. The germinal vesicle, which for a considerable time remains unaltered, also at length begins to grow; and the sharply defined germinal spot which it contains after reaching a certain size completely vanishes. After the atrophy of the germinal spot, there appears in the middle of the ovum a number of roundish yolk granules.

The shape of the ovum becomes more irregular, and chlorophyll granules, in addition to the yolk granules, make their appearance in it. A fresh germinal spot of circular form also arises in the germinal vesicle. Protoplasmic processes are next thrown out in all directions, giving to the ovum a marvellous amœboid character. (Fig. 4.) The amœboid form of the ovum serves no doubt to give it a larger surface for nutrition. Coincidently with the assumption of an amœboid form there appear in the ovum a great number of peculiar bodies. They are vesicles with a thick wall bearing a conical projection into the interior which is filled with fluid. (Fig. 4 B.) These bodies are formed directly from the protoplasm of the ovum, and are to be compared both morphologically and physiologically with the yolk-spherules of such an ovum as that of the Bird. They are called pseudocells by Kleinenberg, and are found with slightly varying characters in many ova of the Hydrozoa.

They first appear as small highly refracting granules; in these a cavity is formed which is at first central but is eventually pushed to one side by the formation of a conical projection from the wall of the vesicle. 
After the growth of the ovum is completed the amœboid processes gradually withdraw themselves, and the ovum assumes a spherical form; still however continuing to be invested by the remaining cells of the ovary. It is important to notice that the egg of Hydra retains throughout its whole development the characters of a single cell, and that the pseudocells and other structures which make their appearance in it are not derived from without, and supply not the slightest ground for regarding the ovum as a structure compounded of more than one cell.

The development of the ova of the Tubularidx, which has been supposed by many investigators to present very special peculiarities, takes place on essentially the same type as that of Hydra, but the germinal vesicle remains permanently very small and difficult to observe. The mode of nutrition of the ovum may be very instructively studied in this type. The process is one of actual feeding, much as an Amœba might feed on other organisms. Adjoining one of the large ova of the ovary there may be seen a number of small germinal cells. (Fig. 3.) The boundary between these cells and the ovum is indistinct. Just beyond the edge of the ovum the small cells have begun to undergo retrogressive changes; while at a little distance from the ovum they are quite normal (g.c.) $)^{1}$.

\section{Platyelminthes.}

(10) P. Hallez. Contributions à l'Histoire naturelle des Turbellariés. Lille, 1879 .

(11) S. Max Schultze. Beiträge z. Naturgeschichte d. Turbellarien. Greifswald, 1851 .

(12) C. Th. von Siebold. "Helminthologische Beiträge." Müller's Archiv, I 836 .

(13) C. Th. von Siebold. Lehrbuch d. vergleich. Anat. d. wirbellosen Thiere. Berlin, i 848 .

(14) E. Zeller. "Weitere Beiträge z. Kenntniss d. Polystomen." Zeit. f. wiss. Zool., Bd. XxviI. I8 76 .

[Vide also Ed. van Beneden] (No. I).

This group, under which I include the Trematodes, Cestodes,

1 The above description of the ova of the Tubularida is founded on sections of the gonophores of Tubularia mesembryanthemum. Dr Kleinenberg informs me however that the absence of a distinct boundary between the germinal cells and the ovum is not usual. 
Turbellarians and Nemertines, has played an important part in all controversies relating to the nature and composition of the ovum. The peculiarity in the development of the ovum in most members of this group consists in the fact that two organs assist in forming what is usually spoken of as the ovum. One of these is known as the ovary proper, and the other as the vitellarium or yolk-gland. In the sequel the term ovum will be restricted to the product of the first of these organs. In Trematodes the ovary forms an unpaired organ directly continuous with an oviduct into which there open the ducts from paired yolk-glands.

The ovary has a sack-like form and contains in some instances a central lumen (Polystomum integerrimum). At the blind end of the organ is placed the germinal tissue. This part is, according to the accounts of the majority of investigators, formed of a polynuclear mass of protoplasm not divided into distinct cells. Whether it is really formed of undivided protoplasm or not, it is quite certain that a little lower down in the organ distinct cells are found, which have been segmented off from the above mass, and are formed of a large nucleus and nucleolus, surrounded by a delicate layer of protoplasm. These cells are the young ova. They usually assume a more or less angular form from mutual pressure, and, in the cases where the ovary has a lumen, constitute a kind of epithelial lining for the ovarian tube. They become successively larger in passing down the ovary, and, though in most cases naked, are in some instances (Polystomum integerrimum) invested by a delicate vitelline membrane. Eventually the ova pass into the oviduct and become free; and at the same time assume a spherical form.

In the oviduct the ovum receives somewhat remarkable investing structures, derived from the organ before spoken of as the yolk-gland. The yolk-gland consists of a number of small vesicles, each provided with a special duct, connected with the main duct of the gland. Each vesicle is lined by an epithelium of cells provided with doubly contoured membranes, and containing nuclei.

As the yolk-cells grow older refracting spherules become deposited in their protoplasm, which either completely hide the 
nucleus, or render it very difficult to see. In the majority of cases the entire cells forming the lining of the vesicles constitute the secretion of the yolk-gland. They invest the ovum, and around them is formed a shell or membrane. In some cases (e.g. Polystomum integerrimum) the yolk-cells retain their cellular character and vitality till the embryo is far developed. In other cases they lose their membrane and nucleus shortly after the formation of the egg-shell, and break up into a fluid, holding in suspension a number of yolk-granules. A partial disorganisation of the yolk-cells can also take place before they surround the ovum; while in some species of Distomum they completely break up before leaving the yolk-gland.

There is thus a complete series of gradations between the investment of the ovum by a number of distinct cells, and its investment by a layer of fluid containing yolk-spherules in suspension. In neither the one case nor the other do the investing structures take any share in the direct formation of the embryo from the ovum. Physiologically speaking they play the same part as the white in the fowl's egg.

The egg-shell, which is usually formed by a secretion of a special shell-gland opening into the oviduct, exhibits one or two peculiarities in the different species of Trematodes. In Amphistomum subclavatum it presents at one extremity a thickened area, which is pierced by a narrow micropyle. In other cases one extremity of the eggshell is produced into a long process, and sometimes even both extremities are armed in this way. Opercula and other types of armature are also found in different forms.

The mode of development of the ovum in Cestodes is very nearly the same as in Trematodes.

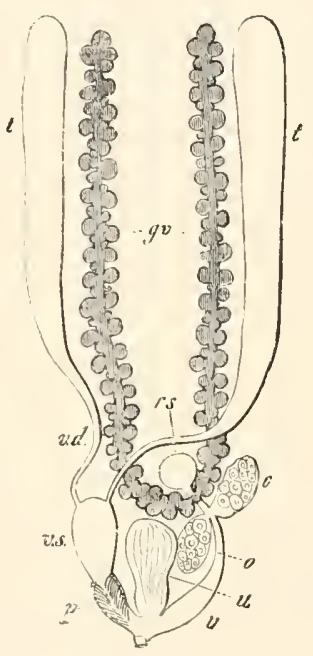

Fig. 9. Generative SYSTEM OF VORTEX VIR1DIs. (From Gegenbaur, after Max Schultze.)

t. Testis. v.d. Vasa differentia. v.s. Seminal vesicle. p. Penis. $\varkappa$. Uterus. o. Ovary. v. Vagina. g.v. Yolk-glands. r.s. Keceptaculum seminis.

The ovum becomes enveloped in the usual secretion of the yolk-gland; and an egg-shell is always formed by the secretion of a special shell-gland.

Amongst the Turbellarians and Nemertines, there are greater variations in the arrangement of the female generative glands, 
than in the preceding types. In most of the Rhabdocœla and fresh-water Dendrocœla these organs resemble in their fundamental characters those of the Trematodes and Cestodes. There are present a paired or single ovary and a paired yolk-gland. The general arrangement of the organs is shewn in fig. 9.

The blind end of the ovaries is usually (Ed. van Beneden, etc.) stated to be formed of a polynuclear protoplasmic basis, but Hallez (No. 10) has recently insisted that, even at the extreme end of the ovary, the germinal cells are quite distinct, and not confounded together.

With one or two exceptions the yolk-cells secreted by the vitellarium retain their vitality till they are swallowed by the embryo, after the development of its mouth. The few not so swallowed become disintegrated. They are granular nucleated cells, and, as was first shewn by von Siebold, are remarkable for exhibiting spontaneous amœboid movements.

Very important light on the nature of the vitellarium is afforded by the structure of the generative organs in Prorhyncus and Macrostomum.

In Prorhyncus there is no separate vitellarium, but the lower part of the ovarian tube functionally and morphologically replaces it. The ovum becomes surrounded by yolk-cells, which according to Hallez (No. 10) retain their vitality for a long time. According to $\mathrm{Ed}$. van Beneden yolk-spherules are formed in the protoplasm of the ovum itself, in addition to and independently of the surrounding yolk-cells. In Convoluta paradoxa a special vitellarium is stated to be absent; though a deposit of yolk is formed round the ovum (Claparède).

In Macrostomum again the yolk-glands are at most represented by a lower specialized part of the ovarian tube. The ova in passing down become filled with yolk-spherules. According to Ed. van Beneden these spherules are formed in the protoplasm of the ovum itself; but this is explicitly denied by Hallez, who finds that they are formed from the lining cells of the ovarian tube, which, instead of retaining their vitality as in Prorhyncus, break up and form a granular mass which is absorbed by the protoplasm of the ovum.

In Prostomum caledonicum (Ed. van Beneden) the generative organs are formed on the same plan as in other Rhabdocœela, but 
the cells which form the yolk-gland give rise to yolk particles which enter the ovum, instead of to a layer of yolk-cells surrounding the ovum.

Amongst the marine dendrocœlous Turbellarians the ova are formed in separate sacks widely distributed in the parenchyma of the body between the alimentary diverticula. In these the ova undergo their complete development, without the intervention of yolk-glands.

The ovaries of the Nemertines more nearly resemble those of the marine Dendrocœla than those of the Rhabdocœla. They consist of a series of sacks situated on the two sides of the body between the prolongations of the digestive canal. The eggs are developed in these sacks in a perfectly normal manner, and in many cases become filled with yolk-spherules which arise as differentiations of the protoplasm of the ovum. The protecting membranes of the ova have not been accurately studied. In some cases ${ }^{1}$ two membranes are present, an internal and an external. The former, immediately investing the vitellus, is very delicate: the external one is thicker and hyaline.

The constitution of the female generative organs of the Trematodes was first clearly ascertained by von Siebold (No. 12). He originally, though not very confidently, propounded the view that the germinal vesicles alone were formed in the ovary and that the protoplasm of the ovum was supplied by the yolk-gland. This view has long been abandoned, and von Siebold (No. 13) himself was the first to recognize that true ova with a protoplasmic body containing a germinal vesicle and germinal spot were formed in the ovary. The Trematodes have however not ceased to play an important part in forming the current views upon the development of ova, and have quite recently served Ed. van Beneden as his type in exposing his general view upon this subject.

His view consists fundamentally in regarding the secretion of the yolk-glands, which in most cases merely invests the ovum, as homologous with the yolk-spherules which fill the protoplasm of many eggs; and he considers the part of the ovary where in most forms the ova receive their supply of yolk particles, as equivalent to the vitellarium of the Platyelminthes. He further appears to regard the primitive state as that exemplified in Trematodes, Cestodes, etc., and holds that the ovarian types characteristic of other forms are secondarily derived from this, by the coalescence of the primitively distinct vitellarium with the ovary proper.

1 Amphiporus lactiflorius and Nemertes gracilis. M'Intosh. Monograph on British Nemertines. Ray Society.

B. II. 
This appears to me a case of putting the cart before the horse. To my mind the vitellarium is, to be regarded, as has already been suggested by Gegenbaur, Hallez, etc. as a special differentiation of the primitively simple ovarian tube, and the instances of Macrostomum and Prorhyncus just cited appear to me to indicate some of the steps in this differentiation. In Macrostomum the cells of the lower part of the oviduct simply supply a kind of nutriment to the ovum in the form of granular yolk particles, while in Prorhyncus the yolk-cells of the lower part of the ovarian tube form a complete investment of independent cells for the ovum. If this lower part of the ovarian tube were to grow out as a special diverticulum we should have produced a normal vitellarium. But even with the above modification the theory of van Beneden appears to me not completely satisfactory. The view that the yolk-spherules are of the same nature as the yolk-cells is mainly supported by the case of Prostomum caledonicum, where the vitellarium produces the yolk particles which fill the ovum. The cases of Prorhyncus and Macrostomum give a different complexion to that of Prostomum caledonicum. From the first of these especially it appears that, even when normal yolk-cells surround the ovum, yolk particles can be deposited independently in the protoplasm of the ovum.

The most probable view of the nature of the vitellarium is that of Gegenbaur, Hallez, etc, according to which it is to be regarded as a specially modified part of the ovarian tube. On this view the nature and function of the yolk-cells admit of a fairly simple explanation. They are to be regarded as primary germinal cells like those in the ovaries of Hydra, Tubularia, etc., which do not become converted into ova. Like these cells they may in some instances, Macrostomum, Prostomum, etc., serve directly in the nutrition of the ovum. In other cases they retain their independence and serve for the late nutrition of the embryo. In both instances they retain the faculty, normally possessed by ova, of forming yolk particles in their protoplasm.

\section{ECHINODERMATA.}

(15) C. K. Hoffmann. "Zur Anatomie d. Echiniden u. Spatangen." Niederländisch. Archiv f. Zoologie, Vol. I. I87 .

(16) C. K. Hoffmann. "Zur Anatomie d. Asteriden." Niederländisch. Archiv f. Zoologie, Vol. II. 1873 .

(17) H. Ludwig. "Beiträge zur Anat. d. Crinoiden." Zeit. f. wiss. Zool., Vol. xxvil. I 877 .

(18) Joh. Müller. "Ueber d. Canal in d. Eiern d. Holothurien." Müller's Archiv, 1854 . 
(19) C. Semper. Holothurien. Leipzig, i868.

(20) E. Selenka. Befruchtung d. Eies v. Toxopneustes variegatus, i 878.

[Vide also Ludwig (No. 4), etc.]

The eggs of the Echinodermata present in their development certain points of interest.

The ovaries themselves are usually surrounded by a special vascular dilatation. In the Asteroidea, the Echinoidea, and the Holothuroidea the organs have the form of sacks; specially surrounded in the two former groups, and probably the latter, by a vascular sinus formed as a dilatation of one of the generative vessels. In the Crinoids they have the form of a hollow rachis completely surrounded by a blood-vessel. (Fig. I I b.) The proximity of the ovaries (generative organs) to the vascular system in these forms has clearly the same physiological significance as the proximity of the ovaries (generative organs) to the radial vessels in the Cœlenterata.

In the Asteroidea, the Echinoidea and the Holothuroidea the ovaries have the form of sacks lined by an epithelium of germinal cells, and the ova are formed by the enlargement of these cells, which, when they have reached a certain size, become detached from the walls, and fall into the cavity of the ovarian sack. In Toxopneustes (Selenka) and very probably in other forms only a few of the epithelial cells undergo conversion into ova: the remainder undergo repeated division, and, as in so many other cases, are eventually employed in the nutrition of the true ova. In the nearly ripe ova of Asterias Fol has described a flattened follicular epithelium the origin of which is unknown.

In Holothuria (Semper) a further differentiation of the germinal cells, not destined to become ova, takes place. They surround the enlarged cell which forms the true ovum, for which they constitute a kind of follicular capsule. This capsule is attached by a stalk to the walls of the ovary, and the ovum lies freely in it except for an area nearly opposite its (the capsule's) point of attachment, where the ovum adheres to the wall of the capsule. Subsequently the follicle cells which form the capsule fuse together, and form a definite membrane in which only the nuclei remain distinct. Within the membranous capsule there is formed for the ovum an albuminous zona radiata. At the point where the ovum is attached to its capsule this membrane cannot be 
developed, and therefore remains incomplete. The perforation so formed, becomes the micropyle of the Holothurian egg, which was first discovered by Joh. Müller. The albuminous membrane just described for Holothurians is also found in Asteroids (fig. 5) and Echinoids. In these groups there is no proper micropyle, though in Ophiothrix a nutritive passage perforates the membrane at the attachment of the ovum before the period when the ovum becomes free (Ludwig). The formation of the zona

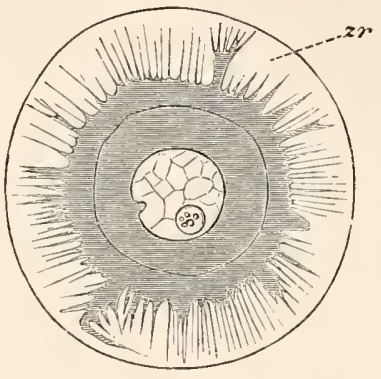

Fig. 10. Ovum of ToxoPNEUSTES VARIEGATUS WITH THE PSEUDOPODIA-LIKE PROJECTIONS OF THE PROTOPI.ASM PENETRATING THE ZONA RADIATA $(z r)$. (After Selenka.)

radiata has been studied by Selenka. It is secreted by the protoplasm of the ovum, and has a gelatinous consistency, and after it is formed the peripheral layer of the protoplasm of the ovum sends out through it pseudopodia-like processes to absorb nutriment from without. These processes are at first large and irregular, but soon become finer and finer (fig. IO), and acquire a regular radiating arrangement. They are withdrawn when the ovum is ripe, but they nevertheless give rise to the finely radiated appearance of the membrane, the radii being in reality delicate pores.

In the Crinoids the generative rachis consists of a tube, the epithelium of which is formed of the primary germinal cells. (Fig. II.) While some of these cells enlarge and become ova, the remainder supply the elements for a follicular epithelium, which is established round the ova, exactly as in Holothurians.

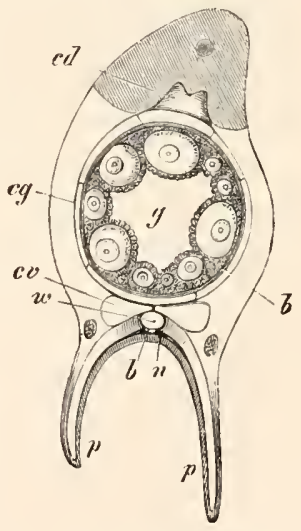

Fig. II. Transverse SECTION THROUGH THE PINNA OF A SEXUALLY MATURE COMATULA. (From Gegenbaur, after Ludwig.)

$p$. Tentacle. $g$. Lumen of genital rachis. $w$. Water-vascular vessel. $n$. Nerve cord. $\quad b$. Blood-vessel on nerve cord and round genital rachis. cg. Genital canal. $c d$. Dorsal section of the body cavity. $c v$. Ventral section of body cavity. 


\section{MolluscA.}

\section{Lamellibranchiata.}

(21) H. Lacaze-Duthiers. "Organes génitaux des Acéphales Lamellibranches." Ann. Sci. Nat., $4^{\text {me }}$ série, Vol. II. I854.

(22) W. Flemming. "Ueb. d. er. Entwick. am Ei d. Teichmuschel." Archio f. mikr. Anat., Vol. x. I87t.

(23) W. Flemming. "Studien üb. d. Entwick. d. Najaden." Sitz. d. $k$. Akad. Wiss. Wien, Vol, Lxxi. I875.

(24) Th. von Hessling. "Einige Bemerkungen, etc." Zeit. f. zeiss. Zool., Bd. v. $18_{54}$.

(25) H. von Jhering. "Zur Kenntniss d. Eibildung bei d. Muscheln." Zeit. f. wiss. Zool., Vol. xxix. I 877 .

(26) Keber. De Introitu Spermatozoorum in onula, etc. Königsberg, I 853.

(27) Fr. Leydig. "Kleinere Mittheilung etc." Mïller's Archiv, I 854.

\section{Gasteropoda.}

(28) C. Semper. "Beiträge z. Anat. u. Physiol. d. Pulmonaten." Zeit. f. wiss. Zool., Vol. VIII. I857.

(29) H. Eisig. "Beiträge 2. Anat. u. Entwick. d. Pulmonaten." Zeit.f. wiss. Zool., Vol. xix. i 869 .

(30) Fr. Leydig. "Ueb. Paludina vivipara." Zeit.f. wiss. Zool, Vol. II. I 850.

\section{Cephalopoda.}

(31) Al. Kölliker. Entwicklungsgeschichted. Cephalopoden. Zurich, I844.

(32) E. R. Lankester. "On the developmental History of the Mollusca." Phil. Trans., I875.

\section{Lamellibranchiata.}

The ova of the Lamellibranchiata present several points of interest. They are developed in pouches of the ovary which are lined by a flattened germinal epithelium, or sometimes (?) a syncytium. Some of the cells of this epithelium enlarge and become ova, but remain attached to the walls of their pouches by protoplasmic stalks. Round the ovum there appears in some forms (Anodon, Unio) a delicate vitelline membrane, which is incomplete at the protoplasmic stalk, and is therefore perforated by an aperture which forms the micropyle. (Fig. I2.) As the 
ovum becomes ripe a large space filled with albuminous fluid becomes established between the ovum and its membrane, but the ovum remains attached to the membrane at the micropyle. In Scrobicularia (von Jhering, No. 25) the membrane round the ovum appears from the first as an albuminous layer, the outermost stratum of which becomes subsequently hardened as the vitelline membrane. In this form also the protoplasmic stalk becomes, in pouches largely filled with ova, extremely long. The ova become eventually detached by the stalk rupturing, and the portion of it which remains attached to the vitelline membrane falling off. The function of the stalk and of the micropyle during the development of the ovum is undoubtedly a nutritive one.

In Anodon and Unio yolk granules similar to those deposited in the protoplasm of the ovum are also found in the epithelial cells of the ovarian pouches (Flemming, 22), and there can be but little doubt that they are directly transported from these cells into the ovum. These cells would seem therefore to play much the same part as the yolk-glands of some Turbellarians (Prostomum caledonicum). In Scrobicularia yolk granules are not found in the epithelium of the pouches, but are contained in the dilated disc by which the ovum is attached to

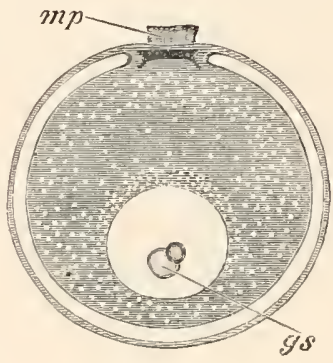

Fig, 12. Medium-SIZEU OVUM OF ANODONTA COMPLANATA. (After Flemming.) $m p$. micropyle. gs. germinal spot. the wall of its pouch, as well as in the ovum itself.

On the ovum becoming detached the micropyle still remains as an aperture, which probably has the function of admitting the spermatozoa.

The shape and form of the micropyle vary greatly. In Anodon and Unio it is a projecting trumpet-shaped structure, which after fertilization becomes shortened and reduced to a mere aperture which is finally stopped up. (Fig. I2.)

In other forms it is simply a perforation in the vitelline membrane which is sometimes very large. In a species of Arca, which I had an opportunity of observing at Valparaizo, it was equal to nearly the circumference of the ovum. 
The eggs of the Lamellibranchiata are not only remarkable in the possession of a micropyle, but in certain peculiarities of the yolk and of the germinal vesicle.

In the fresh-water mussels there is usally found in young and medium-sized ova a peculiar lens-shaped body-Keber's corpuscle-which is placed immediately internal to the micropyle. It is probably in some way connected with the nutrition of the ovum, though the fact that it is not always present shews that it cannot be of great importance.

A dark body found by von Jhering in the neighbourhood of the germinal vesicle in the ripe ovum of Scrobicularia is probably of a similar nature to Keber's corpuscle. Both bodies may be placed in the same category as the so-called yolk nucleus of the spider's and frog's ova.

In all except the youngest ova of Anodon and Unio the germinal spot is composed of two nearly complete spheres united together for a small part of their circumference. (Fig. I2, gs.) The smaller of these has a higher refractive index than the larger, and often contains a vacuole: the two parts together appear to be the separated components (though not by simple division) of the primitive nucleolus. A nucleolus of this character is not universal amongst Lamellibranchiata, but a similar separation of the constituents of the germinal spot has been found by Flemming in Tichogonia, in which however the more highly refracting body envelopes part of the less highly refracting body in a cap-like fashion.

\section{Gasteropoda.}

The ova of the Gasteropoda are developed, like those of the Lamellibranchiata, from the epithelial cells of the ovarian acini or pouches. In the hermaphrodite forms both ova and spermatozoa are produced in the same pouches (fig. I3), some of the epithelial cells becoming ova and others spermatozoa. The ova are usually formed in the wall of the pouch, and the spermatozoa internally (Pulmonata) (fig. I $3 A$ ), or a further differentiation of parts may take place (fig. I $3 B$ ). The ova of Gasteropods are exceptional in the fact that a vitelline membrane is 
rarely or never developed around them. The ovum in its passage to the exterior becomes enclosed in a secretion of the albuminous gland, which hardens externally to form a special membrane.
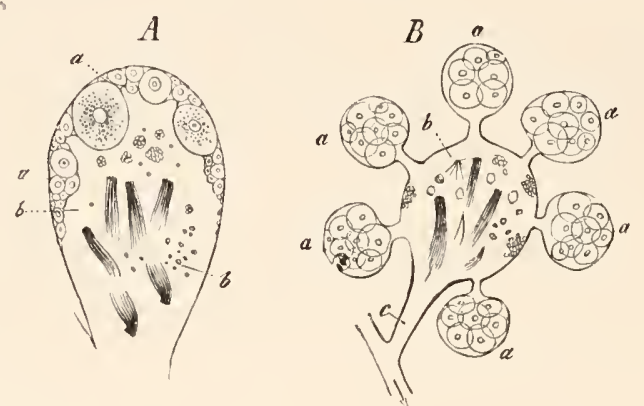

Fig. I3. Follicles of the hermaphrodite Glands of Gasteropoda. (From Gegenbaur.)

A. Of Helix hortensis. The ova $(a a)$ are developed on the wall of the follicle, and the seminal masses $(b)$ internally.

$B$. Of Aeolidia. The seminal portion of a follicle is beset peripherally by ovarian saccules $(a)$. c. Common afferent duct.

\section{Cephalopoda.}

Lankester (No. 32) has brought out some very interesting points with reference to the nutrition of the eggs of Sepia during their growth. The eggs develope in connective-tissue pouches which early give rise to a double pedunculated capsule of connective tissue. The cells of the inner layer of this capsule soon assume an epithelial character, and become a definite follicular epithelium, while between the two layers there penetrates a network of vascular channels. The follicular epithelium becomes after the establishment of these vascular channels folded in a most remarkable manner. The folds, which are shewn in section in fig. I4, $i c$, project into and nearly completely fill up the body of the ovum. An enormous increase is thus effected in the nutritive surface exposed by the epithelium. Each fold is thoroughly supplied with blood-vessels. The plications of the follicular epithelium give rise to a basket-work tracery on the surface of the ovum. During the stage when the follicular epithelium has the above structure, its cells have a 
character similar to that of the goblet-cells of a mucous membrane, and pour out their metamorphosed protoplasm into the body of the ovum.

After the above mode of nutrition has gone on for a certain time a change takes place, and the ridges gradually disappear. This is caused by the epithelial cells passing off from the ridges into the protoplasm of the ovum; and becoming assimilated, after retaining their individuality for a longer or shorter period. When the absorption of the

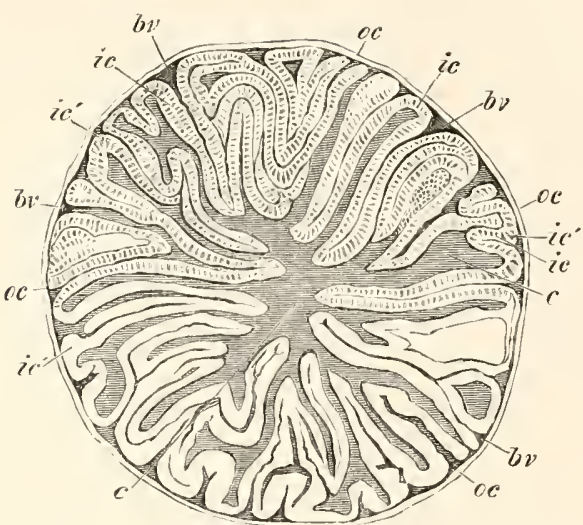

Fig. I4. Transverse section throvgh an OVARIAN EGG OF SEPIA. (Copied from Lankester.) o.c. outer capsular membrane. i.c. inner capsular membrane with follicular epithelium. b. $\%$. blood-vessels in section between the outer and inner capsular membranes. c. vitellus.

The section shews the folds of the inner capsule with their epithelium, which penetrate into the substance of the ovum for the purpose of supplying it with nourishment.

ridges is completed the surface of the ovum assumes a perfectly regular outline. The capsule of the ovum then bursts at the opposite pole to the peduncle, and the ovum falls into the oviduct.

The ova of the Cephalopoda, like those of the Gasteropoda, are quite naked, being without a vitelline membrane or chorion. The egg-capsule which is formed for them in their passage down the oviduct is perforated in Sepia by a micropylar aperture.

\section{Chetopoda.}

(33) Ed. C.Iaparède. "Les Annelides Chætopodes d. Golfe de Naples." Mém. d. l. Sociét. phys. et d"hist. nat. de Genive i $868-9$ and i 870 .

(34) E. Ehlers. Dic Borstenwiömer nach system. und anat. Untersuchungen. Leipzig, $186_{4}-68$.

(35) E. Selenka. "Das Gefäss-System d. Aphrodite aculeata." Nieder. landisches Archio f. Zool., Vol. II. I873.

The ova of the Chrtopoda are in most cases developed from the special tracts of the epithelial cells lining parts of the body 
cavity, which constitute a germinal epithelium (fig. I5). Very frequently (Aphrodite, Arenicola), as is so common in other types, these tracts of germinal cells surround the blood-vessels.

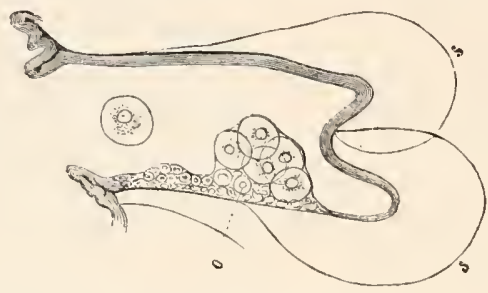

Fig. 15. A Parapodium of Tomopteris. (From Gegenbaur.)

o. Collection of germinal epithelial cells lining the body cavity.

In some cases the germinal epithelium thickens to form a compact organ, for which the outermost cells may form a more or less definite membranous covering (Oligochæta, etc.). The ova are formed by the enlargement, accompanied by other changes, of these germinal cells. During their early development the ova are frequently surrounded by a special capsule, which is often stalked, and provided at its attachment with a large micropylar aperture. In Aphrodite and Polynoe this arrangement, which is clearly connected with the nutrition of the ovum, is very easily seen. The ovum is dehisced into the body cavity by the bursting of its capsule or the rupture of the stalk. The capsule is always eventually thrown off; but a vitelline membrane is frequently developed after the detachment of the ovum into the body cavity. The vitelline membrane of Spio and other Polychrta is provided with an equatorial ring of ampulliform vesicles.

\section{DISCOPHORA.}

(36) H. Dorner. "Ueber d. Gattung Branchiobdella." Zeit. f. ziiss. Zool, Vol. xv. i $86_{5}$.

(37) R. Leuckart. Die menschlichen Parasiten.

(38) Fr. Leydig. "Zur Anatomie v. Piscicola geometrica, etc." Zeit.f. wiss. Zool., Vol. 1. $18+9$.

(39) C. O. Whitman. "Embryology of Clepsine." Quart. F. of Micr. Sci., Vol. XVIII, is;8.

The ovary of the Discophora is formed of a mass of cells enveloped in a membranous sack. In Branchiobdella there is 
placed in the central axis of these cells a column of nucleated protoplasm from which the cells themselves are budded off. The development of the ovum takes place by the enlargement, etc. of one of the peripheral cells, which eventually bursts the wall of the sack and is freely dehisced into the body cavity.

In most other Leeches (except Piscicola and its allies) there is found a more specialized arrangement of the same nature as in Branchiobdella. There are one or more coiled egg-strings which lie freely in a delicate sack continuous with the oviduct. Each egg-string is formed of a central rachis and of a peripheral layer of cells ${ }^{1}$. The ova are formed by the enlargement of the peripheral cells accompanied by a deposition of food-yolk. Food-yolk appears to be formed in the rachis even more energetically than in the protoplasm of the ova. When ripe the ova fall into the ovarian sack.

In Piscicola the development of the ovum is somewhat peculiar but resembles in certain respects that of Bonellia (p. 45). The ova are developed from the primitive germinal cells which fill up the ovarian sack. The nuclei in these cells increase in number, and a nucleated peripheral layer of each cell becomes separated from the central part, which also contains nuclei. This latter part next divides into numerous cells, of which one eventually forms the ovum, and the remainder constitute a mass of cells adjoining it as in Bonellia (fig. 16). This mass of cells eventually disappears, and is probably employed in the nutrition of the ovum.

The ovaries of the Leech appear to belong to the tubular type in that the ova are not formed from part of the epithelium lining the body cavity; but if, as seems probable, the true affinities of the Leeches are with the Chætopoda, the investment of the ovaries must be of a secondary nature. It should be noted that the ova are not, as in the ordinary tubular ovary, developed from the epithelium lining the ovarian tube.

1 The rachis is stated by Whitman (No. 39), and other observers to be formed of nucleated protoplasm, but further investigations on this point are still required. 


\section{GEPHYREA.}

(40) Keferstein u. Ehlers. Zoologische Beiträge. Leipzig, I86I.

(41) C. Semper. Holothurien, I868, p. 145.

(42) J. W. Spengel. "Beiträge z. Kenntniss d. Gephyreen." Beiträge $a . d$. zool. Station z. Neapel, Vol. I. I 879 .

(43) J. W. Spengel. "Anatomische Mittheilungen üb. Gephyreen." Tagebl. d. Naturf. Vers. München, I877.

In the Gephyrea, as in the Chætopoda, the ova are developed from the lining cells of the peritoneum and frequently from the cells surrounding parts of the vascular system (Bonellia, Thalassema). In many cases (Sipunculus, Phascolosoma, Echiurus) the main growth of the ovum takes place after it has been dehisced into the body cavity.

In Sipunculus the ova in the body cavity are surrounded by. a follicle which is thrown off before they become ripe.

Brandt denies the existence of this follicle or rather its cellular nature Spengel's (43) observations are conclusive in favour of the correctness of the original interpretation of Keferstein and Ehlers. The follicles would seem to be formed after the ova have become free. In Phascolosoma there is no follicle (Semper, Spengel).

In both Phascolosoma and Sipunculus a vitelline membrane with radial pores-zona radiata-is formed, and in Phascolosoma the external part of this is separated off as a structureless vitelline membrane. The formation of both these membranes from the protoplasm of the ovum is rendered certain in the latter case by the absence of a follicular epithelium.

Some interesting observations on the growth and origin of the ovum in Bonellia have been made by Spengel.

The ova originate from certain cells (germinal cells) in the peritoneal investment of the ventral vessel, overlying the nervous cord. These cells, which are well marked off from the surrounding flattened peritoneal elements, increase in number by division, and form small masses surrounded by a follicle of peritoneal cells, and attached by a stalk to the peritoneum. The central cell of each mass grows larger than the rest, which arrange themselves in a columnar fashion round it; it is not, however, destined to become the ovum. On the contrary certain of the other cells adjoining the stalk grow larger, and finally one of these becomes distinguished as the ovum by its greater size and 
the character of its nucleus. The remainder of the larger cells become of the same size as their neighbours. The ovum now becomes more or less separate from the mass of germinal cells, rapidly grows in size, and soon forms the most considerable constituent of the follicle (fig. I6,ov). The remaining germinal cells are quite passive, and though, with the exception of the central cell, they do not appear to atrophy, they soon constitute a relatively small prominence on the surface of the ovum. By the rupture of the stalk the whole follicle becomes eventually detached, and the further development of the ovum takes place in the body cavity. A vitelline membrane is formed, and eventually the ovum is taken into the oviduct (segmental organ). At this time or slightly before,

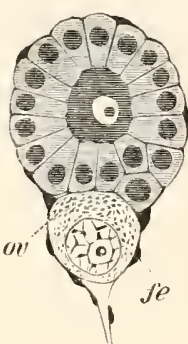

Fig. I6. FOLLICLE OF BONELLIA AT A MEDIUM STAGE OF DEVELOPMENT. (After Spengel.)

ov. ovum. $f e$. flattened follicular epithelium. the follicle cells together with the germinal mass, which throughout exhibits no signs of atrophy, become thrown off, and the ovum is left invested in its vitelline membrane.

\section{NEMATODA.}

(44) Ed. Claparède. De la formation ct de la fécondation des aufs chezles Vers Nématodes. Genève, I859.

(45) R. Leuckart. Dic menschlichen Parasiten.

(46) II. M unk. "Ueb. Ei- u. Samenbildung u. Befruchtung b. d. Nematoden." Zeit. f. wiss. Zool., Vol. IX. 1858 .

(47) H. Nelson. "On the reproduction of Ascaris mystax, etc." Phil. Trans. I 852.

(48) A. Schneider. Monographie d. Nematoden. Berlin, I 866.

The female organs consist as a rule of two cæcal tubes which unite before opening to the exterior. Each of these is divided into a vagina, uterus, oviduct, and ovary. The ovary constitutes the blind end of the tube, and is formed of a common protoplasmic column, holding a number of nuclei in suspension. The protoplasm becomes cleft around the nuclei in the uppermost part of the tube; the circumscription of the ova proceeds, however, very gradually, and since it commences at the periphery of the column the ova remain attached by stalks to a central axis with one end free. In this way there is formed a rod-like 
structure known as the rachis, which consists of a central axis with a series of half circumscribed ova radiately arranged round it. In the lowest part of the ovary the ova become completely isolated and form separate cells.

The protoplasm of the ova, which is clear in the terminal division of the ovary, becomes in most forms filled lower down with yolk-spherules secreted in the body of the ova. These commence to appear at the uppermost extremity of the rachis.

In some instances, c.g. Cucullanus elegans, yolk-spherules are not formed. In the Oxyuridæ the ova are directly segmented off from the terminal syncytium of protoplasm without the intervention of a rachis; and are therefore formed in the same way as amongst Trematodes, etc.

The origin of the membrane around the ova of the Nematoda has been much disputed.

At the time when the ovum is detached from the rachis no membrane is present, but it nevertheless appears from Schneider's observations that the region at which it is detached is softer than other parts, so that a kind of micropyle is here formed which disappears after impregnation. A delicate vitelline membrane then appears, around which there is subsequently established an egg-shell, which is usually stated to be formed as a secretion of the walls of the uterus; but Schneider and Leuckart have given strong grounds for believing that it is really a further differentiation of the vitelline membrane due to the activity of the protoplasm of the ovum. The originally single membrane becomes as it thickens split into two layers. The outer of these forms the true egg-shell, and the fertilization of the ovum appears to be a necessary prelude to its production. Round the eggshell the walls of the uterus often secrete a special albuminous covering.

The egg-shell exhibits in many cases peculiar sculpturings as well as terminal prolongations.

\section{INSECTA.}

(49) A. Brandt. Ueber das Ei u. scine Bildungsstïtte. Leipzig, 1878.

(50) T. H. Huxley. "On the agamic reproduction and morphology of Aphis." Limnean Trans., Vol. xxiı. i858. Vide also Manual of Invertebrated Animals, 1877.

(51) R. Leuckart. "Ueber die Micropyle u. den feinern Bau d. Schalenhaut bei den Insecteneiern." Mïller's Archiv, 1855.

(52) Fr. Leydig. Der Eierstock u. die Samentasched. Insecten. Dresden, 1866.

(53) Lubbock. "The ova and pseudova of Insects." Phil. Trans. 1859.

(54) Stein. Die weiblichen Geschlechtsorgane d. Käfer. Berlin, I8+7.

[Conf. also Claus, Landois, Weismann, Ludwig (No. 4).]

The ovum of Insects has formed the subject of numerous investigations, and has played an important part in the controversies on the nature of the ovum. 
The ovaries are paired organs, rarely directly connected, each consisting of more or fewer ovarian tubes which open into a common oviduct. The oviducts unite into a vagina, usually provided with a spermatheca and accessory glands, which need not be further alluded to. Each ovary is invested by a peritoneal covering, which assumes various characters, and either forms a loose network covering the whole or a special tunic round each egg-tube. It is continuous with the general peritoneal investment. Each ovarian tube (fig. I7) consists of three sections: (I) a terminal thread, (2) the terminal chamber or germogen, (3) the egg-tube proper.

The whole egg-tube is invested in a structureless tunica propria.

The terminal threads are fine prolongations of the ends of the egg-tubes usually continued close up to the heart. At their extremities they frequently anastomose, or even unite into a common thread. In some cases they are absent. They form either direct continuations of the germogen and have the same histological structure, or in other cases are simply prolongations of the tunica propria, and serve as ligaments.

The germogen usually consists of two parts : an upper, filled with nuclei imbedded in protoplasm, and a lower, in which distinct cells have become differentiated.

The lower part of the egg-tubes is filled with ova which advance in development towards the oviduct, and lie in chambers more or less distinctly constricted from each other. In these chambers there are in most forms in addition to the true ova a certain number of nutritive cells. The true egg-tubes are moreover lined by an epithe-

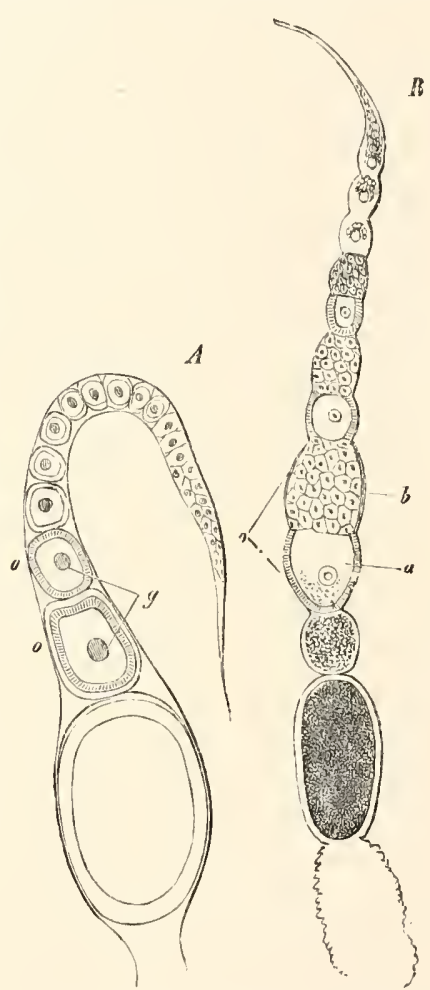

Fig. i $7 . A$. Ovarian tube of the Flea, Pulex irritans. (From Gegenbaur, after Lubbock.) $o$. ovum. g. germinal vesicle.

$B$. Ovarian tube of a Beetle, Carabus violaceus. (After Lubbock.)

$o$. ovarian segment, formed of an ovum $a$, and a mass of yolk-cells, $b$. 
lial layer which passes in and forms more or less complete septa between the successive chambers. The points which have been especially controverted are (I) the relation of the ovum to the germogen, and (2) the relation of the nutritive or yolk-cells to the ovum. To the controversies on these points it will only be possible to give a passing allusion.

As has been already hinted there are two distinct types of ovaries, viz. those without the so-called nutritive or yolkcells and those with them ${ }^{1}$.

The formation of the ovum is most simple in the type without yolk-cells, which will for that reason be first considered (fig. I 7 ).

The germogen is constituted of a number of nuclei imbedded in a scanty cementing protoplasm. In the lower part of the germogen the nuclei are larger, and become separated off from the nucleated protoplasm above, as distinct cells with a thin layer of protoplasm round the germinal vesicle. These cells are the ova. As they pass down the egg-tube their protoplasm increases in bulk, and they become isolated by ingrowths of the epithelial cells the origin of which is still uncertain, which form round each ovum a special follicle, so that the egg-tube is filled by a single row of ova each in an epithelial follicle (fig. I7 $A$ ). The larger the ova the more columnar is the epithelium of the follicle. As the oviductal extremity of the egg-tube is approached the ova increase in size, and their protoplasm is more and more filled with yolk particles.

In the lower part of the egg-tube the epithelium gives rise to a chorion.

The epithelium around each ovum has been spoken of as forming a follicle, and it is implied that the epithelium round each ovum travels down the egg-tube with the ovum. It is however by no means clear from the observations of the majority of writers that this is the case, and in fact the epithelium is generally spoken of as if it were simply the epithelium of the egg-tube. In favour of the view here adopted the following considerations may be urged.

Firstly, there is considerable evidence that the superficial layer of the germogen gives rise to the epithelial cells, simultaneously with the formation of the ova from the deeper layers.

${ }^{1}$ For a list of the genera with and without nutritive cells, vide Brandt, pp. 47 and 48 . 
Secondly, the fact that the epithelium grows in between the separate ova appears to render it almost certain that this part of the epithelium must travel down the egg-tubes with the ova.

Thirdly, the epithelium no doubt gives rise to the chorion, and considering the peculiar structure of the chorion, this seems possible only on the view that the epithelium travels down the egg-tube with the ova.

Fourthly, when, or even before, the egg is laid the epithelium undergoes atrophy, and the remains of it have been compared to the corpora lutea.

If the view about the epithelium here adopted is correct, the epithelium without doubt corresponds to the follicular epithelium of other ova, and has the same origin as the ova themselves.

The ovaries with yolk-cells differ in appearance from those without, mainly in each ovarian chamber of an egg-tube containing two elements, usually more or less distinctly separated. These two elements are (I) at the lower end of the chamber, the ovum, and (2) at the upper, large cells which gradually disappear as the ovum grows larger (fig. I $7 B$ ).

The uppermost part of the egg-tube is formed, as in the previous type, by a mass of nucleated protoplasm, but the germinal cells formed from it do not all become ova. The germinal cells leave the germogen in batches, and in each batch one of the cells may usually be distinguished from the very first as the ovum; the remainder forming the nutritive cells. In the uppermost part of the egg-tube the whole mass of each batch is very small, and the successive batches are very imperfectly constricted from each other. Gradually however both the nutritive cells and the ovum grow in size, and then as a rule, the Diptera forming a marked exception, the chamber containing a batch becomes constricted into an upper section with the nutritive cells and a lower one with the ovum. The ovum in passing down the tube becomes gradually invested by a layer of epithelial cells, which in many cases pass in and partially separate the ovum from the nutritive cells. The epithelium appears not unfrequently to be continued as a flat layer between the nutritive cells and the wall of the egg-tube.

As was first shewn by Huxley and Lubbock, the protoplasm of the ovum is often continued up as a solid cord, which terminates freely between the nutritive cells, and serves to bring to the ovum the material elaborated by them. It is present in its most primitive form in the somewhat B. II. 
aberrant ovary of Coccus. In this ovary the terminal chamber is filled with cells which are united to a central rachis, as in Nematodes, and the prolongation from the ovum is continuous with this rachis. This cord is known as the yolk-duct (Dottergang) by German writers. Although it is not generally present in a distinct form, there is always a passage connecting the ovum and yolk-cells, even when the follicular epithelium grows in and nearly separates them.

The number of nutritive cells varies from two (one ?) to several dozen. After they have reached a maximum they gradually atrophy, and are finally absorbed without apparently fusing directly with the ovum. The two types of insect ovaries appear fundamentally to differ in this. In the one type all the germinal cells develop into ova; in the other the quantity is, so to speak, sacrificed to the quality, and the majority of germinal cells are modified so as to subserve the nutrition of the few. It is still undecided whether the yolk-cells absolutely elaborate yolk particles, or are merely conveyers of nutriment to the ovum.

The egg-membranes of Insects present many points of interest, which are however for the most part beyond the scope of this work. There is always a chorion formed as a cuticular deposit of the follicle cells, which is frequently sculptured, finely perforated, etc., and is in many instances provided with a micropyle, developed, according to Leydig, at the upper end of the ovum.

Its development at this point appears to be due to the fact that the follicle is here incomplete; so that the cuticular membrane deposited by it is also incomplete.

A true vitelline membrane can in many instances be demonstrated (Donacia, etc.).

ARANEINA.

(55) Victor Carus. "Ueb. d. Entwick. d. Spinneneies." Zeit. f. wiss. Zool., Vol. II. I 850 .

(56) v. Wittich. "Die Entstehung d. Arachnideneies im Eierstock, etc." Miiller's Archiv. is 8 9.

[Conf. Leydig, Balbiani, Ludwig (No. 4), etc.]

The ova of many Araneina are remarkable for the presence in the ovum of the so-called yolk-nucleus. The ova develop from the epithelial cells lining the ovarian sack. Certain of these cells grow large and project outwards, invested by the structure- 
less membrane of the ovarian wall. The stalks of projections so formed are turned towards the lumen of the ovary, and are plugged with the epithelial cells which line the ovarian sack. When ripe, the ova pass from their sacks into the cavity of the ovary. The yolk-nucleus, which appears very early, is a solid body present in the protoplasm of the ovum. It is not found in all genera of Araneina. At its full development it exhibits in the fresh condition a granular structure, but very soon shews an irregularly concentric stratification which becomes more marked on the addition of reagents. According to Balbiani this stratification is confined to the superficial layers, while internally there is a body with all the characters of a cell. The yolk-nucleus is still found in the nearly ripe ovum, though it always disappears before development commences. It is probably connected with the nutrition of the ovum, though nothing is certainly known about its function.

\section{Crustacea.}

(57) Aug. Weismann. "Ueb. d. Bildung von Wintereiern bei Leptodora hyalina." Zeit.f. wiss. Zool., Vol. xxvir. is 76 .

[For general literature vide Ludwig No. 4 and Ed. van Beneden, No. 1.]

Amongst the many interesting observations on the Crustacean ova I will only allude to those of Weismann on the ova of Leptodora, a well-known Cladoceran form.

The phenomena of the development of the ova in this form present a close analogy with those in Insects.

The ovary is formed of ( 1 ) a germogen containing at its upper end nucleated protoplasm and lower down germinal cells in groups of four; (2) of a portion formed of successive chambers in each of which there is a row of four germinal cells. Of the four cells only the third develops into an ovum; the remainder are used as pabulum. This is the mode of development in the summer. In the winter the sacrifice of a larger number of germinal cells is required for the development of the ova; and an ovum is produced only in the alternate chambers. In the chambers where an ovum will not be formed an epithelial investment becomes first established round the four germinal cells. The four cells then coalesce, and form a spherical ball of protoplasm from which portions are budded off and absorbed by the 
investing epithelial cells, which at the same time lose their nuclei. When the whole of the central ball is thus absorbed by the epithelial cells, the latter become used by the winter ovum as food. The winter ovum at its full development is formed of a central mass of food-yolk and superficial layer of protoplasm.

\section{ChORdATA.}

\section{Urochorda. (Tunicata.)}

(58) A. Kowalevsky. "Weitere Studien ï. d. Entwicklung d. Ascidien." Archiv f. micr. Anat., Vol. vir. I87.

(59) A. Kowalevsky. "Ueber Entwicklungsgeschichte d. Pyrosoma." Arch. f. micr. Anat., Vol. XI. 1875 .

(60) Kupffer. "Stammverwandtschaft zwischen Ascidien u. Wirbelthieren." Arch.f. micr. Anat., Vol. vi. 1870.

(61) Giard. "Études critiques des travaux, etc." Archives Zool. expériment., Vol. I. 1872 .

(62) C. Semper. "Ueber die Entstehung, etc." Arbeiten a. d. zool.-zoot. Institut Würaburg, Bd. II. 1875 .

\section{Cephalochorda.}

(63) P. Langerhans. “Z. Anatomie d. Amphioxus lanceolatus," pp. 330-3. Archivf. mikr. Anat., Vol. xil. I876.

\section{Craniata.}

(61) F. M. Balfour. "On the structure and development of the Vertebrate Ovary." Quart. F. of Micr. Science, Vol. Xviri. I878.

(65) Th. Eimer. "Untersuchungen ï. d. Eier d. Reptilien." Archiv f. mikr. Anat., Vol. vili. I872.

(66) Pflüger. Die Eierstöcke d. Säugethiere u. d. Menschen. Leipzig, 1863.

(67) J. Foulis. "On the development of the ova and structure of the ovary in Man and other Mammalia." Quart.J. of Micr. Science, Vol. xvi. I876.

(68) J. Foulis. "The development of the ova, etc." Journal of Anat. and Phys., Vol. XiIr. I878-9.

(69) C. Gegenbaur. "Ueb. d. Bau u. d. Entwicklung d. Wirbelthiereier mit partieller Dottertheilung." Müller's Archiv, ı861.

(70) Alex. Götte. Entwicklungsgeschichte d. Unke. Leipzig, 1875.

(71) W. His. Untersuchungen ïb. d. Ei u.d. Eientzicklung bei Knochenfischen. Leipzig, 1873 .

(72) A. Kölliker. Entwicklungsgeschichte d. Menschen z. höherer Thiere. Leipzig, I 878 .

(73) J. M ïller. "Ueber d. zahlreichen Porenkanäle in d. Eikapsel d. Fische." Müller's Archiv, i $8_{54}$.

(74) W. H. Ransom. "On the impregnation of the ovum in the Stickleback." Pro. R. Society, Vol. vil. 1854 .

(75) C. Semper. "Das Urogenitalsystem d. Plagiostomen, etc." Arbeiten a. d. zool.zoot. Instit. IViurzburg, Vol. II. 1875 .

[Cf. Ludwig, No. 4, Ed. van Beneden, No. 1, Waldeyer, No. 6, \&c.] 
There are some very obscure points connected with the growth of the ovum of the Tunicata. When quite young the ovum is a naked cell with a central nucleus containing a single large nucleolus. Around it is a flat follicular epithelium enclosed in a membrana propria folliculi. The follicle cells soon become larger and give rise to an envelope round the egg of the nature of a chorion. At the same time they frequently become cubical or even columnar, and filled with numerous vacuoles.

During or after the completion of the above changes a number of bodies usually spoken of as test-cells make their appearance in the superficial protoplasm of the egg, which by the time the egg is ripe arrange themselves in many species as a definite layer round the periphery of the ovum. These bodies have received their name from the opinion, now known to be erroneous (Hertwig and Semper), that they eventually migrated into the test or mantle of the embryo which becomes developed round the ovum. By Kowalevsky (No. 58) these bodies are regarded as true cells, and are believed to be formed by some of the cells of the original follicular epithelium making their way into the vitellus of the ovum and multiplying there. By Kupfer (No. 60), and Giard (No. 61), and Fol, they are also regarded as true cells but are believed to originate spontaneously in the vitellus. Finally by Semper they are believed not to be cells, but to be amœboid protoplasmic bodies which are pressed out from the vitellus under the stimulus of the sea-water or otherwise.

They do not according to this author naturally appear till the ovum is quite ripe, though they can be artificially produced at an earlier period by the action of reagents or sea-water. When produced in the natural course of things the vitellus undergoes a contraction. They are without any apparent function, and play no part in the embryonic development. Semper's results are very peculiar, but owing to the careful study which his paper displays they no doubt deserve attention. Further investigations are however very desirable. Kowalevsky from his researches on Pyrosoma (No. 59) adheres to his first opinion, though he abandons the view that these cells are connected with the formation of the test.

In the passage of the egg through the oviduct the vacuolated follicle cells grow out into very peculiar long processes or villi. In Ascidia canina these processes become as long as the whole diameter of the vitellus (Kupffer, No. 60). 
In Amphioxus and the Craniata the ova are developed as in the Chætopoda, Gephyrea, etc., from specialized germinal cells of the peritoneal epithelium.

In Amphioxus the germinal epithelium which constitutes the essential part of the ovary is divided into a number of distinct segments: in the Craniata no such division is observable.

In young examples of Amphioxus the generative organs are in an indifferent condition, and the two sexes cannot be distinguished. They form isolated horse-shoe shaped masses of cells, which occupy a position at the base of the myotomes, in the intervals between the successive segments; and extend from the hinder end of the respiratory sack to the abdominal pore. They are situated in the proper body cavity, and are surrounded by the peritoneal membrane. Each generative mass is at first solid, and is formed of an outer layer of more flattened cells and an inner mass of large rounded or polygonal cells. In its interior there appears at a somewhat later period a central cavity. After the cavity has appeared the sexes can be distinguished by the different behaviour of the cells.

In all the Craniata, the ovary forms a paired ridge (unless single by abortion or fusion) attached by a mesentery to the dorsal wall of a more or less extended region of the abdominal cavity. This ridge is at first identical in the two sexes, and arises at an early period of embryonic life. It is essentially formed of a thickening of the peritoneal epithelium, and in Osseous Fish, Ganoids (?) and Amphibia the ovary remains during embryonic life nearly in this condition, though a small prominence of the adjacent stroma also becomes formed. In other Craniata the ridge, though at first in this condition, very soon becomes much more prominent, and is formed of a central core of stroma enclosed in the germinal epithelium (fig. I 8).

The thickened germinal epithelium gives rise (in the case of the female) to the ova and the follicular epithelium. Whether the genital ridge is provided with a core of stroma or no, the germinal epithelium is always in contact on one side with the stroma, from which it is at first separated by a well-marked boundary line; but after a certain time there appear numerous vascular ingrowths from the stroma, which penetrate through all parts of the germinal epithelium, and break it up into a sponge- 
like structure formed of trabeculæ of germinal epithelium interpenetrated by vascular strands of stroma. The trabecula of the germinal epithelium form the egg-tubes of Pflüger.

With reference to the distribution of the stroma in the germinal epithelium, it may be said in a general way that there is a special layer close to the surface of the ovary, which, after the formation of fresh ova has nearly ceased, completely isolates a superficial layer of the germinal epithelium from the deeper and major part of it. The superficial layer is frequently (but erroneously) regarded as constituting the whole of the germinal epithelium. The layer of stroma below the superficial epithelium forms in the mammalian ovary the tunica albuginea. As the follicles are formed in the trabeculæ of germinal epithelium the stroma grows in around them, and forms for each one of them a special tunic.

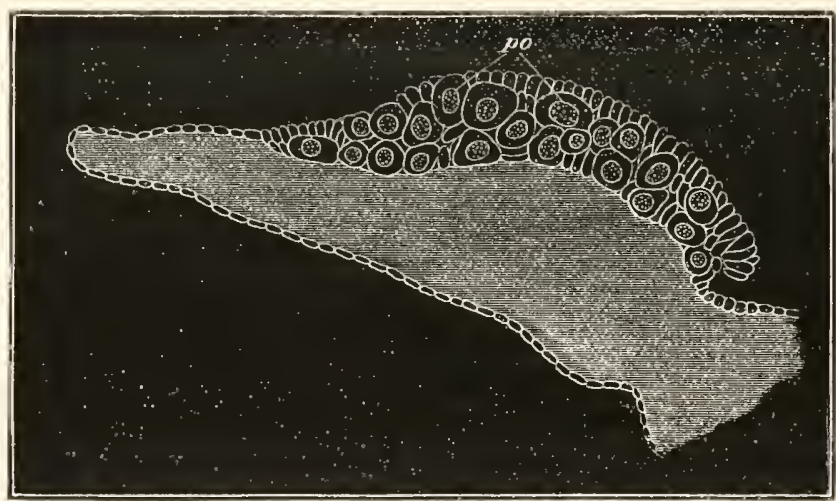

Hig. IS. TRANSYERSE SECTION THROUGH THE OVARY OF A YOUNG HMBRYU UF SCYLliUM CANICULA, TO SHEW THE PRIMITIVE GERMINAL CELLS (po) LYING IN THE GERMINAL EPITHELIUM ON THE OUTER SIDE OF THE OVARIAN RIDGE.

The adult ovaries differ in a corresponding manner to the embryonic genital ridges as to the presence of a core of stroma. The ovaries which are without such a core in the embryo, are also without it in the adult, and are formed of a double layer of tissue entirely derived from the germinal epithelium with its ingrowths of stroma, and composed, for the most part, of ova in all stages of development. In the case of the other ovaries there 
is a hilus of stroma-the zona vasculosa-internal to the eggbearing region.

In Mammalia, proportionately to the ovary, the zona vasculosa is at a maximum, and in Birds and Reptiles it is relatively far less developed. In these forms the germinal epithelium covers the whole surface of the ovary. In Elasmobranchii the structure of the ovary is somewhat different, owing to the presence in the ovarian ridge of a large quantity of a peculiar lymphatic tissue, which has no homologue in the other ovaries; and still more to the fact that the true germinal epithelium is in most forms entirely confined to the outer surface of the ovary, on which it forms a layer of thickened epithelium in the embryo (fig. 17), and of ovigerous tissue in the adult.

In the ovary of Mammalia and Reptilia and possibly other forms there are present in the zona vasculosa during embryonic life cords of epithelial tissue derived from the Malpighian bodies; these cords have no function in the female, but in the male assist in forming the seminiferous tubules.

In considering the development of the ova it is again convenient to distinguish between Amphioxus and the Craniata.

In Amphioxus the germinal cells destined to become ova are first distinguished by the larger size of their germinal vesicles and by the presence of certain refracting granules in their protoplasm. They subsequently rapidly enlarge and form protuberances on the surface of the ovary, which are enveloped for three-quarters of their circumference by the flattened epithelioid cells of the peritoneal membrane, which thus form a kind of follicle. As the ova become ripe yolk-granules are deposited in their protoplasm, first in the superficial layer and subsequently throughout. The germinal vesicle also passes from the centre to the surface. A vitelline membrane is formed when the ova are mature.

In the Craniata the ova are developed from the cells of the germinal epithelium. In the types with larger ova (Teleostei, Elasmobranchii, Amphibia, Reptilia, Aves), at a very early period, sometimes (Elasmobranchii) even before the formation of the genital ridge, certain of the cells which are destined to form ova become distinguished by their greater size, and by the possession of an abundant clear protoplasm and a large spherical granular nucleus. (Fig. I $8, p o$.) Such special cells form primitive germinal cells, and are common to both sexes.

For a considerable period after their first formation these cells remain stationary in their development; but their number in- 
creases, partly, it appears, by an addition of fresh ones, and partly by division. Owing to the latter process the germinal cells come to form small masses or nests. The following description of the further changes of these cells in the female refers in the first instance to Elasmobranchii, but holds good in most respects for other types as well.

It is convenient to distinguish two modes in which the primitive germinal cells may become converted into permanent ova, though the morphological difference between the two modes is of no great importance.

In the first mode the protoplasm of all the cells forming a nest unites into a single mass containing the nuclei of the previously independent ova (fig. I9, $n n$ ). The nuclei in the nest increase in number, probably by division, and at the same time the nest itself increases in size. The nuclei while increasing in

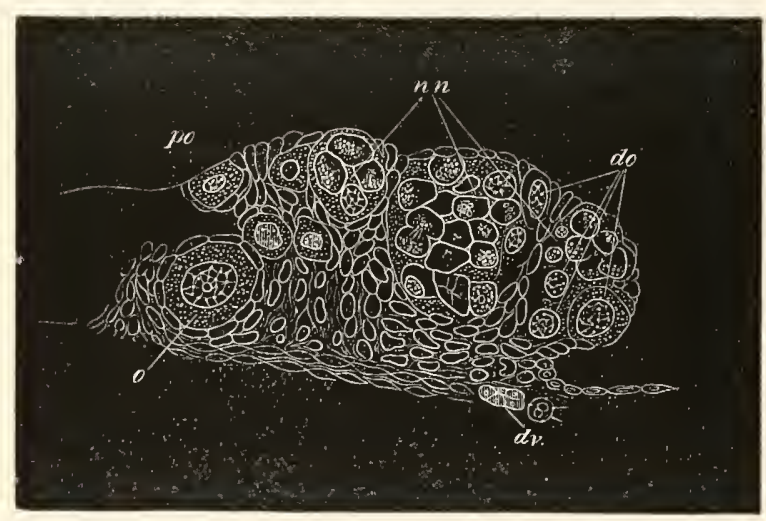

Fig. i9. Section thirough part of the germinal epithelium of the ovary of Scyllium at the time When the primitive grrminal cells are BECOMING CONVERTED INTO OVA.

$n n$. Nests formed of agglomerated germinal cells. The nuclei of these cells are imbedded in undivided protoplasm. do. developing ova. o. ovum with follicle. po. primitive germinal cell. $d v$. blood-vessels.

number also undergo important changes. A segregation of their contents takes place, and the granular part (nuclear substance) forms a mass close to one side of the membrane of the nucleus, while the remainder of the nucleus is filled with a clear fluid. The whole nucleus at the same time increases somewhat in size. The granular mass gradually assumes a stellate form, and finally 
becomes a beautiful reticulum, of the character so well known in nuclei (fig. 19, do). Two or three special nucleoli are present, and form the nodal points of the reticulum, while its meshes are filled up with the clear fluid constituents of the nucleus. Not all the nuclei undergo the above changes; but some of them stop short in their development, undergo atrophy, and appear finally to be absorbed as pabulum by the protoplasm of the nest. Such nuclei in a state of degeneration are shewn in fig. 19. Thus only a few nuclei out of a nest undergo a complete development. At first the protoplasm of the nest is clear and transparent, but as the nuclei undergo their changes the protoplasm becomes more granular, and a specially large quantity of granular protoplasm is generally present around the most developed nuclei, and these with their protoplasm gradually become constricted off from the nest, and constitute the permanent ova (fig. 19, do). The relative number of ova which may develop from a single nest is subject to great variation. The object of the whole occurrence of the fusion of primitive ova and the subsequent atrophy of some of them is to ensure the adequate nutrition of a certain number of them.

In the second and rarer mode of development of permanent ova from primitive germinal cells, the nuclei and protoplasm undergo the same changes as in the first mode, but the cells either remain isolated, and never form part of a nest, or form part of a nest in which no fusion of protoplasm takes place, and in which all the cells develop into permanent ova.

The isolated ova and nests are situated, during the whole of the above changes, amongst the general undifferentiated cells of the germinal epithelium, but as soon as a permanent ovum becomes formed the cells adjoining it arrange themselves around it as a special layer, and so give rise to the epithelium of the follicle (fig. 19,o). The growths of stroma into the germinal epithelium appear shortly after the formation of the earlier follicles.

Mammalia. The development of the ovary in Mammalia differs mainly from that just described in that the formation of primitive germinal cells from the indifferent cells of the germinal epithelium takes place at a relatively much later period.

The stroma grows into the germinal epithelium while it is still formed of rounded indifferent cells, and divides it into trabeculæ 
as described above. At a later period a number of the cells in the deeper layer of the epithelium, as well as certain cells in the superficial part, become primitive germinal cells, while the remainder of the cells become smaller and are destined to form the follicle cells.

The most conspicuous primitive germinal cells are situated in the superficial layer of epithelium ; and the primitive germinal cells in the deeper layers of the germinal epithelium are not nearly so marked as in most Craniata, so that it is difficult in some cases to be sure of their destination till their nucleus commences to undergo its characteristic metamorphosis.

The change of the primitive ova into permanent ova takes place in the same manner in Mammals as in Elasmobranchii, except that the fusion of the primitive ova into polynuclear masses is much rarer. The formation of the at first quite simple follicles takes place while the ova are still aggregated in large masses; and the first follicles are formed in the innermost part of the germinal epithelium. Soon after their formation the follicles become isolated by connective-tissue growths.

\section{Post-embryonic development of the ova.}

The ova of the Vertebrata differ greatly in size and structure. The differences in size depend upon the quantity of the foodyolk. In the Amphioxus and Mammalia, in which the ova are smallest, the comparatively insignificant amount of food-yolk is distributed uniformly through the ovum. A larger quantity of it is present in the ova of Amphibia, Marsipobranchii and Teleostei, and it attains an immense development in the ova of Elasmobranchii, Reptilia, and Aves.

The food-yolk originates from a differentiation of the protoplasm of the egg. It arises as a number of small highly refracting particles in a stratum slightly below the surface.

In the Mammalian ovum these particles spread through the protoplasm of the egg, but do not attain any considerable development. In other forms the case is different. In Elasmobranch Fishes the refracting particles appear to develop into vesicles, in the interior of which there arise solid oval or even rectangular highly refracting bodies, in the substance of which a stratification may usually be observed, which gives them 
an appearance not unlike that of striated muscle. In Teleostei the yolk assumes very different characters in different cases. It is often formed of larger or smaller vesicles containing in their interior other bodies. Stratified plates like those of Elasmobranchii are also not uncommon. In the ripe ovum of Teleostei the food-yolk usually resolves itself into a large vitelline sphere, which occupies the greater part of the ovum, and is formed of a highly refracting fluid material which coagulates on the addition of water. It contains in many instances one or more highly refracting bodies known as oil globules, and is invested by a granular protoplasmic layer continuous with the germinal disc, in which a number of normal yolk-spherules are frequently present. In the ovum of the Herring ${ }^{1}$ no distinct investing protoplasmic layer or germinal disc is present till after impregnation, but the ovum is formed of a superficial layer with minute yolk-spherules, and of a central portion with larger yolk-spheres.

In Amphibia the yolk very often appears in the form of oval or quadrilateral plates. In Reptilia the yolk-spherules are vesicles, somewhat similar to the white yolk-spheres of Aves, but as a rule without the highly refracting spheres in their interior. The peculiar and complicated arrangement and structure of the white and yellow yolk in Birds is fully described in the "Elements of Embryology," and it need only be said that the yolk develops in Birds in the same manner as in other types, and that at first all the yolkspherules appear in the form of white yolk. The yellow yolk-spheres are a peculiar modification of white yolk-spheres, formed comparatively late in the development of the egg (fig. 20).

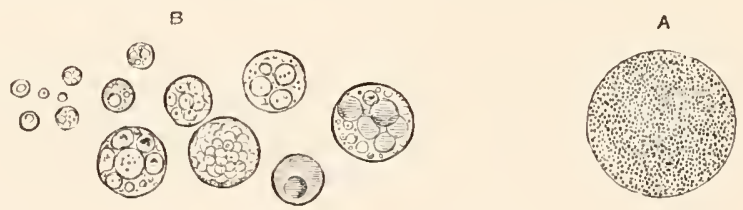

Fig. 20. YOLK ELEMENTS From THE EGG OF THE FOWL. $A$. Yellow yolk. $B$. White yolk.

In the eggs of many Amphibia a dark granular mass known as the yolk nucleus makes its appearance; and is supposed, without any very clear evidence, to be related to the formation of the yolk.

A body in the form of a shell enclosing a dark nucleus, which is perhaps of the same nature, has been described by Eimer in the Reptilian egg: it eventually resolves itself into a number of angular fragments. In Elasmobranchii a similar body is perhaps present.

The food-yolk just described is imbedded in the active protoplasmic portion of the body of the ovum. In the case of the

${ }^{1}$ Kuyffer, Laichen u. Entwicklung des Ostsee-Härings. Berlin, I878. 
mammalian ovum the food-yolk is fairly uniformly distributed, but in the case of all other craniate ova the protoplasm of the ovum is especially concentrated at one pole, which is known as the upper or animal pole, and the food-yolk is more especially concentrated at the opposite pole. The Herring's ovum forms an apparent exception to this statement, in that the concentration of the protoplasm to form the germinal disc does not take place till after impregnation. In Amphibia the animal pole is mainly marked by the smaller size of the yolk-spherules, but in most other forms a small portion of the ovum in the region of the germinal vesicle is nearly free from yolk-spherules, and then forms a more or less specialized part known as the germinal disc. In Aves, Reptilia, and Elasmobranchii the germinal disc shades off insensibly into the yolk; but in Teleostei it is more sharply marked off, and is continued more or less completely round the periphery of the ovum. In ova with true germinal discs it is the germinal disc alone which undergoes segmentation. The protoplasm of vertebrate ova frequently exhibits a reticulate or sponge-like structure (fig. $2 \mathrm{I}$ ) and the reticulum in many cases, e.g. Elasmobranchii and Reptilia, serves to hold the yolkspheres together. In the Tench it has been observed by Bambeke to penetrate into the vitelline sphere.

In the ova of the Craniata the germinal vesicle is generally polynucleolar. In Amphioxus and Petromyzon there is however but a single nucleolus, and in Mammalia there is usually one special nucleolus and two or three accessory ones. The opposite extreme is reached in many osseous fish where the nucleoli are extremely numerous. The protoplasmic reticulum of the embryonic germinal vesicle may in some instances be retained till the ovum is nearly ripe, but usually assumes a very granular form. It is at first connected with the nucleoli which form nodal points in it, but this relation cannot always be detected in the later stages. A membrane, which in the case of the larger ova becomes very thick, is always present round the germinal vesicle. It is said to be perforated in some Reptilian ova (Eimer). As to the position of the germinal vesicle, it is at first situated in the centre of the ovum, but always eventually travels to the animal pole, and as the egg becomes ripe undergoes changes which will be more especially detailed in the next 
chapter. In the ova with a large amount of food-yolk it assumes an eccentric position very early.

The homologies of the primary egg-membranes of Craniata are still involved in some obscurity. There seem to be three membranes, which may all coexist, and of which one or more are almost always present. These membranes are-

(I) An outermost usually homogeneous non-perforated membrane, which is by most authors regarded as a chorion, but is probably a vitelline membrane-by which name I shall speak of it.

(2) A radiately striated membrane (internal to the former when the two cocxist) which can be broken up into a series of separate columns. These give to the membrane its radiate striation, but it is probable that between the columns there are pores sufficiently large to admit of the passage of protoplasmic filaments. This membrane will be spoken of as the zona radiata. It is a differentiation of the outermost layer of the yolk.

(3) Within the zona radiata a third and delicate membrane is occasionally found, especially when the ovum is approaching maturity.

In Elasmobranchii the first membrane to be formed is the vitelline membrane, which appears in some instances before the formation of the follicle-a fact which appears to shew that it is really formed as a differentiation of the protoplasm of the egg. In most Elasmobranchii this membrane attains a very considerable development. A zona radiata is generally (if not always) present in Elasmobranchii, but arises at a later period than the vitelline membrane (fig. $2 \mathrm{I}$, $Z n$ ). The zona radiata always disappears long before the ovum is ripe. The vitelline membrane also gradually atrophies, though it lasts much longer than the zona radiata.

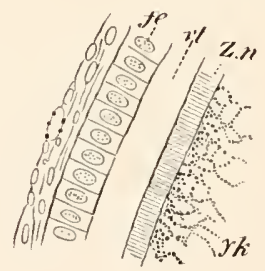

Fig. 2I. SECTION THROUGH A SMALL PART OF THE SURFACE OF AN OVUM OF AN IMMATURE FEMALE OF SCYLliUM CANICULA. $f e$. follicular epithelium. vitelline membrane. $Z n$. zona radiata. $y k$. yolk with protoplasmic network. When the egg is taken up by the oviduct all trace of both membranes has vanished. In Reptilia precisely the same arrangements of the membranes are found as in Elasmobranchii, except that as a rule the zona radiata is relatively more important. 
The vitelline membrane is thin except in the Crocodilia. The third innermost membrane is found according to Eimer in many Reptilia. In birds both vitelline membrane and zona radiata are present, but the latter atrophies early, leaving the former as the sole membrane when the egg is ripe.

In osseous fish the vitelline membrane is usually either absent or may perhaps in some instances, e.g. the Perch, be imperfectly represented. In the ripe ovum of the Herring there is a distinctly developed membrane external to the zona radiata which is probably the vitelline membrane. The zona radiata attains a very great development, and is generally provided with knobs of various shapes on its outer surface. A delicate membrane internal to this--my third membrane-has often been described, but there is still some doubt about its existence. In some cases an external less granular layer of the ovum itself has been described as a special membrane. In the Perch a peculiar mucous capsule, penetrated by irregular branched prolongations of the follicle cells, is present in addition to the ordinary membranes. In Petromyzon a zona radiata appears to be present, which in the adult is divided into two layers, both of them radiately striated according to Calberla, but according to Kupffer and Benecke the outer one is not perforated, and would appear therefore to be a vitelline membrane as defined above. A delicate membrane is formed at a comparatively late period around the ova of the Amphibia, and is stated (Waldeyer, No. 6, and Kolessnikow) to have a delicate radial striation. It probably corresponds with the zona radiata.

In Mammalia a radiately striated membrane-the zona radiata-is generally described as being present, and internal to it, in the nearly ripe egg, a delicate membrane has been shewn by $\mathrm{E}$. van Beneden to exist. Externally to the zona radiata there may be observed a granular membrane irregular on its outer surface on which the cells of the discus are supported. This membrane is more or less distinctly separated from the zona radiata; and by tracing back its development it appears very probable that it is the remnant of the first-formed membrane in the very young ovum, and therefore the vitelline membrane.

A micropyle (first discovered by Ransom, No. 74) is present in a large number of osseous fish and in Petromyzon (Calberla). 
Doubts have been thrown on its existence in the latter form by Kupffer and Benecke; and at any rate it would only seem to perforate the zona radiata. In the osseous fish in which it has been detected, Salmonidæ, Percidæ (Gasterosteus), Clupeidæ, etc., it forms a minute perforation of the zona radiata at the animal pole, just large enough to admit a single spermatozoon. Its characters differ slightly in different cases, but there is usually a shallow depression, in the centre of which it is situated.

The eggs of all Craniata (except Petromyzon (?)) appear to be enclosed in a cellular envelope known as the follicle. The cells which form this are, as has been already explained, derived from the germinal epithelium ${ }^{1}$, and frequently arrange themselves around the ovum before the appearance of the growths of stroma into the epithelium. All young follicles are nearly alike, but as they grow older they exhibit various modifications in the different groups. They retain their simplest condition as a flat epithelial layer in most osseous fish and Amphibia. In most other forms the cells become at some period columnar, and are generally arranged in two or more layers. There is formed externally to the epithelium a delicate membrane-the membrana propria folliculi-which is in its turn enclosed in a vascular connective-tissue sheath.

In Elasmobranchii and many Reptilia (Lacertilia, Ophidia) some of the cells become much larger than the others, and assume a funnel-shaped form with the narrow end in contact with the egg-membrane. These large cells, which have a regular arrangement in the epithelium, are probably in some way connected with the nutrition. They have only been noticed in large-yolked ova. Many observers have described prolongations of the follicle cells through the pores of the zona radiata in Aves, Reptilia and Teleostei.

The most remarkable modification of the follicle is that which is found in Mammalia. At first the follicle is similar to that of other Vertebrata, and is formed of flat cells derived from the germinal cells adjoining the ovum. These cells next become columnar and then one or two layers deep. Later they become

${ }^{1}$ For the different views maintained by Foulis, Kölliker, etc. the reader is referred to the writings of these authors. The grounds for the view here adopted will be found in my paper (No. 64). 
thicker on one side than on the other, and there appears in the thickened mass a cavity, which gradually becomes more distended and is filled with an albuminous fluid. As the cavity enlarges, the ovum with several layers of cells around it forms a prominence projecting into it. The whole structure with its tunic is known as the Graafian follicle. The follicle cells are known as the membrana granulosa, and the projection, in which the ovum lies, as the discus or cumulus proligerus. The cells of the discus in immediate contiguity to the ovum usually form a more or less specialized layer and are somewhat more columnar than the adjoining cells.

\section{The Spermatozoon.}

Although there is no doubt that the spermatozoon in most instances plays as important a part as the ovum in influencing the characters of the organism which is evolved from the coalesced product of the ovum and spermatozoon, yet the actual form of the spermatozoon has not, like the form of the ovum, a secondary influence on the early phases of development. A comparative history of the spermatozoon is therefore of less importance for my purpose than that of the ovum; and I shall confine myself to a few remarks on its general structure, and mode of growth. The primary origin of the male germinal cells, and their relation to the sperm-forming cells, is dealt with in the second part of the treatise.

Although the minute size of most spermatozoa places great difficulties in the way of a satisfactory investigation of them, yet there can be but little doubt that they always have the value of cells. In the vast majority of instances the spermatic cell or spermatozoon is composed of (I) a spherical or oval portion known as the head, formed of a nucleus enveloped in an extremely delicate layer of protoplasm, and (2) of a motile protoplasmic flagellum known as the tail; which together with the investing layer of the head forms the body of the cell.

As might be anticipated, the proportion, size, and relations of the parts of the spermatozoon are subject to great variations. The head is often extremely elongated; and it is in many cases rather on theoretical grounds, than as a result of actual observa-

B. II. 
tion, that a protoplasmic layer is stated to be continued round the nucleus which forms the main constituent of the head. In some of the elongated forms of spermatozoa, e.g. in Insecta, there is no marked distinction, except in the character of the protoplasm, between the head and the tail. A connecting element is frequently interposed between the head and tail, which appears however to be constituted of the same material as the tail, and sometimes forms a thickening on the tail close below the head (Amphioxus). A very remarkable modification of the tail is found in many Amphibia, Reptilia and Mammalia. In these types there is attached to what appears to be a normal tail a delicate membrane, the outer edge of which is thickened to form a kind of secondary filament. In the living spermatozoon this filament is in a state of constant movement. The membrane winds spirally round the tail.

In the majority of forms the tail of the living spermatozoon exhibits sinuous cilia-like movements. In two groups the movements are however of an amoboid character. These groups are the Nematoda and the Crustacea; and the spermatozoa in both of them frequently present very abnormal forms. In Nematoda they are pear-shaped, cylindrical, spine-shaped, etc., and are mainly formed of protoplasm with a highly refracting nucleus. In the Crustacea the variations of form are still greater. In the Malacostraca they are sometimes simply spherical (Squilla), while in Astacus and a large number of Decapoda they are composed of a nucleated body with stellate rays. In Paludina amongst the Mollusca there are two forms of completely developed spermatozoa existing side by side in the same individual.

The spermatozoa are formed by the breaking up of the male germinal cells, or of cells secondarily derived from them by division. The cells which directly give rise by division to the spermatozoa may be called spermospores and are equivalent to the ova or oospores.

Amongst the Sponges (Halisarca, Schultze, No. 141) a germinal cell, similar to that which in the female becomes an ovum, repeatedly divides and eventually gives rise to a ball of cells (a spermosphere or sperm-morula), each constituent cell of which becomes converted into a spermatozoon, and may be designated by the special term 'spermoblast.' 
In most Hydrozoa the subepithelial epiblastic cells become converted into germinal cells (spermospores), and then break up to form spermoblasts, each of which becomes a spermatozoon.

In most higher Metazoa the spermospores usually form the epithelium of an ampulla or tube, though more rarely (many Chætopoda, Gephyrea, etc.) they may be derived from cells lining the body-cavity, as in the case of ova. The spermatozoa are formed either by the direct division of the spermospores into a number of cells, spermoblasts, each of which grows into a spermatozoon; or by the nucleus of the spermospore becoming subdivided within the cell body, the latter differentiating itself into the tails of the spermatozoa while the segments of the nucleus give rise to the main part of the heads.

In many instances interstitial cells which do not give rise to spermatozoa, are intermingled with the spermospores.

In a good many cases, as first pointed out by Blomfield ${ }^{1}$, the whole of each spermospore does not become converted into spermatozoa, but part, either with or without a segment of the original nucleus, remains passive, and carrying as it does the off-budded spermoblasts may be called the 'sperm-blastophor:' This passive portion of protoplasm is not employed in the regeneration of the spermoblast. This very singular phenomenon has been observed in Elasmobranchii, the Frog, the Earthworm, Helix, etc. ${ }^{2}$, and probably has a much wider extension. In Elasmobranchii (Semper) the passive portions of protoplasm are nucleated, and are placed on the outer side of the columnar spermospores which line the testicular ampullæ; they are not distinctly differentiated till the nuclei, segmented from the nucleus of the primitive spermospore to form the heads of the spermatozoa, have become fairly numerous. In the Frog the passive blastophor also occurs as a nucleated mass of protoplasm on the outer side of the spermospore. In the Earthworm the blastophor forms a central non-nucleated portion of the spermospore; and the whole periphery of each spermospore becomes converted into spermoblasts.

It has been already stated in the introduction that the male and female generative products are homodynamous, but the consideration of the development of the products in the two sexes shews that a single spermatozoon is not equivalent to an ovum, but rather that the whole of the spermatozoa derived from a spermospore are together equivalent to one ovum.

1 Quart. Fourn. of Micro. Science, Vol. xx. I8so.

2 Blomfield, loc. cit., p. $8_{3}$, states that he has observed this fact in Lumbricus, Tubifer, Hirudo, Helix, Arion, Paludina, Rana, Salamandra, and Mus. 


\section{CHAPTER II.}

THE MATURATION AND IMPREGNATION OF 'THE OVUM.

\section{Maturation of the ovum and formation of the polar bodies.}

In the preceding chapter the changes in the ovum were described nearly up to the period when it became ripe, and ready to be impregnated. Preparatory to the act of impregnation there take place however a series of remarkable changes, which more especially concern the germinal vesicle.

The attention of a large number of investigators has recently been directed to these changes as well as to the phenomena of impregnation. The results of their investigations will be described in the present chapter ; but for an historical account of these investigations, as well as for a determination of the delicate questions of priority, the reader is referred to Fol's memoir (No. 87), and to a paper by the author (No. 81).

The nature of the changes which take place in the maturation of the ovum may perhaps be most conveniently displayed by following the history of a single ovum. For this purpose the eggs of Asterias glacialis, which have

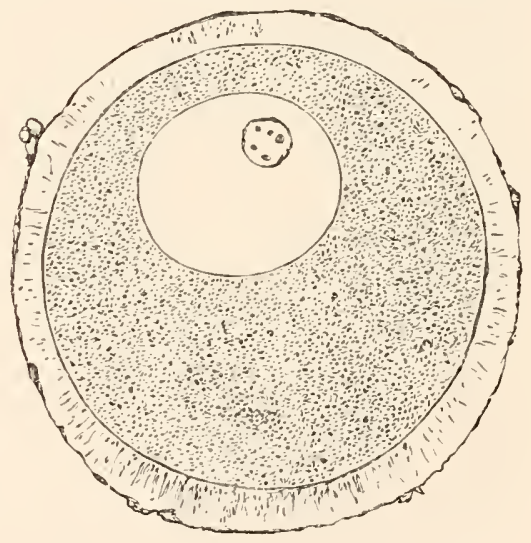

Fig. 22. RIPE OVUM OF Asterias GLACIALIS ENVELOPED IN A MUCILAGINOUS ENVELOPE, AND CONTAINING AN ECCENTRIC GERMINAL VESICLE AND GERMINAL SPOT (copied from $\mathrm{Fol}$ ). recently formed the subject of a series of beautiful researches by Fol (87), may be selected.

The ripe ovum (fig. 22), when detached from the ovary is formed of a granular vitellus enveloped in a mucilaginous coat, 
the zona radiata. It contains an eccentrically-situated germinal vesicle and a germinal spot. In the former is present the usual protoplasmic reticulum. As soon as the ovum reaches the seawater the germinal vesicle commences to undergo a peculiar metamorphosis. It exhibits frequent changes of form, the reti-
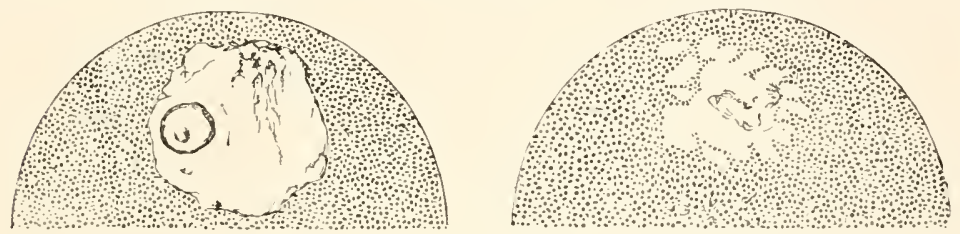

Fig. 23. Two successive stages in the gradual metamorphosis of the GERMINAL VESICLE AND SPOT OF THE OVUM OF ASTERIAS GLACIALIS IMMEDIATELY AFTER IT IS LAID (copied from Fol).

culum vanishes, its membrane becomes gradually absorbed, its outline indented and indistinct, and finally its contents become to a certain extent confounded with the vitellus (fig. 23).

The germinal spot at the same time loses its clearness of outline and gradually disappears from view.

At this stage, and between it and the stage represented in fig. 26 , the action of reagents brings to light certain appearances the nature of which is not yet fully cleared up for Asterias, which have been described somewhat differently by Fol for Ast. glacialis and Hertwig for Asteracanthion.

Fol finds immediately after the stage just described that a star is visible between the remains of the germinal vesicle and the surface of the egg, which is connected with an imperfectlyformed nuclear spindle extending towards the germinal vesicle ${ }^{1}$. At the end of the nuclear spindle may be seen the broken up fragments of the germinal spot.

At a slightly later stage, in the place of the original germinal vesicle there may be observed in the fresh

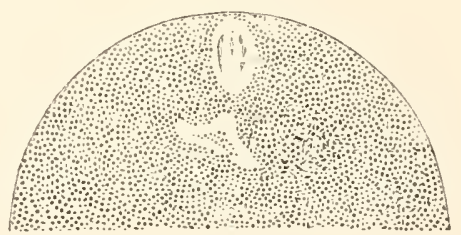

Fig. 24 . Ovum of Asterias glaCIALIS, SHEWING THE CLEAR SPACES IN THE PLACE OF THE GERMINAL VESICLE. FRESH PREPARATION (copied from $\mathrm{Fol}$ ).

${ }^{1}$ By the term 'nuclear spindle' I refer to the peculiar form of a double striated cone assumed by the nucleus just before division, which is no doubt familiar to all my readers. I use the term star for the peculiar stellate figure usually visible at the poles of the nuclear spindle. For a further description of these parts the reader is referred to Chapter IV. 
ovum two clear spaces (fig. 24), one ovoid and nearer the surface, and the second more irregular in form and situated rather deeper in the vitellus. In the upper space parallel striæ may be observed. By treatment with reagents the first clear space is found to be formed of a horizontally-placed spindle with two terminal stars, near which irregular remains of the germinal spot may be seen. Slightly later (fig. 25) there may be seen on the lower side of the spindle a somewhat irregular body, which may possibly be part of the remains of the germinal spot, though Fol holds that it is probably part of the membrane of the germinal vesicle. The lower clear space visible in the fresh ovum now contains a round body, fig. 25. Fol concludes that the spindle is formed out of part of the germinal vesicle and not from the germinal spot, while he sees in the round body present in the lower of the two clear spaces the metamorphosed germinal spot. He will not, however, assert that no fragment of the germinal spot enters into the formation of the spindle.

The following is Hertwig's (No. 92) account of the changes in the germinal vesicle in Asteracanthion. Shortly after the egg is laid the protoplasm on the side of the germinal vesicle towards the surface of the egg

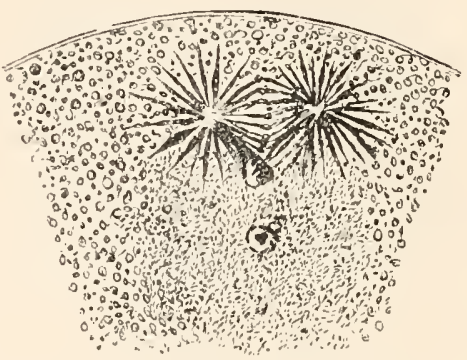

Fig. 25. OvUM OF Asterias glaCIALIS, AT THE SAME STAGE AS FIG. 24 , TREATED WITH PICRIC ACID (copied from Fol). develops a prominence which presses inwards the wall of the vesicle. At the same time the germinal spot develops a large vacuole, in the interior of which is a body consisting of nuclear substance, and formed of a firmer and more refractive material than the remainder of the germinal spot. In the prominence first mentioned as projecting inwards towards the germinal vesicle first one star, formed by radial strix of protoplasm, and then a second make their appearance; while the germinal spot appears to have vanished, the outline of the germinal vesicle to have become indistinct, and its contents to have mingled with the surrounding protoplasm. Treatment with reagents demonstrates that in the process of disappearance of the germinal spot the nuclear mass in its vacuole forms a rod-like body, the free end of which is situated between the two stars which occupy the prominence indenting the germinal vesicle. At a later period granules may be seen at the end of the rod and finally the rod itself vanishes. After these changes by the aid of reagents there may be demonstrated a spindle between the two stars, which Hertwig believes to grow in size as the last remnants of the germinal spot gradually vanish, and he maintains that the spindle is formed at the expense of the germinal spot. The stage with this spindle corresponds with fig. 25 .

Several of Hertwig's figures closely correspond with those of $\mathrm{Fol}$, and considering how conflicting is the evidence before us, it seems necessary 
to leave open for Asterias the question as to what parts of the germinal vesicle are concerned in forming the first spindle.

A clearer view of the phenomena which take place at this stage has been obtained by $\mathrm{Fol}_{\mathrm{O}}$ in the case of Heteropods (Pterotrachæa). In the ovum a few minutes after it has been laid the germinal vesicle becomes very pale, and two stars make their appearance round a clear substance near its poles. The nucleus itself is somewhat elongated, and commences to exhibit at its poles longitudinal striæ, which gradually extend towards the centre at the expense of the nuclear reticulum, from a metamorphosis of which they are directly derived. When the strix of the two sides have nearly met, thickenings may be observed in the recticulum between them, which give rise, where the striæ of the two sides unite, to the central thickenings of the fibres (nuclear plate). In this way a complete nuclear spindle is established ${ }^{1}$.

The important result of Fol's observations on Heteropods, which tallies also with what is found in Asterias, is that a spindle with two stars at its poles is formed from the metamorphosis of the germinal vesicle and surrounding protoplasm (fig. 25).

Polar cells. The spindle has up to this time been situated with its axis parallel to the surface of the egg, but in somewhat older specimens a vertical spindle is found, with one end projecting into a protoplasmic prominence which makes its appearance on the surface of the egg (fig. 26). Hertwig believes that the spindle simply travels towards the surface, and while doing so changes the direction of its axis. Fol asserts, however, that this is not the case, but that between the two phases of the spindle an intermediate one is found in which a

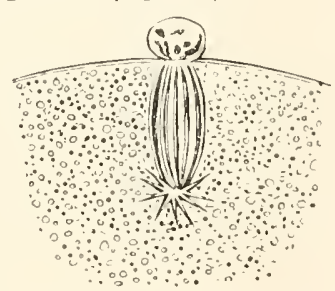

Fig. 26. Portion OF THE OVUM OF ASTERIAS GLACIALIS AT THE MOMENT OF THE DETACHMENT OF THE FIRST POLAR BODY AND THE WITHDRAWAL OF THE REMAINING PART OF THE SPINDLE WITHIN THE OVUM. PICRIC ACID PREPARATION (copied from $\mathrm{Fol}$ ). spindle can no longer be seen in the egg, but its place is taken by a body with a dentated outline. He has not been able to arrive at a conclusion as to what meaning is to be attached to

1 For the further details on the nuclear spindle vide the next Chapter. 
this occurrence, which does not appear to take place in Heteropods.

In any case the spindle which projects into the prominence on the surface of the egg divides into two parts, one in the prominence and one in the egg (fig. 26). The prominence itself with the enclosed portion of the spindle becomes constricted off from the egg to form a body, well known to embryologists

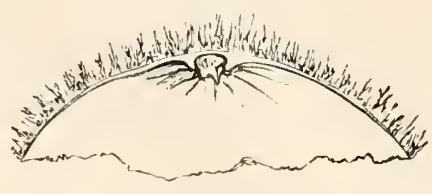

Fig. 27. Portion of the ovum of Asterias glacialis, with the FIRST POLAR CELL AS IT APPEARS WHEN LIVING (copied from Fol). as the polar body or cell (fig. 27). Since more than one polar cell is formed, that which is the earliest to appear may be called the first polar cell.

The part of the spindle which remains in the egg becomes directly converted into a second spindle by the elongation of its fibres, without passing through a typical nuclear condition. A second polar cell next becomes formed in the same manner as the first (fig. 28), and the portion of the spindle remaining in the egg be-

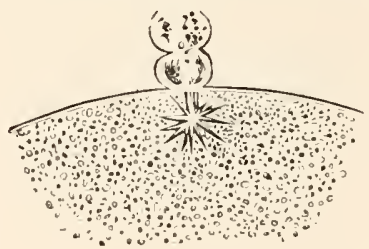

Fig, 28. PORTION OF THE OVUM OF ASTERIAS glacialis IMIEDIATELY AFTER THE FORMIATION OF THE SECOND POLAR CELL. PICRIC ACID PREPARATION (copied from Fol). comes converted into two or three clear vesicles (fig. 29), which soon unite to form a single nucleus (fig. 30). The new nucleus which is clearly derived from part of the original germinal vesicle is called the female pronucleus, for reasons which will appear in the sequel.

The two polar cells appear to be situated between two membranes, the outer of which is very delicate, and only distinct where it covers the polar cells, while the inner one is thicker and becomes, after impregnation, more distinct, and then forms what Fol speaks of as the vitelline membrane. It is clear, as Hertwig has pointed out, that the polar bodies

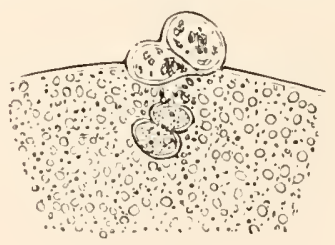

Fig. 29. PORTION OF THE OVUM OF ASTERIAS GLACIALIS AFTER THE FORMATION OF THE SFCOND POLAR CELL, SHEWING THE PART OF THE SPINDLE REMAINING IN THE OVUM BECONING CONVERTED INTO TWO CLEAR VESICLES. PICRIC ACID PREPARATION (copied from Fol). 
originate by a regular process of cell-division and have the value of cells.

A peculiar phenomenon makes its appearance in the eggs of Clepsine shortly after the formation of the polar cells, which has been spoken of by Whitman (No. 100) as the formation of the polar rings. The following is his description of the occurrence.

"Fifteen minutes after the elimination of the polar globules (i.e. cells) a ring-like depression or constriction appears in the yolk around the oral pole, and in this depression a transparent liquid substance (nuclear?) is collected forming the first polar ring.... The same phenomena repeat themselves later at the aboral pole.... The rings concentrate to form two discs.... Before the first cleavage both discs plunge deep into the egg."

The nature of these rings is at present quite obscure.

Considering how few ova have been adequately investigated with reference to the behaviour of the germinal vesicle, any general conclusions which may at present be formed are to be regarded as provisional.

There is however abundant evidence that at the time of maturation of the egg the germinal vesicle undergoes peculiar changes, which are, in part at least, of a retrogressive character. These changes may begin considerably before the egg has reached the

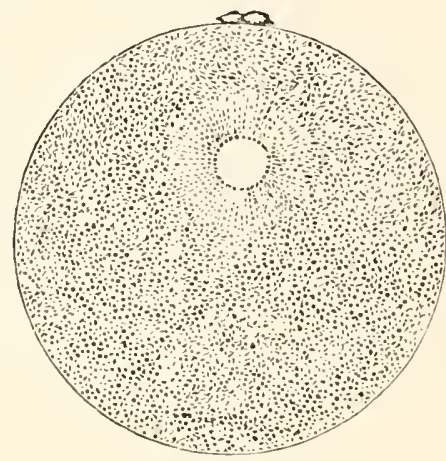

Fig. 30. Ovum of Asterias GLACIALIS WITH THE TWO POLAR CELLS AND THE FEMALE PRONUCLEUS SURROUNDED BY RADIAL STRIE, AS SEEN 1N THE LIVING EGG (copied from $\mathrm{Fol}$ ). period of maturity, or may not take place till after it has been laid. They consist in an appearance of irregularity and obscurity in the outline of the germinal vesicle, the absorption of its membrane, the partial absorption of its contents in the yolk, the disappearance of the reticulum, and the breaking up and disappearance of the germinal spot. The exact fate of the single germinal spot, or the numerous spots where they are present, is still obscure.

The retrogressive metamorphosis of the germinal vesicle is followed in a large number of instances by the conversion of what remains into a striated spindle similar in character to a nucleus previous to division. This spindle travels to the surface of the ovum and undergoes division to form the polar cell or cells in the 
manner above described. The part which remains in the egg forms eventually the female pronucleus.

The germinal vesicle has up to the present time only been observed to undergo the above series of changes in a certain number of instances, which, however, include examples from several divisions of the Cœlenterata, the Echinodermata, and the Mollusca, some of the Vermes [Turbellarians (Leptoplana), Nematodes, Hirudinea, Alciope, Sagitta], Ascidians, etc. It is very possible, not to say probable, that such changes are universal in the animal kingdom, but the present state of our knowledge does not justify us in saying so.

In the Craniata especially our knowledge of the formation of the polar bodies is very unsatisfactory. In Petromyzon Kupffer and Benecke have brought forward evidence to shew that one polar body is formed prior to the impregnation, and a second in connection with a peculiar prominence of protoplasm after impregnation. Part of the germinal vesicle remains in the egg as the female pronucleus. In the Sturgeon the germinal vesicle atrophies and breaks up before impregnation, and afterwards part is found as a granular mass on the surface of the egg, while part forms a female pronucleus.

In Amphibia the observations of Hertwig (90) and Bambeke (77) tend to shew that after the germinal vesicle has assumed a superficial situation at the pigmented pole of the ovum its contents become intermingled with the yolk, and are in part extruded from the ovum as a granular mass after impregnation. Part of them remains in the ovum and forms a female pronucleus. Whether there is a proper division of the germinal vesicle as in typical cases is not known.

Oellacher (95) by a series of careful observations upon the egg of the trout, and subsequently of the bird, demonstrated that in the ovum while still in the ovary, the germinal vesicle underwent a kind of degeneration and eventually became ejected, in part at any rate. My own observations on Elasmobranchs, which require enlargement and confirmation, tend to shew that this part may be the membrane. Ed. van Beneden (78) has contributed some important observations on the rabbit. His account is as follows. As the ovum approaches maturity the germinal vesicle assumes an eccentric position, and fuses with the peripheral layer of the egg to constitute the cicatricular lens. The germinal spot next travels to the surface of the cicatricular lens and forms the muclear disc: at the same time the membrane of the germinal vesicle vanishes, though it probably unites with the nuclear disc. The plasma of the nucleus then collects into a definite mass and forms the nucleoplasmic body. Finally the nuclear disc assumes an ellipsoidal form and becomes the nuclear body. Nothing is now left of the original germinal vesicle but the nuclear body and the nucleoplasmic body, both still situated within the ovum. In the next stage no trace of the germinal 
vesicle can be detected in the ovum, but outside it, close to the point where the modified remnants of the vesicle were previously situated, there is present a polar body which is composed of two parts, one of which stains deeply and resembles the nuclear body, and the other does not stain but is similar to the nucleoplasmic body. Van Beneden concludes that the parts of the polar body are the two ejected products of the germinal vesicle. We may be perhaps permitted to hold that further observations on this difficult object will demonstrate that part of the germinal vesicle remains in the ovum to form the female pronucleus.

With reference to invertebrate forms attention may be called to the observations of Bütschli $(80)$. Although in Cucullanus a normal formation of the polar bodies takes place, yet in the Nematodes generally, Bütschli has been unable to find the spindle modification of the germinal vesicle, but states that the germinal vesicle undergoes degeneration, its outline becoming indistinct and the germinal spot vanishing. The position of the germinal vesicle continues to be marked by a clear space, which gradually approaches the surface of the egg. When it is in contact with the surface a small spherical body, the remnant of the germinal vesicle, comes into view, and eventually becomes ejected. The clear space subsequently disappears.

In addition to the types just quoted, which may very probably turn out to be normal in the mode of formation of the polar bodies, there is a large number of types, including the whole of the Rotifera and Arthropoda with a few doubtful exceptions $^{1}$, in which the polar cells cannot as yet be said to have been satisfactorily observed.

The more important of the doubtful cases amongst the Rotifera and Arthropoda are the following.

Flemming (83) finds that in the summer and probably parthenogenetic eggs of Lacinularia socialis the germinal vesicle approaches the surface and becomes invisible, and that subsequently a slight indentation in the outline of the egg marks the point of its disappearance. In the hollow of the indentation Flemming believes a polar cell to be situated, though he has not definitely seen one.

Hoek ${ }^{2}$ believes that he has found a polar body in the ovum of Balanus balanoides, but his observations are not perfectly satisfactory.

1 The best instance of what appears like a polar cell in Arthropoda is a body recently found by Grobben ("Entwicklungsgeschichte d. Moina rectirostris." Claus' Arbeiten, Vol. II., Wien, I879) near the surface of the protoplasm at the animal pole of the summer and parthenogenetic eggs of Moina rectirostris, one of the Cladocera. The body stains deeply with carmine, but differs from normal polar cells in not being separated from the ovum; and its identification as a polar cell must remain doubtful till it has been shewn to originate from the germinal vesicle.

2 "Zur Entwicklung d. Entomostraken." Niederlandischer Archiv. f. Zoologie, Vol. III. p. 62. 
Bütschli, who has expressly searched for the polar bodies in the ova of Rotifera, was unable to find any trace of them, though he found that as the egg became ripe the germinal vesicle became half its original size. In the parthenogenetic eggs of Aphis he also failed to find a trace of polar bodies, though the germinal vesicle, after the germinal spot had broken up into fragments, approached the surface and disappeared.

Whatever may be the eventual result of more extended investigation, it is clear that the formation of polar cells according to the type described above is a very constant occurrence. Its importance is increased by the discovery by Strasburger of the existence of an analogous process amongst plants. Two questions about it obviously present themselves for solution: (I) What are the conditions of its occurrence with reference to impregnation? (2) What meaning has it in the development of the ovum or the embryo?

The answer to the first of these questions is not difficult to find. The formation of the polar bodies is independent of impregnation, and is the final act of the normal growth of the ovum. In a few types the polar cells are formed while the ovum is still in the ovary, as, for instance, in some species of Echini, Hydra, etc., but, according to our present knowledge, far more usually after the ovum has been laid. In some instances the budding-off of the polar cells precedes, and in other instances follows impregnation; but there is no evidence to shew that in the latter cases the process is influenced by the contact with the male element. In Asterias, as has been shewn by O. Hertwig and Fol, the formation of the polar cells may indifferently either precede or follow impregnation-a fact which affords a clear demonstration of the independence of the two occurrences.

To the second of the two questions it does not unfortunately seem possible at present to give an answer which can be regarded as satisfactory.

The retrogressive changes in the membrane of the germinal vesicle which usher in the formation of the polar bodies may very probably be viewed as a prelude to a renewed activity of the contents of the vesicle; and are perhaps rendered the more necessary from the thickness of the membrane which results from a protracted period of passive growth. This suggestion does not, however, help us to explain the formation of polar 
bodies by a process identical with cell-division. The ejection of part of the germinal vesicle in the formation of the polar cells may probably be paralleled by the ejection of part or the whole of the original nucleus which, if we may trust the beautiful researches of Buitschli, takes place during conjugation in Infusoria as a preliminary to the formation of a fresh nucleus. This comparison is due to Buitschli, and according to it the formation of the polar bodies would have to be regarded as assisting, in some as yet unknown way, the process of regeneration of the germinal vesicle. Views analogous to this are held by Strasburger and Hertwig, who regard the formation of the polar bodies in the light of a process of excretion or removal of useless material. Such hypotheses do not, unfortunately, carry us very far.

I would suggest that in the formation of the polar cells part of the constituents of the germinal vesicle, which are requisite for its functions as a complete and independent nucleus, is removed, to make room for the supply of the necessary parts to it again by the spermatic nucleus.

My view amounts to the following, viz. that after the formation of the polar cells the remainder of the germinal vesicle within the ovum (the female pronucleus) is incapable of further development without the addition of the nuclear part of the male element (spermatozoon), and that if polar cells were not formed parthenogenesis might normally occur. A strong support for this hypothesis would be afforded were it to be definitely established that a polar body is not formed in the Arthropoda and Rotifera; since the normal occurrence of parthenogenesis is confined to these two groups. It is certainly a remarkable coincidence that they are the only two groups in which polar bodies have not so far been satisfactorily observed.

It is perhaps possible that the part removed in the formation of the polar cells is not absolutely essential; and this seems at first sight to follow from the fact of parthenogenesis being possible in instances where impregnation is the normal occurrence. The genuineness of the observations on this head is too long a subject to enter into here', but after admitting,

1 The instances quoted by Siebold, Parthenogenesis $d$. Arthropoden, are not quite satisfactory. In Hensen's case, p. 234 , impregnation would have been possible if we can suppose the spermatozoa to be capable of passing into the body-cavity through the 
as we probably must, that there are genuine cases of such parthenogenesis, it cannot be taken for granted without more extended observation that the occurrence of development in these rare instances may not be due to the polar cells not having been formed as usual, and that when the polar cells are formed the development without impregnation is impossible.

Selenka found in the case of Purpura lapillus that no polar body was formed in the eggs which did not develop, but in the case of Neritina, Bütschli has found that this does not hold good.

The remarkable observations of Greeff (No. 88) on the parthenogenetic development of the eggs of Asterias mbens tell, however, very strongly against the above hypothesis. Greeff has found that under normal circumstances the eggs of this species of starfish will develop without impregnation in simple sea-water. The development is quite regular and normal, though much slower than in the case of impregnated eggs. It is not definitely stated that polar cells are formed, but there can be no doubt that this is implied. Greeff's account is so precise and circumstantial that it is not easy to believe that any error can have crept in; but neither Hertwig nor Fol have been able to repeat his experiments, and we may be permitted to wait for further confirmation before absolutely accepting them.

To the suggestion already made with reference to the function of the polar cells, I will venture to add the further one, that the function of forming polar cells has been acquired by the owum for the express purpose of preventing parthenogenesis.

The explanation given by Mr Darwin of the evil effects of self-fertilization, viz. the want of sufficient differentiation in the sexual elements ${ }^{1}$, would apply with far greater force to cases of parthenogenesis.

In the production of fresh individuals, two circumstances are obviously favourable to the species. (I) That the maximum number possible of fresh individuals should be produced, (2) That the individuals should be as vigorous as possible. Sexual differentiation (even in hermaphrodites) is clearly very inimical to the production of the maximum number of individuals. There can be little doubt that the ovum is potentially capable of developing by itself into a fresh individual, and therefore, unless the absence of sexual differentiation was very injurious to the vigour of the progeny, parthenogenesis would most certainly be a very constant occurrence; and, on the analogy of the arrangements in plants to prevent selffertilization, we might expect to find some contrivance both in animals and in

open end of the uninjured oviduct ; and though Oellacher's instances are more valuable, yet sufficient care seems hardly to have been taken, especially when it is not certain for what length of time spermatozoa may be able to live in the oviduct. For Oellacher's precautions, vide Zeit. fur Wiss. Zool., Bd. xxii., p. 202. A better instance is that of a sow given by Bischoff, Ann. Sci. Nat., series 3, Vol. II., I8+4. The unimpregnated eggs were found divided into segments, but the segments did not contain the usual nucleus, and were perhaps nothing else than the parts of an ovum in a state of disruption.

1 Darwin, Cross- and Self-Fertilization of Plants, p. 443. 
plants to prevent the ovum developing by itself without fertilization. If my view about the polar cells is correct, the formation of these bodies functions as such a contrivance.

Reproduction by budding or fission has probably arisen as a means of increasing the number of individuals produced, so that the co-existence of asexual with sexual reproduction is to be looked on as a kind of compromise for the loss of the power of rapid reproduction due to the absence of parthenogenesis. In the Arthropoda and Rotifera the place of budding has been taken by parthenogenesis, which may be a frequent, though not always a necessary occurrence, as in various Branchiopoda (Apus, Limnadia, etc.) and Lepidoptera (Psyche helix, etc.); or a regular occurrence for the production of one sex, as in Bees, Wasps, Nematus, etc.; or an occurrence confined to a certain stage in the cycle of development in which all the individuals reproduce their kind parthenogenetically, as in Aphis, Cecidomyia, Gall Insects (Neuroterus, etc.), Daphnia ${ }^{3}$.

On my hypothesis the possibility of parthenogenesis, or at any rate its frequency, in Arthropoda and Rotifera is possibly due to the absence of polar cells. In the case of all animals, so far as is known to me, fertilization of the ovum occasionally occurs ${ }^{2}$, but there are instances in the vegetable kingdom where so-called parthenogenesis appears to be capable of recurring for an indefinite period. One of the best instances appears to be that of Cœlebogyne, an introduced exotic Euphorbiaceous plant which regularly produces fertile seeds although a male flower never appears. The recent researches of Strasburger have however shewn that in Cœlebogyne and other parthenogenetic flowering plants, embryos are formed by the budding and subsequent development of cells belonging to the ovule. This being the case, it is impossible to assert of these plants that they are really parthenogenetic, for the embryos contained in the seed of a flower which has certainly not been fertilized, may have been formed, not by the development of the ovum, but by budding from the surrounding tissue of the ovule.

The above view with reference to the nature of the polar bodies is not to be regarded as forming more than an hypothesis.

\section{Impregnation of the Ovum.}

A far greater amount of certainty has been attained as to the effects of impregnation than as to the changes of the germinal vesicle which precede this, and there appears, moreover, to be a greater uniformity in the series of resulting phenomena.

1 Mr J. A. Osborne has recently shewn (Nature, Sept. 4, I879), that the eggs of a Beetle (Gastrophysa raphani) may occasionally develop, up to a certain point at any rate, without the male influence.

2 Dicyema, which is an apparent exception, has not yet been certainly shewn to develop true ova. If its germs are true ova it forms an exception to the above rule. 
It will be convenient again to take Asterias glacialis as the type. The part of the germinal vesicle which remains in the egg, after the formation of the second polar cell, becomes converted into a number of small vesicles (fig. 29), which aggregate

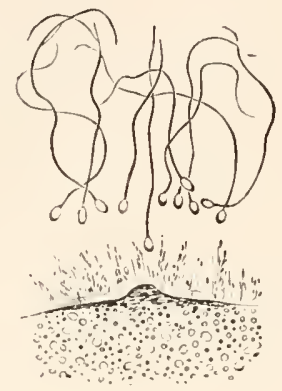

A.

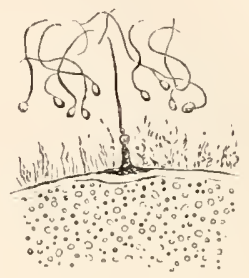

B.

Fig. 3I. Small portions of the ovum of Asterias glacialis. The SpermaTOZOA ARE SHEWN ENVELOPED IN THE MUCILAGINOUS COAT. IN A. A PROMINENCE IS RISING FROM THE SURFACE OF THE EGG TOWARIS THE NEAREST SPERMATOZOON; AND IN B. THE SPERMATOZOON AND PROMINENCE HAVE MET. (Copied from Fol.)

themselves into a single clear nucleus, which gradually travels toward the centre of the egg and around which, as a centre, the protoplasm becomes radiately striated (fig. 30). This nucleus is known as the female pronucleus. By the action of reagents a nucleolus may be shewn in it. In Asterias glacialis the most favourable period for fecundation is about an hour after the formation of the female pronucleus. If at this time the spermatozoa are allowed to come in contact with the egg, their heads soon become enveloped in the investing mucilaginous coat. A prominence, pointing towards the nearest spermatozoon, now arises from the superficial layer of protoplasm of the egg, and grows till it comes in contact with the spermatozoon (fig. $3 \mathrm{I}, \mathrm{A}$ and $\mathrm{B}$ ). Under normal circumstances the spermatozoon which meets the prominence is the only one concerned in the fertilization,

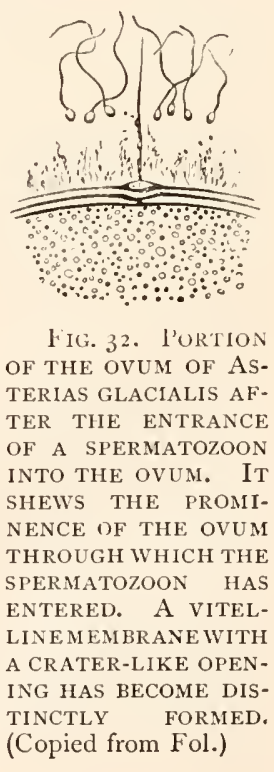

FIG. 32. L'URTION OF THE OVUM OF ASTERIAS GLACIALIS AFTER THE ENTRANCE SHEIVS THE PROMINENCE OF THE OVUM THROUGH WHICH THE SPERMATOZOON HAS ENTERED. A VITELLINEMEMBRANE WITH TINCTLY FORMED. (Copied from Fol.) 
and it makes its way into the egg by passing through the prominence. The tail of the spermatozoon, no longer motile, remains visible for some time after the head has bored its way in, but its place is soon taken by a pale conical body, which is, however, probably in part a product of the metamorphosis of the tail itself (fig. 32). It eventually becomes absorbed into the body of the ovum.

At the moment of contact between the spermatozoon and the egg the outermost layer of the protoplasm of the latter raises itself as a distinct membrane, which separates from the egg and prevents the entrance of other spermatozoa. At the point where the spermatozoon entered a crater-like opening is left in the membrane, through which the metamorphosed tail of the spermatozoon may at first be seen projecting (fig. 32).

The head of the spermatozoon when in the egg forms a nucleus, for which the name male pronucleus may be conveniently adopted. It grows in size, probably by assimilating material from the ovum, and around it is formed a clear space free from yolk-spherules. Shortly after its formation the protoplasm in its neighbourhood assumes a radiate arrangement (fig. 33). At whatever point of the egg the spermatozoon may have entered, it gradually travels towards the female pronucleus. The latter, around which the protoplasm no longer has a radiate arrangement, re-

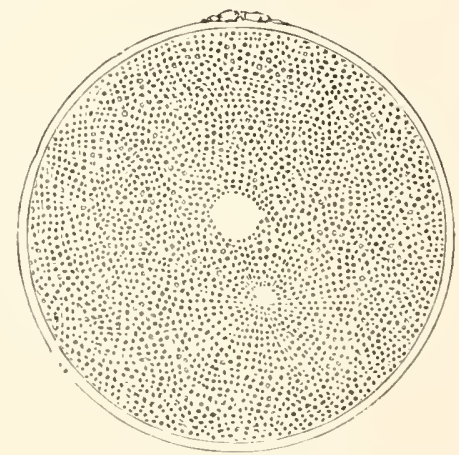

Fig. 33. OVum OF Asterias GLACIALIS, WITH MALE AND FEMALE PRONUCLEUS AND A RADIAL STRIATION OF THE PROTOPLASM AROUND THE FORMER. (Copied from Fol.) mains motionless till the rays of the male pronucleus come in contact with it, after which its condition of repose is exchanged for one of activity, and it rapidly approaches the male pronucleus, apparently by means of its inherent amoboid contractions, and eventually fuses with it (figs. 34--36).

As the male pronucleus approaches the female the latter, according to Selenka, sends out protoplasmic processes which B. II. 
embrace the former. The actual fusion does not take place till after the pronuclei have been in contact for some time. While the two pronuclei are approaching one another the protoplasm of the egg exhibits amœboid movements.

The product of the fusion of the two pronuclei forms the first segmentation nucleus (fig. 37), which soon, however, divides into the two nuclei of the two first segmentation spheres.

The phenomenon which has just been described consists essentially in the fusion of the male cell and the female cell. In this act the protoplasm of the two cells as well as their nuclei coalesce, since the whole spermatozoon which has been absorbed into the ovum is a cell of which the head is the nucleus.

It is clear that the ovum after fertilization is an entirely different body to the ovum prior to that act, and unless the use of the same term for the two conditions of the ovum had become very familiar, a special term, such as oosperm, for the ovum after its fusion with the spermatozoon, would be very convenient.
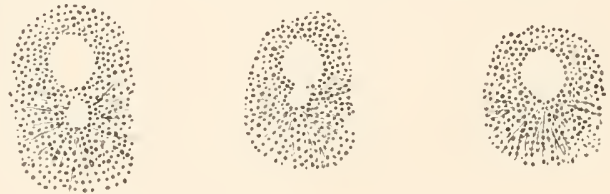

Figs. 34,35 , AND 36 . Three successive stages in the COALescence of the male and Female pronuClei in Asterias glacialis. From the living ovum. (Copied from Fol.)

Of the earlier observations on this subject there need perhaps only be cited one of $\mathrm{E}$. van Beneden, on the rabbit's ovum, shewing the presence of two nuclei before the commencement of segmentation. Bütschli was the earliest to state from observations on Rhabditis dolichura that the first segmentation nucleus arose from the fusion of two nuclei, and this was subsequently shewn with greater detail for Ascaris nigrovenosa, by Auerbach (76). Neither of these authors gave at the first the correct interpretation of their results. At a later period Bütschli (80) arrived at the conclusion that in a large number of instances (Lymnaus, Nephelis, Cucullanus, $\& \mathrm{c}$.), the nucleus in question was formed

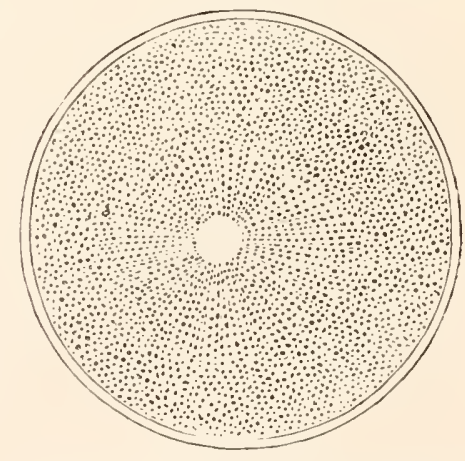

Fig. 37. Ovum of Asterias GLACIALIS, AFTER THE COALESCENCE OF THE MALE AND FEMALE PRONUCLEI. (Copied from Fol.) 
by the fusion of two or more nuclei, and Strasburger at first made a similar statement for Phallusia, though he has since withdrawn it. Though Bütschli's statements depend, as it seems, upon a false interpretation of appearances, he nevertheless arrived at a correct view with reference to what occurs in impregnation. Van Beneden ( 78 ) described in the rabbit the formation of the original segmentation nucleus from two nuclei, one peripheral and the other central, and deduced from his observations that the peripheral nucleus was derived from the spermatic element. It was reserved for Oscar Hertwig (89) to describe in Echinus lividus the entrance of a spermatozoon into the egg and the formation from it of the male pronucleus.

The general fact that impregnation consists in the fusion of the spermatozoon and ovum has now been established for some forms in the majority of invertebrate groups (Arthropoda and Rotifera excepted). Amongst Vertebrata also it has been shewn by E. van Beneden that the first segmentation nucleus is formed by the coalescence of the male and female pronucleus. Calberla, and Kupffer and Benecke have demonstrated that a single spermatozoon enters at first the ovum of Petromyzon.

The contact of the spermatozoon with the egg-membrane causes in Petromyzon active movements of the protoplasm of the ovum, and a retreat of the protoplasm from the membrane.

In Amphibia the appearance of a peculiar pigmented streak extending inwards from the surface of the pigmented pole of the ovum, and containing in a clear space at its inner extremity a nucleus, has been demonstrated as the result of impregnation by Bambeke (77) and Hertwig (90). There can be little doubt that this nucleus is the male pronucleus, and that the pigmented streak indicates its path inwards. Close to it Hertwig has shewn that another nucleus is to be found, the female pronucleus, and that eventually the two join together. In Amphibia the phenomena accompanying impregnation are clearly of the same nature as in the Invertebrata. A precisely similar series of phenomena to those in Amphibia has been shewn by Salensky to take place in the Sturgeon.

Although there is a general agreement between the most recent observers, Hertwig, Fol, Selenka, Strasburger, \&c., as to the main facts connected with the entrance of one spermatozoon into the egg, the formation of the male pronucleus, and its fusion with the female pronucleus, there still exist differences of detail in the different descriptions, which partly, no doubt, 
depend upon the difficulties of observation, but partly also upon the observations not having all been made upon the same species. Hertwig does not enter into details with reference to the actual entrance of the spermatozoon into the egg, but in his latest paper points out that considerable differences may be observed in the occurrences which succeed impregnation, according to the relative period at which this takes place. When, in Asterias, the impregnation is effected about an hour after the egg is laid, and previously to the formation of the polar cells, the male pronucleus appears at first to exert but little influence on the protoplasm, but after the formation of the second polar cell, the radial striæ around it become very marked, and the pronucleus rapidly grows in size. When it finally unites with the female pronucleus it is equal in size to the latter. In the case when the impregnation is deferred for four hours the male pronucleus never becomes so large as the female pronucleus. With reference to the effect of the time at which impregnation takes place, Asterias would seem to serve as a type. Thus in Hirudinea, Mollusca, and Nematoidea impregnation normally takes place before the formation of the polar bodies is completed, and the male pronucleus is accordingly as large as the female. In Echinus, on the other hand, where the polar bodies are formed in the ovary, the male pronucleus is always small.

Selenka, who has investigated the formation of the male pronucleus in Toxopncustes variegatus, differs in certain points from Fol. He finds that usually, though not always, a single spermatozoon enters the egg, and that though the entrance may be effected at any part of the surface it generally occurs at the point marked by a small prominence where the polar cells are formed. The spermatozoon first makes its way through the mucous envelope of the egg, within which it swims about, and then bores with its head into the polar prominence.

One important point has been so far only indirectly alluded to, viz. the number of spermatozoa required to effect impregnation.

The concurrent testimony of almost all observers tends to shew that one only is required for this purpose. But the number of cases tested is too small to admit of satisfactory generalization.

Both Hertwig and Fol have made observations on the result of the entrance into the egg of several spermatozoa. Fol finds that when the impregnation has been too long delayed the vitelline membrane is formed with comparative slowness, and several spermatozoa are thus enabled to penetrate. Each spermatozoon forms a separate pronucleus with a surrounding star; and several male pronuclei usually fuse with the female pronucleus. Each male pronucleus appears to exercise a repulsive 
influence on other male pronuclei, but to be attracted by the female pronucleus. When there are several male pronuclei the segmentation is irregular and the resulting larva a monstrosity. These statements of $\mathrm{Fol}$ and Hertwig are up to a certain point in contradiction with the more recent results of Selenka. In Toxopncustes araricgatus Selenka finds that though impregnation is usually effected by a single spermatozoon yet several may be concerned in the act. The development continues, however, to be normal up to the gastrula stage, at any rate, if three or even four spermatozoa enter the egg almost simultaneously. Under such circumstances each spermatozoon forms a separate pronucleus and star. Selenka is of opinion (apparently rather on a priori grounds than as a result of direct observation) that normal development cannot occur when more than one male pronucleus fuses with the female pronucleus; and holds that, where he has observed such normal development after the entrance of more than one spermatozoon, the majority of male pronuclei become absorbed.

It may be noticed that, while the observations of Fol and Hertwig were admittedly made upon eggs in which the impregnation was delayed till they no longer displayed their pristine activity, Selenka's were made upon quite fresh eggs; and it seems not impossible that the pathological symptoms in the embryos reared by the two former authors may have been due to the imperfection of the egg, and not to the entrance of more than one spermatozoon. This, of course, is merely a suggestion which requires to be tested by fresh observations.

Kupffer and Benecke have further shewn that although only one spermatozoon enters the ovum directly in Petromyzon yet other spermatozoa pass through the vitelline membrane, and are taken into a peculiar protoplasmic protuberance of the ovum which appears after impregnation.

The act of impregnation may be described as the fusion of the ovum and spermatozoon, and the most important feature in this act appears to be the fusion of a male and female nucleus; not only does this appear in the actual fusion of the two pronuclei, but it is brought into still greater prominence by the fact that the female pronucleus is a product of the nucleus of a primitive ovum, and the male pronucleus is the metamorphosed 
head of the spermatozoon which, as stated above, contains part of the nucleus of the primitive spermatic cell. The spermatic cells originate from cells indistinguishable from the primitive ova, so that the fusion which takes place is the fusion of morphologically similar parts in the two sexes.

These conclusions tally very satisfactorily with the view adopted in the Introduction, that impregnation amongst the Metazoa was derived from the process of conjugation amongst the Protozoa.

\section{Summary.}

In what may probably be regarded as a normal case the following series of events accompanies the maturation and impregnation of an ovum :-

(I) Transportation of the germinal vesicle to the surface of the egg.

(2) Absorption of the membrane of the germinal vesicle and metamorphosis of the germinal spot and nuclear reticulum.

(3) Assumption of a spindle character by the remains of the germinal vesicle, these remains being probably in part formed from the germinal spot.

(4) Entrance of one end of the spindle into a protoplasmic prominence at the surface of the egg.

(5) Division of the spindle into two halves, one remaining in the egg, the other in the prominence; the prominence becoming at the same time nearly constricted off from the egg as a polar cell.

(6) Formation of a second polar cell in the same manner as the first, part of the spindle still remaining in the egg.

(7) Conversion of the part of the spindle remaining in the egg into a nucleus - the female pronucleus.

(8) Transportation of the female pronucleus towards the centre of the egg.

(9) Entrance of one spermatozoon into the egg.

(Io) Conversion of the head of the spermatozoon into a nucleus-the male pronucleus.

(I I) Appearance of radial strix round the male pronucleus, which gradually travels towards the female pronucleus. 
(12) Fusion of male and female pronuclei to form the first segmentation nucleus.

(76) Auerbach. Organologische Studien, Heft 2. Breslau, I $87+$.

(77) Bambeke. "Recherches s. Embryologie des Batraciens." Bull. de T Acad. royale de Belgique, zme Sér., T. Lixi., i876.

(78) E. van Beneden. "La Maturation de l'Cuf des Mammiféres." Bull. de l'Acad. royale de Belogique, zme Sér., T. XL. No. I2, I875.

(79) I dem. "Contributions à l'Histoire de la Vésicule Germinative, \&c." Bull. de 1 Acad. royale de Belgique, 2 me Sér., T. XLI. No. 1 , i 876 .

(80) O. Bütschli. Eizelle, Zelltheilung, und Conjugation der Infusorien. Frankfurt, 1876 .

(81) F. M. Balfour. "On the Phenomena accompanying the Maturation and Impregnation of the Ovum." Quart. F. of Micros. Science, Vol. xvill., i 878.

(8:) Calberla. "Befruchtungsvorgang beim Ei von Petromyzon Planeri." Zeit. f. wiss. Zool., Vol. xxx.

(83) W. Flemming. "Studien in d. Entwickelungsgeschichte der Najaden." Sitz. d. k. Akad. Wiin, 1B. Lxxi., I 875 .

(81) II. Fol. "Die erste Entwickelung des Geryonideneies." Fenaische Zeitschrift, Vol. VII., I 873 .

(85) Idem. "Sur le Développement des Ptéropodes." Archives de Zoologie Expérimentale et Gónérale, Vol. Iv. and v., I875-6.

(86) Idem. "Sur le Commencement de l'Hénogénie." Archives des Sciences Physiques et Naturelles. Genève, I877.

(87) Idem. Recherches s. l. Fúcondation et l. commen. d. lHénogénic. Geneve, 1879 .

(88) R. Greeff. "Ueb. d. Bau u. d. Entwickelung d. Echinodermen." Sitzun. der Gesellschaft z. Beförderung d. gesammten Naturwiss. z. Marburg, No. 5, 1876 .

(89) Oscar Hertwig. "Beit. z. Kenntniss d. Bildung, \&c., d. thier. Eies." Morphologisches Fahrbuch, Vol. I., I 876.

(90) Idem. Ibid. Morphologisches Fahrbuch, Vol. III. Heft I, I877.

(91) I d en. "Weitere Beiträge, \&c." Morphologisches Fahrbuch, Vol. 111., 1877, Heft 3 .

(92) Idem. "Beit. z. Kenntniss, \&c." Morphologisches Fahrbuch, Vol. Iv. Heft $I$ and 2,1878 .

(93) N. Kleinenberg. Hyclra. Leipzig, is72.

(94) C. Kupffer u. D. Benecke. Der Vorgang d. Befruchtung am Eie d. Neunaugen. Königsberg, $18_{7} 8$.

(95) J. Oellacher. "Beiträge zur Geschichte des Keimbläschens im Wirbelthie reie." Archivf. micr. Anat., Bd. vill., 1872.

(96) W. Salensky. "Befuchtung u. Furchung d. Sterlets-Eies." Zoologischer Anzeiger, No. II, 1878 .

(97) E. Selenka. Befruchtung des Eics von Toxopnoustes variegatus. Leipzig, I 878 .

(98) Strasburger. Ucber Zellbildang u. Zelltheilung. Jena, I876.

(99) I dem. Ucber Befruchtung u. Zelltheilung. Jena, 1878 .

(100) C. O. Whitman. "The Embryology of Clepsine." Quart. F. of Micr. Science, Vol. xvili., i 878 . 


\section{CHAP'TER III.}

\section{THE SEGMENTATION OF THE OVUM.}

THE immediate result of the fusion of the male and female pronucleus is the segmentation or division of the ovum usually into two, four, eight, etc. successive parts. The segmentation may be dealt with from two points of view, viz. (I) the nature of the vital phenomena which take place in the ovum during its occurrence, which may be described as the internal phenomena of segmentation. (2) The external characters of the segmentation.

\section{Intemal Phenomena of Segmontation.}

Numerous descriptions have been given during the last few years of the internal phenomena of segmentation. The most recent contribution on this head is that of Fol (No. 87). He appears to have been more successful than other observers in obtaining a complete history of the changes which take place, and it will therefore be convenient to take as type the ovum of Toxopncustcs (Echinus) lividus, on which he made his most complete series of observations. The changes which take place may be divided into a series of stages. The ovum immediately after the fusion of the male and female pronucleus contains a central segmentation nucleus.

In the first stage a clear protoplasmic layer derived from the plasma of the cell is formed round the nucleus, from which there start outwards a number of radial strix, which are rendered conspicuous by the radial arrangement of the yolk-granules 
between them. The nucleus during this process remains perfectly passive.

In the second stage the nucleus becomes less distinct and somewhat elongated, and around it the protoplasmic layer of the earlier stage is arranged in the form of a disc-shaped ring, compared by Fol to Saturn's ring. The protoplasmic rays still take their origin from the perinuclear protoplasm. This stage has a considerable duration (20 minutes).

In the third stage the protoplasm around the nucleus becomes transported to the two nuclear poles, at each of which it forms a clear mass surrounded by a star-shaped figure formed by radial stria. The nucleus is hardly visible in the fresh condition, but when brought into view by reagents is found to contain many highly refractive particles, and to be still enveloped in a membrane.

In the fourth stage the nucleus when treated by reagents has assumed the well-known spindle form. The striae of which it is composed are continuous from one end of the spindle to the other and are thickened at the centre. The central thickenings constitute the so-called nuclear plate. The clear protoplasmic masses and stars are present as before at the apices of the nucleus, and the rays of the latter converge as if they would meet at the centre of the clear masses, but stop short at their periphery. There is no trace of a membrane round either the nuclear spindle or the clear masses; and in the centre of the latter is a collection of granules. The striæ of the polar stars are very fine but distinct.

Between the stage with a completely formed spindle and the previous one the intermediate steps have not been made out for Toxopneustes; but for Heteropods Fol has been able to demonstrate that the strize of the spindle and their central thickenings are formed, as in the case of the spindle derived from the germinal vesicle, from the metamorphosis of the muclcar reticulum. They commence to be formed at the two poles, and are then (in Heteropods) in immediate contiguity with the stria of the stars. The strize gradually grow towards the centre of the nucleus and there meet.

In the fifth stage the central thickenings of the spindle separate into two sets, which travel symmetrically outwards 
towards the clear masses, growing in size during the process. They remain however united for a short time by delicate filaments-named by Fol connective filaments-which very soon disappear. The clear masses also increase in size. During this stage the protoplasm of the ovum exhibits active amoboid movements preparatory to division.

In the sixth stage, which commences when the central thickenings of the spindle have reached the clear polar masses, the division of the ovum into two parts is effected by an equatorial constriction at right angles to the long axis of the nucleus. The inner vitelline membrane follows the furrow for a certain distance, but does not divide with the ovum. All connection between the two parts of the spindle becomes lost during this stage, and the thickenings of the fibres of the spindle give rise to a number of spherical vesicular bodies, which pass into the clear masses and become intermingled with the granules which are placed there. The radii of the stars now extend round the whole circumference of each of the clear masses.

In the seventh stage the two clear masses become elongated and travel towards the outer sides of their segments; while the radii connected with them become somewhat bent, as if a certain amount of traction had been exercised on them in the movement of the clear masses. Shortly afterwards the spherical vesicles, each of which appears like a small nucleus and contains a central nucleolus, begin to unite amongst themselves, and to coalesce with the neighbouring granules. Those in each segment finally unite to form a nucleus which absorbs the substance of the clear mass. The new mucleus is therefore partly derived from the division of the old one and partly fiom the plasma of the cell. The two segments formed by division are at first spherical, but soon become flattened against each other. In each subsequent division of these cells the whole of the above changes are repeated.

The phenomena which have just been described would appear to occur in the segmentation of ova with remarkable constancy and without any very considerable variations.

The division of the ovum constitutes a special case of cell division, and it is important to determine to what extent the phenomena of ordinary cell division are related to those which take place in the division of the ovum. 
Without attempting a full discussion of the subject I will confine myself to a few remarks suggested by the observations of Flemming, Peremeschko and Klein. The observations of these authors shew that in the course of the division of nuclei in the salamander, newt, etc. the nuclear reticulum undergoes a series of peculiar changes of form, and after the membrane of the nucleus has vanished divides into two masses. The masses form the basis for the new nuclei, and become reconverted into an ordinary nuclear reticulum after repeating, in the reverse order, the changes of form undergone by the reticulum previous to its division.

It is clear without further explanation that the conversion of the nuclear reticulum of the segmentation nucleus into the striæ of the spindle is a special case of the same phenomenon as that first described by Flemming in the salamander. There are however some considerable differences. In the first place the fibres in the salamander do not, according to Flemming, unite in the middle line, though they appear to do so in the newt. This clearly cannot be regarded as a fact of great importance; nor can the existence of the central thickenings of the stria (nuclear plate), constant as it is for the division of the nucleus of the ovum, be considered as constituting a fundamental difference between the two cases. More important is the fact that the strice in the case of the ovum do not appear, at any rate have not been shewn, to form themselves again into a nuclear network.

With reference to the last point it is however to be borne in mind ( $\mathrm{I}$ ) that the gradual travelling outwards of the two halves of the nuclear plate is up to a certain point a repetition, in the reverse order, of the mode of formation of the strix of the spindle, since the striæ first appeared at the poles and gradually grew towards the middle of the spindle: (2) that there is still considerable doubt as to how the vesicular bodies formed out of the nuclear plate reconstitute themselves into a nucleus.

The layer of clear protoplasm around the nucleus during its division has its homologue in the case of the division of the nuclei of the salamander, and the rays starting from this are also found. Klein has suggested that the extra-nuclear rays of the stars around the poles of the nucleus are derived from a metamorphosis of the extra-nuclear reticulum, which he believes to be continuous with the intra-nuclear reticulum.

The delicate connective filaments usually visible between the two halves of the nuclear plate would seem from Strasburger's latest observations (No. 104) to be derived from the nuclear substance between the striæ of the spindle, and to become eventually reabsorbed into the newly-formed nuclei.

We are it appears to me still in complete ignorance as to the physical causes of segmentation. The view that the nucleus is a single centre of attraction, and that by its division the centre of attraction becomes double and thereby causes division, appears to be quite untenable. The description already given of the phenomena of segmentation is in itself sufficient to refute this view. 
Nor is it in the least proved by the fact (shewn by Hallez) that the plane of division of the cell always bears a definite relation to the direction of the axis of the nucleus.

The arguments by which Kleinenberg (93) attempted to demonstrate that cell division was a phenomenon caused by alterations in the molecular cohesion of the protoplasm of the ovum still in my opinion hold good, but recent discoveries as to the changes which take place in the nucleus during division probably indicate that the molecular changes which take place in the cohesion of the protoplasm are closely related to, and possibly caused by, those in the nucleus. These alterations of cohesion are produced by a series of molecular changes, the external indications of which are to be found in the visible alterations in the constitution of the body of the cell and of the nucleus prior to division.

\section{BIBLIOGRAPHY.}

In addition to the papers cited in the last Chapter, vide

(101) W. Flemming. "Beiträge z. Kenntniss d. Zelle u. ihrer Lebenserscheinungen." Archiv f. mikr. Anat., Vol, xvi., i 878 .

(102) E. Klein. "Observations on the glandular epithelium and division of nuclei in the skin of the Newt." Quart. F. of Micr. Science, Vol. xix., is79.

(103) Peremeschko. "Ueber d. Theilung d. thierischen Zellen." Archio f. mikr. Anat., Vol. Xvi., I $8 ; 8$.

(104) E. Strasburger. " Ueber ein z. Demonstration geeignetes ZelltheilungsObject." Sitz. d. Fonaischen Gesell.f. Med.u. Naturviss., July i8, 1879 .

\section{External Features of Segmentation.}

In the simplest known type of segmentation the ovum first
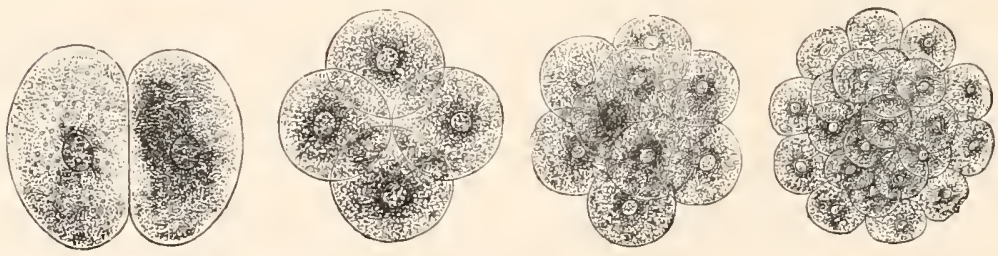

Fig. 38 . Various stages in process of Segmentation. (After Gegenbaur.) of all divides into two, then four, eight, sixteen, thirty-two, sixtyfour, etc. cells (fig. 38 ). These cells so long as they are fairlylarge are usually known as segments or spheres. At the close of such 
a simple segmentation the ovum becomes converted into a sphere composed of segments of a uniform size. These segments usually form a wall (fig. 39, E), one row of cells thick, round a central cavity, which is known as the segmentation cavity or cavity of Von Baer. Such a sphere is known as a blastosphere. The central cavity usually appears very early in the segmentation, in many cases when only four segments are present (fig. 39, B).

In other instances, which however are rarer than those in which a segmentation cavity is present, there is no trace of a central cavity, and the sphere at the close of segmentation is quite solid. In such instances the solid sphere is known as a morula. It is found in some Sponges, many Cœlenterata, some Nemertines, etc., and in Mammals ; in which group the segmentation is not however quite regular. All intermediate conditions between a large segmentation cavity, and a very minute central cavity which may be surrounded by more than a single row of cells have been described.

The segmentation cavity has occasionally, as in Sycandra, the Ctenophora and Amphioxus, the form of an axial perforation of the ovum open at both extremities.
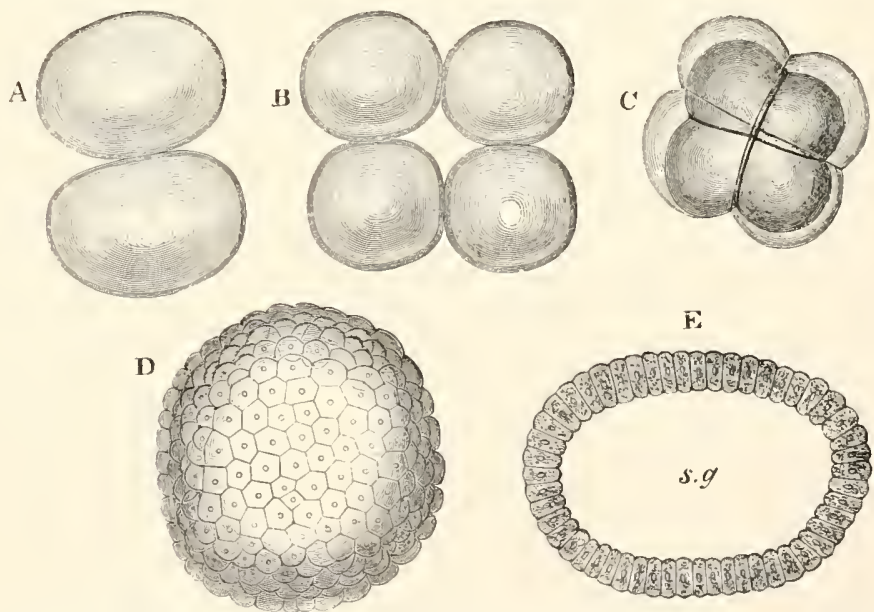

Fig. 39. The Segmextation of Amphioxus. (Copied from Kowalevsly.)

sg. segmentation cavity. A. Stage with two equal segments. B. Stage with four equal segments. C. Stage after the four segments have become divided by an equatorial furrow into eight equal segments. D. Stage in which a single layer of cells encloses a central segmentation cavity. E. Somewhat older stage in optical section. 
When the process of regular segmentation is examined somewhat more in detail it is found to follow as a rule a rather definite rhythm. The ovum is first divided in a plane which may be called vertical, into two equal parts (fig. $39, \mathrm{~A}$ ). This division is followed by a second, also in a vertical plane, but at right angles to the first plane, and by it each of the previous segments is halved (fig. 39, B.) In the third segmentation the plane of division is horizontal or equatorial and divides each of the four segments into two halves, making eight segments in all (fig. 39, C). In the fourth period the segmentation takes place in two vertical planes each at an angle of $45^{\circ}$ with one of the previous vertical planes. All the segments are thus again divided into two equal parts. In the fifth period there are two equatorial planes one on each side of the original equatorial plane, and thirty-two spheres are present at the close of this period. Sixty-four segments are formed at the sixth period, but beyond the fourth and fifth periods the original regularity is not usually preserved.

In many instances the type of segmentation just described cannot be distinctly recognized. All that can be noticed is that at each fresh segmentation every segment becomes divided into two equal parts. It is not absolutely certain that there is not always some slight inequality in the segments formed, by which, what are known as the animal and vegetative poles of the ovum, can very early be distinguished. A regular segmentation is found in species in most groups of the animal kingdom. It is very common in Sponges and Cœelenterates. Though less common so far as is known amongst the Vermes, it is yet found in many of the lower types, viz. Nematoidea, Gordiacea, Trematoda, Nemertea (apparently as a rule), Sagitta, Chatonotus, some Gephyrea (Phoronis); though not usual it occurs amongst Chætopoda, e.g. Serpula. It is the usual type of segmentation amongst the Echinodermata. Amongst the Crustacea it appears (for the earlier phases of segmentation at any rate) not infrequently amongst the lower forms, and even occurs amongst the Amphipoda (Phronima). It is however very rare amongst the Tracheata, Podura affording the one example of it known to me. It is almost as rare amongst Mollusca as amongst the Tracheata, but occurs in Chiton and is nearly approached in some Nudibranchiata. In Vertebrata it is most nearly approached in Amphioxus ${ }^{1}$.

Most of the eggs which have a perfectly regular segmentation are of a very insignificant size and rarely contain much food-

1 In the Rabbit and probably other Monodelphous Mammalia the segmentation is nearly though not quite regular. 
yolk: in the vast majority of eggs there is present however a considerable bulk of food material usually in the form of highly refracting yolk-spherules. These yolk-spherules lie embedded in the protoplasm of the ovum, but are in most instances not distributed uniformly, being less closely packed and smaller at one pole of the ovum than elsewhere. Where the yolk-spherules are fewest the active protoplasm is necessarily most concentrated, and we can lay down as a general law ${ }^{1}$ that the velocity of segmentation in any part of the ovum is roughly speaking proportional to the concentration of the protoplasm there; and that the size of the segments is inversely proportional to the concentration of the protoplasm. Thus the segments produced from that part of an egg where the yolk-spherules are most bulky, and where therefore the protoplasm is least concentrated, are larger than the remaining segments, and their formation proceeds more slowly.

Though where much food-yolk is present it is generally distributed unequally, yet there are many cases in which it is not possible to notice this very distinctly. In most of these cases the segmentation is all the same unequal, and it is probable that they form apparent rather than real exceptions to the law laid down above. Although before segmentation the protoplasm may be uniformly distributed, yet in many instances, $\ell . g$. Mollusca, Vermes, etc., during or at the commencement of segmentation the protoplasm becomes aggregated at one pole, and one of the segments formed consists of clear protoplasm, all the food-yolk being contained in the other and larger segment.

Unequal Segmentation. The type of segmentation I now proceed to describe has been called by Haeckel (No. 10.5) 'unequal segmentation', a term which may conveniently be adopted. I commence by describing it as it occurs in the wellknown and typical instance of the Frog ${ }^{2}$.

The ripe ovum of the common Frog and of most other tailless Amphibians presents the following structure. One half appears black and the other white. The former I shall call the upper

I Vide F. M. Balfour, "Comparison of the early stages of development in Vertebrates." Quart. Four. of Aficr. Science, July, 1875 .

2 Vide Remak, Entwicklung d. Wirbclthiere; and Götte, Entwicklung d. Unke. 
pole, the latter the lower. The ovum is composed of protoplasm containing in suspension numerous yolk-spherules. The largest
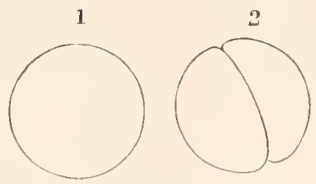

16
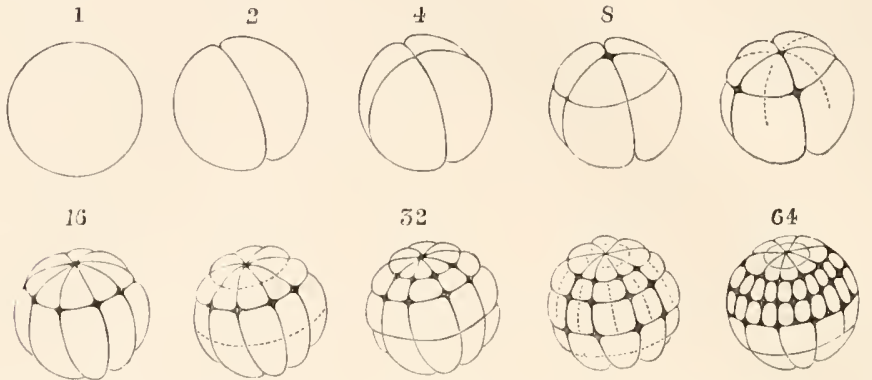

Fig. +o. Segmentation of Common Frog. Rana Temporaria. (Copied from Ecker.)

The numbers above the figures refer to the number of segments at the stage figured.

of these are situated at the lower pole, the smaller ones at the upper pole, and the smallest of all in the peripheral layer of the upper pole, in which also pigment is scattered and causes the black colour visible from the surface.

The first formed furrow is a vertical furrow. It commences in the upper half of the ovum, through which it extends rapidly, and then more slowly through the lower. As soon as the first furrow has extended through the egg, and the two halves have become separated from each other, a second vertical furrow appears at right angles to the first and behaves in the same way (fig. 40, 4).

The next furrow is equatorial or horizontal (fig. 40, 8). It does not arise at the true equator of the egg, but much nearer to its upper pole. It extends rapidly round the egg and divides each of the four previous segments into two parts, one larger and one smaller. Thus at the end of this stage there are present four small and four large segments. At the meeting point of these a

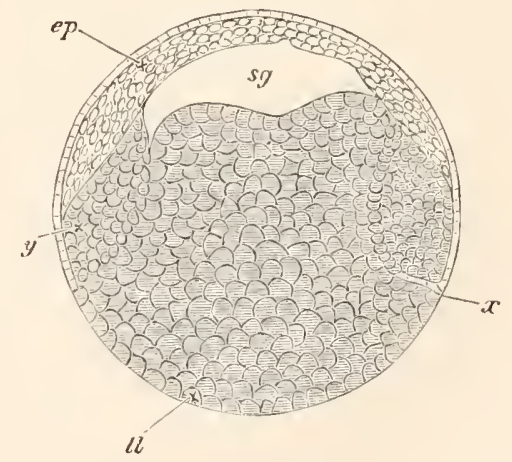

Fig. + I. Section throvgh Frog's OVUM AT THE CLOSE OF SEGMENTATION. $s g$. segmentation cavity. $l l$. large yolk-containing cells. $c p$. small cells at formative pole (epiblast). 
small cavity appears, which is the segmentation cavity, already described for uniformly segmenting eggs. It increases in size in subsequent stages, its roof being formed of the smaller cells and its floor of the larger. The appearance of the equatorial furrow is followed by a period of repose, after which two rapidly succeeding vertical furrows are formed in the upper pole, dividing each of the four segments of which this is composed into two. After a short period these furrows extend to the lower pole, and when completed 16 segments are present-eight larger and eight smaller (fig. 40, 16). A pause now ensues, after which the eight upper segments become divided by an equatorial furrow, and somewhat later a similar furrow divides the eight lower segments. At the end of this stage there are therefore present $\mathrm{I} \sigma$ smaller and 16 larger segments (fig. 40, 32). After 64 segments have been formed by vertical furrows which arise symmetrically in the two poles (fig. 40,64), two equatorial furrows appear in the upper pole before a fresh furrow arises in the lower; so that there are 128 segments in the upper half, and only 32 in the lower. The regularity is quite lost in subsequent stages, but the upper pole continues to undergo a more rapid segmentation than the lower. While the segments have been increasing in number the segmentation cavity has been rapidly growing in size; and at the close of segmentation the egg forms a sphere, containing an excentric cavity, and composed of two unequal parts (fig. 4I). The upper part, which forms the roof of the segmentation cavity, is formed of smaller cells: the lower of larger yolk-containing cells.

The mode of segmentation of the Frog's ovum is typical for unequally segmenting ova, and it deserves to be noticed that as regards the first three or more furrows the segmentation occurs with the same rhythm in the unequally segmenting ova as in those which have an uniform segmentation. There appear two vertical furrows followed by an equatorial furrow. The general laws which were stated with reference to the velocity of segmentation and the size of the resulting segments are well exemplified in the case of the Frog's ovum.

The majority of the smaller segments in the segmented Frog's ovum are destined to form into the epiblast, and the larger segments become hypoblast and mesoblast.

B. II. 
With a few exceptions (the Rabbit, Lymnæus, etc.) the majority of the smaller segments always become epiblast and of the larger segments hypoblast.

The Frog's ovum serves as a good medium type for unequally segmenting ova. There are many cases however in which a regular segmentation is far more closely approached, and others in which it is less so.

One familiar instance in which a regular segmentation is nearly approached is afforded by the Rabbit's ovum, which has indeed usually been regarded as offering an example of a regular segmentation.

The ovum of the Rabbit ${ }^{1}$ becomes first divided into two subequal spheres. The larger and more transparent of the two may, from its eventual fate, be called the epiblastic sphere, and the other the hypoblastic. The two spheres are divided into four, and then by an equatorial furrow into eight-four epiblastic and four hypoblastic. One of the latter assumes a central position. The four epiblastic spheres now divide before the four hypoblastic. There is thus introduced a stage with twelve spheres. It is followed by one with sixteen, and that by one with twenty-four. During the stages with sixteen spheres and onwards the epiblastic spheres gradually envelop the hypoblastic, which remain exposed on the surface at one point only. There is no segmentation cavity.

In Pedicellina, one of the entoproctous Polyzoa, there is a subregular segmentation, where however the two primary spheres can be distinguished much in the same way as in the case of the Rabbit.

A very characteristic type of unequal segmentation is that presented by the majority of Gasteropods and Pteropods and probably also of some Lamellibranchiata. It is also found in some Turbellarians, in Bonellia, some Annelids, etc. In many instances it offers a good example of the type where in the course of segmentation the protoplasm becomes aggregated at one pole of the ovum, or of its segments, to become separated off as a clear sphere.

The first four segments formed by two vertical furrows at

1 Van Beneden, "Développement embryonnaire des Mammifères." Bull. de l'Acad. Belgique, $\mathrm{i} 8 ;+$. 
right angles are equal, but from these there are budded off four smaller segments, which in subsequent stages divide rapidly, receiving however, a continual accession of segments budded off from the larger spheres. The four larger spheres remain conspicuous till near the close of the segmentation. The process of budding, by which the smaller spheres become separated from the larger, consists in a larger sphere throwing out a prominence, which then becomes constricted off from it.

In the extreme forms of this unequal segmentation we find at the end of the second cleavage two larger spheres filled with yolk material and two smaller clear spheres; and in the later stages, though the large spheres continue to bud off small spheres, only the two smaller ones undergo a regular segmentation, and eventually completely envelop the former. Such a case as this has been described in Aplysia by Lankester ${ }^{1}$.

The types I have described serve to exemplify unequal segmentation. The Rabbit's ovum stands at one end of the series, that of Aplysia at the other; and the Frog's ovum between the two.

Great variations are presented by the ova with unequal segmentation as to the presence of a segmentation cavity. In some instances, e.g. the Frog, such a cavity is well developed. In other cases it is small, $\operatorname{c.g}$. most Mollusca, while not unfrequently it is altogether absent.

Before leaving this important type of segmentation, it will be well to enter with slightly greater detail into some of the more typical as well as some of the special forms which it presents.

As an example of the typical Molluscan type the normal Heteropod segmentation, accurately described by $\mathrm{Fol}^{2}$, may be selected.

The ovum divides into two and then four equal segments in the usual vertical planes. Each segment has a protoplasmic and a vitelline pole. The protoplasmic pole is turned towards the polar bodies. In the third segmentation, which takes place along an equatorial plane, four small protoplasmic cells or segments are segmented or rather budded off from the four large segments, so that there are four small segments in one plane and four large below these. In the fourth segmentation the four large segments alone are active and give rise to four small and four large cells; so that there are formed in all eight small and four large cells. The four small cells of the

1 Phil. Trans. 1875.

2 Fol, Archives de Zoologie Expérimentale, Vol. 1V. 1875 . 
third generation next divide, forming in all twelve small cells and four large. The small cells of the fourth generation then divide, and subsequently the four large cells give rise to four new small ones, so that there are twenty small cells and four large. The small cells form a cap embracing the upper pole of the large segments. It may be noted that from the third stage onwards the cells increase in arithmetical progression-a characteristic feature of the typical gasteropod segmentation.

In the later stages of segmentation the large cells cease to give rise to smaller ones in the same manner as before. One of them divides first into two unequal parts, of which the smaller becomes pushed in towards the centre of the ego. The larger cell then divides again into two, and the three cells so formed occupy the centre of a shallow depression. The remaining larger cells divide in the same way, and give rise to smaller cells which line a pit which becomes formed on one side of the ovum. The original smaller cells continue in the meantime to divide and so form a layer enclosing the larger, leaving exposed however the opening of the pit lined by the latest products of the larger cells.
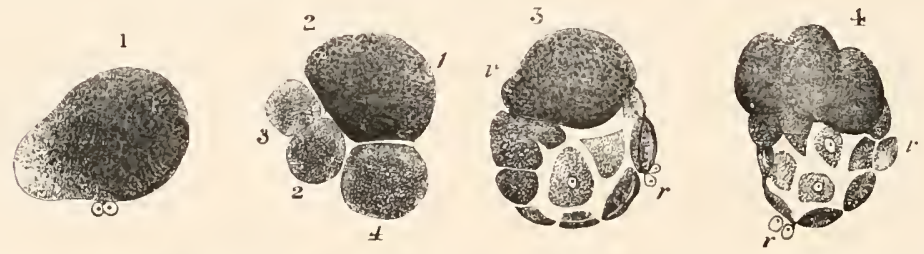

Fig. 42. Segmentation of Anodon piscinalis. (Copied rom Flemming.) $r$ polar cells. $v$. vitelline sphere. I. Commencing division into two segments; one mainly formed of protoplasm, the other of yolk. 2. Stage with four segments. 3. Formation of blastosphere, and segmentation cavity. 4. Definite segmentation of the yolk sphere.

The eggs of Anodon and Unio serve as excellent examples of the type in which the ovum has a uniform structure before the commencement of segmentation, but in which a separation into a protoplasmic and a nutritive portion becomes obvious during segmentation.

In Anodon ${ }^{1}$ the egg is at first uniformly granular, but after impregnation it throws out on one side a protuberance nearly free from granules (fig. $42,1)$.

In the case of this clear protuberance and of the similar protuberances which follow it, the protoplasm is not at first quite free from food-yolk, but only becomes so on being separated from the yolk-containing part of the ovum. We must therefore suppose that the production of the clear segments is in part at least due to the yolk spherules becoming used up to form protoplasm. Such a formation of protoplasm from yolk spherules has been clearly shewn to occur in other types by Bobretzky and Fol.

1 Flemming, "Entwick. der Najaden," Sitz. d. Akad. Wiss. Wien, Bd. 4, I875. 
The protuberance soon becomes separated off from the larger part of the egg as a small segment composed of clear protoplasm. From the larger segment filled with food-yolk, a second small clear segment is next budded off, and simultaneously (fig. 42,2 ) the original small segment divides into two. Thus there are formed four segments, one large and three small; the large segment as before being filled with food-yolk. The continuation of a similar process of budding off and segmentation eventually results in the formation of a considerable number of small and of one large segment (fig. 42,3). Between this large and the small segments is a segmentation cavity.

Eventually the large yolk segment, which has hitherto merely budded off a series of small segments free from yolk, itself divides into two similar parts. This process is then repeated (fig. 42,4) and there is at last formed a number of yolk segments filled with yolk spheres, which occupy the place of the original large yolk segment. Between these yolk segments and the small segments is placed the segmentation cavity.

The segmentation of the ovum of Euaxes ${ }^{1}$ resembles that of Unio in the budding off of clear segments from those filled with yolk, but presents many interesting individualities.

A very peculiar modification of the ordinary Gasteropod segmentation is that described by Bobretzky for Nassa mutabilis².

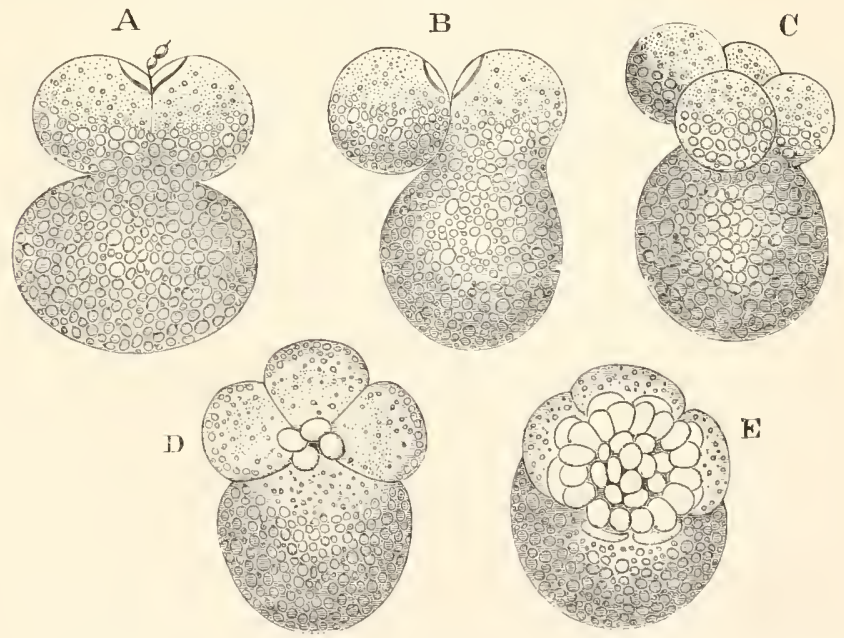

Fig. 43. Segmentation of Nassa intabilis (from Bobretzky). A. Upper half divided into two segments. B. One of these has fused with the large lower segment. C. Four small and one large segment, one of the former fusing with the large segment. D. Each of the four segments has given rise to a small segment. E. Small segments have increased to thirty-six.

1 Kowalevsky, Mim. Akad. Petersburg, Series v11. is

${ }^{2}$ Archiv. f. mikr. Anat. Vol, xill. isij. 
The ovum contains a large amount of food-yolk, and the protoplasm is aggregated at the formative pole, adjoining which are placed the polar bodies. An equatorial and a vertical furrow (fig. $43 \mathrm{~A}$ ), the former near the upper pole, appear simultaneously, and divide the ovum into three segments, two small, each with a protoplasmic pole, and one large entirely formed of yolk material. One of the two small segments next completely fuses with the large segment (fig. $43 \mathrm{~B}$ ), and after the fusion is complete, a triple segmentation of the large segment takes place as at the first division, and at the same time the single small segment divides into two. In this way four partially protoplasmic segments and one yolk segment are formed (fig. 43 C). One of the small segments again fuses with the large segment, so that the number of segments becomes again reduced to four, three small and one large. The protoplasmic ends of these segments are turned towards each other, and where they meet four very small cells become budded off, one from each segment (fig. 43 D). Four small cells are again budded off twice in succession, while the original small cells remain passive, so that there come to be twelve small and four large cells. In later stages the four first-formed small cells give rise to still smaller cells and then the nextformed do the same. The large cells continue also to give rise to small ones, and finally, by a continuous process of division, and fresh budding of small cells from large cells, a cap of small cells becomes formed covering the four large cells which have in the meantime pressed themselves together (fig. $43 \mathrm{E}$ ). A segmentation cavity of not inconsiderable dimensions becomes established between this cap of small cells and the large cells.

Many eggs, such as those of the Myriapods', present an irregular segmentation; but the segmentation is hardly unequal in the sense in which I have been using the term. Such cases should perhaps be placed in the first rather than in the present category.

The type of unequal segmentation is on the whole the most widely distributed in the animal kingdom. There is hardly a group without examples of it.

It occurrs in Porifera, Hydrozoa, Actinozoa and Ctenophora. Amongst the Ctenophora this segmentation is of the most typical kind. Four equal segments are first formed in the two first periods. In the third period a circumferential furrow separates four smaller from four larger segments.

This type is also widely distributed amongst the unsegmented (Gephyrea, Turbellaria), as well as the segmented Vermes, and is typical for the Rotifera. It appears to be very rare in Echinoderms (Echinaster Sarsii). It is not uncommon in early stages of the segmentation of the lower Crustacea.

For Mollusca (except Cephalopoda) it is typical. Amongst the Ascidia it occurs in several forms (Salpa, Molgula) and amongst the Craniata it is typical in the Cyclostomata, Amphibia, and some Ganoids, e.g. Accipenser.

1 Metschnikoff, Zeitschrift f. wiss. Zoologie, I874. 
Partial segmentation. The next type of segmentation we have to deal with has long been recognized as partial segmentation. It is a type in which only part of the ovum, called the germinal disc, undergoes segmentation, the remainder usually forming an appendage of the embryo known as the yolk-sack. Ova belonging to the two groups already dealt with are frequently classed together as holoblastic ova, in opposition to ova of the present group in which the segmentation is only partial, and which are therefore called meroblastic. For embryological
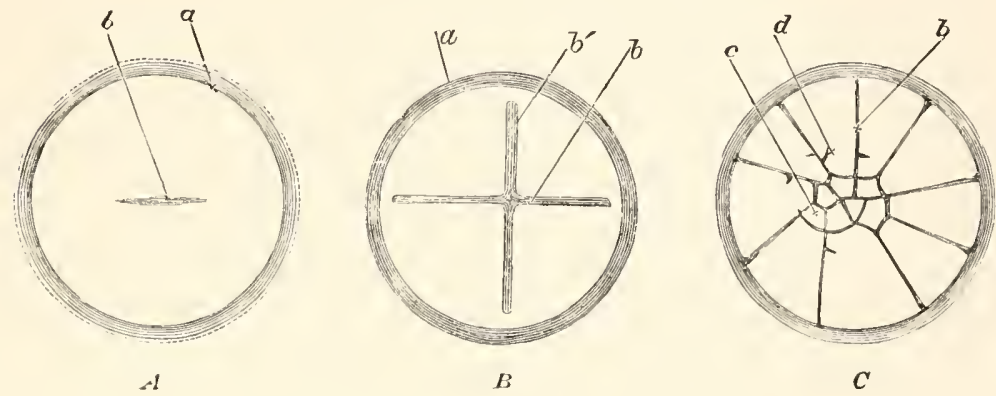

Fig. 44. Surface views of the early stages of the segmentation in a Fowl's EGG. (After Coste.)

$a$. edge of germinal disc. b. vertical furrow. $c$. small central segment. $d$. larger peripheral segment.

purposes this is in many ways a very convenient classification, but ova belonging to the present group are in reality separated by no sharp line from those belonging to the group just described.

The origin and nature of meroblastic ova will best be understood by taking an ovum with an unequal segmentation, such as that of the frog, and considering what would take place in accordance with the laws already laid down, supposing the amount of food-yolk at the vitelline pole to be enormously increased. What would happen may be conveniently illustrated by fig. 44, representing the segmentation of a fowl's egg. There would first obviously appear a vertical furrow at the formative or protoplasmic pole. (Fig. 44 A, b.) This would gradually advance round the ovum and commence to divide it into two halves. Before the furrow had however proceeded very far it 
would come to the vitelline part of the ovum; here, according to the law previously enunciated, it would travel very slowly, and if the amount of the food-yolk was practically infinite as compared with the protoplasm, it would absolutely cease to advance. A second vertical furrow would soon be formed, crossing the first at right angles, and like it not advancing beyond the edge of the germinal disc. (Fig. 44 B.)

The next furrow should be an equatorial one (as a matter of fact in the fowl's ovum an equatorial furrow is not formed till after two more vertical furrows have appeared). The equatorial furrow would however, in accordance with the analogy of the frog, not be formed at the equator, but very close to the formative pole. It would therefore separate off as a distinct segment (fig. $44 \mathrm{C}, c$ ), a small central, i.e. polar, portion of each of the imperfect segments formed by the previous vertical furrows. By a continuation of the process of segmentation, with the same alternation of vertical and equatorial furrows as in the frog, a cap or disc of small segments would obviously be formed at the protoplasmic pole of the ovum, outside which would be a number of deepradiating grooves (fig. 45), formed by the vertical furrows, the advance of which

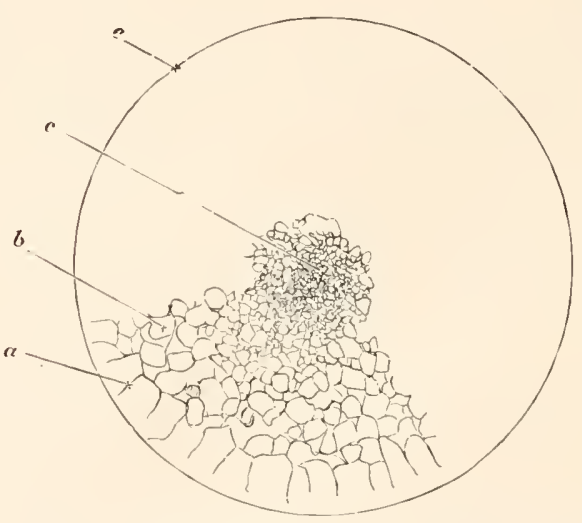

Fig. 45. Surface View of the germinal disc OF FOWL'S EGG DURING A LATE STAGE OF TIIE SEGMENTATION.

$c$. small central segmentation spheres; $b$. larger segments outside these; $a$. large, imperfectly circumscribed, marginal segments; $e$. margin of germinal disc. round the ovum has come to an end owing to the too great proportion of yolk spheres at the vitelline pole.

It is clear from the above that an immense accumulation of food-yolk at the vitelline pole necessarily causes a partial segmentation. It is equally clear that the part of meroblastic ova which does not undergo segmentation is not a new addition 
absent in other cases. It is on the contrary to be regarded merely as a part of the ovum in which the yolk spherules have attained to a very great bulk as compared with the protoplasm; sometimes even to the complete exclusion of the protoplasm.

An ordinary meroblastic ovum consists then of a small disc at the formative pole, known as the germinal disc, composed mainly of protoplasm in which comparatively little food-yolk is present. This graduates into the remainder of the ovum, being separated from it by a more or less sharp line. This remainder of the ovum, which almost always forms the major part, usually consists of numerous yolk spherules, embedded in a very scanty protoplasmic matrix.

In some cases, e.g. the eggs of Elasmobranchii ${ }^{1}$, the protoplasm is present in the form of a delicate network; in other and perhaps the majority of cases, too little protoplasm is present to be detected, or the protoplasm may even be completely absent. In some Osseous Fishes, e.g. Lota, the yolk forms a homogeneous transparent albuminoid substance containing a large globule at the pole furthest removed from the germinal disc. In this case the germinal disc is sharply separated from the yolk. In other Osseous Fishes the separation between the two parts is not so sharp². In these cases we find adjoining the germinal disc a finely granular material containing a large proportion of protoplasm; this graduates into a material with very little protoplasm and numerous yolk spherules, which is in its turn continuous with an homogeneous albuminoid yolk substance. In Elasmobranchii we find that immediately beneath the germinal disc there is present a finely granular matter, rich in protoplasm, which is continuous with the normal yolk.

The Elasmobranch ovum may conveniently serve as type for the Vertebrata. The ovum is formed of a spherical vitellus without any investing membrane. The germinal disc is recognizable on this as a small yellow spot about $\mathrm{I} \frac{1}{2}$ millimetres in diameter. In the germinal disc a furrow appears bisecting the disc, followed by a second furrow at right angles to the first. Thus after the formation of the second furrow the disc is divided into four equal areas. Fresh furrows continue to rise, and eventually a circular furrow, equivalent to the equatorial furrow of the frog's ovum, makes its appearance, and separates off a number of smaller central segments from peripheral larger segments. In the later stages the smaller segments at first divide more rapidly than the larger, but eventually the latter also divide rapidly, and the germinal disc becomes finally formed of a series of segments

1 Iride Schultze, Archiv. f. mikr. Anat. Vol. xı.; and F. M. Balfour, Monograph on the Development of Elasmobranch Fishes.

2 Vide Klein, Quart. Fournal of Micr. Scicnce, April, is 76 . Bambeke, Mim. Cour. Acad. Belgique, I875. His, Zeit. für Anat. u. Entroicklung: Vol. I. 
of a fairly uniform size. So much may be observed in surface views of the segmenting ovum, and it may be noted that there is not much difference to be observed between the segmentation of the germinal disc of the Fowl's ovum and that of the Elasmobranchii. Indeed the figure of the former (fig. 44) would serve fairly well for the latter. When however we examine the segmenting germinal discs by means of sections, there are some differences between the two types, and several interesting features which deserve to be noticed in the segmentation of the Elasmobranchii. In the first stages the furrows visible on the surface are merely furrows, which do not meet so as to isolate distinct segments; they merely, in fact, form a surface pattern. It is not till after the appearance of the equatorial furrow that the segments begin to be distinctly isolated. In the subsequent stages not only do the segments already existing in the germinal disc increase by division, but fresh segments are continually being formed from the adjacent yolk, and added to those already present in the germinal disc. (Fig. 46.)

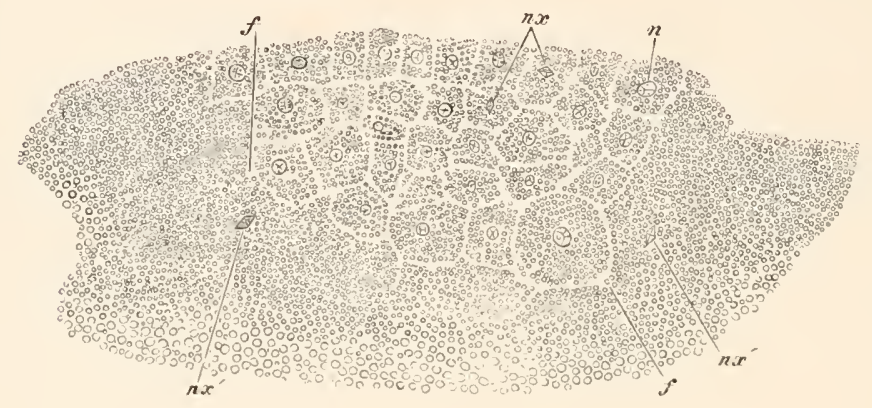

Fig. 46. Section through germinal disc of a Pristiurus embrio during THE SEGMENTATION.

$n$. nucleus; $n x$. nucleus modified prior to division; $n x^{\prime}$. modified nucleus of the yolk; $f$. furrow appearing in the yolk adjacent to the germinal disc.

This fact is one out of many which prove that the germinal disc is merely part of the ovum characterized by the presence of more protoplasm than the remainder which forms the so-called food-yolk. During the latest stages of segmentation there appear in the yolk around the blastoderm a number of nuclei. (Fig. 46, nx'.) These are connected with a special protoplasmic network (already described) which penetrates through the yolk. Towards the end of segmentation, and during the early periods of development which succeed the segmentation, these nuclei become very numerous. (Fig. 47 A, $n^{\prime}$.) Around many of them a protoplasmic investment is established, and cells are thus formed which eventually enter the blastoderm.

The result of segmentation is the formation of a lens-shaped mass of cells lying in a depression on the yolk. In this a cavity appears, the homologue of the segmentation cavity already spoken of. It lies at first in 
the midst of the cells of the blastoderm, but very soon its floor of cells vanishes, and it lies between the yolk and the blastoderm. (Fig. 47 A.) Its subsequent history is given in a future Chapter.

Segmentation proceeds in Osseous Fishes in nearly the same manner as in Elasmobranchii. In some cases the germinal disc is small as compared with the yolk, in other cases it is almost as large as the yolk. The only points which deserve special notice are the following: (I) Nuclei, precisely similar to those in the Elasmobranch yolk, appear in the protoplasmic matter around the germinal disc ; (2) After the deposition of the ova there is present in some forms a network of protoplasm extending from the germinal disc through the yolk ${ }^{1}$. At impregnation this withdraws itself from the yolk. It is to be compared to the protoplasmic network of the Elasmobranch ovum.
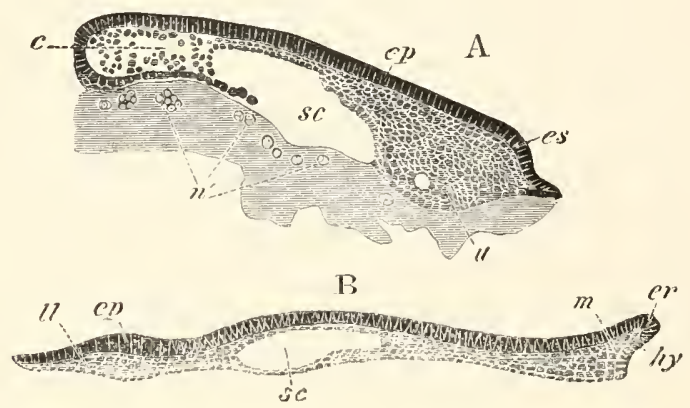

Fig. 47. Two longitudinal sections of the blastoderm of a Pristiurus EMBRYO AT STAGES PRIOR TO THE FORMATION OF THE MEDULLARY GROOVE.

$e p$. epiblast; $l l$. lower layer cells; $m$. mesoblast; hy. hypoblast; sc. segmentation cavity; es. embryo swelling; $n^{\prime}$. nuclei of yolk; er. embryonic rim.

There are two types of meroblastic ova. In one of these (Aves, Elasmobranchii) the germinal disc is formed in the ovarian ovum. In the second type the germinal disc is formed after impregnation by a concentration of the protoplasm at one pole. This concentration is analogous to what has already been described for Anodon and other Molluscan ova (p. IOO).

The ova of some Teleostei are intermediate between the two types.

The ovum of the wood-louse, Oniscus murarius ${ }^{2}$, may be taken as an example of the second type of meroblastic ovum. In this egg development commences by the appearance of a small clear mass with numerous transparent vesicles. This mass is the protoplasm which has become

1 Vide Bambeke, loc. cit.

2 Vide Bobretzky, Zeitschrift für wiss. Zoologie, Vol. xxıv., ${ }_{1} 8_{74}$. 
separated from the yolk. It undergoes segmentation in a perfectly normal fashion. Examples of other cases of this kind have been described by Van Beneden and Bessels ${ }^{1}$ in Anchorella, and in Hessia by Van Beneden $^{2}$. It appears from their researches that the protoplasm collects itself together, first of all in the interior of the egg, and then travels to the surface. It arrives at the surface after having already divided into two or more segments, which then rapidly divide in the usual manner to form the blastoderm.

There are some grounds for thinking that the cases of partial segmentation in the Arthropoda are not really quite comparable with those in other groups, but more probably fall under the next type of segmentation to be described. The grounds for this view are mentioned in connection with the next type.

In most if not all meroblastic ova there appear during and after segmentation a number of nuclei in the yolk adjoining the blastoderm, around which cells become differentiated. (Figs. 46 and 47.) These cells join the part of the blastoderm formed by the normal segmentation of the germinal disc. Such nuclei are formed in all craniate meroblastic ova ${ }^{3}$. In Cephalopods they have been found by Lankester, and in Oniscus by Bobretzky. They have been by some authors supposed to originate from the nuclei of the blastoderm, and by others spontaneously in the yolk.

Some of the earliest observations on these nuclei were made by Lankester ${ }^{*}$ in the Cephalopods. He found that they appeared first in a ringlike series round the edge of the blastoderm, and subsequently all over the yolk in a layer a little below the surface. He observed their development in the living ovum and found that they "commenced as minute points, gradually increasing in size like other free-formed nuclei." A cell area subsequently forms around them.

By E. van Beneden ${ }^{5}$ they were observed in a Teleostean ovum to appear nearly simultaneously in considerable numbers in the granular matter beneath the blastoderm. Van Beneden concludes from the simultaneous appearance of these bodies that they develop autogenously. Kupffer at an earlier period arrived at a similar conclusion. My own observations on these nuclei in Elasmobranchii on the whole support the conclusions to be derived from Lankester's, Kupffer's and Van Beneden's observations. As mentioned above, the nuclei in Elasmobranchii do not appear simultaneously, but

1 Loc. cit.

2 Bulletins de l'Acad. Betgique, Tom. xxix., is 80.

3 Though less obvious in the ovum of the fowl than in that of some other types, they may nevertheless be demonstrated there without very much difficulty.

4 Quart. Foum. of Micr. Science, Vol. xv. pp. 39, to.

5 Quart. Fourn. of Micr. Science, Vol. xvill. p. $+\mathrm{I}$. 
increase in number as development proceeds; and it is possible that Van Beneden may be mistaken on this point. No evidence came before me or derivation from pre-existing nuclei in the blastoderm. My observations prove however that the nuclei increase by division. This is shewn by the fact that I have found them with the spindle modification (fig. $46, n x^{\prime}$ ), and that in most cases they usually exhibit the form of a number of aggregated vesicles $^{1}$, which is a character of nuclei which have just undergone division. It should be mentioned however that I failed to find a spindle modification of the nuclei in the later stages. Against these observations must be set those of Bobretzky, according to which the nuclei in Oniscus are really the nuclei of cells which have migrated from the blastoderm. Bobretzky's observations do not however appear to be very conclusive.

It must be admitted that the general evidence at our command appears to indicate that the nuclei of the yolk in meroblastic ova originate spontanconsly. There is however a difficulty in accepting this conclusion in the fact that all the other nuclei of the embryo are descendants of the first segmentation nucleus; and for this reason it still appears to me possible that the nuclei of the yolk will be found to originate from the continued division of one primitive nucleus, itself derived from the segmentation nucleus.

The existence of these nuclei in the yolk and the formation of a distinct cell body around them is a strong piece of evidence in favour of the view above maintained, (which is not universally accepted,) that the part of the ovum of meroblastic ova which does not segment is of the same nature as that which does segment, and differs only in being relatively deficient in active protoplasm.

The following forms have meroblastic ova of the first type: the Cephalopoda, Pyrosoma, Elasmobranchii, Teleostei, Reptilia, Aves, Ornithodelphia (?). The second type of meroblastic segmentation occurs in many Crustacea, (parasitic Copepoda, Isopoda Mysis, etc.). It is also stated to be found in Scorpio.

The ova of the majority of groups in the animal kingdom segment according to one of the types which have just been described. These types are not sharply separated, but form an unbroken series, commencing with the ovum which segments uniformly, and ending with the meroblastic ovum.

1 At the time when my observations on Elasmobranchii were carried out, this peculiar condition of the nucleus had not been elucidated. 
It is convenient to distinguish the ova which segment uniformly by some term; and I should propose for this the term alecithal', as implying that they are without food-yolk, or that what little food-yolk there is, is distributed uniformly.

The ova in which the yolk is especially concentrated at one pole I should propose to call telolecithal. They constitute together a group with an unequal or partial segmentation.

The telolecithal ova may be defined in the following way: ova in which the food-yolk is not distributed uniformly, but is concentrated at one pole of the ovum. When only a moderate quantity of food-yolk is present the pole at which it is concentrated merely segments more slowly than the opposite pole; but when food-yolk is present in very large quantity the part of the ovum in which it is located is incapable of segmentation, and forms a special appendage known as the yolk-sack.

There is a third group of ova including a series of types of segmentation nearly parallel to the telolecithal group. This group takes its start from the alecithal ovum as do the telolecithal ova, and equally with these includes a series of varieties of segmentation running parallel to the regular and unequal types of segmentation which directly result from the presence of a greater or smaller quantity of food-yolk. The food-yolk is however placed, not at one pole, but at the contre of the ovum. This group of ova I propose to name centrolecithal. It is especially characteristic of the Arthropoda, if not entirely confined to that group.

Centrolecithal ova. As might be anticipated on the analogy of the types of segmentation already described, the concentration of the food-yolk at the centre of the ovum does not always take place before segmentation, but is sometimes deferred till even the later stages of this process.

Examples of a regular segmentation in centrolecithal ova are afforded by Palæmon (Bobretzky) and Penæus (Hæckel). A type of unequal segmentation like that of the Frog occurs in Gammarus locusta (Beneden and Bessels), where however the formation of a central yolk mass does not appear to take place

${ }^{1}$ For this term as well as for the terms telolecithal and centrolecithal I am indebted to Mr Lankester. 
till rather late in the segmentation. More irregular examples of unequal segmentation are also afforded by other Crustaceans, e.g. various members of the genus Chondracanthus (Beneden and Bessels) and by Myriapods. In all these cases segmentation ends in the formation of a layer of cells enclosing a central mass of food-yolk.

The peculiarity of the centrolecithal ova with regular or unequal segmentation is that (owing to the presence of the yolk in the interior) the furrows which appear on the surface are not
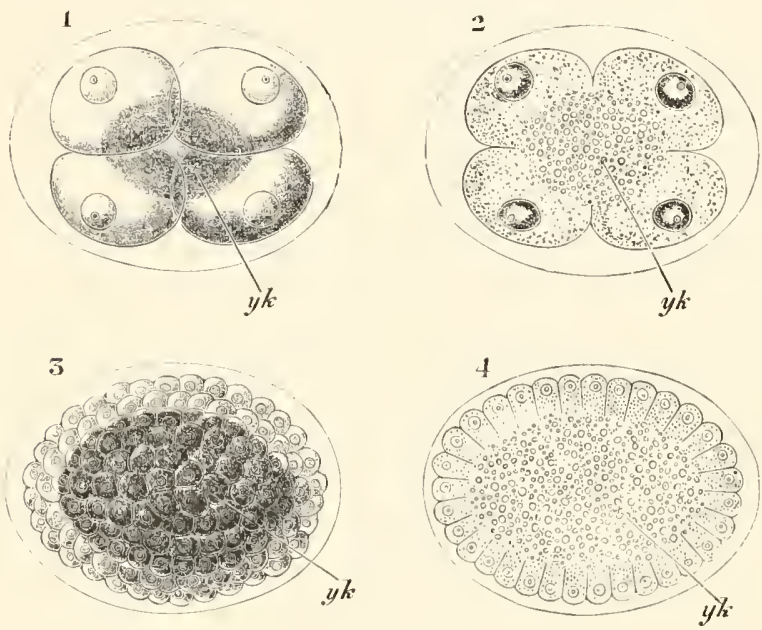

Fig. 48. Segmentation of a Crustacean ovum (Peneus). (After Hreckel.)

The sections illustrate the type of segmentation in which the yolk is aggregated at the centre of the ovum.

$y k$. central yolk mass.

$I$ and 2. Surface view and section of the stage with four segments. In 2 it is seen that the furrows visible on the surface do not penetrate to the centre of the ovum.

3 and 4 . Surface view and section of ovum near the end of segmentation. The central yolk mass is very clearly seen in $\psi$.

continued to the centre of the egg. The spheres which are thus distinct on the surface are really united internally. Fig. 48 , copied from Hæckel, shews this in a diagrammatic way.

Many ova, which in the later stages of segmentation exhibit the characteristics of true centrolecithal ova, in the carly stages actually pass through nearly the same phases as holoblastic ova. 
Thus in Eupagurus pridcauxii ${ }^{1}$ (fig. 49), and probably in the majority of Decapods, the egg is divided successively into two, four and eight distinct segments, and it is not till after the fourth phase of the segmentation that the spheres fuse in the centre of the egg. Such ova belong to a type which is really intermediate

A

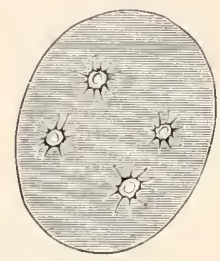

C

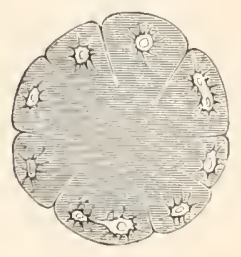

B

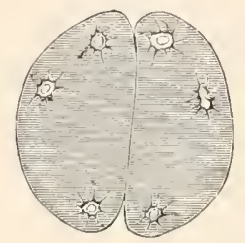

D

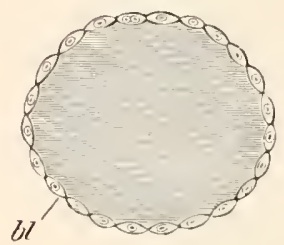

Fig. 49. T'ransverse section through four stages in the SEgmentation of Eupagurus Prideauxil. (After P. Mayer.)

between the ordinary type of segmentation and that with a central yolk mass. Eupagurus presents one striking peculiarity, viz. that the nucleus divides into two, four and eight nuclei, each surrounded by a delicate layer of protoplasm prolonged into a reticulum, before the ovum itself commences to become segmented. The ovum before segmentation is therefore in the condition of a syncytium.

The segmentation of Asellus aquaticus ${ }^{2}$ is very similar to that of Eupagurus, etc. but the ovum at the very first divides into as many segments (viz. eight) as there are nuclei.

In Gammarus locusta the resemblance to ordinary unequal segmentation is very striking, and it is not till a considerable number of segments have been formed that a central yolk mass appears.

1 Mayer, Fenaische Zeitschrift, Vol. XI.

${ }^{2}$ Ed. van Beneden, Bull. d. l'Acad. roy. Belgique, $2^{\text {me }}$ série, Tom. xxviri. No. 7 , 1869 , p. 54. 
In all the above types, as segmentation proceeds, the protoplasm becomes more and more concentrated at the surface, and finally a superficial layer of flat blastoderm cells is completely segmented off from the yolk below (fig. 49 D).

In cases like those of Penæus, Eupagurus, etc., the yolk in the interior is at first nearly homogeneous, but at a later period it generally becomes divided up partially or completely into a number of distinct spheres, which may have nuclei and therefore have the value of cells. In many cases nuclei have however not been demonstrated in these yolk spheres, though probably present; yet, till they have been demonstrated, some doubt must remain on the nature of these yolk spheres. It is probable that not all the nuclei which result from the division of the first segmentation nucleus become concerned in the formation of the superficial blastoderm, but that some remain in the interior of the ovum to become the nuclei of the yolk spheres.

In Myriapods (Chilognatha) a peculiar form of segmentation has been

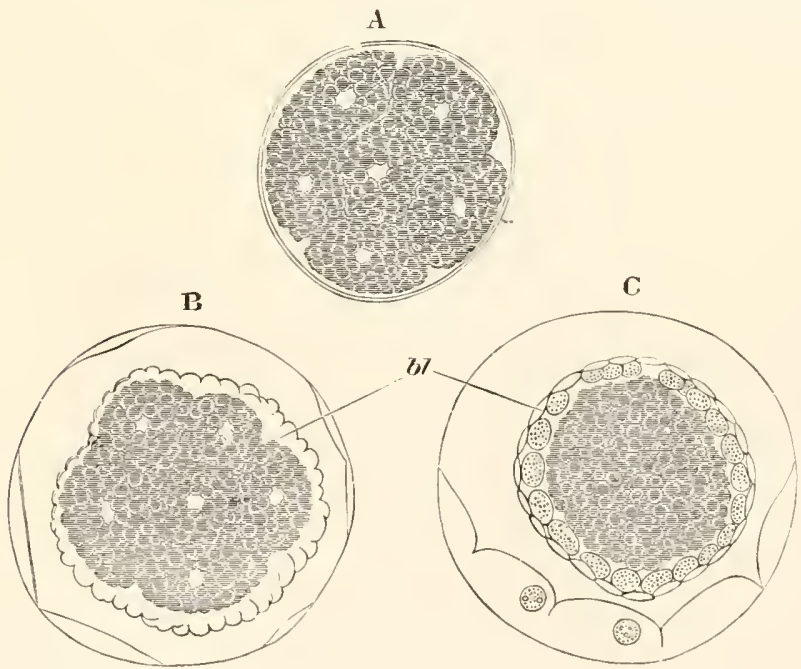

Fig. 50. Segmentation and formation of the blastoderm in Chelifer.

(After Metschnikoff.)

In $\mathrm{A}$ the ovum is divided into a number of separate segments. In $\mathrm{B}$ a number of small cells have appeared $(b l)$ which form a blastoderm enveloping the large yolk spheres. In $\mathrm{C}$ the blastoderm has become divided into two layers.

B. II. 
observed by Metschnikoff ${ }^{1}$. The ovum commences by undergoing a perfectly normal, though rather irregular total segmentation. But after the process of division has reached a certain point, scattered masses of very small cells make their appearance on the surface of the large spheres. These small cells have probably arisen in a manner analogous to that which characterizes the formation of the superficial cells of the blastoderm in the types of centrolecithal ova already described. They rapidly increase in number and eventually form a continuous blastoderm; while the original large segments remain in the centre as the yolk mass. In the interesting Arachnid Chelifer segmentation takes place in nearly the same manner as in Myriapods (fig. 50).

It is clear that it is not possible in centrolecithal ova to have any type of segmentation exactly comparable with that of meroblastic ova. There are however some types which fill the place of the meroblastic ova in the present group, in as much as they are characterised by the presence of a large bulk of food-yolk which either does not segment, or does not do so till a very late stage in the development. The essential character of this type of segmentation consists in the division of the germinal vesicle in

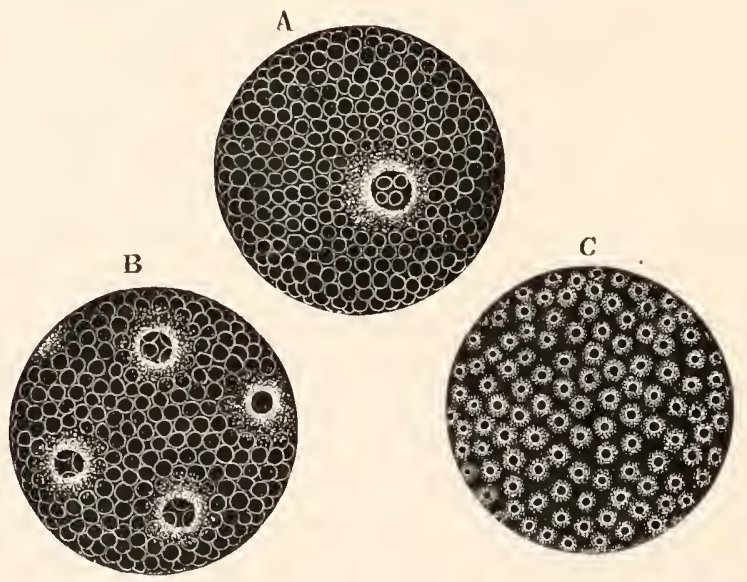

Fig. 5i. Four successive stages in the segmentation of the egg of TetraNychus Telarius. (After Claparède.)

the interior, or at the surface of the ovum into two, four, etc. nuclei (fig. 5I). These nuclei are each of them surrounded by a specially concentrated layer of protoplasm (fig. 5I) which is

1 Znitschrifl für wiss. Zool., Vol. xxiv. 1874 . 
continuous with a general protoplasmic reticulum passing through the ovum [not shewn in fig. $5 \mathrm{I}$ ]. The yolk is contained in the meshes of this reticulum in the manner already described for other ova.

The ovum, like that of Eupagurus before segmentation, is now a syncytium. Eventually the nuclei, having increased by division and become very numerous, travel, unless previously situated there, to the surface of the ovum. They then either simultaneously or in succession become, together with protoplasm around them, segmented off from the yolk, and give rise to a peripheral blastoderm enclosing a central yolk mass. In the latter however many of the nuclei usually remain, and it also very often undergoes a secondary segmentation into a number of yolk spheres.

The eggs of Insects afford numerous examples of this mode of segmentation, of which the egg of Porthesia ${ }^{1}$ may be taken as type. After impregnation it consists of a central mass of yolk which passes without a sharp line of demarcation into a peripheral layer of more transparent (protoplasmic) material. In the earliest stage observed by Bobretzky there were two bodies in the interior of the egg, each consisting of a nucleus enclosed in a thin protoplasmic layer with stellate prolongations. This stage corresponds with the division into two, but though the nucleus divides, the preponderating amount of yolk prevents the egg from segmenting at the same time. By a continuous division of the nuclei there becomes scattered through the interior of the ovum a series of bodies, each formed of nucleus and a thin layer of protoplasm with reticulate processes. After a certain stage some of these bodies pass to the surface, simultaneously (in Porthesia) or in some cases successively. At the surface the protoplasm round each nucleus contracts itself into a rounded cell body, distinctly cut off from the adjacent yolk.

The cells so formed give rise to a superficial blastoderm of a single layer of cells. Many of the nucleated bodies remain in the yolk, and after a certain time, which varies in different forms, the yolk becomes segmented up into a number of rounded or polygonal bodies, in the interior of each of which one of the

1 Bobretzky, Zeit.f. wiss. Zool., Bd. Xxxı. 1878 . 
above nuclei with its protoplasm is present. This process, known as the secondary segmentation of the yolk, is really part of the true segmentation, and the bodies to which it gives rise are true cells.

Other examples of this type may be cited. In Aphis ${ }^{1}$ Metschnikoff shewed that the first segmentation nucleus divides into two, each of which takes up a position in the clearer peripheral protoplasmic layer of the egg (fig. 52, I and 2). Following upon further division the nuclei enveloped in a continuous layer of protoplasm arrange themselves in a regular manner, and form a syncytium, which becomes segmented into definite cells (fig. 52, 3 and 4). The existence of a special clear superficial layer of protoplasm has been questioned by Brandt.
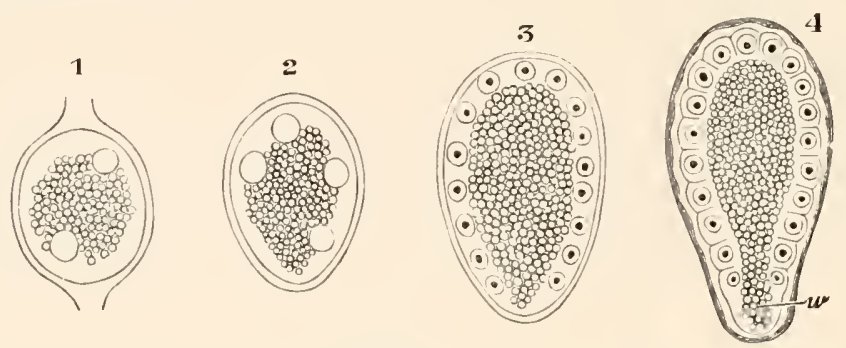

Fig. 52. Segmentation of Aphis rosae. (Copied from Metschnikoff.)

In all the stages there is seen to be a central yolk mass surrounded by a layer of protoplasm.

In this protoplasm two nuclei have appeared in $\mathbf{I}$, four nuclei in 2 . In 3 the nuclei have arranged themselves regularly, and in 4 the protoplasm has become divided into a number of columnar cells corresponding to the nuclei.

w. pole of the blastoderm which has no share in forming the embryo.

In Tetranychus telarius, one of the mites, Claparède found on the surface of the ovum a nucleus surrounded by granular protoplasm (fig. 5I); which is no doubt the first segmentation nucleus. By a series of divisions, all on the surface, a layer of cells becomes formed round a central yolk mass. The result here is the same as in Insects, but the nucleus with its granular protoplasm is from the first superficial. In other cases, such as that of the common $\mathrm{fly}^{2}$, a layer of protoplasm is stated to appear investing the yolk; and in this there arise simultaneously (?) a number of nuclei at regular intervals, around each of which the protoplasm separates itself to form a distinct cell. Closely allied is the type observed by Kowalevsky in Apis. Development here commences by the appearance of a number of protoplasmic

1 Metschnikoff, "Embry. Stud. Insecten," Zcit. für wiss. Zool., Bd. Xvi. I 866. My own observations on this form accord in the main with those of Metschnikoff.

2 Vide Weismann, Entwicklung d. Dipteren; and Auerbach, Organologische Studien. 
prominences, each forming a cell provided with a nucleus, the nuclei having no doubt been formed by previous division in the interior of the ovum. They appear at the edge of the yolk, and are separated from one another by short intervals. Shortly after their appearance a second batch of similar bodies appears, filling up the interspaces between the first-formed prominences. In the fresh-water Gammarus fluviatilis the protoplasm is stated first of all to collect at the centre of the ovum, where no doubt the segmentation nucleus divides. Subsequently cells appear at numerous points on the surface, and by repeated division constitute an uniform blastoderm investing the central yolk mass. This mode of formation of the blastoderm is closely allied to that observed by Kowalevsky in Apis.

Between ova with a segmentation like that of Insects, and those with a segmentation like that of Penæus, there is more than one intermediate form. The Eupagurus type, with the division of the first nucleus into eight nuclei before the division

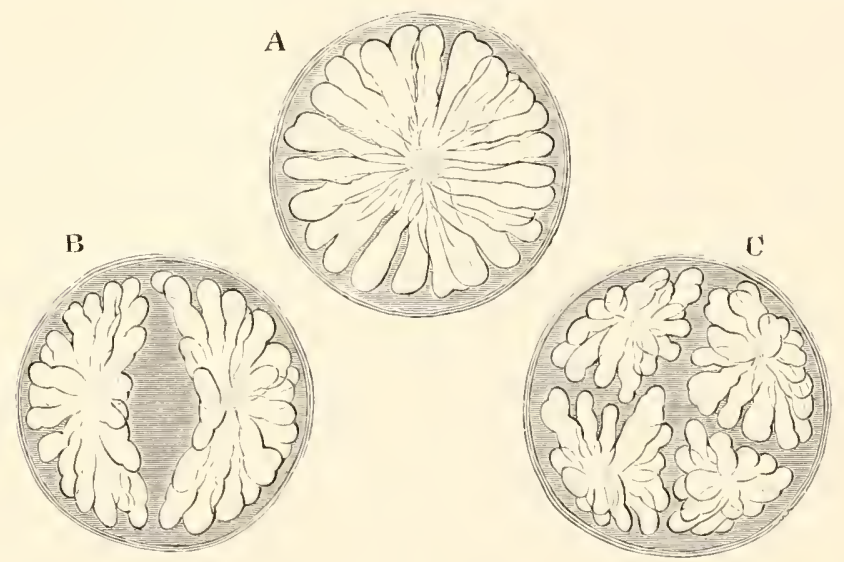

Fig. 53. Three stages in the segmentation of Philodromus limbatus. (After Hub. Ludwig.)

of the ovum, must be regarded in this light; but the most instructive example of such a transitional type of segmentation is that afforded by Spiders ${ }^{1}$.

The first phenomenon which can be observed after impregnation is the conglomeration of the yolk spheres into cylindrical columns, which finally assume a radiating form diverging from the centre of the egg. In the centre of the radiate figure is a protoplasmic mass, probably containing a nucleus, which sends

1 Vide Ludwig, Zeit. f. wiss. Zool., 1876 . 
out protoplasmic filaments through the columns (fig. 53 A). After a certain period of repose the figure becomes divided into two rosette-like masses, which remain united for some time by a protoplasmic thread: this thread is finally ruptured (fig. $53 \mathrm{~B}$ ). The whole egg does not in this process divide into two segments, but merely the radiate figure, which is enclosed in a finely granular material. The two rosettes next become simultaneously divided, giving rise to four rosettes (fig. $53 \mathrm{C}$ ) : and the whole process is repeated with the same rhythm as in a regular segmentation till there are formed thirty-two rosettes in all (fig. $54 \mathrm{~A}$ ). The rosettes by this time have become simple columns, which by mutual pressure arrange themselves radiately around the centre of the egg, which however they do not quite reach.

When only two rosettes are present the protoplasm with its nucleus occupies a central position in each rosette, but gradually, in the course of the subsequent subdivisions, it travels towards the periphery, and finally occupies, when the stage with thirtytwo rosettes is reached, a peripheral position. The peripheral protoplasm next becomes separated off as a nucleated layer
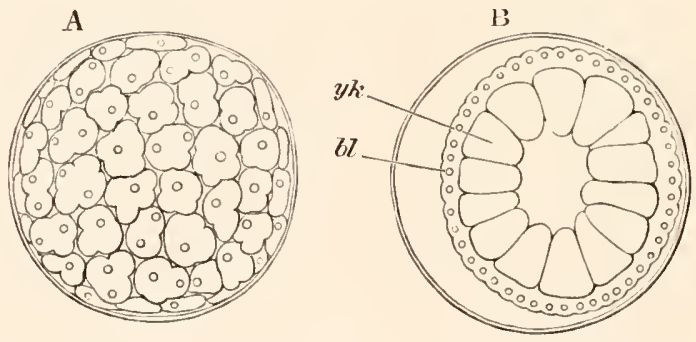

Fig. 54. Surface view and optical Section of a late stage in the segmentation of Philodronus limbatus (Koch). (After Hub. Ludwig.)

bl. blastoderm ; $y k$. yolk spheres.

(fig. 54 B). It forms the proper blastoderm, and in it the nuclei rapidly multiply and finally around each an hexagonal or polygonal area of protoplasm is marked off; and a blastoderm, formed of a single layer of flattened cells, is thus constituted. The columns within the blastoderm now form (fig. $54 \mathrm{~B}$ ) more or less distinct masses, which are stated by Ludwig to be without protoplasm. 
From observations of my own I am inclined to differ from Ludwig as to the nature of the parts within the blastoderm. My observations have been made on Agelena labyrinthica and commence at the close of the segmentation. At this time I find a superficial layer of flattened cells, and within these a number of large polyhedral yolk cells. In many, and I believe all, of the yolk cells there is a nucleus surrounded by protoplasm. It is generally placed at one side and not in the centre of a yolk cell, and the nuclei are so often double that I have no doubt they are rapidly undergoing division. It appears to me probable that, at the time when the superficial layer of protoplasm is segmented off from the yolk below, the nuclei undergo division, and that a nucleus with surrounding protoplasm is left with each yolk column. For further details vide Chapter on Arachnida.

Although by the close of the segmentation the protoplasm has travelled to a superficial position, it may be noted that at first it forms a small mass in the centre of the egg, and only eventually assumes its peripheral situation. It is moreover clear that in the Spider's ovum there is, so to speak, an attempt at a complete segmentation, which however only results in an arrangement of the constituents of the ovum in masses round each nucleus, and not in a true division of the ovum into distinct segments.

It seems very probable that Ludwig's observations on the segmentation of Spiders only hold good for species with comparatively small ova.

In connection with the segmentation of the Insects' ovum and allied types it should be mentioned that Bobretzky, to whose observations we are largely indebted for our knowledge of this subject, holds somewhat different views from those adopted in the text. He regards the nuclei surrounded by protoplasm, which are produced by the division of the primitive segmentation nucleus, as so many distinct cells. These cells are supposed to move about freely in the yolk, which acts as a kind of intercellular medium. This view does not commend itself to me. It is opposed to my own observations on similar nuclei in the Spiders. It does not fit in with our knowledge of the nature of the ovum, and it cannot be reconciled with the segmentation of such types as Spiders or even Eupagurus, with which the segmentation in Insects is undoubtedly closely related.

The majority if not all the cases in which a central yolk mass is formed occur in the Arthropoda, in which group centrolecithal ova are undoubtedly in a majority. In Alcyonium palmatum the segmentation appears however to resemble that of many insects.

One or two peculiar varieties in the segmentation of ova of this type may be spoken of here. The first one I shall mention is detailed in the important paper of E. Van Beneden and Bessels which I have already so often had occasion to quote: it is characteristic of the eggs of most of the 
species of Chondracanthus, a genus of parasitic Crustaceans. The ovum divides in the usual way but somewhat irregularly into $2,4,8$ segments which meet in a central yolk mass; but after the third division instead of each segment dividing into two equal parts it divides at once into four, and the division into four having started, reappears at every successive division. Thus the number of the segments at successive periods is $2,4,8,32,128$, etc. In another peculiar case, an instance of which ${ }^{\mathrm{I}}$ is afforded by Asellus aquaticus, after each of the earlier segmentations all the segments fuse and become indistinguishable, but at the succeeding segmentation double the number of segments appears.

Although, as has been already stated, it does not seem possible to have a true meroblastic segmentation in centrolecithal ova, it does nevertheless appear probable that the apparent cases of a meroblastic segmentation in the Arthropoda are derivatives of this type of segmentation. The manner in which the one type might pass into the other may perhaps be explained by the segmentation in Asellus aquaticus ${ }^{1}$. In this ovum large segments are at first formed around a central yolk mass, in the peculiar manner mentioned in the previous paragraph, but at the close of the first period of segmentation minute cells, which eventually form a superficial blastoderm, are produced from the yolk cells. They do not however appear at once round the whole periphery of the egg, but at first only on the ventral surface and later on the dorsal surface. If the amount of food-yolk in the egg were to increase so as to render the formation of the yolk cells impossible, and at the same time the formation of the blastodermic cells were to take place at the commencement, instead of towards the close of the segmentation, a mass of protoplasm with a nucleus might first appear at the surface on the future ventral side of the egg, then divide in the usual way for meroblastic ova, and give rise to a layer of cells gradually extending round to the dorsal surface. A meroblastic segmentation might perhaps be even more easily derived from the type found in lnsects. It is probable that the cases of Scorpio, Mysis, Oniscus, the parasitic Isopoda, and some parasitic Copepoda belong to this category; and it may be noticed that in these cases the blastopore would be situated on the dorsal and not on the ventral side of the ovum. The morphological importance of this latter fact will appear in the sequel.

The results arrived at in the present section may be shortly restated in the following way.

(I) A comparatively small number of ova contain very little or no food-yolk embedded in their protoplasm; and have what food-yolk may be present distributed uniformly. In such ova the segmentation is regular. They may be described as alecithal ova.

1 Ed. van Beneden, Bull. Acad. Belgique, Vol. xxv11. I869. 
(2) The distribution of food-yolk in the protoplasm of the ovum exercises an important influence on the segmentation.

The rapidity with which any part of an ovum segments varies ceteris paribus with the relative amount of protoplasm it contains; and the size of the segments formed varies inversely to the relative amount of protoplasm. When the proportion of protoplasm in any part of an ovum becomes extremely small, segmentation does not occur in that part.

Ova with food-yolk may be divided into two great groups according to the eventual arrangement of the food-yolk in the protoplasm. In one of these, the food-yolk when present is concentrated at the vegetative pole of the ovum. In the other group it is concentrated at the centre of the ovum. Ova belonging to the former group are known as telolecithal ova, those to the latter as centrolecithal.

In each group more than one type may be distinguished. In the first group these types are (I) unequal segmentation, (2) partial segmentation. The features of these three types have been already so fully explained that I need not repeat them here.

In the second group there are three distinct types, (I) equal segmentation, (2) unequal segmentation. These two being externally similar to the similarly named types in the first group. (3) Superficial segmentation. This is unlike anything which is present in the first group, and is characterized by the appearance of a superficial layer of cells round a central yolk mass. These cells may either appear simultaneously or successively, and their nuclei are derived from the segmentation within the ovum of the first segmentation nucleus.

The types of ova in relation to the characters of the segmentation may be tabulated in the following way:

Segmentation.

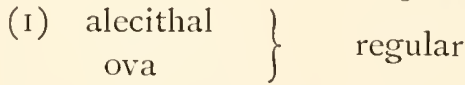

(2) telolecithal ( a) unequal ova $\quad$ (b) partial

(3) centro- $\quad \begin{gathered}\text { (a) regular (with segments united in } \\ \text { central yolk mass) }\end{gathered}$ lecithal ova
(b) uncqual ,
(b) unequal , , ,
(c) superficial. 
Although the various types of segmentation which have been described present very different aspects, they must nevertheless be looked on as manifestations of the same inherited tendency to division, which differ only according to the conditions under which the tendency displays itself.

This tendency is probably to be regarded as the embryological repetition of that phase in the evolution of the Metazoa, which constituted the transition from the protozoon to the metazoon condition.

From the facts narrated in this chapter the reader will have gathered that similarity or dissimilarity of segmentation is no safe guide to affinities. In many cases, it is true, a special type of segmentation may characterize a whole group; but in other cases very closely allied animals present the greatest differences with respect to their segmentation; as for instance the different species of the genus Gammarus. The character of the segmentation has great influence on the early phenomena of development, though naturally none on the adult form.

\section{External Features of Segmentation.}

(105) E. Haeckel. "Die Gastrula u. Eifurchung." Jenaische Zeitschrift, Vol. $1 \mathrm{x} .1877$.

(106) Fr. Leydig. "Die Dotterfurchung nach ihrem Vorkommen in d. Thierwelt u. n. ihrer Bedeutung." Oken Isis. 1848 . 


\section{PART I.}

SYSTEMATIC EMBRYOLOGY. 



\section{PART I. \\ SYSTEMATIC EMBRYOLOGY.}

\section{INTRODUCTION.}

IN all the Metazoa the segmentation is followed by a series of changes which result in the grouping of the embryonic cells into definite layers, or membranes, known as the germinal layers. There are always two of these layers, known as the epiblast and hypoblast; and in the majority of instances a third layer, known as the mesoblast, becomes interposed between them. It is by the further differentiation of the germinal layers that the organs of the adult become built up. Owing to this it is usual, in the language of Embryology, to speak of the organs as derived from such or such a germinal layer.

At the close of the section of this work devoted to systematic embryology, there is a discussion of the difficult questions which arise as to the complete or partial homology of these layers throughout the Metazoa, and as to the meaning to be attached to the various processes by which they take their origin; but a few words as to the general fate of the layers, and the general nature of the processes by which they are formed, will not be out of place here.

Of the three layers the epiblast and hypoblast are to be regarded as the primary. The epiblast is essentially the primitive integument, and constitutes the protective and sensory layer. It gives rise to the skin, cuticle, nervous system, and organs of special sense. The hypoblast is essentially the digestive and secretory layer, and gives rise to the epithelium lining the alimentary tract and the glands connected with it. 
The mesoblast is only found in a fully developed condition in the forms more highly organized than the Colenterata. It gives origin to the general connective tissue, internal skeleton, the muscular system, the lining of the body-cavity, the vascular, and excretory systems. It probably in the first instance originated from differentiations of the two primary layers, and in all groups with a well-developed body-cavity it is divided into two strata. One of them forms part of the body-wall and is known as the somatic mesoblast, the other forms part of the wall of the viscera and is known as the splanchnic mesoblast.

A very large number not to say the majority of organs are derived from parts of two of the germinal layers. Many glands for instance have a lining of hypoblast which is coated by a mesoblastic layer.

The processes by which the germinal layers take their origin are largely influenced by the character of the segmentation, which, as was shewn in the last chapter, is mainly dependent on the distribution of the foodyolk. When the segmentation is regular, and results in the formation of a blastosphere,

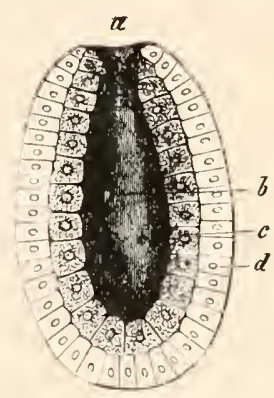

Fig. 55. DIAGRAM of a Gastrula. (From Gegenbaur.)

$a$. blastopore; $b$. archenteron; $c$. hypoblast ; $d$. epiblast. the epiblast and hypoblast are usually differentiated from the uniform cells forming the wall of the blastosphere in one of the two following ways.

(I) One-half of the blastosphere may be pushed in towards the other half. A two-layered hemisphere is thus established which soon elongates, while its opening narrows to a small pore (fig. 55). The embryonic form produced by this process is known as a gastrula. The process by which it originates is known as embolic invagination, or shortly invagination. Of the two layers of which it is formed the inner one $(c)$ is known as the hypoblast and the outer $(d)$ as the epiblast, while the pore leading into its cavity lined by the hypoblast is the blastopore (a). The cavity itself is the archenteron (b).

(2) The cells of the blastosphere may divide themselves by a process of concentric splitting into two layers (fig. 56, 3). The two layers are as before the epiblast and hypoblast, and the 
process by which they originate is known as delamination. The central cavity or archenteron $(F)$ is in the case of delamination the original segmentation cavity; and not an entirely new cavity as in the case of invagination. By the perforation of the closed two-walled vesicle resulting from delamination an embry-
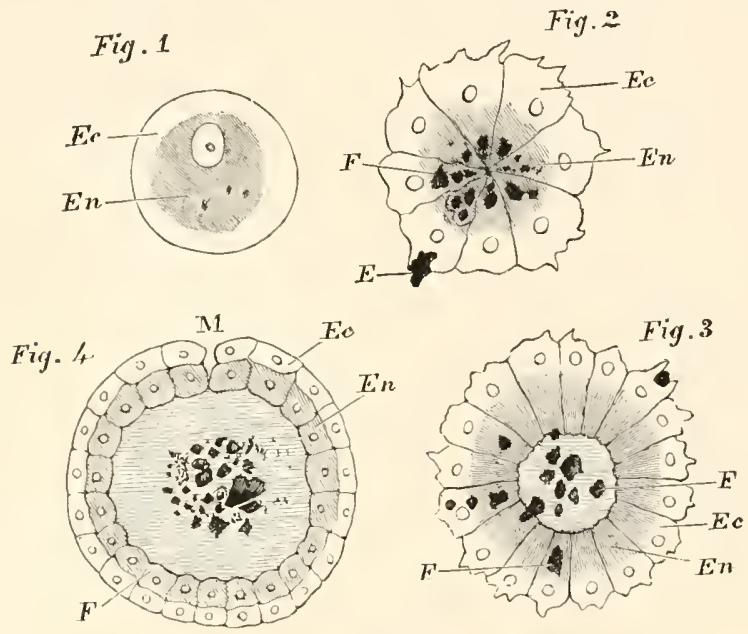

Fig. 56. Diagram sheiving the formation of a Gastrula by delamination.

Fig. I. Ovum.

(From Lankester.)

Fig. 2. Stage in segmentation.

Fig. 3. Commencement of delamination after the appearance of a central cavity.

Fig. 4. Delamination completed, mouth forming at $M$.

In fig. I, 2 and $3 E c$. is ectoplasm, and $E_{n}$. is entoplasm.

In fig. $+E c$. is epiblast and $E n$. hypoblast.

onic form is produced which cannot be distinguished in structure from the gastrula produced by invagination (fig. 56,4). The opening $(M)$ in this case is not however known as the blastopore but as the mouth.

When segmentation does not take place on the regular type the processes above described are as a rule somewhat modified. The yolk is usually concentrated in the cells which would, in the case of a simple gastrula, be invaginated. As a consequence of this, these cells become (I) distinctly marked off from the epiblast cells during the segmentation; and (2) very much more bulky than the epiblast cells. The bulkiness of the 
hypoblast cells necessitates a modification of the normal process of embolic invagination, and causes another process to be substituted for it, viz. the growth of the epiblast cells as a thin layer over the hypoblast. This process (fig. 57) is known as epibolic invagination. The point where the complete enclosure of the hypoblast cells is effected is known as the blastopore. All intermediate conditions between epibolic and

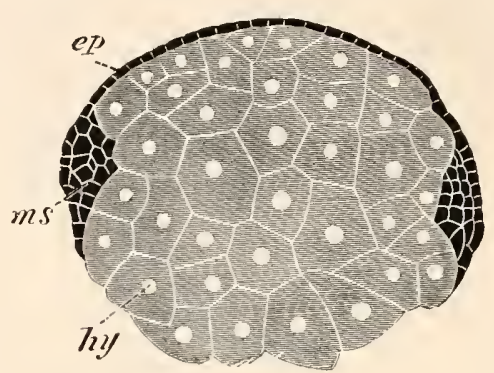

Fig, 57. Transverse Section THROUGH THE OVUM OF EUAXES DURING AN EARLY STAGE OF DEVELOPMENT. (After Kowalevsky.)

ep. epiblast; ms. mesoblastic band; hy. hypoblast. embolic invagination have been found.

In delamination, when the segmentation is not uniform, or when a solid morula is formed, the differentiation of the epiblast and hypoblast is effected by the separation of the central solid mass of cells from the peripheral cells (fig. $5^{8} \mathrm{~A}$ ).

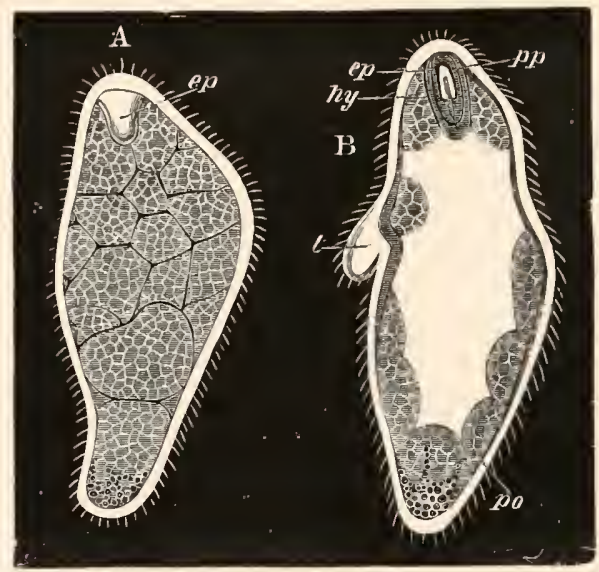

Fig. 58. Two stages in the developmext of Stephanomia pictum. (After Metschnikoff.)

A. Stage after the delamination. ep. epiblastic invagination to form pneumatocyst.

B. Later stage after the formation of the gastric cavity in the solid hypoblast, $p o$. polypite; $t$. tentacle; $p p$. pneumatophore; $c p$. epiblastic invagination to form pneumatocyst; $h y$. hypoblast surrounding pneumatocyst. 
In the case of epibolic invagination as well as in that of the type of delamination just spoken of, the archenteric cavity is in most cases secondarily formed in the solid mass of hypoblast (fig. $5^{8} \mathrm{~B}$ ).

In ova with a partial segmentation there is usually some modification of the epibolic gastrula.

Many varieties are found in the animal kingdom of the types of invagination and delamination just characterized, and in not a few forms the layers originate in a manner which cannot be brought into connection with either of these processes.
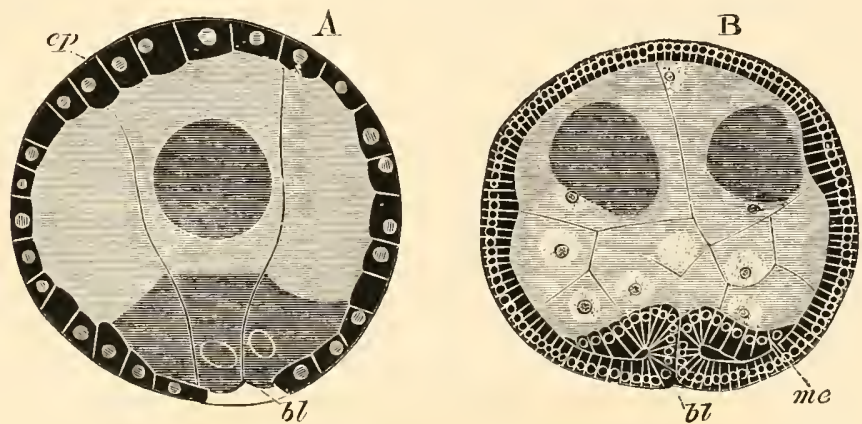

Fig. 59. Epiboitic gastrula of Bonellia. (After Spengel.)

A. Stage when the four hypoblast cells are nearly enclosed.

B. Stage after the formation of the mesoblast has commenced by an infolding of the lips of the blastopore.

ef. epiblast ; me. mesoblast ; bl. bliastopore.

The mesoblast usually originates subsequently to the two primary layers. It then springs from one or both of the other layers, but its modes of origin are so various that it would be useless to attempt to classify them here. In cases of invagination it often arises at the lips of the blastopore (fig. 57 and 59), and in other cases part of it springs as paired hollow outgrowths of the walls of the archenteron. Such outgrowths are shewn in fig. 6o, $\mathrm{B}$ and $\mathrm{C}$ at $p v$. The cavity of the outgrowths forms the body cavity, and the walls of the outgrowths the somatic and splanchnic layers of mesoblast (fig. C. sp. and so.). The archenteron is in part always converted into a section of the permanent alimentary tract; and the section of the alimentary tract so derived is known as the mesenteron. There are however usually two additional parts of the alimentary tract, known as

B. II. 


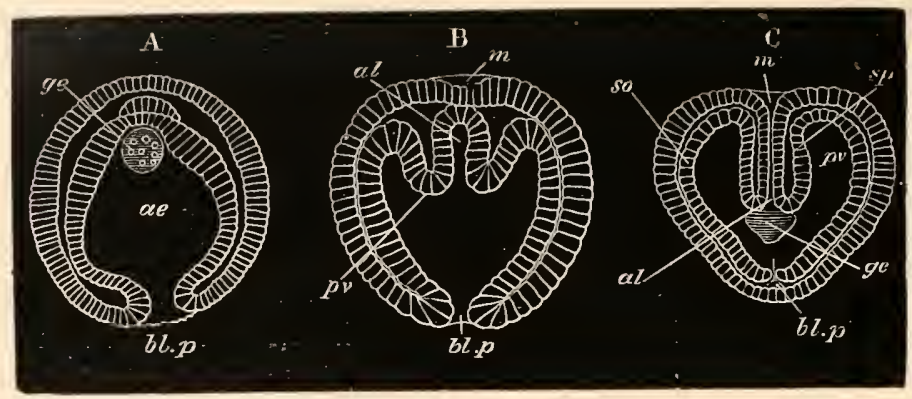

Fig. 6o. Three stages in the development of Sagitta. (A and C after Bütschli and B after Kowalevsky.) The three embryos are represented in the same positions.

A. Represents the gastrula stage.

B. Represents a succeeding stage in which the primitive archenteron is commencing to be divided into three parts, the two lateral of which are destined to form the mesoblast.

C. Represents a later stage in which the mouth involution $(m)$ lias become continuous with alimentary tract, and the blastopore has become closed.

$m$. mouth; $a l$. alimentary canal; $a \ell$. archenteron ; $b \%$. $p$. blastopore; $f v$. perivisceral cavity; sp. splanchnic mesoblast; so. somatic mesoblast; ge. generative organs. the stomodaeum and proctodaeum, derived from epiblastic invaginations. They give rise respectively to the oral and anal extremities of the alimentary tract.

\section{BIBLIOGRAPHY.}

(107) K. E. von Baer. "Ueb. Entwicklungsgeschichte d. Thiere." Königsberg, $1828-1837$.

(108) C. Claus. Grundzüge d. Zoologie. Marburg und Leipzig, 1879.

(109) C. Gegenbaur. Grundriss d. vergleichenden Anatomie. Leipzig, 1878. Vide also Translation. Etements of Comparative Anatomy. Macmillan and Co., 1878 .

(110) E. Haeckel. Studien z. Gastraa-Theorie. Jena, I877, and also Jenaische Zeitschrift, Vols. virI, and IX.

(111) E. Haeckel. Schöffungsgeschichte. Leipzig. Vide also Translation. The History of Creation. King and Co., London, 1876 .

(112) E. Haeckel. Anthropogenie. Leipzig. Vide also Translation. Anthropogeny (Translation). Kegan Paul and Co., London, I878.

(113) Th. H. Huxley. The Anatomy of Invertebrated Animats. Churchill, 1877 .

(114) E. R. Lankester. "Notes on Embryology and Classification." Quart. J. of. Aicr. Science, Vol. xvir. 1877 .

(115) A. S. P. Packard. Life Histories of Animals, including Man, or Outlines of Comparative Embryology. Holt and Co., New York, 1876.

(116) H. Rathke. Abhandlungen z. Bitdung- und Entwicklungsgesch. d. Menschen 2 . d. Thiere. Leipzig, I 833 . 


\section{CHAPTER IV.}

\section{DICYEMIDÆ AND ORTHONECTIDÆ.}

\section{DICYEMIDA.}

THE structure and development of these remarkable parasites in the renal organs of the Cephalopoda have recently been greatly elucidated by the researches of E. van Beneden; and although a male element has not been discovered, yet the embryos originate from bodies which have a close similarity to ordinary ova.

Van Beneden has shewn that Dicyema consists in the adult state of (I) a single layer of ciliated epiblast cells, somewhat modified anteriorly to form a cephalic enlargement; and of (2) one large nucleated hypoblast cell enclosed within the epiblast. There are two kinds of embryo, both developed from germs which originate in the hypoblast cell. The two kinds of embryo arise in individuals of somewhat different forms. The one kind, called by Van Beneden the vermiform embryo, arises in the more elongated and thinner examples of Dicyema which have been named Nematogens. These embryos pass directly into the parent form without metamorphosis.

The second kind of embryo, called infusoriform, is very different from the parent, and has a free existence. Its eventual history is not known. It originates in the shorter and thicker individuals of Dicyema; which have been called Rhombogens.

The Vermiform Embryos. The germs or cells which give rise to the vermiform embryos originate endogenously in the protoplasmic reticulum of the axial hypoblast cell. They appear as small but well-defined spheres, with a minute body in the 
centre. In these spheres a cortical layer becomes differentiated, which gradually increases in thickness and gives rise to the body of a cell, the nucleus and nucleolus of which are respectively formed from the inner part of the original sphere and the minute central body. These germs can originate in all parts of the hypoblast cell and are frequently very numerous.

The germ when completely formed undergoes a segmentation very similar to that of an ordinary ovum. It divides first into two and then into four approximately equal segments. Of the four segments one, however, remains passive for the remainder of the development. The other three divide and arrange themselves so as partially to enclose in a cup-like fashion the passive cell (fig. 6I A). The six cells resulting from their division again divide, giving rise to twelve cells, which nearly enclose the passive cell, leaving only a small aperture at one point. The whole process by which the central cell becomes enclosed is, as E. van Beneden points out, identical with a gastrula formation by epibole, and the space where the central cell is left uncovered is the blastopore. The central cell itself gives origin to the hypoblast cell of the

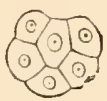

A.

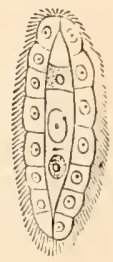

B.

Fig. 6i. A. Gastrula STAGE OF DICYEMA TYPUS. B. VERMIFORM EMBRIO OF Dicyema TYPUS. (From Gegenbaur, after E. van Beneden.) adult, and the peripheral cells to the epiblast.

By this time the embryo has assumed an oval form, and the blastopore is situated at the pole of the long axis of the oval where the cephalic enlargement is eventually formed.

The subsequent development consists mainly in the closure of the blastopore, and an increase in the number of the epiblast cells. Before the development is completed, and while the embryo is still in the body of the parent, two germs, destined themselves to give rise to fresh embryos, appear in the hypoblast cell, one on each side of the nucleus (fig. 6I B). The embryo continues to elongate, while the anterior cells become converted into the polar cells. Cilia appear simultaneously over the general surface, and the embryo makes its way out of the body of the parent, usually at the cephalic pole, and becomes itself parasitic in the renal organ of the host in which it finds itself. 
At the time of birth the embryo may contain a number of germs and sometimes even developing embryos.

Infusoriform Embryos. The infusoriform embryos are capable of living in sea-water and almost certainly lead a free existence. In their most fully developed condition so far known they have the following rather complicated structure (fig. $62 \mathrm{D}$, E, $F, G$ ).

The body is somewhat pyriform, with a blunt extremity which is directed forwards in swimming, and a more pointed extremity directed backwards. The former may be spoken of as the anterior, and the latter as the posterior extremity or tail. At the anterior extremity are situated a pair of refractive bodies $(r)$ which lie above an unpaired organ which may be called the urn.

The structure of the urn, the refractive bodies, and the tail may be dealt with in succession.

The urn consists of three parts: (I) a wall $(u),(2)$ a lid (l), and (3) contents $(g r)$. The wall of the urn is hemispherical in form, and composed of two halves in apposition (fig. F). Its concavity is directed forwards, and in its edge are imbedded a number of rod-like corpuscles which appear as a ring near the surface in a full-face view (fig. D). The lid has the form of a low pyramid with its apex directed outwards. It is made up of four segments (fig. D). The contents of the urn, which completely fill up its cavity, are four polynuclear cells arranged in the form of a cross which appear with low powers as granular bodies (fig. F). They are frequently ejected, apparently at the will of the embryo.

The refractive bodies $(r)$, two in number, one on each side of the middle line, are composed of a material which is not of a fatty nature, and which is passive to the majority of reagents. Each is enveloped in a special capsule, and at times more than one refractive body is present in each capsule. The tail is a conical structure formed of ciliated granular cells.

No plausible guess has been made as to the function either of the urn or of the refractive bodies.

The infusoriform embryos originate from germs, which have however a different origin to the germs of the vermiform embryos. One to five cells appear in the axial hypoblast cell, in 
a way not clearly made out, and each of them gives rise by an endogenous process to several generations of cells, all of which develop into infusoriform embryos.

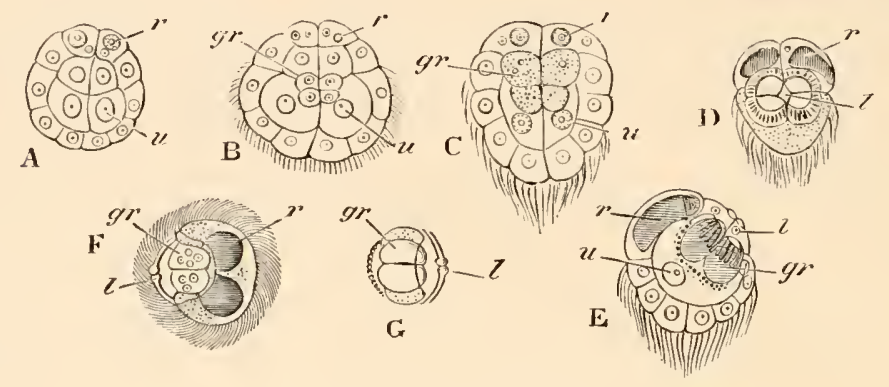

Fig. 62. Infusoriform EMIBRYO OF DiCyema.

A. B. C. Three of the later stages in the development.

D. E. F. Three different views of the full-grown larva. D. from the front, E. from the side, and $\mathrm{F}$. from above.

G. side view of urn.

u. wall of urn; $l$. lid of urn; $r$. refractive bodies; $g r$. granular bodies filling the interior of the urn.

The primitive cell is called by Van Beneden a Germogen. In its protoplasm a number of germs first appear endogenously, but the nucleus of the germogen does not assist in their formation. They eventually become detached from the parent cell, around which they are concentrically arranged. A second and then a third generation of germs are formed in the same way, till the whole of the protoplasm of the primitive cell is absorbed in the formation of these germs, and nothing of it remains but the nucleus. The germs so formed are arranged in about three concentric layers, of which the innermost is the youngest. One to five masses of germs may be present in a single Rhombogen. The germs undergo a division, in the course of which their nuclei exhibit very beautifully a spindle modification. In the course of the segmentation the embryo gradually assumes its permanent form, and four of the cells composing it can be distinguished from the remainder by their greater size (fig. $62 \mathrm{~A}, u$ ). The two largest of these give rise to the wall of the urn, and also give origin to four smaller cells (fig. $62 \mathrm{~B}, \mathrm{gr}$ ) which eventually become polynuclear and constitute the four granular cells in the urn. The two other cells become the lid of the urn. The parts 
of the urn lie at first side by side, but in the course of development the cells which form the wall of the urn travel inwards, and the four granular cells are carried into their concavity. At the same time the cells which form the lid of the urn alter their position so as to overlie the wall of the urn. The two cells immediately above the urn give rise to the refractive bodies (fig. $62 \mathrm{~A}, \mathrm{~B}, \mathrm{C}, r$ ) and the remainder of the cells of the embryo become the tail (fig. $62 \mathrm{C}$ ). The embryo becomes ciliated, and attains its nearly full development before leaving the parental tissues. It usually passes out at the cephalic extremity.

As has already been stated, it is probable that the infusoriform embryos leave the renal organs of their host and lead a free existence. What becomes of them afterwards is not however known, though there can be little doubt that they serve to carry the species to new hosts.

Till the further development of the infusoriform embryo is known it is not possible to arrive at a definite conclusion as to the affinities of this strange parasite. Van Beneden is anxious to form it, on account of its simple organization, into a group between the Protozoa and the Metazoa. It appears however very possible that the simplicity of its organization is the result of a parasitic existence; a view which receives confirmation from the common occurrence of the process of endogenous cell-formation in the axial hypoblast cell. It has been clearly shewn by Strasburger that endogenous cell-formation is secondarily derived from cell-division; so that the occurrence of this process in Dicyema probably indicates that the hypoblast was primitively multicellular. It is not improbable that the enigmatical infusoriform embryo may develop into a sexual form, the progeny of which are destined to complete the cycle of development by becoming again parasitic in the renal organ of a Cephalopod.

\section{BIBLIOGRAPIIY.}

(117) E. van Beneden. "Recherches sur les Dicyemides." Bull. d. l'Académie roy. de Belgique, $2^{\mathrm{e}}$ sér. T. Xli. No. 6 and T. xull. No. 7, I8; 6 . Vide this paper for a full account of the literature.

(118) A. Kölliker. Ueber Dicyema paradoxum den Schmarotzer der Venenan. hänge der Cephalopoden.

(119) Aug. Krohn. "Ueb. d. Vorkommen von Entozoen, etc." Frorich Notizen, VII. 1839 . 


\section{ORTHONECTID E.}

A number of minute parasites infesting various Nemertines, Turbellarians, and Ophiuroids have recently been studied by Giard and Metschnikoff, the former of whom has placed them in a special group which he calls the Orthonectidee. They were first discovered by W. C. Mclntosh.

In the adult state they are ${ }^{1}$ (Metschnikoff) somewhat pear-shaped bodies formed of a kind of plasmodium of cells with irregular lobate processes. In the interior of this body are eggs in all stages of development. In the type observed by Metschnikoff (Intoshia gigas) the ova undergo a regular segmentation, resulting in the formation of a blastosphere in which an inner layer is subsequently formed by delamination. A smaller and a larger kind of embryo are formed; but all the embryos in each female belong to one type. The larger become females and the smaller males.

The female embryos are ovoid. The outer layer of cells or epiblast becomes ciliated, and divided into nine segments, of which the second is marked off from the remainder by the absence of cilia, and by being provided with refractive corpuscles. The inner layer which surrounds a central cavity, and might be supposed to be the hypoblast, becomes according to Metschnikoff converted into ova.

The male embryos are more elongated than the female, from which they further differ in only having six segments. The cells of the inner layer eventually divide up into spermatozoa.

The larvæ probably become free, and while in the free state impregnation would appear to be effected. When the female larve become parasitic they undergo a metamorpliosis, the stages of which have not been observed; but in the course of which the epiblast cells probably unite into a plasmodium.

The observations of Giard are in several points irreconcilable with those of Metschnikoff, but from the statements of the latter it appears possible that Giard has made two genera from the males and females of one species; and that Giard's account of an unequal segmentation followed by an epibolic gastrula, in one of his species, has arisen from two segmenting ova temporarily fusing together. Giard has given a description of internal gemmiparous reproduction, upon the accuracy of which doubts have been thrown by Metschnikoff. The affinities of the Orthonectidx are as obscure as those of the Dicyemidx; though there can be but little doubt that their organization has been much simplified in correlation with their parasitic habits. The origin of the genital products in the axial tissue is a feature they have in common with the Dicyemidæ.

1 This at any rate holds true for the type investigated by Metschnikoff. The full history of other forms is not yet known. 


\section{BIBLIOGRAPHY.}

(120) Alf. Giard. "Les Orthonectida classe nouv. d. Phylum des Vers." Journal de l'Anat. et de la Physiol., Vol. xv. I879.

(121) El. Metschnikoff. "Zur Naturgeschichte d. Orthonectidx." Zoologischer Anzeiger, No. +o-43, I879.

[Ch. Julin. "Rech. sur l'organization et le devel. d'Orthonectides." Arch. Biol. Vol. III. 1882.

E. Metschnikoff. " "Untersuchungen iib. Orthonectidie." Zcit. f. Wiss. Zoologie, Vol. xxxv. Is8I.

For general account of Orthonectidx, vide Spengel. Biolog. Cenlralblatt, No. 6.] 


\title{
CHAPTER V.
}

\author{
PORIFERA.
}

Although within the last few years greater advances have probably been made in our knowledge of the development of the Porifera than of any other group, yet there is much that is still very obscure, and it is not possible to make general statements applying to the whole group.

Calcispongiæ. The form which has so far been most completely worked out is Sycandra raphamus, one of the Calcispongiæ (Metschnikoff, Nos. 132 and 134, F. E. Schulze, Nos. 139 and 142), and I shall commence my account with the life-history of this species.

The ovum in Sycandra as in other Spongida has the form of a naked amceboid nucleated mass of protoplasm. From the analogy of the other members of the group, there is no doubt that it is fertilized by a male spermatic element, though this has not as yet been shewn to be the case-and the changes which accompany fertilization are quite unknown.

The segmentation and early stages of development take place in the tissues of the parent. The segmentation is somewhat peculiar, though a modification of a regular segmentation. The ovum divides along a vertical plane, first into two, and then into four equal segments. But even when two segments are formed, each of them has one end pointed and the other broader. The pointed ends give rise to the ciliated cells of the future larva, and the broad ends to the granular cells. Instead of the next division taking place, as is usually the case, in a horizontal (equatorial) plane, it is actually effected along two vertical planes 
intermediate in position between the two first planes of segmentation. Eight equal segments are thus formed, each of which has the form of a pyramid. All the segments are situated in a single tier, and are so arranged as to give to the whole ovum the form of a flat cone, the apex of which is formed by the pointed extremities of the constituent segments (fig. $\sigma_{3} \mathrm{~B}$ ). The apices of the segments do not however quite meet, but they leave a central space, which is an actual perforation (fig. $63 \mathrm{~A}$ ) through the axis of the ovum, open at both ends. The first indications of this perforation appear when only four segments are present,

$\Lambda$
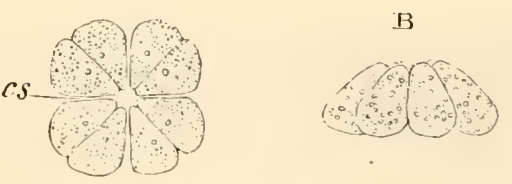

E
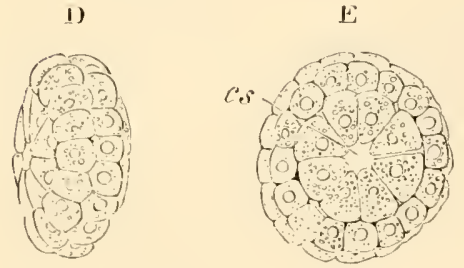
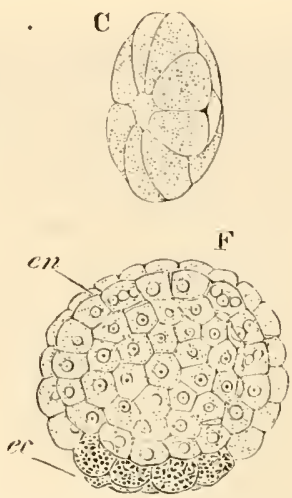

Fig. 63. Successive stages in the segmentation of Sycandora raphanus.

(Copied from F. E. Schulze.)

A. stage with eight segments still arranged in pairs, from above.

B. side view of stage with eight segments.

C. side view of stage with sixteen segments.

D. side view of stage with forty-eight segments.

E. view from above of stage with forty-eight segments.

F. side view of embryo in the blastosphere stage, eight of the granular cells which give rise to the epiblast of the adult are present at the lower pole.

cs. segmentation cavity; $e c$. granular cells which form the epiblast ; $c n$. clear cells which form the hypoblast.

and it is to be regarded as the homologue of the segmentation cavity of other ova. The next plane of division is horizontal (equatorial), and the apices of the eight cells are segmented off as a tier of small cells. At the completion of this division (fig. 63 C), the ovum is formed of sixteen cells arranged in two superimposed tiers. The ovum now assumes somewhat the form of a biconvex lens, in the axis of which the central perforation is still 
present. At the close of the next stage, forty-eight cells are present arranged in four tiers (fig. $\sigma_{3} \mathrm{D}$ and $\mathrm{E}$ ), the two outer tiers containing eight cells each, and the two inner sixteen. The two inner tiers probably arise by the simultaneous appearance of two equatorial furrows dividing the original tiers into two, and by the subsequent simple division of the cells of the two inner of the tiers so formed. At the close of the stage the eight basal cells become granular (fig. $63 \mathrm{~F}$ ). At the same time the central part of the segmentation cavity becomes enlarged, while its terminal apertures become narrowed and finally, shortly after the end of this stage, closed. The axial perforation thus acquires the

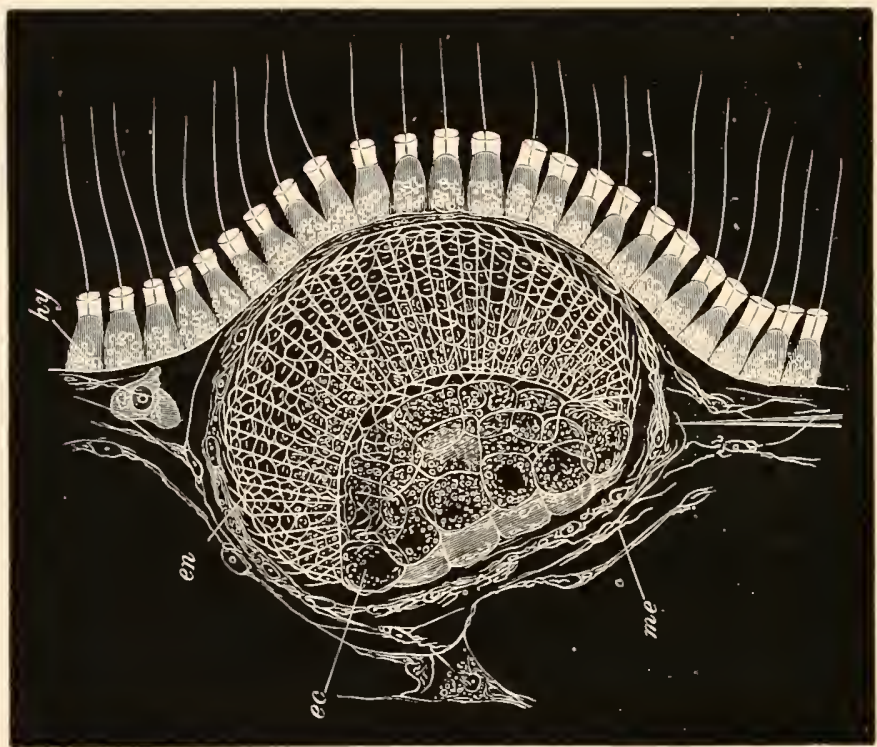

Fig. 64. Larva of Sycandra Raphanus at pseudogastrula stage, in situ in the maternal, tissues. (Copied from F. E. Schulze.)

me. mesoblast of adult ; hy. collared cells forming hypoblast of the adult; $c$. clear cells of larva which eventually become involuted to form the hypoblast; $e c$. granular cells of larva which give rise to the epiblast, which at this stage are partially involuted.

character of a closed segmentation cavity. While the ovum itself becomes at the same time a blastosphere.

This stage nearly completes the segmentation: in the next one, the cells of the poles of the blastosphere increase in number, 
and the cells of the greater part of the blastosphere become columnar and ciliated, (fig. $64 \mathrm{en}$.) while the granular cells $(e c$. increase to about thirty-two in number and appear to be (partially at least) involuted into the segmentation cavity, reducing this latter to a mere slit. This stage forms the last passed by the embryo in the tissues of the parent. The general position of the embryo while still in this situation may be gathered from fig. 64 , representing the embryo in situ. The embryo is always placed close to one of the radial canals. From this situation it makes its way through the lining cells into a canal and is thence transported to the surrounding water. By the time the larva has become free, the semi-invaginated granular cells have increased in bulk and become everted so as to project very much more prominently than in the encapsuled state. To the gastrula stage, if it deserves the name, passed through by the embryo in the tissues of the parent, no importance can be attached.

The larva, after it has left the parental tissues, has an oval form and is transversely divided into two areas (fig. $65 \mathrm{~A}$ ). One

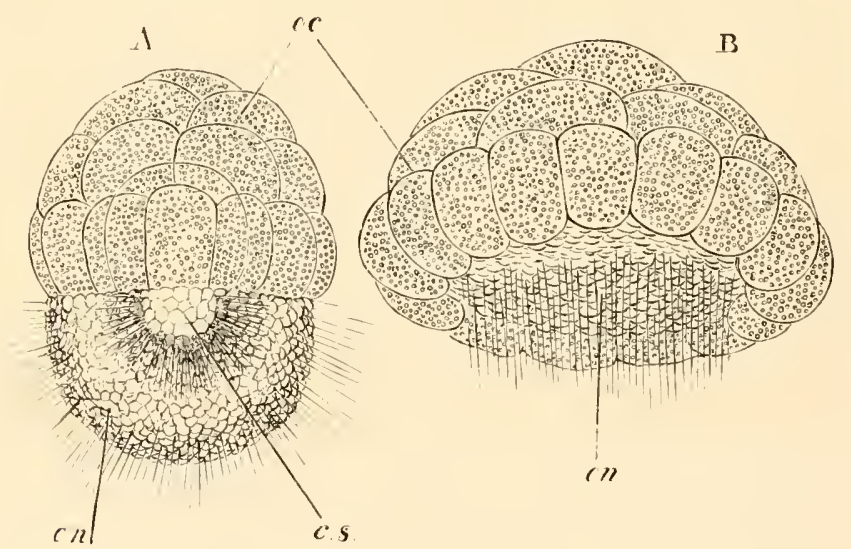

Fig. 6.5. Two free Stages in the DeVelopment of Sycandra raphanus. (Copied from Schulze.)

A. Amphiblastula stage.

B. A later stage after the ciliated cells have commenced to become invaginated.

cs. segmentation cavity; cc. granular cells which will form the epiblast; en. ciliated cells which become invaginated to form the hypoblast.

of these areas is formed of the elongated, clear, ciliated cells, with a small amount of pigment near their inner ends $(e n$.$) , and$ 
the other and larger area of the thirty-two granular cells already mentioned $(c c$.$) . Fifteen or sixteen of these are arranged as a$ special ring on the border of the clear cells. In the centre of the embryo is a segmentation cavity (c.s.) which lies between the granular and the clear cells, but is mainly bounded by the vaulted inner surface of the latter. This stage is known as the amphiblastula stage. During the later periods of the amphiblastula stage a cavity appears in the granular cells dividing them into two layers. After the larva has for some time enjoyed a free existence, a remarkable series of changes take place, which result in the invagination of the half of it formed of the clear cells, and form a prelude to the permanent attachment of the larva. The entire process of invagination is completed in about half an hour. The whole embryo first becomes flattened, but especially the ciliated half, which gradually becomes less prominent (fig. $65 \mathrm{~B}$ ); and still later the cells composing it undergo a true process of invagination. As a result of this invagination the segmentation cavity is obliterated, and the larva assumes a compressed planoconvex form, with a central gastrula cavity, and a blastopore in the middle of the flattened surface. The two layers of the gastrula may now be spoken of as epiblast and hypoblast. The blastopore becomes gradually narrowed by the growth over it of the outer row of granular cells. When it has become very small the attachment of

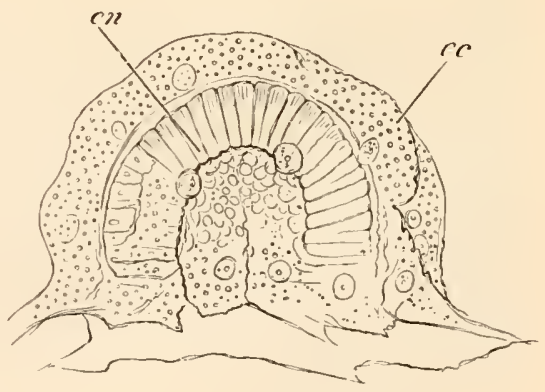

Fig. 66. Fixed Gastrula stage of Sycandra Raphanus. (Copied from Schulze.)

The figure shews the amoboid epiblast cells $(e c$.) derived from the granular cells of the earlier stage, and the columnar hypoblast cells, lining the gastrula cavity, derived from the ciliated cells of the earlier stage. The larva is fixed by the amoboid cells on the side on which the blastopore is situated.

the larva takes place by the flat surface where the blastopore is situated. It is effected by protoplasmic processes of the outer ring of epiblast cells, which, together with the other 
epiblast cells, now become amœboid. They become at the same time clearer and permit a view of the interior of the gastrula. Between the epiblast cells and the hypoblast cells which line the gastrula cavity there arises a hyaline structureless layer, which is more closely attached to the epiblast than to the hypoblast, and is probably derived from the former. A view of the gastrula stage after the larva has become fixed is given in fig. 66 .

There would seem according to Metschnikoff's observations (No. 134) to be a number of mesoblast cells interposed between the two primary layers, which he derives from the inner part of the mass of granular cells.

After invagination the cilia of the hypoblast cells can no longer be seen, and are probably absorbed; and their disappearance is nearly coincident with the complete obliteration of the blastopore, an event which takes place shortly after the attachment of the larva.

Not long after the closure of the blastopore, calcareous spicules make their appearance in the larva as delicate unbranched rods pointed at both extremities. They appear to be formed on the mesoblast cells situated between the epiblast and hypoblast ${ }^{1}$. The larva when once fixed rapidly grows in length and assumes a cylindrical form (fig. 67 A). The sides of the cylinder are beset with calcareous spicules which project beyond the surface, and, in addition to the unbranched forms, spicules are developed with three and four rays as well as some with a blunt extremity and serrated edge. The extremity of the cylinder opposite the attached surface is flattened, and, though surrounded by a ring of four-rayed spicules, is itself free from them. At this extremity a small perforation is formed leading into the gastric cavity, which rapidly increases in size and forms an exhalent osculum (os.). A series of inhalent apertures is also formed at the sides of the cylinder. The relative times of appearance of the single osculum and the smaller apertures are not constant for the different larve. On the central gastrula cavity of the sponge becoming placed in communication with the external water, the hypoblast cells lining it become ciliated

1 Metschnikoff was the first to give this account of the development of the spicules in Sycandra, but Prof. Schulze has informed me by letter that he has arrived at the same result. 
afresh (fig. $67 \mathrm{~B}, \mathrm{cn}$.) and develop the peculiar collar characteristic of the hypoblast cells of the Spongida (vide fig. 64, hy.). When this stage of development is reached we have a fullyformed sponge of the type made known by Haeckel as Olynthus.

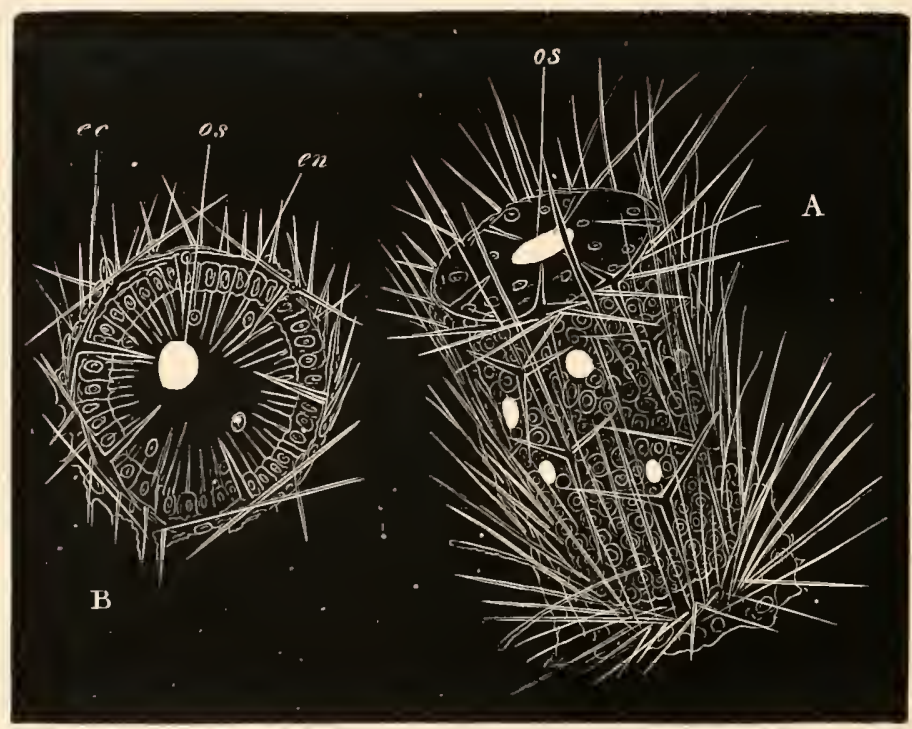

Fig. 67. The Young OF SYCANDRA RAPHANUS SHORTLY AFTER The Develop. MENT OF The SPICUla. (Copied from Schulze.)

A. View from the side.

B. View from the free extremity.

os. osculum ; $c$. epiblast ; $c n$. hypoblast composed of ciliated cells. The terminal osculum and lateral pores are represented as oval white spaces.

When young examples of Sycandra come in contact shortly after their attachment they appear to fuse together temporarily or else permanently. In the latter case colonies are produced by their fusion.

Amongst other calcareous sponges the larva of Ascandra contorta (Haeckel No. 126, Barrois No. 122) presents the typical amphiblastula stage, and so probably does that of Ascandra Licberkïhnii (Keller No. 128). In Lencandra aspera (Keller No. 128, Metschnikoff No. 134) the larva passes through an amphiblastula stage, but the characters of the cells of the two halves of the larva do not differ to nearly the same extent as in Sycandra.

Although the majority of calcareous sponges appear to agree in their 
mode of development with Sycandra, nevertheless the concordant researches of O. Schmidt (No. 139) and Metschnikoff (No. 134) have shewn that this is not true for the genus Ascetta (As. primordialis, clathrus and blanca).

The larve of these forms are very differently constituted to those of Sycandra. They have an oval form and are composed of a single row of ciliated columnar cells: their two extremities only differ in the cells at one extremity being longer than those at the other. Especially at the pole where the shorter cells are situated (Schmidt) a metamorphosis of the cells takes place. One after the other they lose their cilia, become granular, and pass into the interior of the vesicle. Here they become differentiated into two classes (Metschnikoff); one of larger and more granular cells, and the other of smaller cells with clearer protoplasm. Cells of the former class are mainly found at one of the poles. When the larva becomes free the cells in the interior of the vesicle increase in number and nearly fill up its central cavity. After a short free existence the larva becomes fixed, and the epiblast cells lose their cilia and become flattened. At a later period the large granular cells assume a radiate arrangement round a central cavity and become clearly marked out as the hypoblast cells. The smaller cells become placed between the epiblast and hypoblast and constitute the mesoblast.

Myxospongiæ. In this group Halisarca has been investigated by Carter (No. 123), Barrois (No. 122), Schulze (No. 141) and Metschnikoff (No. 134). The ova develop in the mesoblast, and when ripe occupy special chambers lined by a layer of epithelial cells. Schulze has found the spermatozoa of this genus of sponge and has been able to shew that the sexes may be distinct, though many species of Halisarca are hermaphrodite.

The segmentation is, roughly speaking, regular, and a segmentation cavity is early formed, which is never, as in Calcispongix, open at the poles. When the larva leaves the parent it is an oval vesicle formed of a single layer of columnar ciliated cells. Slight differences may be observed between the two extremities of the larve of most species. One of these-the hinder extremity - is directed backwards in swimming.

The further history of the larva has been investigated by Metschnikoff. He has found that the interior of the vesicle becomes gradually filled with mesoblast cells of a peculiar type, called by him rosette-cells, which are probably derived from the walls of the vesicle.

When the metamorphosis commences, the larva assumes a flattened form, and cells of a new type, viz. normal amœboid

B, II. 
cells, grow in amongst the rosette cells. The new cells are also derived from the epiblast. The larvæ appear to fix themselves by the hinder extremity. The cilia gradually disappear, and the epiblast cells flatten out and form a kind of cuticle. For some time the larva remains in the two-layered condition, but gradually canals (? ciliated chambers) lined by hypoblast cells become formed. They appear as closed spaces with walls of ciliated cells derived from the amœboid cells, and the different parts of the system of chambers are established independently. In $H$. pontica the ciliated chambers are formed before the attachment of the larva. The development was not followed up to the formation of the pores placing the canal system in communication with the exterior.

The young sponges at a somewhat later stage have been studied by Schulze and Barrois. They are formed of an external layer of flattened cells, not clearly ciliated as in the adult, within which are a normal mesoblastic tissue, and several spherical chambers lined by ciliated cells exactly like the ciliated chambers of the full-grown sponge. Irregular invaginations of the epiblast give to the young sponge a honeycombed structure. The ciliated chambers in the youngest condition of the sponge are closed; but in slightly older examples they come into communication with the passages lined by hypoblast, and so indirectly with the external medium.

Ceratospongiæ. Amongst the true Ceratospongix the embryos of two of the Aplysinidæ, and of Spongelia and Euspongia have been to some extent worked out by Barrois and Schulze. The form worked out by Barrois is called by him Verongia rosea. The segmentation is nearly regular, but from the first the segments may be divided according to their constitution into two categories. At the close of segmentation the embryo is oval and covered by a single layer of columnar ciliated cells; these cells may however be divided into two categories, corresponding with those observable during the segmentation. A certain number are coloured red and form a definite circular mass at one pole, while the remainder, which constitute the major part of the embryo, have a pale yellowish colour. Those at the red pole lose their cilia in the free larva, but around the area formed by them is a special ring of long cilia. The chief peculiarity of the embryo (made known by Schulze) consists in the fact that the layer of cells which covers the embryo does not, as in other sponge embryos, simply enclose a space, but the interior of the embryo is formed of a mass of stellate cells like the normal mesoblast of full-grown sponges. 
This feature is also characteristic of the embryos of Spongelia and Euspongia.

The embryo of the Gumminex (Gummina mimosa) has been investigated by Barrois (No. 122), and has been shewn closely to resemble the typical larvæ of calcareous sponges; one-half being formed of elongated ciliated cells and the other of rounded granular ones.

Silicispongiæ. The development of marine silicious sponges is but very imperfectly understood. The larvæ of various forms-Reniera (Isodyctia), Esperia (Desmacidon), Raspailia, Halichondria, Tethya-have been described. Barrois has shewn that the egg segments regularly and that in the earlier stages a segmentation cavity is present. In the later stages the embryo appears to become solid. Externally there is a layer of ciliated cells, and within a mass of granular matter in which the separate cells cannot be made out. The granular matter projects at one pole, and forms a prominence possibly equivalent to the granular cells of Sycandra. In some forms, e.g. Reniera, the edge of the unciliated granular prominence may be surrounded by a row of long cilia. In later stages the granular material may project at both poles or even at other points. One remarkable feature in the development of the Silicispongix is the appearance of spicula between the ciliated cells and the central mass, while the larva is still free.

Professor Schulze has informed me that these spicula are developed in mesoblast cells; while the horny fibres of the sponge are developed as cuticular products of special mesoblast cells (spongioblasts).

The attachment and accompanying metamorphosis are so diversely described that no satisfactory account can be given of them. The general statements are in favour of the attachment taking place by the posterior extremity where the granular matter projects.

Carter especially gives a very precise account, with figures, of the attachment of the larva in this way. He also figures the appearance of an osculum at the opposite pole1.

A very elaborate account of the development of Spongilla has been published in Russian by Ganin, of which a German abstract has also appeared (No. 124).

The ovum undergoes a regular segmentation and becomes a solid ova morula. An epiblast of smaller cells is early differentiated, and in the interior of the inner cells an archenteron becomes subsequently formed. The inner cells next become divided into an hypoblastic layer lining the

1 Keller (No. 129) has recently given an account of the development of Halichondria (Chalinula) fertilis. He finds that there is an irregular segmentation, followed by a partial epibolic invagination, the inner mass of cells remaining exposed at one pole and forming there a prominence, equivalent to the granular prominence in the larve of other Silicispongiie. The free swimming larva resembles the larva of other Silicispongix in the possession of spicula, etc., and after becoming laterally compressed attaches itself by one of the flattened sides. A central cavity is formed in the interior with ciliated chambers opening into it, and is subsequently placed in communication with the exterior by the formation of an aperture which constitutes the osculum. 
archenteron, and a mesoblastic layer between this and the now ciliated epiblast. At the narrow hinder end of the embryo the mesoblast becomes thickened, and largely obliterates the archenteron. In this part of the mesoblast silicious spicula are formed. The larva becomes attached by its hinder extremity, and in the course of this process flattens itself out to a disc-like form. From the nearly obliterated archenteric cavity outgrowths take place which give rise to the ciliated chambers. These are not placed directly in communication with the exterior, but open, if I understand Ganin rightly, into a space in the mesoblast, which subsequently acquires an exterior communication - the primitive osculum. The subsequent pores and oscula are also formed as openings leading into the mesoblastic cavity, which communicates in its turn with the ciliated chambers.

It appears that in the present unsatisfactory state of our knowledge the larvæ of the Porifera may be divided into two groups: viz. (I) those which have the form of a blastosphere or else of a solid morula; (2) those which have the amphiblastula form.

In the former type the mesoblast and hypoblast are formed either from cells budded off from the outer cells of the blastosphere or from the solid inner mass of cells; while the outer ciliated cells become the epiblast. This type of larva, which is found in the majority of sponges, is very similar in its general characters and development to many Cœelenterate planulæ.

The second type of larva is very peculiar, and though in its fully developed form it is confined to the Calcispongiæ, where it is the usual form, a larval type with the same characters is perhaps to be found in other sponges, e.g. amongst the Gumminex, and amongst the Silicispongiæ where one-half of the embryo is without cilia, though in the case of the Silicispongiæ the cells of the ciliated part of the embryo correspond to the granular cells of the larva of Sycandra.

The later stages in the development of the larvæ of the Porifera are not similar to anything we know of in other groups.

It might perhaps be possible to regard sponges as degraded descendants of some Actinozoon type such as Alcyonium, with branched prolongations of the gastric cavity, but there does not appear to me to be sufficient evidence for doing so at present. I should rather prefer to regard them as an independent stock of the Metazoa.

In this connection the amphiblastula larva presents some points of interest. Does this larva retain the characters of an ancestral type of the Spongida, and if so, what does its form mean? It is, of course, possible that 
it has no ancestral meaning but has been secondarily acquired; but, assuming that this is not the case, it appears to me that the cliaracters of the larva may be plausibly explained by regarding it as a transitional form between the Protozoa and Metazoa. According to this view the larva is to be considered as a colony of Protozoa, one-half of the individuals of which have become differentiated into nutritive forms, and the other half into locomotor and respiratory forms. The granular amœboid cells represent the nutritive forms, and the ciliated cells represent the locomotor and respiratory forms. That the passage from the Protozoa to the Metazoa may have been effected by such a differentiation is not improbable on a priori grounds.

While the above view seems fairly satisfactory for the free swimming stage of the larval sponge, there arises in the subsequent development a difficulty which appears at first sight fatal to it. This difficulty is the invagination of the ciliated cells instead of the granular ones. If the granular cells represent the nutritive individuals of the colony, they, and not the ciliated cells, ought most certainly to give rise to the lining of the gastrula cavity, according to the generally accepted views of the morphology of the Spongida. The suggestion which I would venture to put forward in explanation of this paradox involves a completely new view of the nature and functions of the germinal layers of adult Spongida.

It is as follows:- When the free swimming ancestor of the Spongida became fixed, the ciliated cells by which its movements used to be effected must have to a great extent become functionless. At the same time the amœboid nutritive cells would need to expose as large a surface as possible. In these two considerations there may, perhaps, be found a sufficient explanation of the invagination of the ciliated cells, and the growth of the amœboid cells over them. Though respiration was, no doubt, mainly effected by the ciliated cells, it is improbable that it was completely localized in them, but they were enabled to continue performing this function through the formation of an osculum and pores. The collared cells which line the ciliated chambers, or in some cases the radial tubes, are undoubtedly derived from the invaginated cells, and, if there is any truth in the above suggestion, the collared cells in the adult sponge must be mainly respiratory and not digestive in function, while the epiblastic cells, which in most cases line the inhalent passages through its substance ${ }^{1}$, ought to be employed to absorb nutriment. The recent researches of Metschnikoff (No. 134) on this head shew that the nutriment is largely carried into the mesoblast cells, which in Sycandra appear to be derived

1 That the greater part of the flat cells which line the passages of most Sponges are really derived from epiblastic invaginations appears to me to be proved by Schulze's and Barrois' observations on the young fixed stages of Halisarca. Schulze's (No. 140) observations have however proved that the flat cells lining the axial gastric chamber of Sycandra are hypoblastic in origin, and the observations of Keller (No. 129) and Ganin (No. 124) have led to the same result for the flat epithelium lining part of the passages of the Silicispongiæ. 
from the granular cells, and also that it is taken up by the cells which line the passages, though not by the superficial epiblast cells. Whether the collared cells generally absorb nutriment is not clear from his statements : but he finds that they do not do so in Silicispongia.

Professor Schulze has informed me by letter that he finds the collared cells to be respiratory in function, while the cells derived from the granular cells in Sycandra are nutritive. Carter ${ }^{1}$, on the contrary, from his observations on Spongilla, has fully satisfied himself that the food is absorbed by the cells lining the ciliated chambers.

If it is eventually proved by further experiments on the nutrition of sponges, that digestion is mainly carried on by the general cells lining the passages and the mesoblast cells, and not for the most part by the ciliated cells, it is clear that the epiblast, mesoblast and hypoblast of sponges will not correspond with the similarly named layers in the Colenterata and other Metazoa. The invaginated hypoblast will be the respiratory layer and the epiblast and mesoblast the digestive and sensory layers; the sensory function being probably mainly localized in the epithelium on the surface, and the digestive one in the epithelium lining the passages and in the mesoblast. Such a fundamental difference in the primary function of the germinal layers between the Spongida and the other Metazoa, would necessarily involve the creation of a special division of the Metazoa for the reception of the former group.

\section{BIBLIOGRAPHY.}

(122) C. Barrois. "Embryologie de quelques éponges de la Manche." Annales des Sc. Nat. Zool., vi. ser., Vol. 111. 1876.

(123) Carter. "Development of the Marine Sponges." Annals and Mag. of Nat. Hist., $4^{\text {th }}$ series, Vol. XIv. I 874 .

(124) Ganin2. "Zur Entwicklung d. Spongilla fluviatilis." Zoologischer Anzeiger. Vol. I. No. 9, 1878 .

(125) Robert Grant. "Observations and Experiments on the Structure and Functions of the Sponge." Edinburgh Phil. F., Vol. X111. and X1v., I825, 1826.

(126) E. Haeckel. Die Kalkschwämme, i872.

(127) E. Haeckel. Studien zur Gastraa-Theorie. Jena, 1877.

(128) C. Keller. Untersuchungen über Anatomie und Entwicklungsgeschichte einiger Spongien. Basel, I 876 .

(129) C. Keller. "Studien üb. Organisation u. Entwick. d. Chalineen." Zeit.f. wiss. Zool., Bd. xxv111. I879.

(130) Lieberkiihn. “Beitr. z. Entwick. d. Spongillen." Müller's Archiv, 1856.

(131) Lieberkühn. "Neue Beiträge zur Anatomie der Spongien." Müller's Archiv, 1859 .

1 "On the Nutritive and Reproductive Processes of Sponges." Ann. and Mag. of Nat. Hist., Vol. 1v. Ser. v. 1879 .

${ }^{2}$ There is a Russian paper by the same author, containing a full account, with clear illustrations, of his observations. 
(132) El. Metschnik off. "Zur Entwicklungsgeschichte der Kalkschwämme." Zeit.f. wiss. Zool., Bd. Xxiv. 1874 .

(133) El. Metschnikoff. "Beiträge zur Morphologie der Spongien." Ziit. f. wiss. Zool., Bd. xxvir. $18 ; 6$.

(134) El. Metschnikoff. "Spongeologische Studien." Zeit. f. wiss. Zool., Bd. Xxxi1. 1879 .

(135) Miklucho Maklay. "Beiträge zur Kenntniss der Spongien." Fenaische Zeitschrift, Bd. IV. I868.

(136) O. Schmidt. "Zur Orientirung über die Entwicklung der Schwämme." Zeit. f. wiss. Zool., Bd. xxv. I875.

(137) O. Schmidt. "Nochmals die Gastrula der Kalkschwämme." Archiv für mikrosk. Anat., Bd. xil. I 876 .

(138) O. Schmidt. "Das Larvenstadium von Ascetta primordialis und Asc. clathrus." Archiv für mikrosk. Anatomie, Bd. XIV. ${ }_{1877}$.

(139) F. E. Schulze. "Ueber den Bau und die Entwicklung von Sycandra raphanus." Zeit. f. wiss. Zool., Bd. xxv. 1875 .

(110) F. E. Schulze. "Zur Entwicklungsgeschichte von Sycandra." Zeit. $f$. wiss. Zool., Bd. xxvin. i $8 ; 6$.

(141) F. E. Schulze. "Untersuchung ïb. d. Bau, etc. Die Gattung Halisarca." Ziit. f. wiss. Zool., Bd. xxvill. I 877 .

(142) F. E. Schulze. "Untersuchungen iib. d. Bau, etc. Die Metamorphose von Sycandra raphanus." Zeit.f. wiss. Zool., Bd. xxxı. 1878 .

(143) F. E. Schulze. "Untersuchungen ï. d. Bau, etc. Die Familie Aplysinidæ." Zeit.f. wiss. Zool., Bd. xxx. i 878 .

(144) F. E. Schulze. "Untersuchungen ii. d. Bau, etc. Die Gattung Spongelia." Zeit. f. wiss. Zool., Bd. xxxı. I878. 


\section{CHAPTER VI.}

\section{COELENTERATA .}

Hydroidea. The most typical mode of development of the Hydroidea is that in which the segmentation leads directly to the formation of a free ciliated two-layered larva, known since Dalyell's observations as a planula. The planula is characteristic of almost all the Hydromedusx with fixed hydrosomes including the Hydrocoralla (Stylasteridæe and Millepora), the most important exceptions being the genus Tubularia and one or two other genera, and the fresh-water Hydra.

In a typical Sertularian the segmentation is approximately regular $^{2}$ and ends according to the usual accounts in the formation of a solid spherical mass of cells. A process of delamination now takes place, which leads to the formation of a superficial layer of cubical or pyramidal cells, enclosing a central solid mass of more or less irregularly arranged cells.

The embryo, in the cases in which it is still contained within the sporosack, now begins to exhibit slight changes of form, and

${ }^{1}$ I. HYDROZOA.
I. Hydromedusæ. $\left\{\begin{array}{l}\text { Hydroidea. } \\ \text { Trachymed }\end{array}\right.$
2. Siphonophora. YCalycophorida.
3. Acraspeda.

II. ACTINOZOA.

1. Alcyonaria. (Octocoralla.)

2. Zoantharia. (Hexacoralla.)

III. CTENOPHORA.

2 For a detailed description of the development of a single species the reader referred to Allman's description of Laomedia flexuosa, No. 149, p. 85 seq. 
one extremity of it begins to elongate. It soon becomes free, and rapidly assumes an elongated cylindrical form, while a coating of cilia, by means of which it moves sluggishly about, appears on its outer surface. A central cavity appears in the interior, and the inner cells form themselves into a definite hypoblast. The larva has now become a planula, and consists of a closed sack with double walls. It continues for some few days to move about, but eventually drops its cilia, and becomes dilated at one extremity, by which it then becomes attached. The base of attachment becomes gradually enlarged so as to form a disc, which spreads out and is frequently divided by fissures into radiating lobes. The free extremity becomes enlarged to form the eventual calyx.

Over the whole exterior a delicate pellicle-the future perisarc-now becomes secreted. Round the edge of the anterior enlargement a row of tentacles makes its appearance. These, in the embryos of the Tubularian genera, lie some little way behind the apex of the body. After a certain time the perisarc, which has hitherto been continuous, becomes ruptured in the region of
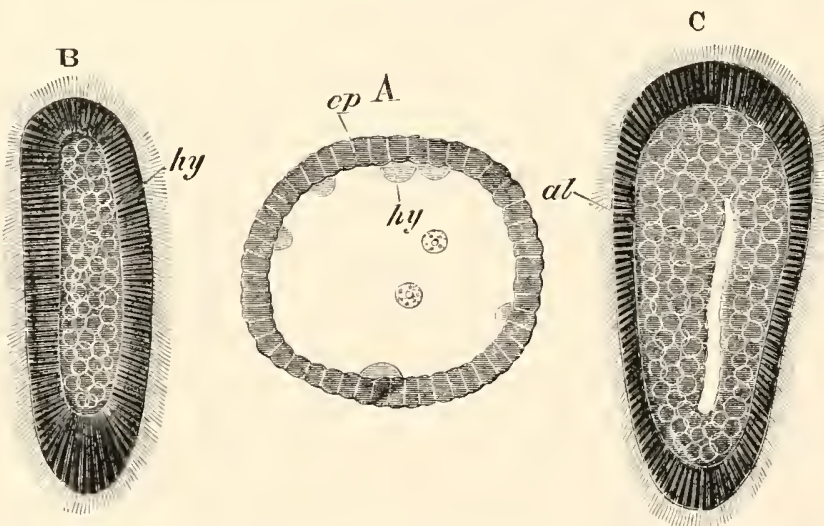

Fig. 68. Three larva stages of Eucope polystyla. (After Kowalevsky.)

A. Blastosphere stage with hypoblast spheres becoming budded off into the central cavity.

B. Planula stage with solid hypoblast.

C. Planula stage with a gastric cavity.

$e p$. epiblast; hy. hypoblast ; al. gastric cavity.

the calyx, and the tentacles become quite free. At about the same period a mouth is formed at the oral apex. 
The development of Eucope polystyla (fig. 68), one of the Campanularidæ, deviates according to Kowalevsky (No. 147) in somewhat important points from the usual type. The whole development takes place after the deposition of the ovum. The segmentation results in the formation of a single-walled blastosphere with a large central cavity (fig. 68 A). This cavity, somewhat as in Ascetta, becomes filled up with a not clearly (?) cellular material derived from the walls of the blastosphere, which must be regarded as the hypoblast (fig. $68 \mathrm{~B}$ ). The larva elongates and becomes ciliated, and the epiblast at its two extremities becomes thickened, and is stated by Kowalevsky also to become divided into two layers. The alimentary cavity appears as a slit in the middle of the hypoblast (fig. $68 \mathrm{C}$ ). The cilia after a time disappear, and the larva then becomes fixed by one extremity. It flattens itself out into a disc-like form, becomes divided into four lobes, and covered by a cuticle (perisarc). From the disc the stalk grows out which dilates at its free extremity into the calyx.

In both the groups (Tubularia and Hydra) which are exceptional in not having a ciliated planula stage, its absence may be put down to an abbreviation of the development, and in fact a two-layered quiescent stage, through which the embryo passes, may be regarded as representing the planula stage.

The development of Tubularia, which has been described in detail by Ciamician, takes place in the gonophore 1 . The segmentation is irregular and leads to the formation of an epibolic gastrula, four large central cells constituting the hypoblast ${ }^{2}$. The larva now elongates, and grows out laterally into two processes which constitute the first pair of tentacles. At this stage it closely resembles the larvæ of some Medusæ. Additional tentacles are soon formed; and a central cavity appears in the hypoblast, the cells of which have in the meantime become more numerous (fig. 69). The tentacles are directed towards

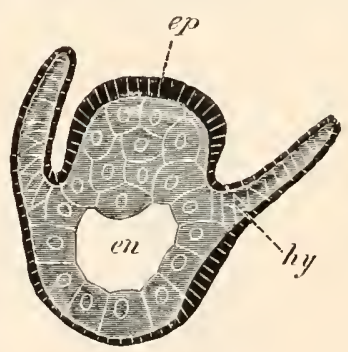

Fig. 69. Longitudinal SECTION THROUGH A LARVA OF TUBUlaria MesembryaritheMUM WHILE STILL IN THE GONOPHORE. The lower end is the oral one.

$e p$. epiblast; hy. hypoblast of tentacle; en. enteric cavity.

1 Vide Ciamician, Zeit.f. wiss. Zool., Bd. Xxxir. IS 79.

2 In examining the segmentation by means of sections I have failed to detect an epibolic gastrula or such irregularity as is described by Ciamician. Prof. Kleinenberg informs me that he has been equally unsuccessful. 
the aboral side, which is considerably more prominent than the oral one. They contain a hypoblastic axis. The aboral end continues to grow and the tentacles gradually assume a horizontal position. A constriction now appears, dividing the larva into an aboral portion which will eventually form the stalk, and an oral portion. At the apex of the latter a row of short tentacles-the future oral tentacles-now appears. The larva has at this stage the form known as Actinula. In this condition it becomes hatched, and shortly afterwards it becomes fixed by the aboral end and grows into a colony.

The development of Myriothela (Allman, No. 150) takes place on the Tubularian type. The ovum invested by a delicate capsule becomes freed by the rupture of the gonophore, and is then taken up by the remarkable claspers characteristic of the genus. In the claspers it becomes fecundated and undergoes its further development. After segmentation a gastric cavity is formed, and provisional tentacles arise as a series of conical involutions which subsequently become evoluted. Permanent tentacles are formed as conical papillæ on a truncated oral process. After hatching it has a few days' free existence, and then becomes attached, and loses its provisional tentacles.

Although Hydra itself constitutes the simplest type of Hydrozoon, its development, which has been fully investigated by Kleinenberg (No. 161), is in some respects a little exceptional. The segmentation is regular, but a segmentation cavity is not formed. The peripheral layer of cells gradually becomes converted into a chitinous membrane, which is perhaps homologous with the perisarc of marine forms. Between the membrane and the germ a second pellicle makes its appearance. The above changes require about four days for their completion, but there next sets in a period of relative quiescence which lasts for some $6-8$ weeks. During this period the remaining development is completed. The cells of the germ first fuse together. In the interior of the protoplasm a clear excentric space arises, which gradually extends itself and forms the rudiment of the gastric cavity. The outer shell in the meantime becomes less firm, and is finally burst and thrown off, owing to the expansion of the embryo within.

The outermost layer of the protoplasm becomes, relatively to the inner layer, clear and transparent, and there thus arises an indication of a division of the walls of the archenteric cavity into two zones, or layers. These layers, which form the epiblast and hypoblast, are definitely established on the appearance of cells with contractile tails ${ }^{1}$ in the clear outer zone, between which the interstitial epiblast cells subsequently arise.

The embryo, still forming a closed double-walled sack, elongates itself, and at one pole its wall becomes very thin. And at this point a rupture takes place which gives rise to the mouth. Simultaneously with the mouth the tentacles become formed as hollow processes, according to Mereschkowsky two being formed first and subsequently the others in pairs. Very shortly

1 These cells are the so-called nerve-muscle cells. Their nature is discussed in the second part of this work. 
afterwards the hitherto uniform hypoblast becomes divided up into distinct cells. The thin inner pellicle which persists after the rupture of the outer membrane becomes in the meantime absorbed. With these changes the embryo practically acquires the characters of the adult.

Trachymedusæ. Amongst the Trachymedusæ, which as has now been satisfactorily established develop directly without alternations of generations, the embryology of species both of the Geryonidx and the Eginidæ has been studied.

In all the types so far investigated the hypoblast is formed by delamination, and there is a more or less well-marked planula stage.

The development of Geryonia (Carmarina) hastata has been studied by Fol (No. 155) and Metschnikoff (No. 163) ${ }^{1}$. The ovum, when laid, is invested by a delicate vitelline membrane and mucous covering. Its protoplasm is formed of an outer granular and dense layer, and a central mass of a more spongy character. The segmentation is complete and regular, and up to the time when thirty-two segments have appeared each segment is composed of both constituents of the protoplasm of the ovum. A segmentation cavity appears when sixteen segments are formed, and becomes somewhat larger at the stage with thirty-two. At this stage the process of delamination commences. Each of the thirty-two segments, as shewn in the accompanying diagram (fig. 70), becomes divided into two unequal parts. The smaller of these is formed almost entirely of granular material; the larger contains portions of both kinds of protoplasm. In the next segmentation the thirty-two large cells only

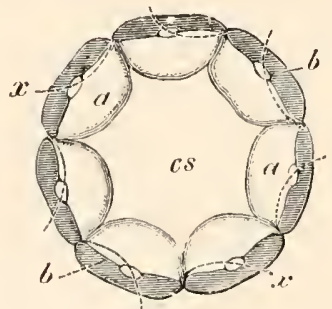

Fig. 70. DiagrammaTIC FIGURE SHEWING THE DELAMINATION OF THE OVUM OF GERYONIA. (Copied from Fol.)

cs. segmentation cavity; $a$. endoplasm; $b$. ectoplasm. The dotted lines shew the course of the next planes of division. are concerned, and in each of these the line of division passes between the granular and the transparent protoplasm. The sixty-four lenticular masses of granular protoplasm thus formed constitute an outer closed epiblastic vesicle, within which the

1 In the succeeding account I have followed $\mathrm{Fol}$, who differs in some minor points from Metschnikoff. 
thirty-two masses of transparent protoplasm form an hypoblastic vesicle. The embryo at this stage is shewn in optical section in fig. $7 \mathrm{I}$.

The epiblastic vesicle now grows rapidly, while the hypoblastic vesicle remains nearly passive and becomes somewhat lens-shaped. At one point its wall comes in close contact with the epiblast. Elsewhere a wide cavity is developed between the two vesicles which becomes filled with gelatinous tissue. At this period cilia appear on the surface, and the larva becomes a planula.

The succeeding changes lead rapidly to the formation of a typical Medusa. Where the epiblast and hypoblast are in contact the former layer becomesthickened and forms a disc-shaped structure. The centre of this becomes somewhat protuberant, fuses with the hypoblast and then becomes perforated to form the mouth (fig. 72 o). The edge of the disc forms a thickened ridge, the rudiment of the velum ( $(v)$, which is entirely formed of epiblast. At its edge six tentacles $(t)$ arise, into which are con-

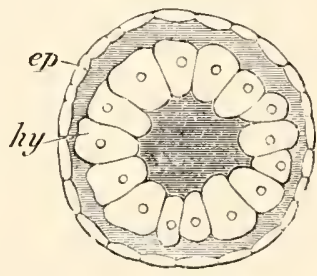

Fig. 7I. EMBRYo of GERYONIA AFTER DELAMINATION. (After Fol.) blast. tinued solid prolongations of the wall of the now somewhat hexagonal gastric chamber. The hypoblastic axes of the tentacles soon lose their connection with the gastric wall.

Up to this time the larva has retained a more or less spherical form, and the cavity on the under side of the umbrella has not yet become developed. The latter now becomes established by the whole disc assuming a vaulted form with the concavity directed downwards. The lining of the cavity so formed is derived from the epiblast

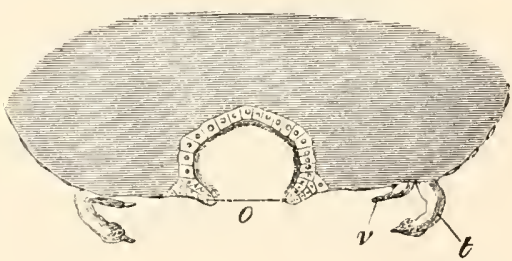

Fig. 72. Optical SECTION THROUgh THE ORAL POLE OF GERYONIA AFTER THF APPEARANCE OF THE GELATINOUS TISSUE OF THE DISC. (After Fol.)

$o$. mouth; $v$. velum; $t$. tentacle.

The shaded part represents the gelatinous tissue. of the disc already spoken of.

The exact mode of formation of the gastrovascular canals has not been worked out. It has however been established by the researches of the 
Hertwigs (No. 146) and Claus (No. 153) that the radial and circular vessels of this system are connected together in adult Medusæ by an hypoblastic lamella; so that these canals would seem to be the remnants of an oncecontinuous gastric cavity. This mode of formation is established in the case of the medusiform buds; and it would therefore seem, as pointed out by the Hertwigs, a fair deduction that it occurs in the larva-a conclusion which is confirmed by the primitive extension of the gastric cavity to the edge of the disc at the time when its walls give rise to the solid axes of the tentacles. In the course of the subsequent retirement of the gastric cavity from the edge of the disc the gastrovascular canals probably take their origin, though Fol was unable to follow the changes which result in their formation.

On the completion of the above changes the larva has become a fully formed Medusa, but it undergoes a not inconsiderable metamorphosis before the attainment of the adult state.

Two species of Aginida have been studied by Metschnikoff (163), viz. Polyxenia leucostyla (Agineta flavescens), and Aiginopsis mediterranea. In both of these forms the segmentation

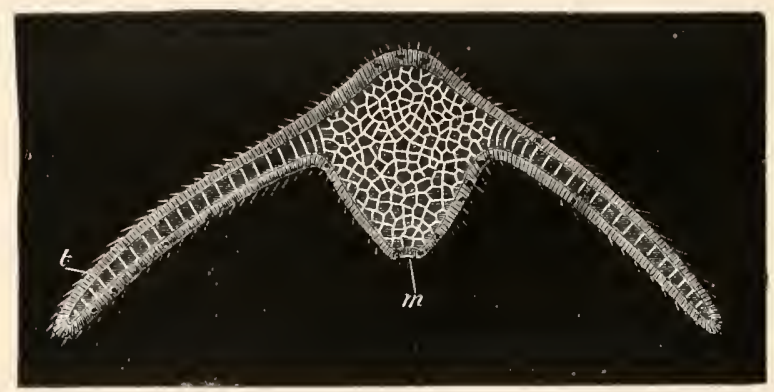

Fig. 73. A threE-DaYs' laRVA OF EgINopsis With two tentacles.

(After Metschnikoff.)

$m$. mouth; $t$. tentacle.

results in the formation of an elongated two-layered ciliated planula, without a central cavity. The two ends of this grow out into two long processes-the rudiments of a pair of at first aborally directed arms-which contain a solid hypoblastic axis (fig. 73). At this stage the larva closely resembles the larva of Tubularia. An alimentary cavity is hollowed out in the centre of the hypoblast which soon opens by a wide oral aperture $(\mathrm{m})$. A second pair of arms becomes formed, which are at first much shorter than the original pair; with their formation a radial symmetry is acquired. Sense-organs become at the same time 
developed, and the whole embryo assumes a medusiform character. Fresh tentacles arise, the velum and cavity of the umbrella become established, but these changes do not involve any points of very special interest.

Siphonophora. The development of the Siphonophora has been the subject of careful investigation by Haeckel (158) and Metschnikoff (163). The ova are large and usually (except Hippopodius) without a membrane.

They are formed of a peripheral denser layer of protoplasm and a central spongy mass. They usually undergo their entire development in the water. In some instances they have been successfully reared by artificial impregnation.

As an example of the Calycophoridæ I shall take Epibulia aurantiaca, a form allied to Diphyes, the development of which has been studied by Metschnikoff ${ }^{1}$.

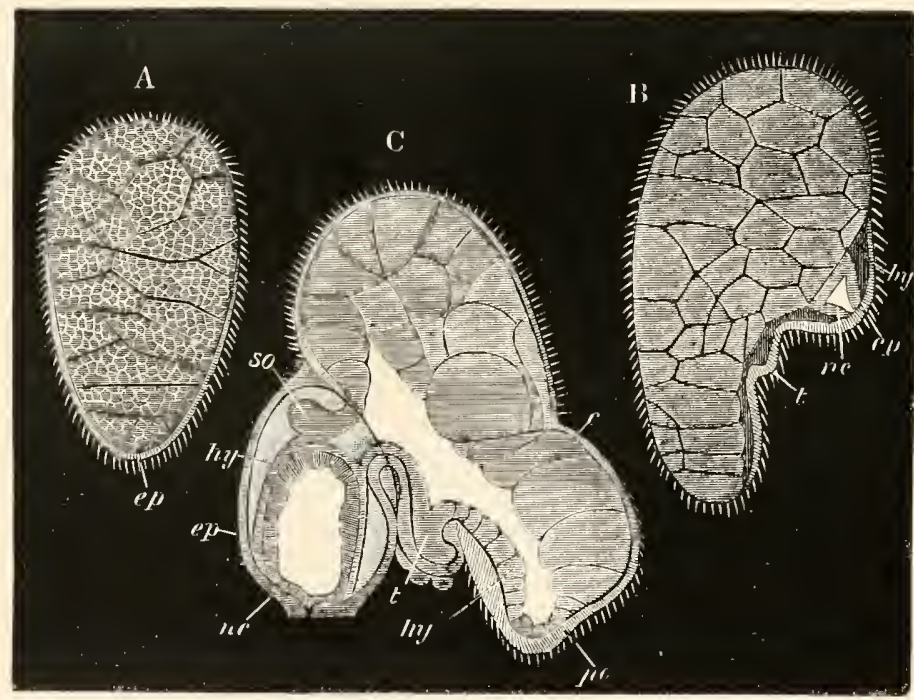

Fig. 74. Three larval stages of Epibulia aurantiaca. (After Metschnikoff.)

A. Planula stage.

B. Six-days' larva with nectocalyx (nc) and tentacle $(t)$.

C. Somewhat older larva with gastric cavity.

ip. epiblast; hy. hypoblast; so. somatocyst; $n c$. nectocalyx; $t$. tentacle; $c$. large yolk cells; po. polypite.

1 In my description of the development of the Siphonophora I employ Huxley's terminology. 
There is a regular segmentation, unaccompanied by the formation of a segmentation cavity. At its close the ovum becomes a spherical ciliated embryo. This embryo soon becomes elongated, and its cells differentiate themselves into a central and a peripheral layer-the epiblast and the hypoblast (fig. $74 \mathrm{~A}$ ). At this stage the larva has the typical planula form. The epiblast is especially thickened at a pole, which may be called the oral pole, and towards the side of this, which will be spoken of as the ventral side. Adjoining this thickened layer of epiblast a special thin layer of hypoblast becomes differentiated, which in opposition to the main mass of large nutritive cells forms the true hypoblastic epithelium (fig. $74 \mathrm{~B}, h y$ ). On this thickening two prominences make their appearance (fig. $74 \mathrm{~B})$. The oral of these is the rudiment of a tentacle $(t)$, and the aboral of a nectocalyx $(n c)$.

The former of these elongates itself in succeeding stages into a process of both epiblast and hypoblast. The central part of the nectocalyx on the otherhand appears to originate from a thickening of the epiblast in which the cavity of the bell becomes subsequently hollowed out. Between this part and the external epiblast which gives origin to the outermost layer of the nectocalyx a layer of hypoblast is interposed. When the nectocalyx has become to a certain extent established a cavity-the commencement of the

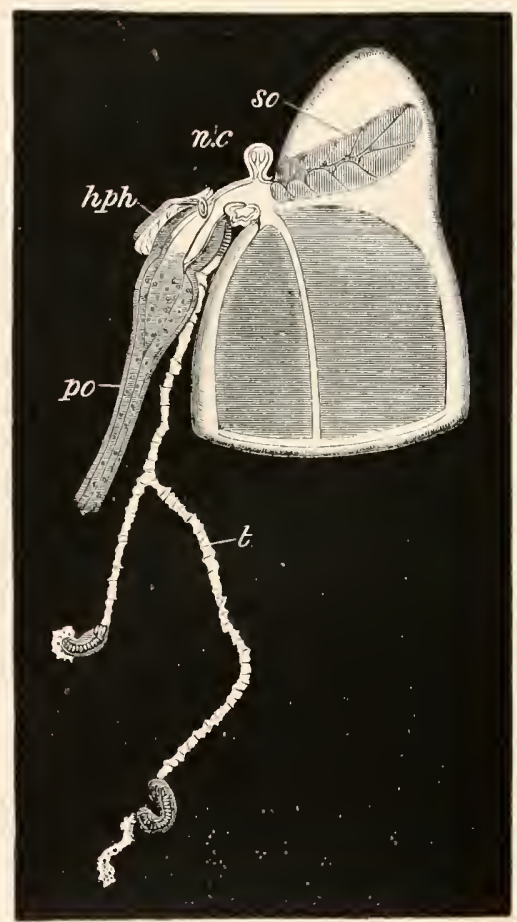

Ficr. 75. AN AdVANCEd larva of EpIBULIA AURANTIACA WITH ONE LARGE NECTOCALYX. (After Metschnikoff.)

so. somatocyst; $n c$. second imperfectly developed nectocalyx; $h p h$. hydrophyllium; $p o$. polypite; $t$. tentacle. 
primitive gastrovascular cavity of the adult-appears in the general hypoblast between the epithelial and nutritive layers in the immediate neighbourhood of its attachment. This cavity becomes prolonged into the nectocalyx to form the four gastrovascular canals; while the hypoblast at the upper end of the nectocalyx forms the somatocyst (fig. $74 \mathrm{C}$, so). The primitive enteric cavity once formed rapidly extends, especially in an oral direction (fig. $74 \mathrm{C}$ ), and forms a widish cavity in the oral part of the embryo. At the pole of this part (fig. 74, po) is eventually formed the opening of the mouth, and the contained cavity becomes in a special sense the gastric cavity. This region of the embryo may be spoken of as the polypite. The nectocalyx grows with great rapidity and soon forms by far the most prominent part of the larva (fig. 75). The true gastric region or polypite (fig. $75, p o$ ) continues also to grow, and a mouth becomes formed at its extremity. The aboral end of the original body of the embryo gradually atrophies.

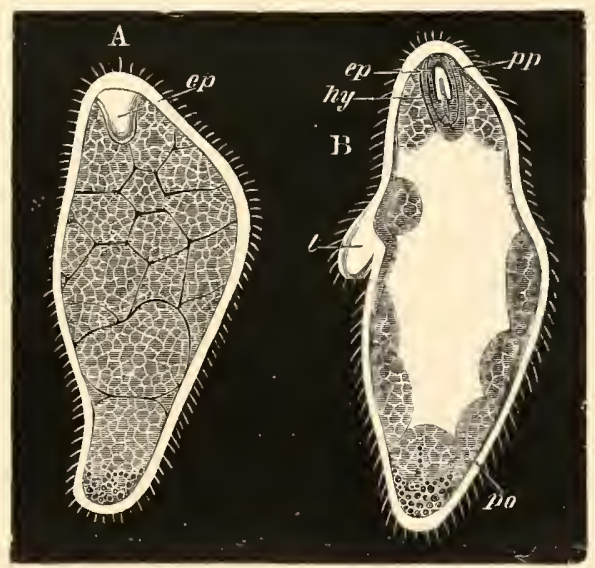

Fig. 76 . Two stages in the development of Stephanomia pictum. (After Metschnikoff.)

A. Stage after the delamination. ep. epiblastic invagination to form pneumatocyst.

B. Later stage after the formation of the gastric cavity in the solid hypoblast, $p o$. polypite; t. tentacle; $p p$. pneumatophore; $e p$. epiblastic invagination to form pneumatocyst; $h y$. hypoblast surrounding pneumatocyst.

At the junction of the nectocalyx and polypite the cœnosarc becomes formed, and rudiments of a second nectocalyx (nc) and

B. II. 
second polypite early become visible; while a hydrophyllium is formed as a bud which covers over the first polypite and tentacle (hph). With the development of the hydrophyllium the first segment, if the term may so be used, is complete. The second segment of which a rudiment is already present as a second polypite is intercalated between the first segment and the nectocalyces.

Amongst the Physophoridx there is a considerable range of variation in development; though the variations concern for the most part not very important points. The simplest type hitherto observed is that of Stephanomia (Halistemma) pictum. The segmentation and formation of a two-layered planula (fig. 76) take place in the usual way. Between the solid central mass of nutritive hypoblast cells and the epiblast an epithelial hypoblastic layer becomes interposed which undergoes a special thickening at the aboral pole. At this pole a solid involution of epiblast next becomes formed, to which a layer of hypoblast becomes applied. The structure so formed is the rudiment of the pneumatocyst $(c p)$. In the next stage the air-cavity of the pneumatocyst becomes established within the epiblast.

The gastrovascular cavity is formed in the midst of the nutritive hypoblast cells, which then become rapidly absorbed leaving the gastrovascular cavity entirely enclosed by the epithelial layer of hypoblast (fig. $76 \mathrm{~B}$ ).

By the above changes the more important organs of the larva have become established. The one end forms the pneumatophore, and the other, the oral part, the polypite. Between the two there is already present the rudiment of a tentacle, and a second tentacle soon becomes formed. The mouth arises as a perforation at the oral end of the larva.

The pneumatophore contains a prolongation of the gastrovascular cavity, the fluid in which bathes the outer hypoblastic wall of the pneumatocyst. It has however no communication with the enclosed cavity of the preumatocyst. In the later developmental stages the size of the pneumatophore becomes immensely reduced in comparison with the remainder of the larva.

The development of Physophora agrees closely with that of Stephanomia except in one somewhat important point, viz. in the development of a 
provisional hydrophyllium. This arises as a prominence at the aboral pole, containing a prolongation of the gastrovascular cavity. Between the epiblast and hypoblast of the prominence gelatinous tissue becomes deposited, and the hydrophyllium is thus converted into a large umbrella-like organ enclosing the polypite. The two together have a close resemblance to an ordinary Medusa, the polypite forming the manubrium, and the hydrophyllium the umbrella. The hydrophyllium is eventually thrown off.

An important type of Physophorid development is exemplified in Crystalloides, a genus closely allied to Agalma. In this type the greater part of the original ovum, instead of directly giving rise to the polypite, becomes a kind of yolk-sack, from which the polypite is secondarily budded (fig. $77, y k$ ). Agalma sarsii is in this respect intermediate between Crystalloides and Physophora. Both these types are remarkable for developing a series of provisional hydrophyllia (fig. $77, h . p h$.). In both genera the first of these develops as in Physophora, and for a long time is the only one functional.

The conclusions to be drawn from the above description may be summed up as follows. In all the Siphonophora, so far observed, the starting-point for further development is a typical ciliated two-layered planula. The inner layer or hypoblast is mainly formed of large nutritive cells. From these cells an epithelial hypoblastic layer becomes secondarily differentiated, the exact relations of which differ somewhat in the various types. The nutritive cells themselves do not appear to become directly converted into the permanent hypoblastic tissues. The development of the adult from the planula commences by the thickening of the epiblastic layer, usually at one pole (the future proximal or aboral pole), and the formation at this pole of a series of bud-like structures (in the growth of which both embryonic layers have a share), which become converted into the hydrophyllia, nectocalyces etc. The main oral part of the planula becomes generally converted into the polypite, though in some instances (Crystalloides) it remains as a yolk-sack, and only secondarily gives rise to a polypite.

Two very different views have been taken as to the nature of the various component parts of the Siphonophora, and the embryological evidence has been appealed to by both sides in confirmation of their views. By Huxley and Metschnikoff the various parts-nectocalyces, hydrophyllia, hydrocysts, polypites, gênerative gonophores etc. are regarded as simple organs, while by Leuckart, Haeckel, Claus etc. they are regarded as so many different individuals forming a compound stock. The difference 
between these two views is not merely as to the definition of an individual ${ }^{1}$. The question really is, are these parts originally derived by the modification of complete zooids like the gonophores and trophosomes of the fixed Hydrozoa stocks, or are they structures derived from the modification of the tentacles or some other parts of a single zooid?

The difficulty of deciding this point on embryological evidence depends on the fact that ontologically a tentacle and a true bud arise in the same way, viz. as papilliform outgrowths containing prolongations of both the primitive germinal layers. The balance of evidence is nevertheless in my opinion in favour of regarding the $\mathrm{Si}$ -

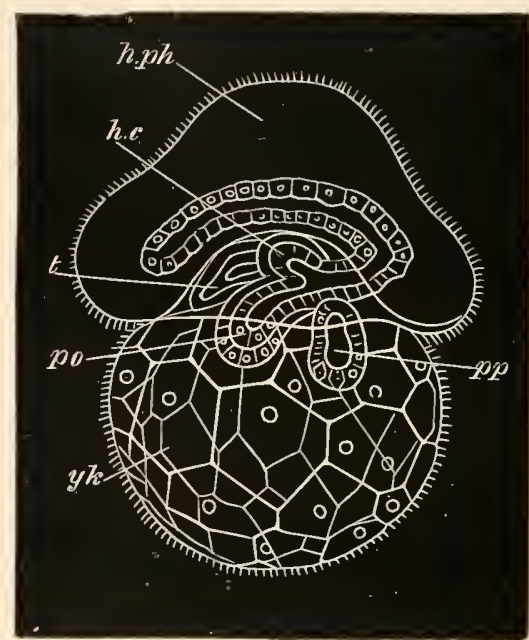

Fig. 77. Larva of Crystallomines. (After Haeckel.)

$h . p h$. hydrophyllium; h. hydrocyst; $t$. tentacle; $p p$. pneumatophore; po. polypite; $y k$. yolk-sack.

phonophora as compound stocks, and the views of Claus on this subject (Zoologie, p. 27 I) appear to me the most satisfactory.

The most primitive condition is probably that like Physophora in an early stage with an hydrophyllium enclosing a polypite (cf. Haeckel and Metschnikoff). In this condition the whole larva may be compared to a single Medusa in which the primitive hydrophyllium represents the umbrella of the Medusa, and the polypite the manubrium. The tentacle which appears so early is probably not to be regarded as a modified zooid, but as a true tentacle. The absence of a ring of tentacles is correlated with the bilateral symmetry of the Siphonophora.

The primitive zooid of a Siphonophora stock is thus a Medusa. Like Sarsia and Wilsia this Medusa must be supposed to have been capable of budding. The ordinary nectocalyces by their resemblance to the umbrellas of typical Medusæ are clearly such buds of the medusiform type. The same may be said of the pneumatophore, which, as pointed out by Metschnikoff, is identical in its development with a nectocalyx. Both are formed by a

1 From the expressions used by Huxley, Anatomy of Invertebrated Animals, p. I 49 , it appears to me possible that his opposition to Leuckart's view is mainly as to the nature of the individual. 
solid process of epiblast in which a cavity-the cavity of the nectocalyx or pneumatocyst-is eventually hollowed out. Around this there appears a double layer of hypoblast containing a prolongation of the gastrovascular cavity; and this is in its turn enclosed by a layer of epiblast which forms the covering of the convex surface of the nectocalyx and the external epiblast of the pneumatophore.

The generative gonophores are clearly also zooids, and the hydrophyllia are probably a rudimentary form of umbrella. In many cases (Epibulia, Stephanomia, Halistemma etc.) the hydrophyllium of the primitive polypite (manubrium) is absent. In such instances it is necessary to suppose that the umbrella of the primitive zooid of the whole colony has become aborted. Leuckart originally took a somewhat different view from the above in that he regarded the starting-point of the Siphonophora to be a compound fixed Hydrozoon stock, which became detached and free-swimming.

Acraspeda ${ }^{1}$. The embryonic development of several of the forms of the Acraspeda has been investigated by Kowalevsky (No. 147) and Claus (No. 153). Their observations seem to point to an invaginate gastrula being characteristic of this group.

Amongst the forms with alternations of generations and a fixed larval form Chrysaora and Cassiopea have been most fully investigated. The ovum of the former undergoes the first embryonic phases while still in the ovary. In the latter it is enclosed amongst the oral processes. A complete and more or less regular segmentation leads to the formation of a single-walled blastosphere with a small segmentation cavity. The wall of the blastosphere next becomes invaginated, giving rise to an archenteron (fig. $78 \mathrm{~A}$ ). The blastopore soon closes up, and the archenteron is converted into a closed sack completely isolated from the epiblast (fig. $78 \mathrm{~B}$ ). The surface of the larva becomes in the meantime covered with cilia. The free larval stage thus reached is similar to the ordinary Hydrozoon planula. After the closure of the blastopore the larva becomes elongated, and one end becomes narrowed. By this narrowed extremity the larva soon attaches itself, and at the opposite and broader end a fresh involution of the epiblast appears (fig. $78 \mathrm{C}$ ); this gives rise to the stomodæum, which is placed in communication with the archenteron on the absorption of the septum dividing them. The relation of the stomodæum to the original blastopore has not been determined.

1 I use this term for the group, often known as the Discophora, which includes the Pelagidæ, Rhizostomidx, and Lucernaridæ. 
At the point of attachment there is developed a peculiar pedal disc, and around the mouth there appears a fold of epiblast which gives rise to an oral disc (fig. 78 D). Two tentacles first make their appearance, but one of these is primarily much the largest, though eventually the second overtakes it in its growth.

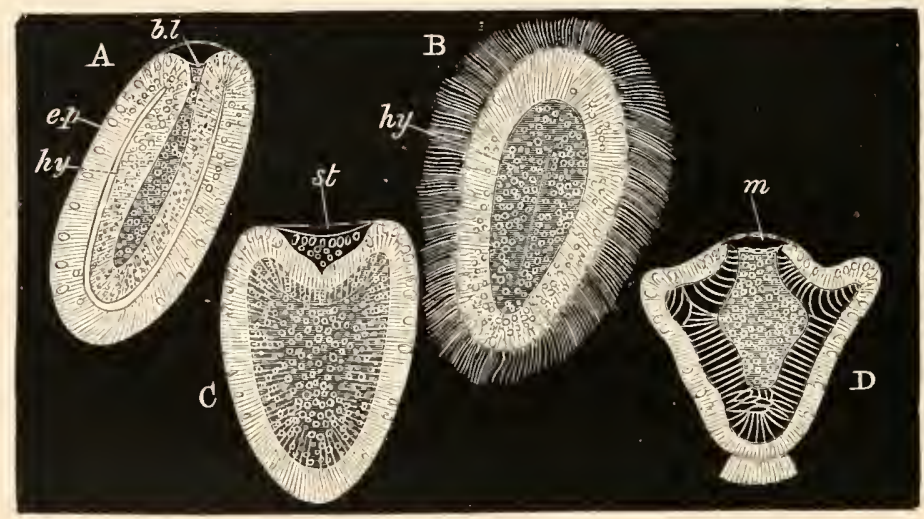

Fig. 78 . Four slages in the development of Chrysaora. (After Claus.)
A. Gastrula stage.
B. Stage after closure of blastopore.
C. Fixed larva with commencing stomodæum.
D. Fixed larva with mouth, short tentacles, etc.
ep. epiblast; hy. hypoblast; st. stomodeum; $m$. mouth; $b l$. blastopore.

A second pair of tentacles next becomes formed, giving to the larva a 4-radial symmetry. Between these four new tentacles subsequently sprout out, and in the intermediate planes four ridge-like thickenings of the hypoblast, projecting in to the cavity of the stomach, make their appearance. They imperfectly divide the stomach into four chambers, to each of which one of the primary tentacles corresponds; they may be regarded as homologous with the mesenteries of the Actinozoa. The number of tentacles goes on increasing somewhat irregularly up to sixteen. All the tentacles contain a solid hypoblastic axis. Muscular elements are developed from the epiblast.

With the above changes the so-called Hydra tuba or Scyphistoma form is reached (vide fig. 85 ). The peculiar strobilization of this form is dealt with in the section devoted to the metamorphosis. 
Aurelia is stated by Kowalevsky to develop in the same way as Cassiopea; and the one stage of Rhizostoma observed is that in which it has a (probably invaginate) gastrula form.

In Pelagia the ovum directly gives rise to a form like the parent. The segmentation and the invagination take place nearly as in Cassiopea, but the archenteric cavity is relatively much smaller, and the large space between it and the epiblast becomes filled with the gelatinous tissue which forms the umbrella. The blastopore does not appear to close but to become directly converted into the mouth. As in Cassiopea the larva takes a somewhat four-sided pyramidal form. The mouth is placed at the base. The pyramid becomes subsequently flatter, and at the four corners four tentacles grow out which increase to eight by division. The flattening continues till the larva reaches a form hardly to be distinguished from the Ephyra resulting from the strobilization of the fixed Scyphistoma form of other Acraspeda.

Alcyonida. In the Alcyonidxe the segmentation appears always to lead to the formation of a solid morula, which becomes a planula by delamination. The true enteric cavity is formed by an absorption of the central cells, but the axial portion of the gastric cavity and mouth are formed by an epiblastic invagination.

The development of these types has been mainly studied by Kowalevsky (147), and my knowledge of his results is derived from German abstracts of the original Russian memoirs.

In Alcyonium palmatum the impregnation is external. The segmentation is very exceptional in character. It commences with the formation of a series of irregular prominences on the surface of the ovum, which become segmented off to form a superficial layer of epiblast cells. The inner mass of protoplasm then divides up into polygonal cells to form the hypoblast, which would thus seem to be formed by a kind of delamination. In Clavu laria crassa (No. 168) there is a complete segmentation followed by a delamination. The larva of $A l$. palmatum elongates and becomes ciliated, and so assumes the characters of a typical planula. The central hypoblast is formed of an outer granular stratum with imperfectly differentiated cells - the true hypoblast-and an inner homogeneous mass with vacuoles.

Some of the larva become fixed, while others coalesce together and form a large mass, the fate of which has not been further studied. An invagination of epiblast takes place at the free end of the fixed larva, which gives rise to the so-called gastric cavity, i.e. the axial portion of the general enteric cavity, which would appear to be in reality a kind of stomodreum. Around the gastric cavity the hypoblast forms eight mesenteries, the chambers between which are filled with the homogeneous material which occupied the centre of the ovum in the previous stage. It is to be presumed, though not stated, that by an absorption of the blind end of the stomodxal invagination the gastric chamber is placed in free 
communication with the spaces between the mesenteries ${ }^{1}$. During the next stage the young Alcyonium also acquires eight tentacles, which arise as hollow papillæe opening into the eight mesenteric chambers. By this stage also the matter filling up the mesenteric chambers is nearly absorbed.

Between the epiblast and hypoblast there is formed an homogeneous membrane, which penetrates in between the two layers of hypoblast which form the mesenteries. On the outer side of this membrane, and therefore presumably derived from the epiblast, is a layer of connectivetissue cells, which eventually gives rise to the abundant gelatinous tissue (cœenenchyma) in which the skeletal elements are deposited. In Sympodium coralloides Kowalevsky (No. 168) has shewn still more completely the derivation of the stellate mesoblast cells from the epiblast. He finds that the calcareous spicula develop in these cells as in the mesoblast cells of sponges. The branched gastrovascular canals in this tissue are outgrowths of the primitive enteric cavity. A layer of circular muscles is formed at a late period from the epiblast, but the longitudinal inuscles of the mesenteries on the inner side of the homogeneous membrane are regarded by Kowalevsky as hypoblastic.

A ciliated planula with delaminated hypoblast is also found in Gorgonia and Corallium rubrum. In the former genus at the time when the larva becomes fixed, the hypoblast is formed of two strata, an outer one of columnar cells, and an inner one of round ciliated cells lining a central enteric cavity. The inner layer is believed by Kowalevsky to become eventually absorbed and to be homologous with the inner granular mass of Alcyonium.

Zoantharia. Amongst the Zoantharia several forms have been investigated by Kowalevsky (147) and Lacaze Duthiers (170), of which some are stated by the former author to pass through an invaginate gastrula stage, while in other instances the hypoblast is probably formed by delamination.

To the first group belongs an edible form of Sea Anemone found near Messina, Cerianthus, and perhaps also Caryophyllium. In the first of these segmentation results in the formation of a blastosphere. A normal invagination obliterating the segmentation cavity then ensues, and the blastopore narrows to form the mouth. The borders of the mouth bend inwards and so give rise to the gastric cavity (stomodaum) which as in the Alcyonidx is lined by epiblast. Simultaneously with the formation of the mouth there appear the two first mesenteries.

In Cerianthus the segmentation is unequal, the early stages are the same as in the Actinia just described, but the hypoblast cells give rise

1 The Cierman abstract is very obscure as to the formation of the mouth. 
to a mass of fatty material filling up the enteric cavity, which becomes eventually absorbed.

In the majority of the Zoantharia so far investigated, including species of Actinia, Sagartia, Bunodes, Astroides, Astrea, the segmentation, which is often unequal ${ }^{2}$ and not accompanied by the formation of a segmentation cavity, results in a solid twolayered ciliated planula. In these forms the impregnation takes place in the ovary, and the early stages of development are passed through in the maternal tissues.

One end of the planula becomes somewhat oval and develops a special bunch of cilia. At the other end a shallow depression appears, which becomes deeper and forms an involution lined by epiblast. This involution is the stomodrum, and becomes the so-called gastric cavity. The true enteric cavity lined by hypoblast is for some time filled with yolk material. The larva always swims with the aboral end directed forwards.

Between the two embryonic layers a homogeneous membrane is formed, similar to that already described in the Alcyonidx.

The further development of the larvæ especially concerns the formation of mesenteries, tentacles and calcareous skeleton. With reference to this subject the observations of Lacaze Duthiers are especially valuable and striking.

In the adult it is usually possible to recognise in the tentacles a symmetry of six. There are six primary tentacles, six secondary, twelve tertiary, twenty-four quaternary, etc. In the hard septa of the skeleton the same law is followed up to the third cycle, but beyond that, in the cases where the point can be verified, there appear to be only twelve septa in each additional cycle. The observations of Lacaze Duthiers have shewn that this symmetry is only secondarily acquired and does not in the least correspond with the succession of the parts in development.

His observations were conducted on three species of Zoantharia without a skeleton, viz. Actinia mesembryanthemum, Sagartia, and Bunodes gemmacea; while Astroides calycularis served as the type for his investigations on the corallum. It will be convenient to commence with his results on Actinia mesembryanthemum which served as his type.

The free cylindrical embryo, with the aboral end directed forwards in swimming, first becomes somewhat flattened and the mouth elongated. A bilateral symmetry is thus brought about. Two mesenteries now make their appearance transversely to the long axis of the mouth, which divide the enteric cavity into two unequal chambers. The mesenteries consist of a fold of hypoblast with a prolongation of the epiblast between the two

I I have this on the authority of Kleinenberg. The existence of an unequal segmentation probably indicates an epibolic gastrula. 
limbs of the fold. The larger chamber next becomes divided by two fresh mesenteries into three, and a similar division then takes place in the smaller chamber. The stage with six chambers is almost immediately succeeded by one with eight, owing to the appearance of two fresh mesenteries in the second-formed set of chambers. At the stage with eight chambers there is a marked period of repose. The number of chambers is increased to ten by the division of the third-formed set of chambers, and to twelve by the division of the fourth-formed set. It will be observed that the number of the chambers increases in arithmetical progression by the continual addition of two, alternately cut off from the primitive large and small chambers. The freshly formed chambers are always formed immediately on one side of the primitive mesenteries. The stages with six and ten are of very short duration. The two primitive chambers are necessarily at the ends of the long axis of the mouth. After the division of the enteric cavity into twelve chambers, these chambers become about equal in size, and the formation of the tentacles commences. The law regulating the appearance of the tentacles is nearly the same as that for the mesenteries, but is not quite so precise. One tentacle makes its appearance for each chamber. The most remarkable feature in the appearance of the tentacles is due to the fact that the tentacle surmounting the primitive largest chamber arises before any of the others, and long retains its supremacy (fig. 8o A). This fact, coupled with the inequality of the two primitive chambers, supplies some grounds for speculating on a possible descent of the Colenterata from bilaterally symmetrical forms with distinctly differentiated dorsal and ventral surfaces. The supremacy of the first-formed tentacle is not confined to the Actinozoa, but as has already been indicated, is also found in the Scyphistoma (p. 166) of the Acraspeda.

After the twelve tentacles have become established they become secondarily divided into two cycles of six respectively larger and smaller tentacles, which alternate with each other. The two tentacles pertaining to the two original chambers belong to the cycle of larger tentacles. The mesenteric filaments appear first of all on the primary pair of septa. The increase in the number of ten-
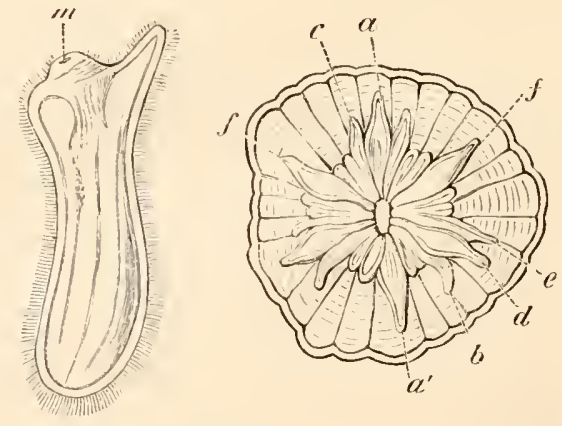

F1G. 80. 'WW STAGES 1N THE DEVELOPMENT OF ACTINIA MESEMBRYANTHEMUM. (After Lacaze Duthiers.)

In the younger ciliated embryo $\mathrm{A}$, viewed from the side, only one tentacle is developed. m. mouth.

The older larva $\mathrm{B}$ is viewed from the face when $2+$ tentacles have just hecome established. The letters shew the true order of succession of the tentacles; but $c$ and $f$ are transposed.

tacles and chambers from 12 to 24 has been found to take place in a very 
remarkable and unexpected way. The law is expressed by Lacaze Duthiers as follows. "The appearance of the new chambers is not, as has been believed, a consequence of the production of a single chamber between each of the twelve already existing chambers, but of the birth of two new chambers in each of the six elements (chambers) of the smaller cycle." The result of this law is that a pair of tentacles of the third cycle is placed in every alternate space, between a large and a small tentacle, of the two already existing cycles, which may conveniently be called the first and second cycles (fig. So B).

The twenty-four tentacles formed in the above manner are obviously at first very irregularly arranged (fig. $80 \mathrm{~B}$ ), but they soon acquire a regular arrangement in three graduated cycles of 6,6 and i2. The first cycle of the six largest tentacles is the large cycle of the previous stage, but the two other cycles are heterogeneous in their origin, each of them being composed partly of the twelve tentacles last formed, and partly of the six tentacles of the second cycle of the previous stage.

The further law of multiplication has been thus expressed by Lacaze Duthiers: "The number of chambers and still later that of the corresponding tentacles is carried from $24-48$ and from $48-96$ by the birth of a pair of elements in each of the 12 or 24 chambers, above which are placed the smallest tentacles which together constitute the fourth or fifth cycle. Since, after the formation of each fresh cycle, the arrangement of the tentacles again becomes symmetrical, it is obvious that all the equal sized cycles except the first are formed of tentacles entirely heterogeneous as to age."

The fixation of the free swimming larva takes place during the period when the tentacles are increasing from 12 to 24 .

The general formation of the chambers in Bunodes and Sagartia is nearly the same as in Actinia.

In the two types of Actinozoa with an embolic gastrula stage the laws as to the formation of the tentacles do not appear to be the same as those regulating the forms observed by Lacaze Duthiers.

In Cerianthus four tentacles are formed simultaneously at the period when only four chambers are present. In Arachnitis (Edwarsia) the succession of the tentacles is stated (A. Agassiz, 166) to resemble that in Cerianthus. There are originally four tentacles, and at one extremity of the long axis of the mouth are the oldest tentacles, while at the other tentacles are constantly added in pairs. An odd tentacle is always found at the extremity of the mouth opposite the oldest tentacles.

In the other species with an embolic gastrula eight tentacles would seem to appear simultaneously at the period when eight chambers are present; though on this point Kowalevsky's description is not very clear. The presence of such a stagre would seem to indicate a close affinity to the Alcyonidae.

Amongst the sclerodermatous Actinozoa, except Caryophyllium, the embryo closely resembles that of the delaminate Malacodermata. The first 
stages occur in the ovary, and the larva is dehisced into the body cavity as a two-layered ciliated planula.

The laws affecting the formation of the first twelve tentacles and septa appear to be nearly the same as for the Malacodermata. The hard parts begin as a rule to be formed when twelve tentacles have appeared, at which period also the fixation of the larva takes place. On fixation the larva becomes very much flattened.

The first parts of the corallum to appear are twelve of the septa, which arise simultaneously in folds of the enteric wall in the chambers between the mesenteries, and correspond therefore with the tentacles and not, as might be supposed, with the mesenteries. Each septum is formed by the coalescence of three calcareous plates which originate in separate centres of calcification. The concrescence of the three produces a Y-shaped plate with the single limb directed inwards and the two limbs outwards (fig. 81). The theca does not arise till after the septa have become formed, and is at first a somewhat membranous cup quite distinct from the septa. The columella is formed still later by the coalescence of a series of nodules which are formed in a central axis enclosed by the inner ends of the septa.

After the formation of the theca the septa become divided into two cycles by the predominant growth of six of them. On the coalescence of the septa with the theca the space between the two limbs of the $\mathrm{Y}$ becomes filled up with calcareous tissue. The law of the formation of the third cycle of septa (12-24) has not been worked out, so that it is not possible to state whether it follows the peculiar principles regulating the growth of the tentacles.

The whole of the skeletal parts occupy a position between the epiblast and hypoblast, and are exactly homologous in this respect with the skeleton of the Alcyonidx. By Lacaze Duthiers they are however believed to originate in the hypoblast, but from the observations of Kowalevsky there can be little doubt that they arise in the connective tissue between the two embryonic layers which is probably epiblastic in

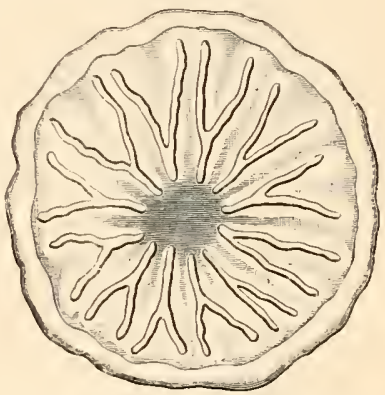

Fig. 81. Larva of Astroldes CALYCULARIS SHORTLY AFTER IT HAS BECOME ATTACHED. (After Lacaze Duthiers.)

The figure shews the development of the $\mathrm{Y}$-shaped septa in the intervals between the mesenteries. The position of the latter is indicated by the faint shading. The theca has become developed externally. origin.

A peculiar larva, probably belonging to the Actinozoa, has been described by Semper ${ }^{1}$. It has an elongated form and is provided with a longitudinal ridge of cilia. There is a mouth at one end of the body and an anus at the opposite extremity. The mouth leads into an œsophagus, which opens

1 "Ueb. einige tropische Larven-formen." Zit.f. wiss. Zool., vol. xvil. 1867. 
freely into a stomach with six mesenteries. In the skin are numerous threadcells. A mesotrochal worm-like larva, also provided with thread-cells, and found at the same time, was conjectured by Semper to be a younger form of this larva.

Ctenophora. The ovum of the Ctenophora is formed of an outer granular protoplasmic layer and an inner spongy mass with fatty spherules. It is enveloped in a delicate vesicle, the diameter of which is very much greater than that of the contained ovum. This vesicle appears to be filled with sea-water, in which the ovum floats.

Fertilized ova may usually be easily obtained by keeping the captured adults in water from $12-24$ hours. The two main authoritics on the development of these forms (Kowalevsky, No. 147 and 178 and Agassiz, No. 172) are unfortunately at variance on one or two of the most fundamental points. It seems however that the embryonic layers are formed by a kind of epibolic gastrula; while the true gastric cavity, as distinct from the gastrovascular, is formed by an invagination, and deserves therefore to be regarded as a form of stomodæum.

The early stages are very closely similar in all the types so far observed. Segmentation commences by the outer layer of the ovum, which throughout behaves as the active layer, forming a protuberance at one pole, which may be called the formative pole. Close below this protuberance is placed the nucleus. In the median line of the protuberance a furrow appears (fig. $82 \mathrm{~A}$ ),
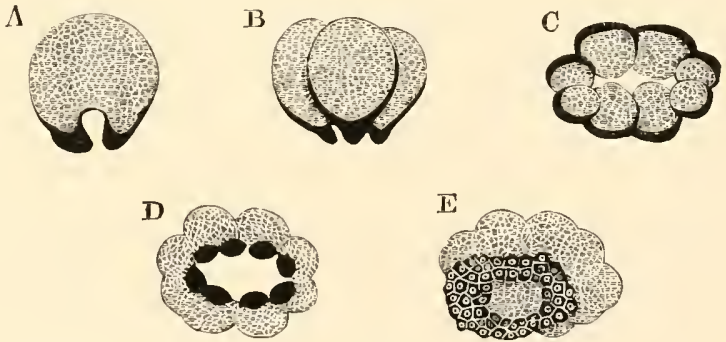

Fig. 82. Five stages in the development of Inyma roseol. (After Agassiz.)

The protoplasmic layer of the ovum is represented in black.

which gradually deepens till it divides the ovum into two. The granular layer follows the furrow so that each of the fresh segments, like the original ovum is completely invested by a layer 
of granular protoplasm. Each segment contains a nucleus. A second similar division at right angles to the first gives rise to four segments (fig. 82 B), and the segments so formed become again divided into eight (fig. $82 \mathrm{C}$ ). In the division into eight, which takes place in a vertical plane, the segments formed are of unequal size, four of them being much smaller than the others. The eight segments are arranged in the form of a slightly curved disc round a vertical axis - the future long axis of the body;and there is a cavity in this axis which, like the segmentation cavity of Sycandra raphanus, is open at both extremities. The disc with its concavity on the side of the formative pole has the shape sometimes of an ellipse (fig. $82 \mathrm{C}$ ) and sometimes of a rectangle, in which the four small spheres occupy the poles of the longer axis. A bilateral symmetry is thus even at this stage clearly indicated.

In the next phase of segmentation the granular layer surrounding each segment again forms a protuberance at the formative pole, but, instead of each segment becoming divided into two equal parts, the protoplasmic protuberance alone is divided off from the main segment. In this way sixteen spheres become formed, of which eight are large and are formed mainly of the yolk material of the inner part of the ovum, and eight are small and entirely composed of the granular protoplasm. The eight small spheres form a ring on the formative surface of the large spheres (fig. 82 D).

The small spheres now increase very rapidly (fig. $82 \mathrm{E}$ ), partly by division and partly by the formation of fresh cells from the large spheres; and spread over the large spheres, forming in this way an epibolic gastrula. They constitute a layer of epiblast. (Fig. $8_{3}$ A.) The large cells in the meantime remain relatively passive, though during the process they divide, in some cases more or less irregularly, while in Eucharis they divide into sixteen. The axial segmentation cavity would seem during the process to become obliterated.

There is an important discrepancy between the statements of Kowalevsky and Agassiz as to the course of the growth of the small cells. According to Agassiz the small cells grow most rapidly at the formative pole and cover this before they meet at the opposite pole. The reverse statement is made by Kowalevsky. It would seem that the above discrepancy is due to an 
interchange on the part of the one or the other of these authors of the two poles of the embryo, in that according to Agassiz the formation of the mouth takes place at the formative pole, and according to Kowalevsky at the pole opposite to this.

Without attempting to decide between the above views, we shall speak of the pole at which the mouth is formed as the oral pole.

The formation of the alimentary cavity commences shortly after the complete investiture of the embryo by the epiblast cells. At the oral pole an invagination of epiblast cells takes place (fig. $8_{3} \mathrm{~B}$ ), which makes its way towards the opposite pole. More especially from the figures given by Agassiz, and from the explanation of his plates, it would seem that a large chamber is formed in the hypoblast at the end of the invaginated tube, into which this tube soon opens (fig. $8_{3} \mathrm{C}$ ). The invaginated tube would seem to give rise to the so-called stomach, while the chamber at its aboral extremity is no doubt the infundibulum, which as may be gathered from Kowalevsky's statements, is lined by a flattened epithelium. At a later period the gastrovascular canals grow out from the infundibulum as four pouches, which are surrounded by, and grow at the expense of, the large central cells, which have in the meantime arranged themselves in four masses, and appear to serve as a kind of yolk. The nuclei of these large cells according to Kowalevsky disappear, and the cells themselves break up into continually smaller masses.

The main difficulty in the above description of Agassiz is the origin of the infundibulum. In the absence of definite statements on this head it
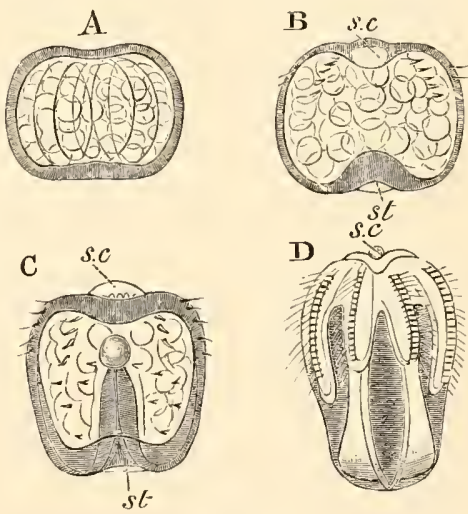

Fig. 83. FOUR STAGES IN THE DEVELOPMENT OF IDYia ROSEOLA. (After Agassiz.)

s.c. sense capsule; st. stomodrum. seems reasonable to conclude that it arises as a space hollowed out in the central cells, and that its walls are formed of elements derived from the yolk cells ${ }^{1}$. On this interpretation the alimentary canal of the Ctenophora would

1 Chun (No. 174) gives a short statement of his observations, which accords with the interpretation in the text. 
consist, as in the Acraspedote Medusæ and Actinozoa, of two sections: (1) A true hypoblastic section consisting of the infundibulum and the gastrovascular canals derived from it; and (2) an epiblastic section-the stomodæum-forming the stomach.

The observations of Kowalevsky on the alimentary system do not wholly tally with those of Agassiz. He finds that the oral side of the embryo becomes hollowed out, and that the hollow, lined by flattened cells, becomes constricted off as the infundibulum, from which the radial canals subsequently grow out. To the infundibulum there leads a narrow canal lined by a columnar epithelium which becomes the gastric cavity.

While the alimentary canal is becoming formed a series of important changes takes place in other parts of the cmbryo. The rows of locomotive paddles first appear as four longitudinal equidistant linear thickenings of the epiblast near the aboral pole (fig. $8_{3} \mathrm{D}$ ). On the projecting surface of these ridges stiff cilia appear which coalesce together to form the paddles. While the embryo is still within the egg the rows of paddles are quite short and also double. There are in Pleurobrachia about eight or nine pairs of paddles in each row. Each double row eventually separates into two.

In all the forms except the Eurostonata (Beroe) two tentacles grow out as thickenings of the epiblast (fig. $84 \mathrm{~B}, t$.). They are placed at the opposite poles of the long transverse axis of the embryo.

A process of the contractile gelatinous tissue of the body, the origin of which is described below, makes its way, according to Kowalevsky, into the tentacles.

The central apparatus of the nervous system and the otoliths are formed at the aboral pole from a thickening of the epiblast, but the full details of their formation have not been elucidated. It may be well to preface my account of their development with a short statement of their adult structure.

They consist in the adult of a vesicle with a ciliated lining situated at the bifurcation of the two anal tubes, and of certain structures connected with this vesicle. From the floor of the vesicle is suspended a mass of otoliths by four leaf-like bodies known as suspenders. The roof is very delicate and has the form of a four-sided pyramid. Six openings lead into the vesicle. Through four of these, placed at the four corners, there pass out four ciliated grooves continuous with the suspenders. These grooves, after leaving the otolithic vesicle, bifurcate and pass to the eight rows of paddles. At the two sides the walls of the vesicle are continuous with two 
thickened ciliated plates with swollen edges, opposite the centres of which are two lateral openings into the vesicle, completing the six openings. Through the lateral openings the sea water is driven by the action of the cilia of the plates.

The development of these parts is as follows-In the aboral thickening of epiblast a cavity makes its appearance, the walls of which constitute the rudiment of the otolithic vesicle (fig. $\$_{3} \mathrm{~B}$ and $\mathrm{C}$, s.c.). The roof of the cavity is extremely delicate. On each side of it a thickening of cells becomes established, regarded by Kowalevsky as the rudiment of the nervous ganglia. These thickenings appear to give origin to the lateral ciliated plates. The otoliths arise from cells at four separate points at the corners of the ciliated plates opposite the rows of paddles (fig. $84 \mathrm{~A}$, ot.).

In Pleurobrachia there is at first only one otolith at each corner. The otoliths are gradually transported towards the centre of the vesicle (fig. $S_{4} \mathrm{~B}, o t$.) and are there attached, though the four leaf-like suspenders do not arise till very late. The otoliths go on increasing in number throughout life.

The gelatinous tissue of the Ctenophora appears as a homogeneous layer between the epiblast and the yolk-cells, and is probably homologous with the layer formed in the same situation in all other cœlenterate forms. Into the layer a number of anastomosing cells,

A

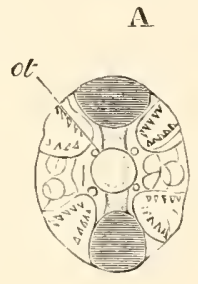

FJg. 84, Two STAGES IN THE DEVELOPMENT OF PLEUROBRACHIA RHODODACTYLA. (After Agassiz.)

ot. otolith; $t$. tentacle. mainly derived from the epiblast, though according to Chun (No. 174) also in part from the hypoblast, make their way. These cells would appear to be mainly, if not entirely (Chun), of a contractile nature. It is probable that the great mass of the gelatinous tissue of the adult is an intercellular substance derived from these cells.

The whole of the above changes are completed while the embryo is still enclosed in the egg capsule. During their accomplishment the oro-anal axis, which was originally very short, increases greatly in length (fig. 83), so that the embryo acquires an oval form similar to that of the adult.

B. II. 
The exact period of leaving the egg does not appear to be very constant but the hatching never takes place till the embryo has practically acquired all the organs of the adult.

In the majority of types the differences between the just hatched larva and the adult are inconsiderable, and in all cases the larva has a somewhat oval form. In the case of the Tæniatæ (Cestum, etc.), the larva has the characteristic oval form, and the subsequent changes amount almost to a metamorphosis.

The larva of the Lobatæ, such as Eucharis, Bolina, etc., can hardly be distinguished from Pleurobrachia, and undergoes therefore considerable changes after hatching.

Eucharis multicornis while still in the larval condition is stated by Chun to become sexually mature.

The new genus Ctenaria recently described by Haeckel, which is intermediate between the Ctenophora and the Medusæ clearly proves that the Ctenophora are more closely related to the Meduse than to the Actinozoa; but their development, especially the presence of a stomodæum, shews that they have affinities (in spite of the rudimentary velum of Ctenaria) with the Acraspedote as well as with the Craspedote Medusæ; and it may be noted that the Acraspeda have undoubted affinities with the Actinozoa.

\section{Summary and general considerations.}

Even in the adult condition the lower forms of Cœlenterata do not rise in complexity much beyond a typical gastrula. Ontogeny nevertheless brings clearly to light the existence of a larval form-the planula-which recurs with fair constancy amongst all the groups except the Ctenophora.

We are probably justified in assuming that the planula is a repetition of a free ancestral form of the Colenterata. The planula, as it most frequently occurs, is a two-layered ciliated nearly cylindrical organism, with at most a rudimentary digestive cavity hollowed out in the inner layer, and as a rule no mouth. In the outer layer are numerous thread-cells.

How many of these characters did the ancestral planula possess? I think it is not unreasonable to assume that the only two characters about which there can be much doubt are the rudimentary condition of the digestive cavity and the absence of a mouth. Paradoxical as it may seem, it appears to me not impossible that the Colenterata may have had an ancestor in which a digestive tract was physiologically replaced by a solid mass of amœboid cells. 
This ancestor was perhaps common to the Turbellarians also. The constant presence of thread-cells in the inner layer of their epiblast fits in with their derivation from a form similar to the planula. While the solid parenchymatous digestive canal of Convoluta and Schizoprora and other forms amongst the Turbellarians, though very probably secondary, may perhaps be explained by such a view of their origin.

The planula in its primitive condition is not bilaterally symmetrical, but frequently, as amongst the Actinozoa, it becomes flattened on two sides before undergoing its conversion into the adult form. Perhaps the bilateral form of planula is the starting point both for the Colenterata and the Turbellaria. In this connection the peculiar unilateral development of a tentacle in Scyphistoma and Actinia should be noted.

The planula occurs in the majority of sessile forms of Hydrozoa except the Tubularidæ and Hydra. It is also characteristic of the Trachymedusæ and Siphonophora. Amongst the Acraspeda it is also present, but has an exceptional mode of ontogeny which is discussed in connection with the germinal layers.

It is characteristic both of the Octocoralla and Hexacoralla, but is not found in the Ctenophora.

In the Tubularidxe and in Hydra an abbreviated development leads no doubt to the absence of a free planula stage, and the absence of a larval form amongst the Ctenophora may, as has already been stated, be probably explained in the same way.

The Coelenterata of all the Metazoa are characterized by the greatest simplicity in the arrangement of their germinal layers; and for this reason very considerable interest attaches to the mode of formation of the layers amongst them. Two germinal layers are constantly found. which correspond in a general way to the epiblast and hypoblast. It might have been anticipated that a certain amount of uniformity would have existed in the mode of formation of the layers. This however is not the case. In perhaps the majority of forms they become differentiated by a process of delamination, but in a not inconsiderable minority the two layers owe their origin to an invagination.

Delamination is constant (with the doubtful exception of some Tubularidæ) amongst the Hydromedusæ and Siphonophora. It is perhaps in the main characteristic of the Actinozoa.

Invagination by embole takes place, so far as is known, constantly amongst the Acraspeda and frequently amongst the 
Actinozoa; and an epibolic invagination is characteristic of the Ctenophora.

If confidence is to be placed in the recorded observations on which this summary is founded, and there is no reason why in a general way it should not be so placed, the conclusion is inevitable that of the above modes of development the one must be primitive and the other a derivative from it, for, if this conclusion be not accepted, the absolutely inadmissible hypothesis of a double origin for the Cœlenterata would have to be adopted.

Two questions arise from these considerations :-

(I) Which is the primitive, delamination or invagination?

(2) How is the one of these to be derived from the other?

There is a great deal to be said in favour of both delamination and invagination; but it will be convenient to defer all discussion of the question to the general chapter on the formation of the layers throughout the animal kingdom.

The hypoblast cells are often filled with yolk material, and secondary modifications are thus produced in the development. The most important examples of such modifications are found in the Siphonophora and Ctenophora.

In the simplest forms amongst the Hydrozoa there is no trace of a third layer or mesoblast. The epiblast is typically formed, as was first shewn by Kleinenberg, of an epithelial layer and a subepithelial interstitial layer of cells. The cells of the former are frequently produced into muscular or nervous tails, and those of the latter give rise to the thread-cells and generative organs and in some cases to muscles ${ }^{1}$. In many cases, amongst all the Cœlenterate groups, and constantly amongst the Ctenophora the epiblast is simplified and reduced to a single layer. The hypoblast undergoes in most cases no such differentiation but simply forms a glandular layer lining the gastric chamber and its prolongations into the tentacles; but in the Actinozoa it appears to give rise to muscles, and strong evidence has been brought forward to shew that in some groups it gives rise to the generative organs.

Between the epiblast and hypoblast a structureless lamella appears always to be interposed.

1 The questions relating to the generative organs of the Colenterata are dealt with in the second part of this work. 
In many Colenterata further differentiations of the epiblast are present. In many forms the layer gives rise to a hard external skeleton. This is most widely spread amongst the Hydrozoa, where in the majority of cases it takes the form of the horny perisarc, and in the Hydrocoralla (Millepora and Stylasteridæ) of a hard calcareous skeleton. The skeleton in these forms, though closely resembling the mesoblastic skeleton of the Actinozoa, has been shewn by Moseley (164) to be epiblastic.

In the Actinozoa an epiblastic skeleton is exceptional, and according to most authorities absent. Quite recently however Koch (167) has found that the axial branched skeleton of most of the Gorgonidæ, viz. the Gorgoninæ and Isidinæ, is separated from the conosarc by an epithelium, which he believes to be epiblastic, and to which no doubt the axial skeleton owes its origin. A similar epithelium surrounds the axis of the Pennatulidæ.

In the Medusæ the epiblast also gives rise to a central nervous system, which however continues to form a constituent part of the layer, and to the organs of special sense'.

A special differentiation of the hypoblast is found in the solid axis of the tentacles. This axis replaces the gastric prolongation found in many forms, and the cells composing it differentiate themselves into a chorda-like tissue, which has a skeletal function, and is no longer connected with nutrition. This axis is placed by many morphologists amongst the mesoblastic structures.

In all the higher Coelenterata certain tissues become interposed between the epiblast and hypoblast, which may be classified together as the mesoblast.

The most important of these are

(I) The various distinct muscular layers.

(2) The gelatinous tissue of the Medusæ and Ctenophora.

(3) The skeletogenous tissue of the Actinozoa.

In most cases the muscular fibres are connected with epithelial cells, but in certain forms amongst the Medusæ and in the majority if not all the Actinozoa they constitute a distinct layer, sometimes separated from the epiblast by a structureless mem-

1 The differentiation of the nervous and muscular systems in the Hydrozoa is treated of in the second part of this work. 
brane, Equorea Mitrocoma. Such layers when on the outer side of the membrane separating epiblast and hypoblast are undoubtedly epiblastic in origin, but in some cases amongst the Actinozoa they adjoin the hypoblast, and are very probably derived from this layer.

The origin of the gelatinous tissue is still involved in much obscurity.

It originates as a homogeneous layer between epiblast and hypoblast, which in the Hydromedusx never becomes cellular though traversed by elastic fibres.

In the Acraspeda it contains anastomosing cells in the main apparently (Claus) derived from the hypoblast, and in the Ctenophora it is richly supplied with muscular stellate cells for the most part of epiblastic origin, though some are stated by Chun to come from the hypoblast. On the whole it seems probable, that the gelatinous tissue may be regarded as a product of both layers; and there are some grounds for thinking that it is an immense development of the membrane always interposed between the two primary layers. It must however be borne in mind that a membrane, regarded by the Hertwigs as the equivalent of the ordinary membrane between the epiblast and hypoblast, can be usually demonstrated on both surfaces of the gelatinous tissues in Medusæ. The skeletogenous layer of the Actinozoa is probably the morphological homologue of the gelatinous tissue; but the evidence we have is on the whole in favour of the connective-tissue cells it contains being epiblastic in origin. It gives rise to the skeleton of the Hexacoralla, to the spicular skeleton of Alcyonium, the axial skeleton of Corallium, and the skeleton of the Helioporidæ and Tubiporidæ.

\section{Alternations of generations.}

Alternation of generations is of common occurrence amongst the Hydrozoa, and something analogous to it has been found to take place in Fungia amongst the Actinozoa. It is not known to occur in the Ctenophora.

The chief interest of its occurrence amongst the Hydromedusæ and Siphonophora is the fact that its origin can be 
traced to a division of labour in the colonial systems of zooids so characteristic of these types.

In the Hydromedusæ an interesting series of relations between alternation of generations and the division of the zooids into gonophores and trophosomes can be made out. In Hydra the generative and nutritive functions are united in the same individual. The generative swellings in these forms cannot, as has been ably argued by Kleinenberg, be regarded as rudimentary gonophores, but are to be compared to the generative bands developed in the Medusæ around parts of the gastro-vascular system. A condition like that of Hydra, in which the ovum directly gives rise to a form like its parent, is no doubt the primitive one, though it is not so certain that Hydra itself is a primitive form. The relation of Hydra to the Tubularidx and Campanularidæ may best be conceived by supposing that in Hydra most ordinary buds did not become detached, so that a compound Hydra became formed; but that at certain periods particular buds retained their primitive capacity of becoming detached and subsequently developed generative organs, while the ordinary buds lost their generative function.

It would obviously be advantageous for the species that the detached buds with generative organs should be locomotive, so as to distribute the species as widely as possible, and such buds in connection with their free existence would naturally acquire a higher organization than the attached trophosomes. It is easy to see how, by a series of steps such as I have sketched out, a division of labour might take place, and it is obvious that the embryos produced by the highly organized gonophores would give rise to a fixed form from which the fixed colony would be budded. Thus an alternation of generations would be established as a necessary sequel to such a division of labour. To test the above explanation it is necessary to review the main facts with reference to alternations of generations amongst the Hydromedusæ.

Hydromedusæ ${ }^{1}$. In many instances amongst the Tubularidæ, Sertularidæ and Campanularidæ medusiform buds are produced which become detached and develop sexual organs.

1 For a full account of this subject the reader is referred to the beautiful memoir of Allman (No. 149). 
Such Medusæ are divided into two great groups, the Ocellata and Vesiculata, according to the characters of the marginal sense organs. In the Ocellata the sense organs have the form of eyes, and in the Vesiculata of auditory vesicles. The latter seem to be usually budded off from the Campanularia stocks, and the generative organs extend in folded bands over the radial canals. These bands have been regarded by Allman as composed of rudimentary gonophores, and he called the Medusæ which give rise to them blastochemes. He regards them as representing a more complicated type of alternation of generations with three instead of two generations in the series. The Hertwigs have brought what appear to me conclusive grounds for rejecting this view, and have demonstrated that the generative organs of these types resemble those of ordinary Medusæ.

In many forms the medusiform buds though fully developed do not become detached; whether detached or not they are known as phanerocodonic gonophores. In other forms again buds which begin as if they were going to form Medusæ never reach that condition but remain permanently in an undeveloped state. They have been called by Allman adelocodonic gonophores.

In all the above cases two generations at the least interpose between the successive sexual periods, viz.:-

( I) A trophosome produced directly from the ovum.

(2) A gonophore budded from this.

In a very large number of types the gonophores do not develop directly on the hydroid stem, but arise on specially modified zooids resembling rudimentary trophosomes which have been named blastostyles by Allman. On the sides of each blastostyle a series of gonophores usually becomes developed. The blastostyles either remain exposed as in all the Gymnoblastic or Tubularian Hydroids, or as in all the Calyptoblastic Hydroids (Sertularidæe and Campanularidæ) they become invested by a special case-known as the gonangium-which is formed of perisarc lined by epiblast. In the forms with blastostyles three generations interpose between the successive stages of sexual reproduction, (I) the trophosome developed directly from the ovum, (2) the blastostyle budded from this, (3) the gonophore budded from the blastostyle.

Such being the main facts, in order to prove that the existing condition of polymorphism amongst the Hydromedusæ is to be explained as hypothetically suggested above, it is still necessary to shew that (I) the free 
medusiform gonophores are really only modified trophosomes, or rather that the trophosomes and gonophores are both modifications of some common type, and (2) that the fixed so-called adelocodonic gonophores are retrograde derivatives of the free medusiform gonophores. Unless these points can be established it might be maintained that the Medusæ were special zooids, developed de novo and not by a modification of trophosome zooids. To demonstrate these propositions at length would carry me too far into the region of simple Comparative Anatomy, and I content myself with referring the reader to a discussion of the Hertwigs (No. 146, p. 62) where the first point appears to me fully established. With reference to the second point I will only say that the structure and development of the adelocodonic gonophores can only be explained on the assumption that they are retrograde forms of the phanerocodonic gonophores, and that the opposite view, that the phanerocodonic gonophores are derived from the adelocodonic, leads to a series of untenable positions.

The Trachymedusæ, as has been shewn above, develop directly. They are probably derived from gonophores in which the trophosome has disappeared from the developmental cycle.

To sum up, three types of development are found amongst the Hydromedusæ.

(I) No alternations of generations. Permanent form, a sexual trophosome. Ex. Hydra.

(2) Alternations of generations. Trophosome fixed, gonophore free or attached. Ex. Gymnoblastic and Calyptoblastic Hydroids, and Hydrocoralla.

(3) No alternations of generations. Permanent form, a sexual Medusa. Ex. Trachymedusæ.

Siphonophora. In the Siphonophora alternations of generations take place in the same way as in the Hydromedusæ, but the starting point appears to be a Medusa. The gonophores may remain fixed or become detached.

Acraspeda. With the exception of Pelagia and Lucernaria, in which the development involves a simple metamorphosis, all the Acraspeda undergo a form of alternations of generations. The ovum, as already described, develops into a fixed form-the Scyphistoma-which increases asexually by normal budding, and can even form a permanent colony.

The formation of the sexual Medusa form takes place by a kind of strobilization of the body of the fixed Scyphistoma. A series of transverse constrictions becomes formed round the body below the mouth, dividing it up into corresponding 
rings, each of which eventually gives rise to a Medusa known as an Ephyra (fig. 85). In each of these rings is a dilation of the stomach, and a section of each of the four rudimentary mesenteries described in connection with the development of the Scyphistoma. As the constrictions become deeper the segments of the body between them become disc-like, and their edges are produced into eight lobes containing prolongations of the gastric cavity (fig. $85 \mathrm{C}$ ). The lower surface of each disc, which forms the future aboral surface of the Medusa, becomes convex, in part owing to the development of gelatinous tissue. On the opposite surface a muscular layer becomes developed. During the above process the body of the Scyphistoma gradually grows in length and continues to be segmented, so that a series of Ephyræ are uninterruptedly formed, of which those near the base are the youngest. The original terminal ring of tentacles of the Scyphistoma gradually atrophies.

In the further development of the Ephyræ each of their eight lobes becomes bifid at its extremity.

As the Ephyræ successively reach this condition they become detached, and by a series of remarkable changes, amounting almost to a metamorphosis, and accompanied by an enormous growth in size, reach the adult condition.

The alternation of generations in the Acraspeda cannot be quite so simply explained as in the Hydromedusæ, though the principle is probably the same in the two cases.

Actinozoa. Amongst the Actinozoa there occurs in Fungia a peculiar process which is, as shewn by Semper (171), in many ways analogous to alternations of generations ${ }^{1}$. From the larva a nurse-stock is developed, at the end of which a cup-like coral

1 Vide also Moseley. Notes by a Naturalist of the Challenger, pp. 524 and 525 . 
resembling the adult is formed as a bud. The bud becomes detached and then gives rise to a permanent sexual Fungia. From the nurse-stock there is formed however a fresh bud at the centre of the scar left on the detachment of the old one. The fresh bud eventually becomes separated from the nurse-stock leaving a small portion of its stem behind; each succeeding bud similarly leaves a small portion of its stem, so that the nursestock eventually acquires a jointed appearance. In the above process we clearly have, as in the Hydromedusæ, a non-sexual form-the nurse-stock-produced directly from the larva, giving rise by budding to a sexual form; all the conditions of an alternation of generations are therefore fulfilled. It seems however possible that the nurse-stock itself may eventually become sexual.

\section{BIBLIOGRAPHY.}

\section{Colenterata. General.}

(145) Alex. Agassiz. Illustrated Catalogue of the Museum of Comparative Anatomy at Harvard College, No. Ir. American Acalepha. Cambridge, U. S., i 865.

(146) O. and R. Hertwig. Der Organismus d. Medusce u. seine Stellung z. Keimbliattertheorie. Jena, 1878 .

(147) A. Kowalevsky. "Untersuchungen ïb. d. Entwicklung d. Coelenteraten." Nachrichten d. kaiser. Gesell. d. Freunde d. Naturer kenntniss d. Anthrofologie u. Ethnographie. Moskau, 1873. (Russian.) For abstract vide Fahresberichti d. Anat. u. Phys. (Hoffman u. Schwalbe), 1873 .

\section{Hydrozoa.}

(148) L. Agassiz. Contributions to the Natural History of the United States of America. Boston, i862. Vol. iv.

(149) G. J. Allman. A Monograph of the Gymnoblastic or Tubulurian Hylloids. Ray Society, I871-2.

(150) G. J. Allman. "On the structure and development of Myriothela." Phil. Trans., Vol. Clxv. p. 2.

(151) P. J. van Beneden. "Mém. sur les Campanulaires de la Côte d'Ostende considérés sous le rapport physiologique, embryogénique, et zoologique." Nozr. Mém. de l'Acad. de Brux., Tom. xviI. 1844 .

(152) P. J. van Beneden. "Recherches sur l'Embryogénie des Tubulaires et I'histoire naturelle des différents genres de cette famille qui habitent la Côte d'Ostende." Nouv. Mém. de l'Acad. de Brux., Tom. xvir. I 844 .

(153) C. Claus. "Polypen u. Quallen d. Adria." Denk. d. math.naturwiss. Classe d. k. k. Akad.d. Wiss. Wien, Vol. xxxvi11. 1877. 1847 .

(154) J. G. Dalyell. Rare and Remarkable Animals of Scotland. London,

(155) H. Fol. "Die erste Entwicklung d. Geryonideneies." Fenaische Zeitschrift, Vol. VII. I873.

(156) Carl Gegenbaur. Zur Lehre vom Generationswechsel und der Fortfflanzung bei Medusen und Polypen. Würzburg, 1854 . 
(157) Thomas Hincks. "On the development of the Hydroid Polypes, Clavatella and Stauridia; with remarks on the relation between the Polype and the Medusoid, and between the Polype and the Medusa." Brit. Assoc. Rep., $186 \mathrm{I}$. 1869 .

(158) E. Haeckel. Zur Entwicklungsgeschichte d. Siphonophoren. Utrecht,

(159) Th. H. Huxley. Oceanic Hydrozoa. Ray Society, 1858.

(160) Geo. Johnston. A History of British Zoophytes. Edin. 1838. and Edition, 1847 .

(161) N. Kleinenberg. Hydra, eine anatomisch-entwicklungsgèschichtliche Untersuchung. Leipzig, I 872 .

(162) El. Metschnikoff. "Ueber die Entwicklung einiger Cœlenteraten." Bull. de l'Acall. de St Pétersbourg, xv. i 870.

(163) El. Metschnik off. "Studien über Entwicklungsgeschichte d. Medusen u. Siphonophoren. Zeit.f. wiss. Zool., Bd. xxiv. 1874 .

(164) H. N. Moseley. "On the structure of the Stylasteridæ." Phil. Trans. ז 878 .

(165) F. E. Schulze. Ueber den Bau und die Entwicklung von Cordylophora lacustris. Leipzig, 1871 .

\section{Actinozoa.}

(166) Al. Agassiz. "Arachnitis (Edwarsia) brachiolata." Proc. Boston Nat. Hist. Society, 1860 .

(167) Koch. "Das Skelet d. Alcyonarien." Morpholog. Fahrbuch, Bd. Iv. 1878 .

(168) A. Kowalevsky. "Z. Entwicklung d. Alcyoniden, Sympodium coralloides und Clavularia crassa." Zoologischer Anzeiger, No. 38, 1879.

(169) H. Lacaze Duthiers. Histoire nat. du Corail. Paris, 1864.

(170) H. Lacaze Duthiers. "Développement des Coralliaires." Archives de Zoologie expérincntale et générale, Vol. I. I872 and Vol. II. 1873.

(171) C. Semper. "Ueber Generationswechsel bei Steinkorallen etc." Zeit. f. wiss. Zool., Bd. Xxi1. Is 72 .

\section{Ctenophora.}

(172) Alex. Agassiz. "Embryology of the Ctenophore." Mem. of the Amer. Acad. of Arts and Sciences, Vol. x. No. I I I. 1874.

(173) G. J. Allman. "Contributions to our knowledge of the structure and development of the Beroidæ." Proc. Roy. Soc. Edinburgh, Vol. IV. I862.

(174) C. Chun. Das Nervensystem u. die Musculatur d. Rippenquallen." Abhand. d. Senkcnberg. Gesellsch., B. xi. I879.

(175) C. Claus. "Bemerkungen u. Ctenophoren u. Medusen." Zeit. f. wiss. Zool., xiv. 1864 .

(176) H. Fol. Ein Beitrag z. Anat. u. Entwickl. einiger Rippenquallen. 1869.

(177) C. Gegenbaur. "Studien ï. Organis. u. System d. Ctenophoren." Archiv f. Naturgesch., xxir. i 856.

(178) A. Kowalevsky. "Entwicklungsgeschichte d. Rippenquallen." Mém. Acad. St Pétersbourg, vir. série, Tom. x. No. 4. 1866. I 8 46.

(179) J. Price. "Embryology of Ciliogrades." Proceed. of British Assoc.,

(180) C. Semper. "Entwicklung d. Eucharis multicornis." Zeit. f. wiss. Zool., Vol. Ix. 1858 . 


\section{CHAPTER VII.}

\section{PLATYELMINTHES ${ }^{\circ}$.}

TURBELLARIA.

Although there is perhaps no group in the animal kingdom the ontogeny of which would better repay a thorough investigagation than the Turbellarians, yet the difficulties to be overcome have hitherto proved too great.

The fresh-water Rhabdocœla and Dendrocœla do not undergo any metamorphosis, and leave the ovum in a condition in which they cannot easily be distinguished in their general appearance from Infusoria. Many marine Dendrocœla also develop directly, while, as was first shewn by Joh. Muiller, other marine Dendrocœla undergo a more or less complicated metamorphosis.

Marine Dendrocœla. Of the marine Dendrocœla which do not undergo a metamorphosis the form most fully worked out is Leptoplana tremellaris-(vide Keferstein, No. 187, and Hallez, No. 185).

The ova are surrounded by large albuminous capsules secreted by a special gland. They are laid a great number at a

I. Turbellaria.

I. Dendrocœla.

2. Rhabdocœla.

II. Nemertea.

I. Anopla.

2. Enopla.

III. Trematoda.

I. Distomeæ.

2. Polystomex.

IV. Cestoda. 
time, and adhere together so as to form masses not unlike the spawn of nudibranchiate Molluscs.

Within the egg-capsule the ovum floats freely and undergoes a segmentation similar in many respects to the characteristic molluscan type. The ovum divides into two, and then into four parts, from each of which a small segment is then separated off. The four small segments, which appear to give rise to the epiblast, increase in number by division and gradually envelop the large segments ${ }^{1}$; so that an epibolic invagination clearly takes place. Between the small and the large cells is a small segmentation cavity, fig. $86 \mathrm{~A}$ and $\mathrm{B}$. At the time when twelve epiblast cells are present, each of the four large cells divides into two unequal parts (Hallez), fig. $86 \mathrm{~A}$. In this way four large (hy) and four small cells $(m)$ are formed. The latter are placed at the opposite pole of the ovum to the epiblast cells, and give rise to the mesoblast, while the four large cells remain as the hypoblast.

In the course of the enclosure of the hypoblast cells by the
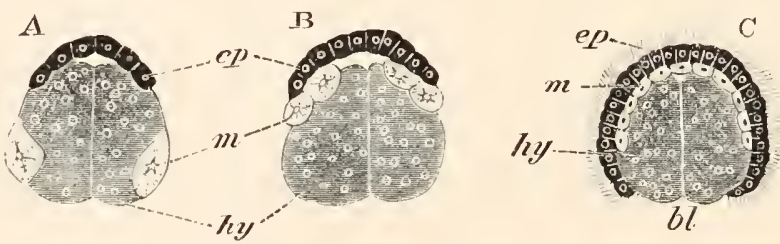

Fig. 86. Sections THROUgh THE OVUM OF LePTOPLANA TREMELLARIS IN THREe StAGES OF DevelopMeNT. (After Hallez.)

$c p$. epiblast ; $m$. mesoblast; hy. yolk cells (hypoblast); $b l$. blastopore.

epiblast, the mesoblast cells gradually travel towards the formative pole (fig. $86 \mathrm{~B}$ ). In the process they become first of all divided so as to form four linear streaks, and finally unite into a continuous layer between the epiblast and hypoblast, which obliterates the segmentation cavity (fig. $86 \mathrm{C}, \mathrm{m}$ ).

Before the completion of the epibole a closely packed layer of fine cilia appears, which causes a rotation of the embryo within the egg-capsule. During the above changes a fifth hypoblast cell is formed by the division of one of those already present; and at a later period four of the hypoblast cells give rise within

1 It is probable, though it has not been observed, that the growth of the layer of small cells is assisted by the formation of fresh cells from the hypoblast spheres. 
the nearly closed blastoporic area to four small cells. In connection with these cells a complete hyploblastic wall becomes subsequently established, which encloses the original large hypoblast cells. The latter then become resolved into a vitelline mass.

From a comparison with other types it may be regarded as probable that the enteric wall originates by a process of continuous budding off of small cells from the large cells, which commences with the formation of the four cells above mentioned.

The blastopore becomes nearly obliterated, but whether it gives rise to the mouth, which is formed in the same place, has not been determined. In front of the mouth a small and very transitory rudiment of an upper lip makes its appearance. The protrusible pharynx is stated by Hallez to arise as an hypoblastic bud, while its sheath has an epiblastic origin. Two pairs of eyes and the supra-œsophageal ganglia also become early developed.

The peripheral ciliated layer of small cells becomes divided into two strata, of which the outer remains ciliated and forms the true epiblast: the inner probably forms the cutis. In it are developed rod-like bodies, which seem to be homologous with the thread cells of the Cœlenterata, so that if the views put forward in the previous chapter as to the similarity of the turbellarian and cœlenterate larvæ are correct, the cutis corresponds with the deeper layer of the cœlenterate epiblast. The mesoblast, like the epiblast, becomes divided into two strata. The outer one is stated to form the circular and longitudinal muscles; the inner one to give rise to a muscular reticulum, the spaces within which constitute the parenchymatous body cavity.

The later changes are not of great importance. At a period slightly after the formation of the mouth and ganglia two pairs of stiff hairs become formed at the sides of the body. The embryo has by this time grown so as to fill up its capsule, in which however it continues rapidly to rotate, and also commences to exhibit active contractions. It next becomes hatched, and passes from a spherical to a flattened elongated form. The ventral oral opening is at first central, but soon, by a process of unequal growth, becomes carried towards the posterior end of the body. The pairs of stiff hairs in the meantime considerably increase in number. The remains of the yolk cells now disappear, and the enteric walls become more distinct. The alimentary canal, which is at first simple in outline like that of a rhabdocœlous Turbel- 
larian, soon assumes a dendritic form. The young animal after these changes resembles its parent, except in the possession of only two pairs of eyes and in the absence of generative organs.

Of the types with a complete metamorphosis the free larvæ of various species of Thysanozoon have been observed by Joh. Müller (190) and Moseley (189), and the complete development of Eurylepta auriculata has been studied by Hallez.

The stages within the egg of this latter type agree precisely with those already described in Leptoplana. After the formation of the mouth the body elongates, remaining however cylindrical. A fold forms on the anterior side of the mouth, giving rise to a large upper lip. Two posterior processes are next formed, and other processes soon arise, constituting the whole of those found in the free

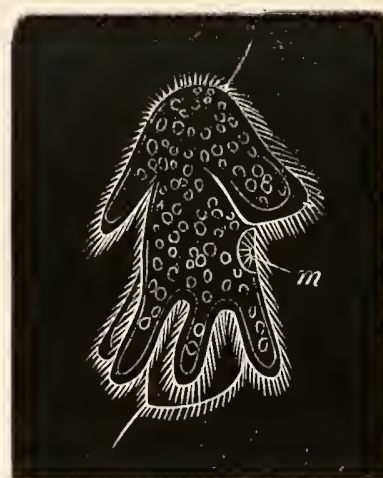

Fig. 87. LaRVa of EURYLEPTA AURICULATA IMMEDIATELY AFTER HATCHING. VIEWED FROM THE SIDE. (After Hallez.)

$m$. mouth.

larva. The embryo next shakes off its egg membranes by a series of vigorous contractions. When free it has the form represented in the annexed figure (fig. 87 ).

It is so similar to Müller's (fig. 88) and Moseley's larvæ that all three may be dealt with together.

The body is somewhat oval, and slightly pointed behind. At the anterior end are placed the eyes, two in the youngest larva of Müller, and twelve in the older larva (fig. 88), and in the middle of the ventral surface is the mouth. It is surrounded by a strong fold, and leads into an alimentary canal, which is at first simple, but in the older larvæ is much branched. A bilobed ganglion connected with two nerve cords is placed anteriorly. The superficial epithelium is ciliated, and below it is a layer of cells (cutis) derived from the primitive epiblast, in which are formed the usual rods (Hallez). The chief peculiarity of the larva consists in the presence of elongated processes covered with long cilia, and so connected together by a ciliated band that the whole together forms, in Müller's larva at any rate, $a$ 
lobed preoral ciliated band (fig. 8S). This band is not quite so clear in Hallez' figures. Müller's youngest larva was provided with eight very long lobes; three were dorsal, viz. a median anterior, and two lateral placed far back; three ventral, viz. a median in the front of the mouth forming a large upper lip, and two processes at the sides of the mouth. The number was completed by two lateral processes of the body. All the processes except the dorsal median one are shewn in fig. 88 . In Hallez' larva, fig. 87 , the six posterior processes form a rather definite ring, while one flagellum projects from the front end of the body immediately below the eyes, and a second flagellum behind. In Moseley's youngest larva six processes only were present, though subsequently eight became formed as in Müller's larvæ.

The metamorphosis consists in the whole animal growing longer and flatter, and in the arms becoming gradually shorter and shorter till they finally disappear altogether, and the larva acquires the ordinary adult form.

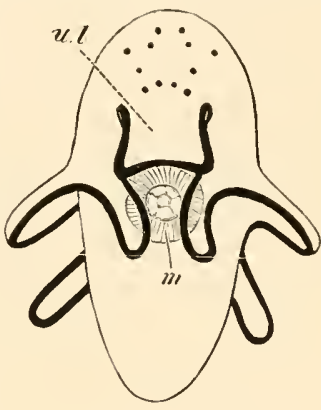

Fig. 88. Muller's TurBELLARIAN LARVA (PROBABLY THYSANOZOON). VIEWED FROM THE VENTRAL SURFACE. (After Miiller.)

The ciliated band is represented by the black line. lip.

The lobed larval form of the Turbellaria has some points of resemblance to the Pilidium form of nemertine larva described below, yet its resemblance to this interesting larva is less close than would appear to be the case with certain turbellarian larval forms recently described by Götte and Metschnikoff, which are in some respects intermediate in character between the larva of Leptoplana and those just described.

The observations of Götte (No. 184) were made on Planaria Neapolitana and Thysanozoon Diesingi, and those of Metschnikoff (No. 188) on Stylochopsis ponticus. The larvæ of all these forms undergo more or less of a metamorphosis, but the accounts of their development are not easily reconciled ${ }^{1}$. The early stages of Planaria are like those of Leptoplana, as

1 The accuunt of Metsclınikoff's observations on Stylochopsis ponticus given in the German abstract is too obscure to be placed in the text, but the following are the more important points which can be gleaned from it.

The ovum becomes first divided into eight segments. By further division along the equatorial zone, a ring of small cells is formed which becomes the epiblast. The

B. II. 
described by Keferstein. Four large hypoblast cells become surrounded by small epiblast cells, which commence to be formed on the dorsal side. The hypoblast cells divide and arrange themselves in two bilaterally-symmetrical rows. A small blastopore is left by the small cells on the ventral surface, which communicates with an otherwise closed and ciliated cavity which is formed between the two rows of hypoblast cells. The blastopore would seem to remain permanently open, and to be placed at the base of a deep pit, lined by epiblast cells, which constitutes the stomodæum.

The embryo now becomes dorsally convex, while the ventral surface becomes marked with a median furrow and grows out laterally into two lobes, and anteriorly into a ventrally-directed upper lip. The whole surface becomes ciliated, and the cilia are especially prominent on the ventral processes and the summit of the dorsal dome. A bunch of strong cilia becomes formed in front of the dome, and a less marked bunch behind. The larva is now stated by Götte closely to resemble a Pilidium. It soon, however, extends itself, and the two bunches of cilia become situated at the anterior and posterior extremities of the body. The ventral processes become inconspicuous prominences of the side of the body. Götte believes that the larva undergoes no further metamorphosis.

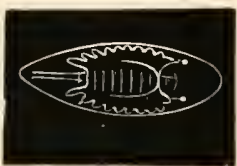

Fig. 89. Plana. RIAN LARVA (PROBABLY PLANARIA ANGUlata). (From Agassiz.)

A type of Planarian larva (figs. 89 and 90)-possibly Plan. angulata, observed by Alex. Agassiz (No. 181),-is very different from any other so far described, and is remarkable for being divided into a series of segments corresponding in number with the diverticula of the digestive cavity. In the youngest specimen (fig. 89) the body was nearly cylindrical, and divided into eleven rings, corresponding with as many digestive diverticula. Two eye-spots were present. In a later stage

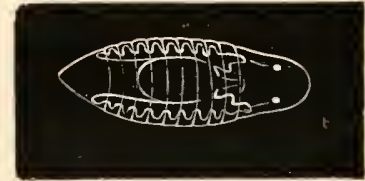

F1G. 90. Planarian larva (IROBAbly PlanaRla ANgUL.1TA). (From Agassiz.)

two poles are at this time formed of large cells. At one pole four small cells appear, which are compared by Metschnikoff to the pole cells of the Diptera (vide Chapter on the development of the Insecta). At the opposite pole a blastopore is formed leading into a small segmentation cavity. The epiblast also now gradually grows over the large cells. At the blastopore pole the large cells give rise to the hypoblast and the small cells at the opposite pole assist in forming the epiblast. The blastopore disappears, and with it the segmentation cavity, while the hypoblast, forming a solid mass, becomes divided into two halves (Cf. Planaria Neapolitana). The embryo becomes ciliated and begins to rotate; and the eyes, and somewhat later (?) the nervous ganglion make their appearance.

In the interior a wide cavity develops between the hypoblast cells, which becomes ciliated and is placed in communication with the exterior by an invaginated stomadxum which forms the pharynx.

The larva now, as in I'lanaria Neapolitana, takes on a Pilidium-like form. Lateral lobes and an anterior lip grow out from the under surface, and become covered with long cilia, while at the upper pole a long flagellum makes its appearance. 
(fig. 90) the body was considerably flattened and had approached more to the planarian form.

If Agassiz' interesting observations can be trusted we have in this larva indications of a distinct segmentation, which are of some morphological importance, especially when taken in connection with the traces of segmentation found amongst the Nemertines.

A further type, with an incomplete metamorphosis, has been observed by Girard (183). It is remarkable for having an uniform,segmentation, and for presenting a quiescent stage after passing through a free larval condition with a large upper lip.

Fresh-water Dendrocœla. The development of the freshwater Dendrocœla has been especially investigated by Knappert (No. 186) and Metschnikoff (No. 188).

The ova are very delicate minute naked cells, which to the number of 4-6 or more become enveloped in a capsule or cocoon together with a large mass of yolk cells derived from the vitellarium. The yolk cells exhibit peristaltic movements and send out amoboid processes. Each ovum when laid becomes surrounded by an extremely delicate membrane, which disappears during the course of development. The capsules consist of a spherical case and a stalk. The latter is first emitted from the female opening as a thread-like body. Its free end becomes attached, and then the remainder of the capsule is ejected.

Impregnation takes place before the formation of the capsule. The segmentation is complete. The ovum first divides into two segments. One of these next divides, forming three segments. There are subsequently stages with four, eight, sixteen, and thirty-two segments.

Metschnikoff's results on the stages subsequent to the segmentation are not in complete harmony with those of Knappert; but no doubt represent an advance in our knowledge, and I shall follow them here. His observations were made on Planaria polychroa.

In the earliest stage observed by him the segmentation was already far advanced, but no membrane was present round the ovum. At a later stage the ovum becomes more or less bell-shaped or hemispherical, and encloses within its concavity a mass of yolk elements. It is now formed of three concentric layers. An outer layer of flattened cells-the epiblast, a middle layer of fused cells-the mesoblast, and an inner solid mass of yolk cellsthe hypoblast.

At the upper pole is formed the protrusible pharynx (cf. Knappert), which is provided with a provisional musculature and a lumen. By its contractions it takes up the yolk elements which surround the embryo, and the rapid growth of the embryo no doubt takes place at their expense. The embryo 
gradually loses its hemispherical form, and assumes an elongated and flattened shape. It acquires a coating of cilia by means of which it rotates. On the fifth day it is hatched.

The alimentary tract long remains solid, even after it has acquired its branched form. The pharynx becomes withdrawn as soon as the larva is hatched. It loses its provisional muscles, and subsequently acquires a permanent musculature. The young after hatching attach themselves to the body of their parent, on which they feed (?).

Rhabdocœla. The development of some of the Rhabdocœla has recently been studied by Hallez. The ova are mostly laid in capsules, one in each capsule. Sometimes the development commences before the capsules are laid, at other times not till afterwards. In certain forms (Mesostomum) there are summer eggs with thin capsules which develop within the parent, while hard capsules, forming what are known as winter eggs, are laid in the autumn, and the embryo hatched in the spring.

The ova of the Rhabdocola like those of the fresh-water Dendrocœla are enveloped in yolk elements derived from the vitellarium.

The segmentation probably takes place in the same way as in Leptoplana. A stage with four equal cells has been observed by Hallez, and there is subsequently an epibolic gastrula. The embryo becomes ciliated while still within the capsule and, according to Hallez, the pharynx arises as a bud of the hypoblast. The proboscis in Prostomum originates as an epiblastic invagination.

\section{NEMERTEA.}

Some Nemertea develop without and some with a metamorphosis.

The most remarkable type of Nemertine development with a metamorphosis is that in which the ovum develops into a peculiar larval form known as Pilidium, within which the perfect worm is subsequently evolved. Closely allied to this type is one in which the sexual worm is developed within a larval form as in Pilidium, but in which the larva has no free swimming stage, and is therefore without the characteristic appendages of the Pilidium. This is known as the type of Desor and is confined (?) to the genus Lineus. The Pilidium and the Desor type may be first considered (vide Barrois, No. 192).

The type of Desor. The segmentation is regular and leads to the formation of a blastosphere with a large segmentation 
cavity. The blastosphere is converted by invagination into a gastrula (fig. 9I A). The blastopore is soon carried relatively

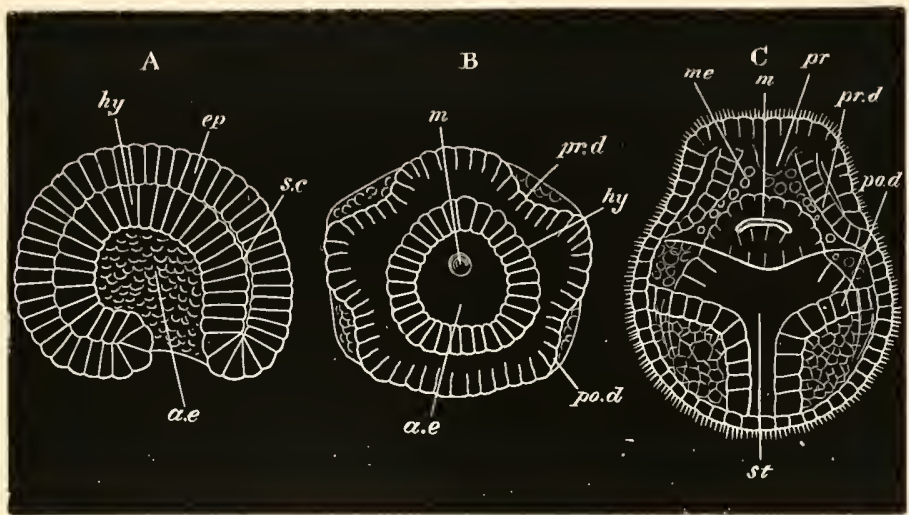

Fig. 9i. Three stages in the development of Lineus. (After Barrois.)

$A$ is a side view in optical section.

$\mathrm{B}$ and $\mathrm{C}$ are two later stages from the ventral (oral) surface.

$a e$. archenteron ; sc. segmentation cavity; hy. hypoblast; me. mesoblast; ep. epiblast; m. mouth; st. stomach; pr.d. prostomial disc; po.d. metastomial disc; pr. proboscis.

forwards by the elongation backwards of the archenteron, and, according to Barrois, actually forms the mouth. Owing to the elongation of the archenteric cavity the embryo assumes a bilateral form (fig. $92 \mathrm{~A}$ ) in which the dorsal and ventral surfaces can be distinguished, the mouth ( $m$.) being situated on the ventral surface.

Immediately after the completion of the gastrula a remarkable series of phenomena takes place. The embryo when viewed from the ventral surface assumes a pentagonal form (fig. 9I B), and four invaginations of the epiblast make their appearance on the ventral surface (fig. $92 \mathrm{~A})$, two in front of (pr.d.) and two behind (po.d.) the month; they result in the formation of four thickened discs. These discs soon become separated from the external skin, which closes in forming an unbroken layer over them (fig. 9I C). The discs grow rapidly, and first the prostomial pair and subsequently the metastomial fuse together, and finally the whole four unite into a continuous ventral plate; analogous it would seem to the ventral plate of chrtopodan and 
arthropodan embryos. The plate so formed gradually extends itself so as to close over the dorsal surface, and to form a complete skin within the primitive larval skin, which at this period is richly ciliated, though the embryo is not yet hatched

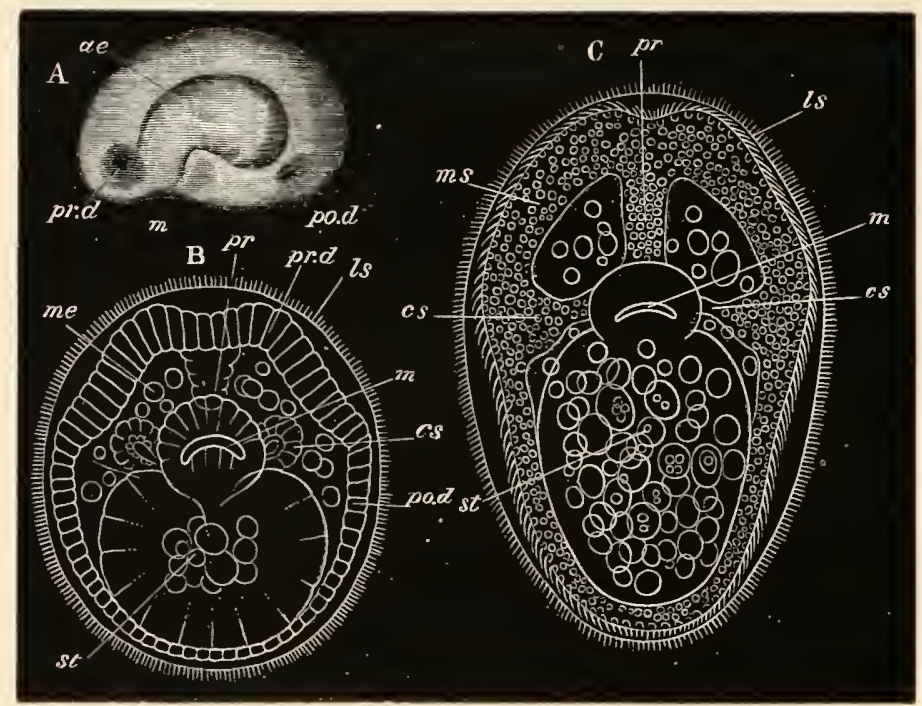

Fig. 92. Three stages in the Development of Lineus. (After Barrois.)

A. Side view of an embryo at a very early stage as an opaque object.

B and C. Two late stages, seen as transparent objects from the ventral surface.

ae. archenteron; $m$. mouth; pr.d. prostomial disc; po.d. metastomial disc; cs. lateral pit developing in $\mathrm{B}$ as a diverticulum from the oesophagus; $p$ r. proboscis ; ms. muscular layer (?); $7 s$. larval skin about to be thrown off; me. mesoblast; st. stomach.

(fig. 9I C). While these changes are taking place, there are budded off from the invaginated discs a number of fatty cells, which fill up the space between the discs and the archenteron, and eventually form the mesoblastic reticulum. During this stage the rudiment of the proboscis also makes its appearance as a solid process of epiblast, which grows backwards from the point of fusion of the two prostomial discs at the front end of the embryo (fig. $9 \mathrm{r} \mathrm{C}, p r$. .). A lumen is excavated in it at a later period. The lateral organs or cephalic pits arise in a somewhat unexpected fashion as a pair of diverticula from the 
œesophagus (fig. $92 \mathrm{~B}, c s.)^{1}$, which soon fuse with the walls of the body at the junction of the prostomial and metastomial plates (fig. $92 \mathrm{C}, c s$.), although they remain for some time attached to the cesophagus by a solid cord.

During these changes the original larval skin separates itself from the subjacent layer formed by the discs (fig. 92, B and C), and is soon thrown off completely, leaving the already cillated (fig. $92 \mathrm{C}$ ) external layer of the invaginated discs as the external skin of the young Nemertine. During, and subsequently to, the casting off of the embryonic skin, important changes take place in the constitution of the various layers of the body, resulting in the formation of the vascular system and other mesoblastic organs, the nervous system, and the permanent alimentary tract. These changes appear to me to stand in need of further elucidation; and the account below must be reccived with a certain amount of caution.

It has been already stated that the two discs give rise to fatty cells, which occupy the space between the walls of the body and the archenteron. At the period of the casting off of the embryonic skin fresh changes take place. The discs become very much thickened, and then divide into two layers, which become the epidermis and subjacent muscular layers. The muscular layers arise in two masses, separated by the two cephalic sacks. The anterior mass is formed as an unpaired anterior thickening, followed by two lateral thickenings. The posterior mass is much thinner, in correspondence with the rapid elongation of the metastomial portion of the embryo.

The cells originally split off from the discs undergo considerable changes, some of them arrange themselves around the proboscis as a definite membrane, which becomes the proboscidean sheath, some also form a true splanchnic layer of mesoblast, and the remainder, which are especially concentrated during early embryonic life in the anterior parts of the body, form the general interstitial connective tissue. The cephalic ganglia are stated to become gradually differentiated in the prostomial mesoblast, and the two cords connected with them in the metastomial mesoblast.

At the time when the larval skin is cast off the original mouth becomes closed, and it is not till some time afterwards that a permanent mouth is formed in the same situation. During the early part of embryonic life the intestine is lined with columnar cells, but, before the loss of the larval skin, the walls of the intestine undergo a peculiar metamorphosis. Their cells either fuse or become indistinguishable, and their protoplasm appears to become converted into yolk-spherules, which fill up the whole space within

1 Buitschli for Pilidium regards these pits as formed by invaginations of the epiblast, but Metschnikoff's statements are in accordance with those in the text. 
the walls of the body, and are only prevented from extending forwards by a membrane of connective tissue. This mass gradually forms itself into a distinct canal, lined by columnar cells.

Pilidium. In the case of the true Pilidium type, the larva is hatched very early and leads the usual existence of surface larva. A regular segmentation is followed by an invagination which does not however cause the complete obliteration of the segmentation cavity (fig. 93 A, a.e.).

The primitive alimentary tract so formed becomes divided into œsophageal and gastric regions (fig. $93 \mathrm{~B}, o e$. and st.). Even while the invagination of the archenteron is proceeding, the larva becomes ciliated throughout, and assumes a somewhat conical form, the apex of the cone being opposite the flat ventral surface on which the mouth is situated (fig. 93, A and B). From

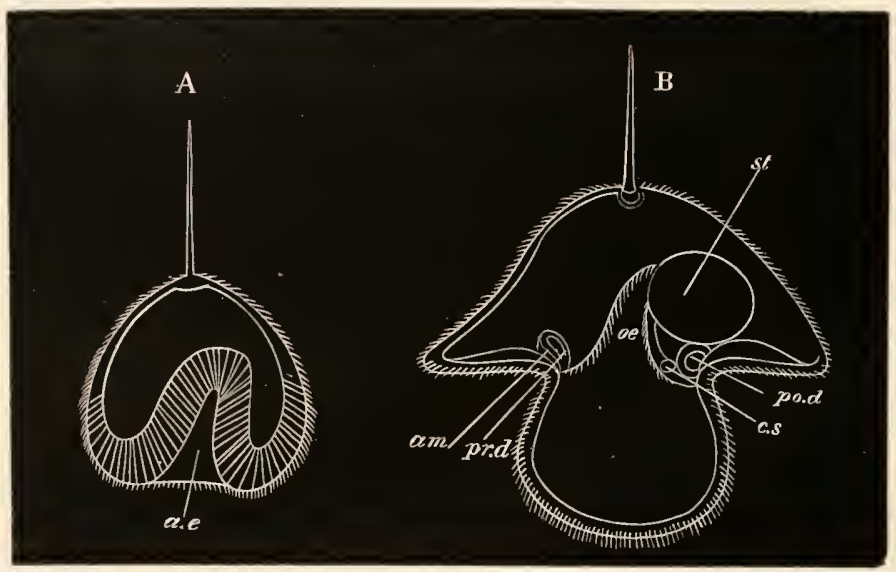

Fig. 93. Two stages in the development of Pilidium. (After Metschnikoff.)

$a \ell$. archenteron ; $a$. œesophagus; st. stomach ; am. amnion ; pr.d. prostomial disc; po.d. metastomial disc; c.s. cephalic sack.

the apex a flagellum projects in many forms, giving the larva a helmet-like appearance. In other forms a bunch of long cilia takes the place of the flagellum (fig. 94), and in others again the flagellum is not represented. After the completion of the invagination a lobe grows out on each side of the mouth, and less well developed lobes may appear anteriorly and posteriorly. Round the edge of the ventral surface a ciliated band makes its appearance. 
Two pairs of invaginations of the skin, just as in the type of Desor, now make their appearance, one pair in front of and the other behind the mouth (fig. $93 \mathrm{~B}$, pr.d. and po.d.), and each of them by the closure of the opening of invagination forms a sack, the outer wall of which becomes very thin and the inner wall (corresponding with the whole invagination of the type of Desor) very thick. The inner walls of the four thickenings, which I may speak of as discs, now fuse together, each disc first uniting with its fellow, and finally the two pairs uniting.

A ventral germinal plate is thus established, which gradually grows round the intestine of the Pilidium to form the skin of the future Nemer-

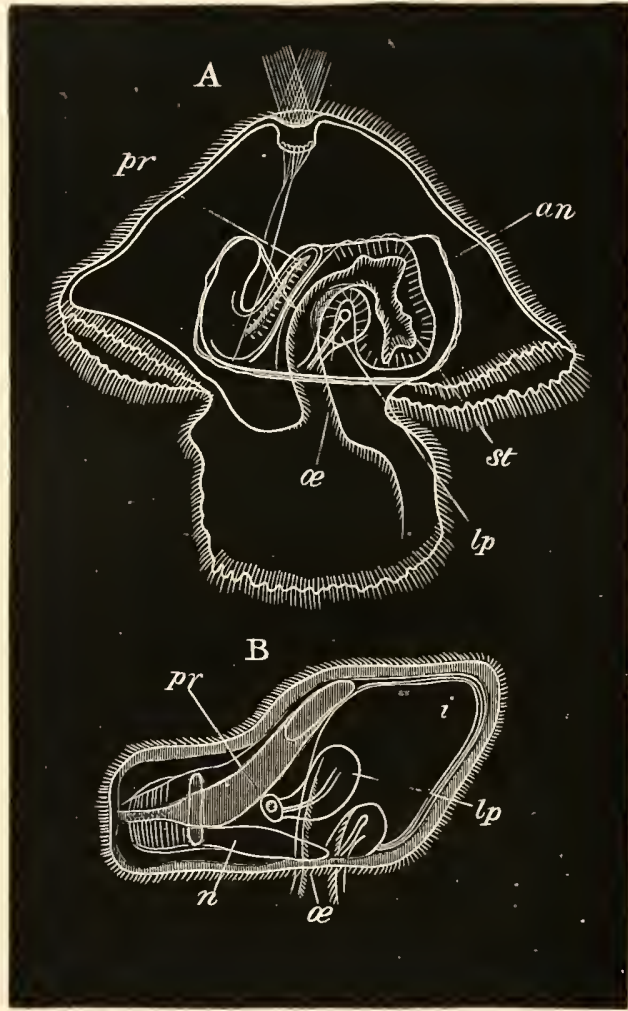

FIG. 94.

A. Pilidium with an advanced nemertine WORM.

B. Ripe embryo of the Nemertea in the position it occupies in Pilidium. (Both after Biitschli.)

$a$. œsophagus; st. stomach ; $i$. intestine; pr. protine. The outer boscis; $l p$. lateral pit; $a n$. amnion; $n$. nervous system. thin layer of each of the discs grows pari passu with the inner layer, and furnishes an amnion-like covering for the embryo which is forming within the Pilidium (fig. 94, an).

In connection with the young vermiform Nemertine there is formed on each side an outgrowth from the œsophagus (fig. 94) which is eventually placed in communication with the exterior 
by a ciliated canal ${ }^{1}$. The proboscis arises as an hollow invagination at the point where the two anterior discs fuse in front.

When the young Nemertine has become pretty well formed within the Pilidium it becomes ciliated, begins to move, and eventually frees itself and leads an independent existence, leaving its amnion in the Pilidium which continues to live for some time.

The central nervous system (fig. 94) is developed either before or after the detachment of the young Nemertine, according to Metschnikoff as a thickening of the epiblast. The young Nemertine is at first without an anus.

The development of the Nemertine within the Pilidium is clearly identical with that of the Lincus embryo within the larval skin; the formation of an amnion in the Pilidium constituting the only important difference which can be pointed out between the modes of origin of the young Nemertine in the two types.

So far as is known the forms which develop in a Pilidium, or according to the type of Desor, all belong to the division of the Nemertines without stylets in the proboscis, known as the Anopla.

Development without Metamorphosis. The majority of the Nemertea, including the whole (?) of the Enopla, develop without a metamorphosis. The observations which have been made on this type are not very satisfactory, but appear to indicate that the formation of the hypoblast may take place either by invagination or by delamination.

Invaginate types have been observed by Barrois (No. 192), Dieck (No. 196) and Hubrecht.

Barrois' fullest observations were made on Amphiporus lactifloreus (one of the Enopla), and those of Dieck on Cephalothrix galathece (one of the Anopla).

A regular segmentation is followed by a blastosphere stage with a small segmentation cavity. In Barrois' type the inner ends of the cells of the blastosphere are stated to fuse into a kind of syncytium. A small invagination takes place, and the cells which take part in it separate from the

1 This is the view of both Metschnikoff (No. 202) and Leuckart and Pagenstecher (No. 201), and is further confirmed by Barrois, but Bütschli (No. 193), though he has not observed the earliest stages of their outgrowth, believes them to be invaginations of the Nemertine skin. 
epiblast, and then fuse with the syncytium within the blastosphere. Dieck finds that in Cephalothrix the invaginated mass simply vanishes.

Barrois' statements about the fusion of the syncytium derived from the epiblast cells with the invaginated cells must be regarded as very doubtful. The formation of the germinal layers takes place, according to Barrois, by the separation of the internal mass of cells into mesoblast and hypoblast. The proboscis is formed, according to this author, from the mesoblastic tissues. Dieck, on the other hand, with greater probability, states that the proboscis is formed by an invagination. In Cephalothrix a further point deserves notice, in that the whole of the primitive epiblast becomes shed. In this fact there may perhaps be recognised the last trace of a metamorphosis like that in the type of Desor.

Delaminate types have been studied by Barrois (No. 192) and Hoffman (No. 198), both of whom give circumstantial accounts of their development.

Hoffman's account is especially deserving of attention, since his observations were, to a great extent, made by means of artificial sections. The following account is taken from him. His observations were made on Tetrastemma varicolor, and Tetrastemma appears to be the genus in which this type of development has been most completely made out. After a regular segmentation the embryo forms a solid mass of cells, the outermost of which soon become distinguished as a separate epiblastic layer. At the same time the larva leaves the egg, and the epiblast cells become coated by an uniform covering of cilia. At the anterior extremity of the body is a bunch of long cilia; and at the hinder end two stiff bristles are formed, but soon disappear.

The internal mass of cells is still quite uniform, but as the larva grows in length the outermost of them arrange themselves as a columnar layer, constituting the mesoblast. Of the cells internal to the mesoblast the outer become columnar, and are converted into the walls of the alimentary tract, while the inner ones undergo fatty degeneration, and form a kind of foodyolk. In the later development the characters of the adult are gradually acquired without metamorphosis, and the larval skin passes directly into that of the adult. Both mouth and anus are formed nearly simultaneously by a rupture of the enteric wall from within. The nervous system arises as a thickening of the epiblast, which Hoffman states he has been able to see in sections. Hoffman also states that the epithelium of the proboscis is formed as a diverticulum of the alimentary tract, and that its sheath is formed by a special mesoblastic growth.

Barrois is less precise than Hoffman, from whom he differs in certain particulars. Hoffman's statements about the proboscis are important if accurate, but require further confirmation.

Malacobdella. The early stages in development of the peculiar ectoparasitic Nemertine Malacobdella have been worked by Hoffman (No. 199) by means of sections, and there appears to be a close agreement between the development of Malacobdella and that of Tetrastemma.

The segmentation is uniform, and there is no trace of a segmentation 
cavity. On the third day after impregnation the outermost cells of the embryo become flattened and ciliated, and distinguished from the remaining spherical cells of the embryo as the epiblast. With the appearance of cilia a rotation of the embryo commences. On the fourth day the embryo becomes oval, and at one of the poles-the future anal pole-a separation takes place between the epiblast and the inner cells, giving rise to the body cavity. In it are a number of loose oval cells, which soon become stellate, and form a mesoblastic reticulum connecting the body-wall and central cells of the embryo, which may now be spoken of as hypoblast. The body-cavity increases in size, leaving at last tle hypoblast and epiblast united only at one point - the oral pole-at which, on the fifth day, a crown of long cilia appears. The solid mass of hypoblast in the interior beconnes differentiated into an outer layer of cells - the true glandular epithelium of the alimentary tract-and an inner core, the cells of which soon undergo fatty degeneration, and serve as food-yolk.

The later stages of development, and the formation of the proboscis, etc., have not been worked out.

General considerations. Of the types of larve hitherto found amongst the Nemertea, those with a metamorphosis, viz. the Pilidium type and that of Desor, are to be regarded as the primitive. But even in Pilidium there are evidences of a great abbreviation in development. Pilidium itself is probably a more or less modified ancestral form, while the peculiar development of the Nemertine within it is to be explained as a very much shortened record of a long series of changes by which the Pilidium became gradually converted into a Nemertine. The formation of the body wall of the Nemertine by four epiblastic invaginations is a remarkable embryological phenomenon, for which it is not easy to assign a satisfactory meaning; and it is probable that it is merely a secondary process of growth similar to the formation of imaginal discs in the larvæ of Diptera (vide Chapter on Tracheata), which has had its origin in the abbreviation of the development just alluded to. The development on the type of Desor is clearly a simplification of the Pilidium type, and its peculiarities are to be explained by the fact that the first larval form has no free existence. The types without metamorphosis have no doubt a development of a still more simplified character; they are remarkable however in presenting us, if the existing descriptions are to be trusted, with examples of delamination and invagination coexisting in closely allied forms, 


\section{TREMATODA.}

The eggs of the Trematoda consist of a germ or true ovum enclosed in a mass of yolk cells, which undergo disintegration and subsequent absorption at varying periods of the development. From the observations of E. van Beneden (No. 218), Zeller (No. 217), etc. it is known that the segmentation is usually complete, but generally somewhat irregular.

Unfortunately we are still completely in the dark as to the mode of formation of the germinal layers. The embryos of the entoparasitic forms or Distomeæ become free in a very imperfect condition, and the ova are small; while in the Polystomeæ the development is as a rule nearly completed before hatching, and the ova are large. It will be convenient to treat separately the development of the two groups.

Distomeæ. The embryos of the Distomex are hatched either in some moist place or more usually in water. In the majority of genera the larvæ pass through a complicated metamorphosis, accompanied by alternations of generations. But for some genera, e.g. Holostomum, etc., the life history has not yet been made out. The whole life history of comparatively few forms has been followed, but sufficient fragments are known to justify us in making certain general statements, which no doubt hold true for a large proportion of the Distomer.

The larvæ are usually ciliated (fig. 95 A), but sometimes naked.

The ciliated forms are generally completely covered with cilia, but in Distomum lanceolatum the cilia are confined to an area at the front end of the body, in the centre of which a median spine is placed. An $\times$ shaped pigment spot, sometimes provided with a rudimentary lens (Monostomum mutabile), is also generally situated on the dorsal surface.

In some intances a more or less completely developed alimentary tract is present (Honostomum capitellum, Amphistomum subclavatum), but usually there can only be distinguished in the interior of the larva a transparent mass of cells bounded by a more or less distinctly marked body wall with ciliated excretory channels.

Ed. van Beneden has shewn that the ciliated covering is developed while the embryo is still in the egg, and long before the yolk cells are completely absorbed. It would seem that even before hatching this ciliated covering is to a great extent independent of the mass within. In the 
larva of Monostomum mutabile (fig. $95 \mathrm{~A}$ ), which offers an example of an extreme case of the kind, there is present within the ciliated epidermis a fully-developed independent worm.

The non-ciliated larvæ are less highly organized than the ciliated forms, and are covered by a cuticle : their anterior extremity is sometimes provided with a circular plate armed with radiate ridges and spines.

The free-swimming or creeping embryos make their way into or on to the body of some invertebrate (occasionally vertebrate) form, usually a Mollusc, to undergo the first stage in their metamorphosis. They may either do this on the gills of their host, or very frequently they bore their way into the interior of the body. Soon after the larva have reached a satisfactory position the epidermis becomes stripped off, and there emerges a second larval form developed in the interior of the first larva, much as a Nemertine is developed within the larva of Desor. In the case of Monostomum mutabile the new worm is, as stated above, fully formed within the ciliated larva at the time of hatching.

The worm which proceeds from the above metamorphosis has different characters corresponding with those of the larva from which it proceeded. If the original larva had an alimentary canal it has one also, and then grows into the form known as a Redia (Fig. 95, B and C).

The Redia has anteriorly a mouth leading into a muscular pharynx and thence into a cæcal stomach. Posteriorly the body is prolonged into a kind of blunt caudal process, at the commencement of which are a pair of lateral papillæ. There is a perivisceral cavity, and the body walls are traversed by excretory tubes.

If the original larva is without an alimentary tract, the second form becomes what is known as a Sporocyst. The Sporocyst is a simple elongated sack with a central body cavity; when derived from the metamorphosis of a ciliated embryo its walls are provided with excretory tubes, but such tubes are absent in Sporocysts developed from non-ciliated larvæ. Some Sporocysts send out numerous branches amongst the viscera of their hosts.

The Redix and Sporocysts rapidly grow in size and sometimes increase by transverse division. In the course of their 
further development one of two things may happen. They may either (I) develop fresh Redia or Sporocysts by a process of internal budding (fig. 95 C) ; or else (2) there may be formed in them, by an analogous process, larvæ with long tails known as Cercariæ (fig. 95 D.) The direct development of Cercariæ is the usual course, though in Distomum globiparum the reverse is true; but where this does not take place the Redia or Sporocysts of the second generation give rise to Cercariæ.

The Cercaria are developed from spherical masses of cells found in the body cavity of the Sporocyst or Redia. The exact origin of these masses is still somewhat obscure, but they are stated by Wagener (No.212)
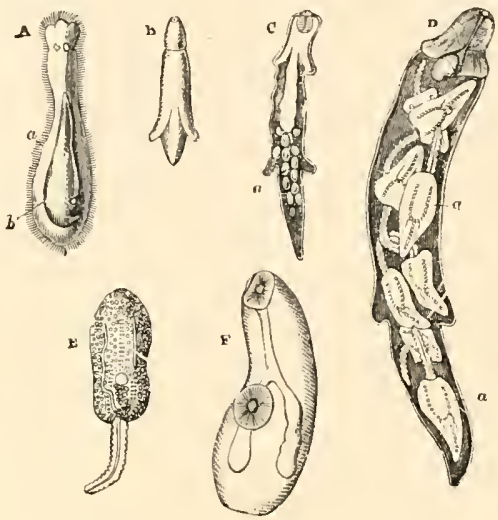

Fig. 95. Various stages in the MetaMORPHOSIS OF THE DISTOMEE (from Huxley.)

A. Ciliated larva of Monostomum mutabile. a. larval skin. b. Redia developed within it. $B$. Redia of Monostomum mutabile. C. Redia of Distomum pacificum, with germs of a second brood of Redix. $D$. Redia containing Cercariæ. E. Cercaria. F. Fullgrown Distomum.

to be derived from the body wall. They are probably to be regarded as internal buds.

The spherical bodies grow rapidly in size, their posterior extremity is prolonged into a process which forms the tail, while the anterior part forms the trunk. When fully formed (fig. $95 \mathrm{E}$ ), the trunk has very much the organization of an adult Distomum. There is an anterior and a ventral sucker, the former of which contains the opening of the mouth, and is often provided with a special chitinous armature. The mouth leads into a muscular pharynx, and this into a bilobed creal alimentary tract. An excretory system of the ordinary type is present, consisting of longitudinal contractile trunks continuous anteriorly with branched ciliated canals, which, as has recently been shewn by Bütschli, may be provided with funnel-shaped ciliated internal openings ${ }^{1}$.

1 O. Bütschli, "Bemerkungen üb. d. excretorischen Gefissapparat d. Trematoden." Zoologischer Anziger, 1879, No. 42. 
The contractile trunks unite posteriorly, but instead of opening directly to the exterior are prolonged into a vessel which traverses the substance of the tail, and after a longer or shorter course bifurcates into two branches which open laterally.

The tail is provided with an axial rod of hyaline connective tissue, like the notochord of the tail of a larval Ascidian, and is frequently provided with membranous expansions. It is used as a swimming organ. Beneath the epidermis are layers of circular and longitudinal muscular fibres, the latter arranged in the tail as two bands.

The Cercarix when fully developed leave the Sporocyst or Redia, and then their host, and become free. In most Rediæ there is a special opening, not far from the mouth, by which they pass out. There is no such opening in Sporocysts, but the Cercaria bore their way through the walls.

After leaving their parent the Cercarix pass into the external medium, and for a short period have a free existence. They soon however enter a new host, making their way into its body by a process of boring, which is effected by the head (especially when armed with chitinous processes) assisted by movements of the tail.

The second host is usually some Invertebrate (Mollusc, Worm, Crustacean, Insect larva, \&c.), but occasionally a Fish or Amphibian or even a vegetable. The tail is very often lost as the Cercaria bores its way into its host, but whether it is so or not, the Cercaria, after it has once reached a suitable post in its new host, assumes a quiescent condition, and surrounds itself with a many-layered capsule. The cephalic armature and tail (if still present) are then exuviated, and the generative organs gradually become apparent though very small. In other respects the organization is not much altered.

Though an encysted Cercaria may remain some months without further change, it eventually dies unless it be introduced into its permanent vertebrate host, an act which is usually effected by the host in which it is encysted being devoured. It then becomes freed from its capsule as a fully formed Trematode, in which the generative organs rapidly complete their development.

In some cases the Redix or Sporocysts do not give rise to 
tailed Cercariæ, but to tailless forms. In such cases, as a rule, the encystment takes place in the host of the Redia or Sporocyst, but the tailless larve sometimes pass through a free stage like the Cercariæ. In the case of Distomm cygnoides, parasitic in the bladder of the Frog, the Cercaria passes directly into the adult host without the intervention of an intermediate host.

The life history of a typical entoparasitic Trematode is shortly' as follows :

(I) It leaves the egg as a ciliated or non-ciliated free larva.

(2) This larva makes its way on to the gills or into the body of some Mollusc or other host, throws off its epidermis and becomes a Redia or Sporocyst.

(3) In the body cavity of the Redia or Sporocyst numerous tailed larvæ, known as Cercariæ, are developed by a process of internal gemmation.

(4) The Cercariæ pass out of the body of their parent, and out of their host, and become for a short time free. They then pass into a second, usually invertebrate host, and encyst.

(5) If their second host is swallowed by the vertebrate host of the adult of the species, the encysted forms become free, and attain to sexual maturity.

The majority of these stages are simply parts of a complicated metamorphosis, but in the coexistence of larval budding (giving rise to Cercariæ or fresh Redix) with true sexual reproduction there is in addition a true alternation of generations.

Polystomeæ. The ova of the Polystomeæ are usually large and not very numerous, and they are in most cases provided with some process for attachment. Some species of Polystomeæ, c.g. Gyrodactylus, are however viviparous. The young leave the egg in a nearly perfect state, and at the utmost undergo a slight metamorphosis and no alternations of generations. Some however (Polystomum, Diplozoon) are provided with temporary cilia, but the number investigated is too small to determine whether ciliation is the rule or the exception. The ciliated larvæ have a short free existence. The cilia are developed on special cells which may be arranged in transverse bands in the same way as in the larvæ of many Chætopods, but are not, in the larvæ at present known, distributed uniformly. When the free larvæ become parasitic the cells with cilia shrink up.

B. II. 
In Polystomum integerrimum, which lives in the urinary bladder of Rana temporaria, the eggs when laid in the spring pass out into the water. The segmentation is complete, and the embryo when hatched is provided with most of the adult organs, but presents certain striking larval characters. It has five rings of ciliated cells. Three of these are placed anteriorly, and are especially developed on the ventral surface, the posterior one being incomplete dorsally; two are placed posteriorly, and are especially developed on the dorsal surface. Anteriorly there is a tuft of cilia.

The larva itself resembles somewhat an adult Gyrodactylus, and is provided ( $\mathbf{I}$ ) with a large posterior disc armed with hooks, and (2) with two pairs of eyes which persist in the adult state. After a certain period of free existence the larva attaches itself to the gills of a tadpole. The rings of ciliated cells shrink up, and some of the six pairs of suckers found in the adult commence to be formed on the posterior disc. When the bladder of the tadpole is developed, the young Polystomum passes down the alimentary tract to the cloaca, and thence to the urinary bladder, where it slowly attains to sexual maturity. When the larva becomes attached to the gills of a very young tadpole, its development is somewhat more rapid in consequence of better nutrition from the more delicate gills. It then reaches its full development in the gill cavity, and, though smaller and provided with differently organised generative organs to the normal form, produces generative products and dies without being transported to the bladder (vide Zeller, Nos. 216 and 217 ).

The ova of Diplozoon, a form parasitic on the gills of freshwater fish (Phoxinus, etc.), are provided with a long spiral filament (Zeller, No. 215). The embryo has five ciliated areas, four lateral and one posterior. The young form is known as Diporpa. Sexual maturity is not attained till two individuals unite permanently together. They unite by the ventral sucker of each of them becoming attached to the dorsal papilla of the other. Subsequently these parts coalesce, and the ventral suckers disappear in the process. Gyrodactylus, parasitic, like Diplozoon, on the gills of freshwater fishes (Gasterosteus, etc.), is remarkable for its mode of reproduction. It is viviparous, producing a single young one at a time, and, what is still more remarkable, the young while still within its parent produces a young one, and this again a young one, so that three generations may be present within the parent. It seems probable that the second and third generations are produced asexually, the generative organs not being developed; while the young Gyrodactylus of the first generation springs from a fertilized ovum (Wagener, No. 214).

\section{Cestoda.}

On anatomical grounds the affinity of the Cestoda to the Trematoda has been insisted on by the majority of anatomists. The existence of such intermediate forms as Amphilina tends to 
strengthen this view; and the striking resemblances between the two groups in the structure of the egg and characters of the metamorphosis appear to me to remove all doubt about the matter.

The ripe egg is formed of a minute germ enveloped in yolk cells, the whole being surrounded by a membrane, which is very delicate in most forms, but in certain types has a firmer consistency, and is provided with an aperture, covered by an operculum, by which the larva escapes.

The early development, up to the formation of a six-hooked larva, generally takes place in the uterus, but in the types with a firmer egg-shell it takes place after the egg has been deposited in water.

The segmentation (E. van Beneden, No. 218, Metschnikoff, No. 228) is complete, and during its occurrence the yolk cells surrounding the germ are gradually absorbed, so that the mass of segmentation spheres grows in size, till at the close of segmentation it fills up nearly the whole egg-shell.

As was first shewn by Kolliker for Bothriocephalus salmonis, the embryonic cells separate themselves at the close of segmentation into a superficial layer and a central mass.

The further development takes place on two types. In the cases where the egg-shell is strong, and the egg is laid prior to the formation of the embryo, a ciliated larva is developed (Bothriocephalus latus, ditremus, Schistocephalus dimorphus, Ligula simplicissima, etc. $\left.{ }^{1}\right)$.

Of these forms Bothriocephalus latus may be taken as type.

The development of the embryo requires many months for its completion. The outer layer becomes ciliated while the central mass has already become developed into a six-hooked embryo. The embryo leaves its shell by the opercular aperture, and for some time swims rapidly about by means of its long cilia. The ciliated coating is eventually stripped off, and the six-hooked larva emerges.

In the second type of embryo the external cellular layer does not become ciliated. This is the most usual arrangement, and is even found in many species of Bothriocephalus.

1 Vide for list of such forms at present known Willemoes Suhm, No. 231. 
The central mass of cells becomes developed, as in the other type, into a six-hooked (rarely four-hooked) embryo (fig. $96 \mathrm{G}$ ), but the superficial layer separates from the central, and either disappears or becomes (Bothrioccphalus proboscidens) a cuticular layer. Between the six-hooked embryo and the outer layer of cells one or more thick membranes become deposited (E. van Beneden). The eggs are carried out of the alimentary canal in the proglottis and transported to various situations on land or in water. They usually remain within the proglottis, invested by their thick shell, till taken up into the alimentary canal of a suitable host, or they may be swallowed after the death and decay of the proglottis. They are subsequently hatched after their shell has become softened by the action of the digestive fluids.

Before proceeding to describe their further history, the close resemblance between the first developmental stages of Cestoda, especially in the case of the ciliated larvæ, and those of Trematoda, may be pointed out.

In both there is a ciliated larva, and in both there is developed

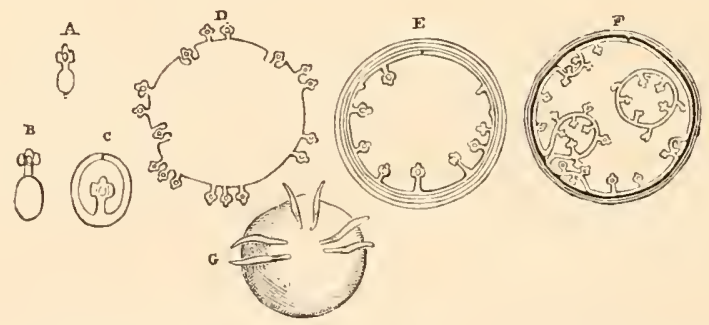

Fig. 96. Diagrams of various stages in the development of the Cestola. (From Huxley.)

A. Cysticercus. B. and C. Cysticerci in the everted (B) and inverted (C) condition. D. Conurus. E. and F. Diagrams of Echinococcus. It is most probable that Trenia heads are not developed directly from the wall of the cyst as represented in the diagram. G. Six-hooked embryo.

within the ciliated skin a second larva, which becomes freed by the stripping off of the ciliated skin.

The type of development has moreover many analogies with that of the Nemertine larva of Desor, p. 163 (cf. Metschnikoff), and is probably like that an abbreviated record of a long history. The suitable host for the six-hooked embryo to enter is 
rarely the same as the host for the sexual form. The embryos having become transported into the alimentary canal of such a host, and become free, if previously invested by the egg-shell, soon make their way, apparently by the help of their hooks, through the wall of the alimentary tract, and are transported in the blood or otherwise into some suitable place for them to undergo their next transformation. This place may be the liver, lungs, muscles, connective tissue, or even the brain (e.g. Comurus cerebralis in the brain of sheep).

Here they become enclosed in a granular deposit from the surrounding tissues, which becomes in its turn enclosed in a connective-tissue coat. Within lies the solid embryo, the hooks of which in many cases disappear or become impossible to make out. In other forms, e.g. Cysticercus limacis, they remain visible, and then mark the anterior pole of the worm (fig. 98, c.). The central part of the body next becomes transformed into a material composed of clear non-nucleated vesicles. Accompanying these changes the embryo grows rapidly in size; a cuticle is deposited by its outer layer, in which also an external layer of circular muscular fibres and an internal layer of longitudinal fibres become differentiated, and internal to both there is formed a layer of granular cells.

With the rapid growth of the body a central cavity is formed, which becomes filled with fluid, and the embryo assumes the form of a vesicle. At the same time a system of excretory vessels, sometimes opening by a posterior pore, becomes visible in the wall of the vesicle.

The embryo has now reached a condition in which it is known as a cystic-or bladder-worm, and may be compared in almost every respect with the sporocyst of a Trematode (Huxley).

The next important change consists in the development of a head, which becomes the head of the adult Tænia. This is formed in an involution of the outer wall of the anterior extremity of the cystic worm. This involution forms a papilliform projection on the inner surface of the wall of the cystic worm, with an axial cavity opening by a pore on the outer surface. The layer of cells forming the papilla soon becomes divided into two laminx, of which the outer forms a kind of investing membrane for the papilla. The papilla itself now becomes 
moulded into a Cestode head, which however is developed in an inverted position. The suckers and hooks (when present) of the head are developed on a surface bounding the axial lumen of the papilla, which is the true morphological outer surface, while the apparent outer surface of the papilla is that which eventually forms the interior of the (at first) hollow head. Before the external armature of the head has become established, four longitudinal excretory vessels, continuous with those in the body of the cystic worm, make their appearance. They are united by a circular vessel at the apex of the head. The development is by no means completed with the simple

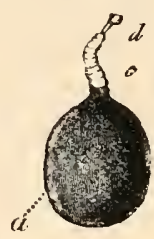

FIG. 97 . CYSTICERCUS CELLULOSA. (From Gegenbaur, after von Siebold.)

a. Caudal vesicle. $c$. Anterior part of body. $d$. head. growth of the head, but the whole inverted papilla continues to grow in length, and gives rise to what afterwards becomes part of the trunk. The whole papilla eventually becomes everted, and then the cystic worm takes the form (fig. 97) of a head and unsegmented trunk with a vesicle - the body of the cystic worm - attached behind. The whole larva is known as a Cysticercus. The term scolex, which is also sometimes employed, may be conveniently retained for the head and trunk only. The head differs mainly from that of the adult in being hollow.

There are great variations in the relative size of the head and the vesicle of Cysticerci. In some forms the vesicle is very small (fig. 98), e.g. Cy'sticercus limacis; it is medium-sized in Cysticerius cellulose (fig. 97), and in some forms is much larger. The embryonic hooks, when they persist, are found at the junction of the trunk and the vesicle (fig. $98 \mathrm{~A}, \mathrm{c}$ ). Though the majority of cystic worms only develope one head, this is not invariably the case. There is a cystic worm found in the brain of the sheep known as Canurus ccrebralis - the larva of Tania canums, parasitic in the intestine of the dog-which forms an exception to this rule. There appears, to start with, a tuft of three or four heads, and finally many hundred heads are developed (fig. $96 \mathrm{D}$ ). They

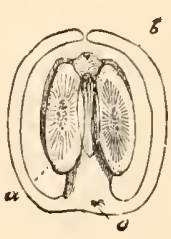

A.

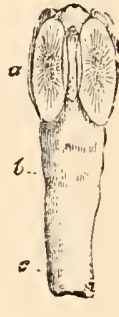

B.

Fig. 98. Cysticercus WITH SMALL CAUDAL VESICLE.

A. Head involuted. B. Head everted.

$a$. Scolex. b. caudal vesicle. c. (in A) six embryonic hooks. are arranged in groups at one (the anterior?) pole of the cystic worm. 
A still more complicated form of cystic worm is that known as Echinococcus, parasitic in the liver, lungs, etc. of man and various domestic Ungulata. In the adult state it is known as Tania echinococcus and infests the intestine of the dog. The cystic worm developed from the six-hooked embryo has usually a spherical form, and is invested in a very thick cuticle (fig. $96 \mathrm{E}$ and F, and fig. 99). It does not itself directly give rise to Tænia heads, but after it reaches a certain size there are formed on the inner side of its walls small protuberances, which soon grow out into vesicles connected with the walls of the cyst by narrow stalks (figs. $96 \mathrm{~F}$ and $99 \mathrm{C}$ ). In the interior of these vesicles a cuticle is developed. It is in these secondary vesicles that the heads originate. According to Leuckart, they either arise as outgrowths of the wall of the vesicle on the inner face of which the armature is developed, which subsequently become involuted and remain attached to the wall of the vesicle by a narrow stalk, or they arise from the first as papilliform projections into the lumen of the vesicle, on the outer side of which the armature is formed. Recent observers only admit the second of these modes of development. The Echinococcus larva, in addition to giving rise to the above head-producing vesicles, also gives rise by budding to fresh cysts, which resemble in all respects the parent cyst. These cysts may either be detached in the interior (fig. $96 \mathrm{~F}$ ) of the parent or externally. They appear to spring in most cases from the walls of the parent cyst, but there are some discrepancies between the various accounts of the process. In the cysts of the second generation vesicles are produced in which new heads are formed. As the primitive cyst grows, it naturally becomes more and more complicated, and the number of heads to which one larva may give rise becomes in this way almost unlimited.

Cysticerci may remain a long time without further develop. ment, and human beings have been known to be infested with an Echinococcus cyst for over thirty years. When however the Cysticercus with its head is fully developed, it is in a condition to be carried into its final host. This takes place by the part of one animal infested with cysticerci becoming eaten by the host in question. In the alimentary canal of the final host the connective-tissue capsule is digested, and then the vesicular caudal appendage undergoes the same fate, while the head, with its suckers and hooks, attaches itself to the walls of the intestine. The head and rudimentary trunk, which have been up to this time hollow, now become solid by the deposition of an axial tissue; and the trunk very soon becomes divided into segments, known as proglottides (fig. 99 A). These segments are not formed in the same succession as those of Chrtopods; the 
youngest of them is that nearest to the head, and the oldest that furthest removed from it. Each segment appears in fact to be a sexual individual, and is capable of becoming detached and leading for some time an independent existence. In some cases, e.g. Cysticercus fasciolaris, the segmentation of the trunk may take place while the larva is still in its intermediate host.

The stages in the evolution of the Cestoda are shortly as follows:

I. Stage with embryonic epidermis either ciliated (Bothriocephalus, etc.) or still enclosed in the egg-shell. This stage corresponds to the ciliated larval stage of the Trematoda.

2. Six-hooked embryonic stage after the embryonic epidermis has been thrown off. During this stage the embryo is transported into the alimentary tract of its intermediate host, and boring its way into the tissues, becomes encapsuled.

3. It develops during the encapsuled state into a cystic worm, equivalent to the sporocyst of Trematoda.

4. The cystic worm while still encapsuled develops a head with suckers and hooks, becoming a Cysticercus. In some forms (Camurus, Echinococcus) reproduction by budding takes place at this stage. The head and trunk are known as the scolex.

5. The Cysticercus is transported into the second and permanent host by the infested tissue being eaten. The bladderlike remains of the cystic worm are then digested, and by a process of successive budding a chain of sexual proglottides are formed from the head, which remains asexual.

The above development is to be regarded as a case of 
complicated metamorphosis secondarily produced by the necessities of a parasitic condition, to which an alternation of sexual and gemmiparous generations has been added. The alternation of generations only occurs at the last stage of the development, when the socalled head, without generative organs, produces by budding a chain of sexual forms, the embryos of which, after passing through a complicated metamorphosis, again become Cestode heads.

A.
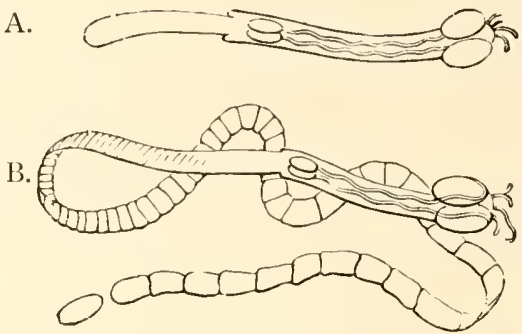

Fig. 99 A. Tetrarhyncus. (From Gegenbaur; after Van Beneden.)

A. Asexual state.

B. Sexual stage with ripe proglottides.

In the case of Conurus and Echinococcus two or more asexual generations are interpolated between the sexual ones. It is not quite clear whether the production of the Tænia head from the cystic worm may not be regarded as a case of budding. There are some grounds for comparing the scolex to the Cercaria of Trematodes, cf. Archigetes.

As might be anticipated from the character of the Cestode metamorphosis, the two hosts required for the development are usually forms so related that the final host feeds upon the intermediate host. As familiar examples of this may be cited the pig, the muscles of which may be infested by Cysticercus cellulose, which becomes the Tania solium of man. Similarly a Cysticercus infesting the muscles of the ox becomes the Tania mediocanellata of man. The Cysticercus pisciformis of the rabbit becomes the Tania serrata of the dog. The Conurus cerebralis of the sheep's brain becomes the Tania canurus of the dog. The Echinococcus of man and the domestic herbivores becomes the Tania echinococcus of the dog.

Cystic wornıs infest not only Mammalian forms, but lower Vertebrates, various fishes which form the food of other fishes, and Invertebrates liable to be preyed on by vertebrate hosts. So far the Cestodes (except Archigetes) are only known to attain sexual maturity in the alimentary tracts of Vertebrata.

The rule that the intermediate host is not the same as the final host does not appear to be without exception. Redon ${ }^{1}$ has shewn by experiments on himself that a Cysticercus (cellulosa) taken from a human subject developes into Tania solium in the intestines of a man. Redon took four cysts of a Cysticercus from a human subject, and after three months passed some proglottides, and subsequently the head of Tania solizm. 
Some important variations of the typical development are known.

The so-called head or scolex may be formed without the intervention of a cystic stage. In Archigetes (Leuckart, No. 227), which infests, in the Cysticercus condition, the body-cavity of various invertebrate forms (Tubifex, etc.), the six-hooked embryo becomes elongated and divided into two sections, one forming the head, while the other, with the six embryonic hooks, forms an appendage, homologous with the caudal vesicle of other Cysticerci.

The embryo of Tania elliptica similarly gives rise to a Cysticercus infesting the dog-louse (Trichodectes canis), without passing through a vesicular condition; but the caudal vesicle disappears, so that it forms simply a scolex. These cases may, it appears to me, be probably regarded as more primitive than the ordinary ones, where the cystic condition has become exaggerated as an effect of a parasitic life.

In some cases the larva of a Tænia has a free existence in the scolex condition. Such a form, the larva of Phyllobothrium, has been observed by Claparède1. It was not ciliated, and was without a caudal vesicle; and was no doubt actively migrating from an intermediate host to its permanent host.

Scolex forms, without a caudal vesicle, are found in the mantle cavity of Cephalopoda, and appear to be occupying an intermediate host in their passage from the host of the cystic worm to that of the sexual form.

Archigetes, already mentioned, has been shewn by Leuckart (No. 227) to become sexually mature in the Cysticercus state, and thus affords an interesting example of pæedogenesis. It is not known for certain whether under normal circumstances it reaches the mature state in another host.

Amphilina. The early stages of this interesting form have been investigated by Salensky (No. 229), and exhibit clear affinities to those of the true Cestoda. An embryonic provisional skin is formed as in Cestodes ; and pole-cells also appear. Within the provisional skin is formed an embryo with ten hooks. After hatching the provisional skin is at once thrown off, and the larva, which is then covered by a layer of very fine cilia, becomes free. The further metamorphosis is not known.

\section{BIBLIOGRAPHY.}

\section{Turbellaria.}

(181) A lex. Agassiz. "On the young stages of a few Annelids" (Planaria angulata). Annals Lyceum Nat. Hist. of Ncw York, Vol. vin. I 866.

(182) Dalyell. "Powers of the Creator."

(183) C. Girard. "Embryonic development of Planocera elliptica." Jour. of Acad. of Nat. Sci. Philadelphia. New Series, Vol. 11. I854.

(184) Alex. Götte. "Zur Entwicklungsgeschichte d. Seeplanarien." Zoologischer Anzeiger, No. 4 , I878.

1 Beobachıngen ïb. Anat. u. Entwick. Wirbell. Thicre. Leipzig, 1863. 
(185) P. Hallez. Contributions à l'histoire naturelle des Turbellariés. Thèsis à la faculté des Sciences p. Le grade d. Docteur ès-sciences naturelles, Lille, I8j9.

(186) Knappert. "Bijdragen tot de Ontwikkelings-Geschiedenis der Zoetwater-Planarien." Provinciaal Utrechtsch Genootschap van Kunsten en Wetenschappen. Utrecht, 1865 .

(187) W. Keferstein. "Beiträge z. Anat. u. Entwick. ein. Seeplanarien von St. Malo." Abh. d. könir. Gesell. d. Wiss. zu Göttingenn. Bd. xrv. г868.

(188) El. Metschnik off. "Untersuchungen iib. d. Entwicklung d. Planarien." Notizen d. neurussischen Gesellschaft d. Naturforscher. Odessa, Bd. v. I877. Vide Hoffman and Schwalbe's Bericht for i8 78 .

(189) H. N. Moseley. "On Stylochus pelagicus and a new species of pelagic Planarian, with notes on other pelagic species, on the larval forms of Thysanozoon, etc." Quart. Fourn. of Hicr. Scicnce. Vol. Xitis. IS77.

(190) J. Müller. "Ueber eine eigenthümliche Wurmlarva a. d. Classe d. Turbellarien, etc." Miiller's Archiz'f. Anat. u. Phys. I8

(191) _- "Ueber verschiedene Formen ron Seethieren." Miuller's Archiv $f$. Anat. und Phy's. I 85̆+

\section{Nemertea.}

(192) J. Barrois. "L'Embryologie des Némertes." An. Sci. Nat. Vol. vi. 1877 .

(193) O. Bütschli. Archiv f. Naturgeschichte, 1873 .

(194) A. Krohn. "Ueb. Pilidium u. Actinotrocha." Müller's Archiv, i 858.

(195) E. Desor. "Embryology of Nemertes." Proceedings of the Boston Nat. History Society, Vol. vi. I $8_{4} 8$.

(196) G. Dieck. "Entwicklungsgeschichte d. Nemertinen." Fenaische Zeitschrift, Vol. vili. I8 $\bar{\jmath}$.

(197) C. Gegen baur. "Bemerkungen üb. Pilidium gyrans, etc." Zeitschrift für wiss. Zool., Bd. v. 1854 .

(198) C. K. H offmann. "Entwicklungsgeschichte von Tetrastemma tricolor." Niederländisches Archiv, Vol. 111. I876, I877.

(199) _ "Zur Anatomie und Ontogenie von Nalacobdella." Niederländisches Archiv, Vol. IV. I87\%.

(200) W. C. Mc Intosh. British Annelids. The Nemerteans. Ray Society, $1873-4$.

(201) Leuckart u. Pagenstecher. "Untersuchungen üb. niedere Seethiere." Miiller's Archiv, i $8_{5} 8$.

(202) E. Metschnikoff. "Studien üb. die Entwicklung d. Echinodermen u. Nemertinen." Mlém. Acad. imp. Pétersbourg, vir. Ser. Tom. Xiv. No. 8, I 869.

\section{Trematoda.}

(203) T. S. Cobbold. Entozoa. Groombridge and Son, I86.t.

(201) Parasites; a Treatise on the Entozoa, etc. Churchill, I879.

(205) Filippi. Mém. p. servir à Thistoire génétique des Trématodes. Ann. Scien. Nat. th Series, Vol. II. I854, and Mem. Acad. Torino, I855-1859.

(206) R. Leuckart. Die menschlichen Parasiten, Vol. I. I863, p. $48_{5}$, et seq.

(207) H. A. Pagenstecher. Trematoden u. Trematodenlarven. Heidelberg, 1857. 
(208) C. Th. von Siebold. Lehrbuch d. vergleich. Anat. wirbelloser Thiere. Berlin, $\mathbf{I} 848$.

(209) J. J. S. Steenstrup. Gcnerationszucchsel. I $8_{+2}$.

(210) R. v. Willemoes-Suhm. "Zur Naturgeschichte d. Polystomum integerrimum, etc." Zeit. f. wiss. Zool. Vol. XXII. I872.

(211) —_Helminthologische Notizen III." Zeit. f. wiss. Zool. Vol. xxiII. 1873. Vide this paper for a summary of known observations and literature.

(212) G. R. Wagener. Beiträge zur Entwicklungsgeschichte d. Eingezveideroürmer. Haarlem, 1855 .

(213) G. K. Wagener. "Helminthologische Bemerkungen, etc." Zeit.f. wiss. Zool. Vol. IX. I 850 .

(214) G. R. Wagener. "Ueb. Gyrodactylus elegans." Archiv f. Anat. u. Phys. 1860 .

(215) E. Zeller. "Untersuchungen iib. d. Entwicklung d. Diplozoon paradoxum." Zeit.f. wiss. Zool. Vol. xxı1. 1872.

(216) E. Zeller. "Untersuchungen ï. d. Entwick. u. Bau d. Polystomum integerrimum." Zeit.f. wiss. Zool. Vol. xxir. I 872.

(217) E. Zeller. "Weitere Beiträge z. Kenntniss d. Polystomen." Zeit. f. wiss. Zool. Vol, xxviı. 1876.

\section{Cestoda.}

(218) Ed. van Beneden. "Recherches sur la composition et la signification d. l'œuf." Mém. cour. Acad. roy. Belgique. Vol. xxxiv, r868.

(219) P. J. van Beneden. "Les vers Cestoïdes considérés sous le rapport physiologique embryogénique, etc." Bul. Acat. Scien. Bruxclles. Vol. xvi1. I850.

(220) T. S. Cobbold. Entozoa. Groombridge and Son, I864.

(221) Parasites; a treatise on the Entozod, etc. Churchill, 1879.

(222) Th. H. Huxley. "On the Anatomy and Development of Echinococcus veterinorum." Proc. Zool. Soc. Vol. xx, 1852.

(223) J. Knoch. "Die Naturgesch, d. breiten Bandwürmer." Mém. Acail. Imp. Pítersbourg, Vol. v. Ser. 7, 1863.

(224) F. Küchenmeister. "Ueber d. Umwandlung d. Finnen Cysticerci in Bandwürmer (Tæenien)." Prag Vierteljahrsschr. 1852 .

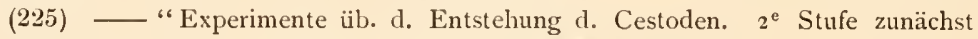
d. Cœnurus cerebralis." Günsburg, Zeitsch. klin. MIcd. Iv. I853.

(226) R. Leuckart. Die Menschlichen Parasiten, Vol. I. Leipzig, 1863. Virle also additions at the end of the Ist and 2 nd volume.

(227) R. Leuckart. "Archigetes Sieboldii, eine geschlechtsreife Cestodenamme." Zeit.f. wiss. Zool., Vol. xxx. Supplement, i 878 .

(228) El. Metschnikoff. "Observations sur le développement de quelques animaux (Bothriocephalus proboscideus)." Bull. Acad. Imp. St Pétersbourg, Vol. Xı11. I 869 .

(229) W. Salensky. "Ueb. d. Bau u. d. Entwicklungsgeschichte d. Amphilina." Zcit. f. wiss. Zool., Vol. xxıv. 1874 .

(230) Von Siebold. Burdach's Physiologie.

(231) R. von Willemoes-Suhm. "Helminthologische Notizen." Zeit. f. wiss. Zool., Vol. xix. xx. xxil. I869, 70 and 73 . 


\title{
CHAPTER VIII.
}

\author{
ROTIFERA.
}

FOR many reasons a complete knowledge of the ontogeny of the Rotifera is desirable. They constitute a group which retain in the trochal disc an organ common to the embryos of many other groups, but which in most other instances is lost in the adult state. In the character of the excretory organs they exhibit affinities with the Platyelminthes, while in other respects they possibly approach the Arthropoda (e.g. Pedalion ?). The interesting Trochosphara aquatorialis of Semper closely resembles a monotrochal polychætous larva.

$\mathrm{U}_{\mathrm{p}}$ to the present time our embryological knowledge is mainly confined to a series of observations by Salensky on Brachionus urceolaris, and to scattered statements on other larval forms by Huxley, etc.

In many cases Rotifers lay summer and winter eggs of a different character. The former are always provided with a thin membrane, and frequently undergo development within the oviduct. They are hatched in the autumn. The winter eggs are always provided with a thick shell.

The summer eggs are of two kinds, viz. smaller eggs which become males, and larger, females. On the authority of Cohn (No. 232) they are believed to develope parthenogenetically. Males are not found in summer, and only seem to be produced from the summer eggs. Cohn's observations, especially on Conochilus volvox, are however not quite satisfactory. Huxley (No. 234) came to the conclusion that the winter eggs of Lacinularia developed without previous fertilization.

The following are the more important results of Salensky's observations (No. 236) on Brachiouus urccolaris.

The ovum is attached by a short stalk to the hind end of the body of the female, in which position it undergoes its development. It will be convenient to treat separately the development of the female and male, and to commence with the former. The 
female ovum divides into two unequal spheres, of which the smaller in the subsequent stages segments more rapidly than the larger. The segmentation ends with the formation of an epibolic gastrula. The solid inner mass of cells derived from the larger sphere constitutes the hypoblast, and is more granular than the epiblast. The evolution of the embryo commences with the formation of a depression on the ventral surface, at the bottom of which the stomodæum is formed by an invagination. At the hinder part of the depression there rises up a rounded protuberance which eventually becomes the caudal appendage or foot. Immediately behind the mouth is formed an underlip.

On the sides of the ventral depression are two ridges which form the lateral boundaries of the trochal disc. They appear to unite with the under lip.

In a later stage the anterior part of the body becomes marked off from the posterior as a præoral lobe, and the hypoblast is at the same time confined to the posterior part. The supra-œsophageal ganglion is early formed as an epiblastic thickening on the dorsal side of the preoral lobe.

The first cilia to appear arise at the apex of the preoral lobe. At a later period the lateral ridges of the trochal disc meet dorsally and so enclose the præoral lobe. They then become coated by a ring of cilia, to which a second ring, completing the double ring of the adult, is added later.

In the trunk an indication of a division into two segments makes its appearance shortly after the development of the præoral lobe. Before this period the proctodæum is established as a shallow pit immediately behind the insertion of the foot. The latter structure soon becomes pointed and forked (fig. IOO, $t$ ).

The complete establishment

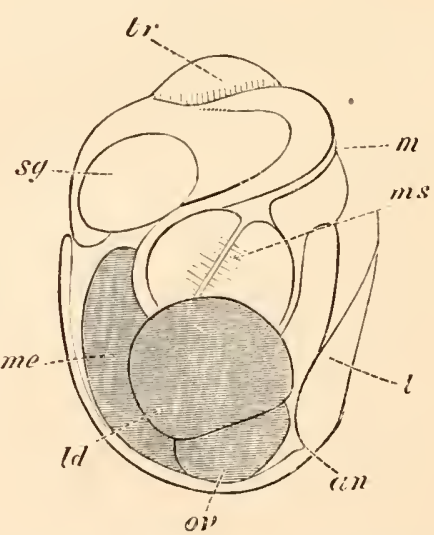

Fig. 100. Embryo of BrachioNUS URCEOLARIS SHORTLY BEFORE IT IS HATCHED. (After Salensky.)

m. mouth ; ms. masticatory apparatus; me. mesenteron; $a n$. anus ; $l d$. lateral gland; $\nu v$. ovary; $t$. tail, i.e. foot ; $t r$. trochal disc ; sg. supra-œesophageal ganglion. 
of the alimentary canal occurs late. The stomodæum (fig. Ioo) gives rise to the mouth $(m)$, cesophagus and masticatory apparatus ( $m s)$. The mesenteron is formed from the median part of the hypoblast; the lateral parts of which appear to give rise to the great lateral glandular structures $(l d)$ which open into the stomach, and to the ovaries (?) (oz') etc. The proctodæum becomes the cloaca and anus $(a n)$. The origin of the mesoblast is not certainly known. The shell is formed before the larva is hatched-an occurrence which does not take place till the larva closely resembles the adult.

The early developmental stages of the male are closely similar to those of the female; and the chief difference between the two appears to consist in the development of the male being arrested at a certain point.

The larvæ of Lacinularia (Huxley, No. 2:34) are provided with a preoral circlet of cilia containing two eye-spots ${ }^{1}$, and a perianal patch of cilia. They closely resemble some telotrochal polychætous larva.

Salensky has compared the larva of Brachionus to that of a cephalophorous Mollusc, more especially to the larva of Calyptræa on which he has made important observations. The præoral lobe, with the ciliated band, no doubt admits of a comparison with the velum of the larva of Molluscs; but it does so equally, as was first pointed out by Huxley, with the ciliated præoral lobe of the larvæ of many Vermes. It further deserves to be noted that the trochal disc of a Rotifer differs from the velum of a Mollusc in that the eyes and ganglia are placed dorsally to it, and not, as in the velum of a Mollusc, within it. The larva of Lacinularia appears to be an exception to this, since two eye-spots are stated to lie within the circlet of cilia. More important in the comparison is the so-called foot (tail), which arises in the embryo as a prominence between the mouth and anus, and in this respect exactly corresponds with the Molluscan foot.

If Salensky's comparison is correct, and there is something to be said for it, the foot or tail of Rotifers is not a post-anal portion of the trunk, but a ventral appendage, and the segmen-

1 In Leydig's figure of the larva, Zeit. f. wiss. Zool. Vol. III. I 851 , the eye-spots lie just outside the ciliated ring. 
tation which it frequently exhibits is not to be compared with a true segmentation of the trunk. If the Rotifers, as seems not impossible, exhibit crustacean affinities, the 'foot' may perhaps be best compared with the peculiar ventral spine of the Nauplius larva of Lepas fascicularis (vide Chapter on Crustacea) which in the arrangement of its spines and other points also exhibits a kind of segmentation.

\section{BIBLIOGRAPHY.}

(232) F. Cohn. "Ueb. d. Fortpflanzung von Räderthiere." Zeit.f. wiss. Zool. Vol. ViI. I 856 .

(233) F. Cohn. "Bemerkungen ii. Räderthiere." Zeit. f. wiss. Zool. Vol. Ix. I 858 , and Vol. XII. 1862 .

(231) T. H. Huxley. "Lacinularia socialis." Trans. of the Microscopical Society, 1853 .

(235) Fr. Leydig. "Ueb. d. Bau u. d. systematische Stellung d. Räderthiere." Zeit. f. wiss. Zool. Vol. vi. 1854.

(236) W. Salensky. "Beit. z. Entwick, von Brachionus urceolaris." Zeit. f. wiss. Zool. Vol. xxil. i 872 .

(237) C. Semper. "Zoologische Aphorismen. Trochosphæra æquatorialis." Zeit.f. wiss. Zool. Vol. Xxiı. I8;2. 


\title{
CHAPTER IX.
}

\author{
MOLLUSCA ${ }^{\prime}$.
}

Although the majority of important developmental features are common to the whole of the Mollusca, yet at the same time many of the subdivisions have well-marked larval types of their own. It will for this reason be convenient in considering the larval characters to deal successively with the different subdivisions, but to take the whole group at once in considering the development of the organs.

Formation of the layers and larval characters.

\section{ODONTOPHORA.}

Gasteropoda and Pteropoda. There is a very close agreement amongst the Gasteropoda and Pteropoda in the general characters of the larva; but owing to the fact that the eggs of

1 The classification of the Mollusca adopted in the present chapter is shewn in the subjoined table :

I. ODONTOPHORA.

I. Gasteropoda.

a. Prosobranchiata.

b. Opisthobranchiata.

c. Pulmonata.

d. Heteropoda.

2. Pteropoda.

II. LAMELLIBRANCHIATA.

a. Dimya.

b. Monomya.

a. Gymnosomata.

b. Thecosomata.

3. Cephalopoda.

a. Tetrabranchiata.

b. Dibranchiata.

4. Polyplacophora.

5. Scaphopoda.

B. II. 
the various species differ immensely as to the amount of foodyolk, considerable differences obtain in the mode of formation of the layers and of the alimentary tract.

The spheres at a very early stage of segmentation ${ }^{1}$ become divided into two categories, one of them destined to give rise mainly to the hypoblast, the other mainly to the epiblast. According as there is much or little food-yolk the hypoblast spheres are either very bulky or the reverse. In all cases the epiblast cells lie at one pole, which may be called the formative pole, and the hypoblast cells at the opposite pole. When the bulk of the food-yolk is very great, the number of hypoblast spheres is small. Thus in Aplysia there are only two such spheres. In other cases, where there is but little food-yolk, they may be nearly as numerous as the epiblast cells. In all these cases, however, as was first shewn by Lankester and Selenka, a gastrula becomes formed either by normal invagination as in the case of Paludina (fig. I07), or by epibole as in Nassa mutabilis (fig. 105). In both cases the hypoblast becomies completely enclosed by the epiblast. The blastopore is always situated opposite the original formative pole. In the large majority of cases (i.e. Marine Gasteropoda, Heteropoda, and Pteropoda) the blastopore becomes gradually narrowed to a circular opening which eventually occupies the position of the mouth. It either closes or remains permanently open at this point. In some cases the blastopore remains permanently open and becomes the anus. The best authenticated instance of this is Paludina vivipara, as was first shewn by Lankester (No. 263).

In some instances the blastopore assumes before closing a very narrow slit-like form, and would seem to extend along the future ventral region of the body from the mouth to the anus. This appears, according to Lankester (No. 262), to be the condition in Lymnaus, but while Lankester believes that the closure proceeds from the oral towards the anal extremity, other investigators hold that it does so in the reverse direction. Fol (No. 249) has also described a similar type of blastopore. In an undetermined marine Gasteropod, with an embolic gastrula, observed by myself at Valparaiso, the blastopore had the same elongated

1 The reader is referred for the segmentation to pp. 98 - ro2, and to the special description of separate types. 
form as in Lymneus, but the whole of it soon became closed except the oral extremity; but whether this finally closed could not be determined. It is probable that the typical form of the blastopore is the elongated form observed by Lankester and myself, in which an unclosed portion can indifferently remain at either extremity; and that from this primitive condition the various modifications above described have been derived ${ }^{3}$.

Before the blastopore closes or becomes converted into the oral or anal aperture, a number of very important embryonic organs make their appearance; but before describing these it will be convenient to state what is known with reference to the third embryonic layer or mesoblast.

This layer generally originates in a number of cells at the lips of the blastopore, which then gradually make their way dorsalwards and forwards, and form a complete layer between the epiblast and hypoblast. The above general mode of formation of the mesoblast may be seen in fig. IO7, representing three stages in the development of Paludina.

In some cases the mesoblast arises from certain of the segmentation spheres intermediate in size between the epiblast and hypoblast spheres. This is the case in Nassa mutabilis, where the mesoblast appears when the epiblast only forms a very small cap at the formative pole of the ovum ; and in this case the mesoblast cells accompany the epiblast cells in their growth over the hypoblast (fig. 105).

In other cases the exact derivation of the mesoblast cells is quite uncertain. The evidence is perhaps in favour of their originating from the hypoblast. It is also uncertain whether the mesoblast is bilaterally symmetrical at the time of its origin. It is stated by Rabl to be so in Lymnæus ${ }^{2}$.

In the case of Paludina the mesoblast becomes two layers

1 Rabl (No. 268) describes a blastopore of this form in Planorbis which closes at the mouth.

2 Rabl (No. 268) has quite recently given a more detailed account than previous observers of the origin of the mesoblast in Planorbis. He finds that it originates from the posterior one of the four large cells which remain distinct throughout the segmentation. By the division of this cell two 'mesoblasts' are formed, one on each side of the middle line at the hinder end of the embryo. Each of these again divides into two, an anterior and a posterior. By the division of the mesoblasts there arise two linear rows of mesoblastic cells-the mesoblastic bands-which are directed 
thick, and then splits into a splanchnic and somatic layer, of which the former attaches itself to the hypoblast, and gives rise to the muscular and connective-tissue wall of the alimentary tract, and the latter attaches itself to the epiblast, and forms the muscular and connective-tissue wall of the body and other structures. The two layers remain connected by protoplasmic strands, and the space between them forms the body cavity (fig. I07). In most instances there would appear to be at first no such definite splitting of the mesoblast, but the layer has the form of a scattered network of cells between the epiblast and the hypoblast. Finally certain of the cells form a definite layer over the walls of the alimentary canal, and constitute the splanchnic mesoblast, and the remaining cells constitute the somatic mesoblast.

We must now return to the embryo at the time when the blastopore is becoming narrowed. First of all it will be necessary to define the terms to be applied to the various regions of the body-and these will best be understood by taking a fully formed larva such as that represented in fig. IOI. The ventral surface I consider to be that comprised between the mouth $(m)$ and the anus, which is very nearly in the position (i) in the figure. As a great protuberance on the ventral surface is placed the foot $f$. The long axis of the body,

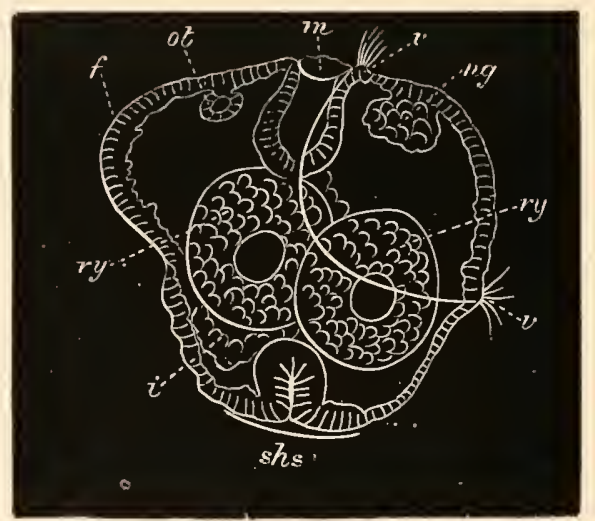

Fig. iol. Diagram of an embryo of PleuRoBRANCHIDIUM. (From Lankester.)

$f$. foot ; ot. otocyst ; $m$. mouth; $v$. velum; ns. nerve ganglion; $r y$. residual yolk spheres; shs. shell-gland; $i$. intestine. at this period though not necessarily in the adult, is that passing

forwards and divided transversely into two parts, an anterior continued from the front mesoblast, and a posterior from the hinder mesoblast.

If Rabl's account is correct, there is a striking similarity between the origin of the mesoblast in Mollusca and in Chrotopoda. It appears to me very probable that the mesoblastic bands are formed (as in Lumbricus) not only from the products of the division of the mesoblasts, but also from cells budded off from one or both of the primary germinal layers. 
through the mouth and the shell-gland (shs.): while the dorsal surface is that opposite the ventral as already defined.

Before the blastopore has attained its final condition three organs make their appearance, which are eminently characteristic of the typical molluscan larva. These organs are (I) the velum, (2) the shell-gland, (3) the foot.

The velum is a provisional larval organ, which has the form of a preoral ring of cilia, supported by a ridge of cells, often in the form of a double row, the ventral end of which lies immediately dorsal to the mouth. Its typical position is shewn in fig. IOI, $v$. There are considerable variations in its mode and extent of development etc., but there is no reason to think that it is entirely absent in any group of Gasteropoda or Pteropoda. In a few individual instances, especially amongst viviparous forms and land Pulmonata, it has been stated to be absent. Semper (No. 274) failed to find it in Vitrina, Bulimus citrinus, Vaginulus luzonicus, and Paludina costata. It is very probably absent in Helix, etc.

In some cases, e.g. Limax (Gegenbaur), Neritina (Claparède), Pterotrachæa (Gegenbaur), the larva is stated to be coated by an uniform covering of cilia before the formation of the velum, but the researches of Fol have thrown very considerable doubt on these statements. In some cases amongst the Nudibranchiata (Haddon) and Pteropoda there are one or two long cilia in the middle of the velar area. In many Nudibranchiata (Haddon) there is present a more or less complete post-oral ring of small cilia, which belongs to the velum.

The cilia on the velum cause a rotation of the larva within the egg capsule. Cilia are in most cases (Paludina, etc.) developed on the foot and on a small anal area.

The shell-gland arises as an epiblastic thickening on the posterior and dorsal side. In this thickening a deep invagination (fig. IOI, shs.) is soon formed, in which a chitinous plug may become developed (Paludina, Cymbulia? etc.), and in abnormal larva such a chitinous plug is generally formed.

The foot is a simple prominence of epiblast on the ventral surface, in the cavity of which there are usually a number of mesoblast cells (fig. IOI, $f$ ). The larval form just described has been named by Lankester the trochosphere larva. 
Before considering the further external changes which the larva undergoes, it will be well to complete the history of the invaginated hypoblast.

The hypoblast has after its invagination either the form of a sack (fig. IO2) or of a solid mass (fig. IOI). Whether the mouth be the blastopore or no, the permanent œesophagus is formed of epiblast cells, so that the osophagus and buccal cavity are always lined by epiblast. When the blastopore remains permanently open the outer part of the cesophagus grows as a prominent ridge round the opening.

The mesenteric sack itself becomes differentiated into a stomach adjoining the cesophagus, a liver opening immediately behind this, and an intestine. The cells forming the hepatic diverticula and

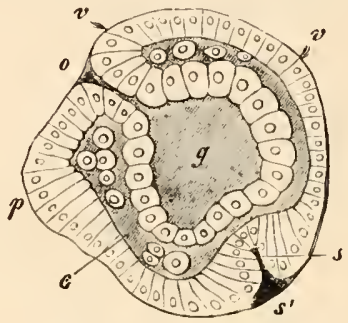

Fig. 102. Limbiryo OF a Heteropod. (Fom Gegenbaur; after Fol.)

o. mouth; $v$. velum; $g$. archenteron; $p$. foot ; $c$. body cavity; s. shell-gland.

sometimes also those of the stomach may during larval life secrete in their interior peculiar albuminous products, similar to ordinary food-yolk.

The proctodreum, except when it is the blastopore, arises later than the mouth. It is frequently developed from a pair of projecting epiblast cells symmetrically placed in the median ventral line behind the foot. It eventually forms a very shallow invagination meeting the intestine. Its opening is the anus. The anus, though at first always symmetrical and ventral, subsequently, on the formation of the pallial cavity, opens into this usually on the right and dorsal side.

In the cases where the hypoblast is not invaginated in the form of a sack the formation of the mesenteron is somewhat complicated, and is described in the sequel.

From the trochosphere stage the larva passes into what has been called by Lankester the veliger stage (fig. IO3), which is especially characteristic of Gasteropod and Pteropod Mollusca.

The shell-gland (with a few exceptions to be spoken of subsequently) of the previous stage flattens out, forming a disc-like area, on the surface of which a delicate shell becomes developed, while the epiblast of the edges of the disc becomes thickened. The disc-like area is the mantle. The edge of the area and with 
it the shell now rapidly extend, especially in a dorsal direction. Up to this time the embryo has been symmetrical, but in most Gasteropods the shell and mantle extend very much more towards the left than towards the right side, and a commencement of the permanent spiral shell is thus produced.

The edge of the mantle forms a projecting lip separating the dorsal visceral sack from the head and foot. An invagination appears, usually on the right in Gasteropods, and eventually extends to the dorsal side (fig. I03 B). It gives rise to the
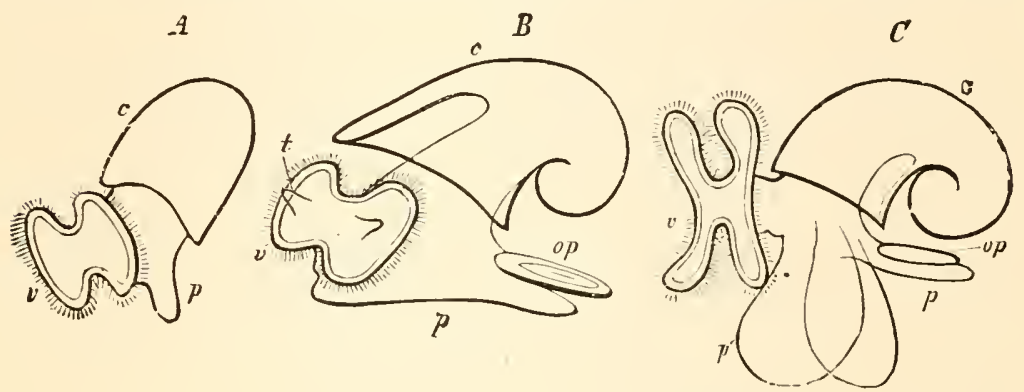

Fig. 103. Larve of Cephalophorous Mollusca in the veliger stage. (From Gegenbaur.)

A. and B. Earlier and later stage of Gasteropod. C. Pteropod (Cymbulia). $v$. velum ; $c$. shell ; $p$. foot ; op. operculum; t. tentacle.

pallial or branchial cavity, and receives also the openings of the digestive, generative and urinary organs. In most Pteropods it is also formed to the right, and usually eventually extends afterwards towards the ventral surface (fig. IO3 C). In the pallial cavity the gills are formed, in those groups in which they are present, as solid processes frequently ciliated. They are coated by epiblast and contain a core of mesoblast. They soon become hollow and contractile.

The velum in the more typical forms loses its simple circular form, and becomes a projecting bilobed organ, which serves the larva after it is hatched as the organ of locomotion (fig. I03 B and $\mathrm{C}$ ). The extent of the development of the velum varies greatly. In the Heteropods especially it becomes very large, and in Atlanta it becomes six-lobed, each lateral half presenting three subdivisions. It is usually armed on its projecting edge with several rows of long cilia, and below this with short cilia 
which bring food to the mouth. It persists in many forms for a very long period. Within the area of the velum there appear the tentacles and eyes (fig. I03 B). The latter are usually formed at the base of the tentacles.

The foot grows in most forms to a very considerable size. On its hinder and dorsal surface is formed the operculum as a chitinos plate which originates in a depression lined by thickened epiblast, much in the same way as the shell (fig. IO3 B and $\mathrm{C}, o p)$. In the typical larval forms it is only possible to distinguish the anterior flattened surface of the foot for locomotion and the posterior opercular region, but special modifications of the foot are found in the Pteropods and Heteropods, which are described with those groups. The foot very often becomes richly ciliated, and otic vesicles are early developed in it (fig. IOI, ot).

All the Gasteropods and Pteropods have a shell-bearing larval form like that first described, with the exception of a few forms, such as Limax and perhaps some other Pulmonata, in which the shell-gland closes up and gives rise to an internal shell.

The subsequent metamorphosis in the different groups is very various, but in all cases it is accompanied by the disappearance of the velum, though in some cases remnants of the velum may persist as the subtentacular lobes (Lymnaus, Lankcstcr) or the lip tentacles (Tergipes, Nordmann). In prosobranchiate Gasteropods the larval shell is gradually added to, and frequently replaced by, a permanent shell, though the free-swimming veligerous larva may have a long existence. In many of the Opisthobranchiata the larval shell is lost in the adult and in others reduced. Lankester, who has especially worked at the early stages of this group, has shewn that the larvæ are in almost every respect identical with those of prosobranchiate Gasteropods. They are all provided with a subnautiloid shell, an operculated foot, etc. The metamorphosis has unfortunately been satisfactorily observed in but few instances. In Heteropods and Pteropods the embryonic shell is in many cases lost in the adult.

The following sections contain a special account of the development in the various groups of Gasteropoda and Pteropoda which will complete the necessarily sketchy account of the preceding pages. 
Gasteropoda. To illustrate the development of the Gasteropoda 1 have given a detailed description of two types, viz. Nassa mutabilis and Paludina vivipara.

Nassa mutabilis. This form, the development of which has been very thoroughly worked out by Bobretzky (No. 242), will serve as an example of a marine Gasteropod with a large food-yolk. The segmentation

A

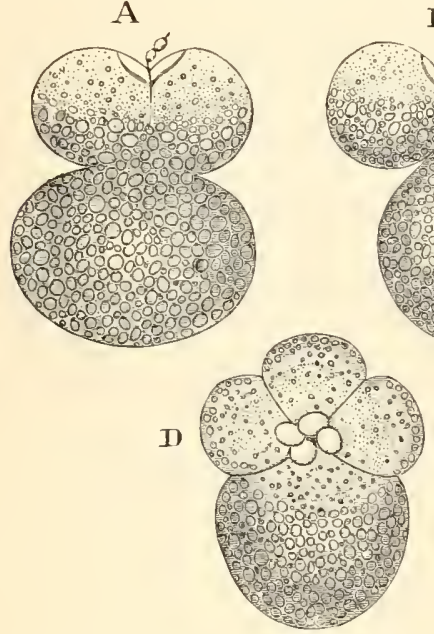

B

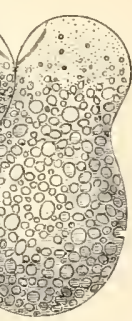

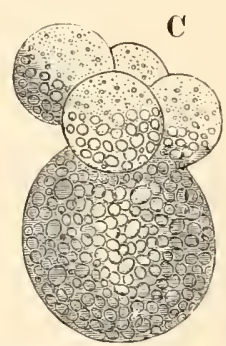

Fig. io4. Segmentation of Nassa mutabilis. (From Bobretzky.)

A. Upper half divided into two segments. B. One of these has fused with the large lower segment. C. Four small and one large segment, one of the former fusing with the large segment. D. Each of the four segments has given rise to a fresh small segment. E. Small segments have increased to thirty-six.

has already been described, p. 102. It will be convenient to take up the development at a late stage of the segmentation. The embryo is then formed of a cap of small cells which may be spoken of as the blastoderm resting upon four large yolk-cells of which one is considerably larger than the others (fig. Iot A). The small and the large cells are separated by a segmentation cavity. The general features at this stage are shewn in fig. I05 A, representing a longitudinal section through the largest yolkcell and a smaller yolk.cell opposite to it. The blastoderm is for the most part one cell thick, but it will be noticed that, at the edge of the blastoderm adjoining the largest yolk-cell, there are placed two cells underneath the edge of the blastoderm (me). These cells are the commencement of the mesoblast. In the later stages of development the blastoderm continues to grow over the yolk-cells, and as it grows the three smaller yolkcells travel round the side of the largest yolk-cell with it. As they do so they give rise to a layer of protoplasmic cells (fig. 105, hy) which form a thickened layer at the edge of the blastoderm and therefore round the 
lips of the blastopore. These cells form the hypoblast. The whole of the protoplasmic matter of the yolk-cells is employed in the formation of the hypoblast. The rest of them remains as a mass of yolk. A longitudinal section of the embryo at a slightly later stage, when the blastopore has become quite narrowed, is represented in fig. $105 \mathrm{C}$. The greater part of the dorsal surface is not represented.

Two definite organs have already become established. One of these is a pit lined by thickened epiblast on the posterior and dorsal side $(s g)$. This
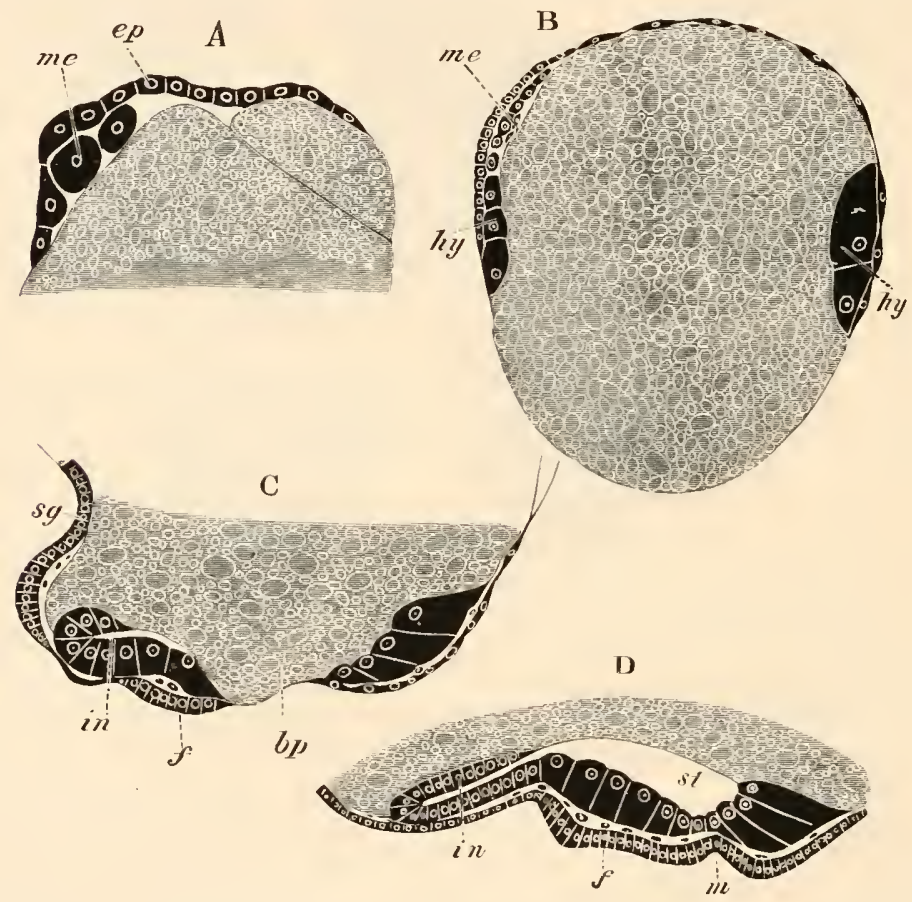

Fig. 105. Longitudinal Section throvgh the embrio of Nassa mutaBil.is. (After Bobretzky.)

A. Stage when the mesoblast is commencing to be formed.

B. Stage when the yolk is half enclosed. The hypoblast is seen at the lips of the blastopore.

C. Stage when the blastopore $(b p)$ is nearly obliterated.

D. The blastopore is closed.

ep. epiblast; me. mesoblast; $h y^{\prime}$. hypoblast; bp. blastopore; in. intestine; st. stomach; f. foot; sg. shell-gland; $m$. mouth.

is the shell-gland. The other is the foot $(f)$ which arises as a ventral prominence of thickened epiblast immediately behind the blastopore. The hypoblast forms a ring of columnar cells round the blastopore. On the 
posterior side its cells have bent over so as to form a narrow tube (in), the rudiment of the intestine.

In the next stage (fig. I05 D) the blastopore completely closes, but its position is marked by a shallow pit $(m)$ where the stomodæum is eventually formed. The foot $(f)$ is more prominent, and on its hinder border is formed the operculum. The shell-gland (not shewn in the figure) has flattened out, and its thickened borders commence to extend especially over the dorsal side of the embryo. A delicate shell has become formed. In front of and dorsal to the mouth, a ciliated ring-shaped ridge of cells, which is however incomplete dorsally, gives rise to the velum. On each side of the foot there appears a protuberance of epiblast cells, which forms a provisional renal organ. The hypoblast now forms a complete layer ventrally, bounding a cavity which may be conveniently spoken of as the stomach (st), which is open to the yolk above. Posteriorly however a completely closed intestine is present, which ends blindly behind (in).

The shell and with it the mantle grow rapidly, and the primitive symmetry is early interfered with by the shell extending much more towards the left than the right. The anus soon becomes formed and places the intestine in communication with the exterior.

With the growth of the shell and mantle the foot and the head become sharply separated from the visceral sack (fig. I06). The asophagus (m) becomes elongated. The eyes and auditory sacks become formed.

With further growth the asymmetry of the embryo becomes more marked. The intestine takes a transverse direction to the right side of the body, and the anus opens on the right side and close to the foot in the mantle cavity which is formed by an epiblastic invagination in this region. The cavity of the stomach (fig. I06, st) increases enormously and passes to the left side of the body, pushing the food-yolk at the same time to the right side, and the point where

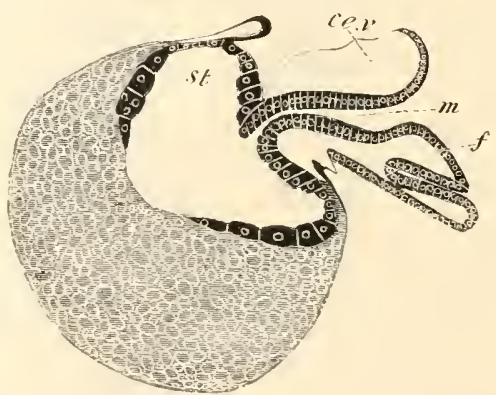

Fig. I06. LONGITUdiNAL SECTION THROUGH AN ADVANCED EMBRYO OF Nassa mutabilis. (After Bobretzky.)

f. foot; $m$. mouth; co.v. cephalic vesicle; st. stomach. it communicates with the intestine becomes carried towards the posterior dorsal end of the visceral sack. The walls of the stomach gradually extend so as to narrow the opening to the yolk. The part of it adjoining the œsophagus becomes the true stomach, the remainder the liver; its interior is filled with coagulable fluid.

Paludina. Paludina-Lankester (No. 263) and Bütschli (No 214)-is a viviparous form characterised by the small amount of food-yolk. The hypoblast and epiblast cells are distinguished very early, but soon become of nearly the same size. 
In the later stages of segmentation the epiblast cells differ from the hypoblast cells in the absence of pigment. The segmentation cavity, if developed, is small, A perfectly regular gastrula is formed (fig. I07 A and B), which is preceded by the embryo assuming a flattened form. The blastopore is at first wide, but gradually narrows, and finally assumes a slightly excentric position. It becomes not the mouth, but the anus.

When the blastopore has become fairly narrow, mesoblast cells (B, me.) appear around it, between the epiblast and hypoblast. Whether they are
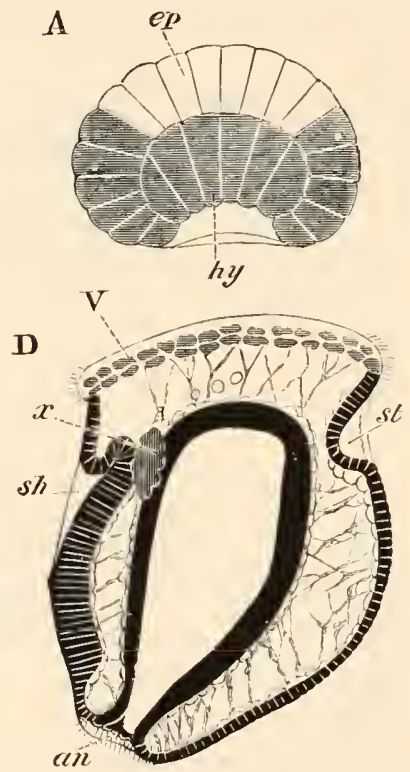
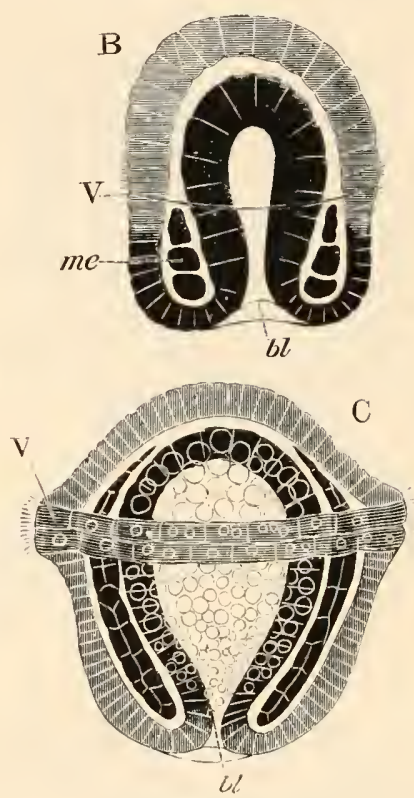

F1G. 107. Four Stages 1N THE DEVElopMENT OF PALUDiNA VIVIPARA. (Copied from Biitschli.)

$c p$. epiblast ; hy. hypoblast ; me. mesoblast ; $b l$. blastopore ; $a n$. anus ; st. stomodreum ; sh. shell-gland ; $I$. velum; $x$. primitive excretory organ.

bilaterally arranged or no is not clear; and though coloured like the hypoblast, their actual development from this layer has not been followed.

The velum appears about the same time as the mesoblast, in the form of a double ring of ciliated cells at about the middle of the body ( $\mathrm{B}$ and $\mathrm{C}, V$ ). The mesoblast rapidly extends so as to occupy the whole space between the epiblast and hypoblast, and at the same time becomes divided into two layers (C). Shortly afterwards a space-the body cavity-appears between the two layers (D) which then attach themselves respectively to the epiblast and hypoblast, and constitute the somatic and splanchnic layers of mesoblast. The two layers remain cornected by transverse strands. 
By a change in the relations of the various parts and especially by the growth of the posterior region of the body, the velum now occupies a position at the end of the body opposite the blastopore. Immediately behind it there appear two organs, one on the dorsal and one on the ventral side. That on the dorsal side $(s h)$ is a deep pit-the shell-glandwhich is continuous with a layer of columnar epiblast which ends near the anus. The other organ (st), situated on the ventral side, is a simple depression, and is the rudiment of the stomodrum. Between it and the dorsally placed anus is a slight prominence-the rudiment of the foot. On the two sides of the body, between the epiblast and hypoblast on a level with the shell-gland are placed two masses of excretory cells, the provisional kidneys $\left(\mathrm{D}, x^{*}\right)$. These are probably not homologous with the provisional renal organ of Nassa and other marine Prosobranchiata. At a later period a ciliated cavity appears in them, which probably communicates with the exterior at the side of the throat.

In the later stages the foot grows rapidly, and forms a very prominent mass between the mouth and the anus. An operculum is developed somewhat late in a shallow groove lined by thickened epiblast.

A provisional chitinous plug is formed in the shell-gland which soon becomes everted. The shell is formed in the usual way on the everted surface of the shell-gland. The thickened edge of this part becomes the edge of the mantle, and soon projects in the neighbourhood of the anus as a marked fold.

With the rapid growth of the larva the invaginated mesenteron becomes relatively reduced in size. In its central part yolk spherules become deposited, while the part adjoining the blastopore (anus) becomes elongated to give rise to the intestine. The stomodæum grows greatly in length and joins the dorsal part of the archenteron which then becomes the stomach. The part of the mesenteron with yolk spherules forms the liver. With the development of the visceral sack the anus shifts its position. It first passes somewhat to the left, and is then carried completely to the right.

The development of Entoconcha mirabilis (Joh. Müller, No. 265), a remarkable Prosobranchiate parasitic in the body cavity of Synapta, which in the adult state is reduced to little more than an hermaphrodite generative sack, deserves a short description. It is viviparous, and the ovum gives rise to a larva which from the hardly sufficient characters of the foot and shell is supposed to be related to Natica.

There is nothing very striking in the development. The food yolk is scanty. The velum, as might be anticipated from the viviparous development, is small. The tentacles are placed not within, but behind the velar area. There is a natica-like shell, a large mantle-cavity, and a large twolobed foot.

In Buccinum, and Neritina only one out of the many ova included in each egg-capsule develops. The rest atrophy and are used as food by the one which develops.

Opisthobranchiata. It will be convenient to take a species of 
Pleurobranchidium (Aplysia), observed by Lankester (No. 239), as a type of Nudibranchiate development. The ovum first divides into two segments, and from these small segments are budded off, which gradually grow round and enclose the two large segments. The small segments now form the epiblast.

At the aboral pole the epiblast becomes thickened and invaginated to form the shell-gland, and shortly afterwards the velum and foot are formed in the normal way, and a stomodæum appears close to the ventral edge of the velum (fig. IOI). The two yolk cells $(r y)$ still remain distinct, but a true hypoblastic layer (probably derived from them, though this has not been made out) soon becomes established. Prominent cells early make their appearance at the base of the foot, which become at a later period invaginated to form the anus. Otolithic sacks $(o t)$ become formed in the foot, and the supraœsophageal ganglia from a differentiation of the epiblast $(n g)$.

At a later period the shell-gland becomes everted, and a nautiloid shell developed. The alimentary tract becomes completed, though the two yolk cells long retain their original distinctness. The shell-muscle is developed, and peculiar pigmented bodies are formed below the velum. The foot becomes prominent and acquires an operculum.

The metamorphosis of Tergipes has been more or less completely worked out by Nordmann and by Schultze (No. 271).

In Tergipes Edwardsii worked out by the former author, the larva when hatched is provided with a large velum, eyes, tentacles, an elongated operculated foot, and mantle. In the next stage both shell and operculum are thrown off, and the body becomes elongated and pointed behind. Still later a pair of gill-processes with hepatic diverticula becomes formed.

The velum next becomes reduced, and two small processes, which give rise to the lip tentacles and a second pair of gills, sprout out. An ecdysis now takes place, and leads to further changes which soon result in the attainment of the adult form.

In Tergipes lacinulatus, observed by Schultze, the velum atrophies before the shell and operculum are thrown off.

Pulmonata. The development of the fresh-water Pulmonata appears from Lankester's observations on the pond-snail (Lymnæus) to be very similar in all important particulars to that of marine Branchiogasteropoda. The velum is however less developed than in most marine forms. The shell-gland, etc. have the normal development. In Lymnæus the blastopore has an elongated form and it is still a matter of dispute whether it closes at the mouth or anus.

In the Helicida there is a gastrula by epibole. The shell-gland, as may be gathered from Von Jhering's figures, has the usual form, and an external shell of the usual larval type is developed. There is a ciliated process above the mouth, which extends into the lumen of the mouth. This process is often regarded as a rudimentary velum, but probably has not this value. There is no other organ which can be homologous with the velum. 
The development of Limax presents some peculiarities. The yolkspheres (hypoblast) form a large mass enclosed by the epiblast cells. A shell-gland is formed in the usual situation, which however, instead of being everted, as in ordinary forms, becomes closed, and in its interior are deposited calcareous plates which give rise to the permanently internal shell. The foot grows out posteriorly, and contains a large provisional contractile vesicle, traversed by muscular strands which contract rhythmically.

Although an external shell is present in Clausilia in the adult, the shell-gland becomes closed in the embryo as in Limax, and an internal plate-like shell is developed. The shell is at first covered by a complete epithelium, which eventually gives way in the centre, leaving covered only the edges of the shell. It thus comes about that the original internal shell becomes an external one. It is very difficult to bring this mode of development of the external shell into relation with that of other forms. Clausilia like Limax develops a large pedal sinus.

In both Limax and Clausilia cilia are early developed and cause a rotation of the embryo, but how far they give rise to a distinct velum is not clear.

Heteropoda. The Heteropod embryos present in their early development the closest resemblance to those of other Gasteropods. The segmentation takes place according to the most usual Gasteropod type; (vide p. 99) and after the yolk cells have ceased to give origin to epiblast cells they divide towards the nutritive pole, become invaginated, and line a spacious archenteron. The epiblast cells at the formative pole gradually envelop the yolk (hypoblast) cells, and the blastopore very early narrows and becomes the permanent mouth.

Sinultaneously with the narrowing of the blastopore, the shell-gland is formed at the aboral pole, and the foot on the ventral side. The velum appears as a patch of cilia on the dorsal side, which then gradually extends ventrally so as to form a complete circle just dorsal to the mouth.

The larva, after these changes have been completed, is represented in fig. IO2.

In later stages the shell-gland becomes everted, and a shell is developed in all the forms both with and without shells in the adult. The foot grows very rapidly, and an operculum is in all cases formed behind. A bilobed invagination in front gives rise to the mucous gland. The velum enlarges and becomes bilobed.

Though the blastopore remains permanently open as the mouth, the œsophagus is formed as an epiblastic ingrowth. The rudiment of the proctodæum appears as two epiblastic cells symmetrically placed behind the foot, which subsequently pass to the right side, and give rise to a shallow invagination which meets the mesenteric sack. In the latter structure the cells of part of the wall develop a peculiar nutritive material, and form a nutritive sack which eventually becomes the liver. The part of the sack connected with the epiblastic œesophagus becomes constricted off as the 
stomach. The remainder, which unites with the proctodæum, forms the intestine.

The structural peculiarities of the adult are formed by a post-larval metamorphosis. The caudal appendage of Pterotrachea and Firoloidea is formed as an outgrowth of the upper border of the hind end of the foot. The so-called fin arises as a cylindrical process in front of the base of the foot, which is eventually flattened laterally. In the Atlantidre it is in some cases at first vermiform, and in other cases attains directly its adult structure. The embryonic foot itself gives rise in Pterotrachea, Firoloidea and Carinaria to the tail, on the dorsal and posterior side of which the operculum may still be seen in young specimens. In Atlanta it forms the posterior part of the foot on which the operculum persists through life.

The embryonic shell is completely lost in Pterotrachea and Firoloidea, and the shell is rudimentary in Carinaria. With its atrophy the mantle region also becomes much reduced.

The velum is enormously developed in many Heteropods. In Atlanta it is six-lobed, each of the two primitive lateral lobes being prolonged into three processes, two in front, and one behind. As in all other cases, it atrophies in the course of the post-larval metamorphosis.

Pteropoda. The early larval form of the Pteropods is closely similar to that of marine Gasteropods. There are usually only three hypoblastic spheres at the close of the segmentation in the Thecosomata, and a somewhat larger number in the Gymnosomata. The blastopore closes at the oral region, on the nutritive side of the ovum, and the shell-gland is placed at the original formative pole. The velum, shell-gland and foot have the usual relations. Although many of the adult forms are symmetrical, there is very early an asymmetry visible in the larva, shewing that the Pteropods are descended from asymmetrical ancestors. In the Gymnosomata there is a second larval stage after the loss of the shell when the larva is provided with three rings of cilia (fig. 109). In most forms of Pteropods the dorsal part of the body, covered by the mantle, is produced into a visceral sack like that of the Cephalopoda (fig. ro8).

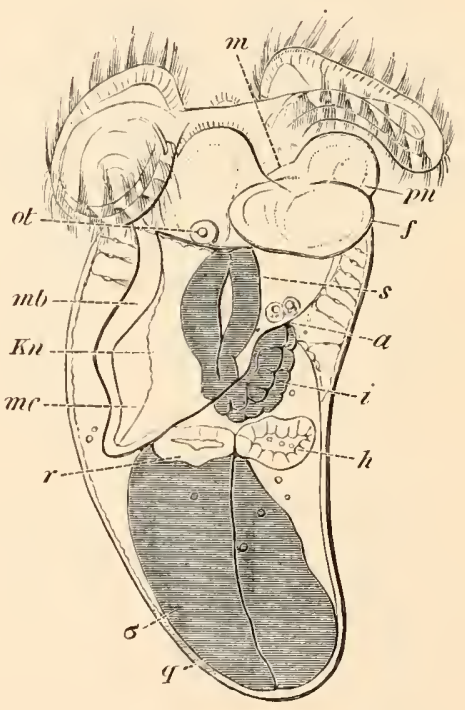

Fig. io8. Embryo of Cavolinia (Hyalea) tridentata. (After Fol.)

$m$. mouth ; $a$. anus; s. stomach; $i$. intestine; $\sigma$. nutritive sack; $m b$. mantle; $m c$. mantle cavity; $K n$. contractile sinus; $h$. heart; $r$. renal sack : $f$. foot; $p n$. epipodia ; q. shell; ot. otolithic sack. 
The velum varies considerably in its development in different forms. In the Hyaleidæ it is comparatively small and atrophies early; while in Cymbulia (fig. I03) and the Gymnosomata it is large and bilobed, and persists till after the foot has attained its full development.

The free edge of the velum is provided with long motor cilia, and its lower border with small cilia which bring the food to the mouth. In Cleodora there is a median bunch of cilia in the centre of the velum like that in the Lamellibranchiata, Nudibranchiata, etc.

The shell-gland forms a pit at the aboral end of the body, and in Cymbulia a chitinous plug appears to be normally formed in this pit. The pit afterwards everts itself. The edge of the everted area becomes thickened and gradually travels towards the anterior end of the body. On this everted area a small plate is developed, which forms the commencement of the embryonic shell with which the larvæ of all Pteropods are provided.

The remainder of the embryonic shell is secreted in successive rings by the thickened edge of the mantle, and grows with this till it reaches the neck (fig. I08). The permanent shell is added subsequently, usually on a very different model to the larval shell. The fate of the embryonic shell is very various in different forms. In the Hyaleidæ the animal withdraws itself from the larval shell, which becomes shut off from the permanent shell by a diaphragm. The larval shell then becomes detached.

In the Styliolidæ the permanent shell becomes twice the size of the embryonic shell while the animal is still in an embryonic condition, but the larval shell persists for life. In the Cymbulidx there is an embryonic and secondary shell, which persist together during larval life. They are eventually cast off at the same time and replaced by a permanent shell.

In the Gymnosomata an embryonic shell is developed, and a secondary shell added to it during embryonic life. Both are cast off before the adult condition is attained. After the shell
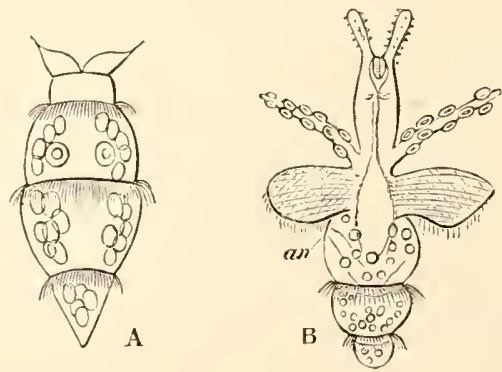

Fig. Io9. Free siviming PNeumodermon LARVIE. (After Gegenbaur, copied from Bronn.)

The velum has atrophied in both larvæ.

In $A$ three ciliated bands are present, and the auditory vesicles are visible.

In $B$ the tentacles with suckers and the epipodia have become developed.

an. anus. has been cast off three ciliated rings are developed (fig. I09). The anterior of these is placed between the velum and the foot, and the two hinder ones on the elongated posterior part of the body.

B. II. 
The ciliated rings give to these larvæ a resemblance to Chætopod larvæ; but there can be no doubt that this resemblance is a purely superficial oneThe anterior ring atrophies early (fig. I09 B), and the second one soon follows suit. It is probable that the hindermost one does not persist through life, although it has been observed in forms with fully developed sexual organs. Most of these larvæ have not been traced to their adult forms. They have been referred to Pneumodermon, Clio, etc.

The most characteristic organ of the Pteropods is the foot, which is prolonged into two enormous lateral wings, the epipodia. These develope at different periods in different larvæ, but are always distinct lateral outgrowths of the foot.

In the Hyaleidie the foot is early conspicuous, and soon sends out two lateral prolongations (fig. Ios $p n$.) which develop with enormous rapidity as compared with the medium portion, and give rise to the epipodia. The whole of the foot becomes ciliated.

In the Cymbulidæ, though not in other forms, an operculum is developed on the hinder surface of the foot (fig. I03 C). The epipodia are late in appearing.

In the Gymnosomata the foot is developed very early, but remains small. The epipodia do not appear till very late in larval life (fig. Io9 B).

In Pneumodermon and some other Gymnosomata there appear on the hinder part of the head peculiar tentacles with suckers like those of the Cephalopoda (fig. $\log$ B). It is not certain that these tentacles are genetically related to the arms of the Cephalopoda.

Cephalopoda. The eggs of the Cephalopoda are usually laid in special capsules formed in the oviduct, which differ considerably in the different members of the group.

In the case of Argonauta each egg is enveloped in an elongated capsule provided with a stalk. By means of the stalk the eggs are attached together in bunches, and these again are connected together and form transparent masses, which are placed in the back of the shell. In octopus the eggs are small and transparent : each of them is enclosed in a stalked capsule. In Loligo the eggs are enveloped in elongated sack-like gelatinous cords, each containing about thirty or forty eggs. The cords are attached in bunches to submarine objects. In Sepia each egg is independently enveloped in a spindle-shaped black capsule, which is attached to a stone or other object.

In a decapod form with pelagic larvæ, described by Grenacher (No. 280), the eggs were enclosed in a somewhat cylindrical gelatinous mass. In each mass there were an immense number of eggs arranged in spirals. Each ovum was enclosed in a structureless membrane, within which it floated in a colourless albumen.

The ovum itself within the capsule is a nearly homogeneous granular mass, without a distinct envelope. Development com- 
mences by the segregation, at the narrow pole of the ovum opposite the egg-stalk, of the greater part of the protoplasmic formative material ${ }^{1}$. This material forms a disc equivalent to the germinal disc of meroblastic vertebrate ova. The germinal disc in Sepia and Loligo does not, however, undergo a quite symmetrical segmentation (Bobretzky, No. 279). When eight segments are present, two of them close together are much smaller and narrower than the remainder; and when, in the succeeding stages small segments are formed from the inner ends of the large ones, those derived from the two smaller segments continue to be smaller than the remainder: so that throughout the segmentation one pole of the blastoderm is formed of smaller segments, and the blastoderm exhibits a bilateral symmetry ${ }^{2}$. The partial segmentation results in the formation of a blastoderm covering one pole of the egg, but, unlike the vertebrate blastoderm, formed of a single row of cells. This blastoderm very soon becomes two or three cells deep at its edge, and the cells below the surface constitute the layer from which the mesoblast and hypoblast originate (fig. I I $\mathrm{ms}$ ). The origin of the mesoblast at the edge of the blastoderm is a phenomenon equivalent to its origin at the lips of the blastopore in so many other types. The external layer forms the epiblast.

The whole blastoderm does not take its origin from the segmentation spheres, but, as was discovered by Lankester (282), a number of nuclei arise spontaneously in the yolk outside the blastoderm, around which cell-bodies become subsequently formed. They make their appearance near to, but not at the surface, extending first in a ring-like series in advance of the margin of the blastoderm, but subsequently appearing indiscriminately over all parts of the egg. They take no share in forming the epiblast, but would seem, according to Lankester, to assist in giving rise to the lower layer cells, and also to a layer of flattened cells which eventually completely encloses the yolk, and may be called the yolk membrane. The cells of the yolk membrane first of all appear at the thickened edge of the

1 In Octopus and Argonauta (Lankester) as soon as the blastoderm is completed the egg reverses its position in the egg-shell ; the cleavage pole taking up a position nearest the stalk.

2 I do not know the relation of this axis of symmetry to the future embryo. 
blastoderm. From this point they spread inwards under the centre of the blastoderm (fig. I $\left.5 m^{\prime}\right)$, and, together with the epiblast cells, outwardsover the yolk generally; so that before long (on the tenth day in Loligo) the yolkbecomescompletely invested by a membrane of cells.

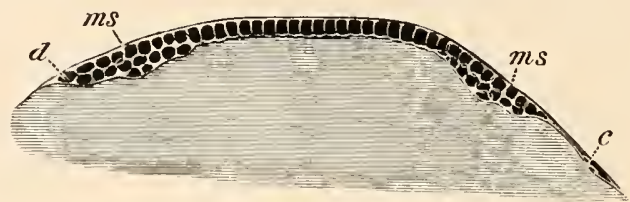

Fig. ilo. Section throvgin the blastoderm OF A LOLIGO OVUM AT THE BEGINNING OF THE FOURTH DAY. (After Bobretzky.)

$m s$. mesoblast; $d$. cell at the edge of the blastoderm ; $c$. one of the segmentation cells.

In the non-germinal region the blastoderm is formed of two layers, (I) a flattened epiblast, and (2) the yolk membrane. In the region of the original germinal disc the epiblast cells become columnar, and below them is placed a ring of lower layer cells, which gradually extends towards the centre so as finally to form a complete layer. Below this again comes the yolk membrane just spoken of.

Before describing the further fate of the separate layers it is necessary to say a few words as to the external features of the embryo. In the adult Cephalopod it is convenient, for the sake of comparison with other Mollusca, to speak of the narrow space enclosed in the arms, which contains the mouth, as the ventral surface; the aboral apex as the dorsal surface; and what is usually called the upper surface as the anterior and the lower one as the posterior.

Employing this terminology the centre of the original blastoderm is the dorsal apex of the embryo. In the typical forms with a large yolk-sack the whole embryo is formed out of the original germinal disc; the part of the blastoderm which is continued as a thin layer over the remainder of the egg forms a large ventral yolk-sack appended to the head of the embryo. The following description applies especially to two types, which form the extremes of the series in reference to the development of the yolk-sack. The first of these with a large yolk-sack is Sepia, of which Kölliker in his classical memoir (No. 281) has published a series of beautiful figures. The second, with a small yolk-sack, is the pelagic larva of an unknown adult described by Grenacher (No. 280). 
In a young blastoderm of Sepia viewed from the dorsal surface, a series of structures appear which are represented in fig. I I A. In the middle is a somewhat rhomboid prominence which forms the rudiment of the mantle $(m t)$. In its centre is a pit which forms the shell-gland. On each side of the mantle is a somewhat curved fold $(f)$. These folds eventually coalesce to form the funnel. They are divided into two parts by a small body which forms the cartilage of the funnel. The smaller part of the fold behind this body gives rise to the true funnel, the part in front becomes (Kölliker) the strong muscle connecting the funnel with the neck-cartilage. In front and to the sides are two kidney-shaped bodies (oc) the optic pits. Behind the mantle are two buds $(b r)$, the rudiments of the gills.

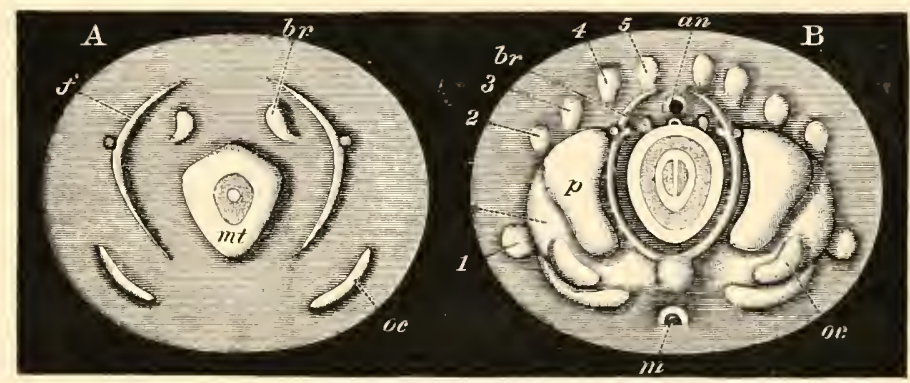

Fig. 11. Two SURface views of the germinal disc of Sepia. (After Kölliker.)

$m t$. mantle; oc. eye; $f$. folds of funnel; $b r$. branchix; $a n$. posterior portion of alimentary tract ; $m$. mouth. $1,2,3,4,5$, arms ; $p$. cephalic lobe.

In the somewhat later stage rudiments of the two posterior pairs of arms make their appearance outside and behind the rudiments of the funnel. The head is indicated by a pair of lateral swellings on each side, the outer of which carries the eyes. The whole embryo now becomes ciliated, though the ciliation does not cause the usual rotation. At a slightly later stage the second, third, and fourth pairs of arms make their appearance slightly in front of those already present. The posterior parts of the funnel rudiments approach each other, and the anterior meet the rudiments of the neck-cartilage. The gills begin to be covered by the mantle-edge, which now projects as a marked fold. At a slightly later period two fresh rudiments may be 
noted, viz. the oral (fig. I I $B, m$ ) and anal invaginations, the latter of which is extremely shallow and appears at the apex of a small papilla which may be spoken of as the anal papilla. These invaginations appear at the two opposite poles (anterior and posterior) of the blastoderm. Shortly after this the rudiment of the first pair of arms arises considerably in front of the other rudiments, at the sides of the outer pair of cephalic swellings (fig. I I I B, 1).

Fig. I I $B$ represents a view from the dorsal surface of an embryo at this stage. In the centre is the mantle with the shellgland which is now very considerably raised beyond the general surface. Concentric with the edge of the mantle are the two
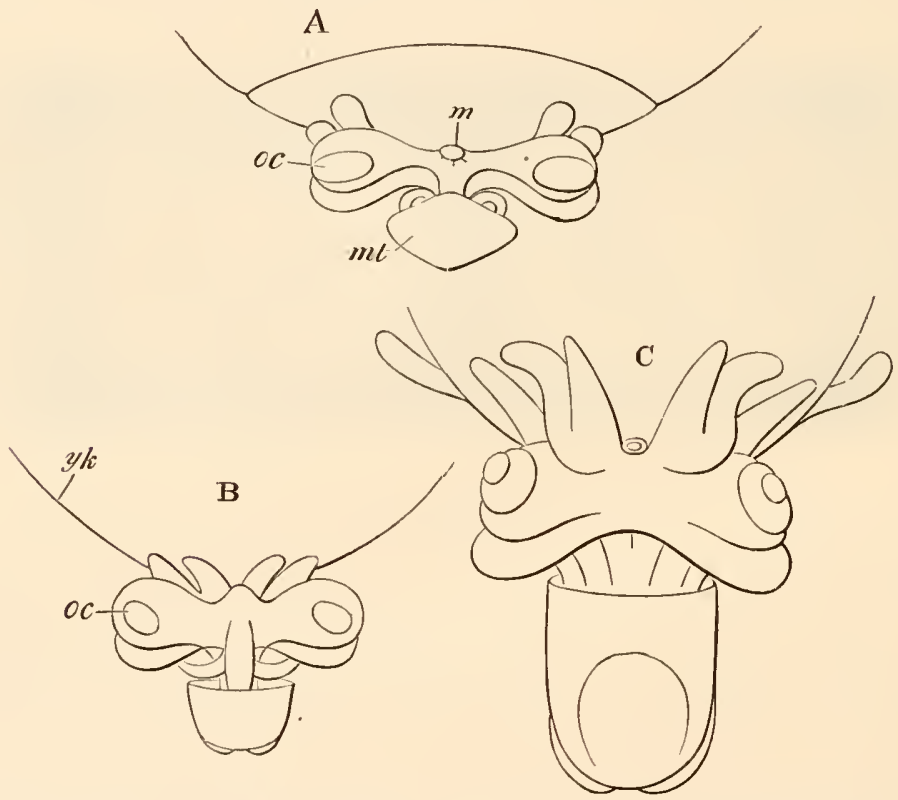

Fig. 1 I2. Side Views of THREe LATE STAges in THE DEVElopment of SEP1A. (After Kölliker.)

m. mouth ; $y k$. yolk-sack; oc. eye; mt. mantle.

halves of the funnel, the anterior half meeting the dorsal or neckcartilage and the posterior halves approaching each other. The oral invagination is shewn at $m$ and the anal immediately in front of $a n$. The gills, nearly covered by the mantle, are seen at br. At $p$ are the cephalic swellings, and the eye is seen at $o c$. 
The arms $\mathrm{I}-5$ form a ring outside these parts. The whole of the embryo, with the exception of the gills, the funnel, and the outer border of the blastoderm, is richly ciliated.

The embryo up to this time has had the form of a disc or saucer on the surface of the yolk. After this stage it rapidly assumes its permanent dome-like form, and becomes at the same time folded off from the yolk. The blastoderm is very slow in enveloping the yolk, and the whole yolk is not completely invested till a considerably later stage than that represented in fig. I I B. As soon as the blastoderm covers the yolk-sack cilia appear upon it. The mantle grows very rapidly, and its free border soon projects over the funnel and gills. After the two halves of the funnel have coalesced into a tube, it comes to project again beyond the edge of the mantle.

On the completion of the above changes the resemblance of the embryo to a Cuttle-fish becomes quite obvious. Three of the stages in the accomplishment of these changes are represented in fig. I 12.

To the ventral side of the embryo is attached the enormous external yolk-sack $(y / k)$, which is continuous with an internal section situated within the body of the embryo. The general relations of the embryo to the yolk will best be understood by reference to the longitudinal section of Loligo, fig. 127.

The arms gradually increase in length, and the second pair passes in front of the first so as eventually to lie completely in front of the mouth. The arms thus come to form a complete ring surrounding the mouth, of which the original second pair, and not, as might be anticipated, the first, completes the circle in front. The second pair develops into the long arms of the adult.

After the embryo has attained more or less completely its definite form (fig. I 2 C) it grows rapidly in size as compared with the yolk-sack. The latter structure is at first four or five times as big as the embryo, but, by the time of hatching, the embryo is two to three times as big as the yolk-sack.

Loligo mainly differs from Sepia in the early enclosure of the yolk by the blastoderm, and in the embryo exhibiting the phenomena of rotation within the egg-capsule so characteristic of other Mollusca.

In Argonauta the yolk-sack is still smaller than in Loligo, and the yolk is 
early completely enclosed by the blastoderm. A well developed outer yolksack is present during early embryonic life, but is completely absorbed within the body before its close. Cilia appear on the blastoderm very early, but vanish again when the yolk is about two-thirds enclosed. There is, during embryonic life, no trace of a shell, but the mantle and other parts of the body become covered by peculiar bunches of fine setæ. The shell-gland develops normally in both Octopus and Argonauta, but disappears again without closing up to form a sack (Lankester).

The pelagic Decapod larva described by Grenacher, which forms my second type, must be placed with reference to the development of the yolk-sack at the opposite pole to Sepia. Segmentation, as in other Cephalopods, is partial, but the blastoderm almost completely envelops the yolk before any organs are developed; and no external yolk-sack is present. At a stage slightly before the closure of the yolk-blastopore the mantle is formed as a slight prominence at the blastodermic pole of the egg, and even at this early stage is marked by the presence of chromatophores. The edge of the blastoderm is ciliated. At a slightly later stage the embryo becomes more cylindrical, the edge of the mantle becomes marked by a fold, which divides the embryo transversely into two unequal parts, a smaller region covered by the mantle, and a larger region beyond this. The yolk is still exposed, but rudiments of the optic pit and of two pairs of arms have appeared. The first-formed arms are apparently the anterior, and not, as in Sepia, the posterior.

At a still later stage, represented in lateral and posterior views in fig. Ir $3 A$ and $B$, considerable changes are effected. The yolk-blastopore is nearly though not quite closed. The mantle fold ( $m t$ ) is much more prominent, and on the posterior side on a level with its edge may be seen the rudiments of the gills $(b r)$. The funnel is formed as two independent folds on each side (inf $f^{1}$ and $i n f^{2}$ ), which apparently correspond with the two divisions of the funnel rudiments in Sepia. The eye has undergone considerable changes. Close to each rudiment of the funnel may be seen a fresh sense-organ-the auditory sack (ac). The ventral (upper in the figure) end of the body now forms a marked protuberance, probably equivalent to the foot of other Mollusca (vide p. 225), at the sides of which are seen the rudiments of the arms $(1,2,3)$. To the two previously present a third one, on the posterior side, has been added. The blastopore 
is placed on the anterior side of the ventral protuberance, and immediately dorsal to this is an invagination (os) which gives rise to the stomodæum. The ciliation at the edge of the blastopore still persists, but does not lead to the rotation of the embryo.

In later stages (fig. I 3 C) the blastopore becomes closed, and the mantle region increases in length as compared with the remainder of the body. The ventral halves of the funnel, each in the form of a half tube, coalesce together to form a single

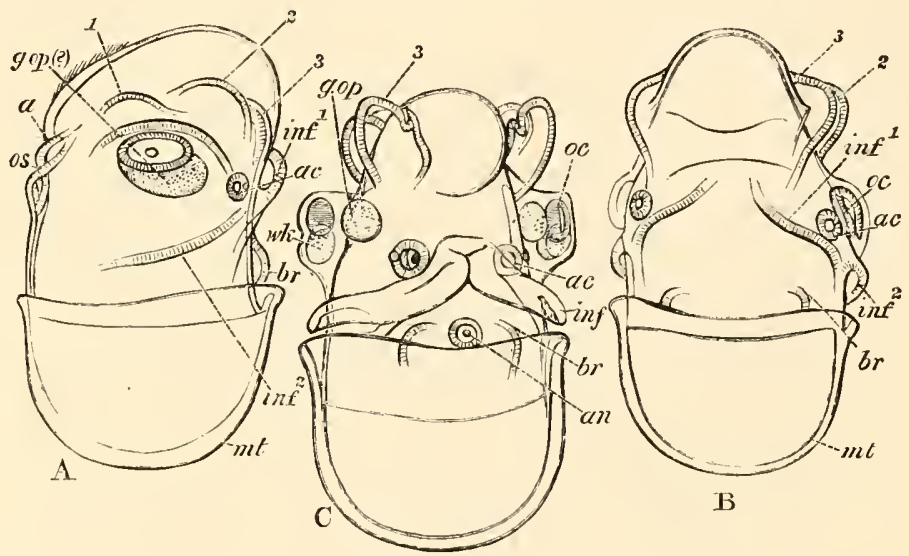

Fig. 113. Three Embryos of a Cephalopod With a Very small yolk-SaCk. (After Grenacher.)

$a$. blastopore; $b r$. branchix; inf. ${ }^{1}$ and $i n f .{ }^{2}$ posterior and anterior folds of the funnel; $g$. op. optic ganglion (?); oc. eye ; wh. white body; $a c$. auditory pit ; os. stomodæum; an. anus; mt. mantle; 1, 2, 3. 1st, 2nd, and 3 rd pairs of arms.

tube (inf) in the same manner as in Sepia. A shallow proctodæum $(a n)$ is formed between the two branchiæ. The eyes $(o c)$ stand out as lateral projections, and the arms become much longer.

Still later a fourth pair of arms is added as a bud from each of the posterior pair, and with the growth in length of the arms the suckers make their appearance. The mouth is gradually carried up so as to be surrounded by the arms. The ciliation of the surface becomes more extensive.

During the whole of the above development the interior of the embryo is filled with yolk, although no external yolk-sack is 
present. The internal yolk-sack falls into three sections; a cephalic section, a section in the neck, and an abdominal section. Of these, that in the neck is the first to be absorbed. The cephalic portion fills out the ventral protuberance already spoken of. The hinder section becomes occupied by the liver which exactly fits itself into this space as it absorbs the material pre. viously there.

It will be convenient at this point to complete the account of the Cephalopoda by a short history of their germinal layers, and by a fuller description of the mantle, shell, and funnel than that given in the preceding pages.

It has already been shewn that in the region of the germinal disc a thick layer of celis becomes interposed between the epiblast and the yolk membrane. This layer (fig. I I $5 \mathrm{~m}$ ) is mainly mesoblastic, but also contains the elements which form the

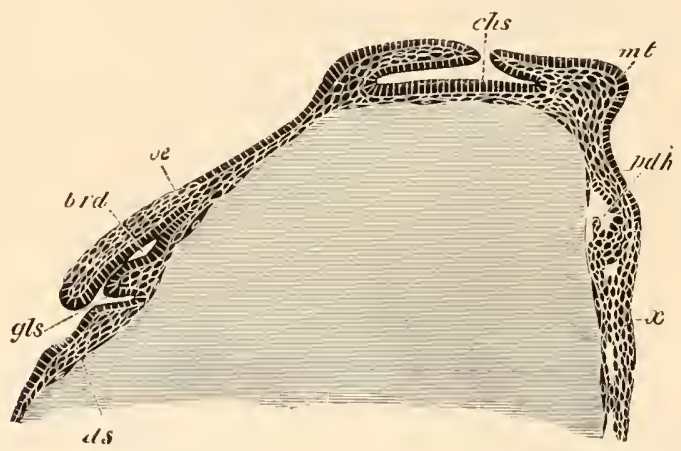

Fig. II 4 . LONGITUDinal VERTICAL SECTION THROUgh a LOLIGU OVUM WHEN THE MESENTERIC CAVITY IS JUST COMMENCING TO BE FORMED.

(After Bobretzky.)

gls. salivary gland; brd. sheath of radula; oe. œsophagus; $d s$. yolk-sack; chs. shell-gland; $m t$. mantle; $p d h$. mesenteron; $x$. epiblastic thickening between the folds of the funnel.

lining of the alimentary tract. Its cells first become differentiated into mesoblast and hypoblast after the shell-gland has become a fairly deep pit. The mode of differentiation is shewn in fig. I I4. On the posterior side of the mantle, at the point marked in fig. I I B, an, a cavity is formed between the yolk membrane and the mesoblast cells (fig. I I 4, pdlh). This cavity is the commencement of the anal extremity of the mesenteron, and the columnar cells lining it constitute the hypoblast. The 
remainder of the lower layer cells are the mesoblast. The mesenteron gradually extends itself till it meets the stomodæum (fig. I27). The proctodæum is formed as a shallow pit close to the first formed part of the mesenteron.

The mesoblast gives rise not only to the organs usually formed in this layer, but also to the nervous centres, etc.

The mantle and shell. The mantle first arises as a thickening of the epiblast on the dorsal surface of the embryo. The thickened integument, with the subjacent mesoblast, soon forms a definite projection, in the centre of which appears a circular pit (figs. I 4 chs and I I 5 shs). This pit, which has already been spoken of as the shell-gland, resembles very closely the shellgland of other Mollusca. The fold around the edge of the shell-

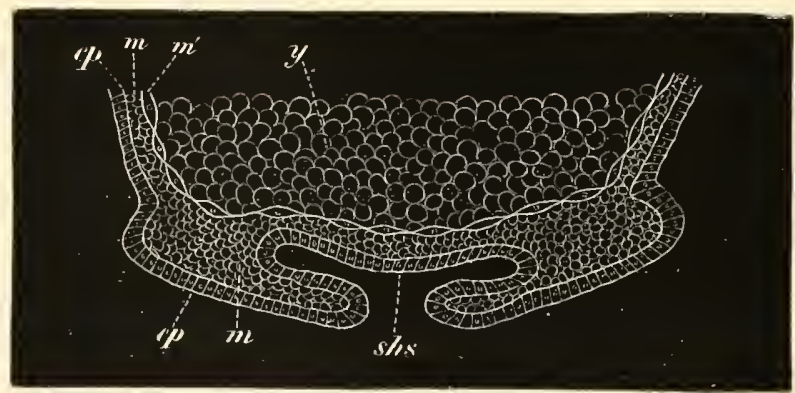

Fig. il 5. Diagram of a vertical section through the mantle region of AN embryo Loligo. (From Lankester.)

[This figure is turned the reverse way up to fig. I I4.]

ef. epiblast; $y$. food-yolk; $m$. mesoblast ; $m^{\prime}$. cellular yolk membrane; shs. shellgland.

gland grows inwards so as gradually to circumscribe its opening, which before long becomes completely obliterated; and the gland forms a closed sack lined by epiblast which grows in an anterior direction (figs. 114 and $127 \mathrm{cch}$ ).

The edges of the mantle now begin to project, especially on the posterior side (fig. 127), and within the cavity formed by this projecting lip there are placed the anus $(\alpha n)$, gills, etc. The projecting lip of the mantle is formed both of epiblast and mesoblast. The whole of the anterior side of the mantle is filled by the elongated shell-sack $(c c h)$, within which the shell or pen soon becomes secreted. 
There are certain difficulties in comparing the shell-gland of the Cephalopoda with that of other Mollusca which will best be rendered clear by the following quotation from Lankester ${ }^{\mathrm{I}}$ :

"The position and mode of development of the shell-gland of the Cephalopoda exactly agree with that of the shell-gland as seen in the other Molluscan embryos figured in this paper. We are therefore fairly entitled to conclude from the embryological evidence that the pen-sack of Cephalopoda is identical with the shell gland of other Mollusca.

"But here-forming an interesting example of the interaction of the various sources of evidence in genealogical biology-palæontology crosses the path of embryology. I think it is certain that if we possessed no fossil remains of Cephalopoda the conclusion that the pen-sack is a special development of the shell-gland would have to be accepted.

"But the consideration of the nature of the shell of the Belemnites and its relation to the pen of living Cuttle-fish brings a new light to bear on the matter. Reserving anything like a decided opinion as to the question in hand, I may briefly state the hypothesis suggested by the facts ascertained as to the Belemnitidæ. The complete shell of a Belemnite is essentially a straightened nautilus-shell (therefore an external shell inherited from a nautilus-like ancestor), which, like the nautiloid shell of Spirula, has become enclosed by growths of the mantle, and unlike the shell of Spirula, has received large additions of calcareous matter from those enclosing overgrowths. On the lower surface of the enclosed nautilus-shell of the Belemnite - the phragmacone-a series of layers of calcareous matter have been thrown down forming the guard; above, the shell has been continued into the extensive chamber formed by the folds of the mantle, so as to form the flattened pen-like pro-ostracum of Huxley.

"Whether in the Belemnites the folds of the mantle which thus covered in and added to the original chambered shell, were completely closed so as to form a sack or remained partially open with contiguous flaps must be doubtful.

"In Spirula we have an originally external shell enclosed but not added to by the enclosing mantle sack.

"In Spirulirostra, a tertiary fossil, we have a shell very similar to that of Spirula, with a small guard of laminated structure developed as in the Belemnite (see the figures in Bronn Classen $u$. Ordnungen des Thierreichs).

"In the Belemnites the original nautiloid shell is small as compared with Spirulirostra. It appears to be largest in Huxley's genus Xiphoteuthis. Hence in the series Spirula, Spirulirostra, Xiphoteuthis, Belemnites, we have evidence of the enclosure of an external shell by growths from the mantle (as in Aplysia), of the addition to that shell of calcareous matter from the walls of its enclosing sack, and of the gradual change of the relative proportions of the original nucleus (the nautiloid phragmacone) and its

1 "Development of Pond Snail." Quart. F. of Micro. Science, 1874, pp. $37 \mathrm{I}-374$. 
superadded pro-ostracal and rostral elements tending to the disappearance of the nucleus (the original external shell). If this view be correct as to the nature of these shells, it is clear that the shell-gland and its plug has nothing to do with them. The shell-gland must have preceded the original nautiloid shell, and must be looked for in such a relation whenever the embryology of the pearly Nautilus can be studied. Now, everything points to the close agreement of the Belemnitidie with the living Dibranchiata. The hooklets on the arms, the ink-bag, the horny jaws, and general form of the body, leave no room for doubt on that point; it is more than probable that the living Dibranchiata are modified descendants of the mesozoic Belemnitidæ. If this be so, the pens of Loligo and Sepia must be traced to the more complex shell of the Belemnite. This is not difficult if we suppose the originally external shell the phragmacone, around which as a nucleus the guard and pro-ostracum were developed, to have finally disappeared. The enclosing folds of the mantle remain as a sack and perform their part, producing the chitinocalcareous pen of the living Dibranch, in which parts can be recognised as corresponding to the pro-ostracum, and probably also to the guard of the Belemnite. If this be the case, if the pen of Sepia and Loligo correspond to the entire Belemnite shell minus the phragmacone-nucleus, it is clear that the sack which develops so early in Loligo and which appears to correspond to the shell-gland of the other Molluscs cannot be held to do so. The sack thus formed in Loïgo must be held to represent the sack formed by the primeval up-growth of mantle-folds over the young nautiloid shell of its Belemnitoid ancestors, and has accordingly no general significance for the whole Molluscan group, but is a special organ belonging only to the Dibranchiate stem, similar to-but not necessarily genetically connected with-the mantle-fold in which the shell of the adult Aplysia and its congeners is concealed. The pen, then, of Cephalopods would not represent the plug of the shell-gland. In regard to this view of the case, it may be remarked that I have found no trace in the embryonic history of the living Dibranchiata of a structure representing the phragmacone; and further, it is possible, though little importance can be attached to this suggestion, that the Dibranchiate pen-sack, as seen in its earliest stage in the embryo Loligo, etc., is fused with the surviving remnants of an embryonic shell-gland. When the einbryology of Nautilus pompilius is worked out, we shall probably know with some certainty the fate of the Molluscan shell-gland in the group of the Cephalopoda."

The funnel. The general development of the funnel has already been sufficiently indicated. The folds of which it is formed are composed both of epiblast and mesoblast. The mesoblast of the anterior part of each half of the funnel would appear to give rise to a muscle passing from the cartilage of the neck to the funnel proper. The posterior parts gradually approximate, but meet in the first instance ventrally. The two 
folds at first merely form the side of a groove or imperfect tube (fig. I I $3 \mathrm{C}$ and I $24 \mathrm{ff}$.), but soon the free edges unite and so give rise to a perfect tube, the primitive origin of which by the coalescence of two halves would not be suspected. In Nautilus the two halves remain permanently separate but overlap each other, so as to form a functional tube.

Polyplacophora. The external characters of the embryo of Chiton have long been known through the classical observations of Lovén (No. 285), while the formation of the layers and the internal phenomena of development have recently been elucidated by Kowalevsky (No. 284). The eggs are laid in April, May, and June, and are enclosed in a kind of chorion with calcareous
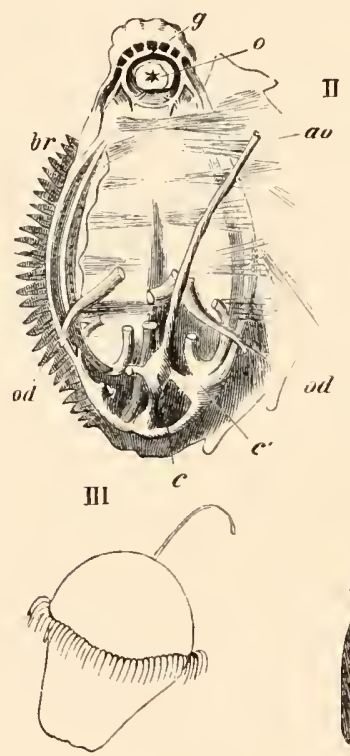

IV

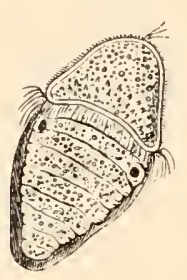

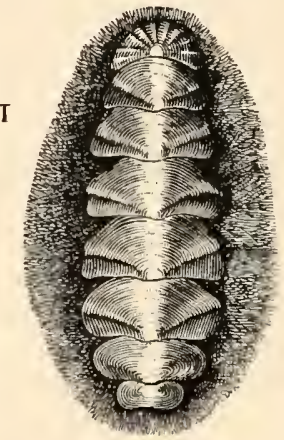

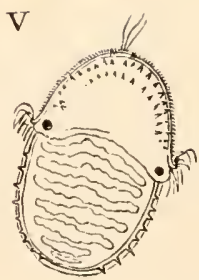

FIG. I 6 .

I. Chiton Wossnessenskil. (After Middendorf.)

II. Chiton Dissected to shew 0 . the mouth; $g$. the nervous ring; $a$. the aorta ; $c$. the ventricle; $c^{\prime}$. an auricle; $b r$. the left branchix; od. oviducts. (After Cuvier.)

III., IV., V. Stages of development of Chiton cinereus. (After Lovén.)

The figure is taken from Huxley.

protuberances. The segmentation remains regular till sixtyfour segments are formed. The cells composing the formative 
half of the ovum then divide more rapidly than the remainder; there is in this way formed an elongated sphere, half of which is composed of small cells and half of larger cells. In the interior is a small segmentation cavity. From its eventual fate the hemisphere of the smaller cells may be called the anterior pole, and that of the larger cells the posterior. An involution of the cells at the apex of the posterior pole (though not of the whole hemisphere of larger cells) now takes place, and gives rise to the archenteron. At the same time an equatorial double ring of large cells appears on the surface between the two poles, which becomes ciliated and forms the velum. At the apex of the anterior pole a tuft of cilia, or at first a single flagellum, is established (fig. I 6 III. and IV.).

In the succeeding developmental period the blastopore, which has so far had the form of a circular pore at the posterior extremity of the body, undergoes a series of very remarkable changes. In conjunction with a gradual elongation of the larva it travels to the ventral side, and is prolonged forwards to the velum as a groove. The middle part of the groove is next converted into a tube, which opens externally in front, and posteriorly communicates with the archenteron. The walls of this tube subsequently fuse together, obliterating the lumen, and necessarily causing at the same time the closure of the blastopore. The tube itself becomes thereby converted into a plate of cells on the ventral surface between the epiblast and the hypoblast ${ }^{1}$.

While the above changes have been taking place the mesoblast has become established. It is derived from the lateral and ventral cells of the hypoblast.

After the establishment of the germinal layers the further evolution of the larva makes rapid progress. A transverse groove is formed immediately behind the velum, which is especially deep on the ventral surface; and the stomodæum is formed as an invagination of the anterior wall of the deeper section of the groove. Behind the stomodxum the remainder of the ventral surface grows out as a flattened foot.

1 There is a striking similarity between the changes of the blastopore in Chiton and the formation of the neurenteric canal of Chordata ; especially if Kowalevsky is correct in stating that the pedal nerves are developed from the ventral plate. 
The dorsal surface behind the velum constitutes the mantle, and becomes divided by six or seven transverse grooves into segment-like areas, which may be called mantle plates (fig. I 6 IV.). These areas would seem (?) to correspond to so many flattened-out shell-glands. Immediately behind the velum the eyes appear as two black spots (fig. I 16 IV.).

While the above external changes take place the archenteron undergoes considerable modifications. Its anterior section gives rise, according to Kowalevsky, to a dorsal (?) sack in which the radula is formed; while the liver arises from it as two lateral diverticula.

From the above statements it would appear that Kowalevsky holds that the œsophagus and radula sack are both derived from the walls of the archenteron and not from the stomodæum. Such an origin for these organs is without parallel amongst Mollusca.

The larva becomes about this time hatched, and after swimming about for some time attaches itself by the foot, throws off its larval organs, cilia, etc., and develops the shell.

The shell appears first of all during larval life in the form of spicula on the middle and sides of the head, and later on the middle and sides of the post-oral mantle plates (fig. $116 \mathrm{v}$.). The permanent shell arises somewhat later as a series of median and lateral calcareous plates, first of all on the posterior part of the velar area, and subsequently on the mantle plates behind. The three calcareous patches of each plate fuse together and give rise to the permanent shell plates. The original spicula are displaced to the sides, where they partly remain, and are partly replaced by new spicula.

The nervous system is formed during larval life as four longitudinal cords:-two lateral-the branchial cords, and two ventral-the pedal. Paired anterior thickenings of the pedal cords meet in front of the mouth to form the œsophageal ring. The pedal cords and their derivatives are believed by Kowalevsky to be developed from the lateral parts of the plate formed by the metamorphosis of the blastopore. The median part of the plate is still visible after the forniation of these parts.

The chief peculiarity of the larva of Chiton (apart from the peculiar ventral plate) consists in the elongation and dorsal segmentation of the posterior part of the body. The velum has the normal situation and relation to its mouth. The position of the eyes behind it is however abnormal.

The elongation and segmentation of the posterior part of the trunk is probably to be regarded as indicating that Chiton has 
early branched off from the main group of the Odontophora along a special line of its own, and not that the remaining Odontophora are descended from Chiton-like ancestral forms. The shell of Mollusca on this view is not to be derived from one of the plates of Chiton, but the plates of Chiton are to be derived from the segmentation of a primitive simple shell. The segmentation exhibited is of a kind which all the trochosphere larval forms seem to have been capable of acquiring. The bilateral symmetry of Chiton, which is quite as well marked as that of the Lamellibranchiata, indicates that it is a primitive phylum of the Odontophora.

Scaphopoda. The external characters of the peculiar larva of this interesting group have been fully worked out by Lacaze Duthiers (No. 286).

The segmentation is unequal and conforms to the usual molluscan type. At its close the embryo becomes somewhat elongated, and there appears on its surface a series of transverse ciliated rings. As soon as these become formed the larva is hatched, and swims about by means of its cilia. Six ciliated bands are formed in all, and in addition a tuft of cilia is formed in a depression at the anterior extremity.

The larva thus constituted is very different in appearance to the larve already described, and its parts very difficult to identify; the next stages in the development shew however that the whole region of the body taken up by the ciliated rings is part of the velar area, while the small papilliform region behind is the post-velar part of the embryo. This latter part grows rapidly, and at the same time the ciliated rings become reduced to four; which gradually approach each other, while the region on which they are placed grows in diameter. The rings finally unite, and form a single ring on a projecting velar ridge. In the centre of this ring is placed the terminal tuft of cilia on a much reduced prominence.

By the time that these changes have been effected in the velum, the post-velar part of the embryo has become by far the largest section of the embryo, so that the velum forms a projecting disc at the front end of an elongated body. The mantle is formed as two lateral outgrowths near the hinder extremity of the body which leave between them a ventral groove lined by

B. II. 
cilia; on their dorsal side is formed a delicate shell. The mantle lobes continue to grow, and by the time the above changes in the velum are effected they meet and unite in the ventral line and convert the groove between them into a complete tube open in front and behind. A stream of water is driven through this tube by the action of the cilia. The shell, which is at first disc-shaped like the shell of other molluscan larvæ, moulds itself upon the mantle and is so converted into a tube. At the front end of the mantle tube, which does not at first cover the velum, there is formed the foot. It arises as a protuberance of the ventral wall of the body, which rapidly grows forwards, becomes trilobed as in the adult, and ciliated.

On the completion of these changes the larva mainly differs in appearance from the adult by the projection of the velum beyond the edge of the shell. The velum soon however begins to atrophy; and the larva sinks to the bottom. The mantle tube and shell grow forward and completely envelop the velum, which shortly afterwards disappears. The mouth is formed on the ventral side of the velum at the base of the foot; at its sides arise the peculiar tentacles so characteristic of the adult Dentalium.

\section{LAMELLIBRANCHIATA.}

The larvæ of Lamellibranchiata have in a general way the same characters as those of Gasteropods and Pteropods. A trochosphere stage with a velum but without a shell is succeeded by a veliger stage with a still more developed velum, a dorsal shell, and a ventral foot.

The segmentation is unequal, and in a general way like that of Gasteropoda, but the specially characteristic Gasteropodan type with four large yolk spheres is only known to occur in Pisidium, and a type of segmentation similar to that of Anodon (p. IOO) appears to be the most frequent.

There is an epibolic or embolic gastrula, but the further history of the formation of the germinal layers has been worked out so imperfectly, and for so few types, that it is not possible to make general statements about it. What is known on this head 
is mentioned in connection with the description of the development of special types.

The blastopore in some cases closes at the point where the anus (Pisidium), and probably in other cases where the mouth, is eventually formed. In Anodon it is stated to close at a point corresponding neither with the mouth nor the anus, but on the dorsal surface!

The embryo assumes a somewhat oval form, and in the free marine forms there appears very early in front of the mouth a well-developed velum. This is formed according to Lovén from two papillæ, and takes the form of a circular ridge armed with long cilia. In the centre of the velar area there is usually
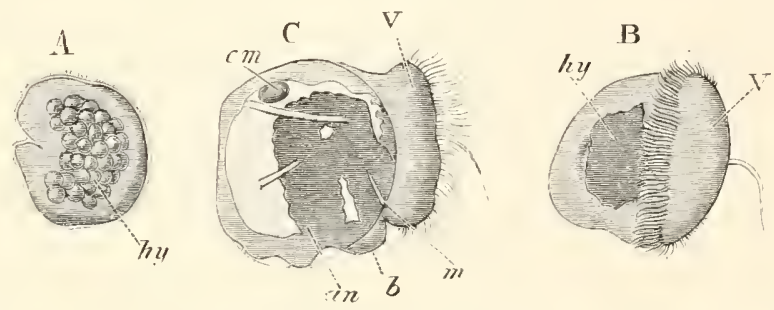

Fig. i i7. Three stages in the development of Cardium. (After Lovén.) hy. hypoblast ; $b$. foot; $m$. mouth; $a n$. anus; $I$. velum; $\mathrm{cm}$. anterior adductor muscle.

present a single long flagellum (fig. I I 7 B and C). The velum never becomes bilobed.

In the later stages, after the development of the shell, the velum becomes highly retractile and can be nearly completely withdrawn within the mantle by special muscles. It forms the chief organ of locomotion of the free larva.

In some fresh-water forms, which have no free larval existence, the velum is very much reduced (Anodon, Unio, Cyclas) or even aborted (Pisidium). In these forms as well as in Teredo and probably other marine forms ( $c . g$. Ostrea) the central flagellum is absent. It has been suggested by Lovén, though without any direct evidence, that the labial tentacles of adult Lamellibranchiata are the remains of the velum. The velar area is in any case the only representative of the head. In some marine forms a general covering of cilia arises before the formation of 
the velum; and in Montacuta and other types there is developed, as in many Gasteropoda, a circum-anal patch of cilia.

A shell-gland appears at a very early period on the dorsal surface in Pisidium, Cyclas and Ostrea, and probably in most marine forms (fig. I i $8, s h s$ ). It is somewhat saddle-shaped, and formed of elongated non-ciliated cells bounding a groove. It flattens out and on its surface is formed the shell, which appears usually to have the form of an unpaired saddle-shaped cuticle, on the two sides of which the valves are subsequently formed by a deposit of calcareous salts. In Pisidium the two valves are stated by Lankester to be at first quite independent and widely separated, and it has been suggested by Lankester, though not proved, that the ligament of the shell is developed in the median part of the groove of the shell-gland.

The mantle lobes are developed as lateral outgrowths of the body: they usually have a considerable extension before they are covered by the shell. In Anodon and Unio the larval mantle lobes are, however, formed in a somewhat exceptional way, and are from the first completely covered by the valves of the larval shell. The larval mantle lobes and shell in Anodon and Unio are subsequently replaced by the permanent structures.

The adductor muscles are formed soon after the appearance of the shell. The posterior sometimes appears first, $\quad$.g.g. Mytilus, and at other times the anterior, e.g. Cardium.

The foot arises in the usual way as a prominence between the mouth and anus. In comparison with Gasteropoda it is late in appearing, and in many cases does not become prominent till the shell has at-

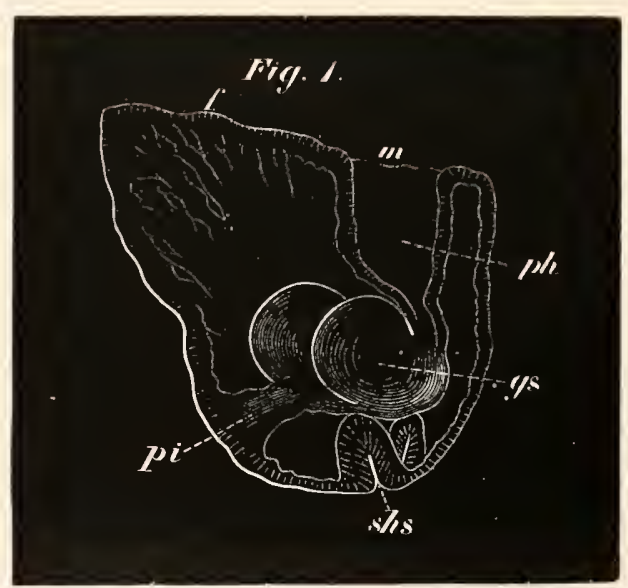

Fig. ir 8. An embryo of Pisidium pusillum. (From Lankester.)

$f$. foot; $m$. mouth ; ph. pharynx ; gs. bilobed stomach; pi. intestine; shs. shell-gland. 
tained a considerable size. In its hinder part a provisional paired byssus-gland is developed from the epidermis in Cyclas and other forms. In other cases, e.g. Mytilus, the byssus-gland is permanent. The byssus-gland occupies very much the position of the Gasteropod operculum, and would appear very probably to correspond with this organ. The anterior part of the foot is usually ciliated.

The gills appear rather late in larval development along the base of the foot on either side, between the mantle and the foot (fig. I20, br). They arise as a linear row of separate ciliated somewhat knobbed papillæ. A second row appears later. The two rows give rise respectively to the two gill lamellæ of each side.

The further history of the development of the gills has been studied by Lacaze Duthiers (No. 297) in Mytilus. The first row of gill papillæ formed becomes the innermost of the two lamellæ of the adult. The number of papillæ goes on increasing from before backwards. When about eleven have been formed, their somewhat swollen free extremities unite together, the basal portions being separated by slits.

The free limb is formed by the free end of the gill lamella bending upon itself towards the inner side and growing towards the line of attachment of the lamella. The free limb is at first not composed of separate bars, but of a continuous membrane. Before this membrane has grown very wide, perforations are formed in it corresponding to the spaces between the bars of the attached limb.

The outer gill lamella develops in precisely the same way as, but somewhat later than, the inner. The rudiments of it appear when about twenty papillæ of the inner lamella are formed. Its first papillæ are formed near the hind border of the inner lamella, and new papillæ are added both in front and behind. Its free limb is on the outer side.

In Mytilus the two limbs (free and attached) of each bar of the gill are joined at wide intervals by extensile processes, the 'inter-lamellar junctions,' and the successive bars are attached together by ciliated junctions. In many other types the concrescences between the various parts of the gills are carried much further; the maximum of concrescence being perhaps attained in Anodon and Unio'.

Large paired auditory sacks seem always to be developed in the foot; and clearly correspond with the auditory sacks in Gasteropoda.

1 R. H. Peck, "Gilis of Lameliibranch Moliusca." Quart. J. of M. Science, Vol. XVII. I 877 . 
Eyes are frequently present in the larva, though they disappear in the adult. In Montacuta and other types a pair of these organs is formed at the base of the velum on each side of the oesophagus, not far from the auditory sacks. They are provided with a lens.

A row of similar organs is present in the larva of Teredo in front of the foot.

Cardium. As an example of a marine Lamellibranchiate I may take Cardium pygmacum, the development of which has been studied by Lovén (No. 291). The ova, surrounded by a thickish capsule, are impregnated in the cloaca. The segmentation takes place much as in Nassa (vide p. Ior), and the small segments gradually envelop the large hypoblast spheres; so that there would seem to be a gastrula by epibole. After the hypoblast has become enveloped by the epiblast, one side of the embryo is somewhat flattened and marked by a deepish depression (fig. i17 A). From Lovén's description it appears to me probable that the depression on the flattened side occupies the position of the blastopore, and that the depression itself is the stomodæum. At this stage the embryo becomes covered with short cilia which cause it to rotate within the egg-capsule.

Close above the mouth there appear two small papillie. These gradually separate and give rise to a circular ridge covered with long cilia, which encircles the embryo anteriorly to the ventrally-placed mouth. This structure is the velum. In its centre is a single long flagellum (fig. $117 \mathrm{~B}$ ). Shortly after this the shell appears as a saddle-shaped structure on the hinder part of the dorsal surface of the embryo. It is formed at first of two halves which meet behind without the trace of a hinge (fig. I17 C). The two valves rapidly grow and partially cover over the velum, and below them the mantle-folds soon sprout out as lateral flaps.

The alimentary tract has by this time become differentiated (fig. II7 C). It consists of a mouth $(m)$ and ciliated œsophagus probably derived from the stomodxum, a stomach and intestine derived from the true hypoblast, and an hepatic organ consisting of two separate lobes opening into the stomach. The anus $(a n)$ appears not far behind the mouth, and between the two is a very slightly developed rudiment of the foot $(b)$. The anterior adductor muscle $(\mathrm{cm})$ appears at this stage, though the posterior is not yet differentiated.

The larva is now ready to be hatched, but the further stages of its development were not followed.

Ostrea. The larvæ of Ostrea, figured by Salensky (No. 293), shew a close resemblance to those of Cardium. The velum is however a simple ring of cilia without a central flagellum. The proctodæum would appear to be formed later than the stomodxum, and the earliest stage figured is too far advanced to throw light on the position of the blastopore.

Pisidium. The development of Pisidium has been investigated by 
Lankester (No. 239). The ovum is invested by a vitelline membrane and undergoes development in a brood-pouch at the base of the inner gill lamella.

The segmentation commences by a division into four equal spheres, each of which, as in so many other Mollusca, then gives rise by budding to a small sphere. The later stages of segmentation have not been followed in detail, but the result of segmentation is a blastosphere. An invagination, presumably at the lower pole, now takes place, and gives rise to an archenteric sack.

The embryo now rapidly grows in size. The blastopore becomes closed and the archenteric sack forms a small mass attached at one point to the walls of the embryonic vesicle (fig. I I $9, h y$ ). In the space between the walls of the archenteron and those of the embryonic vesicle stellate mesoblast cells

A.
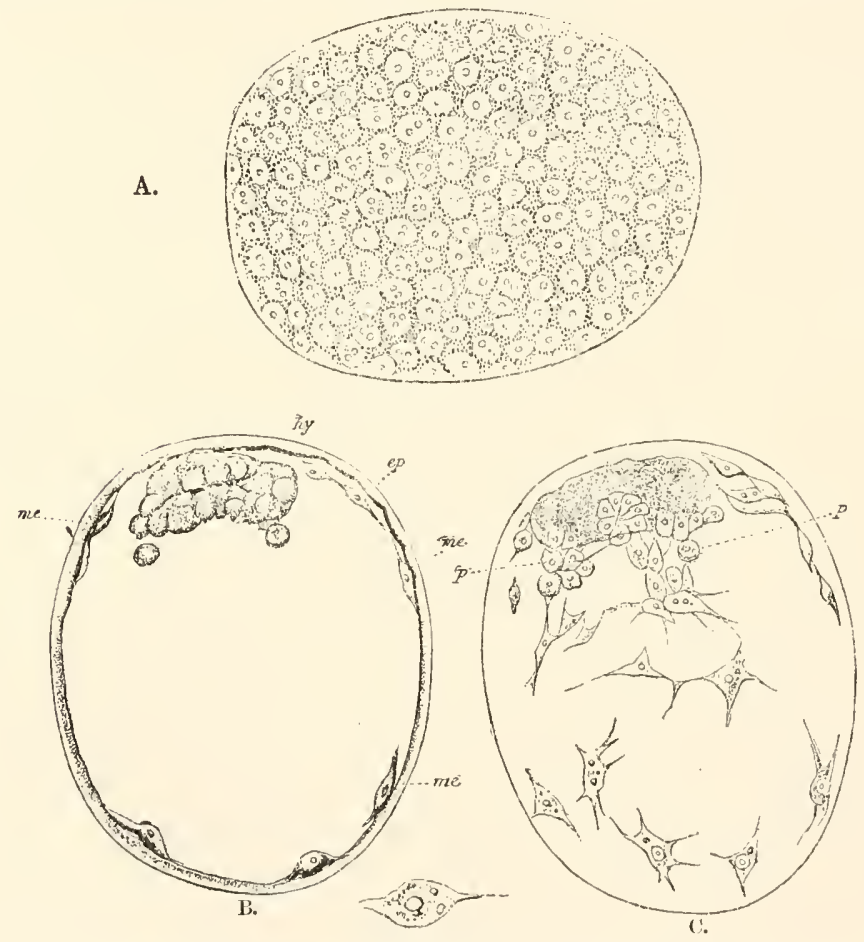

Fig. II9. THREE VIEWS OF AN EMBRYo OF PISIDIUM IMMEliately AFter THE CLOSURE OF THE 1:LASTOPORE. (After Lankester.)

A. View from the surface.

B. Optical section through the median plane.

C. Optical section through a plane a little below the surface.

$e p$. epiblast; me. mesoblast; $h y$. hypoblast; $p$. cells apparently budding from the hypoblast to form mesoblastic elements. 
make their appearance, derived in the main from the epiblast, though probably in part also from the hypoblastic vesicle (vide fig. $119 \mathrm{C}, p$ ). The cavity between the hypoblast and epiblast, which contains these cells, is the body cavity. Fig. 119 represents three views of the embryo at this stage. $A$ is a surface view shewing the epiblast; $B$ is an optical section through the median plane shewing the hypoblast and some of the mesoblast cells; and $\mathrm{C}$ is an optical section shewing the mesoblast cells. A prominence on one side of the embryo now develops which forms the commencement of the foot, and the archenteric sack grows out at its free extremity into two lobes, but remains attached to the epiblast by an imperforate pedicle. The next organ to appear is the stomodæum. It arises as a ciliated epiblastic ingrowth which meets the free end of the archenteric sack, fuses with it, and shortly afterwards opens into it (fig. $118, p h$ ). Between the mouth and the attachment of the enteric pedicle is placed the foot $(f)$, which becomes ciliated. On the dorsal side of the enteric pedicle there appears a saddleshaped patch of epiblast cells bounding the sides of a groove $(s h s)$. This is the rudiment of the shell-gland.

The enteric pedicle, or intestine as it may now be called, soon acquires a lumen, though still imperforate at its termination where the anus is eventually formed. Ventral to the intestine is placed a mass of cells - the rudiment of the organ of Bojanus. It is stated to be developed as an ingrowth of the epiblast.

In a slightly later stage the shell-gland rapidly increases in size and flattens out, and on the two sides of it there appear the rudiments of the two valves, which are at first quite distinct, and separated by a considerable interval (fig. 120). Before the appearance of the valves of the shell, the mantle folds have already grown out from the sides of the body.

At a somewhat later stage the gills appear as a linear series of small independent buds within the folds of the mantle behind the foot (fig. I2O, br). The anterior adductor also becomes differentiated.

The alimentary tract in the meantime has undergone considerable changes. The primitive lateral lobes dilate enormously and become ciliated. At a still later stage their walls undergo peculiar changes, the nature of which is somewhat obscure, but they appear to me to be of the same character as those in many Pteropods and Gasteropods, where the cells of the hepatic diverticula, to which the lobes of Pisidium apparently correspond, become filled with an albuminous material.

The later stages in Pisidium have not been followed.

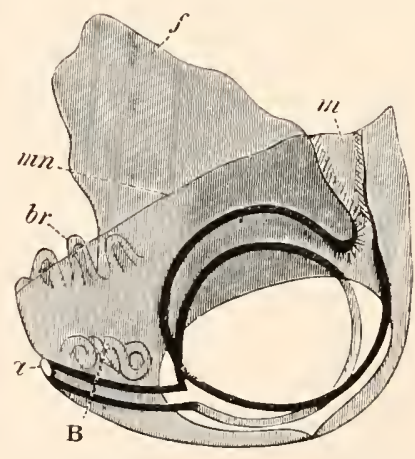

Fig. 1 20. DIAGRAMMATIC VIEW OF ADVANCED LARVA OF PISIDIUM. (Copied from Lankester.)

m. mouth; $a$. anus; B. organ of Bojanus; $m n$. mantle; $f$. foot. 
It is remarkable that in Pisidium a veliger stage does not occur. This is probably due to the development taking place within the brood-pouch. The late development of the otocysts is also remarkable. A byssus-gland was not formed up to the stage observed. In Cyclas calyculata (Schmidt), a byssus-gland also appears to be absent.

Cyclas. The development of Cyclas as described by Von Jhering is very unlike that of Pisidium, and the differences would seem to be too great to be accounted for except by errors of observation.

The segmentation of Cyclas is similar to that of Anodon (vide p. 82), and a mass of large cells enclosed by the smaller cells gives rise to the hypoblast. In the interior of this mass there appears a lumen, and a process from it grows towards and meets the epiblast, and gives rise to the œesophagus and mouth, - a mode of development of these parts without parallel amongst Mollusca. A very rudimentary velum would appear, according to Leydig (No. 290), to be developed at the cephalic extremity. A shell-gland is formed of the same character as in Gasteropods. According to Leydig the shell appears as a single saddle-like structure on the dorsal surface; the lateral parts of this become calcified, and give rise to the two valves, but are united in the middle by the membranous median portion. At the two sides of the body the mantle lobes are formed, as in Pisidium.

Very shortly after the formation of the shell the byssus-gland appears as a pair of small follicles in the hinder part of the foot. It rapidly grows larger and becomes a paired pyriform gland, in which are secreted the byssus threads which serve to attach all the embryos at a common point to the walls of the brood-pouch.

The foot is large, and ciliated anteriorly. Otolithic sacks and peda ganglia are developed in it very early.

Unio. The ovum of Anodonta and Unio is enveloped in a vitelline membrane, the surface of which is raised into a projecting trumpet-like tube perforated at its extremity (fig. 12). This structure is the micropyle. The micropyle disappears in Anodonta piscinalis when the egg is ripe, but in Unio persists during the whole development. The ova are transported, in a manner not certainly made out, into the space between the two limbs of the outer gills of the mother, and there undergo their early development. The animal or upper pole of the egg is placed at the pole opposite to the micropyle.

The segmentation is unequal (vide p. Ioo) and results in the formation of a blastosphere with a large segmentation cavity. The greater part of the circumference of the egg is formed of small uniform spheres, but the lower (with reference to the segmentation) pole is taken up by a single large cell. The small spheres become the epiblast, and the large cell gives rise to hypoblast and mesoblast ${ }^{1}$.

I The account of the remainder of the development till the larva becomes hatched is taken from Rabl, No. 292 . 
The single large cell next divides into two, and then four, and finally into about ten to fifteen cells. These cells form an especial area of more granular cells than the other cells of the blastosphere. Most of them are nearly of the same size, but two of them (according to Rabl), in contact with each other, but placed on the future right and left sides of the embryo, are considerably larger than the remainder. These two cells soon pass into the cavity of the blastosphere, while at the same time the area of granular cells becomes flattened out, and then becomes involuted as a small sack with a transversely elongated opening, which does not nearly fill up the cavity of the blastosphere. This involuted sack is the archenteron.

The two large cells, which lie in immediate contact with what, following Rabl, I shall call the anterior lip of the blastopore, next bud off small cells, which first form a layer covering the walls of the archenteron, but subsequently develop into a network filling up the whole cavity of the primitive blastosphere. The space between these cells is the primitive body cavity. For a long time the two primitive mesoblast cells retain their preponderating size $^{1}$. At the hinder end of the body, and at the end opposite therefore to the two mesoblast cells, are placed three especially large epiblast cells.

In Anodonta and Unio tumidus there appears at this period a patch of long cilia at the anterior end of the body. These cilia cause a rotation of the embryo and would appear to be the velum. In Unio pictorum they do not appear till much later.

Immediately following this stage the changes in the embryo take place with great rapidity. In the first place a special mass of mesoblast cells appears at the hinder end of the archenteric sack; and becoming elongated transversely gives rise to the single adductor muscle. On the subsequent formation of the shell the muscle becomes inserted in its two valves. The blastopore next becomes closed, and the small archenteron grows forwards till it meets the epiblast anteriorly, and at the same time detaches itself from the epiblast in the region where the blastopore was placed. Where it comes in contact with the wall of the body in front a small epiblastic invagination arises, which meets and opens into the archenteric sack and forms the permanent mouth.

While these changes have been taking place the shell is formed as a continuous saddle-shaped plate on the dorsal surface. From this plate the two valves are subsequently differentiated. On the dorsal surface they meet with a straight hinge-line. Each valve is at first rounded, but subsequently becomes triangular with the hinge-line as base. The valves are not quite equi-sided, but the anterior side is less convex than the posterior. At a later period a beak-shaped organ is formed at the apex of each valve in the same manner as the remainder of the shell. This organ is placed at about a right angle with the main portion of the valve. It is pointed at its ex-

1 In this description I follow Rabl's nomenclature. According to his statements the ventral part of the body is the original animal pole-the dorsal the lower pole; the anterior end the mesoblastic side of the opening of invagination. 
tremity and bears numerous sharp spines on its outer side, which are especially large in the median line (vide fig. I2 I A). It is employed in fixing the larva, after it is hatched, on to the fish on which it is for some time parasitic. The shell is perforated by numerous pores.

After the shell has become formed a new structure makes its appearance which is known as the byssus-gland. It is developed as an invagination of the epiblast at the hinder end of the body : RabI was unable to determine whether it was formed from the three large epiblastic cells present there or no. It subsequently forms an elongated gland with three coils or so round the adductor muscle on the left side of the body, but opening in the median ventral line. It secretes an elongated cord by which the larva becomes suspended after hatching.

For some time the ventral portion of the body projects behind the ends of the valves of the shell, but before these are completely formed a median invagination of the body wall takes place, which obliterates to a large extent the body cavity, and gives rise to two great lateral lobes, one for each valve. These lobes are the mantle lobes.

Before the mantle lobes are fully formed peculiar sense-organs, usually four in number, make their appearance on each lobe. Each of them consists of a columnar cell, bearing at its free end a cuticle from which numerous fine bristles proceed. Covering the cell and the parts adjoining it is a delicate membrane perforated for the passage of the bristles. The largest and first formed of these organs is placed near the anterior and dorsal part of the mantle. The three others are placed near the free end of the mantle (vide fig. I2 I A). These organs probably have the function of enabling the larva to detect the passage of a fish in its vicinity, and to assist it therefore in attaching itself. When the embryo is nearly ripe there appears immediately ventral to and behind the velum a shallow pit on each side of the middle line, and the two pits appear to be connected by a median transverse bridge. These structures have been the cause of great perplexity to different investigators, and their meaning is not yet clear. According to Rabl the median structure is the somewhat bilobed archenteron, and according to his view it is not really connected with the laterally placed pits. The cilia of the velum overlie these latter structures and make them appear as if their edges were ciliated. They are regarded by Rabl as the rudiments of the nervous system.

With the development of the shell, the mantle, and the sense-organs, the young mussel reaches its full larval development, and is now known as a Glochidium (fig. I2I A).

If the parent, with Glochidia in its gills, is placed in a tank with fish, it very soon (as I have found from numerous experiments) ejects the larva from its gills, and as soon as this occurs the larva become free from the eggmembrane, attach themselves by the byssus-cord, and when suspended in this position continually close and open their shells by the contraction of the adductor muscle. If the mussels are not placed in a tank with fish the larva may remain for a long time in the gills. 


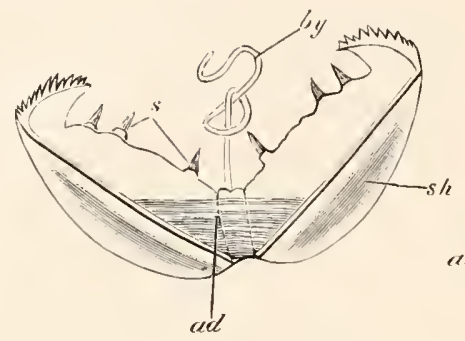

A.

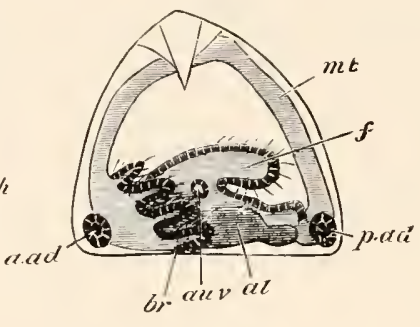

B.

FIG. 121 .

A. Glochidium immediately after it is hatched.

$a d$. adductor; $s h$. shell; $b y$. byssus cord ; s. sense organs.

B. Glochidium After it has been on the Fish For some weEks.

$b r$. branchiæ; $a u . v$. auditory sack ; $f$. foot ; $a . a d$. and $p . a d$. anterior and posterior adductors; al. mesenteron; mt. mantle.

Before passing on to state what is known with reference to the larval metamorphosis, it may be well to call attention to certain, and to my mind not inconsiderable, difficulties in the way of accepting in all particulars Rabl's account of the development.

In all Gasteropod Molluscs the lower or vegetative pole of the ovum is ventral, not dorsal as Rabl would make it in Unio. The blastopore in other Molluscs always coincides either with the mouth or anus, or extends between the two. The surface on which the foot is formed is the ventral surface. On the dorsal surface are placed, (I) the velum near the mouth, ( 2 ) the shellgland near the anus. In Anodon the velum is placed just dorsal to the mouth, then according to Rabl follows the blastopore, and in the region of the blastopore is formed the shell. The blastopore is therefore dorsal in position. It occupies in fact the ordinary place of the shell-gland, and looks very much like this organ (which is not otherwise present in Anodon and Unio). Without necessarily considering Rabl's interpretations false, I think that the above difficulties should have been at any rate discussed in his paper. More especially is this the case when there is no doubt that Rabl has made in his paper on Lymnæus a confusion between the mouth and the shell-gland.

Investigations on the post-embryonic metamorphosis of Glochidium have been made by Braun (No. 287), and several years ago I made a series of observations on this subject, the results of which agree in most points with those of Braun. I was however unsuccessful in carrying on my observations till the young mussel left its host.

The free Glochidia very soon attach themselves to the gills, fins, or other parts of fish which are placed in the tank containing them; after attachment they become covered by a growth of the epidermic cells of their host, and undergo their metamorphosis. 
The first change that takes place is the disappearance of the byssus and the byssus organ. This occurs very soon; shortly afterwards all traces of the velum and sense organs also become lost.

At the time of the disappearance of these bodies, at the point of the projection from which the byssus cord arose, and very possibly from this very projection, the foot arises as a rounded process which rapidly grows and soon becomes ciliated (fig. I2 I $\mathrm{B}, f$ ).

The single adductor muscle begins to atrophy very early, but before its entire disappearance rudiments are formed at the two ends of the body, which at a later period can be distinctly recognised as the anterior and posterior adductor muscles (fig. I2 I B, a.ad and p.ad).

After the formation of these parts the gills arise as solid and at first somewhat knobbed papillæ covered with a ciliated epidermis, on each side of, but somewhat in front of (!) the foot (fig. I I I B, br). In the foot there soon appear the auditory sacks $(a u . v)$, and the foot itself becomes a long tongue-like ciliated organ projecting backwards ${ }^{1}$.

The mantle lobes undergo great changes, and indeed by Braun the mantle lobes are stated to be formed almost entirely de novo. The permanent shell is (Braun) formed on the dorsal surface of the still parasitic larva in the form of two small independent plates. I have not followed the changes of the alimentary canal, etc., but at an early stage there is visible, dorsal to the foot, a simple enteric sack.

By the time the larva leaves its host all the organs of the adult, except the generative organs, have become established.

The post-embryonic development of the organs of Glochidium is similar in the main to that of other Lamellibranchiata. This fact is of some importance on account of the peculiarities of the earlier developmental stages.

The byssus organ, the toothed processes of the shell, and the sense organs of the Glochidium can hardly be ancestral rudiments, but must be organs which have been specially developed for the peculiar mode of life of the Glochidium. Whether the single muscle is to be counted amongst such provisional organs is perhaps a more doubtful point, but I am inclined to think that it ought to be so.

If however the single muscle is an ancestral organ, it is important to observe that it entirely disappears as development goes on and the two adductor muscles in the adult are developed independently of it.

1 The position of the foot and gills in the larva represented in Fig. $119 \mathrm{~B}$ would be more normal if the convex and not the flatter side of the shell were the anterior. I have followed Rabl and Flemming in the determinations of the anterior and posterior end of the embryo, but failed to rear my larvæ up to a stage at which the presence of the heart or some other organ would definitely confirm their interpretation. I originally adopted myself the other view, and in case they are mistaken, the so-called velum would be a circum-anal patch of cilia, while the position of the primitive mesoblast cells as well as of the byssus would better suit my view than that adopted in the text on the authority of the above observers. 


\section{General review of the characters of the Molluscan larve.}

The typical larva of a Mollusc, as has been more especially pointed out by Lankester, is essentially similar to the larva of a number of invertebrate types, and especially the Chrtopoda, with the addition of certain special organs characteristic of the Mollusca.

It has a bent alimentary tract, with a mouth on the ventral surface and a terminal or ventral anus. The alimentary tract is divided into three regions: œesophagus, stomach, and intestine. There is a variously developed præoral lobe with a ring of cilia - the velum, and a perianal lobe, often with a patch of cilia (Paludina, etc.). In all these characters it is essentially similar to a Chætopod larva. The two characteristic molluscan organs are (I) a foot between the mouth and anus, and (2) an invagination of the epiblast on the dorsal side at the hinder end of the body, which is connected with the formation of the shell.

The larvæ of most Gasteropoda, Pteropoda, and Lamellibranchiata present no features which call for special remark; but the larve of the Gymnosomata amongst the Pteropoda, and of the Scaphopoda, Polyplacophora and Cephalopoda present interesting peculiarities.

The larva of the Gymnosomata are peculiar in the presence of three transverse ciliated rings, situated bchind the velum (Fig. I09). These rings might be regarded as indications of a rudimentary segmentation; but, as already indicated, this view is not satisfactory. There is every reason for thinking that these rings have been specially acquired by these larvæ.

At first sight the larvæ of the Gymnosomata might be supposed to resemble those of the Scaphopoda, which are also provided with transverse ciliated rings; but, as shewn above, the rings of the Scaphopoda are merely parts of the extended velar ring.

Thus, the ciliated rings of the two larvæ-so similar in appearance-are in reality structures of entirely different values, being in the one case parts of the velum, and in the other special developments of cilia behind the velum. 
The great peculiarity of the early larva of the Scaphopoda is the enormous development of the præoral lobe, which gives room for the development of the ciliated rings. In the presence of a central tuft of cilia, at the anterior extremity, the larva of the Scaphopoda resembles that of the Lamellibranchiata, etc.

The larva of the Polyplacophora resembles that of Lamellibranchiata in its anterior flagellum, and that of the Scaphopoda in the large development of the preoral lobe ; but is quite peculiar amongst Mollusca in the transverse segmentation of the mantle area.

The embryo of the Cephalopoda agrees very closely with that of normal Odontophora in the formation of the mantle and (?) of the shell-gland, but is quite exceptional (I) in the almost invariable presence of a more or less developed external yolksack, (2) in the absence of a velum, (3) in the absence of a median foot, and in the presence of the arms.

The presence of a yolk-sack may most conveniently be spoken of in connection with the foot, and we may therefore pass on to the question of the velum.

The velum is one of the most characteristic embryonic appendages of the Mollusca, and its absence in the Cephalopoda is certainly very striking. By some investigators the arms have been regarded as representing the velum, but considering that they are primitively placed on the posterior and ventral side of the mouth, and that the velum is essentially an organ on the dorsal side of the mouth, this view cannot, in my opinion, be maintained with any plausibility.

Various views have been put forward with reference to the Cephalopod foot. Huxley's view, which is the one most generally adopted, is given in the following quotation ${ }^{1}$.

"But that which particularly distinguishes the Cephalopoda "is the form and disposition of the foot. The margins of this " organ are, in fact, produced into eight or more processes termed "arms, or brachia; and its antero-lateral portions have grown " over and united in front of the mouth, which thus comes, "apparently, to be placed in the centre of the pedal disk. More- 
"over, two muscular lobes which correspond with the epipodia of "the Pteropods and Branchiogasteropods, developed from the "sides of the foot, unite posteriorly, and, folding over, give rise to "a more or less completely tubular organ-the funnel or infun"dibulum."

Grenacher, from his observations on the development of Cephalopoda, argues strongly against this view, and maintains that no median structure comparable with the foot is present in this group : and that the arms cannot be regarded as taking the place of the foot, but are more probably representatives of the velum.

The difficulty of arriving at a decision on this subject is mainly due to the presence of the yolk-sack, which, amongst the Cephalopoda as amongst the Vertebrata, is the cause of considerable modifications in the course of the development. The foot is essentially a protuberance on the ventral surface, between the mouth and the anus. In Gasteropods it is usually not filled with yolk, but contains a cavity, traversed by contractile mesoblastic cells. In this group the blastopore is a slit-like opening (vide p. I 87 ) extending over the region of the foot, from the mouth to the anus, the final point of the closure of which is usually at the oral but sometimes at the anal extremity. In Cephalopods the position of the Gasteropod foot is occupied by the external yolksack. In normal forms the blastopore closes at the apex of the yolk-sack, and at the two sides of the yolk-sack the arms grow out. These considerations seem to point to the conclusion that the normal Gasteropod foot is represented in the Cephalopod embryo by the yolk-sack, which has, owing to the immense bulk of food-yolk present in the ovum, become filled with food-yolk and enormously dilated. The closure of the blastopore at the apex of the yolk-sack, and not at its oral or anal side, is what might naturally be anticipated from the great extension of this part.

Grenacher's type of larva, where the external yolk-sack is practically absent, appears to me to lend confirmation to this view. If the reader will turn to fig. I 3 , he will observe a prominence between the mouth and anus, which exactly resembles the ordinary Gasteropod foot. At the sides of this prominence are placed the rudiments of the arms. This prominence is filled 
with yolk, and represents the rudiment of the external yolk-sack of the typical Cephalopod embryo. The blastopore, owing to the smaller bulk of the food-yolk, reverts more nearly to its normal position on the oral side of this prominence.

If the above considerations have the weight which I attribute to them, the unpaired part of the Cephalopod foot has been overlooked in the embryo on account of the enormous dilatation it has undergone from being filled with food-yolk; and also owing to the fact that in the adult the median part of the foot is unrepresented. The arms are clearly, as Huxley states, processes of the margin of the foot.

Both Grenacher and Huxley agree in regarding the funnel as representing the coalesced epipodia; but Grenacher points out that the anterior folds which assist in forming the funnel (vide p. 253) represent the great lateral epipodia of the Pteropod foot, and the posterior folds the so-called horse-shoe shaped portion of the Pteropod foot.

\section{Development of Organs.}

The epiblast. With reference to the general structure of the epiblast there is nothing very specially deserving of notice. It gives rise to the whole of the general epidermis and to the epithelium of the organs of sense. The most remarkable feature about it is a negative one, viz. that it does not, in all cases at any rate, give rise to the nervous system.

The epiblast of the mantle has the special capacity of secreting a shell, and the integument of the foot has also a more or less similar property in that it forms the operculum, and a byssus in some Lamellibranchiata, other parts of the integument form the radula, setæe in Chiton, and other similar structures.

Nervous system. The origin of the nervous system in Mollusca is still involved in some obscurity. It is the general opinion amongst the majority of investigators that the nervous ganglia in Gasteropods and Pteropods are formed from detached thickenings of the epiblast. Both Lankester (No. 239) and Fol (No. 249-251) have arrived at this conclusion, and Rabl has shewn by sections that in Planorbis there are two lateral thickenings of the epiblast in the velar area; from which the supra- 
œsophageal ganglia become subsequently separated off. The observations on the pedal ganglia are less precise: they very probably arise as thickenings of the epiblast of the side of the foot.

According to Fol, the nervous system in the Hyaleacea amongst the Pteropoda originates in a somewhat different way. A disc-like area appears in the centre of the velum, which soon becomes nearly divided into two halves. From each of these there is formed by invagination a small sack. The axes of invagination of the two sacks meet at an angle on the surface. The cavities of the sacks become obliterated; the sacks themselves become detached from the surface, fuse in the middle line, and come to lie astride of the œesophagus. Fol has detected a similar process in Limax. The exact origin of the pedal ganglia was not observed, but $\mathrm{Fol}$ is inclined to believe that they develop from the mesoblast of the foot.

A very different view is held by Bobretzky (No. 242), whose observations were made by means of sections.

The supra-œsophageal and pedal ganglia are formed according to this author as independent and ill-defined local thickenings of cells which are apparently mesoblastic. The two sets of ganglia appear nearly simultaneously, and later than the rudiments of the auditory and optic organs.

In the Cephalopoda there seems to be but little doubt, as first pointed out by Lankester, that the various ganglia originate in what is apparently mesoblastic tissue.

There is still very much requiring to be made out with reference to their origin, unless details on this subject are given in Bobretzky's Russian memoir. It would seem however that each ganglion develops as an independent differentiation of the mesoblast (unless the optic and cerebral ganglia are from the first continuous) ${ }^{2}$. The corresponding ganglia of the two sides become subsequently united and the various ganglia become connected by their proper commissural cords. The ganglia are shewn in figures 124,126 , and 127.

In Lamellibranchiata the development of the nervous system has not been worked out.

The two points which are most striking in the development of the nervous system of Mollusca are (I) the fact that in the Cephalopoda at any rate it is developed from tissue apparently mesoblastic; and (2) the fact that the several ganglia frequently originate quite independently, and subsequently become connected.

1 Ussow states that they are independent. 
With reference to the first of these points it should be noticed that the supra-œsophageal and pedal ganglia are at first respectively connected with the optic and auditory organs, and that these sense organs are in some cases at any rate developed anteriorly in point of time to the ganglia. It seems perhaps not impossible that primitively the ganglia may have been simply differentiations of the walls of the sense organ, and perhaps their apparent derivation from the mesoblast is really a derivation from cells which primitively belonged to the walls of these sense organs. Bobretzky's observations on Fusus fit in well with this view.

In the Hyaleacea and in other Pteropods, where the eyes are absent in the adult, Fol finds the supra-œsophageal ganglia resulting from a pair of epiblastic invaginations. May not these invaginations be really rudiments of the eyes as well as of the ganglia? Fol also, it is true, describes a similar mode of origin for these ganglia in Limax. It would be interesting to have further observations on this subject. The independent origin of the pedal and supra-œsophageal ganglia finds its parallel amongst the Chætopoda.

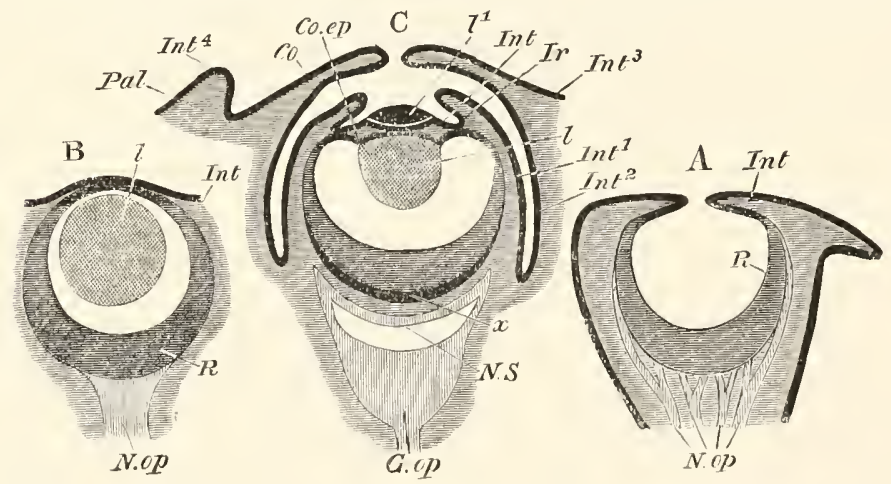

F1G, 122. Three diagrammatic Sections ol the eyes of Mollusca. (After Grenacher.)

A. Nautilus. B. Gasteropod (Limax or Helix). C. Dibranchiate Cephalopod.

Pal. eyelid; Co. cornea ; Co.ep. epithelium of ciliary body ; Ir. iris; Int. Int $t^{1} \ldots$ $I n t^{4}$. different parts of the integument ; $l$. lens ; $l^{1}$. outer segment of lens; $R$. retina; $N . o p$. optic nerve; G.op. optic ganglion; $x$. inner layer of retina; N.S. nervous stratum of retina.

The supra-œsophageal ganglia appear always to develop within the region of the velar area. This area corresponds with the pre-oral lobe of the Chætopod larva, at the apex of which is developed the supra-œsophageal ganglion. Embryology thus confirms the results of Comparative Anatomy in reference to the homology of these ganglia in the $t$ wo groups.

Optic organs'. An cye is present in most Gasteropods and

1 For a fuller account of this subject the reader is referred to the chapter on 'The Development of the Eye.' 
in many larval Pteropods. Although its development has not been fully worked out, yet it has clearly been shewn by Bobretzky and other investigators that it originates as an involution of the epidermis, which first forms a cup and eventually a closed vesicle. The posterior wall of the vesicle gives rise to the retina, the anterior to the inner epithelium of the cornea. The external epidermis becomes continued over the outer surface of the vesicle.

The lens is formed in the interior of the vesicle, probably as a cuticular deposit, which increases by the addition of concentric layers. Pigment becomes deposited between the cells of the retina. Fig. $\mathrm{I} 22 \mathrm{~B}$ is a diagrammatic representation of the adult eye of a Gasteropod.

The Cephalopod eye is formed, as first shewn by Lankester, as a pit in the epiblast round which a fold arises (fig. I23 A) and gradually grows over the mouth of the pit so as to shut it off from communication with the exterior (fig. I23 B).

The epiblast lining the posterior region of the vesicle gives rise to the retina, that lining the anterior region to the ciliary body and processes. It is important to notice that the condition of the eye just before the above pit becomes closed is exactly that which is permanent in Nautilus (vide fig. I22 A). After the pit has become closed a mesoblastic layer grows in between its wall and the

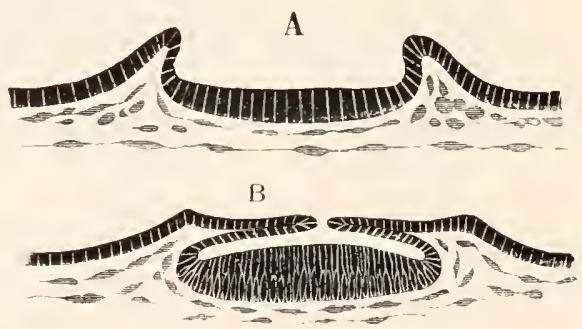

Fig. 123. Two SECtions THROUGH THE DEVELOPING EYE OF A CEPHALOPOD TO SHEW THE FORMATION OF THE OPTIC CUP. (After Lankester.) external epiblast.

The lens becomes formed in two independent segments. The inner and larger of these arises as a rod-like process (fig. I24) projecting from the front wall of the optic vesicle into the cavity of the vesicle. It is a cuticular structure and therefore without cells. By the deposition of a series of concentric layers it soon assumes a spherical form (fig. 125, hl). The condition 
of the eye, with a closed optic vesicle and the lens projecting into it, is that which is permanent in the majority of Gasteropods (vide fig. I22 B). At about the time when the lens first becomes formed a fold composed of epiblast and mesoblast appears round the edge of the optic cup (fig. I $24, c c$ ), and gives rise to a structure

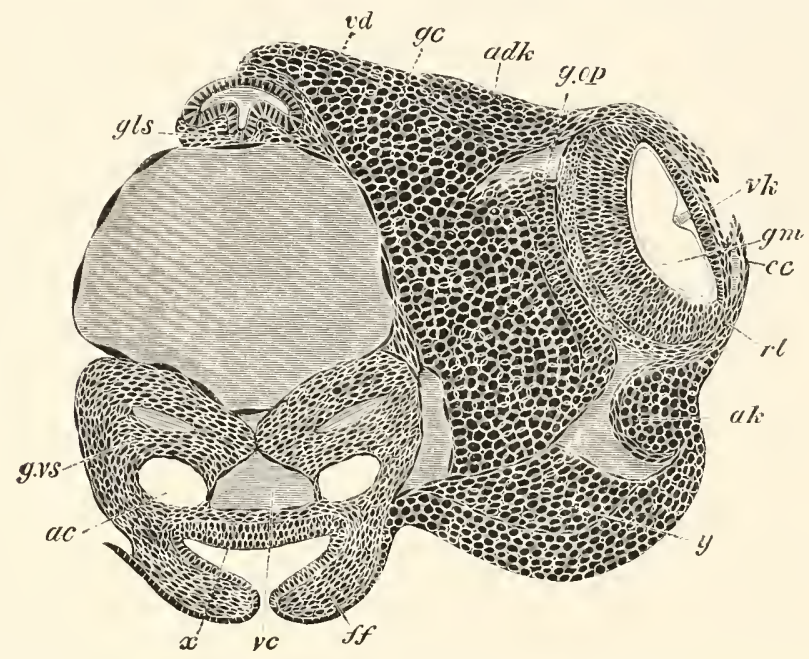

Fig. 124. Transverse section through the head of an advanced embryo of LoLigo. (After Bobretzky.)

$v d$. œsophagus; $g l s$. salivary gland; $g . v s$. visceral ganglion; $g c$. cerebral ganglion; g.op. optic ganglion; $a d k$. optic cartilage; $a k$. and $y$. lateral cartilage or (?) white body; $r t$. retina; $g m$. limiting membrane; $v k$. ciliary region of eye; $c c$. iris; $\alpha c$. auditory sack (the epithelium lining the auditory sacks is not represented); $v c$. vena cava ; ff. folds of funnel.

known in the adult as the iris. Shortly afterwards this becomes more prominent (fig. I25, if), and at the same time the layers of cells of the ciliary region in front of the inner segment of the lens become reduced to the condition of mere membranes (fig. I $25 \mathrm{~B}$ ); and in front of them the anterior or outer segment of the lens becomes formed as a cuticular deposit (fig. I $25 \mathrm{~B}, v l$ ). At a still later period a fresh fold of epiblast and mesoblast appears round the eye and gradually constitutes the anterior optic chamber (vide fig. I22 C, Co). In most forms this chamber communicates with the exterior by a small aperture, but in some it is completely closed. The fold itself gives rise to the cornea in front and to the sclerotic at the sides. At a later 
period another fold may appear forming the eyelids (fig. I22 C, $P a l)$.

Auditory organs. A pair of auditory sacks is found in the larvæ of almost all Gasteropods and Pteropods, and usually originates very early. They are placed in the front part of the foot, and on the formation of the pedal ganglia come into close connection with it, though they receive their nervous supply in the adult from the supra-œsophageal ganglia.

In a very considerable number of cases amongst Gasteropods and Pteropods the auditory organs have been observed to develop as invaginations of the epiblast, which give rise to closed vesicles lying in the foot, c.g. Paludina, Nassa, Heteropods, Limax, some Pteropods (Clio).

This is no doubt the primitive mode of origin, but in other cases, which perhaps require confirmation, the sacks are stated to originate from a differentiation of solid thickenings of the epidermis or of the tissues subjacent to it.

The auditory sacks are provided with an otolith, which according to Fol's observations is first formed in the wall of the sack.

In Cephalopods the auditory organs are formed as epiblastic pits on the posterior surface of the embryo, and are at first widely separated (fig. I I $3, a c$ ). The openings of the pits become narrowed, and finally the original pits form small sacks lined by an epithelium, and communicating with the exterior by narrow ducts, equivalent to the recessus vestibuli of Vertebrates, and named, after their discoverer, Kölliker's ducts. The external openings of these ducts become completely closed at about the same time as the shell-gland, and the ducts remain as ciliated diverticula of the auditory pits. The widely separated auditory sacks gradually approach in the middle ventral line, and are immediately invested by the visceral ganglia (fig. I24, ac). They finally come to lie in contact on the inner side of the funnel.

On the side opposite Kölliker's duct, an epithelial ridge is formed-the crista acustica-the cells of which give rise to an otolith connected with the crista by a granular material. At a later period of development three regions of the epithelium of the sack become especially differentiated. Each of these regions 
is provided with two rows of cells, bearing on their free edges numerous very short auditory hairs. The cells of each row are placed nearly at right angles to those of the adjoining row.

Muscular system. The muscular system in all groups of Molluscs is derived entirely from the mesoblast.

The greater part of the system takes its origin from the somatic mesoblast. In almost all Gasteropod and Pteropod larvæ there is present a well-developed spindle muscle attaching the embryo to the shell. This muscle appears to be absent in the Cephalopoda.

Body cavity and vascular system. The body cavity in Gasteropods and Pteropods originates either by a definite splitting of the mesoblast, or by the appearance of intercellular

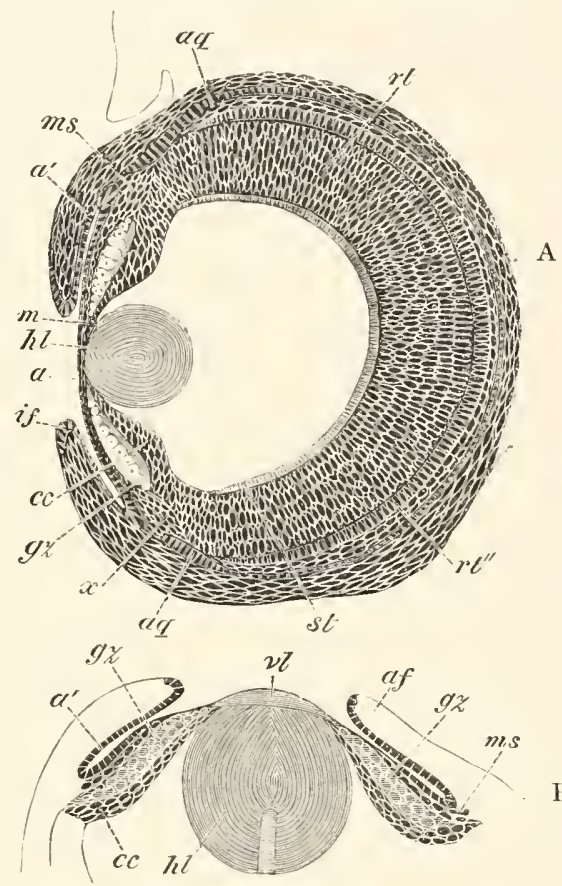

Fig. 125. Sections through The DEVELOPING EYE OF LOLIGO AT TWO STAGES. (After Bobretzky.)

$h l$. inner segment of lens; $v l$. outer segment of lens; $a$ and $a^{\prime}$. epithelium lining the anterior optic chamber; gz. large epiblast cells of ciliary body; cc. small epiblast cells of ciliary body; ms. layer of mesoblast between the two epiblastic layers of the ciliary body; af. and if. fold of iris; $r t$. retina; $r t^{\prime \prime}$. inner layer of retina; st. rods; $a q$. equatorial cartilage. spaces. It becomes divided into numerous sinuses which freely communicate with the vascular system.

Very different accounts have been given by different investigators of the development of the heart in the Gasteropoda and Pteropoda.

It would seem however in most cases to arise as a solid mass of mesoblast cells at the hind end of the pallial cavity, which subsequently becomes hollowed out and divided into an auricle and ventricle. Bobretzky's careful observations have fully established this mode of development for Nassa. 
In Pteropods the heart is formed ( $\mathrm{Fol}$ ) close to the anus, but slightly dorsal to it (fig. $108, h$ ). The pericardium is formed from the mesoblast at a considerably later period than the heart.

A very different account of the formation of the heart is given by Bütschli for Paludina. He states that there appears an immense contractile sack on the left side of the body. This becomes subsequently reduced in size, and in the middle of it appears the heart, probably from a fold of its wall. The original sack would appear to give rise to the pericardium.

In connection with the vascular system mention may be made of certain contractile sinuses frequently found in the larva of Gasteropoda and Pteropoda. One of these is placed at the base of the foot, and the other on the dorsal surface within the mantle cavity immediately below the velum ${ }^{1}$. The completeness of the differentiation of these sinuses varies considerably; in some forms they are true sacks with definite walls, in other cases mere spaces traversed by muscular strands. They are found in the majority of marine Gasteropods, Heteropods and Pteropods. In Limax a large posteriorly placed pedal sinus is well developed, and there is also a sinus in the visceral sack. The rhythmical contraction of the yolk-sack of Cephalopods appears to be a phenomenon of the same nature as the contraction of the foot sinus of Limax.

In Calyptræa (Salensky) there is an enormous provisional cephalic dilatation within the velum which does not appear to be contractile. Similar though less marked cephalic vesicles are found in Fusus, Buccinum and most marine Gasteropods.

In Cephalopods the vascular system is formed by a series of independent (?) spaces originating in the mesoblast, the cells around which give rise to the walls of the vessels. The branchial hearts are formed at about the time at which the shell-gland becomes closed. The aortic heart (fig. $127, c$ ) is formed of two independent halves which subsequently coalesce (Bobretzky).

The true body cavity arises as a space in the mesoblast subsequently to the formation of the main vascular trunks.

Renal organs. Amongst the Gasteropods and Pteropods there are present provisional renal organs, which may be of two kinds, and a permanent renal organ.

1 Rabl holds that there is no contractile dorsal sinus, but that the appearance of contraction there is due to the contractions of the foot. 
The provisional organs consist of either (1) an external paired mass of excretory cells or (2) an internal organ provided with a duct, which is not in all cases certainly known to open externally. The former structure is found especially in the marine Prosobranchiates (Nassa, etc.) where it has been fully studied by Bobretzky. It consists of a mass of cells on each side of the body, close to the base of the foot, and not far behind the velum. This mass grows very large, and below it may be seen a continuous layer of epiblast. The cells forming it fuse together, their nuclei disappear, and numerous vacuoles containing concretions arise in them. At a later stage all the vacuoles unite together and form a cavity filled with a brown granular mass.

The provisional internal renal organ is found in many pulmonate Gasteropods-Lymnæus, Planorbis, etc. It consists of a paired V-shaped ciliated tube with a pedal and cephalic limb. The former has an external opening, but the termination of the latter is still in doubt.

It consists, according to Bütschli's description (No. 244), in the freshwater Pulmonata (Lymnæus, Planorbis) of a round sack, close to the head, opening by an elongated and richly ciliated tube in the neighbourhood of the eye. From the sack a second shorter tube passes off towards the foot, which seems however to end blindly. The cells lining the sack contain concretions, and there is one especially large cell in the lumen of the sack attached on the side turned towards the eye. It coexists in Lymnæus with provisional renal organs of the type of those in marine Prosobranchiata.

A somewhat different description of the structure and development of this organ in Planorbis has recently been given by Rabl (No. 268). It consists of a $\mathbf{V}$-shaped tube on each side with both extremities opening into the body cavity. The one limb is directed towards the velar area, the other towards the foot. It is developed from the mesoblast cells of the anterior part of the mesoblastic band. The large mesoblast (p. 227) of each side grows into two processes, the two limbs of the future organ. A lumen in the cell is continued into each limb, while continuations of the two limbs of the $\mathbf{V}$ are formed from the hollowing out of the central parts of the adjoining mesoblast cells.

In Limax embryos Gegenbaur found a pair of elongated provisional branched renal sacks, the walls of which contained concretions. These sacks are provided with anteriorly directed ducts opening on the dorsal side of the mouth. This organ is 
probably of the same nature as the provisional renal organ in other Pulmonata.

Permanent ronal organ. According to the most recent observer (Rabl, No. 268), whose statements are supported by the sections figured, the permanent renal organ in Gasteropods is developed from a mass of mesoblast cells close to the end of the intestine. This is first carried somewhat to the left side, and then becomes elongated and hollow, and attaches itself to the epiblast on the left side of the anus (fig. Io8, $r$ ). After the formation of the heart the inner end opens into the pericardium and becomes ciliated, the median part becomes glandular and concrements appear in its lining cells, and the terminal part forms the duct.

Previous observers have usually derived this organ from the epiblast; according to Rabl this is owing to their having studied too late a stage in the development.

In Cephalopoda the excretory sacks or organ of Bojanus are apparently differentiations of the mesoblast ${ }^{1}$. At an carly stage part of their walls envelops the branchial veins. From this part of the wall the true glandular section of the organ would seem to be formed. The epithelium forming the inner wall of each sack is at an early age very columnar.

The development of the organ of Bojanus in Lamellibranchiata has been studied by Lankester. He finds that it develops as a paired invagination of the epiblast immediately ventral to the anus.

Generative glands. The generative glands in Mollusca would appear to be usually developed in the post-larval period, but our knowledge on this subject is extremely scanty.

In Pteropods Fol believes that he has proved that the hermaphrodite gland originates from two independent formations, one (the testicular) epiblastic in origin, and the other (the ovarian) hypoblastic.

These views of Fol do not appear to me nearly sufficiently substantiated to be at present accepted.

The generative glands in Cephalopoda appear to be simple differentiations of the mesoblast. They are at first very closely

1 I conclude this from Bobretzky's figures. 
connected with the aortic heart (fig. I27, $k d$ ), but soon become completely separated from it.

Alimentary tract. The formation of the archenteron, and the relation of its opening to the permanent mouth and anus, has already been described and needs no further elucidation. It will be convenient to treat the subject of this section under three headings for each group-viz. (I) the mesenteron, (2) the stomodæum, and (3) the proctodæum.

The mesenteron. In the Gasteropoda and Pteropoda the mesenteron, as has already been mentioned, forms a simple sack, which may however, owing to the presence of food-yolk, be at first without a lumen. Of this sack an anterior portion gives rise to the stomach and liver, and a posterior to the intestine. This latter portion is the first to be distinctly differentiated as such, and forms a narrowish tube connecting the anterior dilatation with the anus. In the meantime the cells of a great part of the anterior portion of the mesenteron undergo peculiar changes. They enlarge, and in each of them a deposit of food material appears, which is often at any rate derived from the absorption of the albumen in which the embryo floats. The cells on the dorsal side, adjoining the œsophageal invagination, and the whole of the cells on the ventral side do not however undergo these changes. There thus arises an anterior and ventral region adjoining the œsophagus, which becomes completely enclosed by small cells and forms the true stomach. The part behind and dorsal to the stomach is lined by the large nutritive cells and forms the liver. It opens into the stomach at the junction of the latter with the intestine, which in the later stages becomes bent somewhat forwards and to the right. Still later the hepatic region becomes branched, the albuminous contents of its cells are replaced by a coloured secretion, and it becomes bodily converted into the liver. The stomach is usually richly ciliated.

The various modifications of the above type of development of the alimentary tract are to be regarded as due to the disturbing influence of food-yolk. Where primitively the hypoblast cells are very buiky, though invaginated in a normal way, the wall of the hepatic region becomes immensely swollen with food-yolk, e.g. Natica. In other cases amongst certain Pteropods (Fol, No. 249) where the hypoblast is still more bulky, part of the archenteric walls becomes converted into a bilobed sack opening 
into the pyloric region, in the walls of which a large deposit of food material is stored, which gradually passes into the remainder of the alimentary tract and is there digested. The bilobed nutritive sack, as it is called by Fol, is eventually completely absorbed, though the liver in some, if not all cases, grows out as a fresh sack from its duct.

The formation of the permanent alimentary tract, when the hypoblast is so bulky that there is no true archenteric cavity, has been especially investigated by Bobretzky (No. 242).

In the case of a species of Fusus the hypoblast, when enclosed by the epiblast, is composed of four cells only. The blastopore remains permanently open at the oral region, and around it the œsophagus grows in a wall-like fashion. The protoplasmic portions of the four hypoblast cells are turned towards the osophageal opening, and from them are budded off small cells which are continuous at the blastopore with the epiblast of the œsophagus. These cells give rise posteriorly to the intestine and anteriorly to the sack, which becomes the stomach and liver. This sack always remains open towards the four primitive yolk cells. The cells of the posterior part of it become larger and larger and form the hepatic sack, which fills up the left and posterior part of the visceral sack, pushing the yolk cells to the right. The cells lining the hepatic sack become pyramidal in shape, and each of them is filled with a peculiar mass of albuminous material. The cells adjoining the opening of the oesophagus remain small, become ciliated, and form the stomach. They are not sharply separated off from the cells of the hepatic sack. The yolk cells remain distinct on the right side of the body during larval life, and their food material is gradually absorbed for the nutrition of the embryo.

A modification of the above mode of development, where the food material is still more bulky and the blastopore closed, is found in Nassa, and has already been described (vide p. 233).

The stomodaum. The stonodaum in most cases is formed as a simple epiblastic invagination which meets and opens into the mesenteron. When the blastopore remains permanently open at the oral region the stomodxum is formed as an epiblastic wall round its opening. In all cases the stomodæum gives rise to the mouth and osophagus. At a subsequent period there are developed in the oral region of the stomodxum the radula in a special ventral pit, and the salivary glands-the latter as simple outgrowths.

The œesophagus is usually ciliated.

The proctodaum. Except where the blastopore remains as the permanent anus (Paludina) the proctodaum is always formed subsequently to the mouth. Its formation is usually preluded by the appearance of two projecting epiblast cells, but it is 
always developed as a very shallow epiblastic invagination, which does not give rise to any part of the true intestine.

In the Cephalopods the alimentary tract is formed, as in other cephalophorous Mollusca, of three sections. (I) A stomodæum, formed by an epiblastic invagination, which gives rise to the mouth, œsophagus and salivary glands. (2) A proctodæum, which is an extremely small epiblastic invagination. (3) A mesenteron, lined by true hypoblast, which forms the main

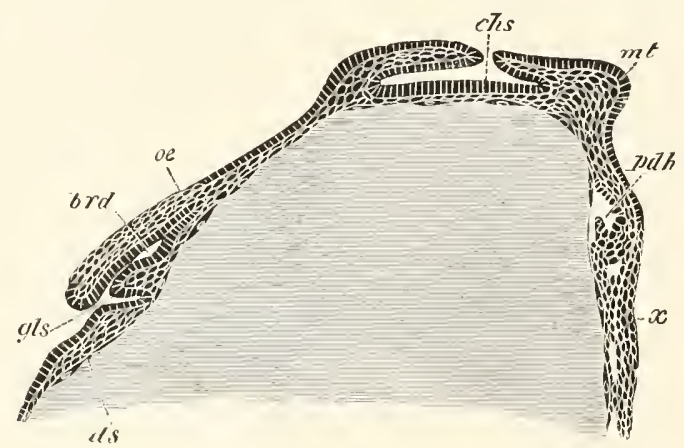

Fig. 126. Longitudinal Vertical Section through a Loligo OVUM When THE MESENTERIC CAVity is just COMMENCING TO BE FORMED, (After Bobretzky.)

gls. salivary gland; $b r d$. sheath of radula; oe. oesophagus : $d s$. yolk-sack; chs. shell-gland; $m t$. mantle; $p d h$. mesenteron ; $x$. epiblastic thickening between the folds of the funnel.

section of the alimentary tract, viz. the stomach, intestine, the liver, and ink sack ${ }^{1}$.

The mesenteron. The mesenteron is first visible from the surface as a small tubercle on the posterior side of the mantle between the rudiments of the two gills (fig. I I $\mathrm{B}, a n$ ). Within this, as was first shewn by Lankester, a cavity appears.

This cavity is as in Gasteropods open to the yolk-sack, and only separated from the yolk itself by the yolk membrane already spoken of. It is at first lined by indifferent cells of the lower layer of the blastoderm, which however soon become columnar and form a definite hypoblastic layer (fig. I26, pdh). Between the hypoblast and epiblast there is a very well marked layer of mesoblast. As the mesenteric cavity extends, its walls 
meet the epiblast, and at the point of contact of the two layers the epiblast becomes slightly pitted in. At this point the anus is formed at a considerably later period (fig. I 27, an).

On the ventral side of the primitive mesenteron an outgrowth appears very early, which becomes the ink sack (fig. 127, bi).

The mesenteric cavity, still open to the yolk, gradually extends itself in a dorsal direction over the yolk-sack, but remains for some time completely open to it ventrally, and only separated from the actual yolk by theyolk membrane. There early grow out from the walls of the mesenteron a pair of hepatic diverticula.

As the mesenteric cavity extends it dilates at its distal extremity into a chamber destined to form the stomach (fig. $127, \mathrm{mg})$. At about this time the anus becomes perforated. Shortly afterwards the mesenteron meets and opens into the osophagus at the dorsal extremity of the yolk sack, but at the time when this takes place the hypoblast has extended round the entire cavity, and has shut it off from the yolk. The yolk membrane throughout the whole of this period is quite passive, and has no

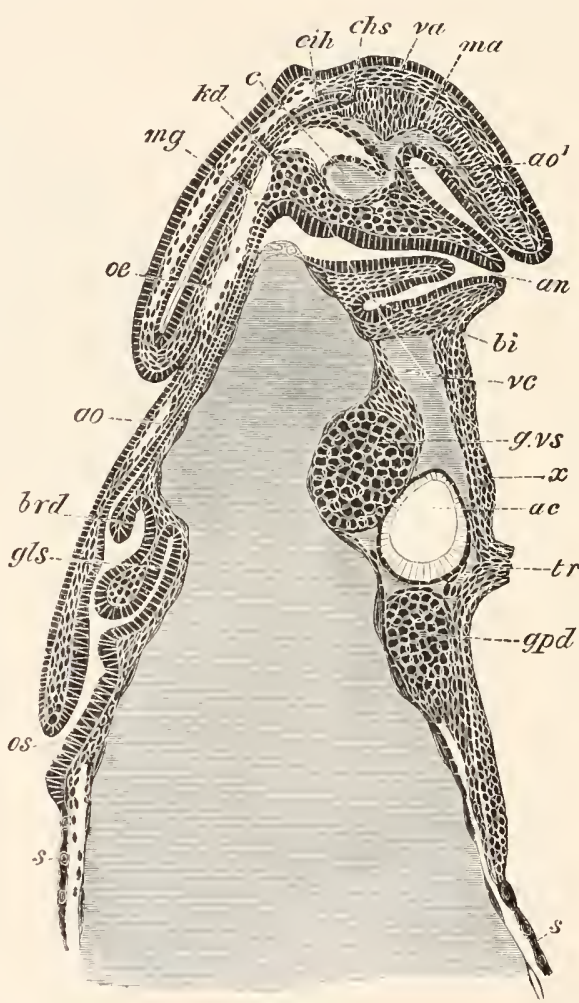

FIG. 127. LONGITUDINAL SECTION THROUGH AN ADVANCED EMBRyo of Loligo. (After Bobretzky.)

os. mouth; gls. salivary gland; brd. sheath of radula; $a o$. anterior aorta; $a o^{1}$. posterior aorta; $z^{\prime} a$. branch of posterior aorta to shell sack; ma. branch of posterior aorta to mantle; $c$. aortic heart ; oe. oesophagus ; $m g$. stomach ; an. anus ; $b i$. ink sack; $k d$. germinal tissue; $c i \hbar$. shell sack; $\tau \tau$. vena cava; $g . v s$. visceral ganglion; $g . p d$. pedal ganglion ; $a c$. auditory sack ; $t r$. funnel. share in forming the walls of the alimentary tract. 
The stomodeum. The stomodrum appears as an epiblastic invagination at the anterior side of the blastoderm, before any trace of the mesenteron is present. It rapidly grows deeper, and, shortly after the mesenteric cavity becomes formed, an outgrowth arises from its wall adjoining the yolk-sack, which gives rise to the salivary glands (figs. I 26 and $127, \mathrm{~g} l s$ ). Immediately behind the opening of the salivary glands there appears on its floor a swelling which becomes the odontophore, and behind this a pocket of the stomodxal wall forms the sheath of the radula (figs. I 26 and $127,6 r d$ ). Behind this again the cesophagus is continued dorsalwards as a very narrow tube, which eventually opens into the stomach (fig. I 27).

The terminal portion of the rudiment of the salivary gland divides into two parts, each of which sends out numerous diverticula which constitute the permanent glands. The greater part of the original outgrowth remains as the unpaired duct of the two glands ${ }^{1}$.

In the larva observed by Grenacher the anterior pair of salivary glands originated from independent lateral outgrowths of the floor of the mouth, close to the opening of the posterior salivary glands.

The yolk-sack of the Cephalopoda. The yolk, as has already been stated, becomes at an early period completely enclosed in a membrane formed of flattened cells, which constitutes a definite yolk-sack. It is, in the more typical forms of Cephalopoda, divided into an external and an internal section, of which the former is probably a special differentiation of the median part of the foot of other cephalophorous Mollusca (vide p. 272). At no period does the yolk-sack communicate with the alimentary tract. The two sections of the yolk-sack are at first not separated by a constriction. In the second half of embryonic life the condition of the yolk-sack undergoes considerable changes. The internal part grows greatly in size at the expense of the external, and the latter diminishes very rapidly and becomes constricted off from the internal part of the sack, with which it remains connected by a narrow vitelline duct.

The internal yolk-sack becomes divided into three sections: a dilated section in the head, a narrow section in the neck, and an enormously developed portion in the mantle region. It is the latter part which mainly grows at the expense of the external yolk-sack. It gives off at its dorsal end two lobes, which pass round and embrace the lower part of the œsopha-

1 In Loligo only a single pair of salivary glands is present. 
gus. The passage of the yolk from the external to the internal yolk-sack is probably largely due to the contractions of the former.

The external yolk-sack is not vascular, and probably the absorption of the yolk for the nutrition of the embryo can only take place in the internal yolk-sack. The most remarkable feature of the Cephalopod yolk-sack is the fact that it lies on the opposite side of the alimentary tract to the yolk cells, which form a rudimentary yolk-sack in such Gasteropoda as Nassa and Fusus. In these forms, the yolk-sack is at first dorsal, but subsequently is carried by the growth of the liver to the right side. In Cephalopoda on the contrary, the yolk-sack is placed on the ventral side of the body.

What is known of the development of the alimentary tract in the Polyplacophora has already been mentioned.

In the Lamellibranchiata (Lankester, No. 239), the mesenteron early grows out into two lateral lobes which form the liver, while the part between them forms the stomach.

In Pisidium the intestine is formed from the original pedicle of invagination, which remains permanently attached to the epiblast. The stomodæum is formed by the usual epiblastic invagination, and becomes the mouth and osophagus. The development of the crystalline rod and its sack do not appear to be known. In the adult the sack of the crystalline rod opens into a part of the alimentary tract which appears to belong to the mesenteron. Were however the development to shew them to be really derived from the stomodreum they might be interpreted as rudiments of the organ which constitutes the odontophore and its sack in cephalophorous Mollusca-an interpretation which would be of considerable phylogenetic interest.

\section{BIBLIOGRAPHY.}

\section{General.}

(238) T. II. Huxley. "On the Morphol. of the Cephal. Mollusca." Phil. Trans. 1853 .

(239) E. R. Lankester. "On the developmental history of the Mollusca." Phil. Trans. 1875 .

(240) H. G. Bronn and W. Keferstein. Die Klassen ". Ordnungen d. Thierreichs, Vol. 111, 1862-1866.

\section{Gasteropoda and Pteropoda.}

(241) J. Alder and A. Hancock. "Devel. of Nudibr." Ann. and Magaz. Nat. Hist., Vol. X11. $18_{43}$. 
(242) N. Bobretzky. "Studien über die embryonale Entwicklung d. Gasteropoden." Archiv f. micr. Anat., Vol. xıI.

(243) W. K. Brooks. "Preliminary Observations on the Development of Marine Gasteropods." Chesapeake Zoological Laboratory, Session of 1878 . Baltimore, I 879 .

(244) O. Bütschli. "Entwicklungsgeschichtliche Beiträge (Paludina vivipara)." Zeit.f. zuiss. Zool., Vol. Xxix. I877.

(245) IV. Carpenter. "On the devel. of the embr. of Purpura lapillus." Trans. Micros. Soc., $2^{\mathrm{d}}$ series, Vol. III. 1855.

(246) W. Carpenter. "On the devel. of the Purpura." Ann. and Mag. of Nat. Hist., $2^{\mathrm{d}}$ series, Vol. xx. i 857 .

(247) E. Claparède. "Anatomie u. Entwickl. der Neritina fluviatilis." Müller's Archiv, i 857 .

(248) H. Eisig. "Beitr. z. Anat. u. Entwickl. der Geschlechtsorg. von Lymnæus." Zeitschr.f. wiss. Zool., Vol. xIx. I 869 .

(249) H. Fol. "Sur le développement des Ptéropodes." Archiv. de Zool. expérim. et générale, Vol. IV. I 875 .

(250) H. Fol. "Sur le développement des Gastéropodes pulmonés." Compt. rend., 1875 , pp. $523-526$.

(251) H. Fol. "Sur le développement des Hétéropodes." Archiv. de Zool. expérim. et génírale, Vol. v. I 876 .

(252) C. Gegenbaur. "Beit. z. Entwicklungsgesch. der Landgasteropoden." Zeitschr.f. w. Zool., Vol, III. I 85 I.

(253) C. Gegenbaur. Untersuch. ̈̈b. Pteropoden u. Heteropoden, Leipzig, 1855 .

(254) H. von Jhering. "Entwicklungsgeschichte von Helix." Jenaische Zeitschrifi, Vol. Ix. 1875 .

(255) W. Keferstein and E. Ehlers. "Beob. üb. d. Entwick. v. Eolis peregr." Zool. Beitr., I86.

(256) J. Koren and D. C. Danielssen. "Bemärk. til Mollusk Udvikling." Nyt Mag. f. Naturvidensk., Vol. v. I847. Isis, p. $202 . \quad$ I 848.

(257) J. Koren and D. C. Danielssen. Bidrag til Pectinibr. Udvikl. Bergen, I851 (supplement, 1852). Ann. and Mag. Nat. Hist., i857.

(258) A. Krohn. "Beobacht. aus d. Entwickl. der Pteropoden u. Heterop." Müller's Archiv, i 856 and i 857 .

(259) A. Krohn. Beitr.zur Entwickl. der Pteropoden u. Heteropoden. Leipzig, I 860.

(260) H. de Lacaze-Duthiers. "Mém. sur l'anat. et l'embryog. des Vermets." $2^{\mathrm{e}}$ partie. Ann. sc. nat., $4^{\mathrm{e}}$ série, T. XIII. I 860 .

(261) P. Langerhans. "Zur Entwickl. der Gasterop. Opisthobr." Zeitschr. f. w. Zool., Vol. Xxill. i 873 .

(262) E. R. Lankester. "On the development of the Pond-Snail." Quart. F. of Micr. Scie., Vol. XIv. I874.

(263) E. R. Lankester. "On the coincidence of the blastopore and anus in Paludina vivipara." Quart. F. of Micr. Scic., Vol. xvi. I876.

(264) F. Leydig. "Ueber Paludina vivipara." Zeitschr. f. zo. Zool., Vol. II. I 850 .

(265) J. Mïller. Ueber Synapta dig. u. üh. d. Erseug. v. Schnecken in Holoth., 1852 .

B. II. 
(266) J. Müller. "Bemerk. aus d. Entwickl, der Pteropoden." Monatsber. Berl. Akad., i 857 .

(267) C. Rabl. "Die Ontogenie d. Suisswasser-Pulmonaten." Fenaische Zeitschrift, Vol. IX. 1875 .

(268) C. Rabl. "Ueb. d. Entwick. d. Tellerschnecke (Planorbis)." Morph. Fahrbuch, Vol. v. 1879 .

(269) W. Salensky. "Beitr. zur Entwickl. d. Prosobr." Zeitschr.f. w. Zool., Vol. xxil. I872.

(270) O. Schmidt. "Ueb. Entwick. von Limax agrestis." Muller's Archiv, $185 \mathrm{I}$.

(271) Max S. Schultze. "Ueber d. Entwick. des Tergipes lacinulatus." Arch. f. Naturg., Jahrg. xv. $18+9$.

(272) E. Selenka. "Entwick. von Tergipes claviger." Niederl. Arch.f. Zool., Vol. I. I87I.

(273) E. Selenka. “Die Anlage d. Keimbl. bei Purpura lapillus." Niederl. Arch.f. Zool., Vol. I. I872.

(274) C. Semper. "Entwickl. der Ampullaria polita, etc." Natuurk. Ver. handl. Utrechts Genootsch., 1862.

(275) A n. Stecker. "Furchung u. Keimblatterbildung bei Calyptræa." Morphol. Fahrbuch, Vol. II. 1876 .

(276) A. Stuart. "Ueb. d. Entwickl. einiger Opisthobr." Zeitschr.f.w. Zool., Vol. xv. I865.

(277) N. A. Warneck. "Ueber d. Bild. u. Entwick. d. Embryos bei Gasterop." Bullet. Soc. natural. de Moscou, T. Xxir. 1850.

\section{Cephalopoda.}

(278) P. J. van Beneden. "Kecherches sur l'Embryogénie des Sépioles." Nour. Mém. Acad. Roy. de Bruxelles, Vol. xiv. ir +1 .

(279) N. Bobretzky. Observation on the development of the Cephalopoda (Russian). Nachrichten d. kaiserlichen Gesell. d. Freunde der Natumviss. Anthropolog. Ethnogr. bei d. Universität Moskau.

(280) H. Grenacher. "Zur Entwicklungsgeschichte d. Cephalopoden." Zeit. f. wiss. Zool., Bd. xxiv. I $8_{74}$.

(281) A. Kölliker. Entwickhungsgeschichted. Cephalopoden. Zurich, $18_{4+}$.

(282) E. R. Lankester. "Observations on the development of the Cephalopoda." Quart. F. of Micr. Science, Vol. xv. 1875.

(283) E. Metschnikoff. "Le développement des Sépioles." Archiv d. Sc. phys. et nat., Vol. xxx. Genève, 1867 .

\section{Polyplacophora.}

(284) A. Kowalevsky. "Ueb. d. Entwick. d. Chitonen." Zoologischer Anzeiger, No. 37. 1879 .

(285) S. L. Lovén. "Om utvecklingen hos slägtet Chiton." Stockholm öfversigt, XII. 1855. [Vide also Amn. and MFag. of Nat. Hist., Vol. XVII. ${ }_{1856}$, and Archiv f. Naturgeschichte, 1856.] $^{6}$ 


\section{Scaphopoda.}

(286) H. Lacaze-Duthiers. "Développement du Dentale." Ann. d. Sci. Nat., Series IV. Vol. Vil. I 857 .

\section{Lamellibranchiata.}

(287) M. Braun. "Postembryonale Entwicklung d. Siisswasser-Muscheln." Zoologischer Garten.

(288) C. G. Carus. "Neue Untersuch. iib. d. Entwickl, unserer Flussmuschel." Verh. Leop.-Car. Akad., Vol. xvi. 1832.

(289) W. Flemming. "Studien in d. Entwicklungsgeschichte der Najaden." Sitz.d.k. Akad. Wiss. Wien, Vol. Lxxi. 1875 .

(290) F. Leydig. "Ueber Cyclas Cornea." Müller's Archiv, 1855.

(291) S. L. Lovén. "lBidrag til Känned. om Utweckl. af Moll. Acephala Lamellibr." Vetensk. Akad. Handl., i 848. [Vide also Arch.f. Naturg., 1849.]

(292) C. Rabl. "Ueber d. Entwicklungsgeschichte d. Malermuschel." Fenaische Zeitschrift, Vol. x. $18 ; 6$.

(293) W. Salensky. "Bemerkungen iiber IIaeckels Gastræa-Theorie (Ostrea)." Arch. f. Naturs., I874.

(294) O. Schmidt. "Ueb. d. Entwick. von Cyclas calyculata." Miiller's Arch., 1854 .

(295) O. Schmidt. "Zur Entwickl. der Najaden." Wien, Sitzungsber. math.nat. Cl., Vol. XIX. I 856 .

(296) P. Stepanoff. "Ueber die Geschlechtsorgane u. die Entwicklung von Cyclas." Archiv f. Naturgeschichte, 1865.

(297) H. Lacaze.Duthiers. "Développement d. branchies d. Mollusques Acéphales." An. Sc. Nat., Ser. Iv. Vol. v. 1856 . 


\section{CHAPTER X.}

\section{POLYZOA ${ }^{1}$.}

\section{ENTOPROCTA.}

THE development of the larvæ of Pedicellina is known from the researches of Hatschek (No. 299) far more completely than that of Loxosoma, though it does not apparently differ from it except in certain details. In both the known Entoproctous genera the segmentation is regular or nearly so, though Hatschek believes that he has detected in Pedicellina a slight difference between the two first segmentation spheres, and regards them as constituting the animal and vegetative poles of the embryo. The segmentation in Pedicellina, to which genus alone the remainder of the description applies, results in the formation of a singlelayered blastosphere, with a small segmentation cavity, in which the animal and vegetative poles can readily be distinguished owing to the smaller size of the cells at the animal pole.

The hypoblast cells and the vegetative ${ }^{2}$ pole become invagi-

1 The classification of the Polyzoa adopted in this chapter is shewn in the subjoined table:

I. Entoprocta.

II. Ectoprocta.

1. Gymnolemata $\begin{cases}a . & \text { Chilostomata. } \\ b . & \text { Ctenostomata. } \\ c . & \text { Cyclostomata. }\end{cases}$

2. Phylactolemata.

3. Podostomata (Rhabdopleura).

2 The succeeding statements about the gastrula are derived from Hatschek. According to Salensky a segmentation cavity is not present, and the hypoblast would seen to be formed by delamination or epibole. Barrois finds a gastrula in both Loxosoma and Pedicellina, but gives no details. Uljanin finds a segmentation cavity in Pedicellina, and Schmidt would appear to have observed a gastrula stage in Loxosoma. None of the accounts we have can be compared in fulness of detail to that of Hatschek. 
nated in the normal manner (fig. I2S A), the blastopore becomes narrowed to a slit with an antero-posterior direction, i.e. parallel to the line connecting the mouth and anus in the adult. At the hinder extremity of the blastopore there are present two conspicuously large cells (fig. I $28 \mathrm{~B}$, me), one on each side of the middle line. These cells give rise to the mesoblast. On the completion of the invagination the mesoblasts become covered by the epiblast (fig. I $2 \mathrm{~S} \mathrm{C}$, me). The blastopore then closes, but in the position it occupied the epiblast becomes thickened to form the rudiment of the vestibule, which at this stage constitutes a disc marked off by a shallow groove from the remainder of the body.

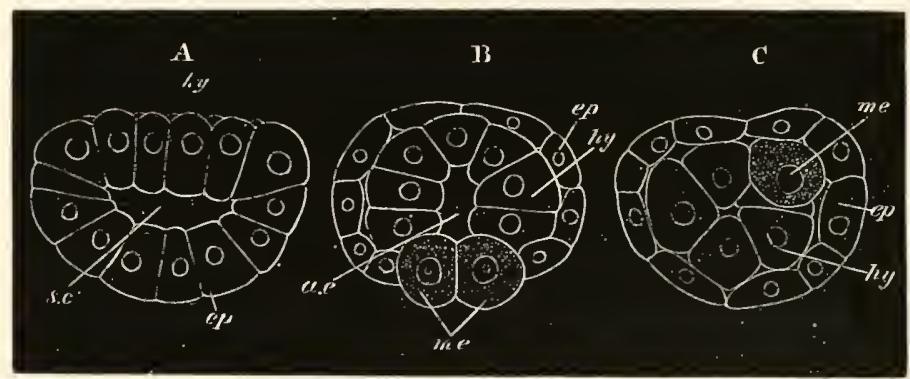

Fig. 128. Three stages in the Development of Pedicellina echinata. (After Hatschek.)

s.c. segmentation cavity; a.e. archenteron; $e p$. epiblast; me. mesoblast; hy. hypoblast.

$\mathrm{A}$ is the commencing gastrula stage from the side in optical section.

$B$ is a slightly later stage from above in optical section. It shews the two primitive mesoblast cells.

$\mathrm{C}$ is a later stage after the closure of the blastopore, viewed from the side in optical section.

At the anterior extremity of this disc an invagination arises to form the œesophagus (fig. I $29 \mathrm{~A}, o e$ ) ; and not long afterwards a posterior invagination to form the rectum (fig. I29 B, an.i). The oral disc and the œsophagus are richly ciliated. The œsophagus first, and afterwards the rectum unite with the archenteron (fig. I30), the walls of which soon become differentiated into a stomach and intestine, and on the upper wall of the former the hepatic cells become especially conspicuous (fig. I 30). 
During the completion of the alimentary canal a number of important structures is formed. The disc in which the oral and anal apertures are situated becomes converted into a true vesti-

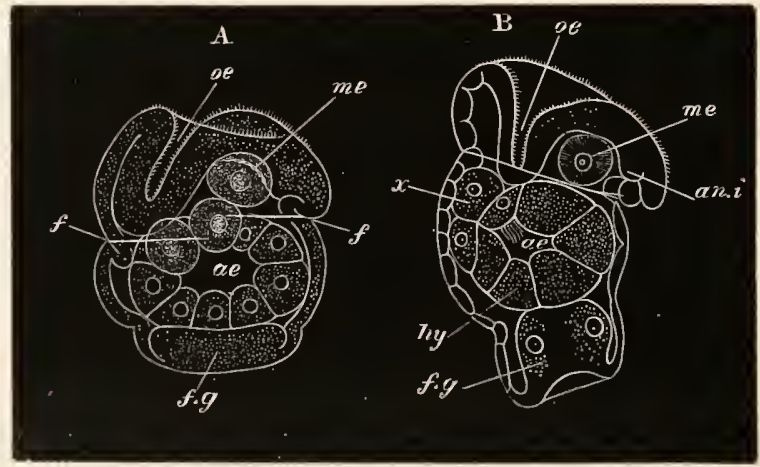

Fig. 129. Two stages in the developane of Pedicellina. (After Hatschek.)

$o e$. œesophagus; $a e$. archenteron; an.i. anal invagination; $f$. fold of epiblast; $f . g$. ciliated disc ; $x$. problematical body derived from hypoblast (probably a bud).

bule. On its floor, between the mouth and the anus, there arises a marked prominence with a tuft of cilia (fig. $130 \mathrm{~B}$ ), which persists in the adult.

This prominence is perhaps equivalent to the epistome of the Phylactolemata and the disc-like organ of Rhabdopleura, which Lankester has compared to the molluscan foot ${ }^{1}$.

Very shortly after the first formation of the vestibule there appears at the opposite end of the larva a thickening of the epiblast, which soon becomes invaginated, and forms an eversible pit (fig. I $29 \mathrm{~A}$ and $\mathrm{B}, \mathrm{f} . g$. ). Round its mouth there is formed a ring of stiff cilia (fig. I $30, f . g$. ). This organ is very possibly equivalent to the cement gland described by Kowalevsky in the adult Loxosoma. I shall speak of it as the ciliated disc.

The epiblast cells early secrete a cuticle.

The two mesoblast cells soon increase by division, and occupy the space between the alimentary canal and the body wall. They do not become divided into a splanchnic and somatic layer; but give rise to the interstitial connective tissue

'Lankester. "Remarks on the Affinities of Rhabdopleura." Quart. F. of Micro. Science, Vol. xiv. 1874 . 
and muscles. From the mesoblast there is also formed, according to Hatschek, a pair of ciliated excretory canals, in the space between the mouth and anus (fig. I $30 \mathrm{~B}$, uph.). The development of the nervous system has not been observed.

At a comparatively late stage in the development there is formed round the edge of the vestibule a ring of long cilia (fig. I $30 \mathrm{~B}, \mathrm{~m}_{\text {.). }}$.

A remarkable organ makes its appearance on the dorsal side of the osophagus (the side opposite the adult ganglion) formed of an oval mass of cells attached to the epiblast at the apex of a small ciliated papilla (fig. I $30 \mathrm{~A}$ and $\mathrm{B}, x$.). This organ will be

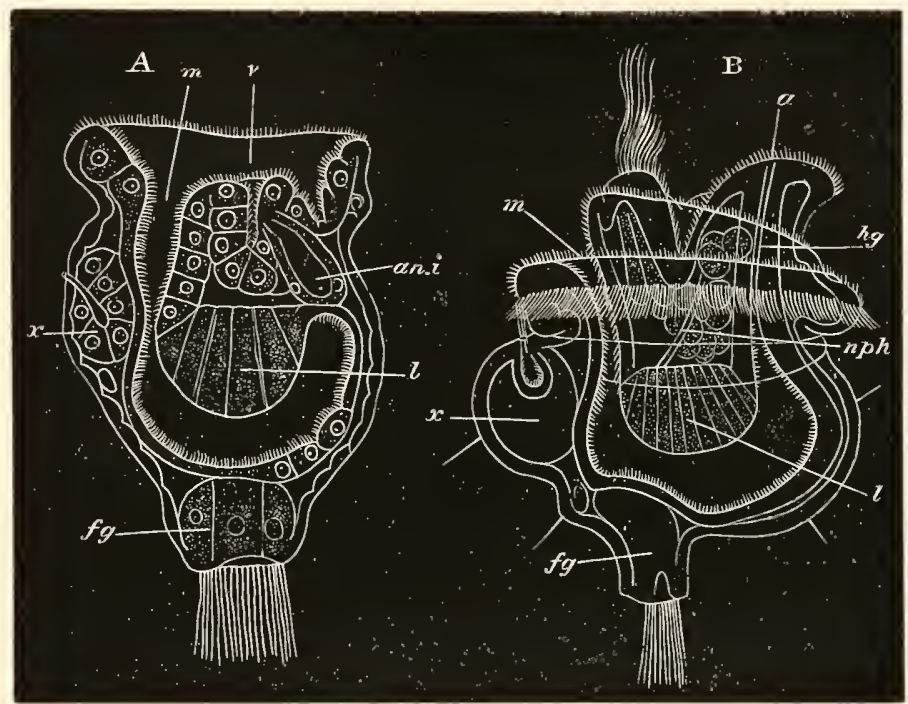

Fig. 130. Two stages in the develofment of Pedicellina. (After Hatschek.)

$v$. vestibule; $m$. mouth ; $l$. liver ; $h g$. hind-gut ; $a$. anus ; an.i. anal invagination; nph. duct of kidney; $f g$. ciliated disc; $x$. dorsal organ (probably bud).

spoken of as the dorsal organ. According to Hatschek it develops as a solid outgrowth of the hypoblastic walls of the mesenteron shortly before the mesenteron joins the osophagus (fig. I $29 \mathrm{~B}, x_{\text {.). }}$ The cells composing it arrange themselves as a sack, which acquires an external opening on the dorsal surface (fig. I $30 \mathrm{~A}, x_{\text {. }}$ ). In a later stage the lumen of the sack disappears, but at the junction of the organ with the epiblast a pit 
is formed, lined with ciliated cells, which is capable of being protruded as a papilla. The organ itself becomes invested by a lining of cells, which Hatschek regards as mesoblastic. A nearly similar organ to this is found in the embryo of Loxosoma [Vogt (No. 302) and Barrois (No. 29s)]. Here however it is double, and forms a kind of disc connected with two eye spots.

Hatschek has made with reference to the dorsal organ the extremely plausible suggestion that it is a rudimentary bud, and that the hypoblastic sack it contains gives rise to the hypoblast of the young polype developed from the bud. Although, owing to the deficiency of our observations on the attachment of the larva, this suggestion has not received direct confirmation, yet the relations of dorsal organs in Pedicellina and Loxosoma respectively strongly confirm Hatschek's view of their nature. Both of these forms increase in the adult state by budding: in Pedicellina there is a single row of buds formed successively on the dorsal side of the stem, corresponding with the single dorsal organ of the embryo; while in Loxosoma a double row of buds, right and left, is formed, in correspondence with the double nature of the dorsal organ.

As to the mode of attachment of the embryo next to nothing is known, the few observations we have being due to Barrois. From these observations it would appear probable that the larva, as is usual amongst Polyzoa, does not become directly converted into the permanent form, but that, on becoming fixed, it undergoes a metamorphosis in the course of which its organs atrophy. I would venture to suggest that the whole free-swimming larva atrophies, while the dorsal organ alone develops into the fixed form ${ }^{1}$.

Although the changes which take place during budding do not fall within the province of this work, it may be well to state that Hatschek has observed during this process the development of the nervous system and the generative organs. The nervous system arises as an unpaired thickening of the epiblastic floor of the vestibule, between the mouth and the anus. On becoming constricted off from the epiblast the nerve ganglion contains a central cavity which afterwards vanishes.

The generative organs originate as a pair of specially large mesoblast cells in the space between the stomach and the floor of the vestibule. These two cells, surrounded by an investment of flattened mesoblast cells, sub-

1 My view of the metamorphosis which takes place during the fixation of the larva involves the supposition that in Loxosoma, about the attachment of which we know absolutely nothing, two buds are directly formed in accordance with the double nature of the dorsal organ. 
sequently divide and form two masses. At a still later period each mass divides into an anterior and a posterior part; the former giving rise to the ovary, the latter to the testis. The similarity of this mode of development of the generative organs to that observed by Bütschli in Sagitta, which is described in the sequel, is very striking.

\section{Ectoprocta.}

Although the embryology of the Ectoprocta has been investigated by a very considerable number of the distinguished naturalists of the century, many points connected with it still stand in great need of further elucidation. The original nature of the embryo was rightly interpreted by Grant, Dalyell and other naturalists, but it was not till Huxley demonstrated the presence of both the ovary and testis that the true sexual origin of the embryo in the ovicells became an established fact in science. The recent memoir of Barrois (No. 298), though it contains the record of a vast amount of research, and marks a great advance in our knowledge, still leaves a great number of points, both with reference to the early development and to the larval metamorphosis in a very unsatisfactory condition.

Four larval forms can be distinguished, viz.

(I) A larval form which with slight modifications is common to all the genera of the Chilostomata (except Membranipora and Flustrella) and of the Ctenostomata.

(2) A bivalved larva of Membranipora known as Cyphonautes, the true nature of which was first recognized by Schneider (No. 322), and the closely allied larva of Flustrella.

(3) The typical Cyclostomatous larva, for the first full description of which we are indebted to Barrois (No. 298).

(4) The larva of the Phylactolæmata.

Chilostomata and Ctenostomata. As an example of the first type of larvæ, Alcyonidium mytili, one of the Ctenostomata, may be conveniently selected for description, as having been more completely worked out by Barrois than perhaps any other form. The segmentation commences in the normal manner by the appearance of two vertical furrows followed by an equatorial furrow, which divide the ovum into eight equal spheres. The stage with eight spheres is followed, according to Barrois, by one with sixteen, formed in a remarkable manner by the simultaneous 
appearance of two vertical furrows, both parallel to one of the original vertical furrows, so that the segmentation spheres at this stage are arranged in two layers of eight each. In the next stage segmentation takes place along two fresh vertical planes, similar to those of the last stage, but at right angles to them, and therefore parallel to the second of the two primitive vertical furrows. At the close of this stage there are thirty-two cells arranged in two layers of sixteen each, and when viewed from the surface each of these layers presents a regularly symmetrical pattern. Up to the stage with sixteen cells the two poles of the egg, separated by the primitive equatorial plane of segmentation, remain equal, but during the stage with thirty-two cells a peculiar change takes place in the character of the cells at the two poles. At the one pole, which will be spoken of as the oral pole, the four central cells become much larger than the twelve peripheral cells.

The stages inmediately following are still involved in much obscurity, and have been described very differently by Barrois in his original memoir (No. 298), and in a subsequent note (No. $307)^{1}$. In the latter he states that the four large cells of the oral face become enclosed by the division and growth of the twelve peripheral cells. They are thus carried into the interior of the ovum; and there divide into a central vitelline mass-the hypoblast-and a peripheral mesoblastic layer.

The eight peripheral cells of the aboral pole divide vertically, and, owing to the eight central cells at the aboral pole dividing transversely so as to form a protuberance on the aboral surface, they constitute a transverse ring of large cells round the ovum, which become ciliated and constitute the main ciliated band of the embryo, corresponding to the ciliated band at the edge of the vestibule of the entoproctous larvæ. They divide the embryo into an aboral and an oral region. The central part of the aboral projection forms a structure which I shall speak of as the ciliated disc. It probably corresponds with the ciliated disc in the Entoprocta. An invagination is next formed on the oral

1 The note (No. 307) refers in the first instance to the changes in the larvæ of the Chilostomata, but the similarity of the larvæ of the Ctenostomata to those of the Chilostomata renders it practically certain that the corrections, in so far as they apply to the one group, apply also to the other. 
surface, which gives rise to a sack opening to the exterior (fig. I $3 \mathrm{I}$, st.). This was originally held by Barrois to be the stomach; but Barrois now prefers to call it 'the internal sack.' To my mind it is probably the stomodæum. The embryo has become in the meantime laterally compressed, and, at what I shall call the anterior end of, the oral disc, a structure makes its appearance (fig. I $3 \mathrm{I}, m$ ), which is probably homologous with the dorsal organ of the larva of Pedicellina and may go by the same name. It was originally interpreted by Barrois as the pharynx.

The larva, having now acquired all the important structures it is destined to possess, becomes free. It is shewn in fig. I $3 \mathrm{I}$; the oral face being turned upwards. There are two rings of

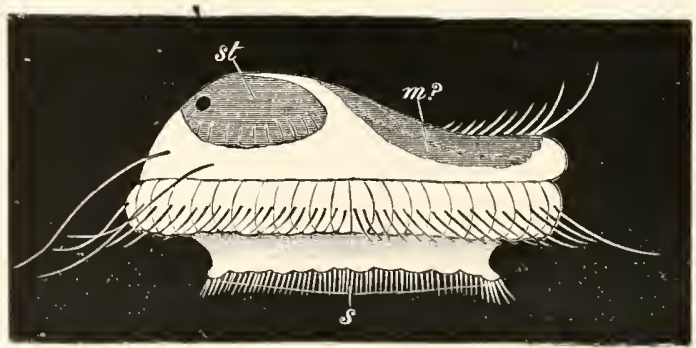

Fig. I3I. Free-swimimg larva of Alcyonidium mytili. (After Barrois.) $m$ (?) dorsal organ ; st. stomodæum (?); s. ciliated disc.

cilia, one round the edge of the ciliated disc, and a second with larger cilia on the ring of large cells described above. This ring projects somewhat; its projecting edge being directed towards the ciliated disc. The dorsal organ $(m$ ? $)$ is placed on the oral face at the bottom of an elongated groove, in front of which is a bunch of long cilia or flagella. Two long flagella are also developed at the posterior extremity of the oral face, and two pairs (an anterior and a posterior) of eye-spots also appear. Towards the posterior extremity of the oral face is seen a body marked st, which forms the internal sack. If I am

1 The interpretation of the larvæ given in the text must be regarded as somewhat tentative. The opacity of the free larvæ is very great, and almost every one of the numerous authors who have worked on these larvæ have arrived at different conclusions, as to the physiological significance of the various parts. 
right in regarding this as the stomodæum, it is probable that it never unites with the invaginated hypoblast, and that the alimentary tract of the larva remains therefore permanently in an imperfect condition.

Careful observations have been made by Repiachoff (No. 318) on the early development of Tendra, which accord in some respects with the results arrived at by Barrois in his second memoir. The observations are not, unfortunately, carried down to the complete development of the larva.

The ovum divides in the normal way into two and then four uniform segments. These four next become divided by an equatorial furrow into four dorsal and four ventral segments, the former constituting the aboral pole and forming the epiblast, and the latter the oral pole. The stages with sixteen and thirty-two cells appear to be formed in the same manner as in Alcyonidium-but between the two layers of cells forming the oral and aboral poles a well-marked segmentation cavity arises at the stage with sixteen segments. At the stage with thirty-two cells the four middle cells of the oral side, which are larger than the others, become divided into two tiers, in such a manner as to form a prominence projecting into the segmentation cavity. By the appearance of a lumen in this prominence it becomes converted into an archenteron, which communicates with the exterior by a blastopore in the middle of the oral surface. The blastopore becomes eventually closed.

The archenteric sack of Repiachoff is clearly the same structure as Barrois' four invaginated cells of the oral face, their further history has unfortunately not been followed out by Repiachoff.

The free larva swims about for some time, and then fixes itself and undergoes a metamorphosis; but the exact course of this metamorphosis is still very imperfectly known.

According to the latest statements of Barrois the attachment takes place by the oral face ${ }^{1}$. The ciliated disc, which in the free larva forms a kind of cup directed towards the aboral end, turns in upon itself towards the oral face. It subsequently undergoes degeneration and forms a nutritive or yolk-mass. The skin of the larva after these changes gives rise to the ectocyst or cell of the future polype. The future polype itself appears to originate, in part at any rate, from the so-called dorsal organ ${ }^{2}$.

1 Barrois himself held the opposite view in his earlier memoir, and other observers have done the same.

2 The statements on this head are so unsatisfactory and contradictory that it does not appear to me worth while quoting them here; even the latest accounts of Barrois, which entirely contradict his early statements, can hardly be regarded as satisfactory. 
The first distinct rudiment of the polype appears as a white body, which gradually develops into the alimentary canal and lophophore. While this is developing the ectocyst grows rapidly larger, and the yolk in its interior separates from the walls and occupies a position in the body cavity of the future polype, usually behind the developing alimentary canal. According to Nitsche (No. 316) it is attached to a protoplasmic cord (funiculus) which connects the fundus of the stomach with the wall of the cell. It is probably (Nitsche, etc.) simply employed as nutritive material, but, according to Barrois, becomes converted into the muscles, especially the retractor muscles.

Adopting the hypothesis already suggested in the case of the Entoprocta the metamorphosis just described would seem to be a case of budding accompanied by the destruction of the original larva.

This view of the nature of the post-embryonic metamorphosis is apparently that of Claparède and Salensky, and is supported by Claparède's statement that the formation of the first polype 'resembles to a hair' that of the subsequent buds. The mode of budding would, however, appear to present certain peculiarities, in that the whole larval skin passes directly into the bud, while from the rudimentary bud of the larva the lophophore and alimentary tract only of the fixed polype are formed.

Flustrella and Cyphonautes. The next group of larval forms is that of which Cyphonautes is the best known type. The larvæ composing it at first sight appear to have but little in common with the larvæ hitherto described. The researches of Barrois (No. 298) and Metschnikoff (No. 314), (but especially those of the former on the early stages of Flustrella hispida, the larva of which is very similar in form to Cyphonautes, though without so great a complexity of organisation), have given a satisfactory basis for a general comparison of Cyphonautes with other ectoproctous larvæ.

The segmentation and early stages of the embryo of Flustrella resemble closely those of Alcyonidium. A projecting ring of large cells is formed, dividing the larva into oral and aboral parts. The oral part soon however becomes very small as compared with the aboral, and becomes vertically flattened so as to be nearly on a level with the ring of large cells. In the next stage the flattening becomes completed; and the ring of large cells 
surrounds, like the vestibule of the Entoprocta, a flat oral disc. The aboral side is dome-shaped, and forms the greater part of the embryo.

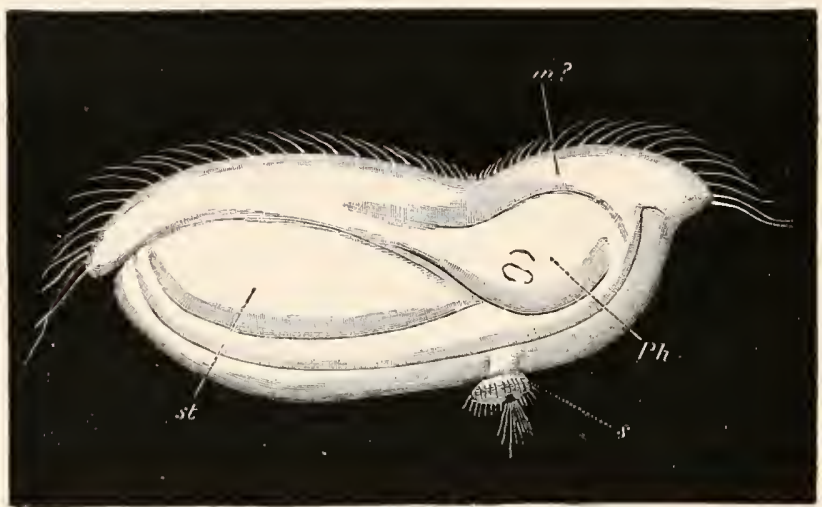

Fig. 132. Advanced larva of Flustrella hispida. (After Barrois.)

$m$ (?) groove above dorsal organ ; Ph. dorsal organ ; st. stomorleum (?); s. ciliated disc at aboral end of body.

In the next stage a small disc-the ciliated disc-is formed in the middle of the aboral dome. The larva becomes laterally compressed. The ring of large cells which now constitute the edge of the vestibule is covered, as in the larva of Pedicellina, by cilia, which are specially long in front of the dorsal organ.

In the next stage the ciliated disc (fig. I 32, s.) becomes reduced in size, but surmounted by a ring of cilia round the edge, and a tuft of cilia in the centre. The chief difference between this larva and that of Alcyonidium depends on the small size of the ciliated disc, and the oral position of the ciliated ring in the former. There are intermediate types between these forms of larvæ.

This stage immediately precedes the liberation of the larva. The free larva differs from that in the ovicell mainly in the possession of a shell formed as a cuticular structure, composed of two valves placed on the two sides of the embryo. The aboral ciliated disc, still more reduced in size, loses its cilia, and becomes enclosed between the two valves of the shell.

The post-embryonic metamorphosis follows, so far as is known, the course already described for the larva of Alcyonidium. 
Cyphonautes (fig. 133) forms at certain seasons of the year one of the commonest captures in the surface net It was originally described by Ehrenberg, but the important discovery of its true nature as the larva of Membranipora (the common species $C$. compressus is the larva of Mem. pilosa), a genus of the chilostomatous Polyzoa, was made by Schneider (No. 322). The younger stages of the larva have not been worked out, but from a comparison with the last described larva it is easy to make out the general relationship of the parts. The larva has a triangular form with an aboral apex, corresponding with the summit of the dome of the Flustrella larva, and an oral base. It is enclosed in a bivalve shell, the two valves of which meet along the two sides, but are separate along the base. At the apex an opening is left between the two valves, through which a ciliated disc $(f \cdot g)$ of the same character and nature as that of previous larvæ can be protruded.

The oral side or base is girthed by a somewhat sinuous ciliated edge, which is continued round the anterior and posterior extremities of the oral disc. It is no doubt equivalent to the ciliated ring of other larvæ. Two openings are present on the oral face, both enclosed in a special lobe of the ciliated ring. The larger of theseleads into a depression, which may be called the vestibule; and is situated on the posterior side of the oral surface. The smaller of the two, on the anterior side, leads into a cavity which is apparently (Hatschek) equivalent to the rudimentary bud or dorsal organ of other larvæ. The deeper part of the vestibule leads into the mouth $(m)$ and œesophagus; the latter is continued till close to the apex of the larva, there bends upon

Fig. 133. Cyphonautes (larva of MemBRANIPORA). (After IIatschek.)

$m$. mouth ; $a^{\prime}$. anus; f.g. ciliated disc; $x$. problematical body (probably a bud).

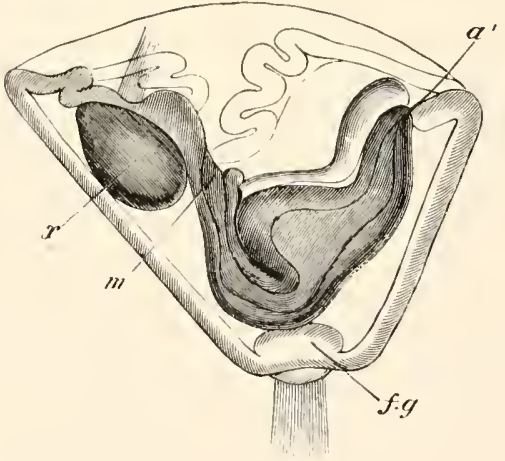


itself, dilates into a stomach, and is continued parallel to the œsophagus as the rectum which opens by an anus $\left(\alpha^{\prime}\right)$ at the posterior end of the vestibule. A peculiar paired organ is situated on each side nearly above the stomach. Its nature is somewhat doubtful. It was regarded as muscular by Claparède (No. 309), though this, as shewn by Schneider, is no doubt a mistake. Allman (No. 305) regards it as hepatic, and Hatschek as a thickening of the epidermis. Close to each of these organs is a small body regarded by Claparède as an accessory muscle. It is placed in the normal position for a Polyzoon ganglion, and may perhaps be therefore regarded as nervous in nature. Allman points out its similarity to a bilobed ganglion, but is not inclined to take this view of it. The constitution of the parts contained in the anterior cavity $(x)$ is somewhat obscure. The most elaborate descriptions of them are given by Schneider and Allman. Lining the cavity is apparently a mass of spherical bodies, connected with which is a tongue-like process provided with long cilia, which can be protruded from the orifice. Internal to this is a striated body. A good figure of the whole structure is given by Schneider.

The general similarity of Cyphonautes to the other larvæ is quite obvious from the above description and figure. In the presence of an anus, a vestibule, and possibly a nervous system, it clearly exhibits a far more complicated organisation than any other Polyzoon larvæ except those of the Entoprocta.

The post-embryonic metamorphosis of Cyphonautes, admirably investigated by Schneider, takes place in the same manner as that of other larvæ, and is accompanied by the degeneration of the larval organs, and the formation of a clear body, which gives rise to the alimentary cavity and lophophore of the fixed polype. The larval shell takes part in the formation of the ectocyst of the polype.

Cyclostomata. We owe to Barrois by far the fullest account of the development of the Cyclostomata, but how far his interpretations are to be trusted is very doubtful. The larvæ differ very considerably from the normal larve of the Chilostomata and Ctenostomata; the difference being mainly due to the enormous development of the ciliated disc. Barrois has investigated the larvæ of three genera, Phalangella, Crisia, and Diastopora, 
and states that they very closely resemble each other. The ovum is extremely minute.

The segmentation, so far as it has been made out, is regular. During the segmentation growth is very rapid, and eventually there is formed a blastosphere many times larger than the original ovum. The blastosphere becomes flattened, and is converted into a gastrula by bending up into a cup-like form. The gastrula opening is stated to remain as the permanent mouth, which has a terminal and central position. A transverse ring-like thickening is formed round the larva, which probably corresponds with the ciliated ring of previous larvæ; and the body of the larva in front of this ring becomes ciliated. The aboral end of the larva becomes thickened, and grows out into an elongated prominence, which probably corresponds to the ciliated disc. The ring before mentioned becomes at the same time more prominent, and forms a cylindrical sheath for the ciliated disc. At the time when the larva becomes liberated from the maternal cell it has the form of a barrel with a slight constriction in the middle separating the oral from the aboral end. At the centre of the oral face is situated the mouth, leading into a wide stomach, while the aboral end is formed of the ciliated disc enclosed in its sheath. The whole surface is now ciliated. No structure equivalent to the dorsal organ or bud is described by Barrois, but in other respects, if the ciliated disc is really equivalent in the two forms, a general comparison on the line indicated above between this larva and the normal larvæ of the Ctenostomata and Chilostomata seems quite possible. The fixation and subsequent development of the larva take place in the normal manner.

Phylactolæmata. The development of the phylactolæmatous Polyzoa has been studied by Metschnikoff (No. 315), who describes the eggs as undergoing a complete segmentation within a peculiar brood-pouch developed from the walls of the body of the parent. After segmentation the cells of the embryo arrange themselves in two layers round a central cavity. The embryo then forms the well-known cyst, from which a colony is formed by a process of budding.

\section{General considerations on the Larve of the Polyzon.}

The different forms of embryo amongst the Polyzoa are represented in figs. I 30 B, I $3 \mathrm{I}, \mathrm{I} 32$, and $\mathrm{I} 33$ in what I regard as identical positions, and fig. $133 \mathrm{~A}$ is a figure of what may be regarded as an idealized larval Polyzoon. In all the larva there is present a ciliated ring, which separates an oral from an aboral face, and is apparently homologous throughout the series. In the adult it is probably represented by the lophophore. On the 
oral face is situated in all cases the mouth, and in the entoproctous larvæ and Cyphonautes also the anus. It thus appears that Cyphonautes, though the larva of an ectoproctous form, is itself entoproctous - a fact which tends to shew that the Entoprocta are the more primitive forms. In all the larvæ, except possibly those of the Cyclostomata, there is present on the anterior side of the mouth, in the Ectoprocta on the oral, and in the Entoprocta on the aboral side of the ciliated ring, an organ, to which is attached externally a plume of long cilia. This organ has been identified throughout the series in accordance with Hatschek's view as the dorsal organ or rudimentary bud; but it is well to bear in mind that this identification is of a purely hypothetical character.

On the aboral side of the ciliated ring there is present in all the larva an organ, which has been called the ciliated disc, which is probably homo-

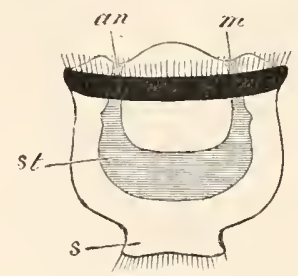

Fig. I33 A. Diagram of AN IDEAL LARVA OF A POLYZOON.

m. mouth; an. anus; st. stomach; s. ciliated disc. logous throughout the series. It perhaps remains in the adult of Loxosoma as the cement gland, but not in other forms.

The Polyzoa present a simple and almost certainly degraded organisation in the adult state; it is therefore more than usually necessary to turn to their larvæ for the elucidation of their affinities, and various plausible suggestions have been made as to the interpretation of the characters of the larva.

Lankester $^{1}$ has suggested that the larvæ are essentially similar to those of Molluscs. He compares the main ciliated ring to the velum, but has ingeniously suggested that it represents not the simple velar ring of most molluscan larvæ, but a more extended longitudinal ring, of which the gills of Lamellibranchiata are supposed by him to be remnants, and to which the Echinoderm larvæ with one continuous ciliated band furnish a parallel.

The foot he finds in the epistome of the Phylactolæmata, and the disc of Rhabdopleura-both situated between the mouth and anus, and therefore in the situation of the molluscan

${ }^{1}$ Lankester. "Remarks on the affinities of Rhabdopleura." Quart. J. of Micro. Science, Vol. XIv. I 874 . 
foot. The peculiar prominence between the mouth and the anus in Pedicellina (vide fig. $\mathrm{I} 30 \mathrm{~B}$ ) and Loxosoma is probably the same structure.

Finally he identifies my ciliated disc, which as mentioned above is perhaps equivalent to the cement gland in the adult Loxosoma, as the molluscan shell-gland. Lankester's interpretations are very plausible, but at the same time they appear to me to involve considerable difficulties.

There is absolutely no evidence amongst the Mollusca of the existence of a primitive longitudinal ciliated ring, such as he supposes to have existed, and Lankester is debarred from regarding the ciliated ring of the Polyzoa as equivalent to the simple velar ring of the Mollusca, because his shell-gland lies in the centre and not as it should do on the posterior side of the ciliated ring.

Another difficulty which I find is the invariable ciliation of Lankester's shell-gland-a ciliation which never occurs amongst Mollusca.

It appears to me that a more satisfactory comparison of the larvæ of the Polyzoa with those of the Mollusca is obtained by dropping the view that the ciliated disc is the shell-gland, and by regarding the ciliated ring as equivalent to the velum. This mode of comparison has been adopted by Hatschek.

The larva ceases however on this view to have any special molluscan characters (except possibly the organ which Lankester has identified as the foot), and only resembles a molluscan larva to the same extent as it does a larva of the Polychæta. The ciliated disc lies according to this view in the centre of the velar area or præ-oral lobe, and therefore in the situation in which a tuft of cilia is often present in lamellibranchiate and other molluscan larvæ, and also in the larvæ of most Chætopoda. It is moreover at this point that the supra-œesophageal ganglion is always formed in the Mollusca and Chætopoda as a thickening of the epiblast (fig. I34, sg.), so that the thickening of the epiblast in the ciliated disc of the Polyzoa may perhaps be a rudiment of the supra-œsophageal ganglion, which entirely atrophies in the adult after the attachment has been effected in the region of this disc.

The comparison between the Polyzoon larva and that of a 
Chætopod becomes very much strengthened by taking as types Mitraria $^{1}$ (fig. I34) and Cyphonautes (fig. I33). The similarity

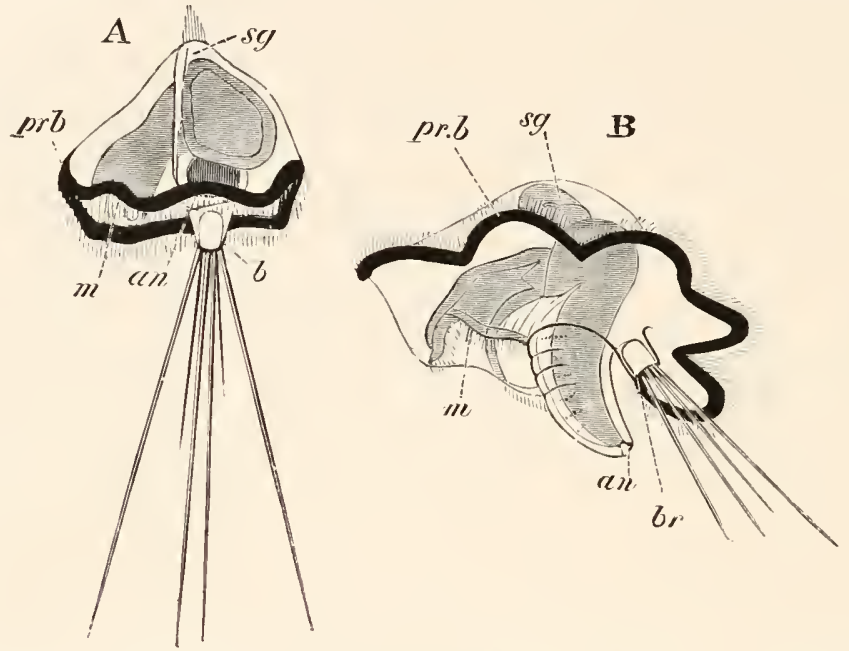

Fig. I3+. Two stages in the development of Mitraria. (After Metschnikoff.)

$m$. mouth; an. anus; $s g$. supra-œsophageal ganglion; $b r$. and $b$. provisional bristles; pr.b. pre-oral ciliated band.

between these two forms is so striking that I am certainly inclined to view the larva of the Polyzoa as trochospheres similar to those of Chætopods, Rotifera, etc., which become fixcd in the adult by the extremity of their pre-oral lobe.

The attachment of the larva by the præ-oral lobe is not more extraordinary than the attachment of a Barnacle by its head, and after such a mode of attachment the atrophy of the supraœesophageal ganglion would be only natural.

There is one important fact which deserves to be noted in the development of the Polyzoa, viz. that if the suggestion in the text as to the mode of development of the adult from the socalled larva is accepted, the Polyzoa exhibit universally the phenomenon of alternations of generations. The ovum gives rise to a free form which never becomes sexual, but produces by budding the sexual attached form.

1 The larva of Mitraria is figured with the aboral surface turned upwards, instead of downwards, as in the figure of Cyphonautes. The cilinted band is also diagrammatically put in black for greater distinctness. 


\section{BIBLIOGRAPHY.}

\section{General.}

(298) J. Barrois. Recherches sur l'embryologie des Bryozoaires. Lille, 1877 .

\section{Entoprocta.}

(299) B. Hatschek. "Embryonalentwicklung u. Knospung d. Pedicellina echinata." Zeitschrift für ziiss. Zool., Bd. Xxix. I877.

(300) M. Salensky. "Etudes sur les Bryozoaires entoproctes." Ann. Scicn. Nat., 6th Ser. Tom. v. 1877 .

(301) O. Schmidt. "Die Gattung Loxosoma." Archiv f. mik. Anat., Bd. XII. I 876 .

(302) C. Vogt. "Sur le Loxosome des Phascolosomes." Archives de Zool. expér. et génér., Tom. v. I 876 .

(303) C. Vogt. "Bemerkungen zu Dr Hatschek's Aufsatz iib. Embryonalentwicklung u. Knospung von Pedicellina echinata." Zeit. f. wiss. Zool., Bd. xxx. I 878 .

\section{Ectoprocta.}

(304) G. J. Allman. Monograph of fresh water Polyzoa. Ray Society.

(305) G. J. Allman. "On the structure of Cyphonautes." Quart. F.of Micr. Scie., Vol. XII. I 872 .

(306) G. J. Allman. "On the structure and development of the Phylactolæmatous Polyzoa." Journal of the Linnean Society, Vol. xiv. No. 77. 1878.

(307) J. Barrois. "Le développement d. Bryozoaires Chilostomes." Comptes rendus, Sept. 23, I 878 .

(308) E. Claparède. "Beiträge zur Anatomie u. Entwicklungsgeschichte d. Seebryozoen." Zeit. für wiss. Zool., Bd. xxI. I8 7 I.

(309) E. Claparède. "Cyphonautes." Anat. u. Entwick. wirbell. Thiere. Leipzig, 1864 .

(310) R. E. Grant. "Observations on the structure and nature of Flustræ." Edinburgh New Philosoph. Fournal, 1827.

(311) B. Hatschek. "Embryonalentwicklung u. Knospung d. Pedicellina echinata" (Description of Cyphonautes). Zeit.f. wiss. Zool., Bd. xxix. I877.

(312) T. H. Huxley. "Note on the reproductive organs of the Cheilostome Polyzoa." Quart. Four. of Micr. Scienct, Vol. IV. 1856.

(313) L. Joliet. "Contributions à l'histoire naturelle des Bryozoaires des còtes de France." Archives de Zoologie Expérimentale, Vol. vi. ${ }_{1} 877$.

(314) E. Metschnikoff. "Ueber d. Metamorphose einiger Seethiere." Göttingische Nachrichten, I869.

(315) E. Metschnikoff. Bull. de I'Acad. de St P'tersbourg, xv. I87I, p. 507.

(316) H. Nitsche. "Beiträge zur Kenntniss d. Bryozoen." Zeit. f. wiss. Zool., Bd. xx. I87o.

(317) W. Repiachoff. "Zur Naturgeschichte d. chilostomen Seebryozoen." Zeit. f. wiss. Zool., Bd. xxvi. 1876 . 
(318) W. Repiach off. "Ueber die ersten Entwicklungsvorgänge bei Tendra zostericola." Zeit.f. wiss. Zool., Bd. xxx. 1878. Supplement.

(319) W. Repiachoff. "Zur Kenntniss der Bryozoen." Zoologischer Anzeiger, No. 10, Vol. I. 1878 .

(320) W. Repiachoff. "Bemerkungen iib. Cyphonautes." Zoologischer An. zeiger, Vol. II. I8 89.

(321) M. Salensky. "Untersuchung an Seebryozoen." Zeit. für wiss. Zool., Bd. XXIY. I8 84 .

(322) A. Schneider. "Die Entwicklung u. syst. Stellung d. Bryozoen u. Gephyreen." Archivf. mikr. Anat., Vol. v. I869.

(323) Smitt. "Om Hafsbryozoernas utveckling och fettkroppar." Aftryck ur öfvers. af Kong. Vet. Akad. Förh. Stockholm, r 865 .

(324) T. Hincks. British Marine and Polyzoa. Van Voorst, I880.

[Conf. also works by Farre, Hincks, Van Beneden, Dalyell, Nordmann.] 


\title{
CHAPTER XI.
}

\author{
BRACHIOPODA ${ }^{1}$.
}

THE observations which have been made on the developmental history of the Brachiopoda have thrown very considerable light on the systematic position of this somewhat isolated group.

\section{Development of the Layers.}

For our knowledge of the early stages in the development of the Brachiopoda we are almost entirely indebted to Kowalevsky ${ }^{2}$ (No. 326). His researches extend to four forms, Argiope, Terebratula, Terebratulina, and Thecidium. The early development of the first three of these takes place on one plan, and that of Thecidium on a second plan.

In Argiope, which may be taken as typical of the first group, the ova are transported into the oviducts (segmental organs) where they undergo their early development. The segmentation leads to the formation of a blastosphere, which then becomes a gastrula by invagination. The blastopore gradually narrows, and finally closes, while at the same time the archenteric cavity

1 The classification of the Brachiopoda adopted in the present chapter is shewn in the subjoined table:
I. Articulata. $\left\{\begin{array}{l}a . \text { Rhynchonellidx. } \\ \text { b. Terebratulidx. }\end{array}\right.$
II. Inarticulata. $\begin{cases}a . & \text { Lingulidæ. } \\ b . & \text { Craniadæ. } \\ c . & \text { Discinidæ. }\end{cases}$

2 Kowalevsky's Memoir is unfortunately written in Russian. The account in the text is derived from an inspection of his figures, and from an abstract in Hoffmann and Schwalbe's Fahresberichtc for 1873 . 
(fig. I $35 \mathrm{~A}$ ) becomes divided into three lobes, a median (me) and two lateral $(f \prime)$. These lobes next become completely separated, and the middle one forms the mesenteron, while the two lateral ones give rise to the body cavity, their outer walls forming the somatic mesoblast, and their inner the splanchnic (fig. $135 \mathrm{~B}$ ). The embryo now elongates, and becomes divided into three successive segments (fig. 135 B), which are usually, though on insufficient grounds (vide Thecidium), regarded as equivalent to the segments of the Chætopoda. The alimentary tract is not continued into the hindermost of them.

In Thecidium the ova are very large, and development takes place in a special incubatory pouch in the ventral valve. The embryos are attached by suspenders to the two cirri of the arms which immediately adjoin the mouth. There is a nearly regular segmentation, and a very small segmentation cavity is developed. There is no invagination; but cells are budded off from the walls of the blastosphere, which soon form a solid central mass, enclosed by an external layer-the epiblast. In this central mass three cavities are developed, which constitute the mesenteron and the two halves of the body cavity. Around these cavities distinct walls become differentiated. The body (Lacaze Duthiers, No. 327) soon after becomes divided into two segments, of which the posterior is the smaller. The hinder part of the large anterior segment next becomes constricted off as a fresh segment, and subsequently the remaining
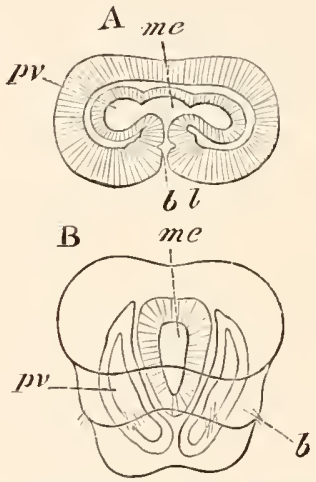

Fig. J35. TWO STAGES IN THE DEVELOPMENT OF Argiope. (After Kowa. levsky.)

A. Late gastrula stage.

B. Stage after the larva has become divided into three segments.

$b l$. blastopore; me. mesenteron; pr. body cavity; b. temporary bristles. part becomes divided into two, of which the anterior is the smallest. The embryo thus becomes divided into four segments, of which the two foremost appear (?) together to correspond to the cephalic segment of Argiope; but these segments are formed not, as in Chætopoda and other truly segmented forms, by the addition of fresh segments between the last-formed segment and 
the unsegmented end of the body, but by the interpolation of fresh segments at the cephalic end of the body as in Cestodes; so that the hindermost segment is the oldest. Assuming the correctness $^{1}$ of Lacaze Duthiers' observations, the mode of formation of these segments appears to me to render it probable that they are not identical with the segments of a Chrtopod. A suspender is attached to the front end of each embryo. Before the four segments are established the whole embryo is covered with cilia $^{2}$, and two and then four rudimentary eyes are developed on the anterior segment of the body.

\section{The history of the Larva and the developmont of the organs of the Adult.}

Articulata. The observations of Kowalevsky and Morse have given us a fairly complete history of the larval metamorphosis of some of the Articulata, while some of the later larval stages in the history of the Inarticulata have been made known to us from the researches of Fritz Müller, Brooks, etc. The embryo of Argiope, which may be taken as the type for the Articulata, was left (fig. $135 \mathrm{~B}$ ) as a three lobed organism with a closed mesenteron and a body cavity divided into two lateral compartments. On the middle segment of the body dorsal and ventral folds, destined to form the mantle lobes, make their appearance, and on the latter two pairs of bundles of setæe are present (fig. I35 B). The setæ together with the mantle folds grow greatly, and the setæ resemble in appearance the provisional setæ of many Chætopods (fig. I52). On the hinder border of the mantle cilia make their appearance. The anterior or cephalic segment assumes a somewhat umbrellalike form, and round its edge is a circlet

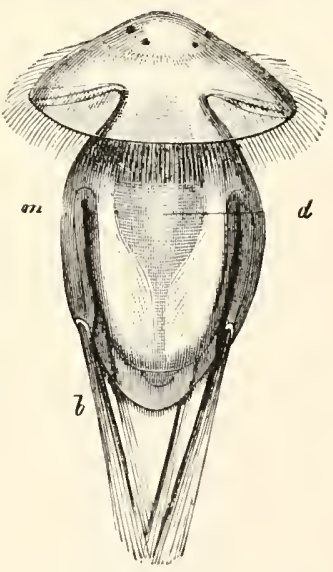

FIG. I36. LARVA OF ARGIOPE. (From Gegenbaur, after Kowalevsky.)

m. mantle; $b$. setæ; $d$. archenteron.

1 It should be stated that it is by no means clear from Kowalevsky's figures that he agrees with Lacaze Duthiers as to the succession of the segments.

${ }^{2}$ Kowalevsky in his figures leaves the penultimate lobe unciliater. 
of long cilia, while elsewhere it is provided with a coating of short cilia. Two pairs of eyes also arise on its anterior surface (fig. 136). After swimming about for some time the larva becomes fixed by its hind lobe, and becomes gradually transformed into the adult. The hind lobe itself becomes the peduncle. After attachment the mantle lobes bend forward (fig. I $37 \mathrm{~A}, m$ ), and enclose the cephalic lobe. The valves of the shell are formed on their outer surface as two delicate chitinous plates (fig. I $37 \mathrm{~B}$ ). At a somewhat later stage the provisional bristles are thrown off, and are eventually replaced by permanent setæ round the edge of the mantle. The cephalic lobe becomes located in the dorsal valve of the shell, and the mouth is formed near the apex of the cephalic lobe immediately ven-

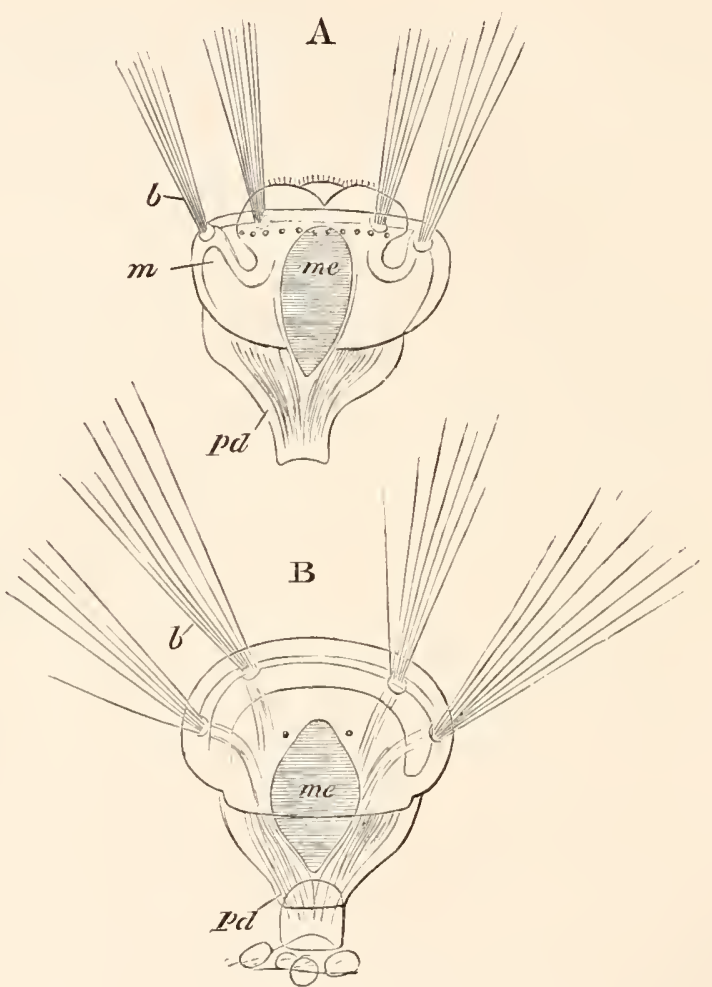

Fig. 137. TWO STAGES IN THE DEVELOPMENT OF ARGIOPE, SHEWING THE FOLIS OF THE MANTLE GROWING OVER tHE CEPHALic LOBE. (After Kowalevsky.)

$m$. mantle fold; $m e$. mesenteron; $p d$. peduncle; $b$. provisional setæ.

tral to the eye-spots, by an epiblastic invagination. The permanent muscles are formed out of the muscles already present in the embryo.

Around the mouth there arises a ring of tentacles, very 
possibly derived from the ciliated ring visible in fig. I $36^{1}$. The ring of tentacles is placed obliquely, and the mouth is situated near its ventral side. The tentacles appear to form a post-oral circlet, like that of Phoronis (Actinotrocha): they gradually increase in number as the larva grows older.

Some of the later stages in the development of the Terebratulidæ have been made known to us by the observations of Morse (No. 328-9) on Terebratulina septentrionalis.

The most interesting point in Morse's observations on the later stages is the description of the gradual conversion of the disc bearing the circlet of tentacles into the arms of the adult. The tentacles, six in number, first form a ring round the edge of a disc springing from the dorsal lobe of the mantle; in their centre is the mouth. In the later stages calcareous spicula become developed on the tentacles. When the embryo is far advanced the tentacles begin to assume a horse-shoe arrangement, which bears a striking, though probably accidental, resemblance to that of the tentacles on the lophophore of the fresh-water Polyzoa. The disc bearing the tentacles is prolonged anteriorly into two processes, the free ends of the future arms. By this change of shape in the disc the tentacles form two rows, one on the anterior and one on the posterior border of the disc, and eventually become the cirri of the arms. The mouth is placed between the two rows of tentacles, where the two arms of the lophophore meet behind. The position of the mouth was the original centre of the ring of tentacles before they became pulled out into a horse-shoe form. In front of the mouth is a lip. The arms grow greatly in length in the adult Terebratulina. In Thecidium the oral disc retains the horse-shoe form, while in Argiope the embryonic circular arrangement of the tentacles is only interfered with by the appearance of marginal sinuations.

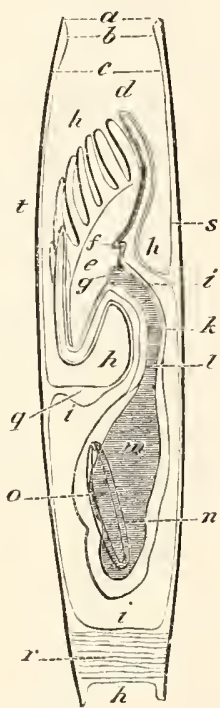

F1G. I38. Diagram of A LONGITUDINAL VERTICAL SECTION OF AN ADVANCED EMBRYo OF LiNGULA. (After Brooks.)

$a$. end of valves; $b$. thickened margin of mantle; $c$. mantle; $d$. dorsal median tentacle; $e$. lophophore; $f$. lip; g. mouth; $h$. mantle cavity; $i$. body cavity; $k$. wall of aesophagus; $l$. œesophagus; $m$. hepatic chamber of stomach; $n$. intestinal chamber of stomach ; 0 . intestine; $q$. ventral gang. lion; $r$. posterior muscle ; $s$. dorsal valve of shell; $t$. ventral valve of shell.

1 In the abstract in Hoffman and Schwalbe Kowalevsky is made to state that the tentacles spring from the border of the mantle. This can hardly be a correct account of what he states, since it does not fit in with the adult anatomy of the parts. The figures he gives might lead to the supposition that they sprang from the edge of the cephalic lobe, or perhaps from the dorsal lobe of the mantle. 
The shell is deposited as to chitinous plates, which subsequently become calcified. It undergoes in the different genera great changes of form during its growth.

With reference to the larval stages of other Articulata, a few points may be noted.

The three-lobed larva of Terebratulina septentrionalis is provided with a special tuft of cilia at the apex of the front lobe. The arms appear to originate, in Terebratulina caput serpentis, as two processes at the sides of the mouth, on which the tentacles are formed.

Provisional sete do not appear to be formed in the lobed embryos of Thecidium and Terebratulina, but they appear at a later stage at the edge of the mantle in the latter form. The third lobe of Thecidium gives rise to the dorsal and ventral mantle lobes.

Inarticulata. The youngest stages in the development of the Inarticulata are not known, and in the earliest stages observed the shell is already developed. The young larve with shells differ however from those of the Articulata in the fact that they are free swimming, and that the peduncle is not developed.

The larva of Discina radiata has been described by Fritz Müller (No. 331). It resembles generally a larva of the Articulata shortly after the tentacles have become developed. Five pairs of long provisional setæ are present, of which all but the hindermost are seated on the ventral lobe of the mantle. Shorter setæ are also lodged on the edge of the dorsal lobe. The mouth is placed on the ventral side of a protrusible oral lobe. It is imperfectly surrounded by four pairs of tentacles, which form a swimming apparatus.

A fuller history of the development of Lingula has been recently supplied by Brooks (No. 325). The youngest larva is enveloped in two nearly similar plate-like valves, covering the two mantle lobes. The mouth is placed at the centre of a disc, attached to the dorsal valve, on the margin of which is a ring of ciliated tentacles. The general position of the disc and its relations may be gathered from fig. $\mathbf{I} 38$, which represents a diagrammatic longitudinal vertical section of the embryo.

With the growth of the embryo the tentacles increase in number, the new pairs being always added between the odd dorsal tentacle and the next pair. There is an axial cavity in the tentacles which, unlike the cavity in the tentacles of the Polyzoa, does not communicate with the perivisceral cavity. As the tentacles increase in number, the lateral parts of the tentacular disc grow out into the two lateral arms of the adult, while the dorsal margin forms the median coiled arm. These changes are not effected till the larva has become fixed.

The attachment of the larva was not observed; but the peduncle, of 
which there is no trace in the young stages, grows out as a simple prolongation of the hinder end of the body while the larva is still free. It had already reached a very great length in the youngest fixed larva observed.

\section{Development of Organs.}

The alimentary tract after the obliteration of the blastopore forms a closed sack, which becomes subsequently placed in communication with the exterior by the stomodæal invagination. The liver is formed as a pair of dorsal outgrowths of the mesenteron. From Brooks' observations on Lingula it would appear that the primitive mesenteron forms the stomach of the adult only, and that the intestine grows out from this as a solid process: this eventually meets the skin, and here the anus is formed. In the Articulata the mesenteron is aproctous.

The origin of the body cavity as paired archenteric diverticula has already been described. Its somatic wall becomes in Lingula ciliated, and its cavity filled with a corpusculated fluid, as in many Chatopods. It is eventually prolonged into the dorsal and ventral mantle lobes as a pair of horn-like prolongations into each lobe, which communicate with the body cavity by large ciliated openings. Some incomplete observations of Brooks on the development of the nervous system in Lingula shew that it arises in the embryo as a ring round the osophagus with a ventral sub-oesophageal (fig. I $3 \& q$ ), and two lateral ganglia, and two dorsal otocysts. The ventral ganglion is formed as a thickening of the epiblast, with which it remains in continuity for life. The remainder of the ring grows out from the ventral ganglion as two cords, which gradually meet on the dorsal side of the osophagus.

\section{General observations on the Affinity of the Brachiopoda.}

The larva of Argiope, as has been noticed by many observers, has undoubtedly very close affinities with the Chrtopoda. It resembles, in fact, a mesotrochal larval Chrtopod with provisional setæ (vide Chapter on Chætopoda). Lacaze Duthiers' observations point to the lobes of the larva not being true segments, and certainly the mesoblast does not in the embryo become segmented as it ought to do were these lobes true segments. If this view is correct the larva is to be compared to an unsegmented Chatopod larva. In Rhynchonella, however, indications of two segments are afforded in the adult in the two pairs of segmental organs.

Though the larval Brachiopod resembles a mesotrochal Chætopod larva, 
it does not appear to resemble the trochosphere larvæ so far described, or the more typical larvæ of the Chætopoda, in that the ring of tentacles, which is probably, as already mentioned, derived from the ciliated ring shewn in fig. 137, is post-oral, and not pra-oral. The ring of tentacles is like the ring in Actinotrocha (the larva of Phoronis) amongst the Gephyrea. Although there is no doubt a striking resemblance between the tentacular disc of a larval Brachiopod and the lophophore of a Polyzoon, which has been pointed out by Lankester, Morse, Brooks, etc., their homology is rendered, to my mind, very doubtful ( $\mathrm{I}$ ) by the fact that the lophophore is præ-oral in Polyzoa ${ }^{1}$ and post-oral in Brachiopoda; and (2) by the fact that the concave side of the lophophore is turned in nearly opposite directions in the two forms. In Brachiopods it is turned dorsalwards, and in phylactolæmatous Polyzoa ventralwards.

The view of Morse, that the Brachiopoda are degraded tubicolous Chætopods, is not so far supported by any definite embryological facts. The development of the tentacular ring as well as its innervation from the sub-œsophageal ganglion prohibit us, as has been pointed out by Gegenbaur, from comparing it with the tentacles of tubicolous Chætopoda.

\section{BIBLIOGRAPIIY.}

(325) W. K. Brooks. "Development of Lingula." Chesapeake Zoological Laboratory, Scientific Results of the Session of 1878 . Baltimore, J. Murphy and Co.

(326) A. Kowalevsky. "Development of the Brachiopoda." Protocol of the First Session of the United Sections of Anatomy, Physiology, and Comparative Anatomy at the Meeting of Russian Naturalists in Kasan, I873. (Russian.)

(327) H. Lacaze Duthiers. "Histoire de la Thécidie." Ann. Scien. Nat. etc. Ser. 4 , Vol, Xv. I861.

(328) Morse. "On the Early Stages of Terebratulina septentrionalis." Mem. Boston Soc. Nat. History, Vol. 1I. I869, also Ann. \& Mag. of Nat. Hist., Series 4, Vol. vili. I87 ז.

(329) - - "On the Embryology of Terebratulina." Mem. Boston Soc. Nat. History, Vol. I1I., I873.

(330) — - "On the Systematic Position of the Brachiopoda." Proceedings of the Boston Soc. of Nat. Hist., I873.

(331) Fritz Müller. "Beschreibung einer Brachiopoden Larve." Müller's Archiv, I860.

1 For the ectoproctous Polyzoa it might be held that the ciliated ring of tentacles is post-oral, but the facts of development recorded in the previous chapter appear to me to shew that this view is untenable. 


\title{
CHAPTER XII.
}

\author{
CHATOPODA 1 .
}

Formation of the Germinal Layers.

Most Chætopoda deposit their eggs before development. The Oligochrta lay them in peculiar cocoons or sacks formed by a secretion of the integument. Some marine Polychæta carry them about during their development. Autolytus cornutus has a special sack on the ventral surface in which they are hatched. In Spirorbis Pagenstecheri they develop inside the opercular tentacle, and in Spirorbis spirillum inside the tube of the parent.

A few forms (e.g. Eunice sanguinea, Syllis vivipara, Nereis diversicolor) are viviparous.

Perhaps the most primitive type of Chætopod development so far observed is that of Serpula (Stossich, No. 357) ${ }^{2}$. There is a regular segmentation resulting in the formation of a blastosphere with a central segmentation cavity. An invagination of the normal type now ensues. The blastopore soon narrows to become the permanent anus, while the invaginated hypoblast forms a small prominence with an imperfectly developed lumen, which does not nearly fill up the segmentation cavity (fig. I 39 A). The embryo, which has in the meantime become completely

1 The following classification of the Chrtopoda is adopted in the present section.

I. Achæta (Polygordius).
II. Polychæta. \{ $\begin{aligned} & \text { Sedentaria. } \\ & \text { Errantia. }\end{aligned}$
III. Oligochæta.

2 The observations of Stossich are not thoroughly satisfactory. 
covered with cilia, now assumes more or less the form of a cone, at the apex of which is the anus, while the base forms the rudiment of a large præ-oral lobe. The alimentary sack grows forwards and then bends upon itself nearly at right angles, and meets a stomodæal invagination from the ventral side some way from the front end of the body.

The alimentary canal soon differentiates itself into three regions (I) œsophagus, (2) stomach, and (3) intestine. With

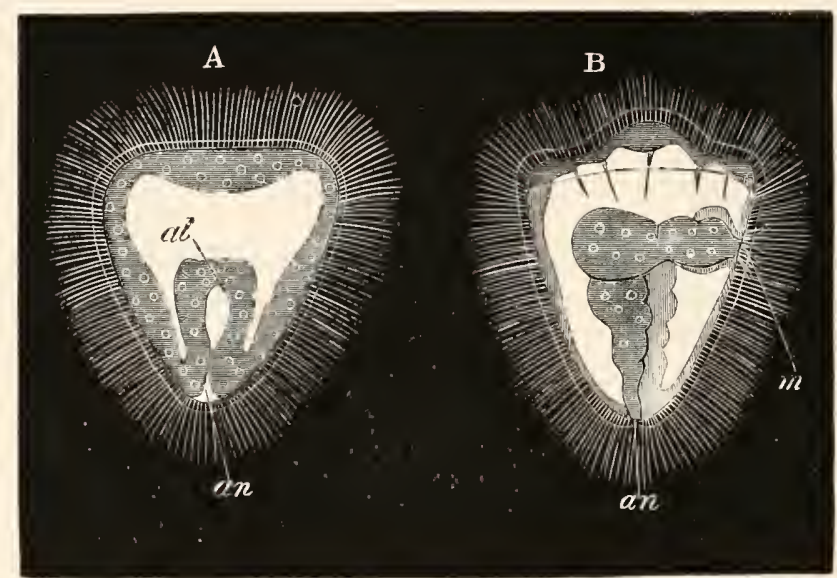

Fig. i39. Two stages in the development of Serpula. (After Stossich.) $m$. mouth; an. anus; al. archenteron.

these changes the larva, which in the meantime becomes hatched, assumes the characters of a typical Annelid larva (fig. I 39 B). In front is a large pre-oral lobe, at the sides of which the eyespots soon appear. The primitive segmentation cavity remains as a wide space between the curved alimentary tract and the body walls, and becomes traversed by muscular fibres passing between the two. The original chorion appears to serve as cuticle, and is perforated by the cilia.

The further changes in this larval form do not present features of general importance. A peculiar vesicle, which in anomalous cases is double, is formed near the anus. If it were shewn to occur widely amongst Chætopoda, it might be perhaps regarded as homologous with the anal vesicles of the Gephyrea.

Serpula is one of the few Chætopoda at present known in 
which the segmentation is quite regular ${ }^{1}$. In other forms it is more or less unequal. The formation of the germinal layers has been far more fully studied in the Oligochæta than in the Polychæta, and though unfortunately the development is much abbreviated in the former group, they nevertheless have to serve as our type; and unless the contrary is indicated the statements in the remainder of the section apply to the Oligochæta. The segmentation is nearly regular in Lumbricus agricola (Kowalevsky) and results in the formation of a flattened blastosphere, one of the sides of which is hypoblastic and the other epiblastic, the hypoblast cells being easily distinguished from the epiblast cells by their clearer aspect. An invagination takes place, in the course of which the hypoblast becomes enclosed by the epiblast, and a somewhat cylindrical two-layered gastrula is formed. The opening of this gastrula at first extends over the whole of what becomes the ventral surface of the future worm, but gradually narrows to a small pore-the permanent mouth-near the front end. The central cavity of the gastrula is lined by hypoblast cells, but the oral opening, which leads by a narrow passage into the gastric cavity, is lined by epiblast cells.

The segmentation of Lumbricus trapezoides (Kleinenberg, No. 341), and of Criodrilus (Hatschek, No. 339), is more unequal and more irregular than that of Lumbricus agricola, and there is an invagination which is intermediate between the embolic and epibolic types.

The segmentation of Lumbricus trapezoides is especially remarkable. It is strangely irregular and at one period the segmentation cavity communicates by a pore with the exterior. Before the completion of the gastrula stage the ovum becomes partially divided into two halves, each of which gives rise to a complete embryo. The two embryos are at first united by an epiblast cord which connects their necks (fig. I4I A), but this cord is very early ruptured, and the two embryos then become quite independent. Some of the peculiarities of the segmentation may no doubt be explained by this remarkable embryonic fission.

The gastrula opening in both Lumbricus trapezoides and Criodrilus is placed on the ventral surface, and eventually narrows to form the mouth or possibly (Criodrilus) closes at the position of the mouth. In Lumbricus trapezoides the oral opening is at first lined by hypoblast, and in Criodrilus is bounded anteriorly by three large peculiar epiblast cells, which are

1 According to Willemoes-Suhm, Terebellides strœmii is also characterised by a regular segmentation.

B. II, 
believed by Hatschek to assist in absorbing the albuminous fluid in which the eggs are suspended. These large cells are eventually covered by the normal epiblast cells and subsequently disappear. In both these types the hypoblast cells undergo, during their invagination, peculiar changes connected with their nutritive function.

In Euaxes (Kowalevsky) the segmentation is far more unequal than in the other types; a typical epibolic invagination takes place (fig. 140), and the blastopore closes completely along the ventral surface.

In all the oligochretous types, with the exception of Euaxes, where the blastopore closes completely, the blastopore becomes, or coincides with the mouth. In Serpula it is stated (Stossich), as we have seen, to coincide with the anus: a statement which receives confirmation from the similar statements of Willemoes-Suhm (No. 358). It is necessary either to suppose a mistake on the part of Stossich, or that we have in Chrtopods a case like that of Gasteropods in which a slit-like blastopore originally extending

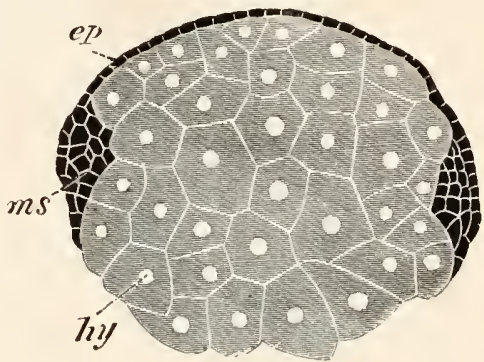

Fig. I 4O. Transverse SECTION THROUgiI THE OVUM OF EUAXES DURING AN EARLY STAGE OF DEVELOPMENT. (After Kowalevsky.)

ep. epiblast; ms. mesoblastic band; $h y$. hypoblast. along the ventral surface may in some forms become reduced to a pore at the oral, or in other forms at the anal extremity.

So far only two germinal layers-the epiblast and the hypoblast-have been spoken of. Before the invagination of the hypoblast is completed the mesoblast makes its appearance in the form of two bands or streaks, extending longitudinally for the whole length of the embryo. These are usually spoken of as germinal streaks, but to avoid the ambiguity of this term they will be spoken of as mesoblastic bands.

Their origin and growth has been most fully studied by Kleinenberg (No. 341) in Lum. trapezoides. They commence in this species shortly before the gastrula stage as two large cells on the surface of the blastoderm, which may be called mesoblasts. These cells lie one on each side of the median line at the hind end of the embryo. They soon travel inwards and become covered by the epiblast (fig. I4 I A, m'), while on their inner and anterior side a row of small cells appears (ms). 
These rows of cells form the commencement of the mesoblastic bands, and in the succeeding stages they extend one on each side of the body (fig. I4I B, ms) till they reach the sides of the mouth. Their forward growth takes place mainly at the expense of the superjacent epiblast cells, but the two mesoblasts

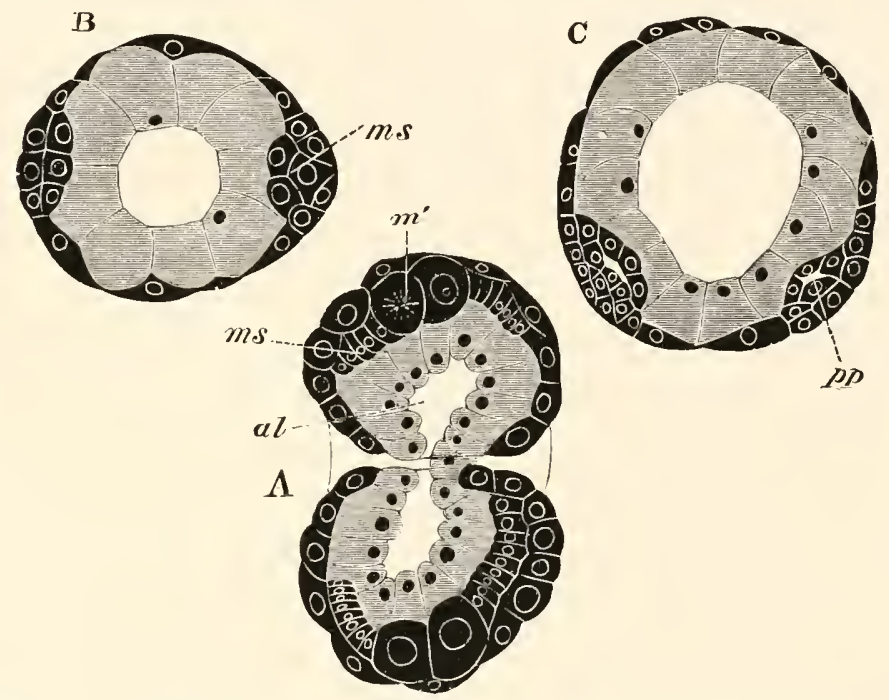

Fig. I4I. Three sections illustrating the Development of LUmbricus TRAPEZOIDES. (After Kleinenberg.)

ms. mesoblastic band; $m^{\prime}$. mesoblast; al. archenteron; $p h$. body cavity.

A. Horizontal and longitudinal section of an embryo which is dividing into two embryos at the gastrula stage. It shews the mesoblasts and the mesoblastic bands proceeding from them.

B. Transverse section shewing the two widely-separated mesoblastic bands.

C. Transverse section at a later stage shewing the mesoblastic bands which have approached the ventral line and developed a body cavity $p p$.

at their hinder extremities probably assist in their growth. Each mesoblastic band is at first composed of only a single row of cells, but soon becomes thicker, first of all in front, and becomes composed of two, three or more rows of cells abreast. From the above it is clear that the mesoblastic bands have, in L. trapezoides at any rate, in a large measure an epiblastic origin.

At first the two bands end in front at the sides of the mouth, but subsequently their front ends grow dorsalwards at the 
expense of the adjoining epiblast cells, and meet above the mouth, forming in this way a mesoblastic dorsal commissure.

The mesoblastic bands soon travel from the lateral position, which they at first occupy, towards the ventral surface. They do not however meet ventrally for some time, but form two bands, one on each side of the median ventral line (fig. I4 I C).

The usual accounts of the origin and growth of the bands differ somewhat from the above. By Kowalevsky (No. 342) and Hatschek (No. 339) they are believed to increase in Lumbricus rubellus and Criodrilus entirely at the expense of the mesoblasts. Kowalevsky moreover holds that in L. rubellus the original mesoblasts spring from the hypoblast. In some forms, e.g. Lumbricus agricola, the mesoblasts are not present.

In Euaxes the origin of the mesoblast bands is somewhat interesting as illustrating the relation of the Chrtopod mesoblastic bands to the mesoblast of other forms. To render intelligible the origin of the mesoblast in this form, it is necessary to say a few words about the segmentation.

By a somewhat abnormal process of segmentation the ovum divides into four spheres, of which one is larger than the others, and occupies a position corresponding with the future hind end of the embryo. The three smaller spheres give rise on their dorsal side by a kind of budding to small cells, which become the epiblast; and the epiblast is also partly formed from the hinder large cell in that this cell produces by budding a small cell, which again divides into two. The anterior of the two cells so formed divides still further and becomes incorporated in the epiblast; the posterior only divides into two which form the two mesoblasts. The remainder of the mesoblast is formed by further division of the three smaller of the primitive large spheres, and at first forms a continuous layer between the dorsal cap of epiblast and the four largest cells which, after giving rise to the epiblast and mesoblast, constitute the hypoblast. As the epiblast spreads over the hypoblast the mesoblastic sheet gives way in the middle, and the mesoblast remains as a ridge of cells at the edge of the epiblastic cup. It forms in fact a thickening of the lips of the blastopore. Behind the thickening is completed by the two mesoblasts. The appearance of the mesoblast in section is shewn in fig. 140. As the epiblast accompanied by the mesoblast grows round the hypoblast, the blastopore assumes an oval form, and the mesoblast appears as two bands - forming the sides of the oval. The epiblast travels over the hypoblast more rapidly than the mesoblast, so that when the blastopore becomes closed ventrally the mesoblastic bands are still some little way apart on the ventral side.

In Euaxes the mesoblast originates in a manner which is very similar to that in some of the Gasteropoda, e.g. Nassa, vide p. 234, and Vermes, e.g. Bonellia, etc. As mentioned in the chapter on the 
Mollusca the origin of the mesoblast in Planorbis, p. 227, is very similar to that in Lumbricus.

Hatschek has shewn that in Polygordius the mesoblast arises in fundamentally the same way as in the Oligochæta.

Besides the mesoblast which arises from the mesoblastic bands, there is evidence of the existence of further mesoblast in the larvæ of many Polychæta in the form of muscular fibres which traverse the space between the body wall and the wall of the enteric cavity prior to the formation of the permanent body cavity. These fibres have already been described in the embryo of Serpula, and are probably represented by stellate cells in the cephalic region (præ-oral lobe) of the Oligochæta. These cells are probably of the same nature as the amœboid cells in the larvæ of Echinodermata, some Mollusca and other types.

\section{The Larval form.}

True larval forms are not found in the Oligochæta where the development is abbreviated. They occur however in the majority of the marine Polychæta.

They present a great variety of characters with variously arranged ciliated bands. Most of these forms can be more or less satisfactorily derived from a larval form, like that of Serpula (fig. I39 B) or Polygordius (fig. I42); and the constant recurrence of this form amongst the Chætopoda, combined with the fact that it presents many points of resemblance to the larval forms of many Rotifers, Molluscs, and Gephyreans, seems to point to its being a primitive ancestral form for all these groups.

The important characters of this larval form are (I) the division of the body into a large præ-oral lobe and a relatively small post-oral region containing the greater part of the alimentary tract; (2) the presence of a curved alimentary canal divided into stomodæum (œsophagus), stomach and intestine, and opening by a ventrally placed mouth, and an anus near the hind end of the body. To these may be added the frequent presence of (I) a ganglion at the apex of the pre-oral lobe, (2) a large cavity between the wall of the gut and the skin, which is the remnant of the segmentation cavity, and is usually traversed by muscular strands, of which one connecting the apex of the præ-oral lobe and the stomach or cesophagus is very commonly present (fig. I42).

The arrangement of the ciliated bands presents great varia- 
tions, though in some instances it is constant through large groups. In Chætopods there is a widely distributed præ-oral ciliated band, which is similarly placed to the ring constantly found in the larvæ of Molluscs, Rotifers, etc. In many of these forms the band is practically double, the opening of the mouth being placed between its two component rings (vide fig. I42). The best introduction to the study of the Chætopod larval forms will be the history of the changes of a typical larval form in becoming converted into the adult.

For this purpose no better form can be selected than the interesting larva of Polygordius (vide Agassiz, No. 332, Schneider, No. 352, and Hatschek, No. 339), which was first discovered by Lovén, and believed by him to be the larva of an ordinary Chætopod. 1ts true nature was determined by Schneider.

At a very young stage the larva has the form (fig. 142) of a flattened sphere, with a small conical knob at the posterior extremity.

At the equator are situated two parallel ciliated bands ${ }^{1}$, between which lies the ventrally placed mouth $(\mathrm{m})$. The more conspicuous ciliated band is formed of a double row

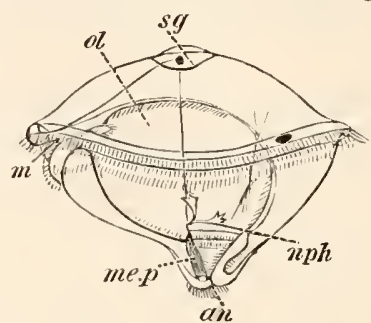

FIG. 142. POLYGordius LARVA. (After Hatschek.)

$m$. mouth; sg. supra-øesophageal ganglion; $n p h$. nephridion; me.p. mesoblastic band; an. anus; ol. stomach. of cilia, and is situated in front of the mouth. The thinner ciliated band behind the mouth appears to be absent in the American species.

The mouth leads into an œesophagus, and this into a globular stomach $(o l)$, which is continuous with a rectum terminating by an anus $(a n)$ placed at the hind end of the posterior conical knob. The whole alimentary tract is ciliated. In the American form of larva there is a ring of cilia round the anus, which is developed at a somewhat later stage in the form observed by Hatschek.

The position of the ciliated bands and the alimentary tract enables us to divide the embryo into three regions: a præ-oral region bounded by the anterior ciliated band, a gastric region in which the embryonic stomach is situated, and an abdominal region formed of the posterior conical

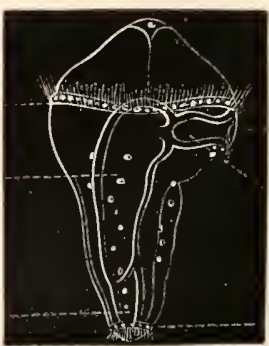

FIG. I43. POLYGoRDIUS LARVA. (From Alex. Agassiz.)

1 These two rings are at first (Hatschek) not quite closed dorsally, calling to mind the early condition of the Echinoderm larve with a præ-oral and post-oral ciliated area. 
portion, which by its subsequent elongation gives rise to the whole segmented portion of the future Polygordius.

At the front end of the pre-oral lobe is situated the early formed supraœsophageal ganglion $(s g$ ) (first noticed by Agassiz) in connection with which is a pair of eyes, and a ramified system of nerves. The ganglion is marked externally by a crown of cilia.

The larval epidermis bears a delicate cuticula, and is separated by a considerable interval from the walls of the alimentary tract. The space between the two represents a provisional body cavity, which is eventually replaced by the permanent body cavity formed between the two layers of the mesoblast. It is doubtful when the replacement takes place in the head. It probably does so very early. The mesoblast is present in the usual form of two bands (me.p) (germinal streaks), which are anteriorly continued into two muscular bands which pass through the embryonic body cavity to the front end of the præ-oral lobe. Another pair of contractile bands passes from the same region of the præ-oral lobe to the œsophagus.

There is no trace of the ventral nerve cord. The most remarkable organ of the larva is a paired excretory organ $(n p h)$ discovered by Hatschek. This is a ciliated canal with at first one and subsequently

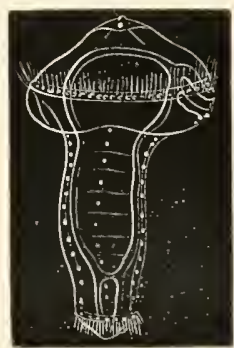

FIG. I+4. POLYGOR DIUS LARVA. (From Alex. Agassiz.) several funnel-shaped openings into the body cavity in front and an external opening behind. It is situated immediately anterior to the lateral band of mesoblast, and is parallel with, and dorsal to, the contractile band which passes off from this. It occupies therefore a position in front of the segmented region of the adult Polygordius.

The changes by which this peculiar larval form reaches the adult condition will be easily gathered from an inspection of figs. I43-I48. They consist essentially in the elongation of what has been termed the abdominal region of the body, and the appearance of a segmentation in the mesoblast; the segments being formed from before backwards, and each fresh segment being interpolated between the anus-bearing end of the body and the last segment.

As the hind portion of the body becomes

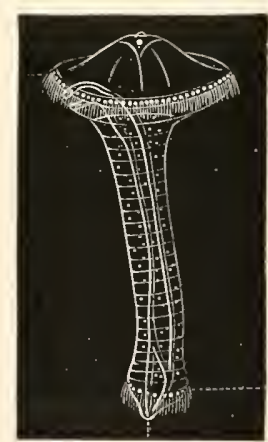

FIG. I45. POLYGORDIUS LARVA. (From Alex. Agassiz.) elongated the stomach extends into it, and gives rise to the mesenteron of the adult (figs. 143, 144, and 145). For a long time the anterior spherical dilated portion of the larva remains very large, consisting of a pre-oral lobe and a post-oral section. The two together may be regarded as constituting the head.

At a comparatively late stage a pair of tentacles arises from the front 
end of the præ-oral lobe (fig. I46), and finally the head becomes relatively reduced as compared with the body, and gives rise to the simple head of

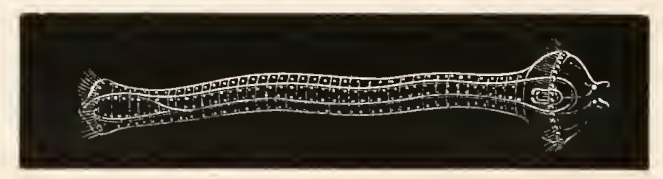

Fig. I $_{+} 6$. Polygordius larva. (From Alex. Agassiz.)

the fully formed worm (fig. 148). The two ciliated bands disappear, the posterior vanishing first. The ciliated band at the hind end of the body also atrophies ; and just in front of it the ring of wart-like prominences used by the adult to attach itself becomes developed.

At the sides of the head there is formed a pair of ciliated pits, also found by Hatschek in the embryo of Criodrilus, and characteristic of many Chætopod larvæ, but persistent in the adult Polygordius, Saccocirrus, Polyophthalmus, etc. They are perhaps the same structures as the ciliated pits in Nemertines.

During the external changes above described, by which the adult form of Polygordius is reached, a series of internal changes also takes place which are for the most part the same as in other Chrtopoda; and do not require a detailed description. The nervous ${ }^{1}$ and muscular systems have precisely the normal development. The division of the mesoblast into somites is not externally indicated. The organs most worthy of notice are the excretory organs.

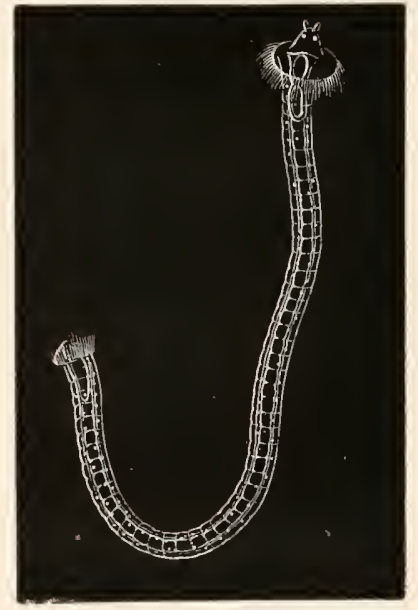

Fig, 147 . Polygordius larva. (From Alex. Agassiz.)

The essential points in the above development of Polygordius are (I) the gradual elongation and corresponding segmentation of the post-cephalic part of the body; and (2) the relative reduction in size of the præ-oral lobe and its conversion together with the oral region into the head; (3) the atrophy of the ciliated bands. The conversion of the larva into the adult takes place in fact by the intercalation of a segmented region

\footnotetext{
1 The structure of the ventral cord in the adult requires further elucidation.
} 
between a large mouth-bearing portion of the primitive body and a small anus-bearing portion ${ }^{1}$.

The general mode of development of Chætopod larvæ is similar to the above except in details, which are however no doubt often of great importance. The history of the larva may

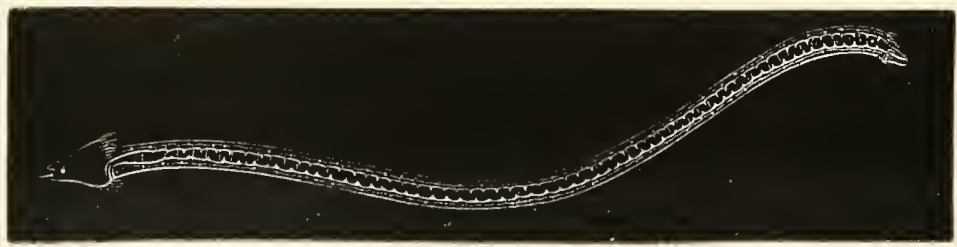

Fig. I 4 8. Polygordius larva. (From Alex. Agassiz.)

be conveniently treated under three heads. (I) The form of the primitive unsegmented larva; (2) the arrangement of the cilia on the unsegmented larva, and on the larva at later stages; (3) the character of the metamorphosis and the development of the permanent external organs.

A larva similar to the Polygordius larva with a greatly developed præ-oral lobe is widely distributed amongst the Annelids.

An almost identical form is that of Nepthys scolopendroides (Claparède and Metschnikoff, No. 336) ; that of Phyllodoce (fig. I49) is also very similar, and that of Saccocirrus (Metsch. and Clap. No. 336, Pl. xill. fig. I), a very primitive form most nearly related to Polygordius, clearly belongs to the same type. Many other larval forms, such as that of Spio fuliginosus (Metsch. and Clap. No. 336), Terebella, Nerine, etc., also closely approach this form.

Other really similar forms at first sight appear very different, but this is mainly

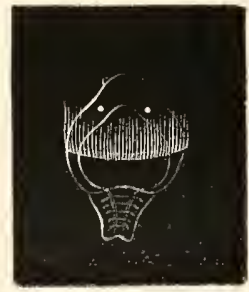

FIG. 149. LARVA OF PHYllodoce. (From Alex. Agassiz.) owing to the fact that their præ-oral lobe never attains a considerable development. Its smallness, though obviously of no deep morphological significance, at once produces a very different appearance in a larva.

1 For Semper's view as to the intercalation of segments in the cephalic region, vide note on $\mathrm{p} \cdot 333$. 
A good example of a larval form with a small præ-oral lobe is afforded by Capitella, which is figured by Clap. and Metsch. (No. 336, Pl. XviI. fig. 2). The imperfect development of the præ-oral lobe is also generally characteristic of the Oligochæta. The persistence of a relatively large præ-oral lobe for so long a time as in Polygordius is very unusual.

The arrangement of the cilia in Chætopod larvæ has been employed as a means of classifying them. Although a classification so framed has no morphological value, yet the terms themselves which have been invented are convenient. The terms most usually employed are Atrochæ, Monotrochæ, Telotrochæ, Polytrochæ, Mesotrochæ. The polytrochæ may again be subdivided into Polytrochæ proper, Nototrochæ, Gasterotrochx, and Amphitrochx.

The atrochæ contain forms (fig. 139) in which the larva is at first coated by an uniform covering of cilia, which, though it may subsequently disappear from certain areas, does not break up into a series of definite bands.

The monotrochæ or cephalotrochæ are larvæ in which only a single præ-oral ring is developed (fig. I $50 \mathrm{~B}$ ).

In the telotrochæ there is present a præ-oral and a postoral, i.e. peri-anal ring (fig. I 50 A); the latter sometimes having the form of a peri-anal patch.

The polytrochæ are segmented larvæ with perfect or imperfect rings of cilia on the segments of the body-usually one ring to each segmentbetween the two characteristic telotrochal rings. When these rings are complete the larvæ
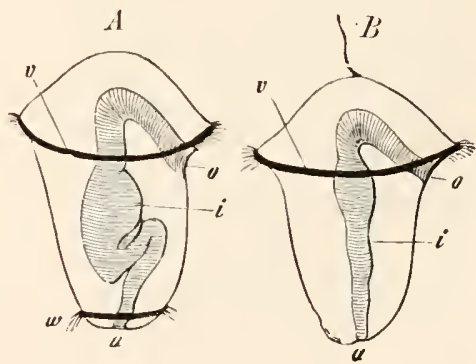

Fig. 150. Two ChæTOPOD LARVA. (From Gegenbaur.)

o. mouth; $i$. intestine; $a$. anus; $\approx$. præ-oral ciliated band; $w$. peri-anal ciliated band. are polytrochæ proper, when they are only half rings they are either nototrochæ or gasterotrochæ. Sometimes there are both dorsal and ventral half rings which do not however correspond, such forms constitute the amphitrochæ.

In the mesotrochx one or two rings are present in the middle of the body, and the characteristic telotrochal rings are absent. 
Larvæ do not necessarily continue to belong to the same group at all ages. A larva may commence as a monotrochal form and then become telotrochal and from this pass into a polytrochal condition, etc.

The atrochal forms are to be regarded as larvæe which never pass beyond the primitive stage of uniform ciliation, which in other instances may precede that of definite rings. They usually lose their cilia early, as in the cases of Serpula and other larvæ described below.

The atrochal larvæ are not common. The following history of an Eunicidan larva (probably Lumbriconereis) from Claparède and Metschnikoff (No. 336) will illustrate their general history.

In the earliest stage noticed the larva has a spherical form, the præ-oral lobe not being very well marked. In the interior is a globular digestive tract. The cilia form a broad central band leaving free a narrow space at the apex of the pre-oral lobe, and also a circumanal space. At the apex of the pre-oral lobe is placed a bunch of long cilia, and a patch of cilia also marks out the anal area.

As the larva grows older it becomes elongated, and the anterior bunch of cilia is absorbed. The alimentary canal divides itself into pharynx and intestine. The former opens (?) by the mouth in the middle of the central band of cilia, the latter in the anal patch. The setæ indicating the segmentation are formed successively in the posterior ring-like area free from cilia. The cilia disappear after the formation of two segments.

In Lumbricus, the embryo of which ought perhaps to be grouped with the atrochæ, the cilia (Kleinenberg) cover a ventral tract of epiblast between the two mesoblastic cords, and are continued anteriorly to form a circle round the mouth.

The monotrochal larva are provided only with the important præ-oral ciliated ring before mentioned. In the majority of cases they are transitional forms destined very shortly to become telotrochal, and in such instances they usually have a more or less spherical body which is nearly divided into two equal halves by a ciliated ring. In some few instances, such as Polynoe, Dasychone, etc., the monotrochal characters are not lost till the larval cilia are exuviated.

The telotrochal forms (of which examples are shewn in figs. I44, I 50, etc.) may (I) start as monotrochal; or (2) from the first have a telotrochal character ; or (3) be derived from atrochal forms. The last mode of origin probably represents the ancestral one. 
Their mode of development is well illustrated by the case of Terebella nebulosa (vide Milne-Edwards, No. 347). The embryo is at first a nearly spherical ciliated mass. One end slightly elongates and becomes free from cilia, and, acquiring dorsally two eye-spots, constitutes a præ-oral lobe. The elongation continues at the opposite end, and near this is formed a narrow area free from cilia. The larva now has the same characters as the atrochal Eunicidan larva described above. It consists of a non-ciliated præ-oral lobe, followed by a wide ciliated band, behind which is a ring-like area free from cilia; and behind this again a peri-anal patch of cilia. The ring-like area free from cilia is, as in the Eunicidan larva, the region which becomes segmented. It soon becomes longer, and is then divided into two segments; a third and fourth etc. non-ciliated segment becomes successively interposed immediately in front of the peri-anal patch; and, after a certain number of segments have become formed, there appear on some of the hinder of them short tubercles, provided with single setæ (the notopodia), which are formed from before backwards, like the segments.

The mouth, anus, and intestine become in the meantime clearly visible. The mouth is on the posterior side of the ciliated band, and the anus in the centre of the peri-anal patch.

The ciliated band in front now becomes contracted and provided with long cilia. It passes below completely in front of the mouth, and constitutes, in fact, a well-marked præ-oral ring, while the cilia behind constitute an equally marked peri-anal ring. The larva has in fact now acquired all the characters of a true telotrochal form.

Only a comparatively small number of Chætopod larvæ remain permanently telotrochal. Of these Terebella nebulosa, already cited (though not Terebella conchilega), is one; Polygordius, Saccocirrus and Capitella are other examples of the same, though in the latter form the whole ventral surface becomes ciliated.

The majority of the originally telotrochal forms become polytrochal.

In most cases the ciliated rings or half rings of the polytrochal forms are placed at equal distances, one for each segment. They are especially prominent in surface-swimming larvæ, and are in rare cases preserved in the adult. In some instances (e.g. Nerine and Spio) the ventral half rings, instead of being segmentally arranged, are somewhat irregularly distributed amongst the segments, so that there does not seem to be a necessary correspondence between the ciliated rings and the segments. This is further shewn by the fact that the ciliated rings are not precursors of the true segmentation, but are 
developed after the establishment of the segments, and thus seem rather to be secondarily adapted to the segments than primarily indicative of them.

In most Polytrochæ the rings are incomplete, so that they fall under the category of Nototrochæe or Gasterotrochæ.

The larva of Odontosyllis is an example of the former, and that of Magelona of the latter. The larvæ of Nerine and Spio, already quoted as examples of an unsegmented arrangement of the ventral ciliated half rings, are both amphitrochal forms.

As an example of a polytrochal form with complete ciliated rings Ophryotrocha puerilis may be cited. This form, discovered by Claparède and Metschnikoff, develops a complete ciliated ring on each segment : and the præ-oral ring, though at first single, becomes at a later period divided into two. This form is further exceptional in that the ciliated rings are persistent in the adult.

The unimportance of the character of the rings in the polytrochal forms is shewn by such facts as the absence of these rings in Terebella nebulosa and the presence of dorsal half rings in Terebella conchilega.

The mesotrochal forms are the rarest of Chætopod larvæ, and would seem to be confined to the Chætopteridæ.

Their most striking character is the presence of one or two complete ciliated rings which girth the body between the mouth and anus. The whole body is further covered with short cilia. The anus has a distinct dorsal situation, while on its ventral side there projects backwards a peculiar papilla.

The total absence of the typical præ-oral and of the peri-anal bands separates the mesotrochal larvæ very sharply from all the previous types.

A characteristic of many Chætopod larvæ is the presence of a bunch of cilia or a single flagellum at the apex of the præ-oral lobe. The presence of such a structure is characteristic of the larval forms of many other groups, Turbellarians, Nemertines, Molluscs, etc.

In the preceding section the mode of multiplication of the segments has already been sufficiently described ${ }^{1}$.

${ }^{1}$ It has been insisted by Semper (No. 355) that certain of the anterior segments, belonging to what he regards as the head region in opposition to the trunk, become interpolated between the trunk and the head. The general evidence, founded on observations of budding, which he brings forward, cannot be discussed here. But the special instance which he cites (founded on Milne-Edwards's (No, 347) observations) 
Apart from the formation of the segments the larval metamorphosis consists in the atrophy of the provisional ciliated rings and other provisional organs, and in the acquirement of the organs of the adult.

The great variations in the nature of the Chætopod appendages render it impossible to treat this part of the developmental history of the Chætopoda in a systematic way.

The mode of development of the appendages is not constant, so that it is difficult to draw conclusions as to the primitive form from which the existing types of appendages are derived.

In a large number of cases the primitive rudiments of the feet exhibit no indication of a division into notopodium and neuropodium; while in other instances (e.g. Terebella and Nerine, fig. I 52) the notopodium is first developed, and subsequently the neuropodium quite independently.

In many cases the setæ appear before there are any other visible rudiments of the feet (e.g. Lumbriconereis); while in other cases the reverse holds good. The gills are usually the last parts to appear.

Not only does the mode of development of the feet differ

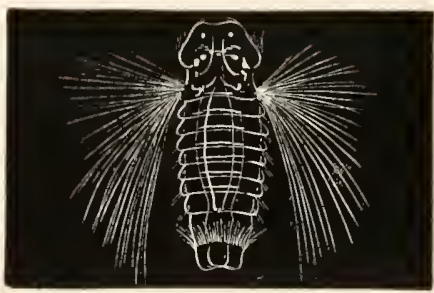

Fig. I52. LARVA OF NERINE, WITH PROVISIONAL SETE. (From Alex. Agassiz.) greatly in different types, but also the period. The appearance of setæ may afford the first external indication of segmentation, or the rudiments of the feet may not appear till a large number of segments are definitely established.

A very considerable number of Chætopod larvæ are provided with very long provisional setæ (figs. I 52 and 153). These setæ

of the interpolation of the head segments, bearing the gills, in Terebella appears to me quite unjustified from Milne-Edwards's own statements; and is clearly shewn to be unfounded by the careful observations of Claparède on Ter. conchilega, where the segments in question are demonstrated to be present from the first. 
are usually placed at the sides of the anterior part of the body, immediately bchind the head, and also sometimes on the posterior parts of the body. In some instances (e.g. fig. I 53)

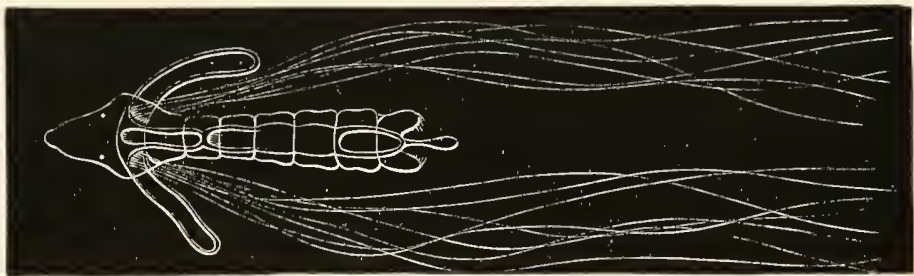

Fig. 153. Embryo Chetolod with provisional setæ. (From Agassiz.)

they form the only appendages of the trunk. Alex. Agassiz has pointed out that setre of this kind, though not found in existing Chætopods, are characteristic of the fossil forms. Setæ of this kind are found in chætopod-like larvæ of some Brachiopods (Argiope, fig. 136 ).

It is tempting to suppose that the long provisional bristles springing from the oral region are the setiform appendages handed down from the unsegmented ancestors of the existing Chætopod forms. Claparède has divided Chætopod larvæ into two great groups of Metachætæ and Perennichætæ, according as they possess or are without provisional setæ.

With reference to the head and its appendages it has already been stated that the head is primarily formed of the præ-oral lobe and of the peristomial region.

The embryological facts are opposed to the view that the præ-oral region either represents a segment or is composed of segments equivalent to those of the trunk. The embryonic peristomial region may, on the other hand, be regarded as in a certain sense the first segment. Its exact relations to the succeeding segments become frequently more or less modified in the adult. The præ-oral region is in most larvæ bounded behind by the ciliated ring already described. On the dorsal part of the præ-oral lobe in front of this ring are placed the eyes, and from it there may spring a variable number of processes which form antennæ or cephalic tentacles. The number and position of these latter are very variable. They appear as simple processes, sometimes arising in pairs, and at 
other times alternating on the two sides. There is frequently a median unpaired tentacle.

The development of the median tentacle in Terebella, where there is in the adult a great number of similar tentacles, is sufficiently remarkable to deserve special notice; vide Milne-Edwards, Claparède, etc. It arises long before any of the other tentacles as a single anterior prolongation of the præ-oral lobe containing a parenchymatous cavity, which communicates freely with the general perivisceral cavity. It soon becomes partially constricted off at its base from the procephalic lobe, but continues to grow till it becomes fully half as long as the remainder of the body. A very characteristic figure of the larva at this stage is given by Claparède and Metschnikoff, Pl. xvir., Fig. I E. It now strikingly resembles the larval proboscis of Balanoglossus, and it is not easy to avoid the conclusion that they are homologous structures.

Another peculiar cephalic structure which deserves notice is the gill apparatus of the Serpulidæ.

In Dasychone (Sabella) the gill apparatus arises (Claparède and Metschnikoff, No. 336) as a pair of membranous wing-like organs on the dorsal side of the pre-oral lobe immediately in front of the ciliated ring. Each subsequently becomes divided into two rays, and new rays then begin to sprout on the ventral side of the two pairs already present. A cartilaginous axis soon becomes formed in these rays, and after this is formed fresh rays sprout irregularly from the cartilaginous skeleton.

In Spirorbis spirillum as observed by Alex. Agassiz, the right gill-tentacle (fig. $\mathrm{I}_{54}, t$ ) first appears, and then the left, and subsequently the odd opercular tentacle which covers the right original tentacle. The third and fourth tentacles are formed successively on the two sides, and rapidly become branched in the succeeding stages.

With reference to the sense

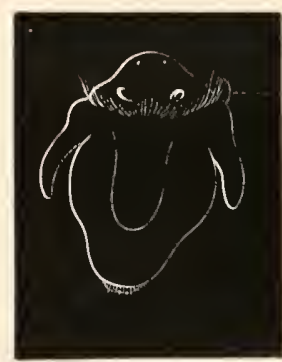

F1G. 154. LARVA OF SP1RORBıs. (From Alex. Agassiz.)

The first odd tentacle $(t)$ is shewn on the right side.

Behind the præ-oral ciliated ring is the large collar.

organs it may be noted that the eyes, or at any rate the cephalic pigment spots, are generally more numerous in the embryo than in the adult, and that they are usually present in the larvæ of the Sedentaria, though absent in the adults of these forms. The Sedentaria thus pass through a larval stage in which they resemble the Errantia.

Paired auditory vesicles of a provisional character have been found on the ventral side of the body, in the fourth segment 
behind the mouth, in the larva of Terebella conchilega (Claparède).

Mitraria. A peculiar larval Chretopod form known as Mitraria, the metamorphosis of which was first worked out by Metschnikoff, deserves a special notice.

This form (fig. $155 \mathrm{~A}$ ) in spite of its remarkable appearance can easily be reduced to the normal type of larva.

The mouth $(m)$ and anus $(a n)$ (fig. $155 \mathrm{~A}$ ) are closely approximated, and situated within a vestibule the edge of which is lined by a simple or lobed ciliated ring. The shape of the body is somewhat conical. The cavity of

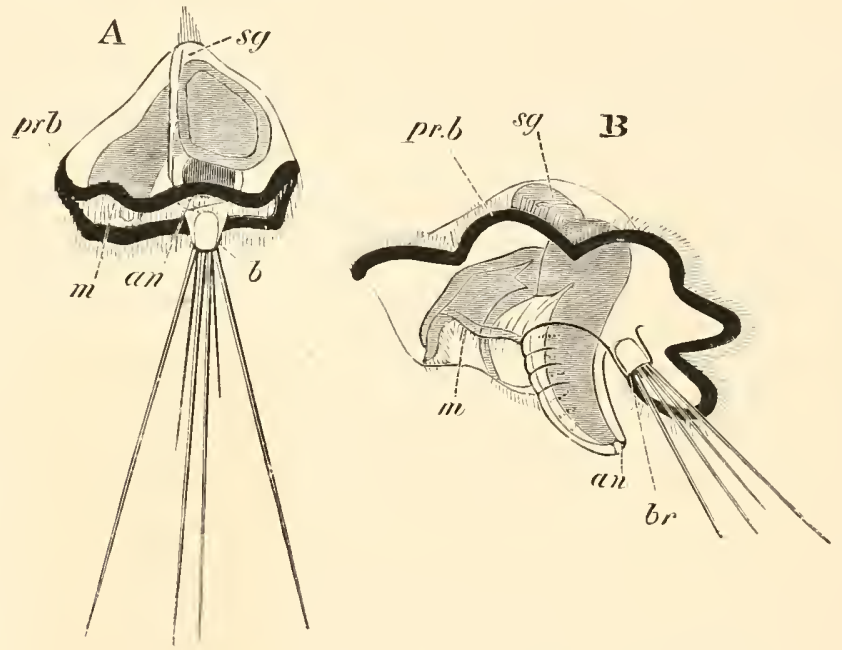

Fig. 15. Two stages in the Development of Mitraria.

(After Metschnikoff.)

m. mouth; an. anus; $s g$. supra-øesophageal ganglion; $b r$. provisional bristles; pr.b. præ-oral ciliated band.

the vestibule forms the base of the cone, and at the apex is placed a ciliated patch $(s g)$. A pair of lobes $(b r)$ bear provisional setæ. The alimentary canal is formed of the three normal parts, œesophagus, stomach, and intestine.

To compare this larva with an ordinary Chætopod larva one must suppose that the alimentary canal is abnormally bent, so that the post-oral ventral surface is reduced to the small space between the mouth and the anus. The ciliated band surrounding the vestibule is merely the usual præ-oral band, borne on the very much extended edge of the præ-oral lobe. The apex of the larva is the front end of the præ-oral lobe with the usual ciliated patch. The two lobes with provisional bristles are really dorsal and not posterior.

B. II. 
The correctness of the above interpretation is clearly shewn by the metamorphosis.

The first change consists in the pushing in of a fold of skin, between the mouth and anus, towards the intestine, which at the same time rapidly elongates, and forms the axis of a conical projection, which thereupon becomes segmented and is thereby shewn to be the rudiment of the trunk (fig. I $55 \mathrm{~B}$ ). On the elongation of the trunk in this way the præ-oral lobe and its ciliated ring assume an appearance not very dissimilar to the same structures in Polygordius. At the ciliated apex of the præ-oral lobe a paired thickening of epiblast gives rise to the supra-cesophageal ganglia $(\mathrm{sg})$. In the further metamorphosis, the præ-oral lobe and its ciliated ring gradually become reduced, and finally atrophy in the normal way, while the trunk elongates and acquires setæ. The dorsally situated processes with provisional setæ last for some time, but finally disappear. The young worm then develops a tube and shews itself as a normal tubicolous Chætopod.

\section{Formation of Organs.}

Except in the case of a few organs our knowledge of the formation of the organs in the Chrtopoda is derived from investigations on the Oligochata.

The embryo of the Oligochæeta has a more or less spherical form, but it soon elongates, and becoming segmented acquires a distinct vermiform character. The ventral surface is however for a considerable time markedly convex as compared to the dorsal.

The ventrally placed mouth is surrounded by a well-marked lip, and in front of it is placed a small præ-oral lobe.

The epiblast. The epiblast cells at the commencement of the gastrula stage become much flattened, and on the completion of the invagination form an investment of flattened cells, only thickened in the neighbourhood of the mesoblastic bands (fig. I4I B and C). In the Polychata at any rate the statements of several investigators would seem to indicate that the cuticle is derived from the chorion. It is difficult to accept this conclusion, but it deserves further investigation.

Nervous system. The most important organ derived from the epiblast

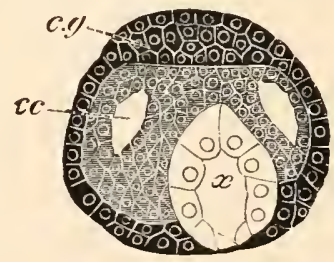

Fig. I56. SECTION THROUGH THE HEAD OF A YOUNG EMBRYO OF LUMBRICUSTRAPEZOIDES. (After Kleinenberg.)

c.g. cephalic ganglion; cc. cephalic portion of the body cavity ; $x$. œsophagus. 
is the nervous system; the origin of which from this layer was first established by Kowalevsky (No. 342).

It $\operatorname{arises}^{1}$ (Kleinenberg, No. 341) from two at first quite distinct structures, viz. (I) the supra-œsophageal rudiment and (2) the rudiment of the ventral cord. The former of these takes its origin as an unpaired dorsal thickening of the epiblast at the front end of the head (fig. I $56, c . g$.), which sends two prolongations downwards and backwards to meet the ventral cord. The latter arises as two independent thickenings of the epiblast, one on each side of the ventral furrow (fig. I $57, V g$ ). These soon unite underneath the furrow, in the median line, and after being differentiated into segmentally arranged ganglionic and interganglionic regions become separated from the epiblast. Both the supra-œsophageal and ventral cord become surrounded by a layer of somatic mesoblast. The junction between the two parts of the central nervous system takes place comparatively late.

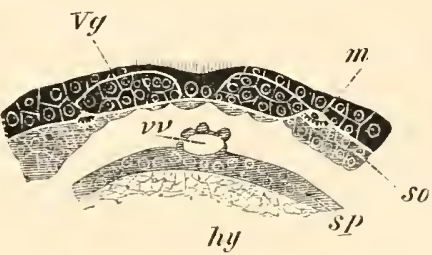

FIG. I 57. SECTION THROUGH PART OF THE VENTRAL WALL OF THE TRUNK OF AN EMBRYO OF LUMBRICUS TRAPEZOIDES. (After Kleinenberg.)

$m$. Iongitudinal muscles; so. somatic mesoblast; sp. splanchnic mesoblast ; $h y$. hypoblast ; $V_{g}$. ventral nerve cord ; vv. ventral vessel.

The mesoblast. It is to Kowalevsky (No. 342) and Kleinenberg (No. 341) that we mainly owe our knowledge of the history of the mesoblast. The fundamental processes which take place are (I) the splitting of the mesoblast into splanchnic and somatic layers with the body cavity between them, (2) the transverse division of the mesoblast of the trunk into distinct somites.

The former process commences in the cephalic mesoblastic commissure, where it results in the formation of a pair of cavities each with a thin somatic and thick splanchnic layer (fig. I 56, $c c)$; and thence extends gradually backwards into the trunk (fig. I $4 \mathrm{I} \mathrm{C}, p p$ ). In the trunk however the division into somites precedes the horizontal splitting of the mesoblast. The former process commences when the mesoblastic bands form widish columns quite separate from each other. These columns become

1 For further details, vide general chapter on Nervous System. 
broken up successively from before backwards into somewhat cubical bodies, in the centre of which a cavity soon appears. The cavity in each somite is obviously bounded by four walls, (I) an outer, the somatic, which is the thickest; (2) an inner, the splanchnic; and $(3,4)$ an anterior and posterior. The adjoining anterior and posterior walls of successive somites unite together to form the transverse dissepiments of the adult, which subsequently become very thin and are perforated in numerous places, thus placing in communication the separate compartments of the body cavity. The somites, though at first confined to a small area on the ventral side, gradually extend so as to meet their fellows above and below and form complete rings (fig. I 57) of which the splanchnic layer $(s p)$ attaches itself to the enteric wall and the somatic ( $s o$ ) to the epiblast. In Polygordius and probably also Saccocirrus and other forms the cavities of the somites of the two sides do not coalesce; and the walls which separate them constitute dorsal and ventral mesenteries. The two cavities in the cephalic commissure unite dorsally, but ventrally open into the first somite of the trunk.

The mesoblastic masses of the head are probably not to be regarded as forming a pair of somites equivalent to those in the trunk, but as forming the mesoblastic part of the præ-oral lobe, of which so much has been said in the preceding pages. Kleinenberg's observations are however of great importance as shewing that the cephalic cavities are simply an anterior part of the true body cavity.

The splanchnic layer of the head cavity gives rise to the musculature of the esophagus.

The somatic layer of the trunk somites becomes converted into the musculature of the body wall and the external peritoneal layer of body cavity. The first part of the muscular system to be definitely formed is the ventral band of longitudinal muscles which arises on each side of the nervous system in contact with the epidermis (fig. I $57, m$ ). How the circular muscles become subsequently formed outside these muscles has not been made out.

The splanchnic layer of the trunk somites gives rise to the muscular and connective-tissue wall of the mesenteron, and also to the walls of the vascular trunks. The ventral vessel is first formed (Kowalevsky) as a solid mass of cells which subsequently 
becomes hollowed out. The dorsal vessel in Lumbricus and Criodrilus is stated by Kowalevsky and Vejdovsky to be formed by the coalescence of two lateral vessels; a peculiarity which is probably to be explained by the late extension of the mesoblast into the dorsal region.

The layer from which the sacks for the setæe and the segmental organs spring is still doubtful. The sacks for the setæ are believed by Kowalevsky (No. 342) to be epiblastic invaginations, but are stated by Hatschek (No. 339) to be mesoblastic products. For the development of the segmental organs the reader is referred to the chapter on the excretory system.

In marine Polychæta the generative organs are no doubt mesoblastic products, as they usually spring from the peritoneal epithelium, especially the parts of it covering the vascular trunks.

The Alimentary Canal, In Lumbricus the enteric cavity is formed during the gastrula stage. In Criodrilus the hypoblast has at first no lumen, but this becomes very soon established. In Euaxes on the other hand, where there is a true epibolic gastrula, the mesenteron is at first represented by a solid mass of yolk (i.e. hypoblast) cells. As the central amongst these become absorbed a cavity is formed. The protoplasm of the yolk cells which line this cavity unites into a continuous polynuclear layer containing at intervals masses of yolk. These masses become gradually absorbed, and the protoplasmic wall of the mesenteron then breaks up into a cylindrical glandular epithelium similar to that of the other types.

In Lumbricus and Criodrilus the blastopore remains as the mouth, but in Euaxes a new mouth or rather stomodæum is formed by an epiblastic invagination between the front end of the two mesoblastic bands. This epiblastic invagination forms the permanent œsophagus; and in Lumbricus trapezoides and Criodrilus, where the oral opening is at first lined by hypoblast, the epiblast soon becomes inflected so as to line the osophageal region. The splanchnic mesoblast of the cephalic region subsequently invests the oesophagus, and some of its cells penetrating between the adjoining epiblast cells give rise to a thick wall for this part of the alimentary tract ; the original epiblast cells being reduced to a thin membrane. This mesoblastic wall is sharply 
separated from the muscular wall outside, which is also formed of splanchnic mesoblast.

The anus is a late formation.

\section{Alternations of generations.}

Amongst Chætopoda a considerable number of forms exhibit the phenomenon of alternations of generations, which in the same general way as in the case of the Colenterata, is secondarily caused by budding or fission.

The process of fission essentially consists in the division of a parent form into two zooids by the formation of a zone of fission between two old rings, which becomes differentiated (I) into an anal zone in front which forms the anal region of the anterior zooid, and (2) into a cephalic zone behind which forms the head and some of the succeeding segments of the posterior zooid. The anal zone is capable, by growth and successive segmentation, of giving rise to an indefinite number of fresh segments.

In Protula Dysteri, as shewn by Huxley, there is a simple fission into two in the way described. Sexual reproduction does not take place at the same time as reproduction by fission, but both zooids produced are quite similar and multiply sexually.

In the freshwater forms Nais and Chætogaster a more or less similar phenomenon takes place. By a continual process of growth in the anal zones, and the formation of fresh zones of fission whenever four or five segments are added in front of an anal zone, complicated chains of adhering zooids are produced, each with a small number of segments. As long as the process of fission continues sexual products are not developed, but eventually the chains break up, the individuals derived from them cease to go on budding, and, after developing a considerably greater number of segments than in the asexual state, reproduce themselves sexually. The forms developed from the ovum then repeat again the phenomenon of budding, etc., and so the cycle is continued ${ }^{1}$.

The phenomena so far can hardly be described as cases of

1 Reproduction by budding and formation of the sexual products to some extent overlap. 
alternation of generations. The process is however in certain types further differentiated. In Syllis (Quatrefages) fission takes place, the parent form dividing into two, of which only the posterior after its detachment develops sexual organs. The anterior asexual zooid continues to produce fresh sexual zooids by fission. In Myrianida also, where a chain of zooids is formed, the sexual elements seem to be confined to the individuals produced by budding.

The cases of Syllis and Myrianida seem to be genuine examples of alternations of generations, but a still better instance is afforded by Autolytus (Krohn, No. 343, and Agassiz, No. 333).

In Autolytus cornutus the parent stock, produced directly from the egg, acquires about $40-45$ segments, and then gives rise by fission, with the production of a zone of fission between about the $\mathrm{I} 3^{\text {th }}$ and $\mathrm{I}^{\mathrm{t}} \mathrm{th}$ rings, to a fresh zooid behind. This after becoming fully developed into either a male or a female is detached from the parent stock, from which it very markedly differs. The males and females are moreover very different from each other. In the female zooid the eggs are carried into a kind of pouch where they undergo their development and give rise to asexual parent stocks. After the young are hatched the female dies. The asexual stock, after budding off one asexual zooid, elongates again and buds off a second zooid. It never develops generative organs.

The life history of some species of the genus Nereis presents certain very striking peculiarities which have not yet been completely elucidated.

As was first shewn by Malmgren asexual examples of various species of Nereis may acquire the characters of Heteronereis and become sexually mature.

The metamorphosis of Nereis Dumerilii has been investigated by Claparède, who has arrived at certain very remarkable conclusions. He finds that there are two distinct sexual generations of the Nereis form of this species, and two distinct sexual generations of the Heteronereis form.

One sexual Nereis, characterized by its small size, is diœcious, the other discovered by Metschnikoff is hermaphrodite.

Of the Heteronereis sexual forms, both are diøcious, one is small, and swins on the surface, the other is larger and lives at the bottom.

How these various generations are mutually related has not been mace out; but Claparède traced the passage of large asexual examples of the Nereis form into the large Heteronereis form. 


\section{BIBLIOGRAPHY.}

(332) Alex. Agassiz. "On the young stages of a few Annelids." Annals Lycezm Nat. Hist. of Nerw York, Vol. vili. 1866.

(333) Alex. Agassiz. "On the embryology of Autolytus cornutus and alternations of generations, etc." Boston Fournal of Nat. History, Vol. vir. 1859-63.

(334) W. Busch. Beobachtungen ï. Anat. u. Entwick. einiger wirbelloser Seethiere, 1851 .

(335) Ed. Claparede. Beobachtungen ï. Anat. ". Entreick. wirbelloser Thiere and. Küiste von Normandie. Leipzig, 1863.

(336) Ed. Claparèrle u. E. Metschnikoff. "Beiträge z. Kenntniss üb. Entwicklungsgeschichte d. Chrtopoden." Zeit. f. wiss. Zool. Vol. xix. I869.

(337) E. Grube. Untersuchungen ïb. Entwicklung d. Anneliden. Königsberg, $184+$.

(338) B. Hatschek. "Beiträge z. Entwick. u. Morphol. d. Anneliden." Sitz. d. k. Akad. Wiss. Wien, Vol. Lxxiv. 1876 .

(339) B. Hatschek. "Studien uiber Entwicklungsgeschichte der Anneliden." Arheiten aus d. zoologischen Institute d. Universität Wien. Von C. Claus. Heft III. 1878 .

(340) Th. H. Huxley. "On hermaphrodite and fissiparous species of tubicolar Annelidæ (Protula)." Edinburgh New Phil. Fournal, Vol. I. I 855.

(341) N. Kleinenberg. "The development of the earthworm Lumbricus trapezoides." Quart. F. of Micr. Science, Vol. xix. 1879. Su'lo sviluppo del Lumbricus trapezoides. Napoli, $\mathbf{1} 878$.

(342) A. Kowalevsky. "Embryologische Studien an Würmern u. Arthropoden." Mém. Acad. Pítersbourg, Series vir. Vol. xvi. $187 \mathbf{I}$.

(343) A. Krohn. "Ueber die Erscheinungen bei d. Fortpflanzung von Syllis prolifera u. Autolytus prolifer." Archiv f. Naturgesch. I 852.

(34t) R. Leuckart. "Ueb. d. Jugendzustände ein. Anneliden, etc." Archiz f. Naturgesch. 1855 .

(345) S. Lovén. "Beobachtungen ii. die Metamorphose von Anneliden." Weigmann's Archiv, $18+2$.

(3t6) E. Metschnik off. "Ueber die Metamorphose einiger Seethiere (Mitraria)." Zeit.f. wiss. Zool. Vol. xxı. 187 r.

(347) M. Milne-Edwards. "Recherches zoologiques, etc." Ann. Scie. Natur. I1I. Série, Vol. 111. I $8+5$.

(348) J. Mïller. "Ueb. d. Jugendzustände einiger Seethiere." Monats. d. k. Akad. Wiss. Berlin, $185 \mathrm{I}$.

(349) Max Miiller. "Ueber d. weit. Entwick. von Mesotrocha sexoculata." Mïller's Archiv, 1855 .

(350) Quatrefages. "Mémoire s. l'embryogénie des Annelides." Ann. Scie. Natur. III. Série, Vol. x. 1848 .

(351) M. Sars. "Zur Entwicklung d. Anneliden." Archiv f. Naturgeschichte, Vol. Xi. I 845 .

(352) A. Schneider. "Ueber Bau u. Entwicklung von Polygordius." Miiller's Archiv, 1868.

(353) A. Schneider. "Entwicklung u. system. Stell. d. Bryozoen u. Gephyreen (Mitraria)." Archivf. mikr. Anat. Vol. v. 1869. 
(35t) M. Schultze. Ueb. die Entwicklung von Arenicola piscatorum u. anderer Kiemenziïmer. Halle, 1856 .

(355) C. Semper. "Die Verwandschaftbeziehungen d. gegliederten Thiere." Arbeiten a. d. zool..zoot. Instit. Würzburg, Vol. III. i 876-7.

(356) C. Semper. "Beiträge z. Biologie d. Oligochrten." Arbeiten a.d.zool. zoot. Instit. Würzburg, Vol. IV. 1877-8.

(357) M. Stossich. "Beiträge zur Entwicklung d. Chætopoden." Sitz. $d . k$. k. Akad. Wiss. Wien, B. Lxxvir. 1878 .

(358) R. v. Willemoes-Suhm. "Biologische Beobachtungen ï. niedrige Meeresthiere." Zeit.f. wiss. Zool. Bd. xxI. $187 \mathrm{I}$. 


\section{CHAPTER XIII.}

\section{DISCOPHORA ${ }^{2}$.}

THE eggs of the Discophora, each enclosed in a delicate membrane, are enveloped in a kind of mucous case formed by a secretion of the integument, which hardens into a capsule or cocoon. In each cocoon there are a limited number of eggs surrounded by albumen. The cocoons are attached to waterplants, etc. In Clepsine the embryos leave the cocoon very soon after they get rid of the egg membrane, but in Nephelis they remain within the cocoon for a very much longer period (27-28 days after hatching). The young of Clepsine, after their liberation, attach themselves to the ventral surface of their parent.

Our knowledge of the development of the Discophora is in a very unsatisfactory state; but sufficient is known to shew that it has very many points in common with that of the Oligochæta, and that the Discophora are therefore closely related to the Chrtopoda. In Clepsine there is an epibolic gastrula, and mesoblastic bands like those in Euaxes are also formed. In Nephelis however the segmentation is very abnormal, and the formation of the germinal layers cannot easily be reduced to an invaginate gastrula type, though probably it is modified from such a type. Mesoblastic bands similar to those in the Oligochæta occur in this form also.

The embryology of Clepsine, which will serve as type for the Leeches without jaws (Rhyncobdellidæ), has recently been studied by Whitman (No. 365), and that of Nephelis, which will

1 The Discophora are divided into the following groups.
I. Rhyncobdellidæ.
II. Gnathobdellidæ.
III. Branchiobdellidæ. 
serve as type for the Leeches with jaws (Gnathobdellidx), has been studied by Buitschli (No. 359). The early history of both types is imperfectly known ${ }^{1}$.

\section{Formation of the layers.}

Clepsine. It is necessary to give a full account of the segmentation of Clepsine, as the formation of the germinal layers would be otherwise unintelligible.

Segmentation commences with the division of the ovum into two unequal spheres by a vertical cleavage passing from the animal to the vegetative pole. By a second vertical cleavage the large segment is divided into two unequal parts, and the small one into two equal parts. Of the four segments so produced three are relatively small, and one, placed at the posterior end, is large. Each of the four segments next gives rise to a small cell at the animal pole. These small cells form the commencement of the epiblast, and, according to Whitman, the mouth is eventually placed in their centre. Such a position for the mouth, at the animal pole, is extremely unusual, and the statements on this head require further confirmation.

The posterior large segment now divides into two, one of which is dorsal, and the other and larger ventral. The former I shall call with Whitman the neuroblast, and the latter the mesoblast. The mesoblast very shortly divides again. During the formation of the neuroblast and mesoblast additional epiblastic small cells are added from the three spheres which give rise to three of the primitive epiblast cells, which may now be called the vitelline spheres.

The neuroblast next divides into ten cells, of which the two smaller are soon broken up into epiblastic cells, while the remaining eight arrange themselves in two groups of four each, one group on each side

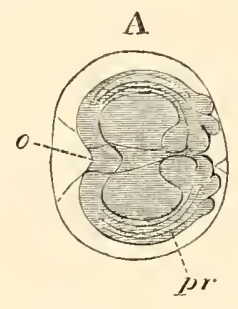

Fig. I58. Two VIEIVS OF THE LARVA OF Clepsine. (After Whitman.)

$o$. oral extremity; $m$ mouth; pr. germinal streak.

A. This figure shews the blastoderm (shaded) with a thickened edge formed by the primitive (i.e. mesoblastic) streaks with the four so-called neuroblasts posteriorly. The vitelline spheres are left withont shading.

B. represents an embryo in which the blastoderm has enclosed the yolk, and in which the division into segments has taken place. At the hind end are shewn the so-called neuroblasts forming the termination of the germinal streak. at the posterior border of the epiblastic cap. The two mesoblasts also take up a position on the right and left sides immediately ventral to the four neuroblasts of each side. The neuroblasts and mesoblasts now commence to

1 Hoffmann's account (No. 36) is so different from that of other observers that I have been unable to make any use of it. 
proliferate at their anterior border, and produce on each side a thickened band of cells underneath the edge of the cap of epiblast cells. Each of these bands is formed of a superficial quadruple ${ }^{1}$ row of neuroblasts budded off from the four primary neuroblasts, and a deeper row of mesoblasts. The compound streaks so formed may be called the germinal streaks.

The general appearance of the embryo as seen from the dorsal surface, after the appearance of the two germinal streaks, may be gathered from fig. $158 \mathrm{~A}$. The epiblastic cap in this figure is shaded. The epiblastic cap, accompanied by the germinal streaks, now rapidly extends and encloses the three vitelline spheres by a process equivalent to that of an ordinary epibolic gastrula; but the front and hind ends of the streaks remain practically stationary. Owing to this mode of growth the edges of the epiblastic cap and the germinal streaks meet in a linear fashion along the ventral surface of the embryo (fig. 159, A and B). The germinal streaks first meet anteriorly (B) and their junction is then gradually continued backwards. The process is completed at about the time of hatching.

During the above changes the nuclei of the vitelline spheres pass to the surface and rapidly divide. Eventually, together with part of the protoplasm of the vitelline spheres, they appear to give rise to a layer of hypoblastic cells. This layer encloses the remains of the vitelline spheres, which become the yolk.

At the front end of the germinal streaks, in a position corresponding with that of the four original epiblast cells, two depressions appear which coalesce to form the single oral invagination; in the centre of which are formed the mouth and pharynx by a second epiblastic invagination.

The most important point in connection with the above history is the fate of what have been called the germinal streaks. According to Whitman they are composed of two kinds of cells, viz. four rows of smaller super-

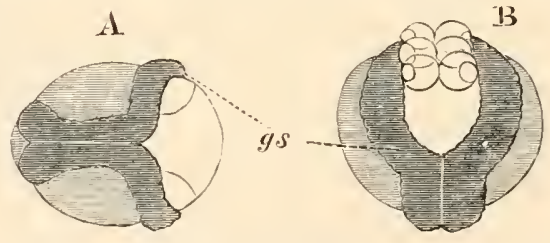

Fig. I 59. Two EMiBRyos of Clepsine in WHICH THE GERMINAL STREAKS HAVE PARTIALLY MIET ALONG THE VENTRAL LINE. (After Rolin )

gs. germinal, i.e. mesoblastic streaks.

The area covered by epiblast is shaded. The so-called neuroblasts at the end of the germinal streaks are shewn in $\mathrm{B}$.

ficial cells, which he calls neuroblasts, and, in the later stages at any rate, a row of deeper large cells, which he calls mesoblasts. As to the eventual fate of these cells he states that the neuroblasts uniting together in the median line form the rudiment of the ventral ganglionic chain, while the mesoblasts equally coalesce and give rise to the mesoblast. Such a mode of origin for a ventral ganglionic chain is, so far as I know, without a parallel in the whole animal kingdom; and whatever evidence Whitman may have that the cells

1 According to Robin it is more usual for there to le only a triple row of primary neuroblasts. 
in question really do give rise to the nervous system he has not thought fit to produce it in his paper. He figures a section with the eight neuroblastic cells in the middle ventral line, and in the next stage described the nervous system is divided up into ganglia! The first stage, in which the so-called nervous system has the form of a single row of eight cells, is quite unlike any rudiment of the nervous system such as is usually met with in the Chætopoda, and not a single stage between this and a ganglionated cord is described or figured. Whitman, whose views seem to have been influenced by a peculiar, and in my opinion erroneous, theory of Rauber's about the relation of the neural groove of Vertebrata to the blastopore, does not seem to be aware that his determination of the fate of his neuroblasts requires any special support.

He quotes the formation of these parts in Euaxes (vide preceding Chapter, p. 324) as similar to that in Clepsine. In this comparison it appears to me probable that he may be quite correct, but the result of the comparison would be to shew that the neuroblasts and mesoblasts composed together a mesoblastic band similar to that of the Oligochæta. Till more evidence is brought forward by Whitman or some other observer in support of the view that the so-called neuroblasts have any share in forming the nervous system, they must in my opinion be regarded as probably forming, in conjunction with the mesoblasts, two simple mesoblastic bands. Kowalevsky has moreover briefly stated that he has satisfied himself that the nervous system in Clepsine originates from the epiblast-a statement which certainly could not be brought into harmony with Whitman's account.

Nephelis. Nephelis will form my type of the Gnathobdellidæ. The segmentation of this form has not yet been thoroughly investigated, but Bütschli's (No. 359) observations are probably the most trustworthy.

The ovum first divides into two, and then into four segments of which two are slightly smaller than the others. Four small cells which form the commencement of the epiblast are now formed. Three of them are derived by budding from the two larger and one of the smaller of the four cells, and the fourth from a subsequent division of one of the larger cells ${ }^{1}$. The three cells which assisted in the formation of the epiblast cells again give rise each to a small cell; and the small cells so formed constitute a layer underneath the epiblast which is the commencement of the hypoblast, while the cells from which they originated form the vitelline spheres. Shortly after the formation of the hypoblast, the large sphere which has hitherto been quiescent divides into two, one of which then gives rise in succession to two small epiblastic elements.

The two large spheres, resulting from the division of the originally quiescent sphere, next divide again on the opposite side of the embryo, and form a layer of epiblast there; so that there is now on one side of the embryo (the ventral according to Robin) a layer of epiblast formed

${ }_{1}$ Doubts have been cast by Whitman on the above account of the origin of the four epiblast cells. 
of six cells, and on the opposite side a layer formed of four cells. The two layers meet at the front border of the embryo and between them are placed the three large vitelline spheres. The two patches of epiblast cells now rapidly increase, and gradually spread over the three large vitelline spheres. Except where they meet each other at the front edge they leave uncovered a large part of the margin of the vitelline spheres.

While these changes have been taking place on the exterior, the hypoblast cells have increased in number (additional cells being probably derived from the three large vitelline spheres) and fill up in a column-like fashion a space which is bounded behind by the three vitelline spheres, and in front by the epiblast of the anterior end of the embryo. At the sides of the hypoblast the mesoblast has become established, probably as two lateral bands. The origin of the cells forming it has not yet been determined. The hypoblast cells in the succeeding stage arrange themselves round a central archenteric cavity, and at the same time rapidly increase in size and become filled with a secondary deposit of food-yolk. Shortly afterwards a mouth and thick-walled œesophagus are formed, probably from an epiblastic invagination. The mesoblast now forms two curved lateral bands at the two sides of the body, equivalent to the mesoblastic bands of the Chætopoda. The three vitelline spheres, still largely uncovered by the epiblast, lie at the posterior end of the body. The embryo grows rapidly, especially anteriorly, and the three vitelline spheres become covered by a layer of flattened epiblast cells. Around the œesophagus a cavity traversed by muscular fibres is established. Elsewhere there is no trace of such a cavity. The cephalic region becomes ciliated, and the dorsal part of it, which represents a rudimentary pre-oral lobe, is especially prominent. The cilia of the oral region are continued into the lumen of the œesophagus, and at a later period are prolonged, as in Lumbricus, along the median line of the ventral surface.

The mesoblastic bands would seem from Bütschli's observations, which receive confirmation from Kleinenberg's researches on Lumbricus, to be prolonged dorsally to the œsophagus into the cephalic region. Posteriorly they abut on the large vitelline spheres, which were supposed by Kowalevsky to give origin to them, and to play the same part as the large mesoblasts in Lumbricus. It has already been shewn that the function of the large cells in Lumbricus has been exaggerated, and Bütschli denies to them in Nephelis any share in the production of the mesoblast. It seems in fact probable that they are homologous with the three vitelline spheres of Clepsine; and that their primitive function is to give origin to the hypoblast. They are visible for a long time at the hind end of the embryo, but eventually break up into smaller cells, the fate of which is unknown.

The embryo of Hirudo would appear from the researches of Robin to develop in nearly the same way as that of Nephelis. The anterior part is not however ciliated. The three large posterior cells disappear relatively early. 


\section{General history of the larva.}

The larva of Clepsine, at the time when the mesoblastic bands have met along the ventral line, is represented in fig. I $58 \mathrm{~B}$. It is seen to be already segmented, the process having proceeded pari passu with the ventral coalescence of the mesoblastic bands. The segments are formed from before backwards as in Chætopoda. The dorsal surface is flat and short, and the ventral very convex. The embryo about this time leaves its capsule, and attaches itself to its parent. It rapidly elongates, and the dorsal surface, growing more rapidly than the ventral, becomes at last the more convex. Eventually thirty-three postoral segments become formed; of which the eight last coalesce to form the posterior sucker.

The general development of the body of Nephelis and Hirudo is nearly the same as that of Clepsine. The embryo passes from a spherical to an oval, and then to a vermiform shape. For full details the reader is referred to Robin's memoir.

The presence of a well-marked protuberance above the œsophagus, which forms the rudiment of a præ-oral lobe, has already been mentioned as characteristic of the embryo of Nephelis; no such structure is found in Clepsine.

\section{History of the germinal layers and development of organs.}

The epiblast. The epiblast is formed of a single layer of cells and early develops a delicate cuticle which is clearly formed quite independently of the egg membrane. It becomes raised into a series of transverse rings which bear no relation to the true somites of the mesoblast.

The nervous system. The nervous system is probably derived from the epiblast, but its origin still requires further investigation. The ventral cord breaks up into a series of ganglia, which at first correspond exactly with the somites of the mesoblast. Of these, four or perhaps three eventually coalesce to form the sub-osophageal ganglion, and seven or eight become united in the posterior sucker.

It would appear from Buitschli's statements that the supra- 
œsophageal ganglion arises, as in Oligochæta, independently of the ventral cord.

Mesoblast. It has already been indicated that the mesoblast probably takes its origin both in Nephelis and Clepsine from the two mesoblastic bands which unite in the median ventral line. The further history of these bands is only imperfectly known. They become segmented from before backwards. The somites formed by the segmentation gradually grow upwards and meet in the dorsal line. Septa are formed between the somites probably in the same way as in the Oligochæta.

In Clepsine the mesoblastic bands are stated by Kowalevsky to become split into somatic and splanchnic layers, between which are placed the so-called lateral sinuses. These sinuses form, according to Whitman, a single continuous tube investing the alimentary tract; a tube which differs therefore to a very small extent from the normal body cavity of the Chrtopoda. The somatic layer of mesoblast no doubt gives rise to the circular and longitudinal muscular layers of the embryo. The former is stated to appear the earliest, while the latter, as in the Oligochrta, first takes its origin on the ventral side.

A delicate musculature, formed mainly of transverse but also of longitudinal fibres, would appear to be developed independently of the mesoblastic bands in Nephelis and Hirudo (Rathke, Leuckart, Robin, and Bütschli). It develops apparently from certain stellate cells which are found between the walls of the alimentary tract and the skin, and which probably correspond to the system of contractile fibres which pass from the body wall to the alimentary tract through the segmentation cavity in the larva of Chætopoda, various Vermes and Mollusca ${ }^{1}$.

The mesoblast, so far as is known, gives rise, in addition to the parts already mentioned, to the excretory organs, generative organs, vascular system, etc.

Excretory organs. There are found in the embryo of Nephelis and Hirudo certain remarkable provisional excretory organs the origin and history of which is not yet fully made out. In Nephelis they appear as one (according to Robin, No. 364), or (according to Bütschli, No. 359) as two successive pairs of

1 According to Robin this system of muscles becomes gradually strengthened and converted into the permanent system. Rathke on the other hand states that it is provisional, and that it is replaced by the muscles developed from the mesoblastic somites. It is possible to suppose that it may really become incorporated in the latter system. 
convoluted tubes on the dorsal side of the embryo, which are stated by the latter author to develop from the scattered mesoblast cells underneath the skin. At their fullest development they extend, according to Robin, from close to the head to near the ventral sucker. Each of them is $U$-shaped, with the open end forwards, each limb of the $U$ being formed by two tubes united in front. No external opening has been clearly made out. Semper believed that the tubes were continuous with the three posterior vitelline cells, but this has been shewn not to be the case. Fürbringer ${ }^{1}$ is inclined from his own researches to believe that they open laterally. They contain a clear fluid.

In Hirudo, Leuckart (No. 362) has described three similar pairs of organs the structure of which he has fully elucidated. They are situated in the posterior part of the body, and each of them commences with an enlargement from which a convoluted tube is continued for some distance backwards; it then turns forwards again and afterwards bends upon itself to open to the exterior. The anterior part is broken up into a kind of labyrinthic network.

The true segmental organs are found in a certain number of the segments and are stated (Whitman) to develop from groups of mesoblast cells. Their origin requires however further investigation.

A double row of colossal cells on each side of the body has been described in Clepsine by Whitman as derived from the mesoblastic plates. These cells (fig. $58 \mathrm{~B}$ ), which he calls segment-cells, lie opposite the walls of the septa. The inner row is stated to be connected with the segmental organs. Their eventual history is unknown, but they are conjectured by Whitman to be the mother cells of the testes.

The alimentary tract. This is formed primitively of two parts-the epiblastic stomodæum-forming mouth, pharynx, and osophagus, and the hypoblastic mesenteron. The anus is formed very late as a simple perforation immediately dorsal to the posterior sucker.

In Clepsine, where there is an epibolic gastrula, the rudiment

1 Morphologisches Fahrbuch, Vol. Iv. p. 676. He further speaks of the tube as "feinverzweigt u. netzförmig verästelt," but whether from his own observations is not clear.

B. II. 
of the mesenteron is at first formed of the three vitelline spheres, from the surface of which a true hypoblastic layer enclosing a central yolk mass becomes differentiated, as already described. The mesenteric sack so formed is constricted by the growth of the mesoblastic septa into a series of lobes, while the posterior part forms a narrow and at first very short tube opening by the anus.

The lobed region forms the sacculated stomach of the adult. The sacculations of the stomach by their mode of origin necessarily correspond with the segments. In the adult however the anterior lobe is really double and has two divisions for the two segments it fills, while the posterior lobe, which, as is well known, extends backwards parallel with the rectum, is composed of five segmental sacculations. In connection with the stomodæum a protrusible pharynx is developed.

In Hirudo and Nephelis the mesenteron has from the first a sack-like form. The cells which compose the sack give rise to a secondary deposit of food-yolk. The further changes are practically the same as in Clepsine. In Hirudo the posterior sacculation of the stomach is primitively unpaired. The jaws are formed at about the same time as the eyes as protuberances on the wall of the oral cavity.

\section{BIBLIOGRAPHY.}

(359) O. Biitschli. "Entwicklungsgeschichtliche Beiträge (Nephelis)." Zeit. f. wiss. Zool. Vol. Xxix. 1877 .

(360) E. Grube. Untersuchungen ïb. d. Entwicklungd. Anneliden. Königsberg, i $s_{4+}$.

(361) C. K. Hoffmann. "Zur Entwicklungsgeschichte d. Clepsineen." Niederländ. Archiv f. Zool. Vol. Iv. I877.

(362) R. Leuckart. Die menschlichen Parasiten (Hirudo), Vol. I. p. 686, et seq.

(363) H. Rathke. Beit. z. Entzvickhungsgesch. d. Hirudineen. Leipzig, I862.

(36-1) Ch. Robin. Mém. sur le Díveloppement embryogenique des Hirudinées. Paris, I 875 .

(365) C. O. Whitman. "Embryology of Clepsine." Quart. F. of Micro. Science, Vol. xvili. 1878.

[ Iride also C. Semper (No. 355) and Kowalevsky (No. 342) for isolated observations.] 


\title{
CHAPTER XIV.
}

\author{
GEPHYREA ${ }^{1}$
}

IT is convenient for the purposes of embryology to divide the Gephyrea into two groups, viz. (I) Gephyrea nuda or true Gephyrea; and (2) Gephyrea tubicola formed by the genus Phoronis.

\section{GEPHYREA NUDA.}

Segmentation and formation of the lajers.

An embolic or epibolic gastrula is characteristic of the Gephyrea, and the blastopore appears, in some cases at any rate (Phascolosoma, Thalassema), to become the mouth.

Bonellia. In Bonellia (Spengel, No. 370) the segmentation is unequal but complete, and, as in many Molluscs etc., the ovum exhibits before its commencement a distinction into a protoplasmic and a yoke pole. The ovum first divides into four equal segments, each of them formed of the same constituents as the original ovum. At the animal pole four small cells, entirely formed of protoplasm, are next formed by an equatorial furrow. They soon place themselves in the intervals between the large spheres. Four small cells are again budded off from the large spheres and the eight small cells then divide. By a further continuation of the division of the existing small cells, and the formation of fresh ones from the large spheres, a layer of small

1 The following scheme shews the classification of the Gephyrea adopted in the present chapter :-

I. Gephyrea nuda. $\begin{cases}(1) & \text { Inermia. } \\ (2) \text { Armata. }\end{cases}$

II. Gephyrea tubicola (Phoronis). 
cells is eventually formed, which completely envelops the four large spheres except for a small blastopore at the vegetative pole of the ovum (fig. 160 A). The large spheres continue to give rise to smaller cells which however no longer take a superficial position but lie within the layer of small cells, and give rise to the hypoblast (fig. r6o B). The small cells become the epiblast, and at the blastopore they curl inwards (fig. I60 B) and give
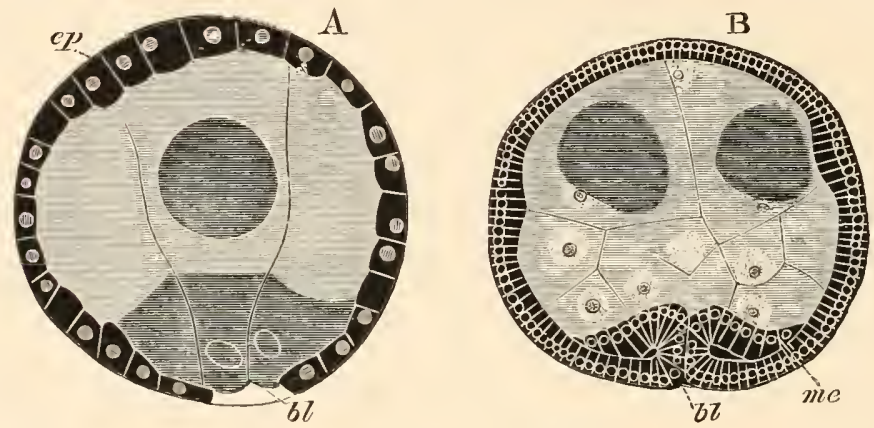

Fig. i6o. Epibolic gastrula of Bonelia. (After Spengel.)

A. Stage when the four hypoblast cells are nearly enclosed.

B. Stage after the formation of the mesoblast has commenced by an infolding of the lips of the blastopore.

ep. epiblast; me. mesoblast; $b l$. blastopore.

rise to a layer of cells, which appears to extend as an unbroken sheet between the epiblast and hypoblast, and to form the mesoblast. The blastopore now closes up, but its position in relation to the parts of the embryo has not been made out.

In Phascolosoma (Selenka, No. 369) the ovum, enclosed in a porous zona radiata, divides into two unequal spheres, of which the smaller next divides into two and then into four. An invagination talies place which is intermediate between the embolic and the epibolic types. The small cells, the number of which is increased by additions from the large sphere, divide, and grow round the large sphere. The latter in the meantime also divides, and the cells produced from it form on the one hand a small sack which opens by the blastopore, and on the other they fill up the segmentation cavity, and become the mesoblast and blood corpuscles. The blastopore becomes the permanent mouth. 


\section{Larial forms and development of organs.}

Amongst the Gephyrea armata the larva has as a rule (Thalassema, Echiurus) the characters of a trochosphere, and closely approaches the typical form characteristic of the larva of Polygordius, often known as Lovén's larva. In Bonellia this larval form is less perfectly preserved.

Echiurus. In Echiurus (Salensky, No. 368) the youngest known larva has all the typical trochosphere characters (fig. I6 I). It is covered with cilia and divided into a pra-oral lobe and post-oral region of nearly equal dimensions. There is a double ciliated ring which separates the two sections of the body as in the larva of Polygordius: the mouth $(m)$ opens between its two elements. The alimentary canal is divided into a stomodreum with a ventral opening, a large stomach, and a short intestine opening by a terminal anus (an). Connecting the oesophagus with the apex of the pre-oral lobe is the usual contractile band, and at the insertion of this band is a thickening of the epiblast which probably represents the rudiment of the supra-cesophageal ganglion. A ventral nerve cord is stated by Salensky to be present, but his observations on this point are not quite satisfactory.

The metamorphosis is accompanied by the loss of swimming power, and consists in the enlargement of the post-oral portion of the trunk, and in the simultaneous reduction of the pre-oral lobe, which remains however permanently as the cylindrical proboscis. A groove which terminates posteriorly at the mouth is very early formed on its ventral side. The ciliated rings gradually disappear during the metamorphosis.

Of the further external

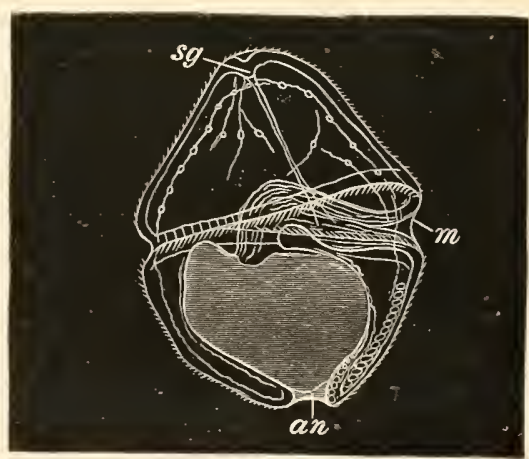

Fig. i6I. Larva of Echiurus. (After Salensky.)

m. mouth; an. anus; sg. supra-cesophageal ganglion (?). 
changes the most important are (I) the early appearance round the anal end of the body of a ring of bristles; and (2) the appearance of a pair of ventral setæ in the anterior part of the body. The anterior ring of bristles characteristic of the adult Echiurus does not appear till a late period.

Of the internal changes the earliest is the formation of the anal respiratory sacks. With the growth of the posterior part of the trunk the intestine elongates, and becomes coiled.

Bonellia. The embryo of Bonellia, while still within the egg, retains a spherical form and acquires an equatorial band of cilia, behind which a second narrower band is soon established, while in front of the first one a pair of eye-spots becomes
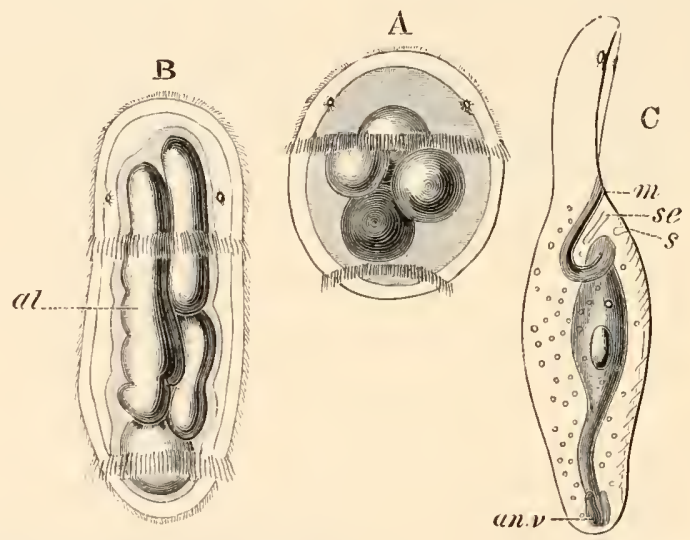

Fig. 162. Three stages in the development of Bonellia. (After Spengel.)

A. Larva with two ciliated bands and two eye-spots.

B. Ripe larva from the dorsal surface.

C. Young female Bonellia from the side.

al. alimentary tract; $m$. mouth; sc. provisional excretory tube; s. ventral hook; an.\%. anal vesicle.

formed (fig. I62 A). The embryo on becoming hatched rapidly elongates, while at the same time it becomes dorso-ventrally flattened and acquires a complete coating of cilia (fig. I62 B). According to Spengel it resembles at this time in its form and habits a rhabdocolous Turbellarian. The anterior part is however somewhat swollen and presents an indication of a pra-oral lobe. 
During the above changes important advances are made in the formation of the organs from the embryonic layers.

The epiblast acquires a superficial cuticula, which is perhaps directly derived from the vitelline membrane. The nervous system is also formed, probably from the epiblast. The band-like supra-œsophageal ganglion is the first part of the nervous system formed, and appears to be undoubtedly derived from the epiblast. The ventral cord arises somewhat later, but the first stages in its development have not been satisfactorily traced. It is continuous with the supra-œsophageal band which completely girths the œsophagus without exhibiting any special dorsal enlargement. After the ventral cord has become completely separated from the epiblast a central fibrous mass becomes differentiated in it, while the lateral parts are composed of ganglion cells. In the arrangement of its cells it presents indications of being composed of two lateral halves. It is, however, without ganglionic swellings.

The mesoblast, though at first very thin, soon exhibits a differentiation into a splanchnic and somatic layer-though the two do not become distinctly separated by a body cavity. The somatic layer rapidly becomes thicker, and enlarges laterally to form two bands united dorsally and ventrally by narrow, thinner bands. The outermost parts of each of these bands become differentiated into an external circular and an internal longitudinal layer of muscles. In the pra-oral lobe the mesoblast assumes a somewhat vacuolated character.

The hypoblast cells form a complete layer round the four yolk cells from which they arise (fig. $162 \mathrm{~B}, a l$ ), but at first no alimentary lumen is developed. The osophagus appears during this period as an, at first solid, but subsequently hollow, outgrowth of the hypoblast towards the epiblast.

The metamorphosis of the larva into the adult female Bonellia commences with the conversion of many of the indifferent mesoblast cells into blood corpuscles, and the introduction into the body cavity of a large amount of fluid, which separates the splanchnic and somatic layers of mesoblast. The fluid is believed by Spengel to be sea-water, introduced by two anal pouches, the development of which is described below.

The body cavity is lined by a peritoneum, and very soon distinct vessels, formed by folds of the peritoneum, become established. Of these there are three trunks, two lateral and a median in the pre-oral lobe (proboscis), and in the body a ventral trunk above the nerve cord, and an intestinal trunk opening anteriorly into the ventral one. The vessels appear to communicate with the body cavity.

In the course of the above changes the two ciliated bands 
disappear, the hinder one first. The cilia covering the general surface become atrophied, with the exception of those on the ventral side of the pra-oral lobe. The latter structure becomes more prominent; the stellate mesoblast cells, which fill up its interior, become contractile, and it gives rise to the proboscis (fig. $162 \mathrm{C}$ ).

At the point where the cesophageal protuberance joined the epiblast at a previous stage the mouth becomes established (fig. $162 \mathrm{C}, \mathrm{m}$ ), and though it is formed subsequently to the atrophy of the anterior ciliated band, yet there is evidence that it is potentially situated behind this band. The lumen of the alimentary canal becomes established by the absorption of the remains of the four central cells. The anus is formed on the ventral side of the posterior end of the body, and close to it the pouches already noticed grow out from the hindermost part of the alimentary tract (fig. $162 \mathrm{C}$, an.v). They are at first simple blind pouches, but subsequently open into the body cavity ${ }^{1}$. They become the anal pouches of the adult. There is present when the mouth is first formed a peculiar process of the alimentary tract projecting into the præ-oral lobe, which appears to atrophy shortly afterwards.

After the formation of the mouth, there are formed on the ventral side of and slightly behind it ( $\mathrm{I}$ ) anteriorly a pair of tubes, which appear to be provisional excretory organs and soon disappear (fig. $162 \mathrm{C}, s c$ ); and (2) behind them a pair of bristles $(s)$ which remain in the adult. The formation of the permanent excretory (?) organ (oviduct and uterus) has not been followed out. The ovary appears very early as a differentiation of the epithelium lining the ventral vessel.

The larve, which become the minute parasitic males, undergo a very different and far less complete metamorphosis than those which become females. They attach themselves to the proboscis of an adult female, and lose their ciliated bands. Germinal cells make their appearance in the mesoblast, which form spherical masses, and, like the germinal balls in the female ovary, consist of a central cell, and an epithelium around it. The central cell becomes very large, while the peripheral cells give rise to the spermatozoa. A body cavity becomes developed in the larvæ, into which the spermatic balls are dehisced. Neither mouth nor anus is formed. The further changes have not been followed out.

1 The fact that these pouches are outgrowths of the alimentary tract appears to preclude the possibility of their being homologous with excretory tubes of the Platyelminthes and Kotifera. 
The larval males make their way into the cesophagus of the female, where they no doubt live for some time, and probably become mature, though the seminal pouch of the adult is not found in many of the males living in the osophagus. When mature the males leave the esophagus, and pass into the uterus.

Phascolosoma. Cilia appear in Phascolosoma (Selenka, No. 369) while the ovum is still segmenting. After segmentation they form a definite band immediately bchind the mouth, which divides the larva into two hemispheres-a pra-oral and a postoral. A pre-oral band of cilia is soon formed close to the postoral band, and at the apex of the pre-oral lobe a tuft of cilia also appears.

The larva has now the characters of a trochosphere, but differs from the typical trochosphere in the post-oral part of the ciliated equatorial ring being more important than the pre-oral, and in the absence of an anus.

The metamorphosis commences very early. The trunk rapidly elongates, and the pre-oral lobe becomes relatively less and less conspicuous. The zona radiata becomes the larval cuticle.

Three pairs of bristles are formed on the trunk, of which the posterior pair appears first, then the anterior, and finally the middle pair: an order of succession which clearly proves they can have no connection with a true segmentation.

The tentacles become developed between the two parts of the ciliated ring, and finally the præ-oral lobe, unlike what takes place in the Gephyrea armata, nearly completely vanishes.

The anus appears fairly late on the dorsal surface, and the ventral nerve cord is established as an unganglionated thickening of the ventral epiblast.

\section{GePHYREA TUBICOLA.}

The larva of Phoronis was known as Actinotrocha long before its connection with Phoronis was established by Kowalevsky (No. 372). There is a complete segmentation leading to the formation of a blastosphere, which is followed by an invagination, the opening of which is said by Kowalevsky to remain as 
the mouth ${ }^{1}$. It is at first terminal, but on the development of a large præ-oral lobe it assumes a ventral position. The anus is formed at a later period at the posterior end of the body.

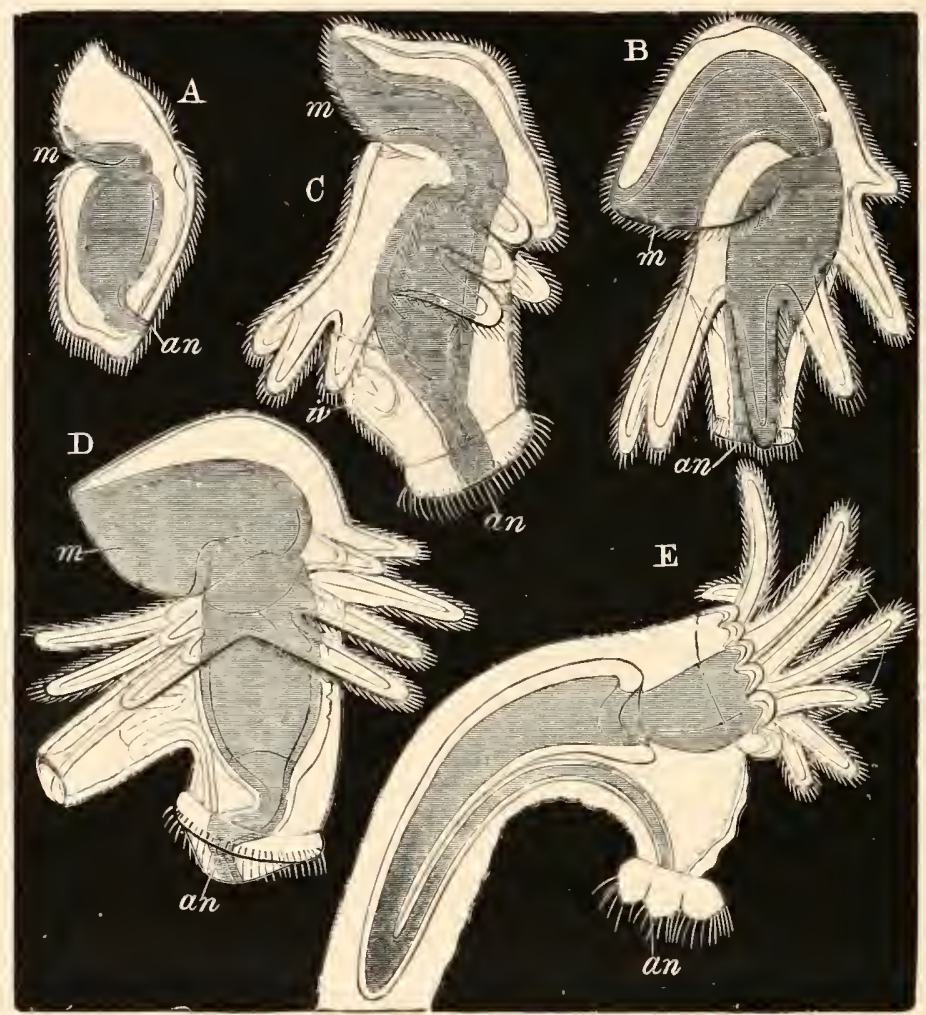

Fig. 163. A SERIES OF STAGES IN THE DEVELOPMENT OF PHORONIS FROM Actinotrocila. (After Metschnikoff.)

A. Young larva.

B. Larva after the formation of post-oral ring of tentacles.

C. Larva with commencing invagination to form the body of Phoronis.

D. Invagination partially everted.

E. Invagination completely everted. $m$. mouth; an. anus; $i v$. invagination to form the body of Phoronis.

The youngest free larva observed by Metschnikoff (No. 373) was less developed than the oldest larva found by Kowalevsky.

1 Kowalevsky states that what I have called the mouth is the anus, but his subsequent descriptions shew that he has transposed the mouth and anus in the embryo, and that the opening, which he asserts to be the anus, is in reality the mouth. 
It probably belongs to a different species. The body is uniformly ciliated (fig. $163 \mathrm{~A}$ ). There is a large contractile præ-oral lobe, and the body ends behind in two processes. The mouth $(m)$ is ventral, and the anus (an) dorsal, and not terminal as in Kowalevsky's larva.

The alimentary tract is divided into stomodæum, stomach and intestine. The two processes at the hind end of the body are the rudiments of the first-formed pair of the arms which are so characteristic of the fully developed Actinotrocha. A second pair of arms next become established on the dorsal side of the previously existing pair, and the region where the anus is placed grows out as a special process. New pairs of arms continue to be formed in succession dorsalwards and forwards, and soon constitute a complete oblique post-oral ring (fig. 163 B). They are covered by long cilia. Round the anal process a very conspicuous ciliated ring also becomes established.

At the period when five pairs of arms are present a delicate membrane becomes visible on the ventral side of the intestine which joins the somatic mesoblast anteriorly. This membrane is the rudiment of the future ventral vessel. The somatic mesoblast is present even before this period as a delicate layer of circular muscular fibres.

When six pairs of arms have become formed an involution (fig. $\mathrm{I} 6_{3} \mathrm{C}, i v$ ) appears on the ventral side, immediately behind the ring of arms. This involution consists both of the epiblast and somatic mesoblast. It grows inwards towards the intestine, and, increasing greatly in length, becomes at the same time much folded.

When it has reached its full development the critical period of the metamorphosis of Actinotrocha into Phoronis is reached, and is completed in about a quarter of an hour. The ventral involution becomes evoluted (fig. I63 D), just as one might turn out the finger of a glove which had been pulled inwards. When the involution has been to a certain extent everted, the alimentary canal passes into it, and at the same time the body of the larva becomes violently contracted. By the time the evagination is completed it forms (fig. I62 E) a long conical body, containing the greater part of the alimentary tract, and constituting the body of the young Phoronis. The original anal process remains on the dorsal side as a small papilla (fig. $162 \mathrm{E}, a n$ ). 
While these changes have been taking place the præ-oral lobe has become much contracted, and partly withdrawn into the stomodæum. At the same time the arms have become bent forward, so as to form a ring round the mouth. Their bases become much thickened. The metamorphosis is completed by the entire withdrawal of the pre-oral lobe within the œesophagus, and by the casting off of the ends of the arms, their bases remaining as the circumoral ring of tentacles, which form however a lophophore rather than a complete ring. The perianal ring of cilia is also thrown off, and the anal process withdrawn into the body of the young Phoronis. There are now three longitudinal vascular trunks, united anteriorly by a circular vessel which is prolonged into the tentacles.

\section{General Considerations.}

The development of Phoronis is so different from that of the other Gephyrea that further investigations are required to shew whether Phoronis is a true Gephyrean. Apart from its peculiar metamorphosis Actinotrocha is a yery interesting larval form, in that it is without a præ-oral ciliated ring, and that the tentacles of the adult are derived from a true post-oral ring, prolonged into arm-like processes.

The other Gephyrea present in their development an obvious similarity to the normal Chrtopoda, but their development stops short of that of the Chretopoda, in that they are clearly without any indications of a true segmentation. In the face of what is known of their development it is hardly credible that they can represent a degenerate Chætopod phylum in which segmentation has become lost. Further than this the Gephyrea armata seem in one respect to be a very primitive type in that they retain through life a well-developed præ-oral lobe, which constitutes their proboscis. In almost all other forms, except Balanoglossus, the larval præ-oral lobe becomes reduced to a relatively insignificant anterior part of the head.

\section{BIBLIOGRAPHY.}

\section{Gephyrea nuda.}

(366) A. Kowalevsky. Sitz. d. zool. Abth. d. III. I'ersam. muss. Naturg. (Thalassema). Zeit.f. wiss. Zool. Vol. xxil. 1872, p. 284 . 
(367) A. Krohn. "Ueb. d. Larve d. Sipunculus nudus nebst Bemerkungen," etc. Mïller's Archiv, i 857 .

(368) M. Salensky. "Ueber die Metamorphose d. Echiurus." Morphologisches Fahrouch, Bd. II.

(369) E. Selenka. "Eifurchung u. Larvenoildung von Phascolosoma elongatum." Zeit.f. zuiss. Zool. is 85, Bd. xxv. p. I.

(370) J. W. Spengel. "Beiträge z. Kenntniss d. Gephyreen (Bonellia)." Mittheil. a. d. zool. Station z. Neapel, Vol. I. I879.

\section{Gephyrea tubicola (Actinotrocha).}

(371) A. Krohn. "Ueb. Pilidium u. Actinotrocha." Müller's Archiv, i 858 .

(372) A. Kowalevsky. "On anatomy and development of Phoronis," Pétersbourg, $1867.2 \mathrm{Pl}$. Russian. Tide Leuckart's Bericht, I866-7.

(373) E. Metschnikoff. "Ueber d. Metamorphose einiger Seethiere (Actinotrocha)." Zeit.f. wiss. Zool. Bd. xxi. r87I.

(374) J. M iiller. "Bericht üb. ein. Thierformen d. Nordsee." Müller's Archiv, 1846 .

(375) An. Schneider. "Ueb. d. Metamorphose d. Actinotrocha branchiata." Miiller's Arch. 1862. 


\section{CHAPTER XV.}

\section{CHETOGNATHA, MYZOSTOMEA AND GASTROTRICHA.}

THE present chapter deals with three small isolated groups, which only resemble each other in that the systematic position of all of them is equally obscure.

\section{Chatognatha.}

The discoveries of Kowalevsky (No. 378) confirmed by Bütschli (No. 376) with reference to the development of Sagitta, though they have not brought us nearer to a knowledge of the systematic position of this remarkable form, are nevertheless of

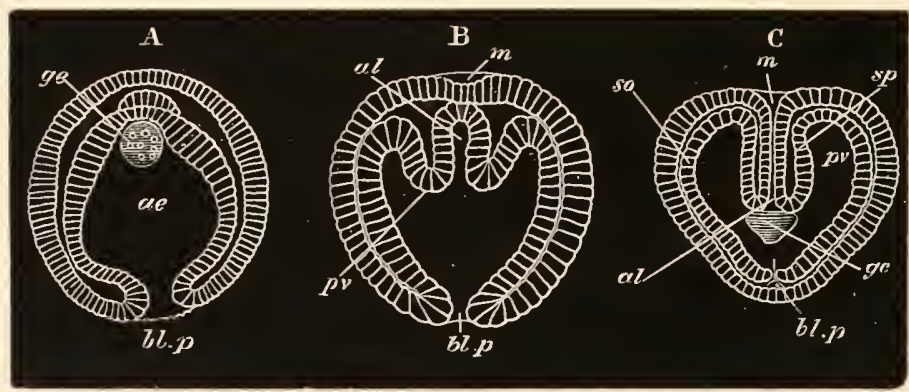

Fig. i64. Three stages in the development of Sagitta. (A and $\mathrm{C}$ after Buitschli and $\mathrm{B}$ after Kowalevsky.) The three embryos are represented in the same positions.

A. The gastrula stage.

B. A succeeding stage in which the primitive archenteron is commencing to be divided into three parts, the two lateral of which are destined to form the body cavity.

C. A later stage in which the mouth involution $(m)$ has become continuous with the alimentary tract, and the blastopore has become closed.

$m$. month; al. alimentary canal; ae. archenteron; $b l . p$. blastopore; pv. perivisceral cavity; sp. splanchnopleuric mesoblast; so. somatopleuric mesoblast; ge. generative organs. 
great value for the more general problems of embryology. The development commences after the eggs are laid. The segmentation is uniform, and a blastosphere, formed of a single layer of columnar cells, is the product of it. An invagination takes place, the opening of which narrows to a blastopore situated at the pole of the embryo opposite that at which the mouth subsequently appears (fig. I64 A). The simple archenteron soon becomes anteriorly divided into three lobes, which communicate freely with the still single cavity behind (fig. I64 B). The two lateral lobes are destined to form the body cavity, and the median lobe the alimentary tract of the adult. An invagination soon arises at the opposite pole of the embryo to the blastopore and forms the mouth and oesophagus (fig. I64 B and C, $m$ ).

At the gastrula stage there is formed a paired mass destined to give rise to the generative organs. It arises as a prominence of six cells, projecting from the hypoblast at the anterior pole of the archenteron, and soon separates itself as a mass, or probably a pair of masses, lying freely in the cavity of the archenteron (fig. I64 A, ge). When the folding of the primitive cavity takes place the generative rudiment is situated at the hind end of the median lobe of the archenteron in the position represented in fig. $164 \mathrm{C}, g e$.

An elongation of the posterior end of the embryo now takes place, and the embryo becomes coiled up in the egg, and when eventually hatched sufficiently resembles the adult to be recognisable as a young Sagitta.

Before hatching takes place various important changes become manifest. The blastopore disappears after being carried to the ventral surface. The middle section of the trilobed region of the archenteron becomes separated from the unpaired posterior part, and forms a tube, blind behind, but opening in front by the mouth (fig. $165 \mathrm{~A}, a l$ ). It constitutes the permanent alimentary tract, and is formed of a pharyngeal epiblastic invagination, and a posterior hypoblastic section derived from the primitive archenteron. The anus is apparently not formed till comparatively late. After the isolation of the alimentary tract the remainder of the archenteron is formed of two cavities in front, which open freely into a single cavity behind (fig. I65 A). The whole of it constitutes the body cavity and its walls 
the mesoblast. The anterior paired part becomes partitioned off into a head section and a trunk section (fig. $6_{5} \mathrm{~A}$ and $\mathrm{B}$ ). The former constitutes a pair of distinct cavities (c.pv) in the head, and the latter two cavities opening freely into the unpaired portion behind. At the junction of the paired cavities with the unpaired cavity are situated the generative organs $(g e)$. The inner wall of each of the paired cavities forms the splanchnopleuric mesoblast, and the outer wall of the whole the somatic mesoblast. The inner walls of the posterior cavities unite above and below the alimentary tract, and form the dorsal and ventral mesenteries, which divide the body cavity into two compartments in the adult. Before the hatching of the embryo takes place this mesentery is continued backwards so as to divide the primitively unpaired caudal part of the body cavity in the same way.

From the somatic mesoblast of the trunk is derived the single layer of longitudinal muscles of Sagitta, and part of the epithelioid lining of the body cavity. The anterior termination of the trunk division of the body cavity is marked in the adult by the mesentery dividing into two laminæ, which bend outwards to join the body wall.

The cephalic section of the body cavity seems to atrophy, and its walls to becomeconverted into the complicated system of muscles present in the head of the adult Sagitta.

In the presence of a section of the body cavity in the head the embryo of Sagitta resembles Lumbricus, Spiders, etc.

The generative rudiment of each side divides into an anterior and a posterior part

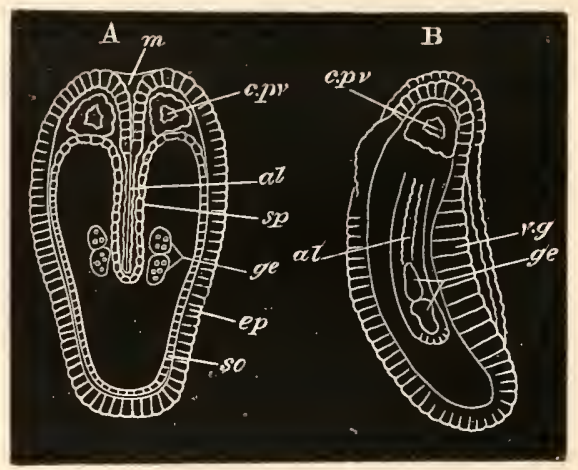

FIG. 165. TWO VIEWS OF A LATE EMBRYO OF SAGitTA. A. from the dorsal surface. B. from the side. (After Buitschli.)

$m$. mouth; al. alimentary canal; v.g. ventral ganglion (thickening of epiblast); $c p$. epiblast; c.pv. cephalic section of body cavity; so. somatopleure; $s p$. splanchnopleure; ge. generative organs. 
(fig. $165, g_{e}$ ). The former constitutes the ovary, and is situated in front of the septum dividing the tail from the body; and the latter, in the caudal region of the trunk, forms the testis.

The nervous system originates from the epiblast. There is a ventral thickening (fig. $165 \mathrm{~B}, a^{\prime}, g$ ) in the anterior region of the trunk, and a dorsal one in the head. The two are at first continuous, and on becoming separated from the epiblast remain united by thin cords.

The ventral ganglion is far more prominent during embryonic life than in the adult. Its position and early prominence in the embryo perhaps indicate that it is the homologue of the ventral cord of Chætopoda ${ }^{1}$.

\section{BIBLIOGRAPHY.}

(376) O. Biitschli. "Zur Entwicklungsgeschichte der Sagitta." Zeitschrift f. wiss. Zool., Vol. xxi11. 1873 .

(377) C. Gegenbaur. "Über die Entwicklung der Sagitta." Abhand. d. naturforschenden Gesellschaft in Halle, 1857 .

(378) A. Kowalevsky. "Embryologische Studien an Würmern u. Arthropoden." Mém. Acad. Pétersbourg, viı. sér., Tom. xvi., No. I2. is 7 I.

\section{MYZOSTOMEA.}

The development of these peculiar parasites on Crinoids has been investigated by Metschnikoff (No. 380), Semper (No. 381), and Graff (No. 379).

The segmentation is unequal, and would appear to be followed by an epibolic invagination. The outer layer of cells (epiblast) becomes covered with cilia, and the inner is transformed into a non-cellular (?) central yolk mass. At this stage the larva is hatched, and commences to lead a free existence. In the next stage observed by Metschnikoff, the mouth, csophagus, stomach, and anus had become developed; and two pairs of feet were present. In both of these feet Chætopod-like setæ were present, which in the hinder pair were simple fine bristles without a terminal hook. The papilliform portion of the foot is at first undeveloped. The feet become successively added, like Chætopod segments, and the stomach does not become dendriform till the whole complement of feet ( 5 pairs) are present.

In the primitive covering of cilia, combined with a subsequent indication

' Langerhans has recently made some important investigations on the nervous system of Sagitta, and identifies the ventral ganglion with the parieto-splanchnic ganglia of Molluscs, while he has found a pair of new ganglia, the development of which is unknown, which he calls the subesophageal or pedal ganglia. The embryological facts do not appear to be in favour of these interpretations.

B. II. 
of segments in the formation of the feet and setæ, the larva of the Myzostomea shews an approximation to the Chætopoda, and the group is probably to be regarded as an early Chrtopod type specially modified in connection with its parasitic habits.

\section{BIBLIOGRAPHY.}

(379) L. Graff. Das Genus Myzostoma. Leipzig, 1877 .

(380) E. Metschnikoff. "Zur Entwicklungsgeschichte d. Myzostomum." Zeit.f. wiss. Zool., Vol. xvi. 1866.

(381) C. Semper. "Z. Anat. u. Entwick. d. Gat. Myzostomum." Zeit.f. wiss. Zool., Vol. IX. is 858 .

\section{GASTROTRICHA.}

A few observations of Ludwig on the winter eggs of Ichthydium larus shew that the segmentation is a total and apparently a regular one. It leads to the formation of a solid morula. The embryo has a ventral curvature, and the caudal forks are early formed as cuticular structures. By the time the embryo leaves the egg, it has almost reached the adult state. The ventral cilia arise some little time prior to the hatching.

\section{BIBLIOGRAPHY.}

(382) H. Ludwig. "Ueber die Ordnung Gastrotricha Metschn." Zeit. f. wiss. Zool., Vol. Xxvi. $\quad$ i 876 . 


\section{CHAPTER XVI.}

\section{NEMATELMINTHES AND ACANTHOCEPHALA.}

\section{NeMatelminthes ${ }^{1}$.}

Nematoidea. Although the ova of various Nematodes have formed some of the earliest, as well as the most frequent objects of embryological observation, their development is still but very imperfectly known. Both viviparous and oviparous forms are common, and in the case of the oviparous forms the eggs are usually enveloped in a hard shell. The segmentation is total and nearly regular, though the two first segments are often unequal. The relation of the segmentation spheres to the germinal layers is however only satisfactorily established (through the researches of Bütschli (No. 383)) in the case of Cucullanus elegans, a form parasitic in the Perch".

The early development of this embryo takes place within the body of the parent, and the egg is enveloped in a delicate membrane. After the completion of the early stages of segmentation the embryo acquires the form of a thin flat plate composed of two layers of cells (fig. I66 A and B). The two layers of this plate give rise respectively to the epiblast and hypoblast, and at a certain stage the hypoblastic layer ceases to

1 The following classification of the Nematoda is employed in this chapter:
I. Nematoidea. $\left\{\begin{array}{l}\text { Ascaridæ. } \\ \text { Strongylidx. } \\ \text { Trichinidx. } \\ \text { Filaridæ. } \\ \text { Nermithidæ. } \\ \text { Anguillulidæ. }\end{array}\right.$
II. Gordioidea.
III. Chætosomoidea.

2 The ova of Anguillula aceti are stated by Hallez to undergo a similar development to those of Cucullanus. 
grow, while the growth of the epiblastic layer continues. As a consequence of this the sides of the plate begin to fold over towards the side of the hypoblast (fig. I66 D.) This folding results in the formation of a remarkably constituted gastrula, which has the form of a hollow two-layered cylinder with an incompletely closed slit on one side (fig. I $66 \mathrm{E}, b l . p$ ). This slit has the value of a blastopore. It becomes closed by the coalescence of the two edges, a process which commences posteriorly,

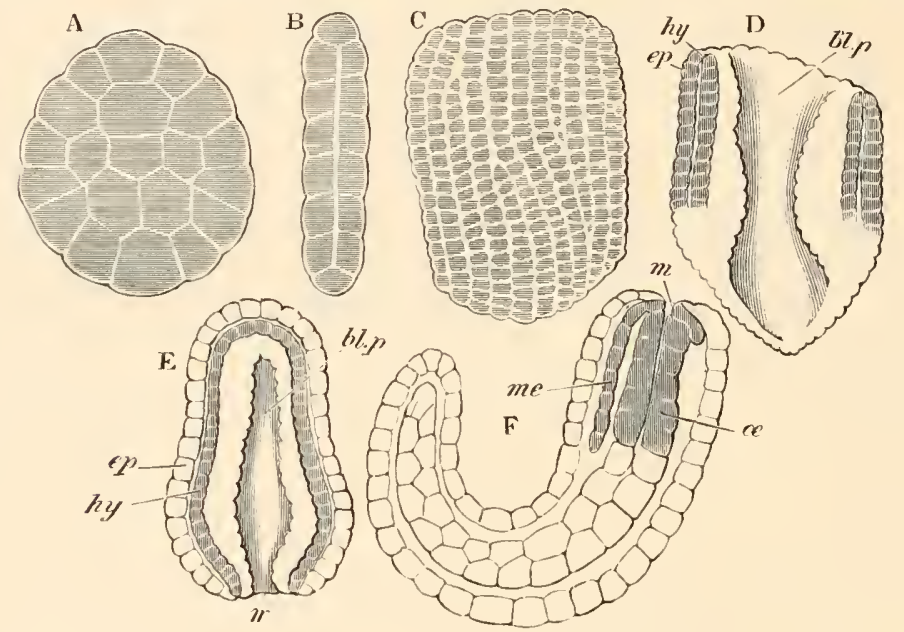

Fig. i66. Various stages in the development of Cucullanus elegans. (From Bütschli.)

A. Surface view of flattened enbryo at an early stage in the segmentation.

B. Side view of an embryo at a somewhat later stage, in optical section.

C. Flattened embryo at the completion of segmentation.

D. Embryo at the commencement of the gastrula stage.

E. Embryo when the blastopore is reduced to a mere slit.

F. Vermiform embryo after the division of the alimentary tract into œesophageal and glandular divisions.

$m$. mouth; ep. epiblast ; hy. hypoblast ; me. mesoblast ; $\alpha$. cesophagus; bl.p. blastopore.

and then gradually extends forwards. In front the blastopore never becomes completely closed, but remains as the permanent mouth. The embryo after these changes has a worm-like form, which becomes the more obvious as it grows in length and becomes curved (fig. I66 F).

The hypoblast of the embryo gives rise to the alimentary 
canal, and soon becomes divided into an œesophageal section (fig. I66 F, a) formed of granular cells, and a posterior division formed of clear cells. The mesoblast (fig. I66, me) takes its origin from certain special hypoblast cells around the mouth, and thence grows backwards towards the posterior end of the body.

The young Cucullanus becomes hatched while still in the generative ducts of its parent, and is distinguished by the presence of a remarkable thread-like tail. On the dorsal surface is a provisional boring apparatus in the form of a conical papilla. A firm cuticle enveloping the body is already present. In this condition it leaves its parent and host, and leads for a time a free existence in the water. Its metamorphosis is dealt with in another section.

The ova of the Oxyuridæe parasitic in Insects are stated by Galeb (No. 386) to take the form of a blastosphere at the close of segmentation. An inner layer is then formed by delamination. What the inner layer gives rise to is not clear, since the whole alimentary canal is stated to be derived from two buds, which arise at opposite ends of the body, and grow inwards till they meet.

The generative organs. The study of the development of the generative organs of Nematodes has led to some interesting results. In the case of both sexes the generative organs originate (Schneider, No. 390) from a single cell. This cell elongates and its nuclei multiply. After assuming a somewhat columnar form, it divides into ( $\mathrm{I}$ ) a superficial investing layer, and (2) an axial portion.

In the female the superficial layer is only developed distinctly in the median part of the column. In the course of the further development the two ends of the column become the blind ends of the ovary, and the axial tissue they contain forms the germinal tissue of nucleated protoplasm. The superficial layer gives rise to the epithelium of the uterus and oviduct. The germinal tissue, which is originally continuous, is interrupted in the middle part (where the superficial layer gives rise to the uterus and oviduct), and is confined to the two blind extremities of the tube.

In the male the superficial layer, which gives rise to the epithelium of the vas deferens, is only formed at the hinder end of 
the original column. In other respects the development takes place as in the female.

Gordioidea. The ovum of Gordius undergoes a regular segmentation. According to Villot (No. 391) it forms at the close of segmentation a morula, which becomes two-layered by delamination. The embryo is at first spherical, but soon becomes elongated.

By an invagination at the anterior extremity the head is formed. It consists of a basal portion, armed with three rings of stylets, and a conical proboscis, armed with three large stylets. When the larva becomes free the head becomes everted, though it remains retractile. By the time the embryo is hatched a complete alimentary tract is formed with an oral opening at the end of the proboscis, and a subterminal ventral anal opening. It is divided into an œesophagus and stomach, and a large gland opens into it at the base of the proboscis.

The body has a number of transverse folds, which give it a ringed appearance.

\section{Metamorphosis and life history.}

Nematoidea. Although a large number of Nematodes have a free existence and simple life history, yet the greater number of known genera are parasitic, and undergo a more or less complicated metamorphosis ${ }^{1}$. According to this metamorphosis they may be divided into two groups (which by no means closely correspond with the natural divisions), viz. those which have a single host, and those with two hosts. Each of these main divisions may be subdivided again into two.

In the first group with one host the simplest cases are those in which the adult sexual form of parasite lays its eggs in the alimentary tract of its host, and the eggs are thence transported to the exterior. The embryo still in the egg, if favoured by sufficient warmth and moisture, completes its development up to a certain point, and, if then swallowed by an individual of the species in which it is parasitic in the adult condition, it is denuded of its shell by the action of the gastric juice, and develops directly into the sexual form.

Leuckart has experimentally established this metamorphosis in the case of Trichocephalus affinis, Oxyurus ambigua, and Heterakis vermicularis. The Oxyuridæ of Blatta and Hydrophilus have a similar life history

1 The following facts are mainly derived from Leuckart's exhaustive treatise (No. 388). 
(Galeb, No. 386), and it is almost certain that the metamorphosis of the human parasites, Ascaris lumbricoides and Oxyurus vermicularis, is of this nature.

A slightly more complicated metamorphosis is common in the genera Ascaris and Strongylus. In these cases the egg-shell is thin, and the embryo becomes free externally, and enjoys for a shorter or longer period a free existence in water or moist earth. During this period it grows in size, and though not sexual usually closely resembles the adult form of the permanently free genus Rhabditis. In some cases the free larva becomes parasitic in a freshwater Mollusc, but without thereby undergoing any change. It eventually enters the alimentary tract of its proper host and there become sexual.

As examples of this form of development worked out by Leuckart may be mentioned Dochmius trigonocephalus, parasitic in the dog, and Ascaris acuminata, in the frog. The human parasite Dochmius duodenale undergoes the same metamorphosis as Dochmius trigonocephalus.

A remarkable modification of this type of metamorphosis is found in Ascaris (Rhabdonema) nigrovenosa, which in its most developed condition is parasitic in the lungs of the frog (Metschnikoff, Leuckart, No. 388). The embryos pass through their first developmental phases in the body of the parent. They have the typical Rhabditis form, and make their way after birth into the frog's rectum. From this they pass to the exterior, and then living either in moist earth, or the feces of the frog, develop into a sexual form, but are very much smaller than in the adult condition. The sexes are distinct, and the males are distinguished from the females by their smaller size, shorter and rounded tails, and thinner bodies. The females have paired ovaries with a very small number of eggs, but the testis of the males is unpaired. Impregnation takes place in the usual way, and in summer time about four embryos are developed in each female, which soon burst their egg-capsules, and then move freely in the uterus. Their active movements soon burst the uterine walls, and they then come to lie freely in the body cavity. The remaining viscera of the mother are next reduced to a finely granular material, which serves for the nutrition of the young forms which continue to live in the maternal skin. The larvæ eventually become free, and though in many respects different from the parent form which gave rise to them, have nevertheless the Rhabditis form. They live in water or slime, and sometimes become parasitic in water-snails; in neither case however do they undergo important changes unless eventually swallowed by a frog. They then pass down the trachea into the lungs and there rapidly develop into the adult form. No separate males have been found in the lungs of the frog, but it has been shewn by Schneider (No. 390) that the so-called females are really hermaphrodites; the same gland giving origin 
to both spermatozoa and ova, the former being developed before the latter ${ }^{1}$. The remarkable feature of the above life history is the fact that in the stage corresponding with the free larval stage of the previous forms the larva of this species become sexual, and give rise to a second free larval generation, which develops into the adult form on again becoming parasitic in the original host. It constitutes a somewhat exceptional case of heterogamy as defined in the introduction.

Amongst the Nematodes with but a single host a remarkable parasite in wheat has its place. This form, known as Anguillula scandens, inhabits in the adult condition the ears of wheat, in which it lays its eggs. After hatching, the larvæ become encysted, but become free on the death of the plant. They now inhabit moist earth, but eventually make their way into the ears of the young wheat and become sexually mature.

The second group of parasitic Nematodes with two hosts may be divided into two groups, according to whether the larva has a free existence before passing into its first or intermediate host, or is taken into it while still in the egg. In the majority of cases the larval forms live in special connective tissue capsules, or sometimes free in the tissues of their intermediate hosts; but the adults, as in the cases of other parasitic Nematodes, inhabit the alimentary tract.

The life history of Spiroptera obtusa may be cited as an example of a Nematode with two hosts in which the embryo is transported into its intermediate host while still within the egg. The adult of this form is parasitic in the mouse, and the ova pass out of the alimentary tract with the excreta, and may commonly be found in barns, etc. If one of the ova is now eaten by the meal-worm (larva of Tenebrio), it passes into the body cavity of this worm and undergoes further development. After about five weeks it becomes encapsuled between the 'fat bodies' of the meal-worm. It then undergoes an ecdysis, and, if the meal-worm with its parasites is now eaten by the mouse, the parasites leave their capsule and develop into the sexual form.

As examples of life histories in which a free state intervenes before the intermediate host, Cucullanus elegans and Dracunculus may be selected. The adult Cucullanus elegans is parasitic in the alimentary tract of the Perch and other freshwater fishes. It is a viviparous form, and the young after birth pass out into the water. They next become parasitic in Cyclops, passing in through the mouth, so into the alimentary tract, and thence into the body cavity. They soon undergo an ecdysis, in the course of which the csophagus becomes divided into a muscular pharynx and true glandular

1 Leuckart does not appear to be satisfied as to the hermaphroditism of these forms; and holds that it is quite possible that the ova may develop parthenogenetically. 
œsophagus. They then grow rapidly in length, and at a second ecdysis acquire a peculiar beaker-like mouth cavity approaching that of the adult. They do not become encapsuled. No further development of the worm takes place so long as it remains in the Cyclops, but, if the Cyclops is now swallowed by a Perch, the worm undergoes a further ecdysis, and rapidly attains to sexual maturity.

The observations of Fedschenko on Dracunculus medinensis ${ }^{1}$, which is parasitic in the subcutaneous connective tissue in Man, would seem to shew that it undergoes a metamorphosis very similar to that of Cucullanus. There is moreover a striking resemblance between the larva of the two forms. The larva of Dracunculus become transported into water, and then make their way into the body cavity of a Cyclops by boring through the soft skin between the segments on the ventral surface of the body. In the body cavity the larvæ undergo an ecdysis and further development. But on reaching a certain stage of development, though they remain a long time in the Cyclops, they grow no further. The remaining history is unknown, but probably the next host is man, in which the larva comes to maturity. In the adult condition only females of Dracunculus are known, and it has been suggested by various writers that the apparent females are in reality hermaphrodites, like Ascaris nigrovenosa, in which the male organs come to maturity before the female.

Another very remarkable human parasite belonging to the same group as Dracunculus is the form known as Filaria sanguinis hominis, or Filaria Bancrofti ${ }^{2}$.

The sexual form is parasitic in warm climates in the human tissues, and produces multitudes of larve which pass into the blood, and are sometimes voided with the urine. The larva in the blood do not undergo a further development, and unless transported to an intermediate host die before very long. Some, though as yet hardly sufficient, evidence has been brought forward to shew that if the blood of an infected patient is sucked by a mosquito the larva develop further in the alimentary tract of the mosquito, pass through a more or less quiescent stage, and eventually grow considerably in size, and on the death of the mosquito pass into the water. From the water they are probably transported directly or indirectly into the human intestines, and then bore their way into the tissues in which they are parasitic, and become sexually mature.

The well-known Trichina spiralis has a life history unlike that of other known Nematodes, though there can be little doubt that this form should be classified in respect to its life history with the last described forms. The peculiarity of the life history of Trichina is that the embryos set free in the alimentary canal pass through the walls into the muscular tissues and there encyst; but do not in a general way pass out from the alimentary

1 Tïde Leuckart, D. men. Par., Vol. 1I. p. 704.

2 Vide D. P. Manson, "On the development of Filaria sanguinis hominis." Fournal of the Linnean Socity", Vol. xiv. No. 75. 
canal of one host and thence into a fresh host to encyst. It occasionally however happens that this inigration does take place, and the life history of Trichina spiralis then becomes almost identical with that of some of the forms of the third type. Trichina is parasitic in man, and in swine, and also in the rat, mouse, cat, fox and other forms which feed upon them. Artificially it can be introduced into various herbivorous forms (rabbit, guinea-pig, horse) and even birds.

The sexual form inhabits the alimentary canal. The female is viviparous, and produces myriads of embryos, which pass into the alimentary canal of their host, through the walls of which they make their way, and travelling along lines of connective tissue pass into the muscles. Here the embryos, which are born in a very imperfect condition, rapidly develop, and eventually assume a quiescent condition in a space inclosed by sarcolemma. Within the sarcolemma a firm capsule is developed for each larva, which after some months becomes calcified; and after the atrophy of the sarcolemma a connective tissue layer is formed around it. Within its capsule the larva can live for many years, even ten or more, witlout undergoing further development, but if at last the infected flesh is eaten by a suitable form, e.g. the infected flesh of the pig by man, the quiescent state of the larva is brought to a close, and sexual maturity is attained in the alimentary tract of the new host.

Gordioidea. The free larva of Gordius already described usually penetrates into the larva of Chironomus where it becomes encysted. On the Chironomus being eaten by some fish (Villot, No. 39) (Phoxinus lavis or Cobitis barbatula), it penetrates into the wall of the intestine of its second host, becomes again encysted and remains quiescent for some time. Eventually in the spring it leaves its capsule, and enters the intestine, and passes to the exterior with the freces. It then undergoes a gradual metamorphosis, in the course of which it loses its ringed structure and cephalic armature, grows in length, acquires its ventral cord, and on the development of the generative organs loses the greater part of its alimentary tract.

Young examples of Gordius have often been found in various terrestrial carnivorous Insecta, but the meaning of this fact is not yet clear.

\section{BibliogRAPHY̌.}

(383) O. Biitschli. "Entwicklungsgeschichte d. Cucullanus elegans." Zeit.f. wiss. Zool., B. xxvr. 1876 .

(384) T. S. Cobbold. Entozoa. Groombridge and Son, 1864.

(385) T. S. Cobbold. Parasites; A Treatise on the Entozoa of Man and Animals. Churchill, 1879 .

(386) O. Galeb. "Organisation et développement des Oxyuridés," \&c. Archives de Zool. expér. et génér., Vol. vil. 1878 .

(387) R. Leuckart. Untorsuchungen üb. Trichina spiralis. 2nd ed. Leipzig, I 866.

(388) R. Leuckart. Die menschlichon Parasitcn, Bd. 1s. 1876. 
(389) H. A. Pagenstecher. Die Trichinen nach Versuchen dargestellt. Leipzig, 1865 .

(390) A. Schneider. Monographie d. Nematoden. Berlin, 1866.

(391) A. Villot. "Monographie des Dragoneaux" (Gordioidea). Archives de Zool. expér. et génér., Vol. III. I8it.

\section{ACANTHOCEPIIALA.}

The Acanthocephala appear to be always viviparous. At the time of impregnation the ovum is a naked cell, and undergoes in this condition the earlier phases of segmentation.

The segmentation is unequal (Leuckart, No. 393), but whether there is an epibolic gastrula has not clearly been made out.

Before segmentation is completed there are formed round the ovum thick protecting membranes, which are usually three in number, the middle one being the strongest. After segmentation the central cells of the ovum fuse together to give rise to a granular mass, while the peripheral cells at a slightly later period form a more transparent syncytium. At the anterior end of the embryo there appears a superficial cuticle bearing in front a ring of hooks.

The embryo is now carried out with the excreta from the intestine of the vertebrate host in which its parent lives. It is then swallowed by some invertebrate host ${ }^{1}$.

In the intestine of the invertebrate host the larva is freed from its membranes, and is found to have a somewhat elongated conical form, terminating anteriorly in an obliquely placed disc, turned slightly towards the ventral surface and armed with hooks. Between this disc and the granular mass, already described as formed from the central cells of the embryo, is a rather conspicuous solid body. Leuckart supposes that this body may represent a rudimentary functionless pharynx, while the granular mass in his opinion is an equally rudimentary and functionless intestine. The body wall is formed of a semifluid internal layer surrounding the rudimentary intestine, if such it be, and of a firmer outer wall immediately within the cuticle.

The adult Echinorhyncus is formed by a remarkable process of development within the body of the larva, and the skin is the only part of the larva which is carried over to the adult.

In Echinorhyncus proteus the larva remains mobile during the formation of the adult, but in other forms the metamorphosis takes place during a quiescent condition of the larva.

The organs of the adult are differentiated from a mass of cells which appears to be a product of the central embryonic granular mass, and is

1 Echin. proteus, which is parasitic in the adult state in many freshwater fish, passes through its larval condition in the body cavity of Gammarus pulex. Ech. angustatus, parasitic in the Perch, is found in the larval condition in the body cavity of Asellus aquaticus. Ech. gigas, parasitic in swine, is stated by Schneider (No. 394) to pass through its larval stages in maggots. 
called by Leuckart the embryonic nucleus. The embryonic nucleus becomes divided into four linearly arranged groups of cells, of which the hindermost but one is the largest, and very early differentiates itself into ( $\mathrm{I}$ ) a peripheral layer, and (2) a central mass formed of two distinct bodies. The peripheral layer of this segment grows forwards and backwards, and embraces the other segments, with the exception of the front end of the first one which is left uncovered. The envelope so formed gives rise to the splanchnic and somatic mesoblast of the adult worm. Of the four groups of cells within it the anterior gives rise to the proboscis, the next to the nerve ganglion, the third, formed of two bodies, to the paired generatives, and the fourth to the generative ducts. The whole of the above complex rapidly elongates, and as it does so the enveloping membrane becomes split into two layers; of which the outer forms the muscular wall of the body (somatic mesoblast), and the inner the muscular sheath of the proboscis and the so-called generative ligament enveloping the generative organs. The inner layer may be called the splanchnic niesoblast in spite of the absence of an intestine. The cavity between the two mesoblastic layers forms the body cavity.

The various parts of the adult continue to differentiate themselves as the whole increases in size. The generative masses very early shew traces of becoming differentiated into testes or ovaries. In the male the two generative masses remain spherical, but in the female become elongated: the rudiment of the generative ducts becomes divided into three sections in both sexes. The most remarkable changes are, however, those undergone by the rudiment of the proboscis.

In its interior there is formed a cavity, but the wall bounding the front end of the cavity soon disappears. By the time that this has taken place the body of the adult completely fills up the larval skin, to which it very soon attaches itself. The hollow rudiment of the proboscis then becomes everted, and forms a papilla at the end of the body, immediately adjoining the larval skin. This papilla, with the larval skin covering it, constitutes the permanent proboscis. The original larval cuticle is either now or at an earlier period thrown off and a fresh cuticle developed. The hooks of the proboscis are formed from cells of the above papilla, which grow through the larval skin as conical prominences, on the apex of which a chitinous hook is modelled. The remainder of the larval skin forms the skin of the adult, and at a later period develops in its deeper layer the peculiar plexus of vessels so characteristic of the Acanthocephala. The anterior oval appendages of the adult cutis, known as the lemnisci, are outgrowths from the larval skin.

The Echinorhyncus has with the completion of these changes practically acquired its adult structure; but in the female the ovaries undergo at this period remarkable changes, in that they break up into a number of spherical masses, which lie in the lumen of the generative ligaments, and also make their way into the body cavity.

The young Echinorhyncus requires to be transported to its permanent host, which feeds on its larval host, before attaining to sexual maturity. 


\section{BIBLIOGRAPHY.}

(392) R. Greeff. "Untersuchungen ii. d. Bau u. Entwicklung des Echin. miliarius." Archio f. Naturgesch. is $86_{4}$.

(393) R. I,euckart. Die menschlichion Parasiten. Vol. 11. p. Sor et seq. I $8 ; 6$.

(391) An. Schneider. "Ueb. d. Bau d. Acanthocephalen." Archiof. Anat. u. Phys. I 868 .

(395) G. R. Wagener. Buträger z. Entwicklungsgeschichte d. Eingezweidewürmer. Haarlem, 1865. 


\section{CHAPTER XVII.}

TRACHEATA.

\section{PROTOTRACHEATA.}

THE remarkable researches of Moseley (No. 396) on Peripatus

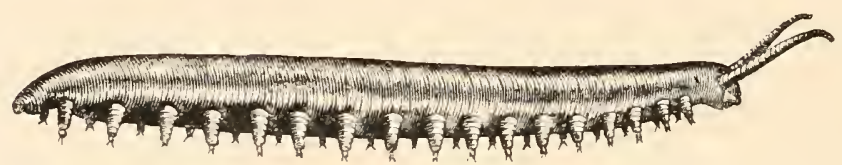

Fig. i67. Adult example of Peripatus capensis, natural size.

(From Moseley.)

capensis have brought clearly to light the affinities of this form with the tracheate Arthropoda; and its numerous primitive
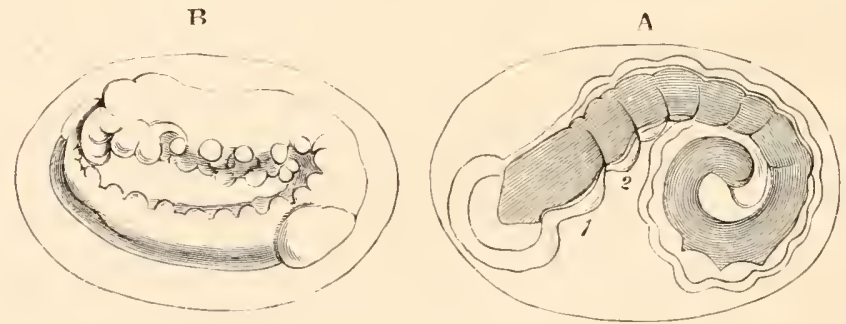

Fig. 168. Two stages in the development of Peripatus capensis.

(After Moseley.)

A. Youngest stage hitherto observed before the appearance of the legs.

B. Later stage after the legs and antennæ have become developed.

Both figures represent the larva as it appears within the egg.

I and 2. First and second post-oral appendages.

characters, such as the generally distributed tracheal apertures, the imperfectly segmented limbs, the diverging ventral nerve 
cords with imperfectly marked ganglia, and the nephridia (segmental organs ${ }^{1}$ ), would render its embryology of peculiar interest. Unfortunately Moseley was unable, from want of material, to make so complete a study of its development as of its anatomy. The youngest embryo observed was in part distinctly segmented, and coiled up within the egg (fig. I68 A). The procephalic lobes resemble those of the Arthropoda generally, and are unlike the præ-oral lobe of Chætopods or Discophora. They are not marked off by a transverse constriction from the succeeding segments. The three embryonic layers are differentiated, and the interior is filled with a brownish mass - the remnant of the yolk-which is probably enclosed in a distinct intestinal wall, and is lobed in correspondence with the segmentation of the body. The mouth invagination is not present, and but two pairs of slight prominences mark the rudiments of the two anterior post-oral appendages.

The single pair of antenne is formed in the next stage, and is followed by the remaining post-oral appendages, which arise in succession from before backwards somewhat later than the segments to which they appertain.

The posterior part of the embryo becomes uncoiled, and the whole embryo bent double in the egg (fig. I68 B).

The mouth appears as a slit-like opening between and below the procephalic

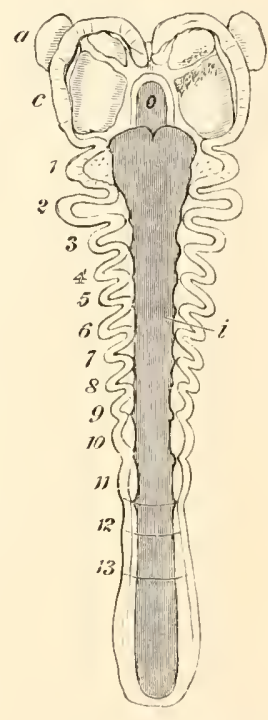

Fig. 169. Embryo of Peripatus capensis. Slightly older than A in fig. 168 ; unrolled. (After Moseley.)

$a$. antennx; $o$. mouth ; $i$. intestine; $c$. procephalic lohe. I, 2,3 , etc., postoral appendages. lobes. On each side and somewhat behind it there grows out an appendage-the first post-oral pair (fig. I69, I)-while in front and behind it are formed the upper and lower lips. These two appendages next turn inwards towards the mouth, and their

1 F. M. Balfour, "On certain points in the Anatomy of Peripatus capensis." Quart. Foum. of Micros. Science, Vol. x1x. I879. 
bases become gradually closed over by two processes of the procephalic region (fig. I $70, m$ ) The whole of these structures assist in forming a kind of secondary mouth cavity, which is at a later period further completed by the processes of the procephalic region meeting above the mouth, covering over the labrum, and growing backwards to near the origin of the second pair of post-oral appendages.

The antennæ early become jointed, and fresh joints continue to be added throughout embryonic life; in the adult there are present fully thirty

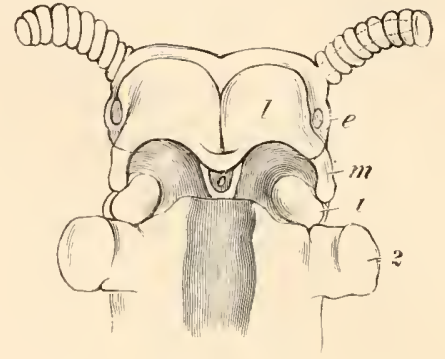

Fig. 170. VENTRAL VIEW OF THE HEAD OF AN FMBRYO OF PERIPATUS CAPENSIS AT A LATE STAGE OF DEVELOPMENT,

l. thickening of epiblast of procephalic lobe to form supra-œesophageal ganglion; $m$. process from procephalic lobe growing over the first post-oral appendage ; 0 . mouth; $e$. eye; 1 and 2 , first and second pair of post-oral appendages. joints. It appears to me probable (though Mr Moseley takes the contrary view) from the late development of the paired processes of the procephalic lobes, which give rise to the circular lip of the adult, that they are not true appendages. The next pair therefore to the antenna is the first post-oral pair. It is the only pair connected with the mouth. At their extremities there is formed a pair of claws similar to those of the ambulatory legs (fig. I7I). The next and largest pair of appendages in the embryo are the oral papilla. They are chiefly remarkable for

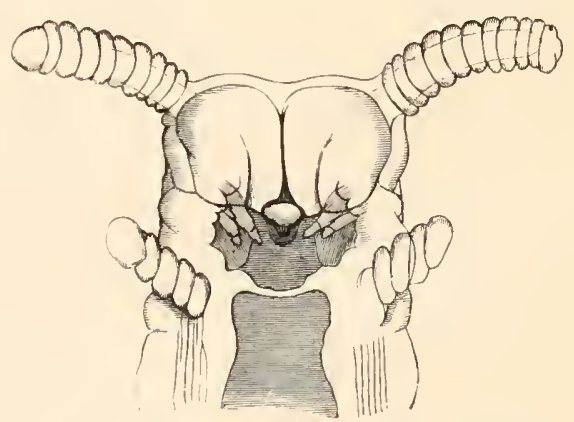

Fig. i71. Head of an enibryo PeripaTUS. (From Moseley.)

The figure shews the jaws (mandibles), and close to them epiblastic involutions, which grow into the supra-œesophageal ganglia. The antennæe, oral cavity, and oral papillæ are also shewn. containing the ducts of the slime glands which open at their bases. They are without claws. The succeeding appendages become eventually imperfectly five-jointed; two claws are 
formed as cuticular investments of papillæ in pockets of the skin at the ends of their terminal joints.

I have been able to make a few observations on the internal structure of the embryos from specimens supplied to me by Moseley. These are so far confined to a few stages, one slightly earlier, the others slightly later, than the embryo represented in fig. $168 \mathrm{~B}$. The epiblast is formed of a layer of columnar cells, two deep on the ventral surface, except along the median line where there is a well-marked groove and the epiblast is much thinner (fig. 172).

The ventral cords of the trunk are formed as two independent epiblastic thickenings. In my earlier stage these are barely separated from the epiblast, but in the later ones are quite independent (fig. 172, v.n), and partly surrounded by mesoblast.

The supra-œsophageal ganglia are formed as thickenings of the epiblast of the ventral side of the procephalic lobes in front of the stomodæum. They are shewn at $l$ in fig. 170. The thickenings of the two sides are at first independent. At a somewhat later period an invagination of the epiblast grows into each of these lobes. The openings of these invaginations extend from the oral cavity forwards; and they are shewn in fig. $17 \mathbf{I}^{1}$. Their openings become closed, and the walls of the invaginations constitute a large part of the embryonic supra-œsophageal ganglia.

Similar epiblastic invaginations assist in forming the supra-œsophageal ganglia of other Tracheata. They are described in the sequel for Insects, Spiders and Scorpions. The position of the supraœsophageal ganglia on the ventral side of the procephalic lobes is the same as that in other Tracheata.

The mesoblast is formed, in the earliest of my embryos, of scattered cells in the fairly wide space between the mesenteron and the epiblast. There are two distinct bands of mesoblast on the outer sides of the nervous cords. In the later stage the mesoblast is divided into distinct somatic and splanchnic layers, both very thin; but the two layers are connected by transverse strands (fig. I72). There

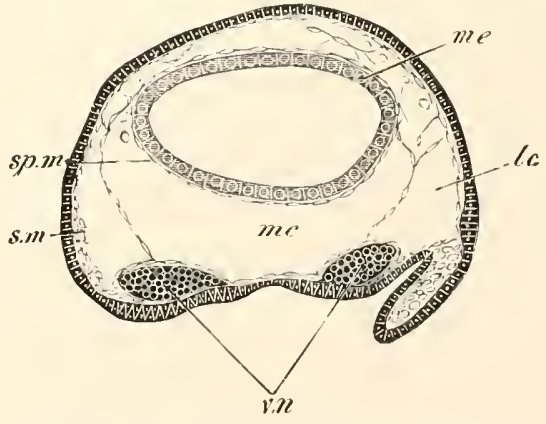

Fig. 172. Section through the trunk of an embryo of Peripatus. The embryo from which the section is taken was somewhat younger than fig. $17 \mathrm{r}$.

3 This figure is taken from Moseley. The epiblastic invaginations are represented in it very accurately, and though not mentioned in the text of the paper, Moseley informs me that he has long been aware of the homology of these folds with those in various other Tracheata. 
are tivo special longitudinal septa dividing the body cavity into three compartments, a median ( $m c)$, containing the mesenteron, and two lateral (lc) containing the nerve cords. This division of the body cavity persists, as I have elsewhere shewn, in the adult. A similar division is found in some Chætopoda, e.g. Polygordius.

I failed to make out that the mesoblast was divided into somites, and feel fairly confident that it is not so in the stages I have investigated.

There is a section of the body cavity in the limbs as in embryo Myriapods, Spiders, etc.

In the procephalic lobe there is a well-developed section of the body cavity, which lies dorsal to and in front of the rudiment of the supraœsophageal ganglia.

The alimentary tract is formed of a mesenteron (fig. I72), a stomodæum, and proctodæum. The wall of the mesenteron is formed, in the stages investigated by me, of a single layer of cells with yolk particles, and encloses a lumen free from yolk. The forward extension of the mesenteron is remarkable.

The stomodæum in the earlier stage is a simple pit, which meets but does not open into the mesenteron. In the later stage the external opening of the pit is complicated by the structures already described. The proctodæum is a moderately deep pit near the hinder end of the body.

The existence of a tracheal system ${ }^{1}$ is in itself almost sufficient to demonstrate the affinities of Peripatus with the Tracheata, in spite of the presence of nephridia. The embryological characters of the procephalic lobes, of the limbs and claws, place however this conclusion beyond the reach of scepticism. If the reader will compare the figure of Peripatus with that of an embryo Scorpion (fig. I96 A) or Spider (fig. 200 C) or better still with Metschnikoff's figure of Geophilus (No. 399) Pl. XxI. fig. I I, he will be satisfied on this point.

The homologies of the anterior appendages are not very easy to determine; but since there does not appear to me to be sufficient evidence to shew that any of the anterior appendages have become aborted, the first post-oral appendages embedded in the lips may provisionally be regarded as equivalent to the mandibles, and the oral papillæ to the first pair of maxillæ, etc. Moseley is somewhat doubtful about the homologies of the appendages, and hesitates between considering the oral papillæ as equivalent to the second pair of maxillæ (on account of their containing the openings of the mucous glands, which he compares with the spinning glands of caterpillars), or to the poison claws (fourth

1 The specimens shewing tracheæ which Moseley has placed in my hands are quite sufficient to leave no doubt whatever in my mind as to the general accuracy of his description of the tracheal system. 
post-oral appendages) of the Chilopoda (on account of the poison-glands which he thinks may be homologous with the mucous glands).

The arguments for either of these views do not appear to me conclusive. There are glands opening into various anterior appendages in the Tracheata, such as the poison glands in the Cheliceræ (mandibles) of Spiders, and there is some evidence in Insects for the existence of a gland belonging to the first pair of maxillæ, which might be compared with the mucous gland of Peripatus. For reasons already stated I do not regard the processes of the cephalic lobes, which form the lips, as a pair of true appendages.

\section{BIBLIOGRAPHY.}

(396) H. N. Moseley. "On the Structure and Development of Peripatus capensis." Phil. Trans. Vol. $164,1874$.

\section{MYRIAPODA ${ }^{1}$.}

Chilognatha. The first stages in the development of the Chilognatha have been investigated by Metschnikoff and Stecker, but their accounts are so contradictory as hardly to admit of reconciliation.

According to Metschnikoff, by whom the following four species have been investigated, viz., Strongylosoma Guerinii, Polydesmus complanatus, Polyxenus lagurus, and Julus Moneletei, the segmentation is at first regular and complete, but, when the segments are still fairly large, the regular segmentation is supplemented by the appearance of a number of small cells at various points on the surface, which in time give rise to a continuous blastoderm.

The blastoderm becomes thickened on the ventral surface, and so forms a ventral plate ${ }^{2}$.

1 The classification of the Myriapoda employed in the present section is

I. Chilognatha. (Millipedes.)

II. Chilopoda. (Centipedes.)

2 Stecker's (No. 400) observations were made on the eggs of Julus fasciatus, Julus foetidus, Craspedosoma marmoratum, Polydesmus complanatus, and Strongylosoma pallipes, and though carried on by means of sections, still leave some points very obscure, and do not appear to me deserving of much confidence. The two species of Julus and Craspedosoma undergo, according to Stecker, a nearly identical development. The egg before segmentation is constituted of two substances, a central protoplasmic, and a peripheral deutoplastic. It first divides into two equal segments, and coincidentally with their formation part of the central protoplasm travels to the 

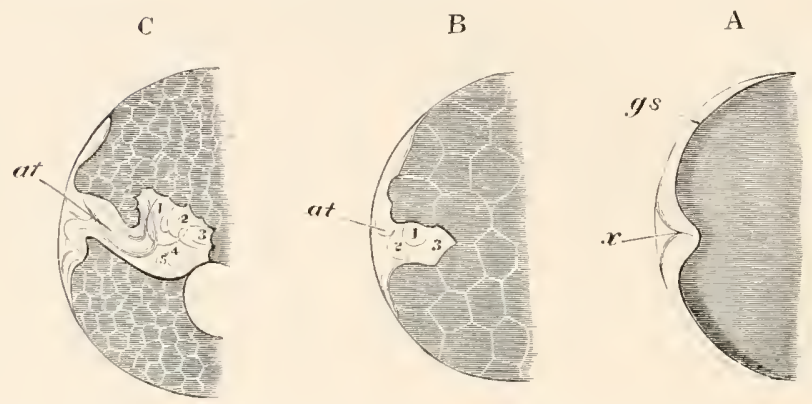

Fig. 173. Three Stages in the development of Strongylosoma Guerini. (After Metschnikoff.)

A. Embryo on eleventh day with commencing ventral flexure $(x)$.

B. Embryo with three pairs of post-oral appendages.

C. Embryo with five pairs of post-oral appendages.

gs. ventral plate; at. antennx; $1-5$ post-oral appendages; $x$. point of flexure of the ventral plate.

surface as two clear fluid segments. The ovum is thus composed of two yolk segments to two protoplasmic segments. The two former next divide into four, with the production of two fresh protoplasmic segments. The four protoplasmic segments now constitute the upper or animal pole of the egg, and occupy the position of the future ventral plate. The yolk segments form the lower pole, which is however dorsal in relation to the future animal. The protoplasmic segments increase in number by a regular division, and arrange themselves in three rows, of which the two outermost rapidly grow over the yolk segments. A large segmentation cavity is stated to be present in the interior of the ovum.

It would appear from Stecker's description that the yolk segments (hypoblast) next become regularly invaginated, so as to enclose a gastric cavity, opening externally by a blastopore; but it is difficult to believe that a typical gastrula, such as that represented by Stecker, really comes into the cycle of development of the Chilognatha.

The mesoblast is stated to be derived mainly from the epiblast. This layer in the region of the future ventral plate becomes reduced to two rows of cells, and the inner of these by the division of its constituent elements gives rise to the mesoblast. The development of Polydesmus and Strongylosoma is not very different from that of Julus. The protoplasm at the upper pole occupies from the first a superficial position. Segmentation commences at the lower pole, where the food yolk is mainly present ! The gastrula is stated to be similar to that of Julus. The mesoblast is formed in Polydesmus as a layer of cells split off from the epiblast, but in Strongylosoma as an outgrowth from the lips of the blastopore. Stecker, in spite of the statements in his paper as to the origin of the mesoblast from the epiblast, sums up at the end to the effect that both the primary layers have a share in the formation of the mesoblast, which originates by a process of endogenous cell-division!

It may be noted that the closure of the blastopore takes place, according to Stecker, on the dorsal side of the embryo. 
The most important sources of information for the general embryology of the Chilognatha are the papers of Newport (No. 397) and Metschnikoff (No. 398). The development of Strongylosoma may be taken as fairly typical for the group; and the subsequent statements, unless the reverse is stated, apply to the species of Strongylosoma investigated by Metschnikoff.

After the segmentation and formation of the layers the first observable structure is a transverse furrow in the thickening of the epiblast on the ventral surface of the embryo. This furrow rapidly deepens, and gives rise to a ventral flexure of the embryo (fig. I7 $3 \mathrm{~A}, x$ ), which is much later in making its appearance in Julus than in Strongylosoma and Polyxenus. A pair of appendages, which become the antennæ, makes its appearance shortly after the formation of the transverse furrow, and there soon follow in order the next three pairs of appendages. All these parts are formed in the infolded portion of the ventral thickening of the blastoderm (fig. I73 B). The ventral thickening has in the meantime become marked by a longitudinal furrow, but whether this is connected with the formation of the nervous system, or is equivalent to the mesoblastic furrow in Insects, and connected with the formation of the mesoblast, has not been made out. Shortly after the appearance of the three pairs of appendages behind the antennæ two further pairs become added, and at the same time oral and anal invaginations become formed (fig. I73 C). In front of the oral opening an unpaired upper lip is developed. The præ-oral part of the ventral plate develops into the bilobed procephalic lobes, the epiblast of which is mainly employed in the formation of the supra-cesophageal ganglia. The next important change which takes place is the segmentation of the body of the embryo (fig. I74 A), the most essential feature in which is the division of the mesoblast into somites. Segments are formed in order from before backwards, and soon extend to the region behind the appendages. On the appearance of segmentation the appendages commence to assume their permanent form. The two anterior pairs of post-oral appendages become jaws; and the part of the embryo which carries them and the antennæ is marked off from the trunk as the head. The three following pairs of appendages grow in length and assume a form suited for locomotion. Behind 
the three existing pairs of limbs there are developed three fresh pairs, of which the two anterior belong to a single primitive segment. While the above changes take place in the appendages the embryo undergoes an ecdysis, which gives rise to a cuticular membrane within the single egg-membrane (chorion, Metschnikoff). On this cuticle a tooth-like process is developed, the function of which is to assist in the hatching of the embryo (fig. I $74 \mathrm{~A}$ ).

In Polyxenus a cuticular membrane is present as in Strongylosoma, but it is not provided with a tooth-like process. In the same form amœboid cells separate themselves from the blastoderm at an early period. These cells have been compared to the embryonic envelopes of Insects described below.

In Julus two cuticular membranes are present at the time of hatching: the inner one is very strongly developed and encloses the embryo after hatching. After leaving the chorion the embryo Julus remains connected with it by a structureless membrane which is probably the outer of the two cuticular membranes.

At the time when the embryo of Strongylosoma is hatched (fig. I74 B) nine post-cephalic segments appear to be present.

A

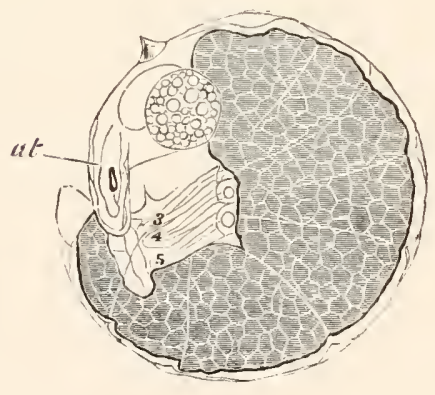

B

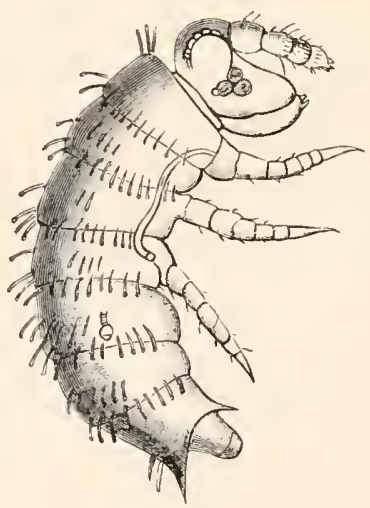

Fig. I74. Two stages in the Development of Strongylosoma Guerinil. (After Metschnikoff.)

A. A seventeen days' embryo, aiready segmented.

B. A just-hatched larva.

Of these segments the second is apparently (from Metschnikoff's figure, I74 B) without a pair of appendages; the third and 
fourth are each provided with a single functional pair of limbs; the fifth segment is provided with two pairs of rudimentary limbs, which are involuted in a single sack and not visible without preparation, and therefore not shewn in the figure. The sixth segment is provided with but a single pair of appendages, though a second pair is subsequently developed on it $^{1}$.

Julus, at the time it leaves the chorion, is imperfectly segmented, but is provided with antennæ, mandibles, and maxillæ, and seven pairs of limbs, of which the first three are much more developed than the remainder. Segmentation soon makes its appearance, and the head becomes distinct from the trunk, and on each of the three anterior trunk segments a single pair of limbs is very conspicuous (Metschnikoff) ${ }^{2}$. Each of the succeeding segments bears eventually two pairs of appendages. At the time when the inner embryonic cuticle is cast off, the larva appears to be hexapodous, like the young Strongylosoma, but there are in reality four pairs of rudimentary appendages behind the three functional pairs. The latter only appear on the surface after the first post-embryonic ecdysis. Pauropus (Lubbock) is hexapodous in a young stage. At the next moult two pairs of appendages are added, and subsequently one pair at each moult.

There appear to be eight post-oral segments in Julus at the time of hatching. According to Newport fresh segments are added in post-embryonic life by successive budding from a blastema between the penultimate segment and that in front of it. They arise in batches of six at the successive ecdyses, till the full number is completed. A functional, though not a real hexapodous condition, appears to be characteristic of Chilognatha generally at the time of hatching.

The most interesting anatomical feature of the Chilognatha is the double character of their segments, the feet (except the first three or four, or more), the circulatory, the respiratory, and the nervous systems shewing this peculiarity. Newport's and

1 Though the superficially hexapodous larva of Strongylosoma and other Chilognatha has a striking resemblance to some larval Insects, no real comparison is possible between them, even on the assumption that the three functional appendages of both are homologous, because Embryology clearly proves that the hexapodous Insect type has originated from an ancestor with numerous appendages by the atrophy of those appendages, and not from an hexapodous larval form prior to the development of the full number of adult appendages.

2 Newport states however that a pair of limbs is present on the first, second, and fourth post-oral segments, but that the third segment is apodous; and this is undoubtedly the case in the adult. 
Metschnikoff's observations have not thrown as much light on the nature of the double segments as might have been hoped, but it appears probable that they have not originated from a fusion of two primitively distinct segments, but from a later imperfect division of each of the primitive segments into two, and the supply to each of the divisions of a primitive segment of a complete set of organs.

Chilopoda. Up to the present time the development of only one type of Chilopoda, viz. that of Geophilus, has been worked out. Most forms lay their eggs, but Scolopendra is viviparous.
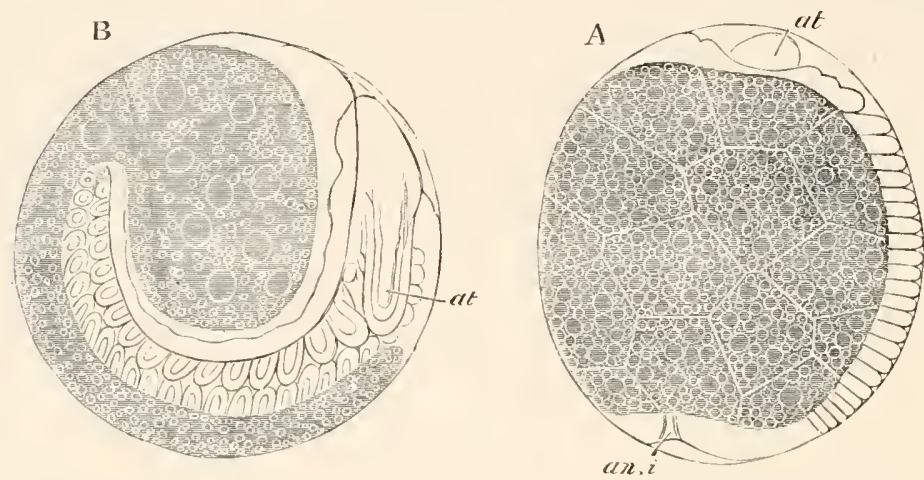

Fig. I75. Two stages in the development of Geophilus.

(After Metschnikoff.)

A. Side-view of embryo at the stage when the segments are beginning to be formed.

B. Later stage after the appendages have become established. at. antennæ; an.i. proctodæum.

The segmentation appears to resemble that in the Chilognatha, and at its close there is present a blastoderm surrounding a central mass of yolk cells. A ventral thickening of the blastoderm is soon formed. It becomes divided into numerous segments, which continue to be formed successively from the posterior unsegmented part. The antennæ are the first appendages to appear, and are well developed when eighteen segments have become visible (fig. I75 A). The post-oral appendages are formed slightly later, and in order from before backwards. As the embryo grows in length, and fresh segments continue to be formed, the posterior part of it becomes bent over so as to face the ventral surface of the anterior, and it acquires an 
appearance something like that of many embryo Crustaceans (fig. 175 B). Between forty and fifty segments are formed while the embryo is still in the egg. The appendages long remain unjointed. The fourth post-oral appendage, which becomes the poison-claw, is early marked out by its greater size: on the third post-oral there is formed a temporary spine to open the egg membrane.

It does not appear, from Metschnikoff's figures of Geophilus, that any of the anterior segments are without appendages, and it is very probable that Newport is mistaken in supposing that the embryo has a segment without appendages behind that with the poison claws, which coalesces with the segment of the latter. It also appears to me rather doubtful whether the third pair of post-oral appendages, i.e. those in front of the poison-claws, can fairly be considered as forming part of the basilar plate. The basilar plate is really the segment of the poison-claws, and may fuse more or less completely with the segment in front and behind it, and the latter is sometimes without a pair of appendages (Lithobius, Scutigera).

Geophilus, at the time of birth, has a rounded form like that of the Chilognatha.

The young of Lithobius is born with only six pairs of limbs.

\section{General observation on the homologies of the appendages of Myriapoda.}

The chief difficulty in this connection is the homology of the third pair of post-oral appendages.

In adult Chilognatha there is present behind the mandibles a four-lobed plate, which is usually regarded as representing two pairs of appendages, viz. the first and second pairs of maxillæ of Insects. Metschnikoff's observations seem however to shew that this plate represents but a single pair of appendages, which clearly corresponds with the first.pair of maxillæ in Insects. The pair of appendages behind this plate is ambulatory, but turned towards the head; it is in the embryo the foremost of the three functional pairs of legs with which the larva is born. Is it equivalent to the second pair of maxillæ of Insects or to the first pair of limbs of Insects? In favour of the former view is the fact (I) that in embryo Insects the second pair of maxillæ sometimes resembles the limbs rather than the jaws, so that it might be supposed that in Chilognatha a primitive ambulatory condition of the third pair of appendages has been retained; (2) that the disappearance of a pair of appendages would have to be postulated if the second alternative is adopted, and that if Insects are descended from forms related to the Myriapods it is surprising to find a pair of appendages always present in the former, absent in the latter. 
The arguments which can be urged for the opposite view do not appear to me to have much weight, so that the homology of the appendages in question with the second pair of maxillæ may be provisionally assumed.

The third pair of post-oral appendages of the Chilopoda may probably also be assumed to be equivalent to the second pair of maxillæ, though they are limb-like and not connected with the head. The subjoined table shews the probable homologies of the appendages.

\begin{tabular}{|c|c|c|c|c|c|c|c|}
\hline & & & $\begin{array}{l}\text { Chilognatha (Strongylo- } \\
\text { soma at time of birth). }\end{array}$ & \multicolumn{4}{|c|}{$\begin{array}{l}\text { CHilopoda (Scolopendra } \\
\text { adult). }\end{array}$} \\
\hline \multicolumn{3}{|c|}{ Pre-oral region. } & Antennæ. & \multicolumn{4}{|c|}{ Antennæ. } \\
\hline \multicolumn{3}{|c|}{ Ist Post-oral segment. } & Mandibles. & \multicolumn{4}{|c|}{ Mandibles. } \\
\hline 2nd & & ", & $\begin{array}{l}\text { Maxillx I. (Four-lobed } \\
\text { plate in adult, but a sim- } \\
\text { ple pair of appendages } \\
\text { in embryo). }\end{array}$ & \multicolumn{4}{|c|}{$\begin{array}{l}\text { Maxille I. } \\
\text { (Palp and bilobed median } \\
\text { process). }\end{array}$} \\
\hline \multicolumn{3}{|c|}{$\begin{array}{l}\text { 3rd } \\
\text { (probably equivalent to } \\
\text { segment bearing } 2 \text { nd pair } \\
\text { of maxillæ in Insects). }\end{array}$} & $\begin{array}{l}\text { Ist pair of ambulatory } \\
\text { limbs. }\end{array}$ & \multicolumn{4}{|c|}{$\begin{array}{l}\text { Limb-like appendages with } \\
\text { basal parts in contact. }\end{array}$} \\
\hline $4^{\text {th }}$ & , & ,", & (?) Apodous. & \multicolumn{4}{|c|}{ Poison claws. } \\
\hline $5^{\text {th }}$ & , & , & $\begin{array}{l}\text { 2nd pair of ambulatory } \\
\text { limbs. }\end{array}$ & \multicolumn{4}{|c|}{$\begin{array}{l}\text { Ist pair of ambulatory } \\
\text { limbs. }\end{array}$} \\
\hline 6 th &, & , & $3^{\text {rd }} \quad, \quad, \quad$, & 2nd & " & , & ", \\
\hline $7^{\text {th }}$ & , & ", & $\begin{array}{l}4^{\text {th }} \text { and } 5^{\text {th }} ", " \\
\text { (rudimentary.) }\end{array}$ & $3^{\mathrm{rd}}$ & , & $"$ & , \\
\hline 8th & ," & , & $\begin{array}{l}\text { 6th } \\
\text { (the } 7 \text { th pair is developed } \\
\text { in this segment later). }\end{array}$ & $t^{\text {th }}$ & $"$ & $"$ & , \\
\hline $9^{\text {th }}$ & ", &, & A podous. & $5^{\text {th }}$ & , & ", & 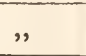 \\
\hline roth & ", & , & $\begin{array}{l}\text { (last segment in } \\
\text { embryo). }\end{array}$ & 6 th & $"$ & " & , \\
\hline
\end{tabular}

\section{The germinal layers and formation of organs.}

The development of the organs of the Myriapoda, and the origin of the germinal layers, are very imperfectly known: Myriapoda appear however to be closely similar to Insects in this part of their development, and the general question of the layers will be treated more fully in connection with that group.

The greater part of the blastoderm gives rise to the epiblast, which furnishes the skin, nervous system, tracheal system, and the stomodæum and proctodæum. 
The mesoblast arises in connection with the ventral thickening of the blastoderm, but the details of its formation are not known. Metschnikoff describes a longitudinal furrow which appears very early in Strongylosoma, which is perhaps equivalent to the mesoblastic furrows of Insects, and so connected with the formation of the mesoblast.

The mesoblast is divided up into a series of protovertebra-like bodiesthe mesoblastic somites-the cavities of which become the body cavity and the walls the muscles and probably the heart. They are (Metschnikoff) prolonged into the legs, though the prolongations become subsequently segmented off from the main masses. The splanchnic mesoblast is, according to Metschnikoff, formed independently of the somites, but this point requires further observation.

The origin of the hypoblast remains uncertain, but it appears probable that it originates, in a large measure at least, from the yolk segments. In the Chilognatha the mesenteron is formed in the interior of the yolk segments, so that those yolk segments which are not employed in the formation of the alimentary canal lie freely in the body cavity. In the relation of the yolk segments to the alimentary canal the Chilopoda present a strong contrast to the Chilognatha, in that the greater part of the yolk lies within their mesenteron. The mesenteron is at first a closed sack, but is eventually placed in communication with the stomodæum and the proctodæum. The Malpighian bodies arise as outgrowths from the blind extremity of the latter.

\section{BIBLIOGRAPHY.}

(397) G. New port. "On the Organs of Reproduction and Development of the Myriapoda." Philosophical Transactions, $184 \mathbf{1}$.

(398) E. Metschnik off. " Embryologie der doppeltfiissigen Myriapoden (Chilognatha)." Zeit.f. wiss. Zool., Vol. xxiv. 1874 .

(399) — "Embryologisches iber Geophilus." Zeit. f. wiss. Zool., Vol. xxv. 1875 .

(400) Anton Stecker. "Die Anlage d. Keimblatter bei den Diplopoden." Archiv f. mik. Anatomie, Bd. XIv. 1877 .

\section{INSECTA ${ }^{1}$.}

The formation of the embryonic layers in Insects has not been followed out in detail in a large number of types; but, as

1 The following classification of the Insecta is employed in this chapter.
I. Aptera. $\begin{cases}(I) & \text { Collembola. } \\ (2) & \text { Thysanura. }\end{cases}$

II. Orthoptera. $\left\{\begin{array}{cc}(\mathrm{I}) & \text { Orthoptera genuina (Blatta, Locusta, etc.). } \\ (2) & , \quad \text { pseudoneuroptera (Termes, Ephemera, } \\ \text { Libellula). }\end{array}\right.$

III. Hemiptera. $\left\{\begin{array}{ccc}\text { (I) } & \text { Hemiptera heteroptera (Cimex, Notonecta, etc. } \\ (2) & , & \text { homoptera (Aphis, Cicada, etc.). } \\ (3) & , & \text { parasita (Pidiculus, etc.). }\end{array}\right.$ 
in so many other instances, some of the most complete histories we have are due to Kowalevsky (No. 416). The development
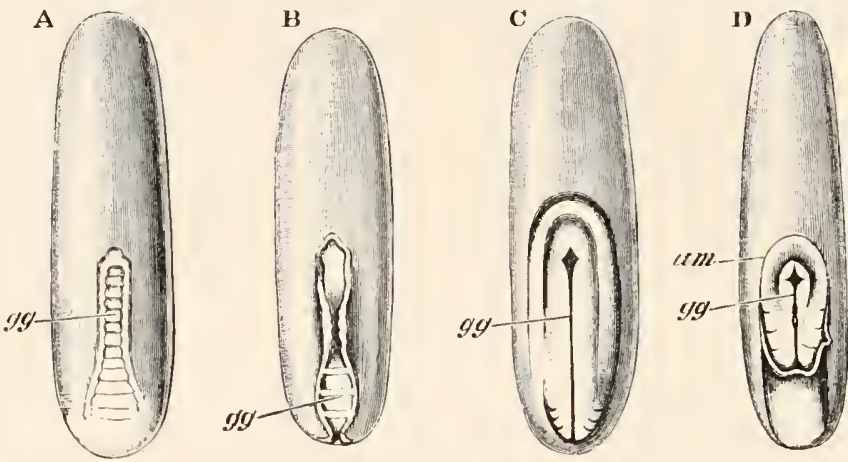

FiG. 176, HUUR EMBRYOS OF IIYURUPHILUS PICEUS IIEWED FROM THE VENTRAL SURFACE. (After Kowalevsky.)

The upper end is the anterior. gg. germinal groove; $a m$. amnion.

of Hydrophilus has been worked out by him more fully than that of any other form, and will serve as a type for comparison with other forms.

The segmentation has not been studied, but no doubt belongs to the centrolecithal type (vide pp. IIO-I20). At its close there is an uniform layer of cells enclosing a central mass of yolk. These cells, in the earliest observed stage, were flat on the dorsal, but columnar on part of the ventral surface of the egg, where they form a thickening which will be called the ventral plate. At the posterior part of the ventral plate two folds, with a furrow between them, make their appearance. They form a structure which may be spoken of as the germinal groove (fig.

IV. Diptera. $\left\{\begin{array}{ccc}(\text { I } & \text { Diptera genuina (Musca, Tipula, etc.). } \\ (2) & , & \text { aphaniptera (Pulex, etc.). } \\ (3) & ,, & \text { pupipara (Braula, etc.). }\end{array}\right.$

V. Neuroptera. $\{(\mathrm{I})$ Neuroptera planipennia (Myrmelcon, etc.).

VI. Coleoptera.

VII. Lepidoptera.

VIII. Hymenoptera. $\left\{\begin{array}{ccc}(\mathrm{I}) & \text { Hymenoptera aculeata (Apis, Formica, etc.). } \\ (2) & ", & \text { entomophaga (Ichncumon, Platy- } \\ & \text { gaster, etc). } & \text { phytophaga (Tenthredo, Sirex, etc.). }\end{array}\right.$ (2) $\quad, \quad$ trichoptera (Phryganea, etc.). 
I $76 \mathrm{~A}, g g)$. The cells which form the floor of the groove are far more columnar than those of other parts of the blastoderm (fig. 177 A). The two folds on each side of it gradually approach each other. They do so at first behind, and then in the middle; from the latter point the approximation gradually extends backwards and forwards (fig. I $76 \mathrm{~B}$ and C). In the middle and hinder parts of the ventral plate the groove becomes, by the coalescence of the folds, converted into a canal (fig. I78 A, $g g$ ), the central cavity of which soon disappears, while at the same time the cells of the wall undergo division, become more rounded, and form a definite layer $(m e)$-the mesoblast-beneath the columnar cells of the surface. Anteriorly the process is slightly different, though it leads to the similar formation of mesoblast (fig. I $77 \mathrm{~B}$ ). The flat floor of the groove becomes in front bodily converted into the mesoblast, but the groove itself is never converted into a canal. The two folds simply meet above, and form a continuous superficial layer.

During the later stages of the process last described remarkable structures, eminently characteristic of the Insecta, have made their first appearance. These structures are certain embryonic membranes or coverings, which present in their mode of formation and arrangement a startling similarity to the true and false amnion of the Vertebrata. They appear as a double fold of the blastoderm round the edge of the germinal area, which spreads over the ventral plate, from behind forwards, in a 
general way in the same manner as the amnion in, for instance, the chick. The folds at their origin are shewn in surface view in fig. $176 \mathrm{D}$, $a m$, and in section in fig. $177 \mathrm{~B}$, am. The folds eventually meet, coalesce (fig. 178 , $a m)$ and give rise to two membranes covering the ventral plate, viz. an inner one, which is continuous with the edge of the ventral plate; and an outer, continuous with the remainder of the blastoderm. The vertebrate nomenclature may be conveniently employed for these membranes. The inner limb of the

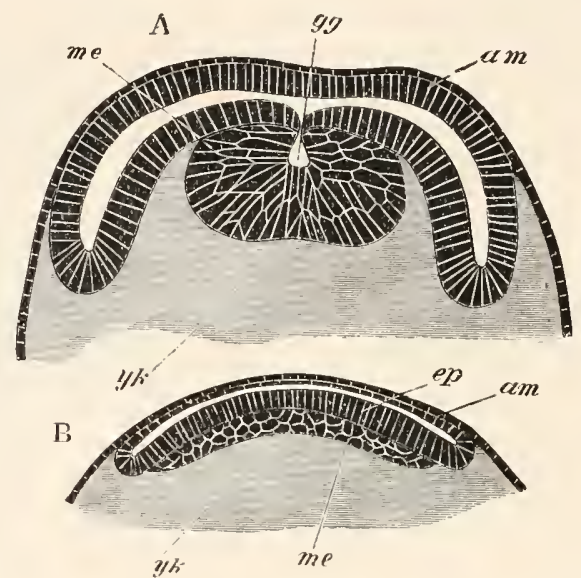

Fig. 7 78. SECTIONS THROUGH TWO EMBryos of IIydrophilus piceus. (After Kowalevsky.)

A. Section through the posterior part of the embryo fig. i $76 \mathrm{D}$, shewing the completely closed amnion and the germinal groove.

B. Section through an older embryo in which the mesoblast has grown out into a continuous plate beneath the epiblast.

gg. germinal groove; am. amnion; $y k$. yolk; cp. epiblast.

fold will therefore be spoken of as the amnion, and the outer one, including the dorsal part of the blastoderm, as the serous envelope ${ }^{1}$. A slight consideration of the mode of formation of the membranes, or an inspection of the figures illustrating their formation, makes it at once clear that the yolk can pass in freely between the amnion and serous envelope (vide fig. I8I). At the hind end of the embryo this actually takes place, so that the ventral plate covered by the amnion appears to become completely imbedded in the yolk: elsewhere the two membranes are in contact. At first (fig. I76) the ventral plate occupies but a small portion of the ventral surface of the egg, but during the changes above described it extends over the whole ventral surface, and even slightly on the dorsal surface both in front and behind. It becomes at the same time (fig. I79) divided

1 The reverse nomenclature to this is rather inconveniently employed by Metschnikoff. 
by a series of transverse lines into segments, which increase in number and finally amount in all to seventeen, not including the most anterior section, which gives off as lateral outgrowths the two procephalic lobes ( $p c . l)$. The changes so far described are included within what Kowalevsky calls his first embryonic period; at its close the parts contained within the chorion have the arrangement shewn in fig. I78 B. The whole of the body of the embryo is formed from the ventral plate, and no part from the amnion or serous envelope.

The general history of the succeeding stages may be briefly told.

The appendages appear as very small rudiments at the close of the last stage, but soon become much more prominent (fig.

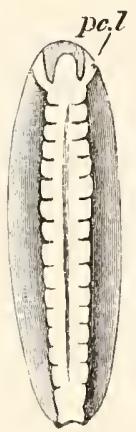

FIG. I79. EMBRYO OF HYDROPHILUS PICEUS VIEWED FROM THE VENTRAL SURFACE. (After Kowalevsky.)

pc.l. procephalic lobe. I $80 \mathrm{~A})$. They are formed as outgrowths of both layers, and arise nearly simultaneously. There are in all eight pairs of appendages. The anterior or antennæe $(a t)$ spring from the procephalic lobes, and the succeeding appendages from the segments following. The last pair of embryonic appendages, which disappears very early, is formed behind the third pair of the future thoracic limbs. Paired epiblastic involutions, shewn as pits in the posterior segments in fig. I $80 \mathrm{~A}$, give rise to the trachex; and the nervous system is formed as two lateral epiblastic thickenings, one on each side of the midventral line. These eventually become split off from the skin; while between them there passes in a median invagination of the skin

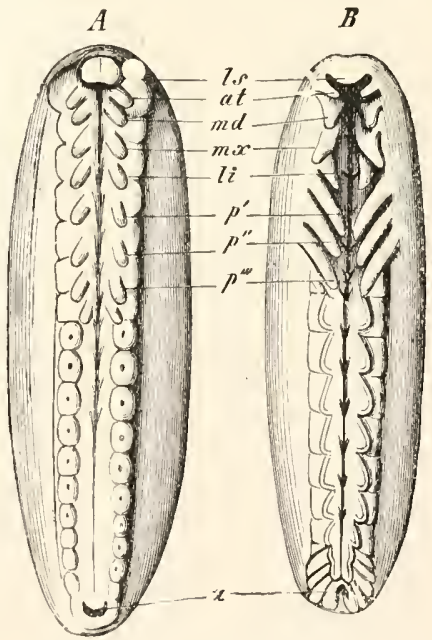

Fig, iso. Two stages in the DEVELOPMENT OF HYDROPHILUS PICEUS. (From Gegenbaur, after Kowalevsky.)

ls. labrum; at. antenna; $m d$. mandible; $m x$. maxilla I. ; li. maxilla II.; $p^{\prime} p^{\prime \prime} p^{\prime \prime \prime}$. feet ; $a$. anus. 
(fig. I89 C). The two nervous strands are continuous in front with the supra-œsophageal ganglia, which are formed of the epiblast of the procephalic lobes. These plates gradually grow round the dorsal side of the embryo, and there is formed immediately behind them an oral invagination, in front of which there appears an upper lip (fig. I $80, l s$ ). A proctodæum is formed at the hind end of the body slightly later than the stomodæum. The mesoblast cells become divided into two bands, one on each side of the middle line (fig. I89 A), and split into splanchnic and somatic layers. The central yolk mass at about the stage represented in fig. I79 begins to break up into yolk spheres. The hypoblast is formed first on the ventral side at the junction of the mesoblast and the yolk, and gradually extends and forms a complete sack-like mesenteron, enveloping the yolk (fig. I $85 \mathrm{al}$ ). The amnion and serous membrane retain their primitive constitution for some time, but gradually become thinner on the ventral surface, where a rupture appears eventually to take place. The greater part of them disappears, but in the closure of the dorsal parietes the serous envelope plays a peculiar part, which is not yet understood. It is described on p. 404. The heart is formed from the mesoblastic layers, where they meet in the middle dorsal line (fig. I85 C, $h t$ ). The somatic mesoblast gives rise to the muscles and connective tissue, and the splanchnic mesoblast to the muscular part of the wall of the alimentary tract, which accompanies the hypoblast in its growth round the yolk. The proctodæum forms the rectum and Malpighian bodies ${ }^{1}$, and the stomodæum the cesophagus and proventriculus. The two epiblastic sections of the alimentary tract are eventually placed in communication with the mesenteron.

The development of Hydrophilus is a fair type of that of Insects generally, but it is necessary to follow with somewhat greater detail the comparative history of the various parts which have been briefly described for this type.

\section{The embryonic mombrancs and the formation of the layers.}

All Insects have at the close of segmentation a blastoderm formed of a single row of cells enclosing a central yolk mass,

\footnotetext{
1 This has not been shewn in the case of Hydrophilus,
} 
which usually contains nuclei, and in the Poduridx is divided up in the ordinary segmentation into distinct yolk cells. The first definite structure formed is a thickening of the blastoderm, which forms a ventral plate.

The ventral plate is very differently situated in relation to the yolk in different types. In most Diptera, Hymenoptera and (?) Neuroptera (Phryganea) it forms from the first a thickening extending over nearly the whole ventral surface of the ovum, and in many cases extends in its subsequent growth not only over the whole ventral surface, but over a considerable part of the apparent dorsal surface as well (Chironomus, Simulia, Gryllotalpa, etc.). In Coleoptera, so far as is known, it commences as a less extended thickening either of the central part (Donacia) or posterior part (Hydrophilus) of the ventral surface, and gradually grows in both directions, passing over to the dorsal surface behind.

Embryonic membranes. In the majority of Insects there are developed enveloping membranes like those of Hydrophilus.

The typical mode of formation of these membranes is represented diagrammatically in fig. I $8 \mathrm{I} A$ and $B$. A fold of the blastoderm arises round the edge of the ventral plate. This fold, like the amniotic fold of the higher Vertebrata, is formed of two limbs, an outer, the serous membrane (se), and an inner, the true amnion $(\mathrm{am})$. Both limbs extend so as to cover over the ventral plate, and finally meet and coalesce, so that a double membrane is present over the ventral plate. Atthe same time (fig. I8 I B)

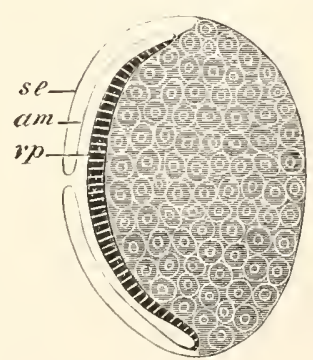

A

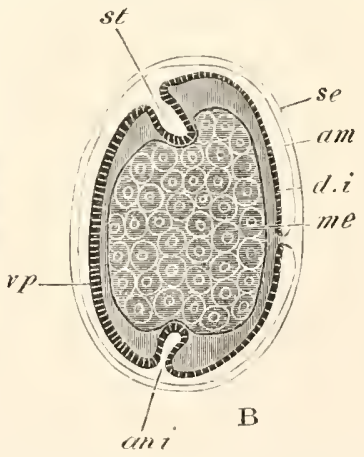

Fig. I8I. Diagrammatic LongITUdinal SECTIONS OF AN INSECT EMBRYO AT TWO STAGES TO SHEW THE DEVELOPMENT OF THE EMBRYONIC ENVELOPES.

In $\mathrm{A}$ the amniotic folds have not quite met so as to cover the ventral plate. The yolk is represented as divided into yolk cells. In $\mathbf{B}$ the sides of the ventral plate have extended so as nearly to complete the dorsal integument. The mesenteron is represented as a closed sack filled with yolk cells. am. amnion; se. serous envelope; v.p. ventral plate; $d . i$. dorsal integument; me. mesenteron; st. stomodæum ; an $i$. proctodæum.

the point where the fold originates is carricd dorsalwards by the 
dorsal extension of the edges of the ventral plate, which give rise to the dorsal integument $(d . i)$. This process continues till the whole dorsal surface, is covered by the integument. The amnion then separates from the dorsal integument, and the embryo becomes enveloped in two membranes-an inner, the amnion, and an outer, the serous membrane. In fig. I 8 I $B$ the embryo is represented at the stage immediately preceding the closure of the dorsal surface.

By the time that these changes are effected, the serous membrane and amnion are both very thin and not easily separable. The amnion appears to be usually absorbed before hatching; but in hatching both membranes, if present, are either absorbed, or else ruptured and thrown off.

The above mode of development of the embryonic membranes has been especially established by the researches of Kowalevsky (No. 416) and Graber (No. 412) for various Hymenoptera (Apis), Diptera (Chironomus), Lepidoptera and Coleoptera (Melolontha, Lina).

Considerable variations in the development of the enveloping membranes are known.

When the fold which gives rise to the membranes is first formed, there is, as is obvious in fig. 18I A, a perfectly free passage by which the yolk can pass in between the amnion and serous membrane. Such a passage of the yolk between the two membranes takes place posteriorly in Hydrophilus and Donacia: in Lepidoptera the yolk passes in everywhere, so that in this form the ventral plate becomes first of all imbedded in the yolk, and finally, on the completion of the dorsal integument, the embryo is enclosed in a complete envelope of yolk contained between the amnion and the serous membrane. During the formation of the dorsal integument the external yolk sack communicates by a dorsally situated umbilical canal with the yolk cavity within the body. On the rupture of the amnion the embryo is nourished at the expense of the yolk contained in the external yolk sack.

In the Hemiptera and the Libellulidæ the ventral plate also becomes imbedded in the yolk, but in a somewhat different fashion to the Lepidoptera, which more resembles on an exaggerated scale what takes place in Hydrophilus.

In the Libellulidæ (Calopteryx) there is first of all formed (Brandt, No. 403) a small ventral and posterior thickening of the blastoderm (fig. I82 A). The hinder part of this becomes infolded into the yolk as a projection (fig. I82 B), which consists of two laminæ, an anterior and a posterior, continuous at the apex of the invagination. The whole structure, which is completely imbedded within the yolk, rapidly grows in length, and turns towards the front end of the egg (fig. I $82 \mathrm{C}$ ). Its anterior lamina remains thick and gives rise to the ventral plate $(p s)$, the posterior $(a m)$ on the other hand 
becomes very thin, and forms a covering corresponding with the amnion of the more ordinary types. The remainder of the blastoderm covering the yolk (se) forms the homologue of the serous membrane of other types. The ventral surface of the ventral plate is turned towards the dorsal side (retaining the same nomenclature as in ordinary cases) of the egg, and the cephalic extremity is situated at the point of origin of the infolding.

The further history is however somewhat peculiar. The amnion is at first (fig. $182 \mathrm{C}$ ) continuous with the serous envelope on the posterior side only, so that the serous envelope does not form a continuous sack, but has an opening close to the head of the embryo.

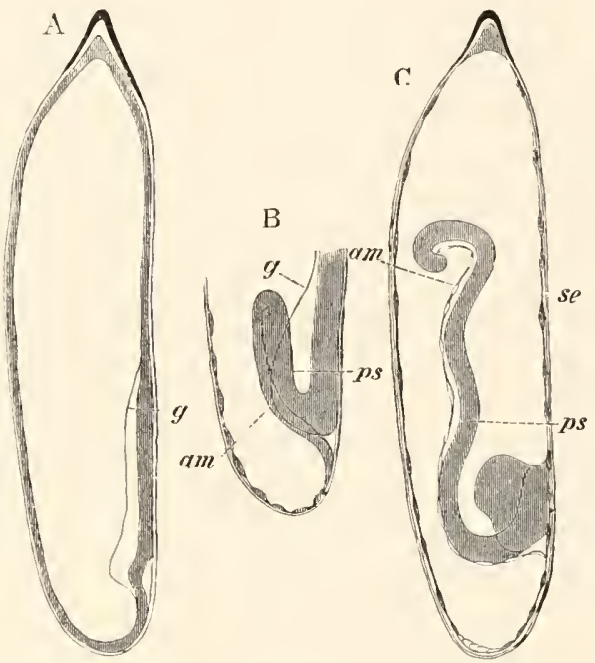

Fig. I 82. THREE STAGES IN THE DEVELOPMENT of the embryo of Calopteryx. (After Brandt.)

The embryo is represented in the egg-shell.

A. Embryo with ventral plate.

B. Commencing involution of ventral plate.

C. Involution of ventral plate completed.

$p s$. ventral plate; $g$. edge of ventral plate; $a m$. amnion; se. serous envelope.

In the Hemiptera parasita this opening (Melnikow, No. 422) remains permanent, and the embryo, after it has reached a certain stage of development, becomes everted through it, while the yolk, enclosed in the continuous membrane formed by the amnion and serous envelope, forms a yolk sack on the dorsal surface. In the Libellulidæ however and most Hemiptera, a fusion of the two limbs of the serous membrane takes place in the usual way, so as to convert it into a completely closed sack (fig. $183 \mathrm{~A}$ ). After the formation of the appendages a fusion takes place between the amnion and serous envelope over a small area close to the head of the embryo. In the middle of this area a rupture is then effected, and the head of the embryo followed by the body is gradually pushed through the opening (fig. $183 \mathrm{~B}$ and C). The embryo becomes in the process completely rotated, and carried into a position in the egg-shell identical with that of the embryos of other orders of Insects (nig. I $83 \mathrm{C}$ ).

Owing to the rupture of the embryonic envelopes taking place at the point where they are fused into one, the yolk does not escape in the above process, but is carried into a kind of yolk sack, on the dorsal surface of the embryo, formed of the remains of the amnion and serous envelope. The 
walls of the yolk sack either assist in forming the dorsal parietes of the body, or are more probably enclosed within the body by the growth of the dorsal parietes from the edge of the ventral plate.

In Hydrophilus and apparently in the Phryganidre also, there are certain remarkable peculiarities in the closure of the dorsal surface. The fullest observations on the subject have been made by Kowalevsky (No. 416), but Dohrn (No. 408) has with some probability thrown doubts on Kowalevsky's interpretations. According to Dohrn the part of the serous envelope which covers the dorsal surface becomes thickened, and gives rise to a peculiar dorsal plate which is shewn in surface view in ventral parts of the amnion and serous membrane have either been ruptured or have disappeared. While the dorsal plate is being formed, the mesoblast, and somewhat later the lateral parts of the epiblast of the ventral plate gradually grow towards the dorsal side and enclose the dorsal plate, the wall of which in the process appears to be folded over so as first of all to form a groove and finally a canal. The stages in this growth are shewn from the surface in fig. I 84 $\mathrm{B}$ and $\mathrm{C}$ and in section in

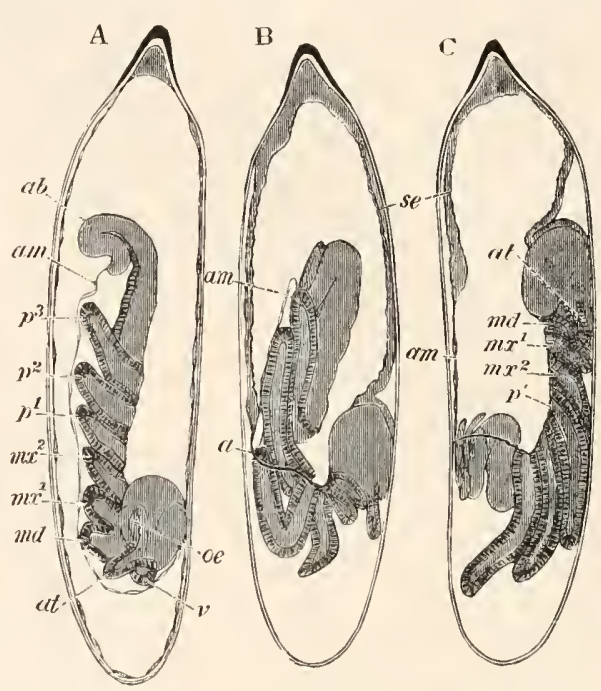

F1G. I 83. THREE STAGES IN THE DEVELOPMENT of Calopteryx. (After Brandt.)

The embryo is represented in the egg-shell; $\mathbf{B}$. and $\mathrm{C}$. shew the inversion of the embryo.

se. serous envelope; am. amnion; $a b$. abdomen; v. anterior end of head; at. antennæ; $m d$. mandible; $m x^{1}$. maxilla $\mathrm{I} ; m x^{2}$. maxilla $2 ; p^{1}-p^{3}$. three pairs of legs; oe. oesophagus.

fig. $184 \mathrm{~A}, d o$, and in section in fig. $185 \mathrm{~A}, d o$. The
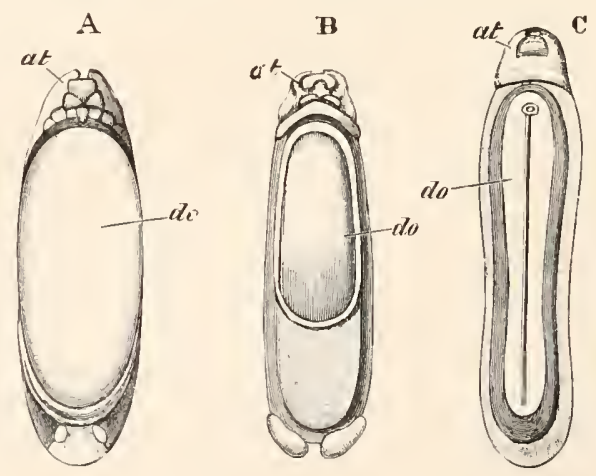

F1G. I 8 . Three larval Stages of HydroPHILUS FROM THE DORSAL SIDE, SHEWING THE GRADUAL CLOSING IN OF THE DORSAL REGION WITH THE FORMATION OF THE PECULIAR DORSAL ORGAN do. (After Kowalevsky.)

do. dorsal organ; at. antennæ. 
fig. I $85 \mathrm{~B}, \mathrm{do}$. The canal is buried on the dorsal part of the yolk, but for some time remains open by a round aperture in front (fig. I $84 \mathrm{C}$ ). The whole structure is known as the dorsal canal. It appears to atrophy without leaving a trace. The heart when formed lies immediately dorsal to it?

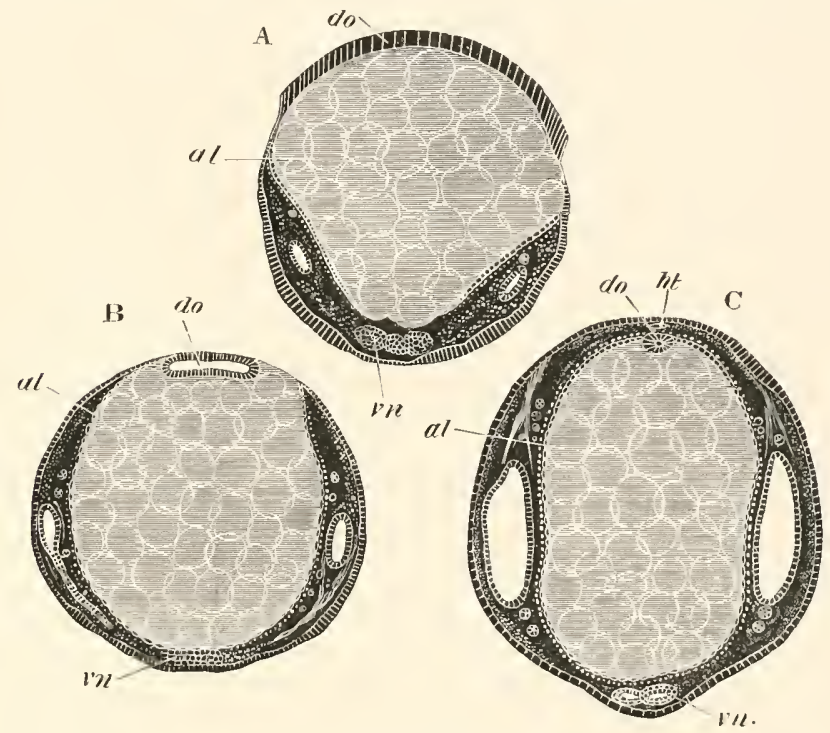

Fig. I85. Three transverse sections through ADVANCED EMBRYOS OF IIYDROPHILUS.

A. Section through the posterior part of the body of the same age as fig. $18_{4} \mathrm{~A}$.

B. Section through the embryo of the same age as fig. $18+C$.

C. Section through a still older embryo.

do. dorsal plate; $v n$. ventral nerve cord; al. mesenteron; ht. heart.

The large spaces at the sides are parts of the body cavity.

In the Poduridx the embryonic membranes appear to be at any rate imperfect. Metschnikoff states in his paper on Geophilus that in some ants no true embryonic membranes are found, but merely scattered cells which take their place. In the Ichneumonidæ the existence of two embryonic membranes is very doubtful.

Formation of the embryonic layers. The formation of the layers has been studied in sections by Kowalevsky (No. 416),

1 According to Kowalevsky the history of the dorsal plate is somewhat different. He believes that on the absorption of the amnion the ventral plate unites with the serous membrane, and that the latter directly gives rise to the dorsal integument, while the thickened part of it becomes involuted to form the dorsal tube already described. 
Hatschek (No. 414), and Graber (No. 412), etc. From their researches it would appear that the formation of the mesoblast always takes place in a manner closely resembling that in Hydrophilus. The essential features of the process (figs. I77 and I78) appear to be that a groove is formed along the median line of the ventral plate, and that the sides of this groove either (I) simply close over like the walls of the medullary groove in Vertebrates, and so convert the groove into a tube, which soon becomes solid and forms a mass or plate of cells internal to the epiblast; or (2) that the cells on each side of the groove grow over it and meet in the middle line, forming a layer external to the cells which lined the groove. The former of these processes is the most usual ; and in the Muscidæ the dimensions of the groove are very considerable (Graber, No. 411). In both cases the process is fundamentally the same, and causes the ventral plate to become divided into two layers ${ }^{1}$. The external layer or epiblast is an uniform sheet forming the main part of the ventral plate (fig. $178 \mathrm{~B}, c p$ ). It is continuous at its edge with the amnion. The inner layer or mesoblast constitutes an independent plate of cells internal to the epiblast (fig. I $78 \mathrm{~B}, m e$ ). The mesoblast soon becomes divided into two lateral bands.

The origin of the hypoblast is still in dispute. It will be remembered (vide pp. II4 and I I6) that after the segmentation a number of nuclei remain in the yolk; and that eventually a secondary segmentation of the yolk takes place around these nuclei, and gives rise to a mass of yolk cells, which fill up the interior of the embryo. These cells are diagrammatically shewn in figs. I 8 I and I89, and it is probable that they constitute the true hypoblast. Their further history is given below.

\section{Formation of the organs and their relation to the germinal layers.}

The segments and appendages. One of the earliest phenomena in the development is the appearance of transverse lines indicating segmentation (fig. I86). The transverse lines are apparently caused by shallow superficial grooves, and also in

1 Tichomiroff (No.420) denies the existence of a true invagination to form the mesoblast, and also asserts that a separation of mesoblast cells from the epiblast can take place at other parts besides the median ventral line. 
many cases by the division of the mesoblastic bands into separate somites. The most anterior line marks off a præ-oral segment, which soon sends out two lateral wings--the procephalic lobes. The remaining segments are at first fairly uniform. Their number does not, however, appear to be very constant. So far as is known they never exceed seventeen, and this number is probably the typical one (figs. i 86 and i 87 ).

In Diptera the number appears to be usually fifteen though it may be only fourteen. In Lepidoptera and in Apis there appear to be sixteen segments. These and other variations affect only the number of the segments which form the abdomen of the adult.

The appendages arise as paired pouchlike outgrowths of the epiblast and mesoblast; and their number and the order of their appearance are subject to considerable variation, the meaning of which is not yet clear. As a rule they arise subsequently to the segmentation of the parts of the body to which they belong. There is always formed one pair of appendages which spring from the lateral lobes of the procephalic region, or from the boundary line between these and the median ventral part of this region. These appendages are the antennæ. They have in the embryo a distinctly ventral position as compared to that which they have in the adult.

In the median ventral part of the pro-

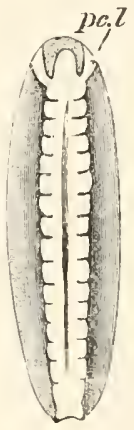

Fig. 186. EMBRYo OF HYDROPHILUS PICEUS VIEWED FROM THE VENTRAL SURFACE.

(After Kowalevsky.)

pc.l. procephalic lobe. cephalic region there arises the labrum (fig. I $87, l s$ ). It is formed by the coalescence of a pair of prominences very similar to true appendages, though it is probable that they have not this value $^{1}$.

1 If these structures are equivalent to appendages, they may correspond to one of the pairs of antennæ of Crustacea. From a figure by Fritz Müller of the larva of Calotermes (Fenaische Zeit. Vol. XI. pl. 11, fig. 12) it would appear that they lie in front of the true antennæ, and would therefore on the above hypothesis correspond to the first pair of antennæ of Crustacea. Buitschli (No.405) describes in the Bee a pair of prominences immediately in front of the mandibles which eventually unite to form a kind of underlip; they in some ways resemble true appendages. 
The antenne themselves can hardly be considered to have the same morphological value as the succeeding appendages. They are rather equivalent to paired processes of the præ-oral lobes of the Chætopoda.

From the first three post-oral segments there grow out the mandibles and two pairs of maxillæe, and from the three following segments the three pairs of thoracic appendages. In many Insects (cf. Hydrophilus) a certain number of appendages of the same nature as the anterior ones are visible in the embryo on the abdominal segments, a fact which shews that Insects are descended from ancestors with more than three pairs of ambulatory appendages.

In Apis according to Bütschli (No. 405) all the abdominal segments are provided with appendages, which always remain in a very rudimentary condition. All trace of them as well as of the thoracic appendages is lost by the time the embryo is hatched. In the phytophagous $\mathrm{Hy}$ menoptera the larva is provided with 9-I I pairs of legs.

In the embryo of Lepidoptera there would appear from Kowalevsky's figures to be rudiments of ten pairs of post-thoracic appendages. In the caterpillar of this group there are at the maximum five pairs of such rudimentary feet, viz. a pair on the $3 \mathrm{rd}, 4$ th, 5 th, and $6 \mathrm{th}$, and on the last abdominal segment. The embryos of Hydrophilus (fig. I87), Mantis, etc. are also provided with additional appendages. In various Thysanura small prominences are present on more or fewer of the abdominal segments (fig. I92), which may probably be regarded as rudimentary feet.

Whether all or any of the appendages of various kinds connected with the hindermost segments belong to the same

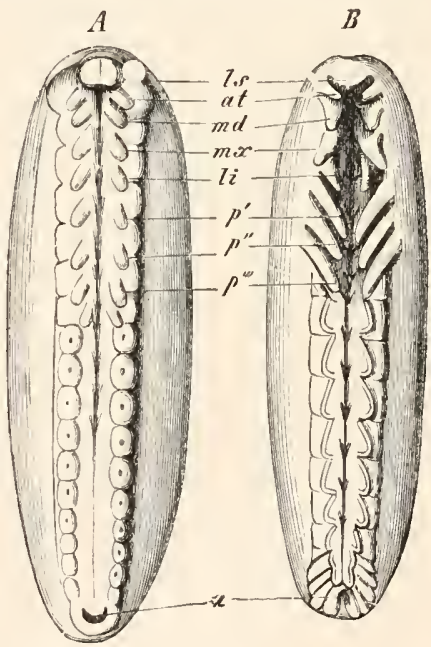

Fig. I 87. Two stages in the DEVELOPMENT OF HYDROPHILUS PICEUS. (From Gegenbaur, after Kowalevsky.)

ls. labrum; at. antemna; $m d$. mandible; mx. maxilla I.; li. $\max$ illa II.; $p^{\prime} p " p^{\prime \prime}$. feet; $a$. anus. category as the legs is very doubtful. Their usual absence in the embryo or in any case their late appearance appears to me against so regarding them; but Bütschli is of opinion that in the Bee the parts of the sting are related genetically to the appendages of the penultimate and antepenultimate abdominal segments, and this view is to some extent supported by more recent 
observations (Kraepelin, etc.), and if it holds true for the Bee must be regarded as correct for other cases also.

As to the order of the appearance of the appendages observations are as yet too scanty to form any complete scheme. In many cases all the appendages appear approximately at the same moment, e.g. Hydrophilus, but whether this holds good for all Coleoptera is by no means certain. In Apis the appendages are stated by Bütschli to arise simultaneously, but according to Kowalevsky the two mouth appendages first appear, then the antennæ, and still later the thoracic appendages. In the Diptera the mouth appendages are first formed, and either simultaneously with these, or slightly later, the antennæ. In the Hemiptera and Libellulidæe the thoracic appendages are the first to be formed, and the second pair of maxillæ makes its appearance before the other cephalic appendages.

The history of the changes in the embryonic appendages during the attainment of the adult condition is beyond the scope of this treatise, but it may be noted that the second pair of maxilla are relatively very large in the embryo, and not infrequently (Libellula, etc.) have more resemblance to the ambulatory than to the masticatory appendages.

The exact nature of the wings and their relation to the other segments is still very obscure. They appear as dorsal leaf-like appendages on the 2nd and 3 rd thoracic segments, and are in many respects similar to the tracheal gills of the larvæ of Ephemeridæ and Phryganidæ (fig. I88 A), of which they are supposed by Gegenbaur and Lubbock to be modifications. The undoubtedly secondary character of the closed tracheal system of larve with tracheal gills tells against this view. Fritz Müller finds in the larvæ of Calotermes ru-
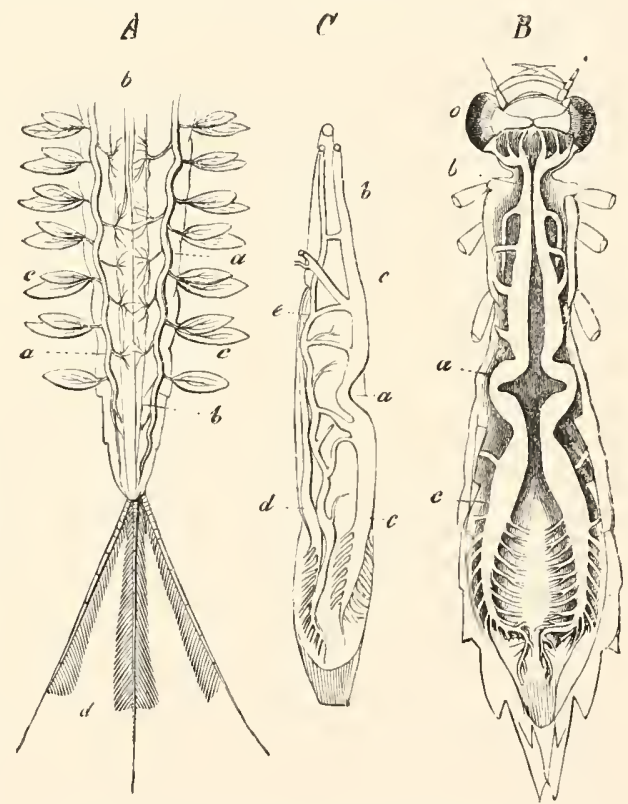

Fig. 188. FiguRES ILLUSTRATING AQUATIC RESPIRATION in INSECTS. (After Gegenbaur.)

A. Hinder portion of the body of Ephemera vulgata. $a$. longitudinal tracheal trunks; $b$. alimentary canal; $c$. tracheal gills.

B. Larva of Aischna grandis. a. superior longitudinal tracheal trunks; $b$. their anterior end; $c$. portion branching on proctodæum ; 0 . eyes.

C. Alimentary canal of the same larva from the side. $a, b$, and $c$. as in $\mathbf{B}$; $d$. inferior tracheal trunk; e. transverse branches between upper and lower tracheal trunks. 
gosus (one of the Termites) that peculiar and similar dorsal appendages are present on the two anterior of the thoracic segments. They are without tracheæ. The anterior atrophies, and the posterior acquires tracheæ and gives rise to the first pair of wings. The second pair of wings is formed from small processes on the third thoracic segment like those on the other two. Fritz Müller concludes from these facts that the wings of Insects are developed from dorsal processes of the body, not equivalent to the ventral appendages. What the primitive function of these appendages was is not clear. Fritz Müller suggests that they may have been employed as respiratory organs in the passage from an aqueous to a terrestrial existence, when the Termite ancestors lived in moist habitations-a function for which processes supplied with blood-channels would be well adapted. The undoubted affinity of Insects to Myriapods, coupled with the discovery by Moseley of a tracheal system in Peripatus, is however nearly fatal to the view that Insects can have sprung directly from aquatic ancestors not provided with trachex. But although this suggestion of Fritz Müller cannot be accepted, it is still possible that the processes discovered by him may have been the earliest rudiments of wings, which were employed first as organs of propulsion by a water-inhabiting Insect ancestor which had not yet acquired the power of flying.

The nervous system. The nervous system arises entirely from the epiblast; but the development of the pra-oral and post-oral sections may be best considered separately.

The post-oral section, or ventral cord of the adult, arises as two longitudinal thickenings of the epiblast, one on each side of the median line (fig. I $89 \mathrm{~B}, \mathrm{on}$ ), which are subsequently split off from the superficial skin and give rise to the two lateral strands of the ventral cord. At a later period they undergo a differentiation into ganglia and connecting cords.

Between these two embryonic nerve cords there is at first a shallow furrow, which soon becomes a deep groove (fig. I89 C). At this stage the differentiation of the lateral elements into ganglia and commissures takes place, and, according to Hatschek (No. 414), the median groove becomes in the region of the ganglia converted into a canal, the walls of which soon fuse with those of the ganglionic enlargements of the lateral cords, and connect them across the middle line. Between the ganglia on the other hand the median groove undergoes atrophy, becoming first a solid cord interposed between the lateral strands of the nervous system, and finally disappearing without giving rise to any part of the nervous system. It is probable that Hatschek is entirely mistaken about the entrance of a median element into the ventral cord, and that the appearances he has described are due to shrinkage. In Spiders the absence of a median element can be shewn with great certainty, and, as already stated, this element is not present in 
Peripatus. Hatschek states that in the mandibular segment the median element is absorbed, and that the two lateral cords of that part give rise to the œsophageal commissures, while the sub-œsophageal ganglion is formed from the fusion of the ganglia of the two maxillary segments.

The præ-oral portion of the nervous system consists entirely of the supra-cesophageal ganglion. It is formed, according to Hatschek, of three parts. Firstly and mainly, of a layer sepa-
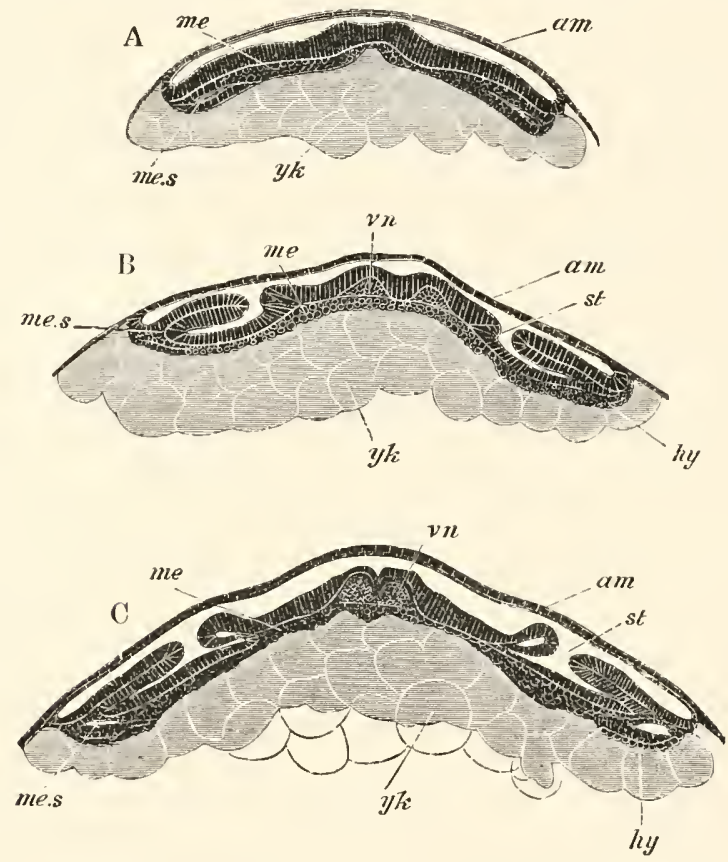

Fig. 189. Three transverse Sections through the embryo of HYDRopHiLus. (After Kowalevsky.)

A. Transverse section through the larva represented in fig. $187 \mathrm{~A}$.

B. Transverse section through a somewhat older embryo in the region of one of the stigmata.

C. Transverse section through the larva represented in fig. $187 \mathrm{~B}$.

vn. ventral nerve cord; am. amnion and serous membrane; me. mesoblast; me.s. somatic mesoblast; hy. hypoblast (?); $y k$. yolk cells (true hypoblast); st. stigma of trachea.

rated from the thickened inner part of the cephalic lobe on each side; secondly, of an anterior continuation of the lateral cords; and thirdly, of a pit of skin invaginated on each side close to the 
dorsal border of the antennæ. This pit is at first provided with a lumen, which is subsequently obliterated; while the walls of the pit become converted into true ganglion cells. The two supra-øesophageal ganglia remain disconnected on the dorsal side till quite the close of embryonic life.

The tracheæ and salivary glands. The tracheæ, as was first shewn by Bütschli (No. 405), arise as independent segmentally arranged paired invaginations of the epiblast (fig. I $89 \mathrm{~B}$ and $\mathrm{C}, s t$ ). Their openings are ahways placed on the outer sides of the appendages of their segments, where such are present.

Although in the adult stigmata are never found in the space between the prothorax and head ${ }^{1}$, in the embryo and the larva tracheal invaginations may be developed in all the thoracic (and possibly in the three jaw-bearing segments) and in all the abdominal segments except the two posterior.

In the embryo of the Lepidoptera, according to Hatschek (No. 414), there are 14 pairs of stigmata, belonging to the I4 segments of the body behind the mouth; but Tichomiroff states that Hatschek is in error in making this statement for the foremost post-oral segments. The last two segments are without stigmata. In the larvæ of Lepidoptera as well as those of many Hymenoptera, Coleoptera and Diptera, stigmata are present on all the postcephalic segments except the and and 3rd thoracic and the two last abdominal. In Apis there are eleven pairs of tracheal invaginations according to Kowalevsky (No. 416), but according to Bütschli (No. 405) only ten, the prothorax being without one. In the Bee they appear simultaneously, and before the appendages.

The blind ends of the tracheal invaginations frequently (e.g. Apis) unite together into a common longitudinal canal, which forms a longitudinal tracheal stem. In other cases (e.g. Gryllotalpa, Dolim, No. 408) they remain distinct, and each tracheal stem has a system of branches of its own.

The development of the tracheæ strongly supports the view, arrived at by Moseley from his investigations on Peripatus, that they are modifications of cutaneous glands.

The salivary and spinning glands are epiblastic structures, which in their mode of development are very similar to the tracheæ, and perhaps have a similar origin. The salivary glands

1 In Smynthurus, one of the Collembola, there are, according to Lubbock, only two stigmata, which are placed on the head. 
arise as paired epiblastic invaginations, not, as might be expected, of the Stomodxum, but of the ventral plate behind the mouth on the inner side of the mandibles. At first independent, they eventually unite in a common duct, which falls into the mouth. The spinning glands arise on the inner side of the second pair of maxillæ in Apis and Lepidoptera, and form elongated glands extending through nearly the whole length of the body. They are very similar in their structure and development to salivary glands, and are only employed during larval life. They no doubt resemble the mucous glands of the oral papillæ of Peripatus, with which they have been compared by Moseley. The mucous glands of Peripatus may perhaps be the homologous organs of the first pair of maxillæ, for the existence of which there appears to be some evidence amongst Insects.

Mesoblast. It has been stated that the mesoblast becomes divided in the region of the body into two lateral bands (fig. I 89 A). These bands in many, if not all forms, become divided into a series of somites corresponding with the segments of the body. In each of them a cavity appears-the commencing perivisceral cavity-which divides them into a somatic plate in contact with the epiblast, and a splanchnic plate in contact with the hypoblast (fig. I89). In the interspaces between the segments the mesoblast is continuous across the median ventral line. The mesoblast is prolonged into each of the appendages as these are formed, and in the appendages there is present a central cavity. By Metschnikoff these cavities are stated to be continuous, as in Myriapods and Arachnida, with those of the somites; but by Hatschek (No. 414) they are stated to be independent of those in the somites and to be open to the yolk.

The further details of the history of the mesoblast are very imperfectly known, and the fullest account we have is that by Dohrn (No. 408) for Gryllotalpa. It would appear that the mesoblast grows round and encloses the dorsal side of the yolk earlier than the epiblast. In Gryllotalpa it forms a pulsating membrane. As the epiblast extends dorsalwards the median dorsal part of the membrane is constricted off as a tube which forms the heart. At the same time the free space between the pulsating membrane and the yolk is obliterated, but transverse passages are left at the lines between the somites, through which the blood passes from the ventral part of the body to corresponding openings in the wall of the heart. The greater part of the membrane gives rise to the muscles of the trunk. 
Ventrally the mesoblastic bands soon meet across the median line. The cavities in the appendages become obliterated and their mesoblastic walls form the muscles, etc. The cavities in the separate mesoblastic somites also cease to be distinctly circumscribed.

The splanchnic mesoblast follows the hypoblast in its growth, and gives rise to the connective tissue and muscular parts of the walls of the alimentary tract. The mesoblastic wall of the proctodæum is probably formed independently of the mesoblastic somites. In the head the mesoblast is stated to form at first a median ventral mass, which does not pass into the procephalic lobe; though it assists in forming both the antennæ and upper lip.

The alimentary canal. The alimentary tract of Insects is formed of three distinct sections (fig. 18I) - a mesenteron or middle section (me), a stomodxum (st) and a proctodæum $(a n)$. The stomodæum and proctodreum are invaginations of the epiblast, while the mesenteron is lined by the hypoblast. The distinction between the three is usually well marked in the adult by the epiblastic derivatives being lined by chitin. The stomodæum consists of mouth, œsophagus, crop, and proventriculus or gizzard, when such are present. The mesenteron includes the stomach, and is sometimes (Orthoptera, etc.) provided at its front end with pyloric diverticula-posteriorly it terminates just in front of the Malpighian bodies. These latter fall into the proctodæum, which includes the whole of the region from their insertion to the anus.

The oral invagination appears nearly coincidently with the first formation of segments at the front end of the groove between the lateral nerve cords, and the anal invagination appears slightly later at the hindermost end of the ventral plate.

The Malpighian bodies arise as two pairs of ontgrowths of the epiblast of the proctodaum, whether solid at first is not certain. The subsequent increase which usually takes place in their number is due to sproutings (at first solid) of the two original vessels.

The glandular walls of the mesenteron are formed from the hypoblast; but the exact origin of the layer has not been thoroughly worked out in all cases. In Hydrophilus it is stated by Kowalevsky (No. 416) to appear as two sheets split off from the lateral masses of mesoblast, which gradually grow round the yolk, and a similar mode of formation would seem to hold good for Apis. Tichomiroff (No.420) confirms Kowalevsky on this point, 
and further states that these two masses meet first ventrally and much later on the dorsal side. In Lepidoptera, on the other hand, Hatschek finds that the hypoblast arises as a median mass of polygonal cells in the anterior part of the ventral plate. These cells increase by absorbing material from the yolk, and then gradually extend themselves and grow round the yolk.

Dohrn (No. 408) believes that the yolk cells, the origin of which has already been spoken of, give rise to the hypoblastic walls of the mesenteron, and this view appears to be shared by Graber (No. 412), though the latter author holds that some of the yolk cells are derived by budding from the blastoderm ${ }^{1}$.

From the analogy of Spiders I am inclined to accept Dohrn's and Graber's view. It appears to me probable that Kowalevsky's observations are to be explained by supposing that the hypoblast plates which he believes to be split off from the mesoblast are really separated from the yolk.

It will be convenient to add here a few details to what has already been stated as to the origin of the yolk cells. As mentioned above, the central yolk breaks up at a period, which is not constant in the different forms, into polygonal or rounded masses, in each of which a nucleus has in many instances been clearly demonstrated although in others such nuclei have not been made out. It is probable however that nuclei are in all cases really present, and that these masses must be therefore regarded as cells. They constitute in fact the yolk cells. The periphery of the yolk breaks up into cells while the centre is still quite homogeneous.

The hypoblastic walls of the mesenteron appear to be formed in the first instance laterally (fig. I $89 \mathrm{~B}$ and $\mathrm{C}, h y$ ). They then meet ventrally (fig. I85 A and B), and finally close in the mesenteron on the dorsal side.

The mesenteron is at first a closed sack, independent of both stomodæum and proctodæum; and in the case of the Bee it so remains even after the close of embryonic life. The only glandular organs of the mesenteron are the not unfrequent pyloric tubes, which are simple outgrowths of its anterior end. It is possible that in some instances they may be formed in situ around the lateral parts of the yolk.

In many instances the whole of the yolk is enclosed in the walls of the mesenteron, but in other cases, as in Chirononus and Simulia (Weismann, No. 430 ; Metschnikoff, No. 423), part of the yolk may be left between the ventral wall of the mesenteron and the ventral plate. In Chironomus the

${ }^{1}$ Graber's view on this point may probably be explained by supposing that he has mistaken a passage of yolk cells into the blastoderm for a passage of blastoderm cells into the yolk. The former occurrence takes place, as I have found, largely in Spiders, and probably therefore also occurs in Insects. 
mass of yolk external to the mesenteron takes the form of a median and two lateral streaks. Some of the yolk cells either prior to the establishment of the mesenteron, or derived from the unenclosed portions of the yolk, pass into the developing organs (Dohrn, 408) and serve as a kind of nutritive cell. They also form blood corpuscles and connective-tissue elements. Such yolk cells may be compared to the peculiar bodies described by Reichenbach in Astacus, which form the secondary mesoblast. Similar cells play a very important part in the development of Spiders.

Generative organs. The observations on the development of the generative organs are somewhat scanty. In Diptera certain cells--known as the pole cells-are stated by both Metschnikoff (No.423) and Leuckart to give rise to the generative organs. The cells in question (in Chironomus and Musca vomitoria, Weismann, No. 430) appear at the hinder end of the ovum before any other cells of the blastoderm. They soon separate from the blastoderm and increase by division. In the embryo, produced by the viviparous larva of Cecidomyia, there is at first a single pole cell, which eventually divides into four, and the resulting cells become enclosed within the blastoderm. They next divide into two masses, which are stated by Metschnikoff (No.423) to become surrounded by indifferent embryonic cells ${ }^{1}$. Their protoplasm then fuses, and their nuclei divide, and they give rise to the larval ovaries, for which the enclosing cells form the tunics.

In Aphis Metschnikoff (No. 423) detected at a very early stage a mass of cells which give rise to the generative organs. These cells are situated at the hind end of the ventral plate; and, except in the case of one of the cells which gives rise by division to a green mass adjoining the fat body, the protoplasm of the separate cells fuses into a syncytium. Towards the close of embryonic life the syncytium assumes a horse-shoe form. The mass is next divided into two, and the peripheral layer of each part gives rise to the tunic, while from the hinder extremity of each part an at first solid duct-the egg-tube-grows out. The masses themselves form the germogens. The oviduct is formed by a coalescence of the ducts from each germogen.

Ganin derives the generative organs in Platygaster (vide p. 347) from the hind end of the ventral plate close to the proctodæum; while Suckow states that the generative organs are outgrowths of the proctodæum. According to these two sets of observations the generative organs would appear to have an epiblastic origin-an origin which is not incompatible with that from the pole cells.

In Lepidoptera the genital organs are present in the later periods of embryonic life as distinct paired organs, one on each side of the heart, in the eighth postcephalic segment. They are elliptical bodies with a duct passing off from the posterior end in the female or from the middle in the male. The egg-tubes or seminal tubes are outgrowths of the elliptical bodies.

I This point requires further observation. 
In other Insects the later stages in the development of the generative organs closely resemble those in the Lepidoptera, and the organs are usually distinctly visible in the later stages of embryonic life.

It may probably be laid down, in spite of some of Metschnikoff's observations above quoted, that the original generative mass gives rise to both the true genital glands and their ducts. It appears also to be fairly clear that the genital glands of both sexes have an identical origin.

\section{Special types of larve.}

Certain of the Hymenopterous forms, which deposit their eggs in the eggs or larvæ of other Insects, present very peculiar modifications in their development. Platygaster, which Iays its egg in the larvæ of Cecidomyia, undergoes perhaps the most remarkable development amongst these forms. It has been studied especially by Ganin (No. 410), from whom the following account is taken.

The very first stages are unfortunately but imperfectly known, and the interpretations offered by Ganin do not in all cases appear quite satisfactory. In the earliest stage after being laid the egg is enclosed in a capsule produced into a stalk (fig. I90 A). In the interior of the egg there soon appears a single spherical body, regarded by Ganin as a cell (fig. I9o B). In the next stage three similar bodies appear in the vitellus, no doubt derived from the first one (fig. I9o C). The central one presents somewhat different characters to the two others, and, according to Ganin, gives rise to the whole cmbryo. The two peripheral bodies increase by division, and soon appear as nuclei imbedded in a layer of protoplasin (fig. Igo D, E, F). The layer so formed serves as a covering for the embryo, regarded by Ganin as equivalent to the amnion (? serous membrane) of other Irsect embryos. In the embryo cell new cells are stated to be formed by a process
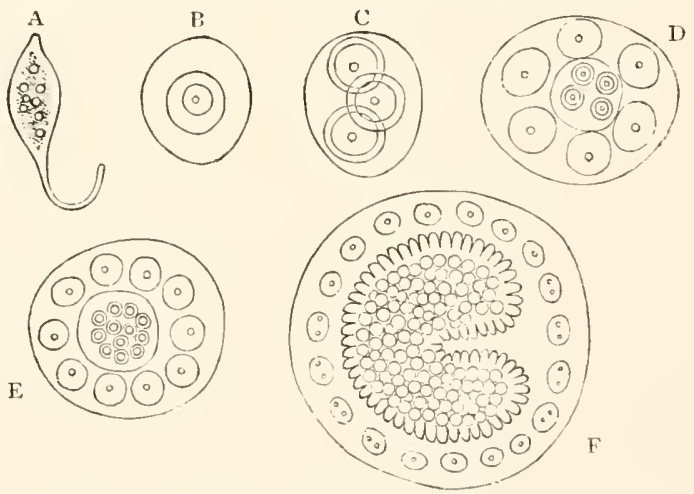

Fig. igo. A series of Stages in the Development of endogenous cell formation (fig. I90 D, E). It appears probable that Ganin has mistaken nuclei for cells in the earlier stages, and that a blastoderm is formed as in other Insects, and that this becomes divided in a way not explained into a superficial layer which gives rise to the serous envelope, and a deeper layer which forms the embryo. However this 
may be, a differentiation into an epiblastic layer of columnar cells and a hypoblastic layer of more rounded cells soon becomes apparent in the body of the embryo. Subsequently to this the embryo grows rapidly, till by a deep transverse constriction on the ventral surface it becomes divided into an anterior cephalothoracic portion and a posterior caudal portion (fig. Igo F). The cephalothorax grows in breadth, and near its anterior end an invagination appears, which gives rise to the mouth and cesophagus. On the ventral side of the cephalothorax there is first formed a pair of claw-like appendages on each side of the mouth, then a posterior pair of appendages near the junction of the cephalothorax and abdomen, and lastly a pair of short conical antennæe in front.

At the same time the hind end of the abdomen becomes bifid, and gives rise to a fork-like caudal appendage; and at a slightly later period four grooves make their appearance in the caudal region, and divide this part of the embryo into successive segments. While these changes have been taking place in the general form of the embryo, the epiblast has given rise to a cuticle, and the hypoblastic cells have become differentiated into a central hypoblastic axis - the mesenteron-and a surrounding layer of mesoblast, some of the cells of which form longitudinal muscles.

With this stage closes what may be regarded as the embryonic development of Platygaster. The embryo becomes free from the amnion, and presents itself as a larva, which from its very remarkable characters has been spoken of as the Cyclops larva by Ganin.

The larvæ of three species have been described by Ganin, which are represented in fig. I $9 \mathrm{I} \mathrm{A,} \mathrm{B,} \mathrm{C.} \mathrm{These} \mathrm{larvæ} \mathrm{are} \mathrm{strangely} \mathrm{dissimilar} \mathrm{to} \mathrm{the} \mathrm{ordinary}$ Hexapod type, whether larval or adult. They are formed of a cephalothoracic shield with the three pairs of appendages $(a, k f, l f g)$, the development of which has already been described, and of an abdomen formed of five segments, the last of which bears the somewhat varying caudal appendages. The nervous system is as yet undeveloped.

The larvæ move about in the tissues of their hosts by means of their claws.

The first larval condition is succeeded by a second with very different characters, and the passage from the first to the second is accompanied by an ecdysis.

The ecdysis commences at the caudal extremity, and the whole of the last segment is completely thrown off. As the ecdysis extends forwards the tail loses its segmentation and becomes strongly compressed, the appendages of the cephalothorax are thrown off, and the whole embryo assumes an oval form without any sharp distinction into different regions and without the slightest indication of segmentation (fig. I9I D). Of the internal changes which take place during the shedding of the cuticle, the first is the formation of a proctodæum $(g / h)$ by an invagination, which ends blindly in contact with the mesenteron. Shortly after this a thickening of the epiblast $(b s m)$ appears along the ventral surface, which gives rise mainly to the ventral nerve cord; this thickening is continuous behind with the 
epiblast which is invaginated to form the proctodæum, and in front is prolonged on each side into two procephalic lobes, in which there are also thickenings of the epiblast ( $g s a c$ ), which become converted into supraœsophageal ganglia, and possibly other parts.

Towards the close of the second larval period the muscles $(\mathrm{lm})$ become segmentally arranged, and give indications of the segmentation which

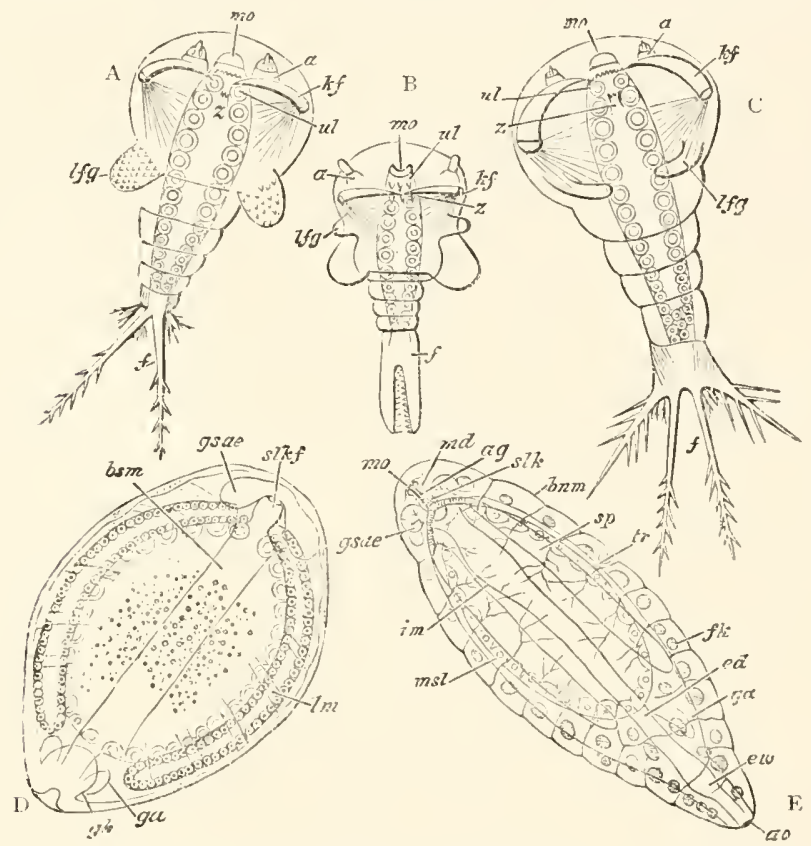

Fig. 191. A series of stages in the Development of Platygaster.

(From Lubbock ; after Ganin.)

A. B. C. Cyclops larvæ of three species of Platygaster.

D. Second larval stage. E. Third larval stage.

mo. mouth; $a$. antenna; $k f$. hooked feet ; lfg. lateral feet; $f$. branches of tail ; ul. lower lip; slkf. œsophagus; osae. supra-œesophageal ganglion; bsm. ventral epiblastic plate; $l m$. lateral muscles (the letters also point in D to the salivary glands); $g h$. proctodæum; $g \alpha$. generative organs; $m d$. mandibles; $a g$. ducts of salivary glands; $s p$. (in E) salivary glands; $m l s$. stomach; $c d$. intestine; $e z v$. rectum; $a o$. anus; tr. tracheæ; fk. fat body.

becomes apparent in the third larval period. The third and last larval stage (fig. I9I E) of Platygaster, during which it still remains in the tissues of its host, presents no very peculiar features. The passage from the second to the third form is accompanied by an ecdysis.

Remarkable as are the larva just described, there can I think be no reason, considering their parasitic habits, for regarding them as ancestral. 


\section{Metamorploosis and heterogamy.}

Metamorphosis. The majority of Insects are born in a condition in which they obviously differ from their parents. The extent of this difference is subject to very great variations, but as a rule the larve pass through a very marked metamorphosis before reaching the adult state. The complete history of this metamorphosis in the different orders of Insects involves a far too considerable amount of zoological detail to be dealt with in this work; and I shall confine myself to a few observations on the general characters and origin of the metamorphosis, and of the histological processes which take place during its occurrence ${ }^{1}$.

In the Aptera the larva differs from the adult only in the number of facets in the cornea and joints in the antennæ.

In most Orthoptera and Hemiptera the larvæ differ from the adult in the absence of wings and in other points. The wings, etc., are gradually acquired in the course of a series of successive moultings. In the Ephemeridæ and Libellulidæ, however, the metamorphosis is more complicated, in that the larvæ have provisional tracheal gills which are exuviated before the final moult. In the Ephemeridæ there are usually a great number of moultings; the tracheal gills appear after the second moult, and the rudiments of the wings when the larva is about half grown. Larval life may last for a very long period.

In all the other groups of Insects, viz. the Diptera, Neuroptera, Coleoptera, Lepidoptera, and Hymenoptera, the larva passes-with a few exceptions-through a quiescent stage, in which it is known as a pupa, before it attains the adult stage. These forms are known as the Holometabola.

In the Diptera the larvæ are apodous. In the true flies (Muscidæ) they are without a distinct head and have the jaws replaced by hooks. In the Tipulidx there is on the other hand a well-developed head with the normal appendages. The pupæ of the Muscidæ are quiescent, and are enclosed in the skin of the larva which shrinks and forms a firm oval case. In the

1 For a systematic account of this subject the reader is referred to Lubbock (No. 420 ) and to Graber (No.411). He will find in Weismann (Nos. 430 and 431) a detailed account of the internal changes which take place. 
Tipulida the larval skin is thrown off at the pupa stage, and in some cases the pupæ continue to move about.

The larvæ of the Neuroptera are hexapodous voracious forms. When the larva becomes a pupa all the external organs of the imago are already established. The pupa is often invested in a cocoon. It is usually quiescent, though sometimes it begins to move about shortly before the imago emerges.

In the Coleoptera there is considerable variety in the larval forms. As a rule the larvæ are hexapodous and resemble wingless Insects. But some herbivorous larva (e.g. the larva of Melolontha) closely resemble true caterpillars, and there are also grub-like larvæ without feet (Curculio) which resemble the larvæ of Hymenoptera. The pupa is quiescent, but has all the parts of the future beetle plainly visible. The most interesting larvæ among the Coleoptera are those of Sitaris, one of the Meloidæ (Fabre, No. 409). They leave the egg as active hexapodous larvæ which attach themselves to the bodies of Hymenoptera, and are thence transported to a cell filled with honey. Here they eat the ovum of the Hymenopterous form. They then undergo an ecdysis, in which they functionally lose their appendages, retaining however small rudiments of them, and become grubs. They feed on the honey and after a further ecdysis become pupæ.

In the Lepidoptera the larva has the well-known form of a caterpillar. The caterpillars have strong jaws, adapted for biting vegetable tissues, which are quite unlike the oral appendages of the adult. They have three pairs of jointed thoracic legs, and a variable number (usually five) of pairs of rudimentary abdominal legs - the so-called pro-legs. The larva undergoes numerous ecdyses, and the external parts of the adult such as the wings, etc., are formed underneath the chitinous exoskeleton before the pupa stage. The pupa is known as a chrysalis and in some Lepidoptera is enveloped in a cocoon.

The Hymenoptera present considerable variations in the character of the larva. In the Aculeata, many Entomophaga, the Cynipidæ, etc., the larvæ are apodous grubs, incapable of going in search of their food; but in the Siricidæ they are hexapodous forms like caterpillars, which are sometimes even provided with pro-legs. In some of the Entomophaga the larvæ have very remarkable characters which have already been described in a special section, vide pp. 4I8, 4I9.

Before proceeding to the consideration of the value of the various larval forms thus shortly enumerated, it is necessary to say a few words as to the internal changes which take place during the occurrence of the above metamorphosis. In the simplest cases, such as those of the Orthoptera and Hemiptera, where the metamorphosis is confined to the gradual formation of the wings, etc. in a series of moults, the wings first appear as two folds of the epidermis beneath the cuticle on the two posterior thoracic segments. At the next moult these processes 
become covered by the freshly formed cuticle, and appear as small projections. At every successive moult these projections become more prominent owing to a growth in the epidermis which has taken place in the preceding interval. Accompanying the formation of such organs as the wings, internal changes necessarily take place in the arrangement of the muscles, etc. of the thorax, which proceed pari passu with the formation of the organs to which they belong. The characters of the metamorphosis in such forms as the Ephemeridæe only differ from the above in the fact that provisional organs are thrown off at the same time that the new ones are formed.

In the case of the Holometabola the internal phenomena of the metamorphosis are of a very much more remarkable character. The details of our knowledge are largely due to Weismann (Nos. 430 and 431). The larvæ of the Holometabola have for the most part a very different mode of life to the adults. A simple series of transitions between the two is impossible, because intermediate forms would be for the most part incapable of existing. The transition from the larval to the adult state is therefore necessarily a more or less sudden one, and takes place during the quiescent pupa condition. Many of the external adult organs are however formed prior to the pupa stage, but do not become visible on the surface. The simplest mode of Holometabolic metamorphosis may be illustrated by the development of Corethra plumicornis, one of the Tipulidæ. This larva, like that of other Tipulidæ, is without thoracic appendages, but before the last larval moult, and therefore shortly before the pupa stage, certain structures are formed, which Weismann has called imaginal discs. These imaginal discs are in Corethra simply invaginations of the epidermis. There are in the thorax six pairs of such structures, three dorsal and three ventral. The three ventral are attached to the terminations of the sensory nerves, and the limbs of the imago are formed as simple outgrowths of them, which as they grow in length take a spiral form. In the interior of these outgrowths are formed the muscles, tracher, etc., of the limbs; which are believed by Weismann (it appears to me without sufficient ground) to be derived from a proliferation of the cells of the neurilemma. The wings are formed from the two posterior dorsal imaginal 
discs. The hypodermis of the larva passes directly into that of the imago.

The pupa stage of Corethra is relatively very short, and the changes in the internal parts which take place during it are not considerable. The larval abdominal muscles pass for the most part unchanged into those of the imago, while the special thoracic muscles connected with the wings, etc., develop directly during the latest larval period from cords of cells already formed in the embryo.

In the Lepidoptera the changes in the passage from the larval to the adult state are not very much more considerable than those in Corethra. Similar imaginal discs give rise during the later larval periods to the wings, etc. The internal changes during the longer pupa period are somewhat more considerable. Important modifications and new formations arise in connection with the alimentary tract, the nervous and muscular systems.

The changes which take place in the true flies (Muscidæ) are far more complicated than either those in Corethra or in the Lepidoptera. The abdomen of the larva of Musca becomes bodily converted into the abdomen of the imago as in the above types, but the whole epidermis and appendages of the head and thorax are derived from imaginal discs which are formed within and (so far as is known) independently of the epidermis of the larva or embryo. These imaginal discs are simple masses of apparently indifferent cells, which for the most part appear at the close of embryonic life, and are attached to nerves or trachex. They grow in size during larval life, but during the relatively long pupa stage they unite together to give rise to a continuous epidermis, from which the appendages grow out as processes. The epidermis of the anterior part of the larva is simply thrown off, and has no share in forming the epidermis of the adult.

There are a pair of cephalic imaginal discs and six pairs of thoracic discs. Two pairs, a dorsal and a ventral, give rise to each thoracic ring, and the appendages attached to it.

Though, as mentioned above, no evidence has yet been produced to shew that the imaginal discs of Musca are derived from the embryonic epiblast, yet their mode of growth and 
eventual fate proves beyond the shadow of a doubt that they are homologous with the imaginal discs of Corethra. Their earliest origin is well worth further investigation.

The metamorphosis of the internal organs is still more striking than that of the external. There is a disruption, total or partial, of all the internal organs except the generative organs. In the case of the alimentary tract, the Malpighian vessels, the heart and the central nervous system, the disruption is of a partial kind, which has been called by Weismann histolysis. The cells of these organs undergo a fatty degeneration, the nuclei alone in some cases remaining. The kind of plasma resulting from this degeneration retains the shape of the organs, and finally becomes built up again into the corresponding organs of the imago. The tracheæ, muscles and peripheral nerves, and an anterior part of the alimentary tract, are entirely disrupted. They seem to be formed again from granular cells derived from the enormous fat body.

The phenomena of the development of the Muscidæ are undoubtedly of rather a surprising character. Leaving for the moment the question of the origin of the pupa stage to which I return below, it will be admitted on all hands that during the pupa stage the larva undergoes a series of changes which, had they taken place by slow degrees, would have involved, in such a case as Musca, a complete though gradual renewal of the tissues. Such being the case, the cells of the organs common to the larva and the imago would, in the natural course of things, not be the same cells as those of the larva but descendants of them. We might therefore expect to find in the rapid conversion of the larval organs into those of the adult some condensation, so to speak, of the process of ordinary cell division. Such condensations are probably represented in the histolysis in the case of the internal organs, and in the formation of imaginal discs in the case of the external ones, and I think it probable that further investigation will shew that the imaginal discs of the Muscidæ are derivatives of the embryonic epiblast. The above considerations by no means explain the whole of Weismann's interesting observations, but an explanation is I believe to be found by following up these lines.

Niore or less parallel phenomena to those in Insects are found in the development of the Platyelminthes and Echinoderms. The four disc-like invaginations of the skin in many larval Nemertines (vide p. 198), which give rise to the permanent body wall of the Nemertine, may be compared to the imaginal discs. The subsequent throwing off of the skin of Pilidium or larva of Desor is a phenomenon like the absorption of part of the larval skin of Musca. The formation of an independent skin within the first larval 
form in the Distomer and in the Cestoda may be compared to the apparently independent formation of the imaginal discs in Musca.

The fact that in a majority of instances it is possible to trace an intimate connection between the surroundings of a larva and its organization proves in the clearest way that the characters of the majority of existing larval forms of Insects have owed their origin to secondary adaptations. A few instances will illustrate this point.

In the simplest types of metamorphosis, e.g. those of the Orthoptera genuina, the larva has precisely the same habits as the adult. We find that a caterpillar form is assumed by phytophagous larve amongst the Lepidoptera, Hymenoptera and Coleoptera. Where the larva has not to go in search of its nutriment the grub-like apodous form is assumed. The existence of such an apodous larva is especially striking in the Hymenoptera, in that rudiments of thoracic and abdominal appendages are present in the embryo and disappear again in the larva. The case of the larva of Sitaris, already described (p. $42 \mathrm{I}$ ), affords another very striking proof that the organization of the larva is adapted to its habits.

It follows from the above that the development of such forms as the Orthoptera genuina is more primitive than that of the holometabolous forms; a conclusion which tallies with the fact

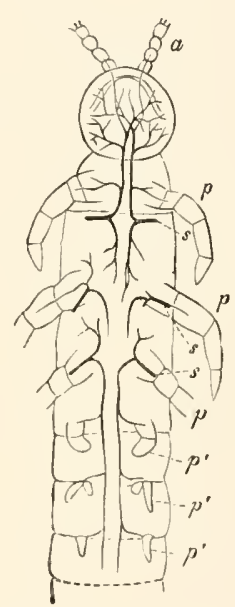

Fig. I92. ANTERIOR HALF OF CAMPODEA FRAGILIS. (From Gegenbaur; after Palmen.)

$a$. antennæ; $p$. feet ; $p$. post-thoracic rudimentary feet; s. stigma. that both palæontological and anatomical evidence shew the Orthoptera to be a very primitive group of Insects.

The above argument probably applies with still greater force to the case of the Thysanura; and it seems to be probable that this group is more nearly related than any other to the primitive wingless ancestors of Insects $^{1}$. The characters of the oral

${ }^{1}$ Brauer and Lubbock (No. 421) have pointed out the primitive characters of these forms, especially of Campodea. 
appendages in this group, the simplicity of their metamorphosis, and the presence of abdominal appendages (fig. 192), all tell in favour of this view, while the resemblance of the adult to the larvæ of the Pseudoneuroptera, etc., points in the same direction. The Thysanura and Collembola are not however to be regarded as belonging to the true stock of the ancestors of Insects, but as degenerated relations of this stock; much as Amphioxus and the Ascidians are degenerate relations of the ancestral stock of Vertebrates, and Peripatus of that of the Tracheata. It is probable that all these forms have succeeded in retaining their primitive characters from their degenerate habits, which prevented them from entering into competition in the struggle for existence with their more highly endowed relatives. While in a general way it is clear that the larval forms of Insects cannot be expected to throw much light on the nature of Insect ancestors, it does nevertheless appear to me probable that such forms as the caterpillars of the Lepidoptera are not without a meaning in this respect. It is easy to conceive that even a secondary larval form may have been produced by the prolongation of one of the embryonic stages; and the general similarity of a caterpillar to Peripatus, and the retention by it of post-thoracic appendages, are facts which appear to favour this view of the origin of the caterpillar form.

The two most obscure points which still remain to be dealt with in the metamorphosis of Insects are (I) the origin of the quiescent pupa stage; (2) the frequent dissimilarity between the masticatory apparatus of the larva and adult.

These two points may be conveniently dealt with together, and some valuable remarks about them will be found in Lubbock (No. 420$)$.

On grounds already indicated it may be considered certain that the groups of Insects without a pupa stage, and with a larva very similarly organised to the adult, preceded the existing holometabolic groups. The starting-point in the metamorphosis of the latter groups was therefore something like that of the Orthoptera. Suppose it became an advantage to a species that the larva and adult should feed in a somewhat different way, a difference in the character of their mouth parts would soon make itself manifest; and, since an intermediate type of mouth parts 
would probably be disadvantageous, there would be a tendency to concentrate into a single moult the transition from the larval to the adult form of mouth parts. At each ordinary moult there is a short period of quiescence, and this period of quiescence would naturally become longer in the important moult at which the change in the mouth parts was effected. In this way a rudimentary pupa stage might be started. The pupa stage, once started, might easily become a more important factor in the metamorphosis. If the larva and imago diverged still more from each other, a continually increasing amount of change would have to be effected at the pupa stage. It would probably be advantageous to the species that the larva should not have rudimentary functionless wings; and the establishment of the wings as external organs would therefore become deferred to the pupa stage. The same would probably apply to other organs.

Insects usually pass through the pupa stage in winter in cold climates and during the dry season in the tropics, this stage serving therefore apparently for the protection of the species during the inclement season of the year. These facts are easily explained on the supposition that the pupa stage has become secondarily adapted to play a part in the economy of the species quite different from that to which it owes its origin.

Heterogamy. The cases of alternations of generations amongst Insects all fall under the heading already defined in the introduction as Heterogamy. Heterogamy amongst Insects has been rendered possible by the existence of parthenogenesis, which, as stated in the introduction, has been taken hold of by natural selection, and has led to the production of generations of parthenogenetic forms, by which a clear economy in reproduction is effected. Parthenogenesis without heterogamy occurs in a large number of forms. In Bees, Wasps, and a Sawfly (Nematus ventricosus) the unfertilized ova give rise to males. In two Lepidopterous genera (Psyche and Solenobia) the unfertilized ova give rise mainly, if not entirely, to females. Heterogamy occurs in none of the above types, but in Psyche and Solenobia males are only occasionally found, so that a series of generations producing female young from unfertilized ova are followed by a generation producing young of both sexes from fertilized ova. It 
would be interesting to know if the unimpregnated female would not after a certain number of generations give rise to both males and females; such an occurrence might be anticipated on grounds of analogy. In the cases of true heterogamy parthenogenesis has become confined to special generations, which differ in their character from the generations which reproduce themselves sexually. The parthenogenetic generations generally flourish during the season when food is abundant; while the sexual generations occur at intervals which are often secondarily regulated by the season, supply of food, etc.

A very simple case of this kind occurs, if we may trust the recent researches of Lichtenstein ${ }^{1}$, in certain Gall Insects (Cynipidx). He finds that the female of a form known as Spathegaster baccarum, of which both males and females are plentiful, pricks a characteristic gall in certain leaves, in which she deposits the fertilized eggs. The eggs from these galls give rise to a winged and apparently adult form, which is not, however, Spathegaster, but is a species considered to belong to a distinct genus known as Neuroterus ventricularis. Only females of Neuroterus are found, and they lay unfertilized ova in peculiar galls which develop into Spathegaster baccarum. Here we have a true case of heterogamy, the females which produce parthenogenetically having become differentiated from those which produce sexually. Another interesting type of heterogamy is that which has been long known in the Aphides. In the autumn impregnated eggs are deposited by females, which give rise in the course of the spring to females which produce parthenogenetically and viviparously. The viviparous females always differ from the females which lay the fertilized eggs. The generative organs are of course differently constituted, and the ova of the viviparous females are much smaller than those of the oviparous females, as is generally the case in closely allied viviparous and oviparous forms; but in addition the former are usually without wings, while the latter are winged. The reverse is however occasionally the case. An indefinite number of generations of viviparous females may be produced if they are artificially kept warm and supplied with food; but in the course of 
nature the viviparous females produce in the autumn males and females which lay eggs with firm shells, and so preserve the species through the winter. The heterogamy of the allied Coccidx is practically the same as that of the Aphidæ. In the case of Chermes and Phylloxera the parthenogenetic generations lay their eggs in the normal way.

The complete history of Phylloxera quercus has been worked out by Balbiani (No. 401). The apterous females during the summer lay eggs developing parthenogenetically into apterous females, which continue the same mode of reproduction. In the autumn, however, the eggs which are laid give rise in part to winged forms and in part to apterous forms. Both of these forms lay smaller and larger eggs, which develop respectively into very minute males and females without digestive organs. The fertilized eggs laid by these forms probably give rise to the parthenogenetic females.

A remarkable case of heterogamy accompanied by pædogenesis was discovered by Wagner to take place in certain species of Cecydomyia (Miastor), a genus of the Diptera. The female lays a few eggs in the bark of trees, etc. These eggs develop in the winter into larvæ, in which ovaries are early formed. The ova become detached into the body cavity, surrounded by their follicles, and grow at the cost of the follicles. They soon commence to undergo a true development, and on becoming hatched they remain for some time in the body cavity of the parent, and are nourished at the expense of its viscera. They finally leave the empty skin of their parent, and subsequently reproduce a fresh batch of larvæ in the same way. After several generations the larvæ undergo in the following summer a metamorphosis, and develop into the sexual form.

Another case of pæedogenesis is that of the larvæ of Chironomus, which have been shewn by Grimm (No. 41:3) to lay eggs which develop exactly in the same way as fertilized eggs into larvæ.

\section{BIBLIOGRAPHY.}

(401) M. Balbiani. "Observations s. la reproduction d. Phylloxera du Chêne." An. Sc. Nat. Ser. v. Vol, xix. isił. 
(402) E. Bessels. "Studien ü. d. Entwicklung d. Sexualdriisen bei den Lepidoptera." Zeit.f. wiss. Zool. Bd. xviı. I 867.

(403) Alex. Brandt. "Beiträge zur Entwicklungsgeschichte d. Libellulida u. Hemiptera, mit besonderer Berücksichtigung d. Embryonalhïllen derselben." Mém. Ac. Pétersbourg, Ser. vir. Vol. xin. I 869 .

(404) A lex. Brandt. Ueber das Ei $u$. seine Bildungsstätte. Leipzig, I878.

(405) O. Biitschli. "Zur Entwicklungsgeschichte d. Biene." Zeit. f. wiss. Zool. Bd. Xx. ז 870 .

(406) H. Dewitz. "Bau u. Entwicklung d. Stachels, etc." Zeit.f. wiss. Zool. Vols. Xxv. and xxviri. 1875 and 1877.

(407) H. Dewitz. "Beiträge zur Kenntniss d. Postembryonalentwicklung d. Gliedmassen bei den Insecten." Zeit.f. wiss. Zool. xxx. Supplement. I878.

(408) A. Dohrn. "Notizen zur Kenntniss d. Insectenentwicklung." Zeitschrift f. wiss. Zool. Bd. xxvi. 1876 .

(409) M. Fabre. "L’hypermétamorphose et les mœurs des MéloÏdes." An. Sci. Nat. Series IV. Vol. viI. I857.

(410) Ganin. "Beiträge zur Erkenntniss d. Ent wicklungsgeschichte d. Insecten." Zeit.f. zuiss. Zool. Bd. Xix. I869.

(411) V. Graber. Die Insecten. München, 1877. .

(412) V. Graber. "Vorlauf. Ergeb. ïb. vergl. Embryologie d. Insecten." Archiv f. mikr. Anat. Vol. XV. I878.

(413) O. v. Grim m. "Ungeschlechtliche Fortpflanzung einer Chironomus Art-u. deren Entwicklung aus dem unbefruchteten Ei." Mím. Acad. Pétersbourg. 1870.

(414) B. Hatschek. "Beiträge zur Entwicklung d. Lepidopteren." Fenaische Zeitschrift, Bd. xI.

(415) A. Kölliker. "Observationes de primâ insectorum genese, etc." Ann.Sc. Nat. Vol. xx. $18+3$.

(416) A. Kowalevsky. "Embryologische Studien an Würmern u. Arthropoden." Mém. Ac. imp. Pítersbourg, Ser. vir. Vol. xvi. r87I.

(417) C. Kraepelin. "Untersuchungen ïb. d. Bau, Mechanismus u. d. Entwick. des Stachels d. bienartigen Thiere." Zeit.f. wiss. Zool. Vol, xxıII. I873.

(418) C. Kupffer. "Faltenblatt an d. Embryonen d. Gattung Chironomus." Arch.f. mikr. Anat. Vol. II. I $\$ 66$.

(419) R. Leuckart. Zur Kenntniss d. Generationswechsels $u$. $d$. Parthenogenese b. $d$. Insecten. Frankfurt, ${ }_{1} 88$.

(420) Lubbock. Origin and Metamorphosis of Insects. I874.

(421) Lubbock. Monograph on Collembola and Thysanura. Ray Society, 1873 .

(422) Melnikow. "Beiträge z. Embryonalentwicklung d. Insecten." Archiv f. Naturgeschichte, Bd. xxxv. I\$69.

(423) E. Metschnikoff. "Embryologische Studien an Insecten." Zeit. $f$. zviss. Zool. Bd. xvı. 1866 .

(42t) P. Meyer. "Ontogenie und Phylogenie d. Insecten." Fenaische Zeitschrift, Vol. x. $18 ; 6$.

(425) Fritz Müller. "Beiträge z. Kenntniss d. Termiten." Fenaische Zeitschrift, Vol. IX. I875.

(426) A. S. Packard. "Embryological Studies on Diplex, Perithemis, and the Thysanurous genus Isotoma." Nem. Peabody Acad. Science, I. 2. 187 I.

(427) Suckow. "Geschlechtsorgane d. Insecten." Heusinger's Zeitschrift f. organ. Physik, Bd. II. 1828 . 
(428) Tichomiroff. "Ueber die Entwicklungsgeschichte des Seidenwürms." Zoologischer Anzciger, II. Jahr. No. 20 (Preliminary Notice).

(429) Aug. Weismann. "Zur Embryologie d. Insecten." Archiv f. Anat. and Phys. 1864 .

(430) Aug. Weismann. "Entwicklung d. Dipteren." Zeit. f. wiss. Zool. Vols. XIIr. and XIv. Leipzig, I863-4.

(431) Aug. Weismann. "Die Metamorphose d. Corethra plumicornis." Zeit. f. wiss. Zool. Vol. xvi. i 866 .

(432) N. Wagner. "Beitrag z. Lehre d. Fortpflanzung d. Insectenlarven." Zeit.f. wiss. Zool. Vol. XIII. I860.

(433) Zaddach. Untersuchungen üb. d. Bau u.d. Entwicklungd. Gliederthiere. Berlin, I $85 t$.

\section{ARACHNIDA ${ }^{1}$.}

The development of several divisions of this interesting group has been worked out; and it will be convenient to deal in the first instance with the special history of each of these divisions, and then to treat in a separate section the development of the organs for the whole group.

Scorpionidæ. The embryonic development always takes place within the female Scorpion. In Buthus it takes place within follicle-like protuberances of the wall of the ovary. In Scorpio also development commences while the egg is still in the follicle, but when the trunk becomes segmented the embryo passes into the ovarian tube. The chief authority for the development of the Scorpionidæ is Metschnikoff (No. 434)

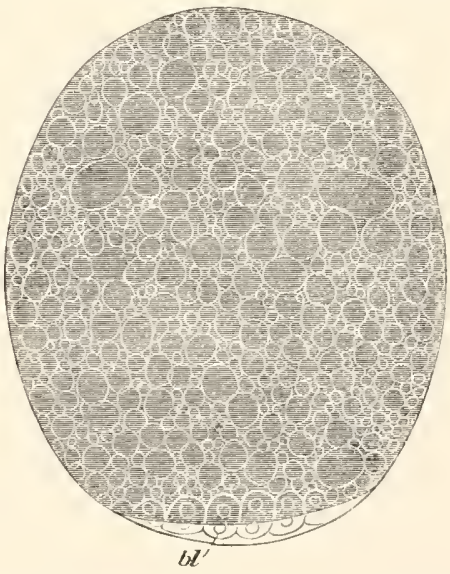

Fig. 193. Ovum of SCORPION With THE ALREADY-FORMED BLASTODERM SHEWING THE PARTIAL SEGMENTATION. (After Metschnikoff.)

$$
\text { bl. blastoderm. }
$$

At the pole of the ovum facing the ovarian tube there is

1 The classification of the Arachnida adopted in the present work is shewn below.
I. Arthrogastra. $\begin{cases}\text { Scorpionidæe } & \text { II. Araneina. } \\ \text { Pedipalpi. } & \text { Psendoscorpionidæ. } \\ \text { Solifugæ. } & \text { III. Acarina. } \\ \text { Phalangidæ. } & \end{cases}$
jTetrapneumones. ¿Dipneumones. 
formed a germinal disc which undergoes a partial segmentation (fig. I93 bl). A somewhat saucer-shaped one-layered blastoderm is then formed, which soon becomes thickened in the centre and then divided into two layers. The outer of these is the epiblast, the inner the mesoblast. Beneath the mesoblast there subsequently appear granular cells, which form the commencement of the hypoblast ${ }^{1}$.

During the formation of the blastoderm a cellular envelope is formed round the embryo. Its origin is doubtful, though it is regarded by Metschnikoff as probably derived from the blastoderm and homologous with the amnion of Insects. It becomes double in the later stages (fig. 195).

During the differentiation of the three embryonic layers the germinal disc becomes somewhat pyriform, the pointed end being the posterior. At this extremity there is a special thickening which is perhaps equivalent to the primitive cumulus of Spiders. The germinal disc continues gradually tospread over the yolk, but the original pyriform area is thicker than the remainder, and is marked off anteriorly and posteriorly by a shallow furrow. It constitutes a structure corresponding with the ventral plate of other Tracheata. It soon becomes grooved by a shallow longitudinal furrow (fig. I94 A) which subsequently becomes less distinct. It is then
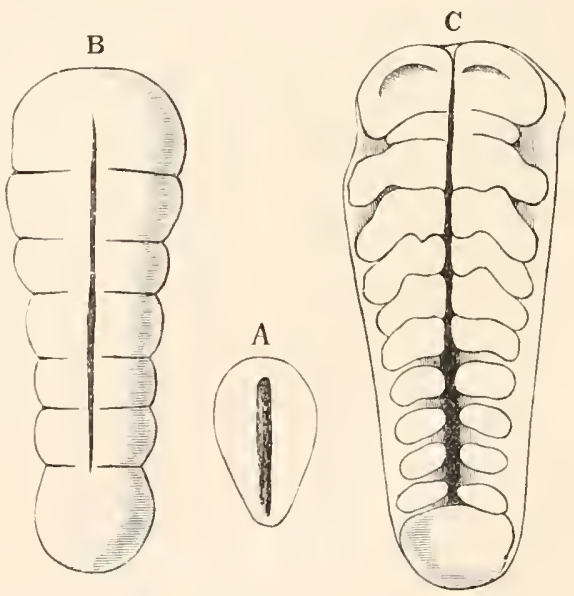

Fig. I94. THREe SURFACE VIEWS OF THE VENTRAL PLATE of a DEVELOPING SCORPION. (After Metschnikoff.)

A. Before segmentation.

B. After five segments have become formed.

C. After the appendages have begun to be formed. divided by two transverse lines into three parts ${ }^{2}$.

1 The origin of the hypoblast cells, if such these cells are, is obscure. Metschnikoff doubtfully derives them from the blastoderm cells; from my investigations on Spiders it appears to me more probable that they originate in the yolk.

"The exact fate of the three original segments is left somewhat obscure by 
In succeeding stages the anterior of the three parts is clearly marked out as the procephalic lobe, and soon becomes somewhat broader. Fresh segments are added from before backwards, and the whole ventral plate increases rapidly in length (fig. I94 B).

When ten segments have become formed, appendages appear as paired outgrowths of the nine posterior segments (fig. I94 C). The second segment bears the pedipalpi, the four succeeding segments the four ambulatory appendages, and the four hindermost segments smaller provisional appendages which subsequently disappear, with the possible exception of the second. The foremost segment, immediately behind the procephalic lobes, is very small, and still without a rudiment of the cheliceræe, which are subsequently formed on it. It would appear from Metschnikoff's figures to be developed later than the other post-oral segments present at this stage. The still unsegmented tail has become very prominent and makes an angle of $180^{\circ}$ with the remainder of the body, over the ventral surface of which it is flexed.

By the time that twelve segments are definitely formed, the procephalic region is distinctly bilobed, and in the median groove extending along it the stomodæum has become formed (fig. $196 \mathrm{~A}$ ). The cheliceræ $(c h)$ appear as small rudiments on the first post-oral segment, and the

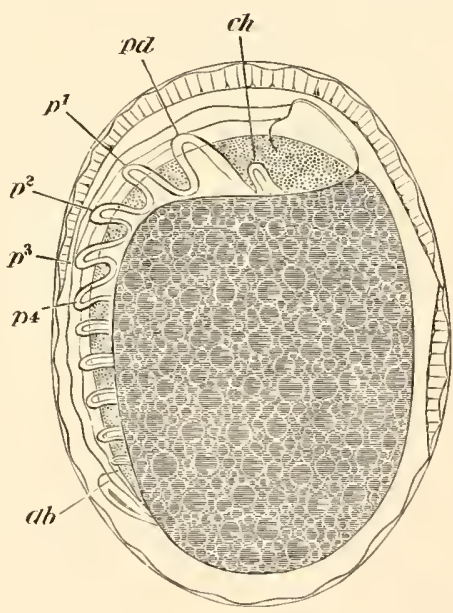

Fig. 195. A FAIRLY-ADVANCED EMBRYO OF THE SCORPION ENVELOPEI) IN ITS MEMbraNes. (After Metschnikoff.)

$c h$. cheliceræ; $p d$. pedipalpi; $p^{1}-p^{4}$. ambulatory appendages; $a b$. post-abdomen (tail).

Metschnikoff. He believes however that the anterior segment forms the procephalic lobes, the posterior probably the telson and five adjoining caudal segments, and the middle one the remainder of the body. This view does not appear to me quite satisfactory, since on the analogy of Spiders and other Arthropoda the fresh somites ought to be added by a continuous segmentation of the posterior lobe.

B. II, 
nerve cords are distinctly differentiated and ganglionated. In the embryonic state there is one ganglion for each segment. The ganglion in the first segment (that bearing the cheliceræ) is very small, but is undoubtedly post-oral.

At this stage, by a growth in which all the three germinal layers have a share, the yolk is completely closed in by the blastoderm. It is a remarkable fact with only few parallels, and those amongst the Arthropoda, that the blastopore, or point where the embryonic membranes meet in closing in the yolk, is situated on the dorsal surface of the embryo.

The general relations of the embryo at about this stage are shewn in fig. 195, where the embryo enclosed in its double cellular membrane is seen in a side view. This embryo is about the same age as that seen from the ventral surface in fig. $196 \mathrm{~A}$.

The general nature of the further changes may easily be gathered from an inspection of fig. $196 \mathrm{~B}$ and C, but a few points may be noted.

An upper lip or labrum is formed as an unpaired organ in the line between the procephalic lobes. The pedipalpi become chelate before becoming jointed, and the cheliceræ also early acquire their characteristic form. Rudimentary appendages appear on the six segments behind the ambulatory legs, five of which are distinctly shewn in fig. 195; they persist only on the second segment, where they appear to form the comb-like organs or pectines. The last abdominal segment, i.e. that next the tail, is without provisional appendages. The embryonic tail is divided into six segments including the telson (fig. $196 \mathrm{C}, a b$ ). The lungs $(s t)$ are formed by paired invaginations, the walls of which subsequently become plicated, on the four last segments which bear rudimentary limbs, and simultaneously with the disappearance of the rudimentary limbs.

Pseudoscorpionidæ. The development of Chelifer has been investigated by Metschnikoff (436), and although (except that it is provided with tracheæ instead of pulmonary sacks) it might be supposed to be closely related to Scorpio, yet in its development is strikingly different.

The eggs after being laid are carried by the female attached to the first segment of the abdomen. The segmentation (vide p. 93) is intermediate between the types of complete and superficial segmentation. The ovum, mainly formed of food-yolk, divides into two, four, and eight equal segments 
(fig. $197 \mathrm{~A}$ ). There then appear one or more clear segments on the surface of these, and finally a complete layer of cells is formed round the central yolk spheres (fig. I97 B), which latter subsequently agglomerate into a central mass. The superficial cells form what may be called a blastoderm, which soon becomes divided into two layers (fig. $197 \mathrm{C}$ ). There now appears a single pair of appendages (the pedipalpi) (fig. $198 \mathrm{~A}, p d$ ), while at the same time the front end of the embryo grows out into a remarkable proboscis-like prominence-a temporary upper lip (concealed in the figure

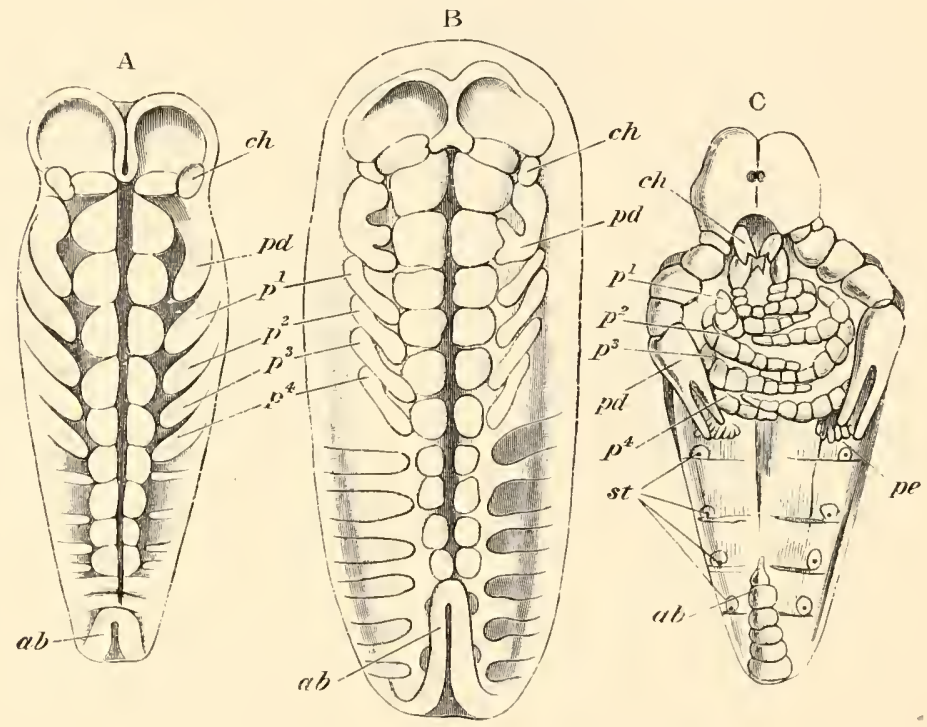

Fig. ig6. Three stages in tile development of the Scorfion. Tile EMBRYOS ARE REPRESENTED AS IF SEEN EXTENDED ON A PLANF.

(After Metschnikoff.)

$c h$. chelicere; $p d$. pedipalpi ; $p^{1}-p^{4}$. ambulatory appendages; $p e$. pecten; st. stigmata; $a b$. post abdomen (tail).

behind the pedipalpus), and the abdomen $(a b)$ becomes bent forwards towards the ventral surface. In this very rudimentary condition, after undergoing an ecdysis, the larva is hatched, although it still remains attached to its parent. After hatching it grows rapidly, and becomes filled with a peculiar transparent material. The first pair of ambulatory appendages is formed behind the pedipalpi and then the three suceeding pairs, while at the same time the cheliceræe appear as small rudiments in front. External signs of segmentation have not yet appeared, but about this period the nervous system is formed. The supra-œsoplageal ganglia are especially distinct, and provided with a central cavity, probably formed by an invagination, as in other Arachnida. In the succeeding stages (fig. I98 $\mathrm{B}$ ) four provisional 
pairs of appendages (shewn as small knobs at $a b$ ) appear behind the ambulatory feet. The abdomen is bent forwards so as to reach almost to the pedipalpi. In the later stages (fig. I98 C) the adult form is gradually attained. The enormous upper lip persists for some time, but subsequently atrophies and is replaced by a normal labrum. The appendages behind the

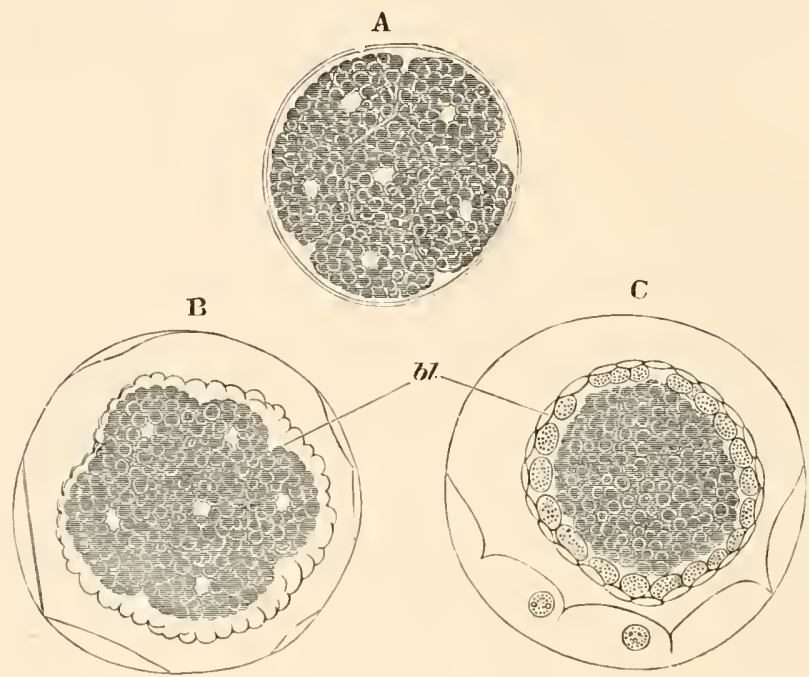

Fig. 197. Segmentation and formation of the blastoderm in Chelifer. (After Metschnikoff.)

In $\mathrm{A}$ the ovum is divided into a number of separate segments. In $\mathrm{B}$ a number of small cells have appeared (bl) which form a blastoderm enveloping the large yolk spheres. In $\mathrm{C}$ the blastoderm has become divided into two layers.

ambulatory feet atrophy, and the tail is gradually bent back into its final position. The segmentation and the gradual growth of the limbs do not call for special description, and the formation of the organs, so far as is known, agrees with other types.

The segmentation of Chthonius is apparently similar to that of Chelifer (Stecker, No. 437).

Phalangidæ. Our knowledge of the development of Phalangium is unfortunately confined to the later stages (Balbiani, No. 438). These stages do not appear however to differ very greatly from those of true Spiders.

Araneina. The eggs of true Spiders are either deposited in nests made specially for them, or are carried about by the females. Species belonging to a considerable number of genera, viz. Pholcus, Epeira, Lycosa, Clubione, Tegenaria and Agelena 
have been studied by Claparède (No. 442), Balbiani (No. 439), Barrois (No. 441) and myself (No. 440), and the close similarity between their embryos leaves but little doubt that there are no great variations in development within the group.

The ovum is enclosed in a delicate vitelline membrane, enveloped in its turn by a chorion secreted by the walls of the oviduct. The chorion is covered by numerous rounded prominences, and occasionally exhibits a pattern corresponding with the areas of the cells which formed it. The segmentation has already been fully described, pp. I I 8 and i I9. At its close there is present an enveloping blastoderm formed of a single layer of large flattened cells. The yolk within is formed of a number of

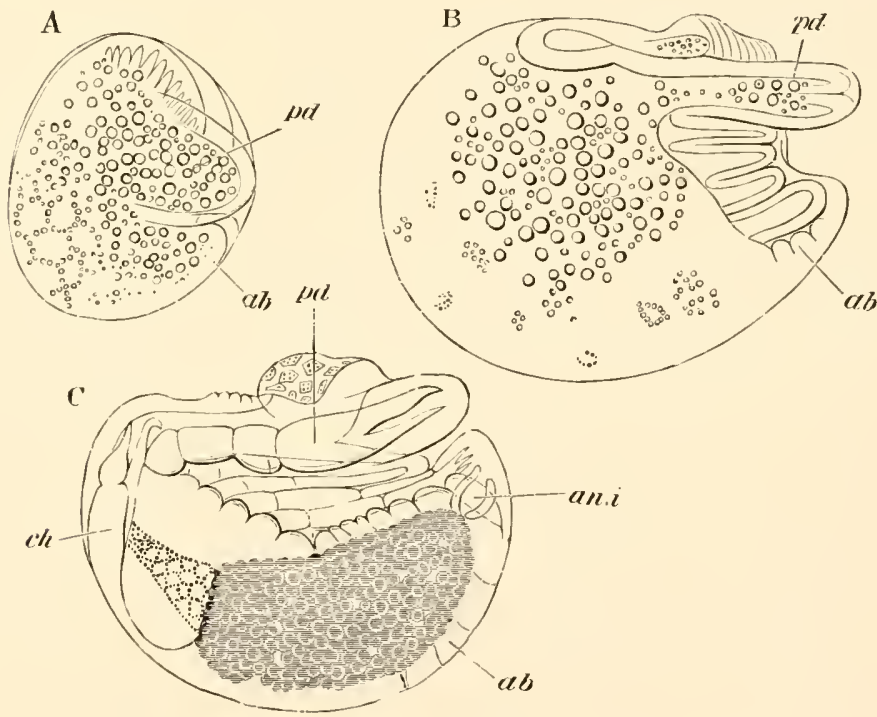

Fig. 198. Three stages in the development of Chlelifek.

(After Metschnikoff.)

$p d$. pedipalpi ; $a b$. abdomen; $a n . i$. anal invagination; $c h$. chelicerre.

large polygonal segments; each of which is composed of large yolk spherules, and contains a nucleus surrounded by a layer of protoplasm, which is prolonged into stellate processes holding together the yolk spherules. The nucleus, surrounded by the major part of the protoplasm of each yolk cell, appears, as a rule, 
to be situated not at the centre, but on one side of its yolk segment.

The further description of the development of Spiders applies more especially to Agelena labyrinthica, the species which formed the subject of my own investigations.

The first differentiation of the blastoderm consists in the cells of nearly the whole of one hemisphere becoming somewhat more columnar than those of the other hemisphere, and in the cells of a small area near one end of the thickened hemisphere becoming distinctly more columnar than elsewhere, and two layers thick. This area forms a protuberance on the surface of the ovum, originally discovered by Claparède, and called by him the primitive cumulus. In the next stage the cells of the thickened hemisphere of the blastoderm become still more columnar; and a second area, at first connected by a whitish streak with the cumulus, makes its appearance. In the second area the blastoderm is also more than one cell deep (fig. 199). It will be noticed that the blastoderm, though more than one cell thick over a large part of the ventral surface, is not divided into distinct layers. The second area appears as a white patch and soon becomes more distinct, while the streak continued to it from the cumulus is no longer visible. It is shewn in surface view in fig. $200 \mathrm{~A}$. Though my observations on this stage are not quite satisfactory, yet it appears to me probable that there is a longitudinal thickened ridge of the blastoderm extending from the primitive cumulus to the large white area. The section represented in fig. 199, which I believe to be oblique, passes through this ridge at its most projecting part.

The nuclei of the yolk cells during the above stages multiply rapidly, and cells are formed in the yolk which join the blastoderm; there can however be no doubt that the main increase in the cells of the blastoderm has been due to the division of the original blastoderm cells.

In the next stage I have been able to observe there is, in the place of the previous thickened half of the blastoderm, a well developed ventral plate with a procephalic lobe in front, a caudal lobe behind, and an intermediate region marked by about three transverse grooves, indicating a division into segments. This plate is throughout two or more rows of 
cells thick, and the cells which form it are divided into two distinct layers-a columnar superficial layer of epiblast cells, and a deeper layer of mesoblast cells (fig. 203 A). In the latter layer there are several very large cells which are in the act of passing from the yolk into the blastoderm. The identification of the structures visible in the previous stage with those visible in the present stage is to a great extent a matter of guess-work, but it appears to me probable that the

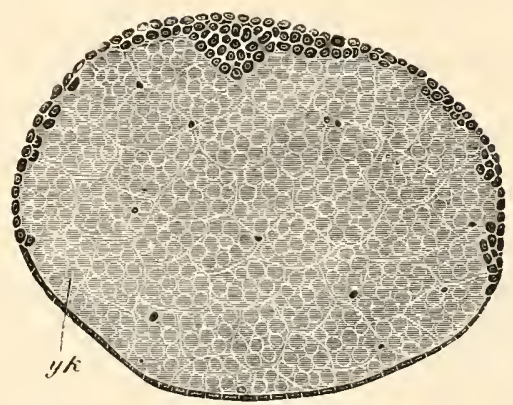

Fig. I99. Section throvgh the eMBRYO OF AGELENA LABYRINTIICA.

The section is from an embryo of the same age as fig. $200 \mathrm{~A}$, and is represented with the ventral plate upwards. In the ventral plate is seen a keel-like thickening, which gives rise to the main mass of the mesoblast.

$y k$. yolk divided into large polygonal cells, in several of which nuclei are shewn. primitive cumulus is still present as a slight prominence visible in surface views on the caudal lobe, and that the other thickened patch persists as the procephalic lobe. However this may be, the significance of the primitive cumulus appears to be that it is the part of the blastoderm where two rows of cells become first established ${ }^{1}$.

The whole region of the blastoderm other than the ventral plate is formed of a single row of flattened epiblast cells. The yolk retains its original constitution.

By this stage the epiblast and mesoblast are distinctly differentiated, and the homologue of the hypoblast is to be sought for in the yolk-cells. The yolk-cells are not however entirely hypoblastic, since they continue for the greater part of the development to give rise to fresh cells which join the mesoblast.

The Spider's blastoderm now resembles that of an Insect (except for the amnion) after the establishment of the mesoblast, and the mode of origin of the mesoblast in both groups is very similar, in that the longitudinal ridge-like thickening of the

1 Various views have been put forward by Claparède and Balliani about the position and significance of the primitive cumulus. For a discussion of which vide self, No. 440. 
mesoblast shewn in fig. 199 is probably the homologue of the mesoblastic groove of the Insects' blastoderm.

The ventral plate continues to grow rapidly, and at a somewhat later stage (fig. $200 \mathrm{~B}$ ) there are six segments interposed between the procephalic and caudal lobes. The two anterior of these $(c h$ and $p d)$, especially the foremost, are less distinct than the remainder; and it is probable that both of them, and in any case the anterior one, are formed later than the three segments following. These two segments are the segments of the chelicere and pedipalpi. The four segments following belong to the four pairs of ambulatory legs. The segments form raised transverse bands separated by transverse grooves. There is at this stage a faintly marked groove extending along the median line of the ventral plate. This groove is mainly caused by the originally single mesoblastic plate having become divided throughout the whole region of the ventral plate, except possibly the procephalic lobes, into two bands, one on each side of the middle line (fig. $203 \mathrm{~B})$.

The segments continue to increase in number by the continuous addition of fresh segments between the one last formed and the caudal lobe. By the stage with nine segments the first rudiments of the limbs make their appearance. The first rudiments to appear are those of the pedipalpi and four ambulatory limbs: the chelicera, like the segment to which they belong, lag behind in development. The limbs appear as small protuberances at the borders of their segments. By the stage when they are formed the procephalic region has become bilobed, and the two lobes of which it is composed are separated by a shallow groove.

By a continuous elongation the ventral plate comes to form a nearly complete equatorial ring round the ovum, the procephalic and caudal lobes being only separated by a very narrow space, the undeveloped dorsal region of the embryo. This is shewn in longitudinal section in fig. 204. In this condition the embryo may be spoken of as having a dorsal flexure. By the time that this stage is reached (fig. $200 \mathrm{C}$ ) the full number of segments and appendages has become established. There are in all sixteen segments (including the caudal lobe). The first six of these bear the permanent appendages of the adult; the 
next four are provided with provisional appendages; while the last six are without appendages. The further features of this stage which deserve notice are (I) the appearance of a shallow depression (st) - the rudiment of the stomodæum-between the hinder part of the two procephalic lobes; (2) the appearance of

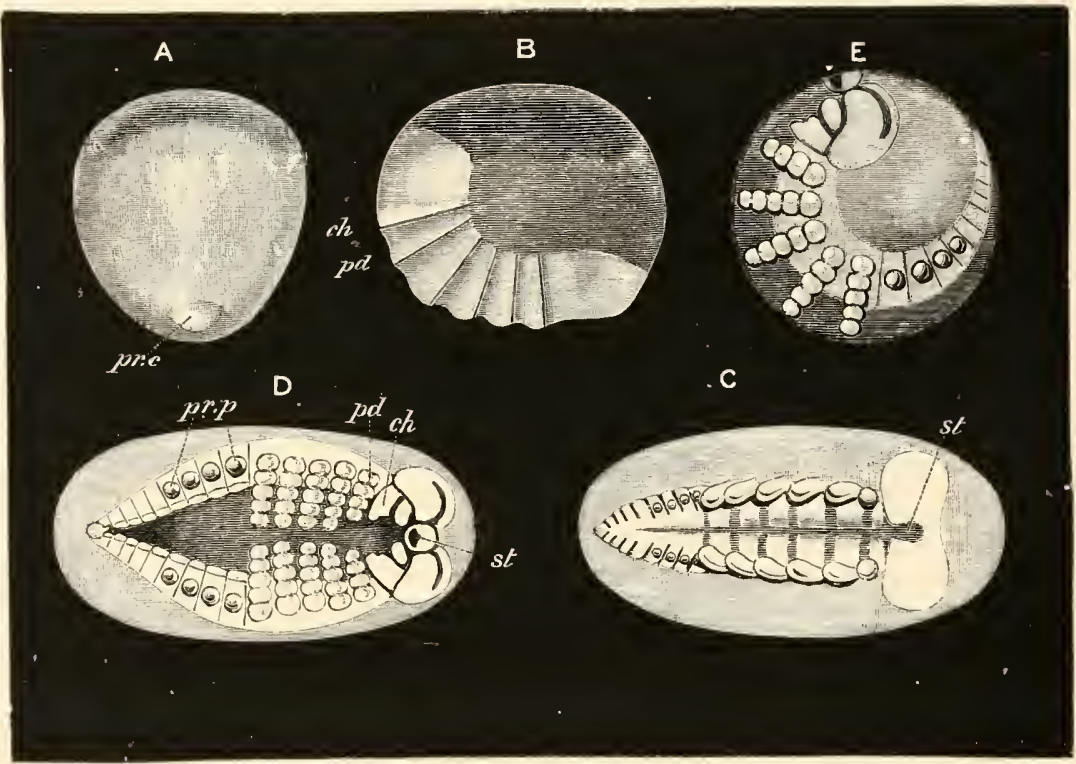

Fig. 200. Four stages in the development of Agelena labyrinthica.

A. Stage when the ventral plate is very imperfectly differentiated. pr.c. primitive cumulus.

B. Ovum viewed from the side when the ventral plate has become divided into six segments. ch. segment of cheliceræe imperfectly separated from procephalic lobe ; $p d$. segment of pedipalpi.

C. Ventral plate ideally unrolled after the full number of segments and appendages are established. st. stomodæum between the two præ-oral lobes. Behind the six pairs of permanent appendages are seen four pairs of provisional appendages.

$\mathrm{D}$ and $\mathrm{E}$. Two views of an embryo at the same stage. D ideally unrolled, $\mathrm{E}$ seen from the side. st. stomodxum; $c h$. chelicese; on their inner side is seen the ganglion belonging to them. $p d$. pedipalpi ; $p r \cdot p \cdot$ provisional appendages.

raised areas on the inner side of the six anterior appendagebearing segments. These are the rudiments of the ventral ganglia. It deserves to be especially noted that the segment of 
the chelicera, like the succeeding segments, is provided with ganglia; and that the ganglia of the chelicere are quite distinct from the supra-œsophageal ganglia derived from the procephalic lobes. (3) The pointed form of the caudal lobe. In Pholcus (Claparède, No. 442) the caudal lobe forms a projecting structure which, like the caudal lobe of the Scorpion, bends forward so as to face the ventral surface of the part of the body immediately in front. In most Spiders such a projecting caudal lobe is not found. While the embryo still retains its dorsal flexure considerable changes are effected in its general constitution. The appendages (fig. $200 \mathrm{D}$ and $\mathrm{E}$ ) become imperfectly jointed, and grow inwards so as to approach each other in the middle line. Even in the stage before this, the ventral integument between the rudiments of the ganglia had become very much thinner, and had in this way divided the ventral plate into two halves. At the present stage the two halves of the ventral plate are still further separated, and there is a wide space on the ventral side only covered by a delicate layer of epiblast. This is shewn in surface view (fig. $200 \mathrm{D}$ ) and in section in fig. $203 \mathrm{C}$.

The stomodæum $(s t)$ is much more conspicuous, and is bounded in front by a prominent upper lip, and by a less marked lip behind. The upper lip becomes less conspicuous in later stages, and is perhaps to be compared with the provisional upper lip of Chelifer. Each procephalic lobe is now marked by a deep semicircular groove.

The next period in the development is characterised by the gradual change in the flexure of the embryo from a dorsal to a ventral one; accompanied by the division of the body into an abdomen and cephalo-thorax, and the gradual assumption of the adult characters.

The change in the flexure of the embryo is caused by the elongation of the dorsal region, which has hitherto been hardly developed. Such an elongation increases the space on the dorsal surface between the procephalic and caudal regions, and therefore necessarily separates the caudal and procephalic lobes; but, since the ventral plate does not become shortened in the process, and the embryo cannot straighten itself in the egg-shell, it necessarily becomes ventrally flexed.

If there were but little food yolk this flexure would naturally 
cause the whole embryo to be bent in so as to have the ventral surface concave. But instead of this the flexure is at first confined to the two bands which form the ventral plate. These bands, as shewn in fig. 20 I A, acquire a true ventral flexure, but the yolk forms a projection-a kind of yolk sack as Barrois (No. 441) calls it-distending the thin integument between the two ventral bands. This yolk sack is shewn in surface view in

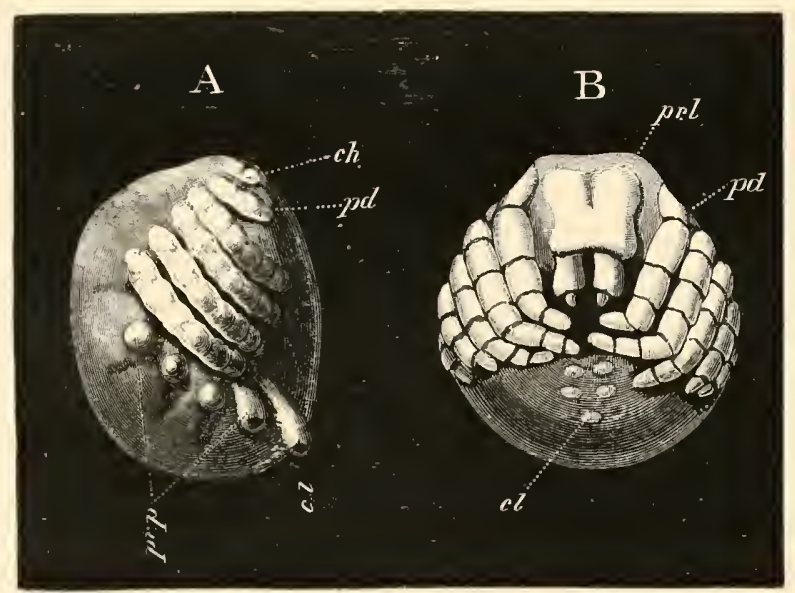

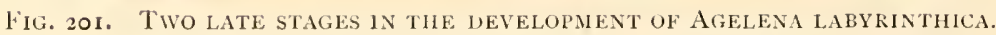

A. Embryo from the side at the stage when there is a large ventral protuberance of yolk. The angle between the line of insertion of the permanent and provisional appendages shews the extent of the ventral flexure.

B. Embryo nearly ready to be hatched. The abdomen which has not quite acquired its permanent form is seen to be pressed against the ventral side of the thorax.

pr.l. procephalic lobe; $p d$. pedipalpi ; ch. chelicere; c.l. caudal lobe; pr.p. provisional appendages.

fig. 201 A and in section in fig. 206. At a later period, when the yolk has become largely absorbed, the true nature of the ventral flexure becomes quite obvious, since the abdomen of the young Spider, while still in the egg, is found to be bent over so as to press against the ventral surface of the thorax (fig. $201 \mathrm{~B}$ ).

The general character of the changes which take place during this period in the development is shewn in fig. 20I $\mathrm{A}$ and $B$ representing two stages in it. In the first of these stages there is no constriction between the future thorax and abdomen. 
The four pairs of provisional appendages exhibit no signs of atrophy; and the extent of the ventral flexure is shewn by the angle formed between the line of their insertion and that of the appendages in front. The yolk has enormously distended the integument between the two halves of the ventral plate, as is illustrated by the fact that, at a somewhat earlier stage than that figured, the limbs cross each other in the median ventral line, while at this stage they do not nearly meet. The limbs have acquired their full complement of joints, and the pedipalpi bear a cutting blade on their basal joint.

The dorsal surface between the prominent caudal lobe and the procephalic lobes forms more than a semicircle. The terga are fully established, and the boundaries between them, especially in the abdomen, are indicated by transverse markings. A large lower lip now bounds the stomodæum, and the upper lip has somewhat atrophied. In the later stage (fig. 20 I B) the greater part of the yolk has passed into the abdomen, which is now to some extent constricted off from the cephalo-thorax. The appendages of the four anterior abdominal somites have disappeared, and the caudal lobe has become very small. In front of it are placed two pairs of spinning mammilla. A delicate cuticle has become established, which is very soon moulted.

Acarina. The development of the Acarina, which has been mainly investigated by Claparède (No. 446), is chiefly remarkable from the frequent occurrence of several larval forms following each other after successive ecdyses. The segmentation (vide p. 116) ends in the formation of a blastoderm of a single layer of cells enclosing a central yolk mass.

A ventral plate is soon formed as a thickening of the blastoderm, in which an indistinct segmentation becomes early observable. In Myobia, which is parasitic on the common mouse, the ventral plate becomes divided by five constrictions into six segments (fig. 202 A), from the five anterior of which paired appendages very soon grow out (fig. $202 \mathrm{~B}$ ) The appendages are the chelicere $(c h)$ and pedipalpi $(p d)$ and the first three pairs of limbs $\left(p^{1}-p^{3}\right)$. On the dorsal side of the cheliceræ a thickened prominence of the ventral plate appears to correspond to the procephalic lobes of other Arachnida. The part of the body behind the five primitive appendage-bearing segments appears to become divided into at least two segments. In other mites the same appendages are formed as in Myobia, but the preceding segmentation of the ventral plate is not always very obvious.

In Myobia two moultings take place while the embryo is still within the primitive egg-shell. The first of these is accompanied by the apparently total disappearance of the three pediform appendages, and the complete 
coalescence of the two gnathiform appendages into a proboscis (fig. $202 \mathrm{C}$ ). The feet next grow out again, and a second ecdysis then takes place. The embryo becomes thus inclosed within three successive membranes, viz. the original egg-shell and two cuticular membranes (fig. $202 \mathrm{D}$ ). After the second ecdysis the appendages assume their final form, and the embryo leaves the egg as an hexapodous larva. The fourth pair of appendages is
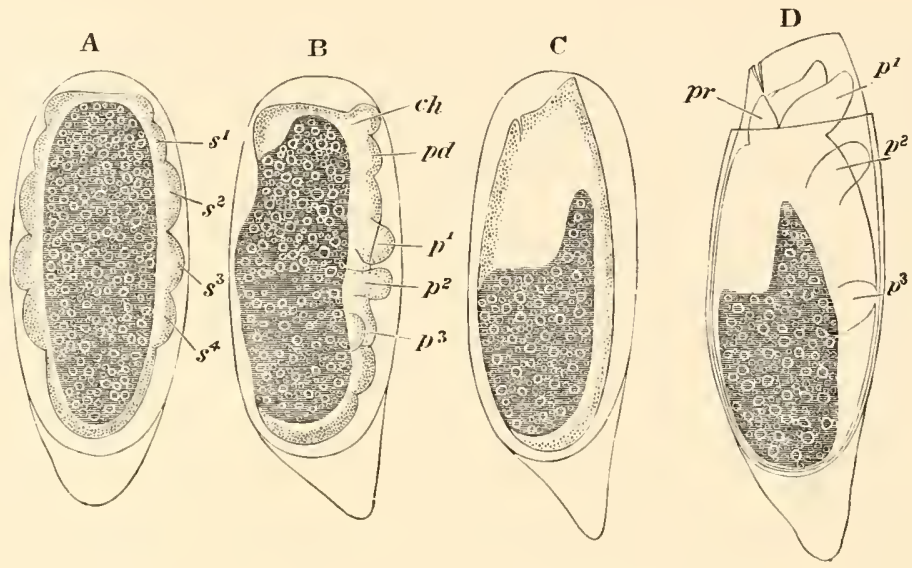

Fig. 202. Fotr successive stages in the develolment of Myobia musculi. (After Claparècle.)

$s^{l}-s^{4}$. post-oral segments; $c h$. chelicerr ; $p d$. pedipalpi ; $p$. proboscis formed by the coalescence of the cheliceræ and pedipalpi ; $p^{1}, p^{2}$, etc. ambulatory appendages.

acquired by a post-embryonic metamorphosis. From the proboscis are formed the rudimentary palpi of the second pair of appendages, and two elongated needles representing the chelicera.

In the cheese mite (Tyroglyphus) the embryo has two ecdyses which are not accompanied by the peculiar changes observable in Myobia: the cheliceræ and pedipalpi fuse however to form the proboscis. The first larval form is hexapodous, and the last pair of appendages is formed at a subsequent ecdysis.

In Atax Bonzi, a form parasitic on Unio, the development and metamorphosis are even more complicated than in Myobia. The first ecdysis occurs before the formation of the limbs, and shortly after the ventral plate has become divided into segments. Within the cuticular membrane resulting from the first ecdysis the anterior five pairs of limbs spring out in the usual fashion. They undergo considerable differentiation; the chelicere and pedipalpi approaching each other at the anterior extremity of the body, and the three ambulatory legs becoming segmented and clawed. An œsophagus, a stomach, and an cesophageal nerve-ring are also formed. When the larva 
has attained this stage the original egg-shell is split into two valves and eventually cast off, but the embryo remains enclosed within the cuticular membrane shed at the first ecdysis. This cuticular membrane is spoken of by Claparède as the deutovum. In the deutovum the embryo undergoes further changes; the cheliceræe and pedipalpi coalesce and form the proboscis; a spacious body cavity with blood corpuscles appears; and the alimentary canal enclosing the yolk is formed.

The larva now begins to move, the cuticular inembrane enclosing it is ruptured, and the larva becomes free. It does not long remain active, but soon bores its way into the gills of its host, undergoes a fresh moult, and becomes quiescent. The cuticular membrane of the moult just effected swells up by the absorption of water and becomes spherical. Peculiar changes take place in the tissues, and the limbs become, as in Myobia, nearly absorbed, remaining however as small knobs. The larva swims about as a spherical body within its shell. The feet next grow out afresh, and the posterior pair is added. From the proboscis the palpi (of the pedipalpi) grow out below. The larva again becomes free, and amongst other changes the cheliceræ grow out from the proboscis. A further ecdysis, with a period of quiescence, intervenes between this second larval form and the adult state.

The changes in the appendages which appear common to the Mites generally are (I) the late development of the fourth pair of appendages, which results in the constant occurrence of an hexapodous larva ; and (2) the early fusion of the chelicerce and pedipalpi to form a proboscis in which no trace of the original appendages can be discerned. In most instances palpi and stilets of variable form are subsequently developed in connexion with the proboscis, and, as indicated in the above descriptions, are assumed to correspond with the two original embryonic appendages.

\section{The history of the germinal layers.}

It is a somewhat remarkable fact that each of the groups of the Arachnida so far studied has a different form of segmentation. The types of Chelifer and the Spiders are simple modifications of the centrolecithal type, while that of Scorpio, though apparently meroblastic, is probably to be regarded in the same light (aide p. 120 and p. 434). The early development begins in the Scorpion and Spiders with the formation of a ventral plate, and there can be but little doubt that Chelifer is provided with an homologous structure, though very probably modified, owing to the small amount of food-yolk and early period of hatching.

The history of the layers and their conversion into the organs has been studied in the case of the Scorpion (Metschnikoff, No. 
4:34), and of the Spiders; and a close agreement has been found to obtain between them.

It will be convenient to take the latter group as type, and simply to call attention to any points in which the two groups differ.

The epiblast. The epiblast, besides giving rise to the skin (hypodermis and cuticle), also supplies the elements for the nervous system and organs of sense, and for the respiratory sacks, the stomodæum and proctodæum.

At the period when the mesoblast is definitely established, the epiblast is formed of a single layer of columnar cells in the region of the ventral plate, and of a layer of flat cells over other parts of the yolk.

When about six segments are present the first changes take place. The epiblast of the ventral plate then becomes somewhat thinner in the median line than at the two sides (fig. 203 B). In succeeding stages the contrast between the median and the lateral parts becomes still more marked, so that the epiblast becomes finally constituted of two lateral thickened bands, which meet in front in the procephalic lobes, and behind in the caudal lobe, and are elsewhere connected by a very thin layer (fig. $203 \mathrm{C}$ ). Shortly after the appendages begin to be formed, the first rudiments of the ventral nerve-cord become established as epiblastic thickenings on the inner side of each of the lateral bands. The thickenings of the epiblast of the two sides are quite independent, as may be seen in fig. $203 \mathrm{C}, \mathrm{z}^{\prime} \mathrm{n}$, taken from a stage somewhat subsequent to their first appearance. They are developed from before backwards, but either from the first, or in any case very soon afterwards, cease to form uniform thickenings, but constitute a linear series of swellings-the future gangliaconnected by very short less prominent thickenings of the epiblast (fig. $200 \mathrm{C}$ ). The rudiments of the ventral nerve-cord are for a long time continuous with the epiblast, but shortly after the establishment of the dorsal surface of the embryo they become separated from the epiblast and constitute two independent cords, the histological structure of which is the same as in other Tracheata (fig. 206, i'n).

The ventral cords are at first composed of as many ganglia as there are segments. The foremost pair, belonging to the 
segment of the cheliceræ, lie immediately behind the stomodæum, and are as independent of each other as the remaining ganglia. Anteriorly they border on the supra-œsophageal ganglia. When the yolk sack is formed in connection with the ventral flexure of the embryo, the two nerve-cords become very widely separated (fig. 206, $2 n$ ) in their middle region. At a later period, at the stage represented in fig. $201 \mathrm{~B}$, they again become approximated in the ventral line, and delicate commissures are formed uniting
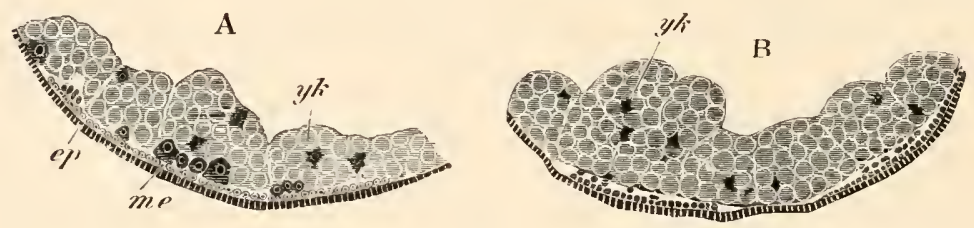

C

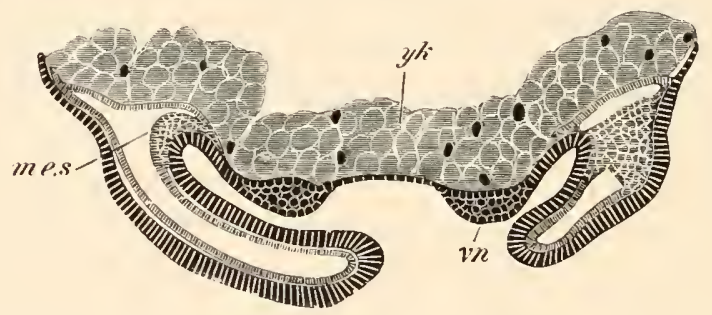

Fig. 203. Transverse sections through tile ventral plate of Agelena LABYRINTIIICA AT TIIREE STAGES.

A. Stage when about three segments are formed. The mesoblastic plate is not divided into two bands.

B. Stage when six segments are present (fig. $200 \mathrm{~B}$ ). The mesoblast is now divided into two bands.

C. Stage represented in fig. 200 D. The ventral cords have begun to be formed on thickenings of the epiblast, and the limbs are established.

ep. epiblast; me. mesoblast; me.s. mesoblastic somite; $\tau^{\prime} n$. ventral nerve-cord; y'k. yolk.

the ganglia of the two sides, but there is no trace at this or any other period of a median invagination of epiblast between the two cords, such as Hatschek and other observers have attempted to establish for various Arthropoda and Chrtopoda. At the stage represented in fig. $20 \mathrm{I}$ A the nerve ganglia are still present in the abdomen, though only about four ganglia can be distinguished. At a later stage these ganglia fuse into two continuous 
cords, united however by commissures corresponding with the previous ganglia.

The ganglia of the cheliceræ have, by the stage represented in fig. $20 \mathrm{I} \mathrm{B}$, completely fused with the supra-cesophageal ganglia and form part of the cesophageal commissure. The cesophageal commissure is however completed ventrally by the ganglia of the pedipalpi.

The supra-cesophageal ganglia are formed independently of the ventral cords as two thickenings of the procephalic lobes (fig. 205). The thickenings of the two lobes are independent, and each of them becomes early marked out by a semicircular groove (fig. $200 \mathrm{D}$ ) running outwards from the upper lip. Each thickening eventually becomes detached from the superficial epiblast, but before this takes place the two grooves become deeper, and on the separation of the ganglia from the epiblast, the cells lining the grooves become involuted and detached from the skin, and form an integral part of the supra-csophageal ganglia.

At the stage represented in fig. $201 \mathrm{~B}$ the supra-œsophageal ganglia are completely detached from the epiblast, and are constituted of the following parts: (I) A dorsal section formed of two hemispherical lobes, mainly formed of the invaginated lining of the semicircular grooves. The original lumen of the groove is still present on the outer side of these lobes. (2) Two central masses, one for each ganglion, formed of punctiform tissue, and connected by a transverse commissure. (3) A ventral anterior lobe. (4) The original ganglia of the cheliceræ, which form the ventral parts of the ganglia ${ }^{\text {. }}$

The later stages in the development of the nervous system have not been worked out.

The development of the nervous system in the Scorpion is almost identical with that in Spiders, but Metschnikoff believes, though without adducing satisfactory evidence, that the median integument between the two nerve cords assists in forming the ventral nerve cord. Grooves are present in the supra-œsophageal garglia similar to those in Spiders.

The mesoblast. The history of the mesoblast, up to the formation of a ventral plate subjacent to the thickened plate of epiblast, has been already given. The ventral plate is shewn in fig. 203 A. It is seen to be formed mainly of small cells,

\footnotetext{
1 For further details vide self, No. 440.
}

B. II. 
but some large cells are shewn in the act of passing into it from the yolk. During a considerable section of the subsequent development the mesoblast is confined to the ventral plate.

The first important change takes place when about six somites are established; the mesoblast then becomes divided

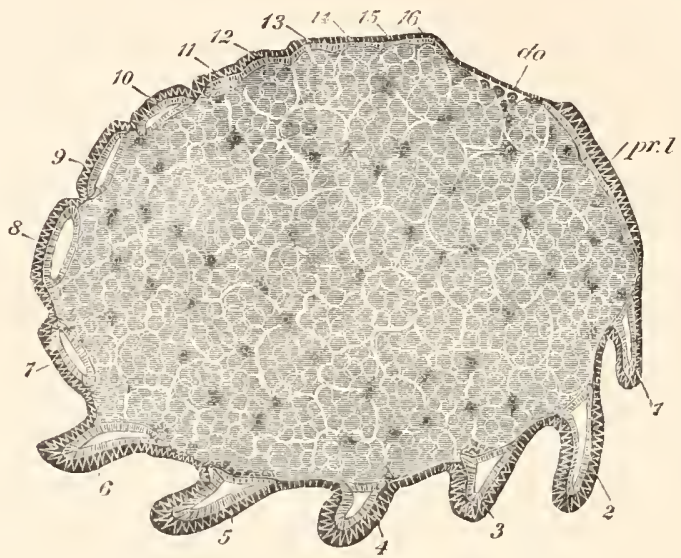

Fig. 204. Longitudinal section through an embryo of Agelena I.ABYRINTHICA.

The section is through an embryo of the same age as that represented in fig. $200 \mathrm{C}$, and is taken slightly to one side of the middle line so as to shew the relation of the mesoblastic somites to the limbs. In the interior are seen the yolk segments and their nuclei.

I-I6. the segments; pr.l. procephalic lobe; do. dorsal integument.

into two lateral bands, shewn in section in fig. $203 \mathrm{~B}$, which meet however in front in the procephalic lobes, and behind in the caudal lobes. Very shortly afterwards these bands become broken up into a number of parts corresponding to the segments, each of which soon becomes divided into two layers, which enclose a cavity between them (vide fig. 204 and fig. 207). The outer layer (somatic) is thicker and attached to the epiblast, and the inner layer (splanchnic) is thinner and mainly, if not entirely, derived (in Agelena) from cells which originate in the yolk. These structures constitute the mesoblastic somites. In the appendage-bearing segments the somatic layer of each of them, together with a prolongation of the cavity, is continued 
into the appendage (fig. $203 \mathrm{C}$ ). Since the cavity of the mesoblastic somites is part of the body cavity, all the appendages contain prolongations of the body cavity. Not only is a pair of mesoblastic somites formed for each segment of the body, but also for the procephalic lobes (fig. 205). The mesoblastic somites for these lobes are established somewhat later than for the true segments, but only differ from them in the fact that the somites of the two sides are united by a median bridge of undivided mesoblast. The development of a somite for the procephalic lobes is similar to what has been described by Kleinenberg for Lumbricus (p. 339), but must not be necessarily supposed to indicate that the procephalic lobes form a segment equivalent to the segments of the trunk. They are rather equivalent to the præ-oral lobe of Chætopod larvæ.

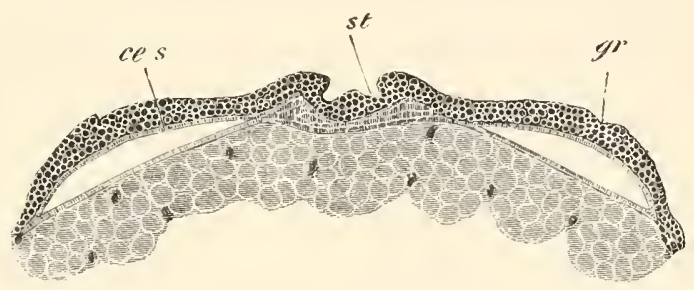

Fig. 205. SECTION THROUgh THE PROCEPHALIC lobes of an embryo of Agelena labyrinthica.

The section is taken from an embryo of the same age as fig. $200 \mathrm{D}$.

st. stomodreum; gr. section through semi-circular groove in procephalic lobe; ce.s. cephalic section of body cavity.

When the dorsal surface of the embryo is established a thick layer of mesoblast becomes formed below the epiblast. This layer is not however derived from an upgrowth of the mesoblast of the somites, but from cells which originate in the yolk. The first traces of the layer are seen in fig. 204, do, and it is fully established as a layer of large round cells in the stage shewn in fig. 206. This layer of cells is seen to be quite independent of the mesoblastic somites (me.s). The mesoblast of the dorsal surface becomes at the stage represented in fig. $20 \mathrm{r} \mathrm{B}$ divided into splanchnic and somatic layers, and in the abdomen at any rate into somites continuous with those of the ventral part of the mesoblast. At the lines of junction of successive somites the splanchnic layer of mesoblast dips into the yolk, and forms a number of transverse septa, which do not reach the middle of the yolk, but leave a central part free, in which the mesenteron is subsequently formed. At the insertion of these septa there 
are developed widish spaces between the layers of somatic and splanchnic mesoblast, which form transversely directed channels passing from the heart outwards. They are probably venous. At a later stage the septa send out lateral offshoots, and divide the peripheral part of the abdominal cavity into a number of compartments filled with yolk. It is probable that the hepatic diverticula are eventually formed in these compartments.

The somatic layer of mesoblast

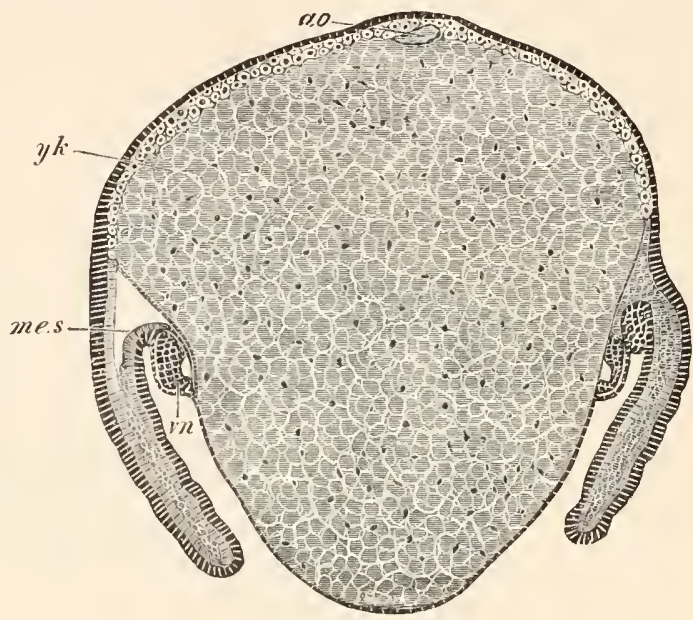

Fig. 206. Transverse SEction tHROUGH THE THORACIC REG1ON OF AN EMBRYO OF AGELENA LABYRINTHICA.

The section is taken from an embryo of the same age as fig. 20I A, and passes through the maximum protuberance of the ventral yolk sack.

vn. ventral nerve cord; $y k$. yolk; me.s. mesoblastic somite; ao. aorta.

is converted into the muscles, both of the limbs and trunk, the superficial connective tissue, nervous sheath, etc. It probably also gives rise to the three muscles attached to the suctorial apparatus of the œsophagus.

The heart and aorta are formed as a solid rod of cells of the dorsal mesoblast, before it is distinctly divided into splanchnic and somatic layers. Eventually the central cells of the heart become blood corpuscles, while its walls are constituted of an outer muscular and inner epithelioid layer. It becomes functional, and acquires its valves, arterial branches, etc., by the stage represented in fig. $20 \mathrm{I} \mathrm{B.}$

The history of the mesoblast, more especially of the mesoblastic somites, of the Scorpion is very similar to that in Spiders : their cavity is continued in the same way into the limbs. The general character of the somites in the tail is shewn in fig. 207. The caudal aorta is stated by Metschnikoff to be formed from part of the mesenteron, but this is too improbable to be accepted without further confirmation. 
The hypoblast and alimentary tract. It has already been stated that the yolk is to be regarded as corresponding to the hypoblast of other types.

For a considerable period it is composed of the polygonal yolk cells already described and shewn in figs. 203, 204, and 205 . The yolk cells divide and become somewhat smaller as development proceeds; but the main products of the division of the yolk nuclei and the protoplasm around them are undoubtedly cells which join the mesoblast (fig. 203 A). The permanent alimentary tract is formed of three sections, viz. stomodæum, proctodæum, and mesenteron. The stomodæum and proctodæum are both formed before the mesenteron. The stomodæum is formed as an epiblastic pit between the two procephalic lobes (figs. 200 and $205, s t)$. It becomes deeper, and by the latest stage figured is a deep pit lined by a cuticle and ending blindly. To its hinder section, which forms

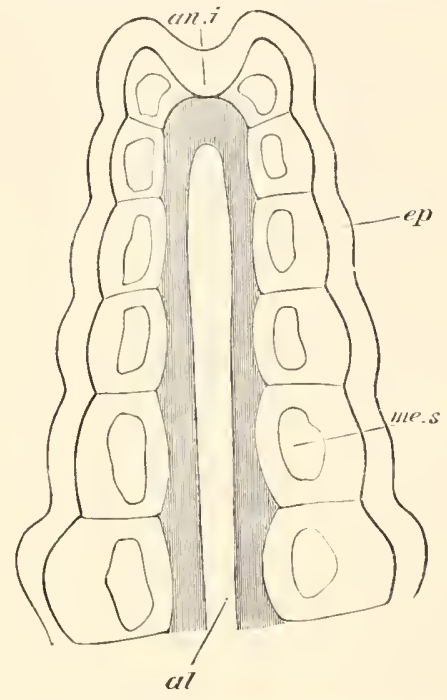

FIG, 207. TA1L OF AN ADVANCED EMBRYO OF THE SCORPION TO ILLUSTRATE THE STRUCTURE OF THE MESOBLASTIC Somites. (After Metschnikoff.)

al. alimentary tract; an.i. anal invagination; ep. epiblast; me.s. mesoblastic somite. the suctorial apparatus of the adult, three powerful muscles (a dorsal and two lateral) are attached.

The proctodæum is formed considerably later than the stomodæum. It is a comparatively shallow involution, which forms the rectum of the adult. It is dilated at its extremity, and two Malpighian vessels early grow out from it.

The mesenteron is formed in the interior of the yolk. Its walls are derived from the cellular elements of the yolk, and the first section to be formed is the hinder extremity, which appears as a short tube ending blindly behind in contact with the proctodæum, and open to the yolk in front. The later history of the mesenteron has not been followed, but it undoubtedly includes 
the whole of the abdominal section of the alimentary canal of the adult, except the rectum, and probably also the thoracic section. The later history of the yolk which encloses the mesenteron has not been satisfactorily studied, though it no doubt gives rise to the hepatic tubes, and probably also to the thoracic diverticula of the alimentary tract.

The general history of the alimentary tract in Scorpio is much the same as in Spiders. The hypoblast, the origin of which as mentioned above is somewhat uncertain, first appears on the ventral side and gradually spreads so as to envelop the yolk, and form the wall of the mesenteron, from which the liver is formed as a pair of lateral outgrowths. The proctodæum and stomodæum are both short, especialiy the former (ride fig. 207).

\section{Summary and general conclusions.}

The embryonic forms of Scorpio and Spiders are very similar, but in spite of the general similarity of Chelifer to Scorpio, the embryo of the former differs far more from that of Scorpio than the latter does from Spiders. This peculiarity is probably to be explained by the early period at which Chelifer is hatched; and though a more thorough investigation of this interesting form is much to be desired, it does not seem probable that its larva is a primitive type.

The larve of the Acarina with their peculiar ecdyses are to be regarded as much modified larval forms. It is not however easy to assign a meaning to the hexapodous stage through which they generally pass.

With reference to the segments and appendages, some interesting points are brought out by the embryological study of these forms.

The maximum number of segments is present in the Scorpion, in which nineteen segments (not including the preoral lobes, but including the telson) are developed. Of these the first twelve segments have traces of appendages, but the appendages of the six last of these (unless the pecten is an appendage) atrophy. In Spiders there are indications in the embryo of sixteen segments; and in all the Arachnida, except the Acarina, at the least four segments bear appendages in the embryo which are without them in the adult. The morphological bearings of this fact are obvious. 
It deserves to be noted that, in both Scorpio and the Spider, the chelicere are borne in the embryo by the first post-oral segment, and provided with a distinct ganglion, so that they cannot correspond (as they are usually supposed to do) with the antennæ of Insects, which are always developed on the præ-oral lobes, and never supplied by an independent ganglion.

The cheliceræ would seem probably to correspond with the mandibles of Insects, and the antennæe to be absent. In favour of this view is the fact that the embryonic ganglion of the mandibles of Insects is stated (cf. Lepidoptera, Hatschek, p. 340) to become, like the ganglion of the cheliceræ, converted into part of the œsophageal commissure.

If the above considerations are correct, the appendages of the Arachnida retain in many respects a very much more primitive condition than those of Insects. In the first place, both the cheliceræe and pedipalpi are much less differentiated than the mandibles and first pair of maxille with which they correspond. In the second place, the first pair of ambulatory limbs must be equivalent to the second pair of maxillæ of Insects, which, for reasons stated above, were probably originally ambulatory. It seems in fact a necessary deduction from the arguments stated that the ancestors of the present Insecta and Arachnida must have diverged from a common stem of the Tracheata at a time when the second pair of maxillæ were still ambulatory in function.

With reference to the order of the development of the appendages and segments, very considerable differences are noticeable in the different Arachnoid types. This fact alone appears to me to be sufficient to prove that the order of appearance of the appendages is often a matter of embryonic convenience, without any deep morphological significance. In Scorpio the segments develop successively, except perhaps the first postoral, which is developed after some of the succeeded segments have been formed. In Spiders the segment of the cheliceræ, and probably also of the pedipalpi, appears later than the next three or four. In both these types the segments arise before the appendages, but the reverse appears to be the case in Chelifer. The permanent appendages, except the cheliceræ, appear simultaneously in Scorpions and Spiders. The second pair appears long before the others in Chelifer, then the third, next the first, and finally the three hindermost. 


\section{BHBLIOGRAPHY.}

\section{Scorpionide.}

(434) El. Metschnikoff. "Embryologie des Scorpions." Zeit.f. wiss. Zool. Bd. xxi. 1870 .

(435) H. Rathke. Reisebemerkungen aus Taurien (Scorpio), Leipzig, i837.

\section{Psentdoscorpionida.}

(436) El. Metschnik off. "Entwicklungsgeschichte d. Chelifer." Zeit.f. wiss. Zool., Bd. xxi. 1870.

(437) A. Stecker. "Entwicklung der Chthonius-Eier im Mutterleibe und die Bildung des Blastoderms." Sitzung. königl.böhmisch. Gesellschaft Wissensch., ı 876 , 3. Heft, and Annal. and Mag. Nat. History, is 86 , xviri. 197.

\section{Phalangida.}

(438) M. Balbiani. "Mémoire sur le développement des Phalangides." Ann. Scion. Nat. Series v. Vol. XVI. 1872 .

\section{Araneina.}

(439) M. Balbiani. "Mémoire sur le développement des Aranéides." Ann. Scicn. Nat. Series v. Vol. xvir. 1873 .

(440) F. M. Balfour. "Notes on the development of the Araneina." Quart. Fourn. of Micr. Science, Vol. xx. 1880.

(411) J. Barrois. "Recherches s. 1. développement des Araignées." Fournal de l'Anat. et de la Physiol. 1878 .

(442) E. Claparède. Recherches s. l'áolution des Araignies. Utrecht, 1862.

(443) If erold. De generatione Araneorum in Ovo. Marburg, 1824.

(444) H. Ludwig. "Ueber die Bildung des Blastoderms bei den Spinnen." Zeit. f. wiss. Zool., Vol. xxvi. 1876 .

\section{Acarina.}

(445) P. van Beneden. "Développement de l'Atax ypsilophora." Acal. Bruxelles, t. $\mathrm{xx} ı \mathrm{v}$.

(446) Ed. Claparède. "Studien über Acarinen." Zeit. f. wiss. Zool., Bd. xVIII. I 868 .

Formation of the layers and the cmbryonic envelopes in the Tracheata.

There is a striking constancy in the mode of formation of the layers throughout the group. In the first place the hypoblast is not formed by a process which can be reduced to invagination: in other words, there is no gastrula stage. 
Efforts have been made to shew that the mesoblastic groove of Insects implies a modified gastrula, but since it is the essence of a gastrula that it should directly or indirectly give rise to the archenteron, the groove in question cannot fall under this category. Although the mesoblastic groove of Insects is not a gastrula, it is quite possible that it is the rudiment of a blastopore, the gastrula corresponding to which has now vanished from the development. It would thus be analogous to the primitive streak of Vertebrates ${ }^{1}$.

The growth of the blastoderm over the yolk in Scorpions admits no doubt of being regarded as an epibolic gastrula. The blastopore would however be situated dorsally, a position which it does not occupy in any gastrula type so far dealt with. This fact, coupled with the consideration that the partial segmentation of Scorpio can be derived without difficulty from the ordinary Arachnidan type (vide p. I20), seems to shew that there is no true epibolic invagination in the development of Scorpio.

On the formation of the blastoderm traces of two embryonic layers are established. The blastoderm itself is essentially the epiblast, while the central yolk is the hypoblast. The formation of the embryo commences in connection with a thickening of the blastoderm, known as the ventral plate. The mesoblast is formed as an unpaired plate split off from the epiblast of the ventral plate. This process takes place in at any rate two ways. In Insects a groove is formed, which becomes constricted off to form the mesoblastic plate: in Spiders there is a kecl-like thickening of the blastoderm, which takes the place of the groove.

The unpaired mesoblastic plate becomes in all forms very soon divided into two mesoblastic bands.

The mesoblastic bands are very similar to, and probably homologous with, those of Chætopoda; but the different modes by which they arise in these two groups are very striking, and probably indicate that profound modifications have taken place in the early development of the Tracheata. In the Chætopoda the bands are from the first widely separated, and gradually approach each other ventrally, though without meeting. In the Tracheata they arise from the division of an unpaired ventral plate.

The further history of the mesoblastic bands is nearly the

1 The primitive streak of Vertebrates, as will appear in the sequel, has no connection with the medullary groove, and is the rudiment of the blastopore. 
same for all the Tracheata so far investigated, and is also very much the same as for the Chætopoda. There is a division into somites, each containing a section of the body cavity. In the cephalic section of the mesoblastic bands a section of the body cavity is also formed. In Arachnida, Myriapoda, and probably also Insecta, the body cavity is primitively prolonged into the limbs.

In Spiders at any rate, and very probably in the other groups of the Tracheata, a large part of the mesoblast is not derived from the mesoblastic plate, but is secondarily added from the yolk-cells.

In all Tracheata the yolk-cells give rise to the mesenteron which, in opposition, as will hereafter appear, to the mesenteron of the Crustacea, forms the main section of the permanent alimentary tract.

One of the points which is still most obscure in connection with the embryology of the Tracheata is the origin of the embryonic membranes. Amongst Insects, with the exception of the Thysanura, such membranes are well developed. In the other groups definite membranes like those of Insects are never found, but in the Scorpion a cellular envelope appears to be formed round the embryo from the cells of the blastoderm, and more or less similar structures have been described in some Myriapods (vide p. 390). These structures no doubt further require investigation, but may provisionally be regarded as homologous with the amnion and serous membrane of Insects. In the present state of our knowledge it does not seem easy to give any explanation of the origin of these membranes, but they may be in some way derived from an early ecdysis. 


\title{
CHAPTER XVIII.
}

\author{
CRUSTACEA
}

History of the larval forms.

THE larval forms of the Crustacea appear to have more faithfully preserved their primitive characters than those of almost any other group.

\section{BRANCHIOPODA.}

The Branchiopoda, comprising under that term the Phyllopoda and Cladocera, contain the Crustacea with the maximum number of segments and the least differentiation of the separate appendages. This and other considerations render it probable that they are to be regarded as the most central group of the Crustaceans, and as in many respects least modified from the ancestral type from which all the groups have originated.

1 The following is the classification of the Crustacea employed in the present chapter.

I. Branchiopoda. $\left\{\begin{array}{l}\text { Phyllopoda. } \\ \text { Cladocera. }\end{array}\right.$ III. Copepoda. $\left\{\begin{array}{l}\text { Eucopepoda } \\ \text { Branchiura }\end{array}\left\{\begin{array}{l}\text { Natantia. } \\ \text { Parasita. }\end{array}\right.\right.$

II. Malacostraca. $\left\{\begin{array}{l}\begin{array}{l}\text { Nebaliadre. } \\ \text { Schizopoda. } \\ \text { Decapoda. } \\ \text { Stomatopoda. } \\ \text { Cumacex. } \\ \text { Edriophthalmata. }\end{array} \text { V. Ostracoda. }\end{array}\left\{\begin{array}{l}\text { Thoracica. } \\ \text { Abdominalia. } \\ \text { Apoda. } \\ \text { Rhizocephala. }\end{array}\right.\right.$

2 The importance of the larval history of the Crustacea, coupled with our comparative ignorance of the formation of the layers, has rendered it necessary for me to diverge somewhat from the general plan of the work, and to defer the account of the formation of the layers till after that of the larval forms. 
The free larval stages when such exist commence with a larval form known as the $\mathrm{Nauplius.}$

The term Nauplius was applied by O. F. Müller to certain larval forms of the Copepoda (fig. 229) in the belief that they were adult.

The term has now been extended to a very large number of larvæ which have certain definite characters in common. They are provided (fig. $208 \mathrm{~A}$ ) with three pairs of appendages, the future two pairs of antennx and mandibles. The first pair of antennæ $\left(\alpha n^{1}\right)$ is uniramous and mainly sensory in function, the second pair of antenne $\left(a n^{2}\right)$ and mandibles $(m d)$ are biramous
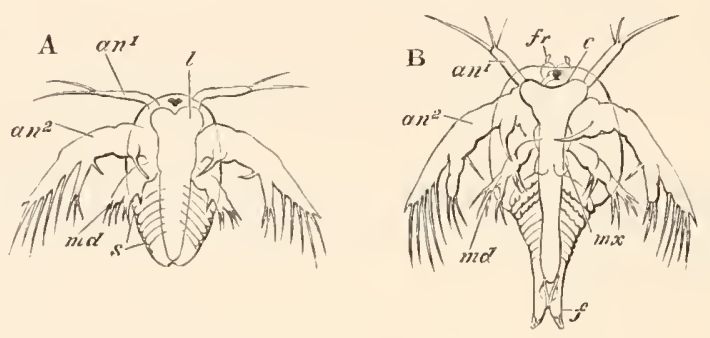

Fig. 208. Two stages in the Development of Apus Cancriformis.

(After Claus.)

A. Nauplius stage at the time of hatching.

B. Stage after first ecdysis.

$a n^{1}$. and $a n^{2}$. First and second antennæ; md. mandible; mx. maxilla ; l. labrum; fr. frontal sense organ; $f$. caudal fork; s. segments.

swimming appendages, and the mandibles are without the future cutting blade. The Nauplius mandibles represent in fact the palp. The two posterior appendages are both provided with hook-like prominences on their basal joints, used in mastication. The body in most cases is unsegmented, and bears anteriorly a single median eye. There is a large upper lip, and an alimentary canal formed of osophagus, stomach and rectum. The anus opens near the hind end of the body. On the dorsal surface small folds of skin frequently represent the commencement of a dorsal shield. One very striking peculiarity of the Nauplius according to Claus and Dohrn is the fact that the second pair of antennæ is innervated from a sub-asophageal ganglion. A larval form with the above characters occurs with more or less frequency in all the Crustacean groups. In most instances it 
does not cxactly conform to the above type, and the divergences are more considerable in the Phyllopods than in most other groups. Its characters in each case are described in the sequel.

Phyllopoda. For the Phyllopoda the development of Apus cancriformis may conveniently be taken as type (Claus, No. 454 ). The embryo at the time it leaves the egg (fig. $208 \mathrm{~A}$ ) is somewhat oval in outline, and narrowed posteriorly. There is a slight $\mathbf{V}$-shaped indentation behind, at the apex of which is situated the anus. The body, unlike that of the typical Nauplius, is already divided into two regions, a cephalic and post-cephalic. On the ventral side of the cephalic region there are present the three normal pairs of appendages. Foremost there are the small anterior antennæ $\left(a n^{1}\right)$, which are simple unjointed rod-like bodies with two moveable hairs at their extremities. They are inserted at the sides of the large upperlip or labrum $(l)$. Behind these are the posterior antenne, which are enormously developed and serve as the most important larval organs of locomotion. They are biramous, being formed of a basal portion with a strong hook-like bristle projecting from its inner side, an inner unjointed branch with three bristles, and an outer large imperfectly five-jointed branch with five long lateral bristles. The hook-like organ attached to this pair of appendages would seem to imply that it served in some ancestral form as jaws (Claus). This character is apparently universal in the embryos of true Phyllopods, and constantly occurs in the Copepoda, etc.

The third pair of appendages or mandibles ( $m d$ ) is attached close below the upper lip. They are as yet unprovided with cutting blades, and terminate in two short branches, the inner with two and the outer with three bristles.

At the front of the head there is the typical unpaired eye. On the dorsal surface there is already present a rudiment of the cephalic shield, continuous anteriorly with the labrum (l) or upper lip, the extraordinary size of which is characteristic of the larvæ of Phyllopods. The post-cephalic region, which afterwards becomes the thorax and abdomen, contains underneath the skin rudiments of the five anterior thoracic segments and their appendages, and presents in this respect an important variation from the typical Nauplius form. After the first ecdysis the 
larva (fig. 208 B) loses its oval form, mainly owing to the elongation of the hinder part of the body and the lateral extension of the cephalic shield, which moreover now completely covers over the head and has begun to grow backwards so as to cover over the thoracic region. At the second ecdysis there appears at its side a rudimentary shell gland. In the cephalic region two small papilla $(f r)$ are now present at the front of the head close to the unpaired eye. They are of the nature of sense organs, and may be called the frontal sense papillx. They have been shewn by Claus to be of some phylogenetic importance. The three pairs of Nauplius appendages have not altered much, but a rudimentary cutting blade has grown out from the basal joint of the mandible. A gland opening at the base of the antennx is now present, which is probably equivalent to the green gland often present in the Malacostraca. Behind the mandibles a pair of simple processes has appeared, which forms the rudiment of the first pair of maxilla ( $m x)$.

In the thoracic region more segments have been added posteriorly, and the appendages of the three anterior segments are very distinctly formed. The tail is distinctly forked. The heart is formed at the second ecdysis, and then extends to the sixth thoracic segment : the posterior chambers are successively added from before backwards.

At the successive ecdyses which the larva undergoes new segments continue to be formed at the posterior end of the body, and limbs arise on the segments already formed. These limbs probably represent the primitive form of an important type of Crustacean appendage, which is of value for interpreting the parts of the various malacostracan appendages. They consist (fig. 209) of a basal portion (protopodite of Huxley) bearing two rami. The basal portion has two projections on the inner side. To the outer side of the basal portion there is attached a dorsally directed branchial sack (br) (epipodite of Huxley). The outer ramus (ex) (exopodite of Huxley) is formed of a single plate with marginal setæ. The inner one (en) (endopodite of Huxley) is four-jointed, and a process similar to those of the basal joint is given off from the inner side of the three proximal joints.

At the third ecdysis several new features appear in the cephalic region, which becomes more prominent in the succeeding 
stages. In the first place the paired eyes are formed at each side of and behind the unpaired eye, secondly the posterior pair of maxillæe is formed though it always remains very rudimentary. The shell gland becomes fully developed opening at the base of the first pair of maxillæ. The dorsal shield gradually grows backwards till it covers its full complement of segments.

After the fifth ecdysis the Nauplius appendages undergo a rapid atrophy. The second pair of antennæe especially becomes reduced in size, and the mandibular palp-the primitive Nauplius portion of the mandible-is contracted to a mere rudiment, which eventually

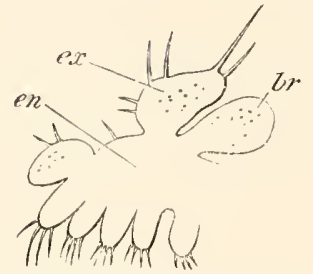

FIG. 209. TYPICAL PHYLLOPOD APPENDAGE. (Copied from Claus.)

$e x$. exopodite; $e n$. endopodite; $b r$. branchial appendage (epipodite). The basal portion bearing the two proximal projections is not sharply separated from the endopodite.

completely disappears, while the blade is correspondingly enlarged and also becomes toothed. The adult condition is only gradually attained after a very large number of successive changes of skin.

The chief point of interest in the above development is the fact of the primitive Nauplius form becoming gradually converted without any special metamorphosis into the adult condition ${ }^{1}$.

Branchipus like Apus is hatched as a somewhat modified Nauplius, which however differs from that of Apus in the hinder region of the body having no indications of segments. It goes through a very similar metamorphosis, but is at no period of its metamorphosis provided with a dorsal shield : the second pair of antennæ does not abort, and in the male is provided with clasping organs, which are perhaps remnants of the embryonic hooks so characteristic of this pair of antennæ.

The larva of Estheria when hatched has a Nauplius form, a large upper lip, caudal fork and single eye. There are two functional pairs of swimming appendages - the second pair of antennæe and mandibles. The first pair of antennæ has not been detected, and a dorsal mantle to form the shell is not developed. At the first moult the anterior pair of antennæ arises as small stump-like structures, and a small dorsal shield is also formed. Rudiments of six or seven pairs of appendages sprout

1 Nothing appears to be known with reference to the manner in which it comes about that more than one appendage is borne on each of the segments from the eleventh to the twentieth. An investigation of this point would be of some interest with reference to the meaning of segmentation. 
out in the usual way, and continue to increase in number at successive moults: the shell is rapidly developed. The chief point of interest in the development of this form is the close resemblance of the young larva to a typical adult Cladocera (Claus). This is shewn in the form of the shell, which has not reached its full anterior extension, the rudimentary anterior antenna, the large locomotor second pair of antennæ, which differ however from the corresponding organs in the Cladocera in the presence of typical larval hooks. Even the abdomen resembles that of Daphnia. These features perhaps indicate that the Cladocera are to be derived from some Phyllopod form like Estheria by a process of retrogressive metamorphosis. The posterior antennx in the adult Estheria are large biramous appendages, and are used for swimming; and though they have lost the embryonic hook, they still retain to a larger extent than in other Phyllopod families their Nauplius characteristics.

The Nauplius form of the Phyllopods is marked by several definite peculiarities. Its body is distinctly divided into a cephalic and post-cephalic region. The upper lip is extraordinarily large, relatively very much more so than at the later stages. The first pair of antennæe is usually rudimentary and sometimes even absent; while the second pair is exceptionally large, and would seem to be capable of functioning not only as a swimming organ, but even as a masticating organ. A dorsal shield is nearly or quite absent.

Cladocera. The probable derivation of the Cladocera from a form similar to Estheria has already been mentioned, and it might have been anticipated that the development would be similar to that of the Phyllopods. The development of the majority of the Cladocera takes place however in the egg, and the young when hatched closely resembles their parents, though in the egg they pass through a Nauplius stage (Dohrn). An exception to the general rule is however offered by the case of the winter eggs of Leptodora, one of the most primitive of the Cladoceran families. The summer eggs develop without metamorphosis, but Sars (No. 461)

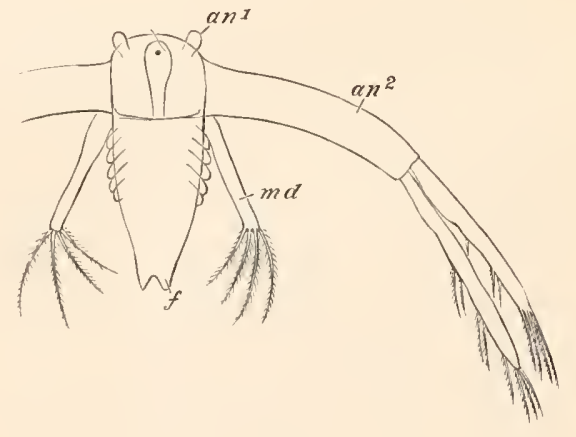

Fig. 209 A. Nauplius larva of Leptodora HYALINA FROM WINTER EGG. (Copied from Bronn; after Sars.)

$a n^{1}$. antenna of first pair; $a n^{2}$. antenna of second pair; md. mandible; f. caudal fork. 
has discovered that the larva leaves the winter eggs in the form of a Nauplius (fig. 209). This Nauplius closely resembles that of the Phyllopods. The body is elongated and in addition to normal Nauplius appendages is marked by six pairs of ridges-the indications of the future feet. The anterior antennx are as usual small; the second large and biramous, but the masticatory bristle characteristic of the Phyllopods is not present. The mandibles are without a cutting blade. A large upper lip and unpaired eye are present.

The adult form is attained in the same manner as amongst the Phyllopods after the third moult.

\section{MaLACostraca.}

Owing to the size and importance of the various forms included in the Malacostraca, greater attention has been paid to their embryology than to that of any other division of the Crustacea; and the proper interpretation of their larval forms involves some of the most interesting problems in the whole range of Embryology.

The majority of Malacostraca pass through a more or less complicated metamorphosis, though in the Nebaliadre, the Cumacex, some of the Schizopoda, a few Decapoda (Astacus, Gecarcinus, etc.), and in the Edriophthalmata, the larva on leaving the egg has nearly the form of the adult. In contradistinction to the lower groups of Crustacea the Nauplius form of larva is rare, though it occurs in the case of one of the Schizopods (Euphausia, fig. 2 12), in some of the lower forms of the Decapods (Penæus, fig. 214), and perhaps also, though this has not been made out, in some of the Stomatopoda.

In the majority of the Decapoda the larva leaves the egg in a form known as the Zoxa (fig. 2ro). This larval form is characterised by the presence of a large cephalothoracic shield usually armed with lateral, anterior, and dorsal spines. The caudal segments are well deB. II,

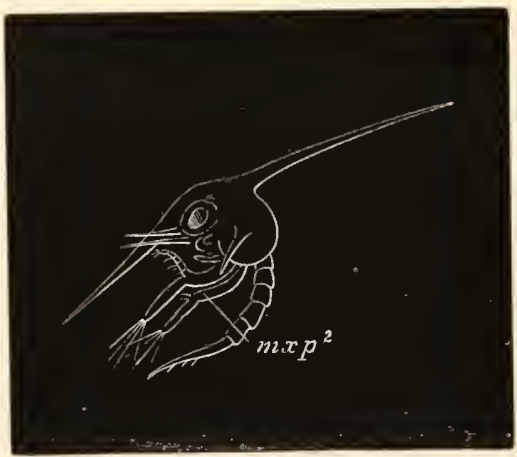

Fig. 2 IO. ZofaA OF Thia POLita. (After Claus.) $m x p^{2}$. second maxillipede. 
veloped, thongh without appendages, and the tail, which functions in swimming, is ztsually forked. The six posterior thoracic segments are, on the other hand, rndimentary or non-existent. There are seven anterior pairs of appendages shewn in detail in fig. $21 \mathrm{I}$, viz. the two pairs of antennæ (At. I. and At. II.), neither of them used as swimming organs, the mandibles without a palp ( $m d)$, well-developed maxillæe (two pairs, $m x \mathrm{I}$ and $m x 2$ ), and two or sometimes (Macrura) three pairs of biramous natatory maxillipeds (mxp I and mxp 2). Two lateral compound stalked eyes are present, together with a median Nauplius eye. The heart has in the majority of cases only one or two (Brachyura) pairs of ostia.

The Zoæa larva, though typically developed in the Decapoda, is not always present (c.g. Astacus and Homarus), and some-

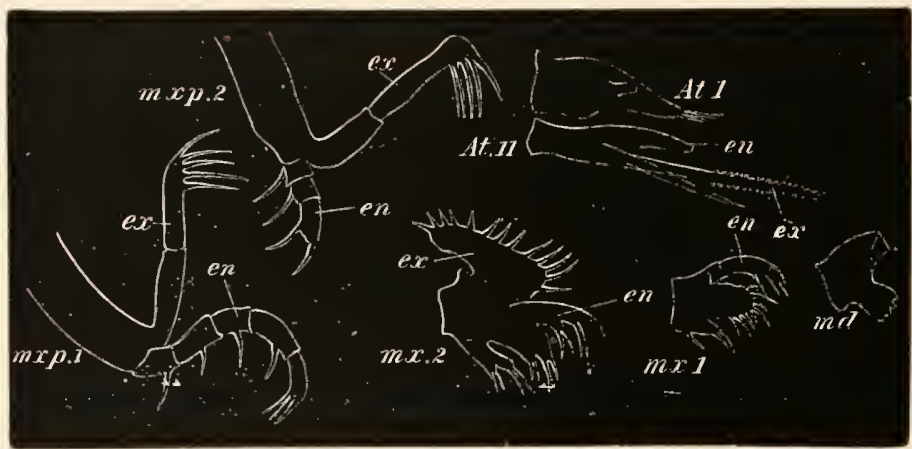

Fig. 2it. The Appendages of a Crab Zoea.

At. I. first antenna; At. II. second antenna; $m d$. mandible (without a palp); $m x$. 1. first maxilla; $m x$. 2. second maxilla; mxp. r. first maxilliped; mxp. 2. second maxilliped.

ex. exopodite ; $e n$. endopodite.

times occurs in a very modified form. It makes its appearance in an altered garb in the ontogeny of some of the other groups.

The two Malacostracan forms, amongst those so far studied, in which the phylogenetic record is most fully preserved in the ontogeny, are Euphausia amongst the Schizopods and Penæus amongst the Decapods.

Schizopoda. Euphausia leaves the egg (Metschnikoff, No. 468-9) as a true Nauplius with only three pairs of appendages, the two hinder 
biramous, and an unsegmented body. The second pair of antennæ has not however the colossal dimensions so common in the lower types. A mouth is present, but the anus is undeveloped.

After the first moult three pairs of prominences-the rudiments of the two maxillæe and ist maxillipeds arise behind the Nauplius appendages (fig. 212). At the same time an anus appears between the two limbs of a rudimentary caudal fork; and an unpaired eye and upper lip appear in front. After another moult (fig. 212) a lower lip is formed (UL) as a pair of prominences very similar to true appendages; and a delicate cephalo-thoracic shield also becomes developed. Still later the cutting blade of the mandible is formed, and the palp (Nauplius appendage) is greatly

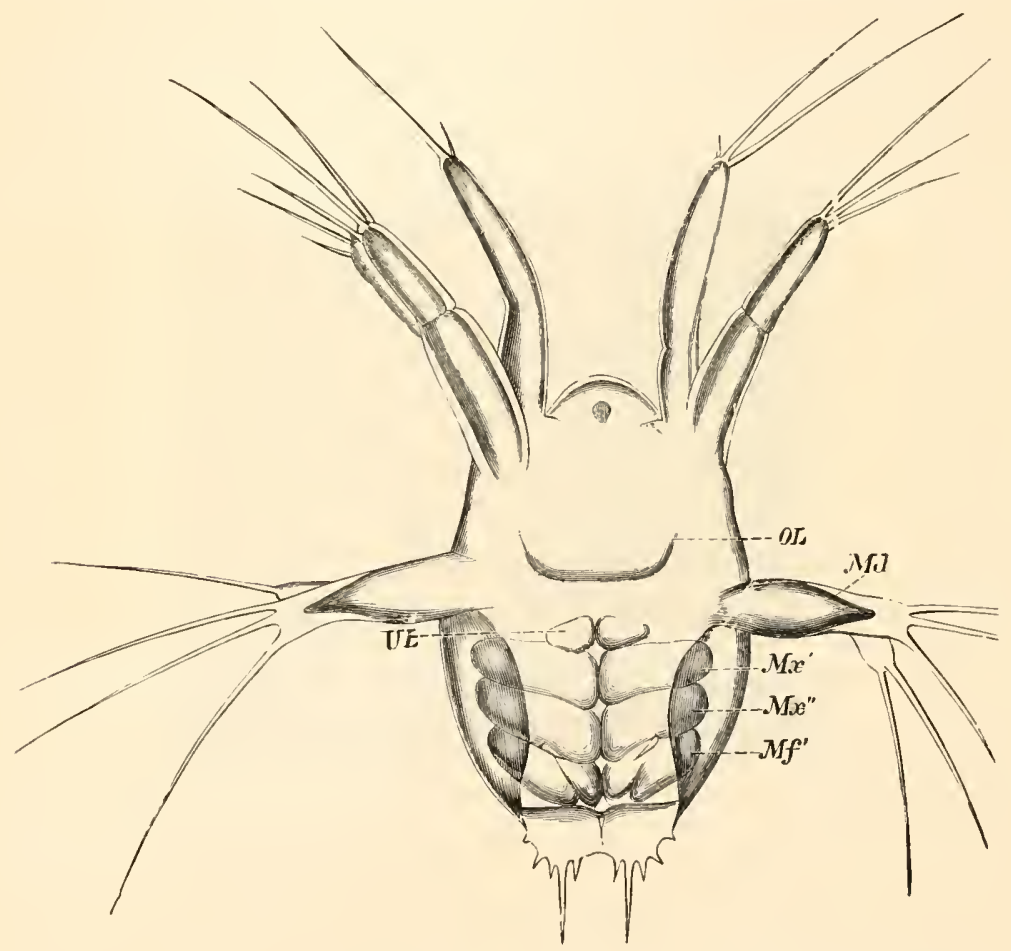

Fig. 21 2. Nauplius of Euphausia. (From Claus; after Metschnikoff.)

The Nauplius is represented shortly before an ecdysis, and in addition to the proper appendages rudiments of the three following pairs are present.

$O L$. upper lip; $U L$. lower lip; $M d$. mandible; $M x^{\prime}$. and $M x^{\prime \prime}$. two pairs of maxillæ; $m f^{\prime}$. maxilliped $\mathbf{I}$.

reduced. The cephalo-thoracic shield grows over the front part of the embryo, and becomes characteristically toothed at its edge. There are also 
two frontal papillæe very similar to those already described in the Phyllopod larvæ. Rudiments of the compound eyes make their appearance, and though no new appendages are added, those already present undergo further differentiations. They remain however very simple; the maxillipeds especially are very short and resemble somewhat Phyllopod appendages.

$U_{p}$ to this stage the tail has remained rudimentary and short, but after a further ecdysis (Claus) it grows greatly in length. At the same time the cephalo-thoracic shield acquires a short spine directed backwards. The larva is now in a condition to which Claus has given the name of Protozoæa (fig. 213 A).

Very shortly afterwards the region immediately following the segments already formed becomes indistinctly segmented, while the tail is still without a trace of segmentation. The region of the thorax proper soon becomes distinctly divided into seven very short segments, while at the same time the now elongated caudal region has become divided into its normal number of segments (fig. $213 \mathrm{~B}$ ). By this stage the larva has become

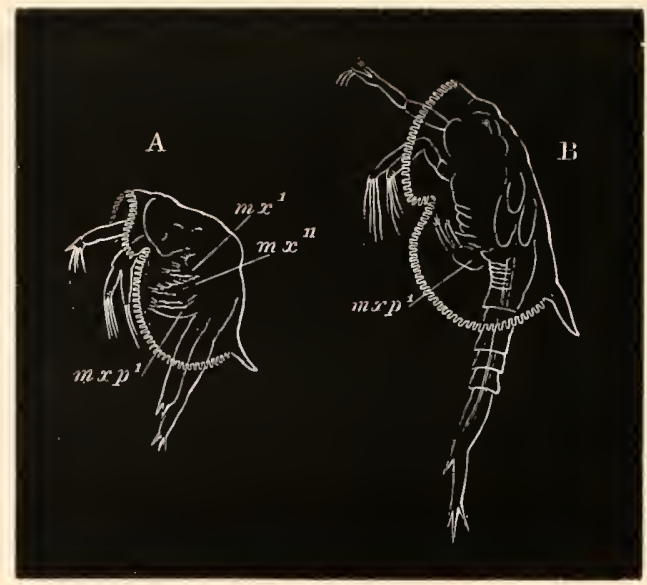

Fig. 21 3. Larva of Euphausia. (After Claus.) From the side.
A. Protozozea larva.
B. Zoxa larva. $m x^{\prime}$. and $m x^{\prime \prime}$. maxillre I and $2 ; m x p^{1}$. maxilliped I.

a true Zoæa-though differing from the normal Zoæa in the fact that the thoracic region is segmented, and in the absence of a second pair of maxillipeds.

The adult characters are very gradually acquired in a series of successive moults; the later development of Euphausia resembling in this respect that of the Phyllopods. On the other hand Euphausia differs from that group in the fact that the abdominal (caudal) and thoracic appendages develop as two independent series from before backwards, of which the abdominal series is the earliest to attain maturity. 
This is shewn in the following table compiled from Claus' observations.

\begin{tabular}{|c|c|c|}
\hline LENGTH OF LARVA. & $\begin{array}{l}\text { APPENDAGES OF THORACIC } \\
\text { REGION; viz. the } 2 \text { nd and } \\
\text { 3rd maxilliped and } 5 \text { ambu- } \\
\text { latory appendages. }\end{array}$ & APPENDAGES OF ABDOMEN. \\
\hline $3-3 \frac{1}{2} \mathrm{~mm}$ & 2nd maxilliped, rudimentary. & Ist abdominal appendage. \\
\hline $3^{\frac{1}{2}}-4 \mathrm{~mm}$ & $\begin{array}{l}\text { 2nd maxilliped, biramous. } \\
\text { 3rd rudimentary. } \\
\text { ist and } 2 \text { nd ainbulatory ap- } \\
\text { pendages, rudimentary. }\end{array}$ & $\begin{array}{l}\text { 2nd and } 3^{\text {rd }} \text { abdominal ap- } \\
\text { pendages. } \\
\text { th and } 5 \text { th rudimentary. }\end{array}$ \\
\hline $4^{\frac{1}{2}}-5 \mathrm{~mm}$ & 3rd maxilliped, biramous. & $\begin{array}{l}4^{\text {th, }} 5 \text { th, and } 6 \text { th fully de- } \\
\text { veloped. }\end{array}$ \\
\hline $5-5 \frac{1}{2} \mathrm{~mm}$. & $\begin{array}{l}3^{\text {rd }} \text { and } 4^{\text {th }} \text { ambulatory ap- } \\
\text { pendages. }\end{array}$ & \\
\hline $6 \mathrm{~mm}$. & $5^{\text {th }}$ ambulatory appendiage. & \\
\hline
\end{tabular}

All the appendages following the second pair of maxillæ are biramous, and the first eight of these bear branched gills as their epipodites. It is remarkable that the epipodite is developed on all the appendages anteriorly in point of time to the outer ramus (exopodite).

Although in Mysis there is no free larval stage, and the development takes place in a maternal incubatory pouch, yet a stage may be detected which clearly corresponds with the Nauplius stage of Euphausia (E. van Beneden, No. 465). At this stage, in which only the three Nauplius appendages are developed, the Mysis embryo is hatched. An ecdysis takes place, but the Nauplius skin is not completely thrown off, and remains as an envelope surrounding the larva during its later development.

Decapoda. Amongst the Decapoda the larva usually leaves the egg in the Zoxa form, but a remarkable exception to this general rule is afforded by the case of one or more species of Penæus. Fritz. Müller was the first to shew that the larva of these forms leaves the egg as a typical Nauplius, and it is probable that in the successive larval stages of these forms the ancestral history of the Decapoda is most fully preserved ${ }^{1}$.

The youngest known larva of Penæus (fig. 2I4) has a somewhat oval unsegmented body. There spring from it the three typical pairs of Nauplius appendages. The first is uniramous, the second and third are biramous, and both of them adapted

1 The doubts which have been thrown upon Miiller's observations appear to be quite unfounded. 
for swimming, and the third of them (mandibles) is without a trace of the future blade. The body has no carapace, and bears anteriorly a single median simple eye. Posteriorly it is produced into two bristles.

After the first moult the larva has a rudiment of a forked tail, while a dorsal fold of skin indicates the commencement of

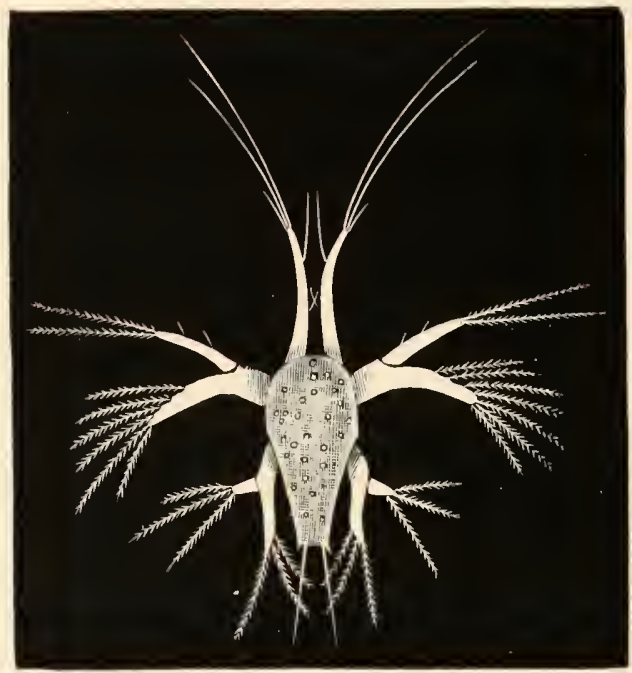

Fig. 2i 4 . Nauplius stage of Penæeus. (After Fritz Muiller.)

the cephalo-thoracic shield. A large provisional helmet-shaped upper lip like that in Phyllopods has also appeared. Behind the appendages already formed there are stump-like rudiments of the four succeeding pairs (two pairs of maxillex and two pairs of maxillipeds); and in a slightly older larva the formation of the mandibular blade has commenced, together with the atrophy of the palp or Nauplius appendage.

Between this and the next observed stage there is possibly a slight lacuna. The next stage (fig. 215) at any rate represents the commencement of the Zoæa series. The cephalo-thoracic shield has greatly grown, and eventually acquires the usual dorsal spine. The posterior region of the body is prolonged into a tail, which is quite as long as the whole of the remainder of the body. The four appendages which were quite functionless at the last stage have now sprouted into full activity. The 
region immediately behind them is divided (fig. 215) into six segments (the six thoracic segments) without appendages, while somewhat later the five anterior abdominal segments become indicated, but are equally with the thoracic segments without feet. The mode of appearance of these segments shews that the thoracic and abdominal segments develop in regular succession from before backwards (Claus). Of the palp of the mandibles, as is usual amongst Zoæa forms, not a trace remains, though in the youngest Zora caught by Fritz

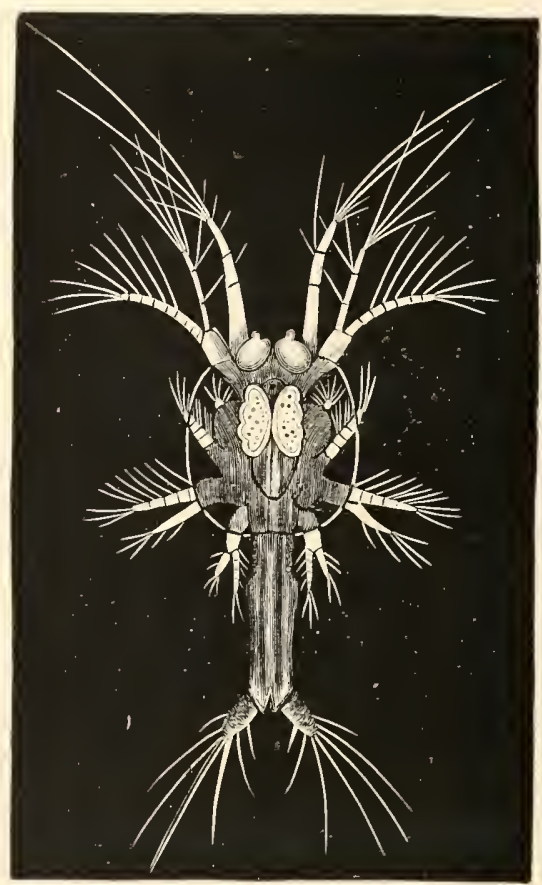

Fig. 2 I5. Protozolea Stage of Peneus. (After Fritz Miiller.)

Müller a very small rudiment of the palp was present. The first pair of antennæ is unusually long, and the second pair continues to function as a biramous swimming organ; the outer ramus is multiarticulate. The other appendages are fully jointed, and the two maxillipeds biramous. On the dorsal surface of the body the unpaired eye is still present, but on each side of it traces of the stalked eyes have appeared. Frontal sense organs like those of Phyllopods are also present.

From the Protozoza form the larva passes into that of a true Zoæa with the usual appendages and spines, characterised however by certain remarkable peculiarities. Of these the most important are (I) the large size of the two pairs of antennæ and the retention of its Nauplius function by the second of them; (2) the fact that the appendages of the six thoracic segments appear as small biramous Schizopod legs, while the abdominal appendages, with the exception of the sixth, are still without 
their swimming feet. The early appearance of the appendages of the sixth abdominal segment is probably correlated with their natatory function in connection with the tail. As a point of smaller importance which may be mentioned is the fact that both pairs of maxille are provided with small respiratory plates (exopodites) for regulating the flow of water under the dorsal shield. From the Zoxa form the larva passes into a Mysis or Schizopod stage (fig. 216), characterised by the thoracic feet and maxillipeds resembling in form and function the biramous feet of Mysis, the outer ramus being at first in many cases much larger than the inner. The gill pouches appear at the base of these feet nearly at the same time as the endopodites become functional. At the same time the antenne become profoundly modified. The anterior antenne shed their long hairs, and from the inner side of the fourth joint there springs a new process,

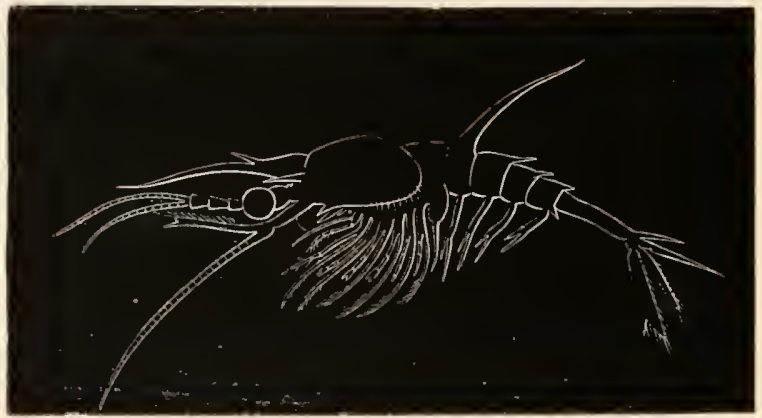

Fig. 2i6. Penæl's larva in the Mysis stage. (After Ciaus.)

which eventually elongates and becomes the inner flagellum. The outer ramus of the posterior antennæ is reduced to a scale, while the flagellum is developed from a stump-like rudiment of the inner ramus (Claus). A palp sprouts on the mandible and the median eye disappears.

The abdominal feet do not appear till the commencement of the Mysis stage, and hardly become functional till its close.

From the Mysis stage the larva passes quite simply into the adult form. The outer ramus of the thoracic feet is more or less completely lost. The maxillipeds, or the two anterior pairs at any rate, lose their ambulatory function, cutting plates develop on the inner side of their basal joints, and the two rami persist 
as small appendages on their outer side. Gill pouches also sprout from their outer side.

The respiratory plate of the second maxilla attains its full development and that on the first maxilla disappears. ${ }^{1}$. The Nauplius, so far as is known, does not occur in any other Decapod form except Penæus.

The next most primitive larval history known is that which appears in the Sergestidæ. The larval history, which has been fully elucidated by Claus, commences with a Protozoxa form (fig. 2 17 ), which develops into a remarkable Zoæa first described by Dohrn as Elaphocaris. This develops into a form originally described by Claus as Acanthosoma, and this into a form known as Mastigopus (fig. 2I 8 ) from which it is easy to pass to the aduit.

The remarkable Protozoæa (fig. 217) is characterised by the presence on the dorsal shield of a frontal, dorsal and two lateral spikes, each richly armed with long side spines. The

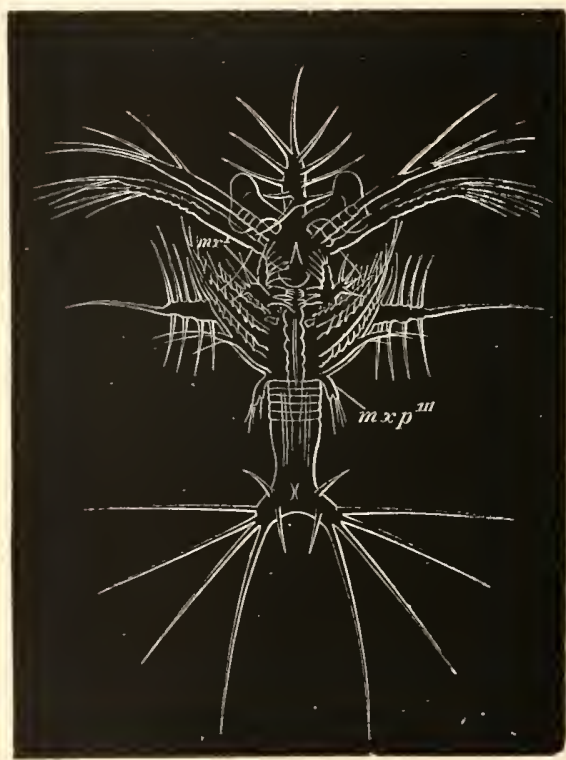

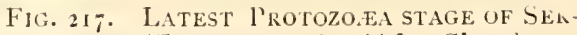
gestes laRva (Elaphocaris). (After Claus.)

mxp" . third pair of maxillipeds. normal Zoæa appendages are present, and in addition to them a small third pair of maxillipeds. The thoracic region is divided into five short rings, but the abdomen is unsegmented. The tail is forked and provided with long spines. The antennæ, like those of Penæus, are long-the second pair biramous; the mandibles unpalped. Both pairs of maxill:e are provided with respiratory plates; the second pair is footlike, and has at its base a glandular mass believed by Claus to be the equivalent of the Entomostracan shell-gland. The maxillipeds have the usual biramous characters. A

1 From Claus' observations (No. 448) it would appear that the respiratory plate is only the exopodite and not, as is usually stated, the coalesced exopodite and epipodite. Huxley in his Comparative Anatomy reserves this point for embryological elucidation. 


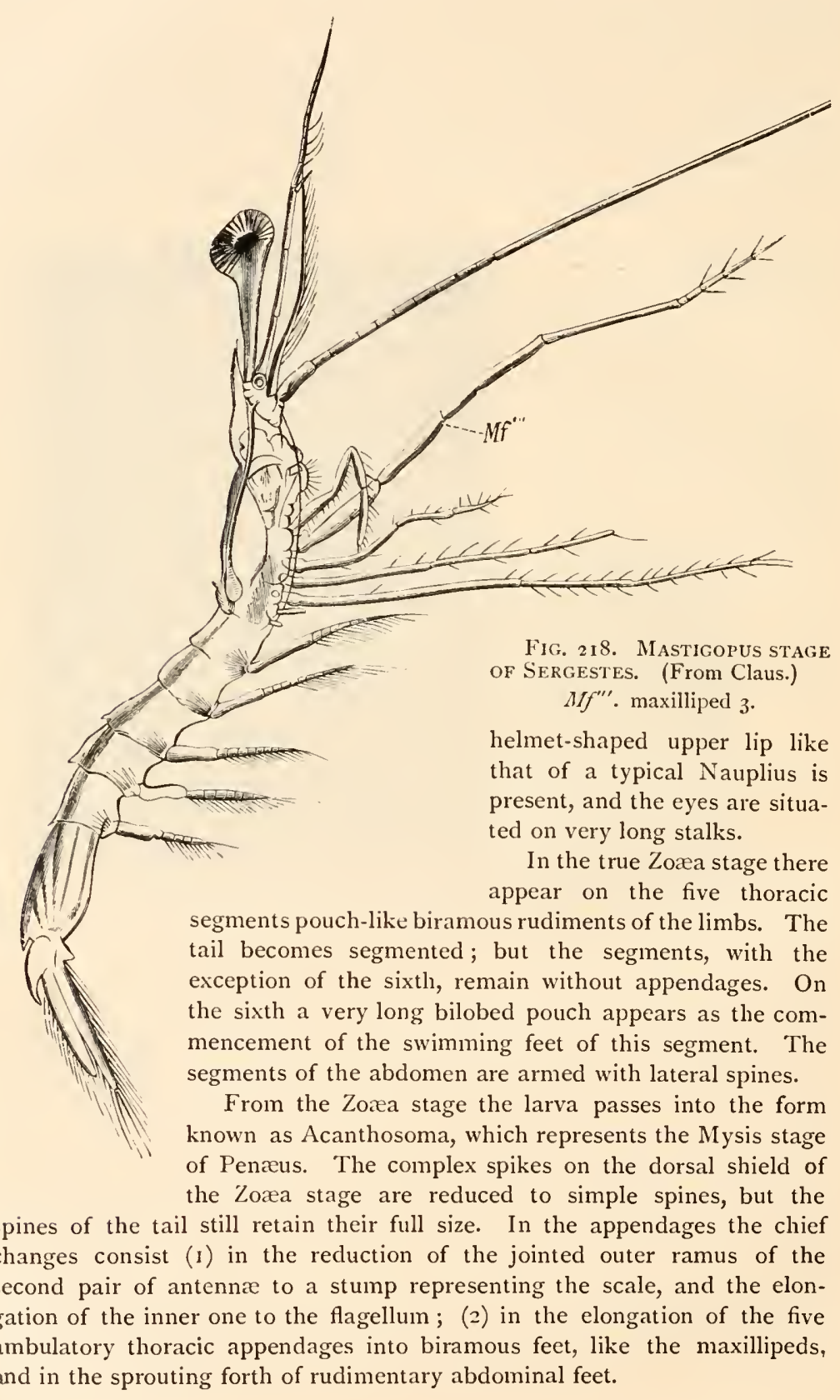


The most obvious external indications of the passage from the Acanthosoma to the Mastigopus stage (fig. 218) are to be found in the elongation of the abdomen, the reduction and flattening of the cephalo-thoracic shield, and the nearly complete obliteration of all the spines but the anterior. The eyes on their elongated stalks are still very characteristic, and the elongation of the flagellum of the second pair of antennæ is very striking.

The maxillæe and maxillipeds undergo considerable metamorphosis, the abdominal feet attain their adult form, and the three anterior thoracic ambulatory legs lose their outer rami. The most remarkable change of all concerns the two last pairs of thoracic appendages, which, instead of being metamorphosed like the preceding ones, are completely or nearly completely thrown off in the moult which inaugurates the Mastigopus stage, and are subsequently redeveloped. With the reappearance of these appendages, and the changes in the other appendages already indicated, the adult form is practically attained.

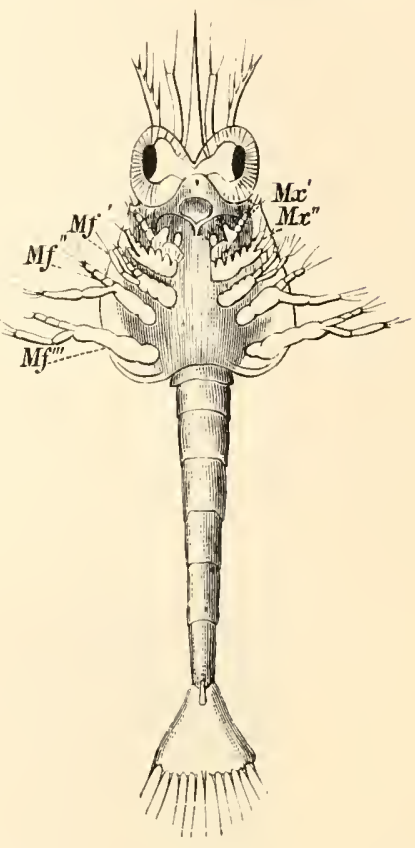

FIG. 219. LARVA OF HipPOLYTE IN ZoAA STAGE. (From Claus.)

$M x^{\prime}$. and $M x^{\prime \prime}$. maxilla I and 2 ; $M f^{\prime} . M f^{\prime \prime}$. $M f^{\prime \prime \prime}$. maxillipeds.

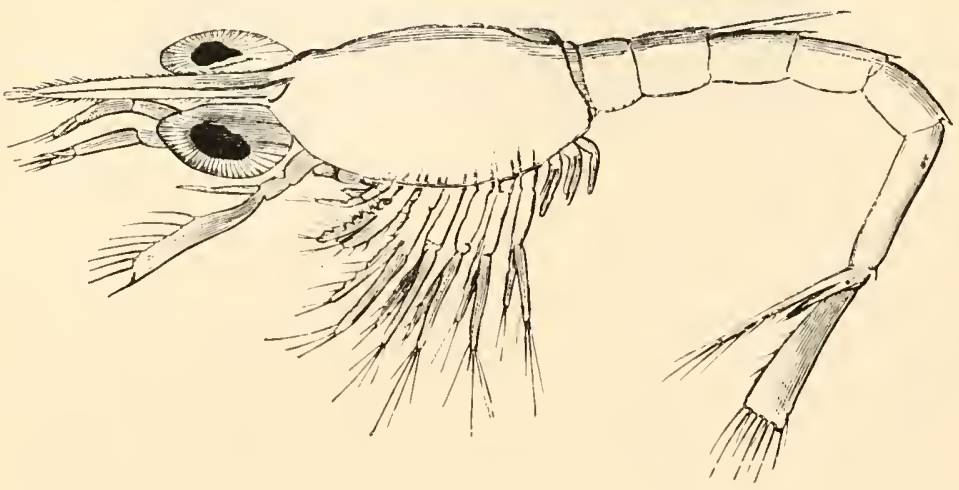

Fig. 220. OLDER larva OF HiPPOLYTE AFTER THE. THORACiC APPENDAges haVE BECOME FORMED. (From Claus.) 
With reference to the development of the majority of the Carabidæ, Penæinæ, Palæmoninæ, Crangoninæ, it may be stated generally that they leave the egg in the Zoæa stage (fig. 219) with anterior appendages up to the third pair of maxillipeds. The thorax is unsegmented and indeed almost unrepresented, but the abdomen is long and divided into distinct segments. Both thoracic and abdominal appendages are absent, and the tail is formed by a simple plate with numerous bristles, not forked, as in the case of the Zoæa of Fritz Müller's Penæus and Sergestes. A dorsal spine is frequently found on the second abdominal segment. From the Zoæa form the embryo passes into a Mysis stage (fig. 220), during which the thoracic appendages gradually appear as biramous swimming feet; they

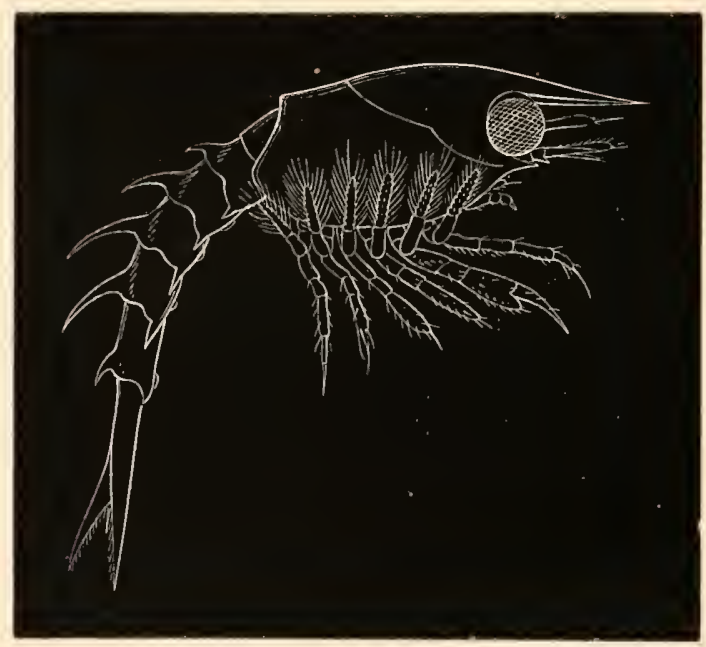

Fig. 221. Newly-hatched larva of the American Lobster. (After Smith.) are all developed before any of the abdominal appendages, except the last. In some cases the development is still further abbreviated. Thus the larvæ of Crangon and Palæmonetes (Faxon, No. 476) possess at hatching the rudiments of the two anterior pairs of thoracic feet, and Palæmon of three pairs ${ }^{1}$.

Amongst the other Macrura the larva generally leaves the egg as a Zoæa similar to that of the prawns. In the case of the

1 Fritz Müller has recently (Zoologischer Anzeiger, No. 52) described a still more abbreviated development of a Palæmon living in brooks near Blumenau. 
Thalassinide and Paguridae a Mysis stage has disappeared. The most remarkable abbreviations of the typical development are presented on the one hand by Homarus and Astacus, and on the other by the Loricata.

The development of Homarus has been fully worked out by S. J. Smith (No. 491) for the American lobster (Homarus americanus). The larva (fig. 221) leaves the egg in an advanced Mysis stage. The cephalo-thoracic shield is fully developed, and armed with a rostrum in front. The first pair of antennæ is unjointed but the second is biramous, the outer ramus forming a large Mysis-like scale. The mandibles, which are palped, the maxillæ, and the two anterior maxillipeds differ only in minor details from the same appendages of the adult. The third pair of maxillipeds is Mysis-like and biramous, and the five ambulatory legs closely resemble them, the endopodite of the first being imperfectly chelate. The abdomen is well developed but without appendages. The second, third, fourth and fifth segments are armed with dorsal and lateral spines.

In the next stage swimming feet have appeared on the second, third, fourth and fifth abdominal segments, and the appendages already present have approached their adult form. Still later, when the larva is about half an inch in length, the approach to the adult form is more marked, and the exopodites of the ambulatory legs though present are relatively much reduced in size. The swimmerets of the sixth abdominal segment are formed. In the next stage observed the larva has entirely lost its Schizopod characters, and though still retaining its free swimming habits differs from the adult form only in generic characters.

As has been already stated, no free larval stages occur in the development of Astacus, but the young is hatched in a form in which it differs only in unimportant details from the adult.

The peculiar larval form of the Loricata (Scyllarus, Palinurus) has long been known under the name Phyllosoma (fig. 222 C), but its true nature was first shewn by Couch (No. 474) [Couch did not however recognise the identity of his larva with Phyllosoma; this was first done by Gerstäcker] and shortly afterwards by Gerbe and Coste. These observations were however for a long time not generally accepted, till Dohrn (No. 477) published his valuable inemoir giving an account of how he succeeded in actually rearing Phyllosoma from the eggs of Scyllarus and Palinurus, and shewing that some of the most remarkable features of the metamorphosis of the Loricata occur before the larva is hatched.

The embryo of Scyllarus in the egg first of all passes through the usual Nauplius stage, and then after the formation of a cuticle develops an elongated thoracico-abdominal region bent completely over the anterior part of the body. There appear moreover a number of appendages and the rudiments of various organs; and the embryo passes into a form which may be described as the embryonic Phyllosoma stage. In this stage there are present on the anterior part of the body, in front of the ventral flexure, two 
pairs of antennæ, mandibles, two pairs of maxillæ, the second commencing to be biramous, and a small stump representing the first pair of maxillipeds. The part of the body bent over consists of a small quadrate caudal plate, and an appendage-bearing region to which are attached anteriorly three pairs of biramous appendages - the second and third maxillipeds, and the anterior pair of ambulatory legs-and two pairs of undivided appendagesthe second and third pairs of ambulatory legs. In a slightly later stage the first pair of maxillæ becomes biramous, as also does the first pair of maxillipeds in a very rudimentary fashion. The second and third pairs of ambulatory legs become biramous, while the second and third maxilliped nearly completely lose their outer ramus. Very small rudiments of the two hinder ambulatory legs become formed. If the embryo is taken at this stage (vide fig. 222 A, which represents a nearly similar larva of Palinurus) out of the egg, it is seen to consist of (I) an anterior enlargement with a vaulted dorsal shield enclosing the yolk, two stalked eyes, and a median eye ; (2) a thoracic region in which the indications of segmentation are visible with the two

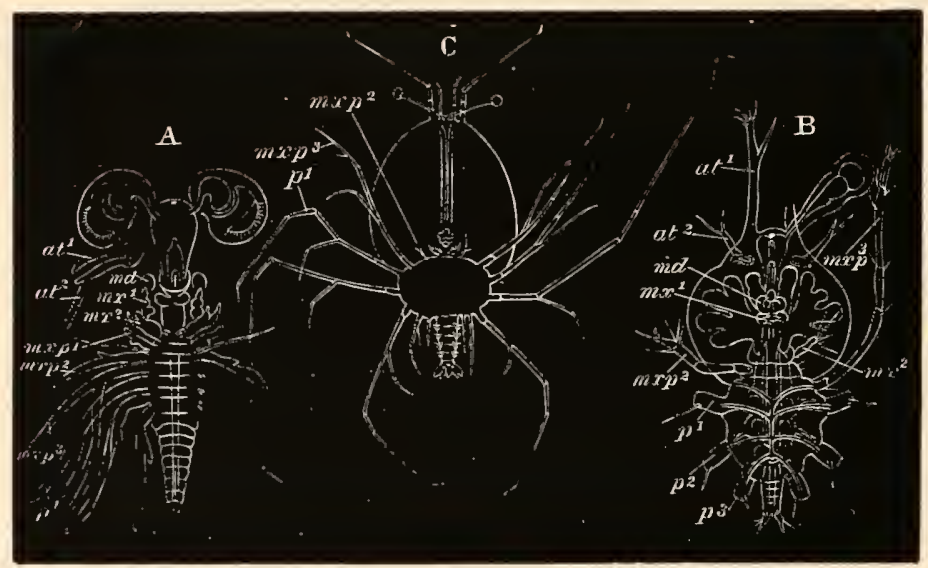

Fig. 222. LaRVE OF THE Loricata. (After Claus.)

A. Embryo of Palinurus shortly before hatching.

B. Young Phyllosoma larva of Scyllarus, without the first maxilliped, the two last thoracic appendages, or the abdominal appendages.

C. Fully-grown Phyllosoma with all the Decapod appendages.

$a t^{1}$. antenna of first pair ; $a t^{2}$. antenna of second pair ; $m d$. mandible ; $m x^{1}$. first maxilla; $m x^{2}$. second maxilla; $m x p^{1}-m x p^{3}$. maxillipeds; $p^{1}-p^{3}$. thoracic appendages.

posterior pairs of maxillipeds $\left(m x p^{2}\right.$ and $\left.m x p^{3}\right)$ and the ambulatory legs $(\not p)$; (3) an abdominal region distinctly divided into segments and ending in a fork.

Before the embryo becomes hatched the first pair of maxillipeds becomes reduced in size and finally vanishes. The second pair of maxillæ becomes reduced to simple stumps with a few bristles, the second pair of antennæ 
also appears to undergo a retrogressive change, while the two last thoracic segments cease to be distinguishable. It thus appears that during embryonic life the second pair of antenne, the second pair of maxillæ, and the second and third pair of maxillipeds and the two hinder ambulatory appendages undergo retrogressive changes, while the first pair of maxillipeds is completely obliterated!

The general form of the larva when hatched (fig. $222 \mathrm{~B}$ ) is not very different from that which it has during the later stages within the egg. The body is divided into three regions: (I) an anterior cephalic ; (2) a middle thoracic, and (3) a small posterior abdominal portion; and all of them are characterised by their extreme dorso-ventral compression, so that the whole animal has the form of a three-lobed disc, the strange appearance of which is much increased by its glass-like transparency.

The cephalic portion is oval and projects slightly behind so as to overlap the thorax. Its upper surface constitutes the dorsal shield, from which there spring anteriorly the two compound eyes on long stalks, between which is a median Nauplius eye. The mouth is situated about the middle of the under surface of the anterior disc. It leads into a stomach from which an anterior and a lateral hepatic diverticulum springs out on each side. The former remains as a simple diverticulum through larval life, but the latter becomes an extremely complicated glandular structure.

At the front border of the disc is placed the unjointed but elongated first pair of antennze $\left(a t^{1}\right)$. Externally to and behind these there spring the short posterior antenna $\left(a t^{2}\right)$. At the base of which the green gland is already formed. Surrounding the mouth are the mandibles ( $m d$ ) and anterior pair of maxillæ $\left(m x^{1}\right)$, and some distance behind the second pair of maxillæ $\left(m x^{2}\right)$, consisting of a cylindrical basal joint and short terminal joint armed with bristles. The first pair of maxillipeds is absent.

The thoracic region is formed of an oval segmented disc attached to the under surface of the cephalic disc. From its front segment arises the second pair of maxillipeds $\left(m x p^{2}\right)$ as single five-jointed appendages, and from the next segment springs the five-jointed elongated but uniramous third pair of maxillipeds $\left(m x p^{3}\right)$, and behind this there arise three pairs of six-jointed ambulatory appendages $\left(p^{1}, p^{2}, p^{3}\right.$, of which only the basal joint is represented in the figure) with an exopodite springing from their second joint. The two posterior thoracic rings and their appendages cannot be made out.

The abdomen is reduced to a short imperfectly segmented stump, ending in a fork, between the prongs of which the anus opens. Even the youngest larval Phyllosoma, such as has just been described, cannot be compared with a Zoæa, but belongs rather, in the possession of biramous thoracic feet, to a Mysis stage. In the forked tail and Nauplius eye there appear however to be certain very primitive characters carried on to this stage.

The passage of this young larva to the fully formed Phyllosoma (fig. $222 \mathrm{C}$ ) is very simple. It consists essentially in the fresh development of the first pair of maxillipeds and the two last ambulatory appendages, the growth and segmentation of the abdomen, and the sprouting on it of biramous 
swimming feet. In the course of these changes the larva becomes a true Decapod in the arrangement and number of its appendages; and indeed it was united with this group before its larval character was made out. In addition to the appearance of new appendages certain changes take place in those already present. The two posterior maxillipeds, in the Palinurus Phyllosonia at any rate, acquire again an exopodite, and together with the biramous ambulatory feet develop epipodites in the form of gill pouches.

The mode of passage of the Phyllosoma to the adult is not known, but it can easily be seen from the oldest Phyllosoma forms that the dorsal cephalic plate grows over the thorax, and gives rise to the cephalo-thoracic shield of the adult.

There are slight structural differences, especially in the antennæ, between the Phyllosoma of Scyllarus and that of Palinurus, but the chief difference in development is that the first pair of maxillipeds of the Palinurus embryo, though reduced in the embryonic state, does not completely vanish, at any rate till after the free larval state has commenced; and it is doubtful if it does so even then. The freshly hatched Palinurus Phyllosoma is very considerably more developed than that of Scyllarus.

Brachyna. All the Brachyura, with the exception of one or more species of land $\operatorname{crabs}^{1}$, leave the egg in the Zoæa condition, and though there are slight variations of structure, yet on the

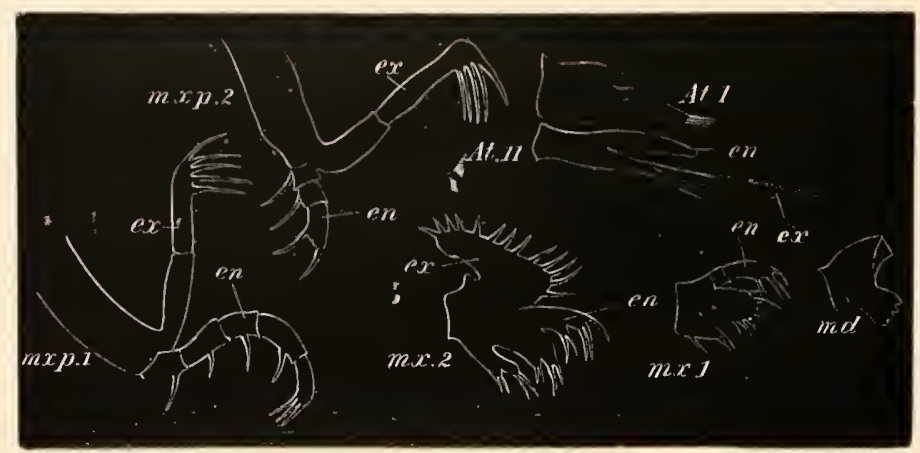

Fig. 223. The appendages of a Crab Zo.eA.

At.I. first antenna; At. II. second antenna; md. mandible (without a palp); $m x$. 1. first maxilla ; mx. 2. second maxilla; $m x .3$. third maxilla; mxp. 1. first maxilliped; $m x p$. 2. second maxilliped.

$e x$. exopodite; $e n$. endopodite.

whole the Crab Zoæa is a very well marked form. Immediately after leaving the egg (fig. 2 IO) it has a somewhat oval shape

1 It has been clearly demonstrated that the majority of land-crabs leave the egg in the Zoæa form. 
with a long distinctly-segmented abdomen bent underneath the thorax. The cephalo-thoracic shield covers over the front part of the body, and is prolonged into a long frontal spine pointing forwards, and springing from the region between the two eyes; a long dorsal spine pointing backwards; and two lateral spines.

To the under surface of the body are attached the anterior appendages up to the second maxilliped, while the six following pairs of thoracic appendages are either absent or represented only in a very rudimentary form. The abdomen is without appendages.

The anterior antennæ are single and unjointed, but provided at their extremity with a few olfactory hairs (only two in Carcinus Mœnas) and one or two bristles. The rudiment of the secondary flagellum appears in very young Zoææ on the inner side of the antennules (fig. 223 At. I.). The posterior antennæ are without the flagellum, but are provided with a scale representing the exopodite (fig. $223 A t . I I . e x$ ) and usually a spinous

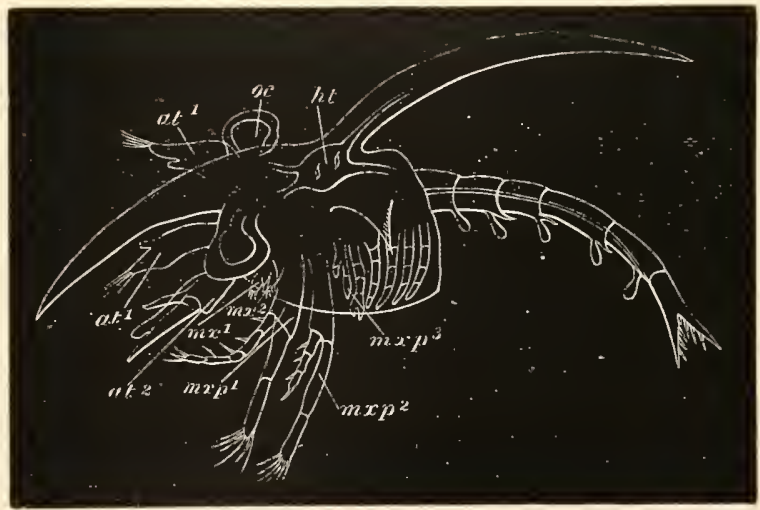

Fig. 224. Crab Zolea after the third pair of Maxillipeds and the THORACIC AND ABDOMINAL APPENDAGES HAVE BECOME DEVELOPED.

$a t^{1}$. antenna of first pair; $a t^{2}$. antenna of second pair; $m x^{1}$. first maxilla; $m x^{2}$. second maxilla; $m x p^{1}$. first maxilliped; $m x p^{2}$. second maxilliped; $m x p^{3}$. third maxilliped; oc. eye; $h t$. heart.

process. The flagellum is very early developed and is represented in fig. 223, At. 11. $\mathrm{cn}$. The mandibles ( $\mathrm{md}$ ) are large but without a palp. The anterior maxillæ $(m x \mathrm{I})$ have a short twojointed endopodite (palp) with a few hairs, and a basal portion

B. II. 
with two blades, of which the distal is the largest, both armed with stiff bristles. The posterior maxillæ have a small respiratory plate (exopodite), an endopodite (palp) shaped like a double blade, and two basal joints each continued into a double blade. The two maxillipeds ( $m x p$ I and $m x p 2$ ) have the form and function of biramous swimming feet. The exopodite of both is two-jointed and bears long bristles at its extremity; the endopodite of the anterior is five-jointed and long, that of the second is three-jointed and comparatively short.

In the six-jointed tail the second segment has usually two dorsally directed spines, and the three succeeding segments each of them two posteriorly directed. The telson or swimming plate is not at first separated from the sixth segment; on each side it is prolonged into two well-marked prongs; and to each prong three bristles are usually attached (fig. 224). The heart (fig. $224 \mathrm{ht}$ ) lies under the dorsal spine and is prolonged into an anterior, posterior, and dorsal aorta. It has only two pairs of venous ostia.

During the Zoxa stage the larva rapidly grows in size, and undergoes considerable changes in its appendages which reach the full Decapod number (fig. 224). On both pairs of antennae a flagellum becomes developed and grows considerably in length. Before the close of the Zorea condition a small and unjointed palp appears on the mandible. Behind the second maxilliped the third maxilliped $\left(m x p^{3}\right)$ early appears as a small biramous appendage, and the five ambulatory feet become distinctly formed as uniramous appendages-the exopodites not being present. The third pair of maxillipeds and three following ambulatory appendages develop gill pouches. The abdominal feet are formed on the second to the sixth segments of the tail as simple pouches.

The oldest Zoæa is transmuted at its moult into a form known as Megalopa, which is really almost identical with an anomurous Decapod. No Schizopod stage is intercalated, which shews that the development is in many respects greatly abbreviated. The essential characters of the Megalopa are to be found in ( $I$ ) the reduction of the two anterior maxillipeds, which cease to function as swimming feet, and together with the appendages in front of them assume the adult form ; (2) the full 
functional development of the five ambulatory appendages; (3) the reduction of the forked telson to an oval swimming plate, and the growth in size of the abdominal feet, which become large swimming plates and are at the same time provided with short endopodites which serve to lock the feet of the two sides.

With these essential characters the form of the Megalopa differs considerably in different cases. In some instances (e.g. Carcinus mœnas) the Zoæa spines of the youngest Megalopa are so large that the larva appears almost more like a Zoæa than a Megalopa (Spence Bate, No. 470). In other cases, e.g. that represented on fig. 225 , the Zorea spines are still present but much reduced; and the cephalo-thoracic shield has very much the adult form. In other cases again (e.g. Portunus) the Zoæa spines are completely thrown off at the youngest Megalopa stage.

There is a gradual passage from the youngest Megalopa to the adult form by a series of moults.

Some of the brachyurous Zoæa forms exhibit considerable divergences from the described type, more espcially in the armature of the shield. In some forms the spines are altogether absent, e.g. Maja (Couch, No. 474) and Eurynome. In other forms the frontal spine may be much reduced or absent (Inachus and Achæus). The dorsal spine may also be absent, and in one form described by Dohrn (No. 478) there is a long frontal spine and two pairs of lateral spines, but no dorsal spine. Both dorsal and

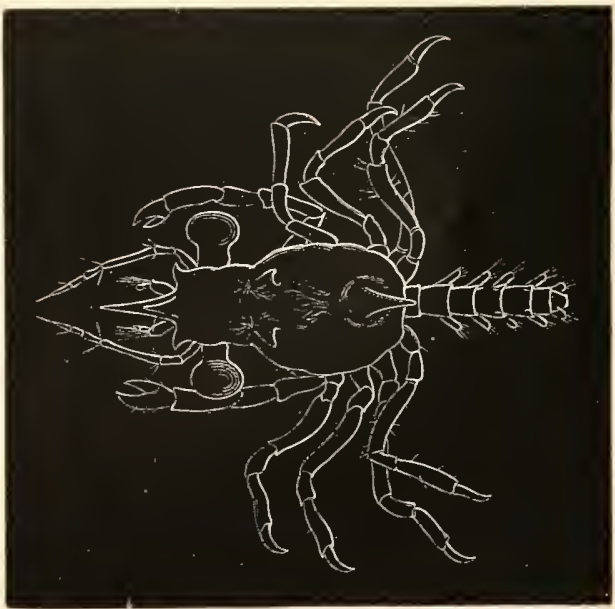

Fig. 225. Megalopa stage of Crab larva. frontal spines may attain enormous dimensions and be swollen at their extremities (Dohrn). A form has been described by Claus as Pterocaris in which the cephalo-thoracic shield is laterally expanded into two wing-like processes.

The Zoæa of Porcellana presents on the whole the most remarkable peculiarities and, as might be anticipated from the systematic position of the adult, is in some respects intermediate between the macrurous Zoæa and that of the Brachyura. It is characterized by the oval form of the body, and by 
the presence of one enormously long frontal spine and two posterior spines. The usual dorsal spine is absent. The tail plate is rounded and has the character of the tail of a macrurous Zoæa, but in the young Zoæa the third pair of maxillipeds is absent and the appendages generally have a brachyurous character. A Megalopa stage is hardly represented, since the adult may almost be regarded as a permanent Megalopa.

Stomatopoda. The history of the larval forms of the Stomatopoda (Squilla etc.) has not unfortunately been thoroughly worked out, but what is known from the researches of Fritz Müller (No. 495) and Claus (No. 494) is of very great importance. There are it appears two types, both of which used to be described as adult forms under the respective names Erichthus and Alima.

The youngest known Erichthus form is about two millimetres in length, and has the characters of a modified Zoæa (fig. 226). The body is divided into three regions, an anterior unsegmented region to which are attached two pairs of antennæ, mandibles, and maxillæ (two pairs). This portion has a dorsal shield covering the next or middle region, which consists of five segments each with a pair of biramous appendages. These appendages represent the five maxillipeds of the adult ${ }^{1}$. The portion of the body behind this is without appendages. It consists of three short anterior segments,- the three posterior thoracic segments of the adult,- and a long unsegmented tail. The three footless thoracic segments are covered by the dorsal shield. Both pairs of antennæ are uniramous and comparatively short. The mandibles, like those of Phyllopods, are without palps, and the two following pairs of maxillæe are small. The five maxillipeds have the characters of normal biramous Zoæa feet. From the front of the head spring a pair of compound eyes with short stalks, which grow longer in the succeeding stages; between them is a median eye. The dorsal shield is attached just behind this eye, and is provided, as in the typical Zoxa, with a frontal spike-while its hinder border is produced into two lateral spikes and one median. In a larva of about three millimetres a pair of biramous appendages arises behind the three footless thoracic segments. It is the anterior pair of abdominal feet (fig. 226). The inner ramus of the second pair of maxillipeds soon grows greatly in length, indicating its subsequent larger size and prehensile form (fig. $227 \mathrm{~g}$ ). When the larva after one or two moults attains a length of six millimetres (fig. 227) the abdomen has six segments

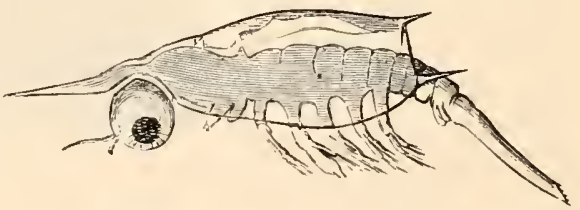

Fig. 226. SECONd Stage OF ERICHTHUS LARVA OF SQUI1.LA WITH FIVE MAXILLIPEDS AND THE FIRST PAIR OF ABDOMINAL APPENDAGES. (From Claus.)

1 These five maxillipeds correspond with the three maxillipeds and two anterior ambulatory appendages of the Decapoda. 
(the sixth hardly differentiated), each with a pair of appendages (the two hindermost still rudimentary) which have become gradually developed from before backwards. The three hindermost thoracic segments are still without appendages.

Some changes of importance have occurred in the other parts. Both antennæ have acquired a second flagellum, but the mandible is still without

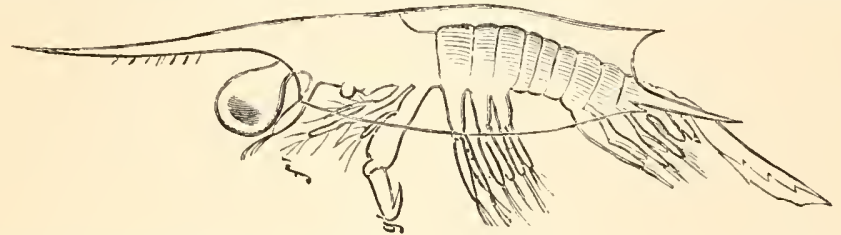

F1G. 227. Advanced Erichthus larva of Souilla with five pairs of ABDOMINAL APPENDAGES. (From Claus.)

$f$. first maxilliped; $g$. second maxilliped.

a palp. The first and second pair of maxillipeds have both undergone important modifications. Their outer ramus (exopodite) has been thrown off, and a gill-plate (epipodite) has appeared as an outgrowth from their basal joint. Each of them is composed of six joints. The three following biramous appendages have retained their earlier characters but have become much reduced in size. In the subsequent moults the most remarkable new features concern the three posterior maxillipeds, which undergo atrophy, and are either completely lost or reduced to mere unjointed sacks (fig. 228). In

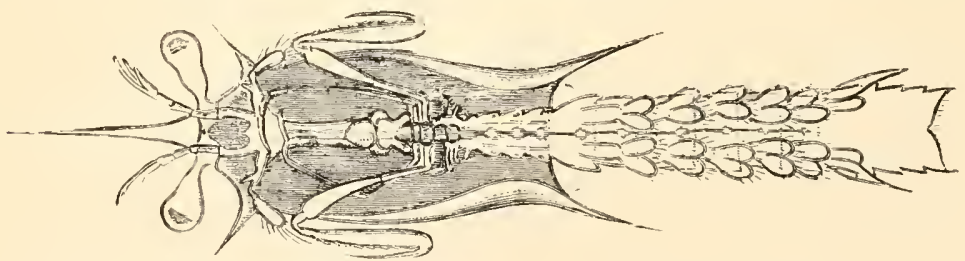

F1g. 228. Advanced Erichtius larva of Squllla ivhen the three POSTERIOR MAXILLIPEDS HAVE BECOME REDUCED TO MINUTE POUCHES.

(From Claus.)

the stage where the complete Erichthus type has been reached, these three appendages have again sprouted forth in their permanent form and each of them is provided with a gill-sack on its coxal joint. Behind them the three ambulatory appendages of the thorax have also appeared, first as simple buds, which subsequently however become biramous. On their development the full number of adult appendages is acquired.

The most noteworthy points in the developmental history detailed above are the following :

(1) The thoracic and abdominal segments (apart from their appendages) develop successively from before backwards. 
(2) The three last maxillipeds develop before the abdominal feet, as biramous appendages, but subsequently completely atrophy, and then sprout out again in their permanent form.

(3) The abdominal feet develop in succession from before backwards, and the whole series of them is fully formed before a trace of the appendages of the three hindermost thoracic segments has appeared. It may be mentioned as a point of some importance that the Zoxa of Squilla has an elongated many-chambered heart, and not the short compact heart usually found in the Zoæa.

The younger stages of the Alima larva are not known ${ }^{1}$, but the earliest stage observed is remarkable for presenting no trace of the three posterior pairs of maxillipeds, or of the three following pairs of thoracic appendages. The segments belonging to these appendages are however well developed. The tail has its full complement of segments with the normal number of well developed swimming feet. The larva represents in fact the stage of the Erichthus larva when the three posterior pairs of maxillipeds have undergone atrophy; but it is probable that these appendages never become developed in this form of larva.

Apart from the above peculiarities the Alima form of larva closely resembles the Erichthus form.

Nebaliadæ. The development of Nebalia is abbreviated, but fron Metschnikoff's figures" may be seen to resemble closely that of Mysis. The abdomen has comparatively little yolk, and is bent over the ventral surface of the thorax. There is in the egg a Nauplius stage with three appendages, and subsequently a stage with the Zoæa appendages.

The larva when it leaves the egg has the majority of its appendages formed, but is still enveloped in a larval skin, and like Mysis bends its abdomen towards the dorsal side. When the larva is finally hatched it does not differ greatly from the adult.

Cumaceæ. The development of the Cumacex takes place for the most part within the egg, and has been shewn by Dohrn (No. 496) to resemble in many points that of the Isopods. A dorsal organ is present, and a fold is formed immediately behind this which gives to the embryo a dorsal flexure. Both of these features are eminently characteristic of the Isopoda.

The formation of the two pairs of antennie, mandibles, and two pairs of maxillæ and the following seven pairs of appendages takes place very early. The pair of appendages behind the second maxillæ assumes an ambulatory form, and exhibits a Schizopod character very carly, differing in both these respects from the homologous appendages in the Isopoda. The cephalo-thoracic shield commences to be formed when the appendages are still quite rudimentary as a pair of folds in the maxillary region. The

1 The observations of Brooks (No. 493) render it probable that the Alima larva leaves the egg in a form not very dissimilar to the youngest known larva.

${ }^{2}$ His paper is unfortunately in Russian. 
eyes are formed slightly later on each side of the head, and only coalesce at a subsequent period to form the peculiar median sessile eye of the adult.

The two pairs of appendages behind the second maxilla become converted into maxillipeds, and the exopodite of the first of them becomes the main ramus, while in the externally similar second maxilliped the exopodite atrophies and the endopodite alone remains.

The larva is hatched without the last pair of thoracic limbs or the abdominal appendages (which are never developed in the female), but in other respects closely resembles the adult. Before hatching the dorsal flexure is exchanged for a ventral one, and the larva acquires a character more like that of a Decapod.

\section{COPEPODA.}

Natantia. The free Copepoda are undoubtedly amongst the lowest forms of those Crustacea which are free or do not lead a parasitic existence. Although some features of their anatomy, such for instance as the frequent absence of a heart, may be put down to a retrogressive development, yet, from their retention of the median frontal eye of the Nauplius as the sole organ of vision ${ }^{1}$, their simple biramous swimming legs, and other characters, they may claim to be very primitive forms, which have diverged to no great extent from the main line of Crustacean development. They supply a long series of transitional steps from the Nauplius stage to the adult condition.

While still within the egg-shell the embryo is divided by two transverse constrictions into three segments, on which the three Nauplius appendages are developed, viz. the two pairs of antennæ and the mandibles. When the embryo is hatched the indication of a division into segments has vanished, but the larva is in the fullest sense a typical Nauplius ${ }^{2}$. There are slight variations in the shape of the Nauplius in different genera, but its general form and character are very constant. It has (fig. 229 A) an oval unsegmented body with three pairs of appendages springing from the ventral surface. The anterior of these (at I) is uniramous, and usually formed of three joints which bear bristles on their under surface. The two posterior

1 The Pontellidx form an exception to this statement, in that they are provided with paired lateral eyes in addition to the median one.

2 The term Nauplius was applied to the larva of Cyclops and allied organisms by O. F. Miiller under the impression that they were adult forms. 
pairs of appendages are both biramous. The second pair of antennæ (at 2) is the largest. Its basal portion (protopodite) bears on its inner side a powerful hook-like bristle. The outer ramus is the longest and many-jointed; the inner ramus has only two joints. The mandibles $(m d)$, though smaller than the second pair of antennæ, have a nearly identical structure. No blade-like projection is as yet developed on their protopodite. Between the points of insertion of the first pair of antennæ is the median eye $(o c)$, which originates by the coalescence of two distinct parts. The mouth is ventral, and placed in the middle line between the second pair of antenne and the mandibles: it

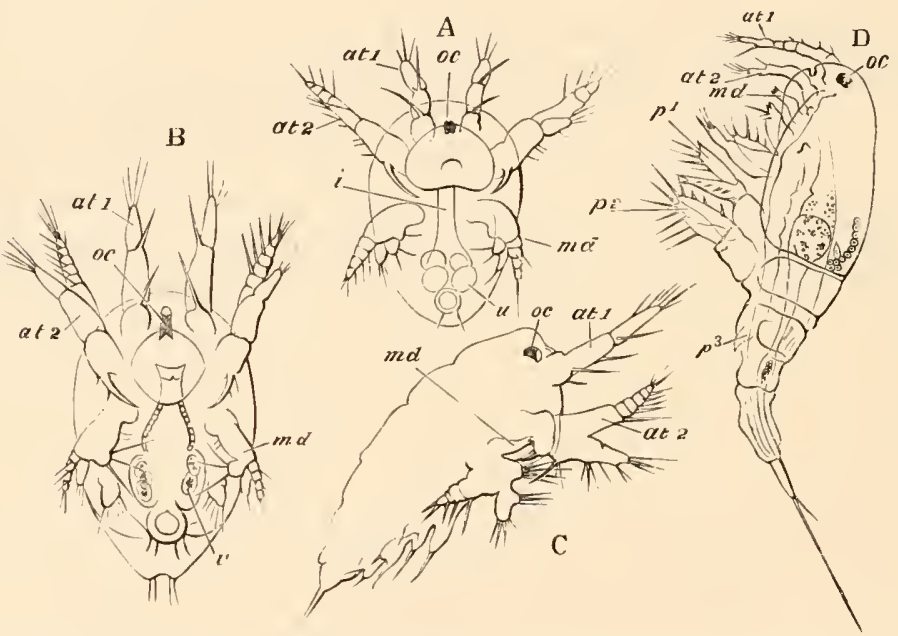

Fig. 229. Successive Stages in the DeVelopment of Cyclops tenuicorNis.

(Copied from Bronn; after Claus.)

A. B. and C. Nauplius stages. D. Youngest Copepod stage. In this figure maxillæ and the two rami of the maxilliped are seen immediately behind the mandible $m d$.

$o c$. eye; $a t^{\mathbf{1}}$. first pair of antennæ; $a t^{2}$. second pair of antennæ; $m d$. mandible; $p^{1}$. first pair of feet ; $p^{2}$. second pair of feet ; $p^{3}$. third pair of feet ; $u$. excretory concretions in the intestine.

is provided with an unpaired upper lip. There are two bristles at the hind end of the embryo between which the anus is placed, and in some cases there is at this part a slight indication of the future caudal fork.

The larva undergoes a number of successive ecdyses, at each of which the body becomes more elongated, and certain other 
changes take place. First of all a pair of appendages arises behind the mandibles, which form the maxillæ (fig. $229 \mathrm{~B}$ ); at the same time the basal joint of the maxillre develops a cuttingblade. Three successive pairs of appendages (fig. 229 C) next become formed-the so-called maxillipeds (the homologues of the second pair of maxillæ), and the two first thoracic limbs. Each of these though very rudimentary is nevertheless bifid. The body becomes greatly elongated, and the caudal fork more developed.

Up to this stage of development the Nauplius appendages have retained their primitive character almost unaltered; but after a few more ecdyses a sudden change takes place; a cephalothoracic shield becomes fully developed, and the larva comes to resemble in character an adult Copepod, from which it mainly differs in the smaller number of segments and appendages. In the earliest 'Cyclops' stage the same number of appendages are present as in the last Nauplius stage. There (fig. 229 D) is a well developed cephalo-thorax, and four free segments behind it. To the cephalo-thoracic region the antennæ, mandibles, maxillæ, the now double pair of maxillipeds (derived from the original single pair of appendages), and first pair of thoracic appendages $\left(p^{1}\right)$ are attached. The second pair of thoracic appendages $\left(p^{2}\right)$ is fixed to the first free segment, and the rudiment of a third pair $\left(p^{3}\right)$ projects from the second free segment. The first pair of antennæ has grown longer by the addition of new joints, and continues to increase in length in the following ecdyses till it attains its full aduit development, and then forms the chief organ of locomotion. The second pair of antennæ is much reduced and has lost one of its rami. The two rami of the mandibles are reduced to a simple palp, while the blade has assumed its full importance. 'The maxillæ and following appendages have greatly increased in size. They are all biramous, though the two rami are not as yet jointed. The adult state is gradually attained after a number of successive ecdyses, at which new segments and appendages are-added, while new joints are formed for those already present.

Parasita. The earliest developmental stages of the parasitic types of Copepoda closely resemble those of the free forms, but, as might be expected from the peculiarly modified forms of the adult, they present a 
large number of secondary characters. So far as is known a more or less modified Nauplius larva is usually preserved.

The development of Achtheres percarum, one of the Lernæopoda parasitic in the mouth, etc. of the common Perch, may be selected to illustrate the mode of development of these forms. The larva leaves the egg as a much simplified Nauplius (fig. $230 \mathrm{~A}$ ). It has an oval body with only the two anterior pairs of Nauplius appendages; both of them in the rudimentary condition of unjointed rods. The usual median eye is present, and there is also found a peculiar sternal papilla, on which opens a spiral canal filled with a glutinous material, which is probably derived from a gland which disappears on the completion of the duct. The probable function of this

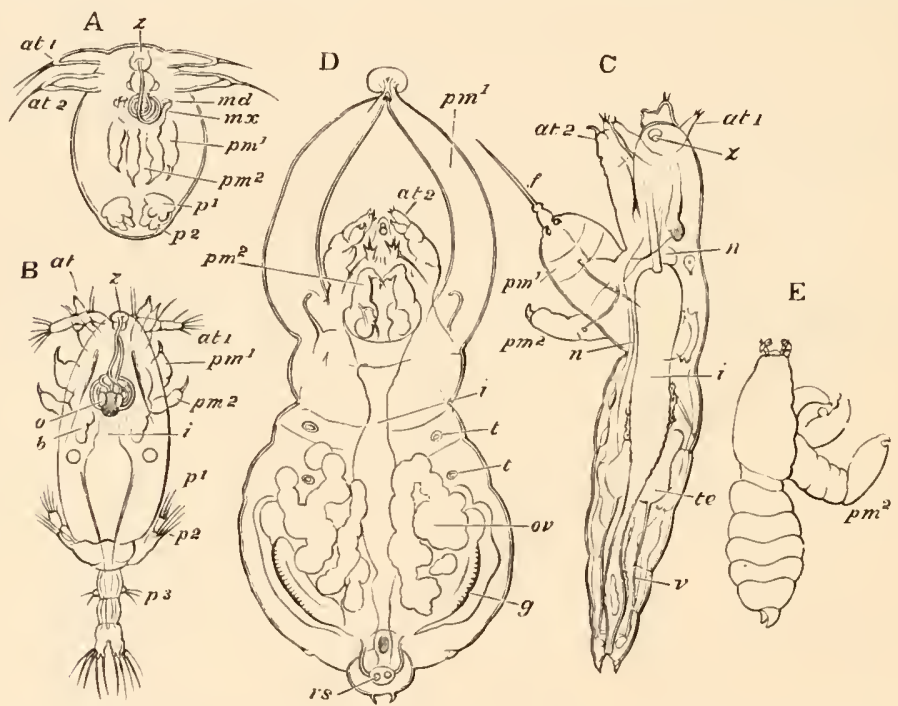

Fig. 230. Successive stages in the development of Achtheres percarun. (Copied from Bronn; after Claus.)

A. Modified Nauplius stage. B. Cyclops stage. C. Late stage of male embryo. D. Sexually mature female. E. Sexually mature male.

$a t^{1}$. first pair of antennæ; $a t^{2}$. second pair of antennæ; $m d$. mandible; $m x$. maxillæ; $p m^{1}$. outer pair of maxillipeds ; $p m^{2}$. inner pair of maxillipeds ; $p^{1}$. first pair of legs; $p^{2}$. second pair of legs; $z$. frontal organ; $i$. intestine; 0 . larval eye $b$. glandular body ; $t$. organ of touch ; ov. ovary ; $f$. rod projecting from coalesced maxillipeds; g. cement gland; rs. receptaculum seminis; $n$. nervous system; te. testis; $v$. vas deferens.

organ is to assist at a later period in the attachment of the parasite to its host. Underneath the Nauplius skin a number of appendages are visible, which become functional after the first ecdysis. This takes place within a few hours after the hatching of the Nauplius, and the larva then passes from 
this rudimentary Nauplius stage into a stage corresponding with the Cyclops stage of the free forms (fig. $230 \mathrm{~B}$ ). In the Cyclops stage the larva has an elongated body with a large cephalo-thoracic shield, and four free posterior segments, the last of which bears a forked tail.

There are now present eight pairs of appendages, viz. antennæ (two pairs), mandibles, maxillæ, maxillipeds, and three pairs of swimming feet. The Nauplius appendages are greatly modified. The first pair of antennæ is three-jointed, and the second biramous. The outer ramus is the longest, and bears a claw-like bristle at its extremity. This pair of appendages is used by the larva for fixing itself. The mandibles are small and connected with the proboscidiform mouth; and the single pair of maxillæ is small and palped. The maxillipeds $\left(p m^{1}\right.$ and $\left.p m^{2}\right)$ are believed by Claus to be primitively a single biramous appendage, but early appear as two distinct structures ${ }^{1}$, the outer and larger of which becomes the main organ by which the larva is fixed. Both are at this stage simple two-jointed appendages. The two anterior pairs of swimming feet have the typical structure, and consist of a protopodite bearing an unjointed exopodite and endopodite. The first pair is attached to the cephalo-thorax and the second $\left(p^{2}\right)$ to the first free thoracic segment. The third pair is very small and attached to the second free segment. The mouth is situated at the end of a kind of proboscis formed by prolongations of the upper and lower lips. The alimentary tract is fairly simple, and the anus opens between the caudal forks.

Between this and the next known stage it is quite possible that one or more may intervene. However this may be the larva in the next stage observed (fig. $230 \mathrm{C}$ ) has already become parasitic in the mouth of the Perch, and has acquired an elongated vermiform aspect. The body is divided into two sections, an anterior unsegmented, and a posterior formed of five segments, of which the foremost is the first thoracic segment which in the earlier stage was fused with the cephalo-thorax. The tail bears a rudimentary fork between the prongs of which the anus opens. The swimming feet have disappeared, so also has the eye and the spiral duct of the embryonic frontal organ. The outer of the two divisions of the maxilliped have undergone the most important modification, in that they have become united at their ends, where they form an organ from which an elongated rod $(f)$ projects, and attaches the larva to the mouth or gills of its host. The antennæ and jaws have nearly acquired their adult form. The nervous system consists of supra- and infra-œesophageal ganglia and two lateral trunks given off from the latter. At this stage the males and females can already be distinguished, not only by certain differences in the rudimentary generative organs, but also by the fact that the outer branch of the maxillipeds is much longer in the female than in the male, and projects beyond the head.

In the next ecdysis the adult condition is reached. The outer maxilli-

1 Van Beneden (No. 506) in the genera investigated by him finds that the two maxillipeds are really distinct pairs of appendages. 
peds of the male (fig. $230 \mathrm{E}, p m^{2}$ ) separate again; while in the female (fig. $230 \mathrm{D})$ they remain fused and develop a sucker. The male is only about one-fifth the length of the female. In both sexes the abdomen is much reduced.

In the genera Anchorella, Lernæopoda, Brachiella and Hessia, Ed. van Beneden (No. 506) has shewn that the embryo, although it passes through a crypto-Nauplius stage in the egg, is when hatched already in the Cyclops stage.

Branchiura. The peculiar parasite Argulus, the affinities of which with the Copepoda have been demonstrated by Claus (No. 511), is hatched in a Cyclops stage, and has no Nauplius stage. At the time of hatching it closely resembles the adult in general form. Its appendages are however very nearly those of a typical larval Copepod. The body is composed of a cephalo-thorax and free region behind this. The cephalo-thorax bears on its under surface antennæ (two pairs), mandibles, maxillipeds, and the first pair of thoracic feet.

The first pair of antennæ is three-jointed, but the basal joint bears a hook. The second pair is biramous, the inner ramus terminating in a hook. The mandible is palped, but the palp is completely separated from the cutting blade1. The maxilla would, according to Claus, appear to be absent.

The two typical divisions of the Copepod maxillipeds are present, viz. an outer and anterior larger division, and an inner and posterior smaller one. The first pair of thoracic feet, as is usual amongst Copepoda, is attached to the cephalo-thorax. It has not the typical biramous Copepod character. There are four free segments behind the cephalo-thorax, the last of which ends in a fork. Three of them bear appendages, which are rudimentary in this early larval stage. On the dorsal surface are present paired eyes as well as an unpaired median eye.

Between the larval condition and that of the adult a number of ecdyses intervene.

\section{CirRIPEDIA.}

The larve of all the Cirripedia, with one or two exceptions, leave the egg in the Nauplius condition. The Nauplii differ somewhat in the separate groups, and the post-nauplial stages vary not inconsiderably.

\section{It will be most convenient to treat successively the larval}

1 It seems not impossible that the appendage regarded by Claus as the mandibular palp may really represent the maxilla, which would otherwise seem to be absent. This mode of interpretation would bring the appendages of Argulus into a much closer agreement with those of the parasitic Copepoda. It does not seem incompatible with the existence of the stylet-like maxillæ detected by Claus in the adult. 
history of the four sub-orders, viz. Thoracica, Abdominalia, Apoda, and Rhizocephala.

Thoracica. The just hatched larvæ at once leave the egg lamellæ of their parent. They pass out through an opening in the mantle near the mouth, and during this passage the shell of the parent is opened and the movements of the cirriform feet cease.

The larval stages commence with a Nauplius ${ }^{1}$ which, though regarded by Claus as closely resembling the Copepod Nauplius (figs. $23 \mathrm{I}$ and $232 \mathrm{~A}$ ), certainly has very marked pecularities of its own, and in some respects approaches the Phyllopod Nauplius. It is in the youngest stage somewhat triangular in form, and covered on the dorsal side by a very delicate and hardly perceptible dorsal shield, which is prolonged laterally into two very peculiar conical horns (fig. 23I $/ / 2$ ), which are the most characteristic structures of the Cirriped Nauplius. They are connected with a glandular mass, the secretion from which passes out at their apex. Anteriorly the dorsal shield has the same extension as the body, but posteriorly it projects slightly.

An unpaired eye is situated on the ventral surface of the head, and immediately behind it there springs a more or less considerable upper lip ( $I b)$, which resembles the Phyllopod labrum rather than that of the Copepoda. Both mouth and anus are present, and the hind end of the body is slightly forked in some forms, but ends in others, e.g. Lepas fascicularis, in an elongated spine. The anterior of the three pairs of Nauplius appendages $\left(A t^{1}\right)$ is uniramous, and the two posterior $\left(A t^{2}\right.$ and $m d)$ are biramous. From the protopodites of both the latter spring strong hooks like those of the Copepod and Phyllopod Nauplii. In some Nauplii, e.g. that of Balanus, the appendages are at first not jointed, but in other Nauplii, e.g. that of Lepas fascicularis, the jointing is well marked. In Lepas fascicularis the earliest free Nauplius is enveloped in a larval skin, which is thrown off after a few hours. The Nauplii of all the Thoracica undergo a considerable number of moults before their appendages increase in number or segmentation of the body appears. During these moults they grow larger, and the posterior part of the

\footnotetext{
1 Alepas squalicola is stated by Koren and Danielssen to form an exception to this rule, and to leave the egg with six pairs of appendages.
} 
body-the future thoracic and abdominal region-grows relatively in length. There also appear close to the sides of the unpaired eye two conical bodies, which correspond with the frontal sense organs of the Phyllopods. During their growth the different larve undergo changes varying greatly in degree.

In Balanus the changes consist for the most part in the full segmentation of the appendages and the growth and distinctness

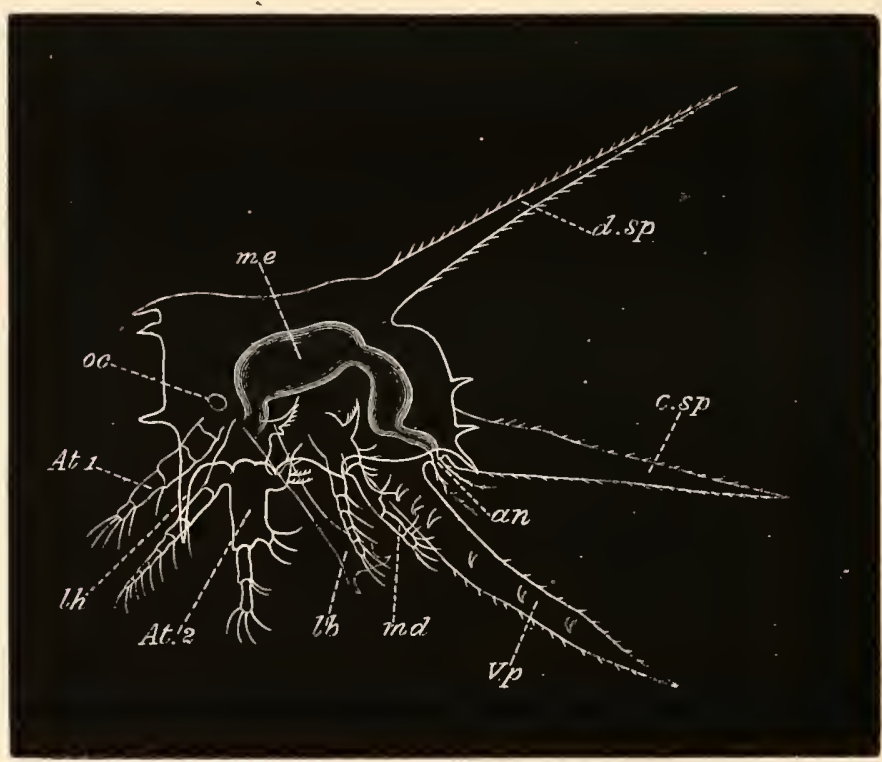

Fig. 23I. Nauplius larva of Lepas fascicularis Viewed from the Side. $o c$. eye ; $A t$. I. antenna of first pair ; $A t .2$. antenna of second pair ; $m d$. mandible; lb. labrum; an. anus; me. mesenteron; $d . s p$. dorsal spine; c.sp. caudal spine; $I p$. ventral spine; $l$. lateral horns.

of the dorsal shield, which forms a somewhat blunt triangular plate, broadest in front, with the anterior horns very long, and two short posterior spines. The tail also becomes produced into a long spine.

In Lepas fascicularis the changes in appearance of the Nauplius, owing to a great spinous development on its shield, are very considerable; and, together with its enormous size, render it a very remarkable form. Dohrn (No. 520), who was the first to describe it, named it Archizoæa gigas. 
The dorsal shield of the Nauplius of Lepas fascicularis (fig. 23r) becomes somewhat hexagonal, and there springs from the middle of the dorsal surface an enormously long spine (d.sp), like the dorsal spine of a Zoæa. The hind end of the shield is also produced into a long caudal spine (c.sp) between which and the dorsal spine are some feather-like processes. From its edge there spring in addition to the primitive frontal horns three main pairs of horns, one pair anterior, one lateral, and one posterior, and smaller ones in addition. All these processes (with the exception of the dorsal and posterior spines) are hollow and open at their extremities, and like the primitive frontal horns contain the ducts of glands situated under the shield. On the under surface of the larva is situated the unpaired eye $(o c)$ on each side of which spring the two-jointed frontal sense organs. Immediately behind these is the enormous upper lip ( $I b)$ which covers the mouth ${ }^{1}$. At the sides of the lip lie the three pairs of Nauplius appendages, which are very characteristic but present no special peculiarities. Posteriorly the body is produced into a long ventral spine-like process $(V p)$ homologous with that of other more normal Nauplii. At the base of this process large moveable paired spines appear at successive moults, six pairs being eventually formed. These spines give to the region in which they are situated a segmented appearance, and perhaps similar structures have given rise to the appearance of segmentation in Spence Bate's figures. The anus is situated on the dorsal side of this ventral process, and between it and the caudal spine of the shield above. The fact that the anus occupies this position appears to indicate that the ventral process is homologous with the caudal fork of the Copepoda, on the dorsal side of which the anus so often opens ${ }^{2}$.

From the Nauplius condition the larvæ pass at a single moult into an entirely different condition known as the Cypris stage. In preparation for this condition there appear, during the last Nauplius moults, the rudiments of several fresh organs, which are more or less developed in different types. In the first place a compound eye is formed on each side of the median eye. Secondly there appears behind the mandibles a fourth pair of appendages-the first pair of maxillæ-and internal to these a pair of small prominences, which are perhaps

1 Willemoes Suhm (No. 530) states that the mouth is situated at the free end of the upper lip, and that the esophagus passes through it. From an examination of some specimens of this Nauplius, for which I am indebted to Moseley, I am inclined to think that this is a mistake, and that a groove on the surface of the upper lip has been taken by Suhm for the œesophagus.

2 The enormous spinous development of the larva of Lepas fascicularis is probably to be explained as a secondary protective adaptation, and has no genetic connection with the somewhat similar spinous armature of the Zora. 
equivalent to the second pair of maxillæ, and give rise to the third pair of jaws in the adult (sometimes spoken of as the lower lip).

Behind these appendages there are moreover formed the rudiments of six pairs of feet. Under the cuticle of the first pair of antennæ there may be seen just before the final moult the fourjointed antennæ of the Cypris stage with the rudiment of a disc on the second joint by which the larvæ eventually become attached.

By the free Cypris stage, into which the larva next passes, a very complete metamorphosis has been effected. The median and paired eyes are present as before, but the dorsal shield has become a bivalve shell, the two valves of which are united along their dorsal, anterior, and posterior margins. The two valves are further kept in place by an adductor muscle situated close below the mouth. Remains of the lateral horns still persist. The anterior antennæ have undergone the metamorphosis already indicated. They are four-jointed, the two basal joints being long, and the second provided with a suctorial disc, in the centre of which is the opening of the duct of the so-called antennary or cement gland, which is a granular mass lying on the ventral side of the anterior region of the body. The gland arises (Willemoes Sulm) during the Nauplius stage in the large upper lip. The two distal joints of the antennæ are short, and the last of them is provided with olfactory hairs. The great upper lip and second pair of antennæ and mandibles have disappeared, but a small papilla, forming the commencement of the adult mandibles, is perhaps developed in the base of the Nauplius mandibles. The first pair of maxillæ have become small papillæ and the second pair probably remain. The six posterior pairs of appendages have grown out as functional biramous swimming feet, which can project beyond the shell and are used in the locomotion of the larva. They are composed of two basal joints, and two rami with swimming hairs, each two-jointed. These feet resemble Copepod feet, and form the main ground for the views of Claus and others that the Copepoda and Cirripedia are closely related. They are regarded by Claus as representing the five pairs of natatory feet of Copepoda, and the generative appendages of the segment behind these. Between 
the natatory feet are delicate chitinous lamella, in the spaces between which the cirriform feet of the adult become developed. The ventral spinous process of the Nauplius stage is much reduced, though usually three-jointed. It becomes completely aborted after the larva is fixed.

In addition to the antennary gland there is present, near the dorsal side of the body above the natatory feet, a peculiar paired glandular mass, the origin of which has not been clearly made out, but which is perhaps equivalent to the entomostracan shell gland. It probably supplies the material for the shell in succeeding stages ${ }^{1}$.

The free Cypris stage is not of long duration; and during it the larva does not take food. It is succeeded by a stage known as the pupa stage (fig. $232 \mathrm{~B}$ ), in which the larva becomes fixed, while underneath the larval skin the adult structures are developed. This stage fully deserves its name, since it is a quies= cent stage during which no nutriment is taken. The attachment takes place by the sucker of the antennæ, and the cement gland $(t)$ supplies the cementing material for effecting it. A retrogressive metamorphosis of a large number of the organs sets in, while at the same time the formation of new adult structures is proceeded with. The eyes become gradually lost, but the Nauplius eye is retained, though in a rudimentary state, and the terminal joints of the antennæ with their olfactory hairs are thrown off. The bivalve shell is moulted about the same time as the eyes, the skin below it remaining as the mantle. The caudal process becomes aborted. Underneath the natatory
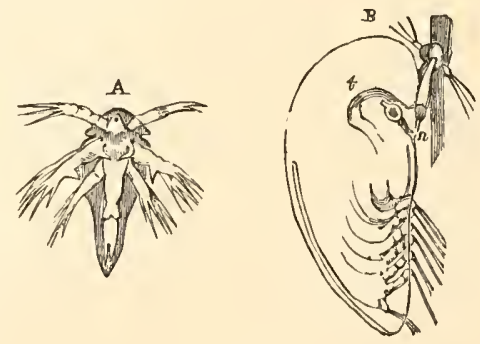

Fig. 232. LARVAL FORMS OF THE Thoracica. (From Huxley.)

A. Nauplius of Balanus balanoides. (After Sp. Bate.) B. Pupa stage of Lepas australis. (After Darwin.)

$n$. antennary apodemes; $t$. cement gland with duct to antenna.

1 There is considerable confusion about the shell gland and antennary gland. In my account Willemoes Suhm has been followed. Claus however regards what I have called the antennary gland as the shell gland, and states that it does not open into the antennæ tili a later period. He does not clearly describe its opening, nor the organ which I have called the shell gland.

B. II. 
feet, and between the above-mentioned chitinous lamellæ, the cirriform feet are formed; and on their completion the natatory feet become thrown off and replaced by the permanent feet. In the Lepadidæ, in which the metamorphosis of the pupa stages has been most fully studied, the anterior part of the body with the antenne gradually grows out into an elongated stalk, into which pass the ovaries, which are formed during the Cypris stage. At the base of the stalk is the protuberant mouth, the appendages of which soon attain a higher development than in the Cypris stage. At the front part of it a large upper lip becomes formed. Above the mantle and between it and the shell there are formed in the Lepadidæ the provisional valves of the shell. These valves are chitinous, and have a fenestrated structure, owing to the chitin being deposited round the margin of the separate epidermis (hypodermis) cells. These valves in the Lepadidx "prefigure in shape, size, and direction of growth, the shelly valves to be formed under and around them" (Darwin, No. 519, p. 129).

Whatever may be the number of valves in the adult the provisional valves never exceed five, viz. the two scuta, the two terga and the carina. They are relatively far smaller than the permanent valves and are therefore separated by considerable membranous intervals. They are often preserved for a long time on the permanent calcareous valves. In the Balanidx the embryonic valves are membranous and do not overlap, but do not present the peculiar fenestrated structure of the primordial valves of the Lepadidæ.

In connection with the moult of the pupa skin, and the conversion of the pupa into the adult form, a remarkable change in the position takes place. The pupa lies with the ventral side parallel to and adjoining the surface of attachment, while the long axis of the body of the young Cirriped is placed nearly at right angles to the surface of attachment. This change is connected with the ecdyses of the antennary apodemes (n), which leave a deep bay on the ventral surface behind the peduncle. The chitinous skin of the Cirriped passes round the head of this bay, but on the moult of the pupa skin taking place becomes stretched out, owing to the posterior part of the larva bending dorsalwards. It is this flexure which causes the change in the position of the larva. 
In addition to the remarkable external metamorphosis undergone during the pupa stage, a series of hardly less considerable internal changes take place, such as the atrophy of the muscles of the antennæ, a change in the position of the stomach, etc.

Abdominalia. In the Alcippidre the larva leaves the egg as a Nauplius, and this stage is eventually followed by a pupa stage closely resembling that of the Thoracica. There are six pairs of thoracic natatory legs (Darwin, No. 519). Of these only the first and the last three are preserved in the adult, the first being bent forward in connection with the mouth. The body moreover partially preserves its segmentation, and the mantle does not secrete calcareous valves.

The very remarkable genus Cryptophialus, the development of which is described by Darwin (No. 519) in his classical memoir, is without a free Nauplius stage. The embryo is at first oval but soon acquires two anterior processes, apparently the first pair of antennæ, and a posterior prominence, the abdomen. In a later stage the abdominal prominence disappears, and the antennary processes, within which the true antennæ are now visible, are carried more towards the ventral surface. The larva next passes into the free Cypris stage, during which it creeps about the mantle cavity of its parent. It is enveloped in a bivalve shell, and the antennæ have the normal cirriped structure. There are no other true appendages, but posteriorly three pairs of bristles are attached to a rudimentary abdomen. Paired compound eyes are present. During the succeeding pupa stage the metamorphosis into the adult form takes place, but this has not been followed out in detail.

In Kochlorine, a form discovered by $\mathrm{Noll}$ ( $\mathrm{No} .526)$ and closely related to Cryptophialus, the larvæ found within the mantle represent apparently two larval stages, similar to two of the larval stages described by Darwin.

Rhizocephala. The Rhizocephala, as might have been antici-

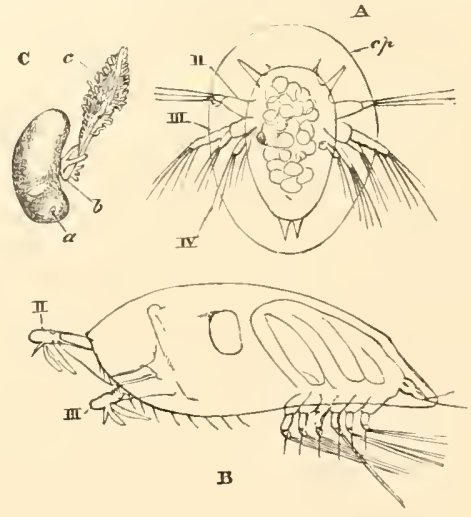

Fig. 233. Stages in the developMent of THE Rhizocephala. (From Huxley, after Fritz Muiller.)

A. Nauplius of Sacculina purpurea. B. Cypris stage of Lernæodiscus porcellane. C. Adult of Peltogaster paguri.

II. III. IV. Two pairs of antennæe and mandibles; $c p$. carapace; $a$. anterior end of body; $b$. generative aperture; $c$. root-like processes. pated from their close relationship to Anelasma squalicola amongst the Thoracica, undergo a development differing nuch less from the type of the Thoracica than that of Cryptophialus and Kochlorine. 
Sacculina leaves the egg as a Nauplius (fig. 233 A), which differs from the ordinary type mainly ( $I$ ) in the large development of an oval dorsal shield $(c p)$ which projects far beyond the edge of the body, but is provided with the typical sternal horns, etc.; and (2) in the absence of a mouth. The Cypris and pupa stages of Sacculina and other Rhizocephala (fig. 233 B) are closely similar to those of the Thoracica, but the paired eye is absent. The attachment takes place in the usual way, but the subsequent metamorphosis leads to the loss of the thoracic feet and generally to retrogressive changes.

\section{OSTRACODA.}

Our knowledge of the development of this remarkable group is entirely due to the investigations of Claus.

Some forms of Cythere are viviparous, and in the marine form Cypridina the embryo develops within the valves of the shell. Cypris attaches its eggs to water plants. The larvæ of Cypris are free, and their development is somewhat complicated. The whole development is completed in nine ecdyses, each of them accompanied by more or less important changes in the constitution of the larva.

In the earliest free stage the larva has the characters of a true Nauplius with three pairs of appendages (fig. $234 \mathrm{~A}$ ). The Nauplius presents how-

$\mathrm{B}$

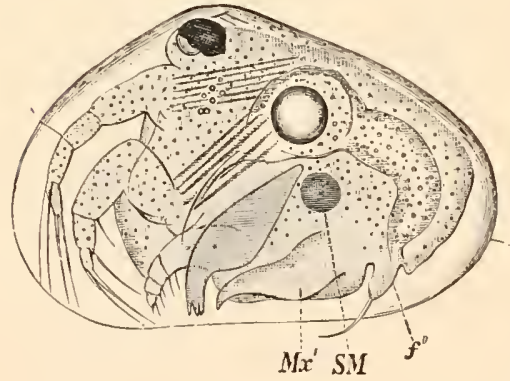

A

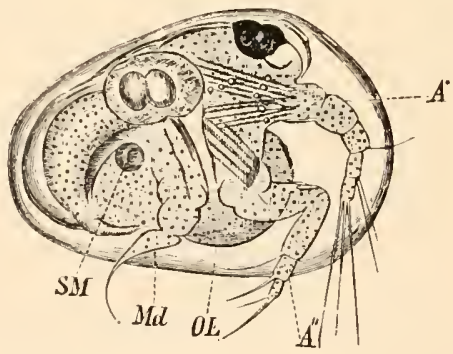

Fig. 234. Two stages in the Development of Cypris. (From Claus.)
A. Earliest (Nauplius) stage.
B. Second stage.

$A^{\prime} . A^{\prime \prime}$. First and second pairs of antennæ; $M d$. mandibles; $O L$. labrum; $M x^{\prime}$. first pair of maxillæ; $f^{\prime \prime}$. first pair of feet.

ever one or two very marked secondary characters. In the first place it is completely enveloped in a fully formed bivalve shell, differing in unessential points from the shell of the adult. An adductor muscle $(S M)$ for the shell is present. Again the second and third appendages, though locomotive in function are neither of them biramous, and the third one already contains a rudiment of the future mandibular blade, and terminates in an anteriorly directed hook-like bristle. The first pair of antennæ is moreover very similar to the second and is used in progression. Neither of the pairs of 
antennæ become much modified in the subsequent metamorphosis. The Nauplius has a single median eye, as in the adult Cypris, and a fully developed alimentary tract.

The second stage (fig. 234 B), inaugurated by the first moult, is mainly characterized by the appearance of two fresh pairs of appendages, viz. the first pair of maxillæe and the first pair of feet ; the second pair of maxillæ not being developed till later. The first pair appear as leaf-like curved
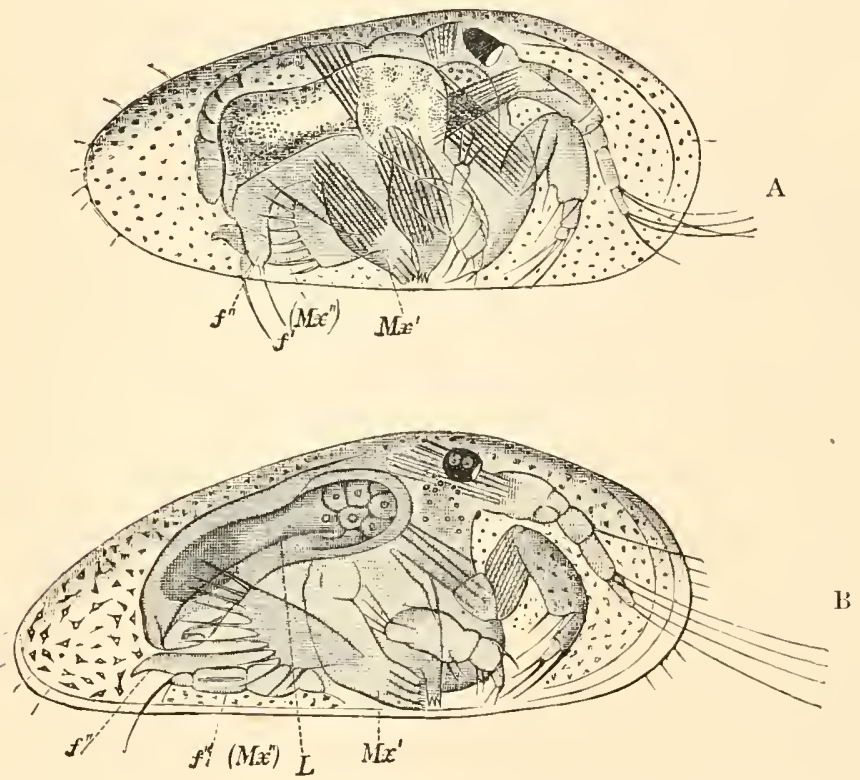

Fig. 235. Stages in the Developmen't of Cypris. (From Claus.)

A. Fourth stage.

B. Fifth stage.

$M x^{\prime}$. first maxilla ; $M x^{\prime \prime}$. and $f^{\prime}$. second maxilla ; $f^{\prime \prime}$. first pair of feet ; $L$. liver.

plates $\left(M x^{\prime}\right)$ more or less like Phyllopod appendages (Claus) though at this stage without an exopodite. The first pair of feet $\left(f^{\prime \prime}\right)$ terminates in a curved claw and is used for adhering. The mandibles have by this stage fully developed blades, and have practically attained their adult form, consisting of a powerful toothed blade and a four-jointed palp.

During the third and fourth stages the first pair of maxillæe acquire their pectinated gill plate (epipodite) and four blades; and in the fourth stage (fig. $235 \mathrm{~A}$ ) the second pair of maxillæ $\left(M x^{\prime \prime}\right)$ arises, as a pair of curved plates, similar to the first pair of maxillæ at their first appearance. The forked tail is indicated during the fourth stage by two bristles. During the fifth stage (fig. 235 B) the number of joints of the first pair of antennæe becomes increased, and the posterior maxillæ develop a blade and become 
four-jointed ambulatory appendages terminating in a hook. The caudal fork becomes more distinct.

In the sixth stage (fig. 236) the second and hindermost pair of feet becomes formed $\left(f^{\prime \prime \prime}\right)$ and the maxillæ of the second pair lose their ambulatory function, and begin to be converted into definite masticatory appendages by the reduced jointing of their palp, and the increase of their cutting blades. By the seventh stage all the appendages have practically attained their

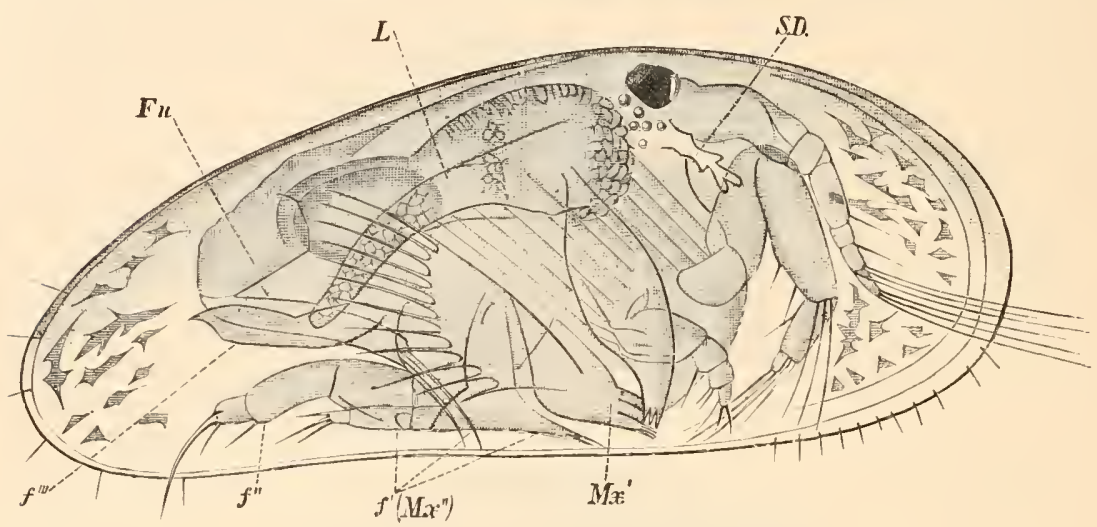

Fig. 236. Sixtil stare in the nevelopment of Cypris. (From Claus.)

$M x^{\prime}$. first maxilla; $M x^{\prime \prime}$. $f^{\prime}$. second maxilla; $f^{\prime \prime}$. and $f^{\prime \prime \prime}$. first and second pair ot feet; Fu. caudal fork ; L. liver ; S.D. shell gland.

permanent form ; the second pair of maxille has acquired small branchial plates, and the two following feet have become jointed. In the eighth and ninth stages the generative organs attain their mature form.

The larva of Cythere at the time of birth has rudiments of all the limbs, but the mandibular palp still functions as a limb, and the three feet (2nd pair of maxillæ and two following appendages) are very rudimentary.

The larvæ of Cypridina are hatched in a condition which to all intents and purposes resembles the adult.

\section{Phylogeny of the Crustaced.}

The classical work of Fritz Müller (No. 452) on the phylogeny of the Crustacea has given a great impetus to the study of their larval forms, and the interpretations of these forms which he has offered have been the subject of a very large amount of criticism and discussion. A great step forward in this discussion has been recently made by Claus in his memoir (No. 448).

The most fundamental question concerns the meaning of the Nauplius. Is the Nauplius the ancestral form of the Crustacea, as is believed by Fritz Müller and Claus, or are its peculiarities and constant occurrence due to some other cause? The most plausible explanation on the second hypothesis 
would seem to be the following. The segments with their appendages of Arthropoda and Annelida are normally formed from before backwards, therefore every member of these two groups with more than three segments must necessarily pass through a stage with only three segments, and the fact that in a particular group this stage is often reached on the larva being hatched is in itself no proof that the ancestor of the group had only three segments with their appendages. This explanation appears to me, so far as it goes, quite valid; but though it relieves us from the necessity of supposing that the primitive Crustacea had only three pairs of appendages, it does not explain several other peculiarities of the Nauplius ${ }^{1}$. The more important of these are the following.

I. That the mandibles have the form of biramous swimming feet and are not provided with a cutting blade.

2. That the second pair of antennæ are biramous swimming feet with a hook used in mastication, and are innervated (?) from the subœsophageal ganglion.

3. The absence of segmentation in the Nauplius body. An absence which is the more striking in that before the Nauplius stage is fully reached the body of the embryo is frequently divided into three segments, e.g. Copepoda and Cirripedia

4. The absence of a heart.

5. The presence of a median single eye as the sole organ of vision.

Of these points the first, second, and fifth appear only to be capable of being explained phylogenetically, while with reference to the absence of a heart it appears very improbable that the ancestral Crustacea were without a central organ of circulation. If the above positions are accepted the conclusion would seem to follow that in a certain sense the Nauplius is an ancestral form-but that, while it no doubt had its three anterior pairs of appendages similar to those of existing Nauplii, it may perhaps have been provided with a segmented body behind provided with simple biramous appendages. A heart and cephalo-thoracic shield may also have been present, though the existence of the latter is perhaps doubtful. There was no doubt a median single eye, but it is difficult to decide whether or no paired compound eyes were also present. The tail ended in a fork between the prongs of which the anus opened; and the mouth was protected by a large upper lip. In fact, it may very probably turn out that the most primitive Crustacea more resembled an Apus larva at the moult immediately before the appendages lose their Nauplius characters (fig. 208 B), or a Cyclops larva just before the Cyclops stage (fig. 229), than the earliest Nauplius of either of these forms.

If the Nauplius ancestor thus reconstructed is admitted to have existed, the next question in the phylogeny of the Crustacea concerns the relations of the various phyla to the Nauplius. Are the different phyla descended from the Nauplius direct, or have they branched at a later period from

1 Fur the characters of Nauplius vide p. +60. 
some central stem? It is perhaps hardly possible as yet to give a full and satisfactory answer to this question, which requires to be dealt with for each separate phylum; but it may probably be safely maintained that the existing Phyllopods are members of a group which was previously much larger, and the most central of all the Crustacean groups; and which more nearly retains in the characters of the second pair of antennæ etc. the Nauplius peculiarities. This view is shared both by Claus and Dohrn, and appears to be in accordance with all the evidence we have both palæontological and morphological. Claus indeed carries this view still further, and believes that the later Nauplius stages of the different Entomostracan groups and the Malacostraca (Penæus larva) exhibit undoubted Phyllopod affinities. He therefore postulates the earlier existence of a Protophyllopod form, which would correspond very closely with the Nauplius as reconstructed above, from which he believes all the Crustacean groups to have diverged.

It is beyond the scope of this work to attempt to grapple with all the difficulties which arise in connection with the origin and relationships of the various phyla, but I confine myself to a few suggestions arising out of the developmental histories recorded above.

Malacostraca. In attempting to reconstitute from the evidence in our possession the ancestral history of the Malacostraca we may omit from consideration the larval history of all those types which leave the egg in nearly the adult form, and confine our attention to those types in which the larval history is most completely preserved.

There are three forms which are of special value in this respect, viz. Euphausia, Penæus and Squilla. From the history of these which has already been given it appears that in the case of the Decapoda four stages (Claus) may be traced in the best preserved larval histories.

I. A Nauplius stage with the usual Nauplius characters.

2. A Protozoæa stage in which the maxillæ and first pair of maxillipeds are formed behind the Nauplius appendages; but in which the tail is still unsegmented. This stage is comparatively rarely preserved and usually not very well marked.

3. A Zoæa stage the chief features of which have already been fully characterised (vide p. 465). Three more or less distinct types of Zoæa are distinguished by Claus. ( $a$ ) That of Penæus, in which the appendages up to the third pair of maxillipeds are formed, and the thorax and abdomen are segmented, the former being however very short. The heart is oval, with one pair of ostia. From this type the Zoæa forms of the other Decapoda are believed by Claus to be derived. (b) That of Euphausia, with but one pair of maxillipeds and those short and Phyllopod-like. The heart oval with one pair of ostia. (c) That of Squilla, with an elongated manychambered heart, two pairs of maxillipeds and the abdominal appendages in full activity.

4. A Mysis stage, which is only found in the macrurous Decapod larva.e.

The embryological questions requiring to be settled concern the value 
of the above stages. Do they represent stages in the actual evolution of the present types, or have their characters been secondarily acquired in larval life?

With reference to the first stage this question has already been discussed, and the conclusion arrived at, that the Nauplius does in a much modified form represent an ancestral type. As to the fourth stage there can be no doubt that it is also ancestral, considering that it is almost the repetition of an actually existing form.

The second stage can clearly only be regarded as an embryonic preparation for the third; and the great difficulty concerns the third stage.

The natural view is that this stage like the others has an ancestral value, and this view was originally put forward by Fritz Müller and has been argued for also by Dohrn. On the other hand the opposite side has been taken by Claus, who has dealt with the question very ably and at great length, and has clearly shewn that some of Fritz Müller's positions are untenable. Though Claus' opinion is entitled to very great weight, an answer can perhaps be given to some of his objections. The view adopted in this section can best be explained by setting forth the chief points which Claus urges against Fritz Müller's view.

The primary question which needs to be settled is whether the Malacostraca have diverged very early from the Nauplius root, or later in the history of the Crustacea from the Phyllopod stem. On this question Claus ${ }^{1}$ brings arguments, which appear to me very conclusive, to shew that the Malacostraca are derived from a late Protophyllopod type, and Claus' view on this point is shared also by Dohrn. The Phyllopoda present so many characters (not possessed by the Nauplius) in common with the Malacostraca or their larval forms, that it is incredible that the whole of these should have originated independently in the two groups. The more important of these characters are the following.

I. The compound eyes, so often stalked in both groups.

2. The absence of a palp on the mandible, a very marked character of the Zoæa as well as of the Phyllopoda.

3. The presence of a pair of frontal sense knobs.

4. The Phyllopod character of many of the appendages. Cf. first pair of maxillipeds of the Euphausia Zoxa.

1 Claus speaks of the various Crustacean phyla as having sprung from a Protophyllopod form, and it might be supposed that he considered that they all diverged from the same form. It is clear however from the context that he regards the Protophyllopod type from which the Malacostraca originated as far more like existing Phyllopods than that from which the Entomostracan groups have sprung. It is not quite easy to get a consistent view of his position on the question, since he states ( $p .77)$ that the Malacostraca and the Copepods diverged from a similar form, which is represented in their respective developments by the Protozoæa and earliest Cyclops stage. Yet if I understand him rightly, he does not consider the Protozoza stage to be the Protophyllopod stage from which the Malacostraca have diverged, but states on p. 7 I that it was not an ancestral form at all. 
5. The presence of gill pouches (epipodites) on many of the appendages ${ }^{1}$.

In addition to these points, to which others might be added, Claus attempts to shew that Nebalia must be regarded as a type intermediate between the Phyllopods and Malacostraca. This view seems fairly established, and if true is conclusive in favour of the Phyllopod origin of the Malacostraca. If the Protophyllopod origin of the Malacostraca is admitted, it seems clear that the ancestral forms of the Malacostraca must have developed their segments regularly from before backwards, and been provided with nearly similar appendages on all the segments. This however is far from the case in existing Malacostraca, and Fritz Müller commences his summary of the characters of the Zoæa in the following words". "The middle body with its appendages, those five pairs of feet to which these animals owe their name, is either entirely wanting or scarcely indicated." This he regards as an ancestral character of the Malacostraca, and is of opinion that their thorax is to be regarded as a later acquirement than the head or abdomen. Claus' answer on this point is that in the most primitive Zoææ, viz. those already spoken of as types, the thoracic and abdominal segments actually develop in regular succession from before backwards, and he therefore concludes that the late development of the thorax in the majority of Zoxa forms is secondary and not an ancestral Phyllopod peculiarity.

This is the main argument used by Claus against the Zoæa having any ancestral meaning. His view as to the meaning of the Zoæa may be gathered from the following passage. After assuming that none of the existing Zoæa types could have been adult animals, he says-" Much more "probably the process of alteration of the metamorphosis, which the Mala" costracan phylum underwent in the course of time and in conjunction "with the divergence of the later Malacostracan groups, led secondarily " to the three different Zoæa configurations to which probably later modifica"tions were added, as for instance in the young form of the Cumacex. We "might with the same justice conclude that adult Insects existed as cater"pillars or pupæ as that the primitive form of the Malacostraca was a "Protozoæa or Zoæa."

Granting Claus' two main positions, viz. that the Malacostraca are derived from Protophyllopods, and that the segments were in the primary ancestral forms developed from before backwards, it does not appear impossible that a secondary and later ancestral form may have existed with a reduced thorax. This reduction may only have been partial, so that the Zoæa ancestor would have had the following form. A large cephalo-thorax and well-developed tail (?) with swimming appendages. The appendages up to the second pair of maxillipeds fully developed, but the thorax very

1 Claus appears to consider it doubtful whether the Malacostracan gills can be compared with the Phyllopod gill-pouches.

2 Facts for Darwin, p. 49. 
imperfect and provided only with delicate foliaceous appendages not projecting beyond the edge of the cephalo-thoracic shield.

Another hypothesis for which there is perhaps still more to be said is that there was a true ancestral Zoæa stage in which the thoracic appendages were completely aborted. Claus maintains that the Zoæa form with aborted thorax is only a larval form; but he would probably admit that its larval characters were acquired to enable the larva to swim better. If this much be admitted it is not easy to see why an actual member of the ancestral series of Crustacea should not have developed the Zoxa peculiarities when the mud-dwelling habits of the Phyllopod ancestors were abandoned, and a swimming mode of life adopted. This view, which involves the supposition that the five (or six including the third maxillipeds) thoracic appendages were lost in the adult for they may be supposed to have been retained in the larva) for a series of generations, and reappeared again in the adult condition, at a later period, may at first sight appear very improbable, but there are, especially in the larval history of the Stomatopoda, some actual facts which receive their most plausible explanation on this hypothesis.

These facts consist in cases of the actual loss of appendages during development, and their subsequent reappearance. The two most striking cases are the following.

I. In the Erichthus form of the Squilla larva the appendages corresponding to the third pair of maxillipeds and first two pairs of ambulatory appendages of the Decapoda are developed in the Protozoaa stage, but completely aborted in the Zoxa stage, and subsequently redeveloped.

2. In the case of the larva of Sergestes in the passage from the Acanthosoma (Mysis) stage to the Mastigopus stage the two hindermost thoracic appendages become atrophied and redevelop again later.

Both of these cases clearly fit in very well with the view that there was an actual period in the history of the Malacostraca in which the ancestors of the present forms were without the appendages which are aborted and redeveloped again in these larval forms. Claus' hypothesis affords no explanation of these remarkable cases.

It is however always possible to maintain that the loss and reappearance of the appendages in these cases may have no ancestral meaning; and the abortion of the first pair of maxillipeds and reduction of some of the other appendages in the case of the Loricata is in favour of this explanation. Similar examples of the abortion and reappearance of appendages, which cannot be explained in the way attempted above, are afforded by the Mites and also by the Insects, e.g. Bees.

On the other hand there is almost a conclusive indication that the loss of the appendages in Sergestes has really the meaning assigned to it, in that in the allied genius Leucifer the two appendages in question are actually absent in the adult, so that the stage with these appendages absent is permanently retained in an adult form. In the absence of the mandibular palp in all the Zoæa forms, its actual atrophy in the Penæus Zoæa, and its 
universal reappearance in adult Malacostraca, are cases which tell in favour of the above explanation. The mandibular palp is permanently absent in Phyllopods, which clearly shews that its absence in the Zoæa stage is due to the retention of an ancestral peculiarity, and that its reappearance in the adult forms was a late occurrence in the Malacostracan history.

The chief obvious difficulty of this view is the redevelopment of the thoracic feet after their disappearance for a certain number of generations. The possibility of such an occurrence appears to me however clearly demonstrated by the case of the mandibular palp, which has undoubtedly been reacquired by the Malacostraca, and by the case of the two last thoracic appendages of Sergestes just mentioned. The above difficulty may be diminished if we suppose that the larvæ of the Zocea ancestors always developed the appendages in question. Such appendages might first only partially atrophy in a particular Zoaa form and then gradually come to be functional again; so that, as a form with functional thoracic limbs came to be developed out of the Zoxa, we should find in the larval history of this form that the limbs were developed in the pre-zoxal larval stages, partially atrophied in the Zoxa stage, and redeveloped in the adult. From this condition it would not be difficult to pass to a further one in which the development of the thoracic limbs became deferred till after the Zoæa stage.

The general arguments in favour of a Zoæa ancestor with partially or completely aborted thoracic appendages having actually existed in the past appear to me very powerful. In all the Malacostracan groups in which the larva leaves the egg in an imperfect form a true Zoæa stage is found. That the forms of these Zoææ should differ considerably is only what might be expected, considering that they lead a free existence and are liable to be acted upon by natural selection, and it is probable that none of those at present existing closely resemble the ancestral form. The spines from their carapace, which vary so much, were probably originally developed, as suggested by Fritz Müller, as a means of defence. The simplicity of the heart-so different from that of Phyllopods-in most forms of Zoxa is a difficulty, but the reduction in the length of the heart may very probably be a secondary modification ; the primitive condition being retained in the Squilla Zoæa. In any case this difficulty is not greater on the hypothesis of the Zoæa being an ancestral form, than on that of its being a purely larval one.

The points of agreement in the number and character of the appendages, form of the abdomen, etc. between the various types of Zoxa appear to me too striking to be explained in the manner attempted by Claus. It seems improbable that a peculiarity of form acquired by the larva of some ancestral Malacostracan should have been retained so permanently in so many groups ${ }^{1}$

1 A secondary larval form is less likely to be repeated in development than an ancestral adult stage, because there is always a strong tendency for the former, which is a secondarily intercalated link in the chain, to drop out by the occurrence of a reversion to the original type of development. 
- more permanently indeed than undoubtedly ancestral forms like that of Mysis - and it would be still more remarkable that a Zoæa form should have been two or more times independently developed.

There are perhaps not sufficient materials to reconstruct the characters of the Zoæa ancestor, but it probably was provided with the anterior appendages up to the second pair of maxillipeds, and (?) with abdominal swimming feet. The heart may very likely have been many-chambered. Whether gill pouches were present on the maxillipeds and abdominal feet does not appear to me capable of being decided. The carapace and general shape were probably the same as in existing Zoæas. It must be left an open question whether the six hindermost thoracic appendages were absent or only very much reduced in size.

On the whole then it may be regarded as probable that the Malacostraca are descended from Protophyllopod forms, in which, on the adoption of swimming habits, six appendages of the middle region of the body were reduced or aborted, and a Zoæa form acquired, and that subsequently the lost appendages were redeveloped in the descendants of these forms, and have finally become the most typical appendages of the group.

The relationship of the various Malacostracan groups is too difficult a subject to be discussed here, but it seems to me most likely that in addition to the groups with a Zoæa stage the Edriophthalmata and Cumaceæ are also post-zoreal forms which have lost the Zoæa stage. Nebalia is however very probably to be regarded as a præ-zoæal form which has survived to the present day; and one might easily fancy that its eight thin thoracic segments with their small Phyllopod-like feet might become nearly aborted.

Copepoda. The Copepoda certainly appear to have diverged very early from the main stem, as is shewn by their simple biramous feet and the retention of the median eye as the sole organ of vision. It may be argued that they have lost the eye by retrogressive changes, and in favour of this view cases of the Pontellidæe and of Argulus may be cited. It is however more than doubtful whether the lateral eyes of the Pontellidæe are related to the compound Phyllopod eye, and the affinities of Argulus are still uncertain. It would moreover be a great paradox if in a large group of Crustacea the lateral eyes had been retained in a parasitic form only (Argulus), but lost in all the free forms.

Cirripedia. The Cirripedia are believed by Claus to belong to the same phylum as the Copepoda. This view does not appear to be completely borne out by their larval history. The Nauplius differs very markedly from that of the Copepoda, and this is still more true of the Cypris stage. The Copepod-like appendages of this stage are chiefly relied upon to support the above view, but this form of appendages was probably very primitive and general, and the number (without taking into consideration the doubtful case of Cryptophialus) does not correspond to that in Copepoda. On the other hand the paired eyes and the bivalve shell form great difficulties in the way of Claus' view. It is clear that the Cypris stage represents more or less 
closely an ancestral form of the Cirripedia, and that both the large bivalve shell and the compound eyes were ancestral characters. These characters would seem incompatible with Copepod affinities, but point to the independent derivation of the Cirripedia from some early bivalve Phyllopod form.

Ostracoda. The independent origin of the Ostracoda from the main Crustacean stem seems probable. Claus points out that the Ostracoda present by no means a simple organisation, and concludes that they were not descended from a form with a more complex organisation and a larger number of appendages. Some simplifications have however undoubtedly taken place, as the loss of the heart, and of the compound eyes in many forms. These simplifications are probably to be explained (as is done by Claus) as adaptations due to the small size of body and its enclosure in a thick bivalve shell. Although Claus is strongly opposed to the view that

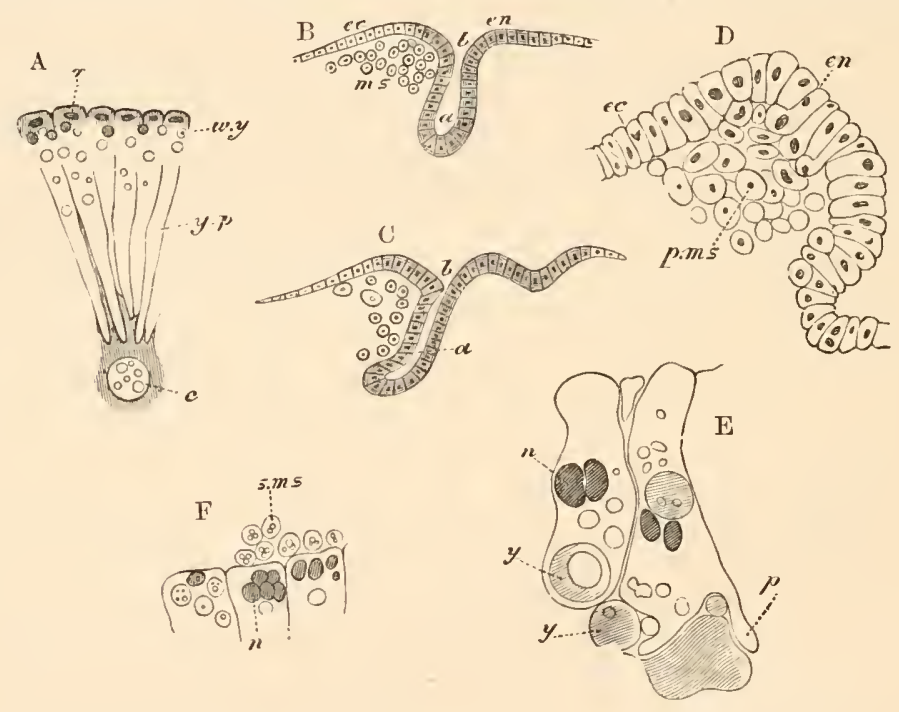

Fig. 237. Figures illustrating the development of Astacus. (From Parker; after Reichenbach.)

A. Section through part of the ovum during segmentation. $n$. nuclei ; $w \cdot y$, white yolk; $y \cdot p$. yolk pyramids; $c$. central yolk mass.

$\mathrm{B}$ and $\mathrm{C}$. Longitudinal sections during the gastrula stage. $a$. archenteron; $b$. blastopore; ms. mesoblast ; $e c$. epiblast; $e n$. hypoblast distinguished from epiblast by shading.

D. Highly magnified view of the anterior lip of blastopore to shew the origin of the primary mesoblast from the wall of the archenteron. p.ms. primary mesoblast; $e c$. epiblast ; $e n$. hypoblast.

E. Two hypoblast cells to shew the amøba-like absorption of yolk spheres. $y$. yolk; $n$. nucleus; $p$. pseudopodial process.

F. Hypoblast cells giving rise endogenously to the secondary mesoblast (s.ms.). n. nuclei. 
the number of the appendages has been reduced, yet the very fact of the (in some respects) complex organisation of this group might seem to indicate that it cannot have diverged from the Phyllopod stem at so early a stage as (on Claus' view of the Nauplius) would seem to be implied by the very small number of appendages which is characteristic of it, and it therefore appears most probable that the present number may be smaller than that of the ancestral forms.

\section{The formation of the germinal layers.}

The formation of the germinal layers has been more fully studied in various Malacostraca, more especially in the Decapoda, than in other groups.

Decapoda. To Bobretzky (No. 472) is due the credit of having been the pioneer in this line of investigation; and his researches have been followed up and enlarged by Haeckel, Reichenbach (No. 488), and Mayer (No.482). The segmentation is centrolecithal and regular (fig. $237 \mathrm{~A}$ ). At its close the blastoderm is formed of a single uniform layer of lens-shaped cells enclosing a central sphere of yolk, in which as a rule all trace of the division into columns, present during the earlier stages of segmentation, has disappeared; though in Palæmon the columns remain for a long period distinct. The cells of the blastoderm are at first uniform, but in Astacus, Eupagurus, and most Decapoda, soon become more columnar for a small area, and form a circular patch. The whole patch either becomes at once invaginated (Eupagurus, Palæmon, fig. $239 \mathrm{~A}$ ) or else the edge of it is invaginated as a roughly speaking circular groove deeper anteriorly than posteriorly, within which the remainder of the patch forms a kind of central plug, which does not become invaginated till a somewhat later period (Astacus, fig. $237 \mathrm{~B}$ and $\mathrm{C}$ ). After the invagination of the above patch the remainder of the blastoderm cells form the epiblast.

The invaginated sack appears to be the archenteron and its mouth the blastopore. The mouth finally becomes closed ${ }^{1}$, and the sack itself then forms the mesenteron.

In Astacus the archenteron gradually grows forwards, its opening is at first wide, but becomes continuously narrowed

1 Bobretzky first stated that the invagination remained open, but subsequently corrected himself. Zeit. f. Wiss. Zool., Bd. xxıv. p. I86. 
and is finally obliterated. Very shortly after this occurrence there is formed, slightly in front of the point where the last trace of the blastopore was observable, a fresh epiblastic invagination, which gives rise to the proctodæum, and the opening of which remains as the definite anus. The proctodxum (fig. $238 \mathrm{~A}, h g$ ) is very soon placed in communication with the mesenteron $(m g)$. The stomodæum $(f g)$ is formed during the same stage as the proctodæum. It gives rise to the œsophagus and stomach. The hypoblast cells which form the wall of the archenteron grow with remarkable rapidity at the expense of the yolk; the spherules of which they absorb and digest in an amœba-like fashion by means of their pseudopodia. They become longer and longer, and finally, after absorbing the whole yolk, acquire a form almost exactly similar to that of the yolk pyramids during segmentation (fig. $238 \mathrm{~B}$ ). They enclose the cavity of the mesenteron, and their nuclei and protoplasm are situated externally. The cells of the mesenteron close to its junction with the proctodæum differ from those elsewhere in being nearly flat.

In Palæmon (Bobretzky) the primitive invagination (fig. 239 A) has far smaller dimensions than in Astacus, and appears before the blastoderm cells have separated from the yolk pyramids. The cells which are situated at the bottom of it pass into the yolk, increase in number, and absorb the whole yolk, forming a solid mass of hypoblast in which the outlines of the individual cells would seem at first not to be distinct.
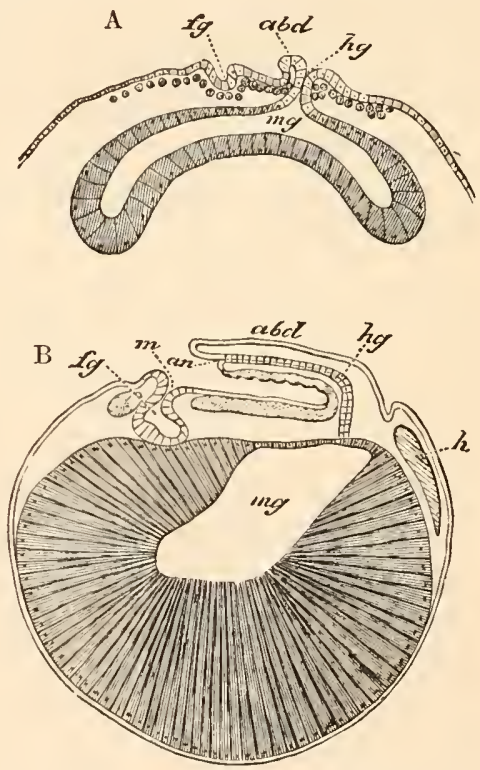

Fig. 238. Two LONGITUdINAL SECTIONS OF THE EMBRYo OF ASTACUS.

(From Parker; after Bobretzky.)

A. Nauplius stage. B. Stage after the hypoblast cells have absorbed the food yolk. The ventral surface is turned upwards. $f g$. stomodrum; $h g$. proctodæum; $a n$. anus; $m$. mouth; $m g$. mesenteron; $a b d$. abdomen; $h$. heart.

The blastopore in the mean- 
time becomes closed. Some of the nuclei now pass to the periphery of the yolk mass; the cells appertaining to them gradually become distinct and assume a pyramidal form (fig. $239 \mathrm{~B}, h y$ ), the inner ends of the cells losing themselves in a central mass of yolk, in the interior of which nuclei are at first present but soon disappear. The mesenteron thus becomes constituted of a layer of pyramidal cells which merge into a central mass of yolk. Some of the hypoblast cells adjoining the junction of the proctodæum and mesenteron become flattened, and in the neighbourhood of these cells a lumen

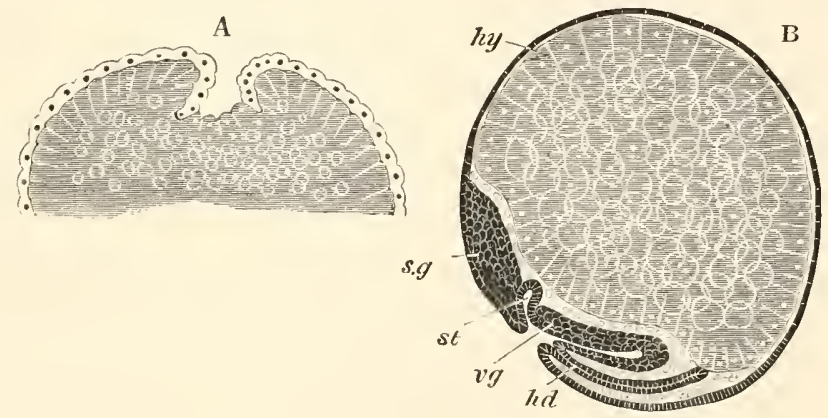

Fig. 239. Two stages in the development of Palemon seen in section. (After Bobretzky.)

A. Gastrula stage.

B. Longitudinal section through a late stage. hy. hypoblast; sg. supra-œesophageal ganglion; $v g$. ventral nerve cord; hl. proctodæum; st. stomodæum.

first appears. The stomodæum and proctodæum are formed as in Astacus. Fig. $239 \mathrm{~B}$ shews the relative positions of the proctodæum, stomodæum, and mesenteron. Although the process of formation of the hypoblast and mesenteron is essentially the same in Astacus and Palæmon, yet the differences between these two forms are very interesting, in that the yolk is cxternal to the mesenteron in Astacus, but enclosed within it in Palæmon. This difference in the position of the yolk is rendered possible by the fact that the invaginated hypoblast cells in Palæmon do not, at first, form a continuous layer enclosing a central cavity, while they do so in Astacus.

The mesoblast appears to be formed of cells budded off from the anterior wall of the archenteron (Astacus, fig. $237 \mathrm{D}$ ),

B. II. 
or from its lateral walls generally (Palæmon). They make their first appearance soon after the invagination of the hypoblast has commenced. The mesoblast cells are at first spherical, and gradually spread, especially in an anterior direction, from their point of origin.

According to Reichenbach there are formed in Astacus at the Nauplius stage a number of peculiar cells which he speaks of as 'secondary mesoblast cells.' His account is not very clear or satisfactory, but it appears that they originate (fig. $237 \mathrm{~F}$ ) in the hypoblast cells by a kind of endogenous growth, and though they have at first certain peculiar characters they soon become indistinguishable from the remaining mesoblast cells.

Towards the end of the Nauplius period the secondary mesoblast cells aggregate themselves into a rod close to the epiblast in the median ventral line, and even bifurcate round the mouth and extend forwards to the extremity of the procephalic lobes. This rod of cells very soon vanishes, and the secondary mesoblast cells become indistinguishable from the primary. Reichenbach believes, on not very clear evidence, that these cells have to do with the formation of the blood.

General form of the body. The ventral thickening of epiblast or ventral plate, continuous with the invaginated patch already mentioned, forms the first indication of the embryo. It is at first oval, but soon becomes elongated and extended anteriorly into two lateral lobes-the procephalic lobes. Its bilateral symmetry is further indicated by a median longitudinal furrow. The posterior end of the ventral plate next becomes raised into a distinct lobe-the abdomen-which in Astacus at first lies in front of the still open blastopore. This lobe rapidly grows in size, and at its extremity is placed the narrow anal opening. It soon forms a well-marked abdomen bent forwards over the region in front (figs. $239 \mathrm{~B}$, and $240 \mathrm{~A}$ and B). Its early development as a distinct outgrowth causes it to be without yolk; and so to contrast very forcibly with the anterior thoracic and cephalic regions of the body. In most cases this process corresponds to the future abdomen, but in some cases (Loricata) it appears to include part of the thorax. Before it has reached a considerable development, three pairs of appendages spring from the region of the head, viz. two pairs of antennæ and the mandibles, and inaugurate a so-called Nauplius stage (fig. 240 A). These three appendages are formed nearly simultaneously, but the hindermost appears to become visible slightly before the two others 
(Bobretzky). The mouth lies slightly behind the anterior pair of antennæ, but distinctly in front of the posterior pair. The other appendages, the number of which at the time of hatching varies greatly in the different Decapods (vide section on larval development), sprout in succession from before backwards (fig. 240 B). The food yolk in the head and thoracic region gradually becomes reduced in quantity with the growth of the embryo, and by the time of hatching the disparity in size between the thorax and abdomen has ceased to exist.

Isopoda. The early embryonic phases of the Isopoda have been studied by means of sections by Bobretzky (No. 498) and Bullar (No. 499) and have been found to present considerable
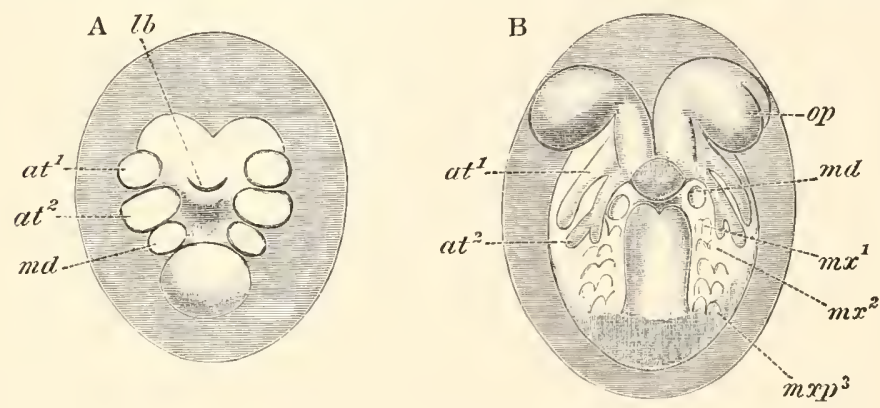

Fig. 240. Two stages in the development of Palamon.

A. Nauplius stage.

B. Stage with eight pairs of appendages. op. eyes; $a t^{1}$. and $a t^{2}$. first and second antennx; $m d$. mandibles; $m x^{1}, m x^{2}$. first and second maxillæ; $m x p^{3}$. third maxillipeds ; $l b$. upper lip.

variations. When laid the egg is enclosed in a chorion, but shortly after the commencement of segmentation (Ed. van Beneden and Bullar) a second membrane appears, which is probably of the nature of a larval membrane.

In all the forms the segmentation is followed by the formation of a blastoderm, completely enclosing the yolk, and thickened along an area which will become the ventral surface of the embryo. In this area the blastoderm is formed of at least two layers of cells-an external columnar epiblast, and an internal layer of scattered cells which form the mesoblast and probably in part also the hypoblast (Oniscus, Bobretzky; Cymothoa, Bullar). 
In Ascllus aquaticus there is a centrolecithal segmentation, ending in the formation of a blastoderm, which appears first on the ventral surface and subsequently extends to the dorsal.

In Oniscus murarius, and Cymothoa the segmentation is partial [for its peculiarities and relationship vide p. I20] and a disc, formed of a single layer of cells, appears at a pole of the egg which corresponds to the future ventral surface (Bobretzky). This layer gradually grows round the yolk partly by division of its cells, though a formation of fresh cells from the yolk may also take place. Before it has extended far round the yolk, the central part of it becomes two or more layers deep, and the cells of the deeper layers rapidly increase in number, and are destined to give rise to the mesoblast and probably also to part or the whole of the hypoblast. In Cymothoa this layer does not at first undergo any important change, but in Oniscus it becomes very thick, and its innermost cells (Bobretzky) become imbedded in the yolk, which they rapidly absorb; and increasing in number first of all form a layer in the periphery of the yolk, and finally fill up the whole of the interior of the yolk (fig. 24I A), absorbing it in the process.

It appears possible that these cells do not, as Bobretzky believes, originate from the blastoderm, but from nuclei in the yolk which have escaped his observation. This mode of origin would be similar to that by which yolk cells originate in the eggs of the Insecta, etc. If Bobretzky's account is correct we must look to Palæmon, as he himself suggests, to find an explanation of the passage of the hypoblast cells into the yolk. The thickening of the primitive germinal disc would, according to this view, be equivalent to the invagination of the archenteron in Astacus, Palæmon, etc.

Whatever may be the origin of the cells in the yolk they no doubt correspond to the hypoblast of other types. In Cymothoa nothing similar to them has been met with, but the hypoblast has a somewhat different origin; being apparently formed from some of the indifferent cells below the epiblast, which collect as a solid mass on the ventral surface, and then divide into two masses which become hollow and give rise to the liver cæca. Their fate, as well as that of the hypoblast in Oniscus, is dealt with in connection with the alimentary tract. The completion of the enclosure of the yolk by the blastoderm takes place on the dorsal surface. In all the Isopods which have been carefully 
studied, there appears before any other organ a provisional structure formed from the epiblast and known as the dorsal organ. An account of it is given in connection with the development of the organs. The general external changes undergone by the larva in its development are as follows. The ventral thickened area of the blastoderm (ventral plate) shapes itself and girths nearly the whole circumference of the ovum in Oniscus (fig. 24I A) but is relatively much shorter in Cymothoa. Anteriorly it dilates into the two procephalic lobes. In Cymothoa it next becomes segmented; and the anterior segments are formed nearly simultaneously, and those of the abdomen somewhat later. At the same time a median depres-

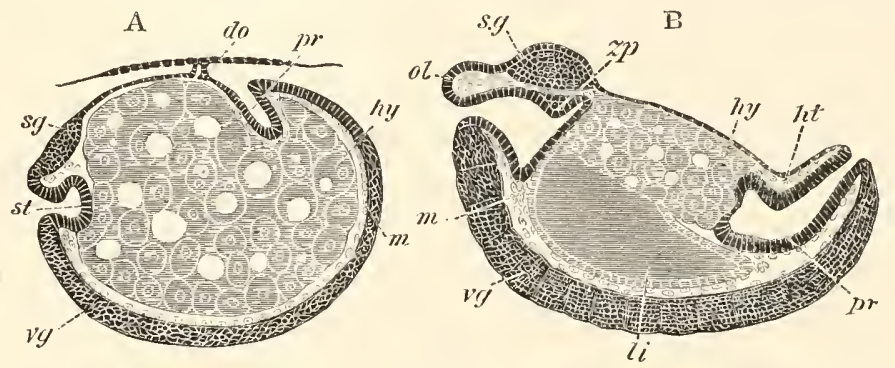

Fig. $2+$ I. Two longitudinal Sections through the embryo of ONiscus MURARIUs. (After Bobretzliy.)

st. stomodæum; pr. proctodæum; hy. hypoblast formed of large nucleated cells

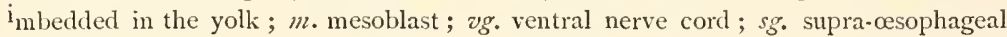
ganglion; $l i$. liver; do. dorsal organ ; zp. rudiment of masticatory apparatus ; ol. upper lip.

sion appears dividing the blastoderm longitudinally into two halves. The appendages are formed later than their segments, and the whole of them are formed nearly simultaneously, with the exception of the last thoracic, which does not appear till comparatively late after the hatching of the embryo. The late development of the seventh thoracic segment and appendage is a feature common to the majority of the Isopoda (Fritz Muiller). In Oniscus the limbs are formed in nearly the same way as in Cymothoa, but in Asellus they do not arise quite simultaneously. First of all, the two antenne and mandibles (the future palp) appear, inaugurating a stage often spoken of as the Nauplius stage, which is supposed to correspond with the free Nauplius 
stage of Penæus and Euphausia. At this stage a cuticle is shed (Van Beneden) which remains as an envelope surrounding the larva till the time of hatching. Similar cuticular envelopes are formed in many Isopoda. Subsequently the appendages of the thorax appear, and finally those of the abdomen. Later than the appendages there arise behind the mouth two prominences which resemble appendages, but give rise to a bilobed lower lip (Dohrn).

In Asellus and Oniscus the ventral plate moulds itself to the shape of the egg, and covers the greater part of the dorsal as well as of the ventral side (fig. 24I A). As a result of this the ventral surface of the embryo is throughout convex; and in Asellus a deep fold appears on the back of the embryo, so that the embryo appears coiled up within the egg with its ventral side outwards and its head and tail in contact. In Oniscus the ventral surface is convex, but the dorsal surface is never bent in as in Asellus. In Cymothoa the egg is very big and the ventral plate does not extend nearly so far round to the dorsal side as in Asellus, in consequence of which the ventral surface is not nearly so convex as in other Isopoda. At the same time the telson is early formed, and is bent forwards so as to lie on the under side of the part of the blastoderm in front. In having this ventral curvature of the telson Cymothoa forms an exception amongst Isopods; and in this respect is intermediate between the embryos of Asellus and those of the Amphipoda.

Amphipoda. Amongst the Amphipoda the segmentation is usually centrolecithal. In the case of Gammarus locusta (Ed. van Beneden and Bessels, No. 503) it commences with an unequal but total segmentation like that of the Frog (vide p. 97), and the separation of a central yolk mass is a late occurrence; and it is noticeable that the part of the egg with the small segments eventually becomes the ventral surface. In the fresh-water species of Gammarus (G. pulex and fluviatilis) the segmentation is more like that of Insects; the blastoderm cells being formed nearly simultaneously over a large part of the surface of the egg.

Both forms of segmentation give rise to a blastoderm covering the whole egg, which soon becomes thickened on the ventral 
surface. There is formed, as in the Isopoda, a larval membrane at about the time when the blastoderm is completed. Very soon after this the egg loses its spherical shape, and becomes produced into a pointed extremity - the future abdomen-which is immediately bent over the ventral surface of the part in front. The ventral curvature of the hinder part of the embryo at so early an age stands in marked contrast to the usual condition of Isopod embryos, and is only approached in this group, so far as is known, in the case of Cymothoa.

At the formation of the first larval membrane the blastoderm cells separate themselves from it, except at one part on the dorsal surface. The patch of cells adherent at this part gives rise to a dorsal organ, comparable with that in Oniscus, connecting the embryo and its first larval skin. A perforation appears in it at a later period.

The segments and limbs of the Amphipoda are all formed before the larva leaves the egg.

Cladocera. The segmentation (Grobben, No. 455) takes place on the normal centrolecithal type, but is somewhat unequal. Before the close of the segmentation there may be seen at the apex of the vegetative pole one cell marked off from the remainder by its granular aspect. It gives rise to the generative organs. One of the cells adjoining it gives rise to the hypoblast, and the other cells which surround it form the commencement of the mesoblast. The remaining cells of the ovum form the epiblast. By a later stage the hypoblast cell is divided into thirty-two cells and the genital cell into four, while the mesoblast forms a circle of twelve cells round the genital mass.

The hypoblast soon becomes involuted ; the blastopore probably closes, and the hypoblast forms a solid cord of cells which eventually becomes the mesenteron. The stomodæum is said to be formed at the point of closure of the blastopore. The mesoblast passes inwards and forms a mass adjoining the hypoblast, and somewhat later the genital mass also becomes covered by the epiblast. The proctodæum appears to be formed later than the stomodæum.

The embryo as first shewn by Dohrn passes through a Nauplius stage in the brood-pouch, but is hatched, except in the case of the winter eggs of Leptodora, in a form closely resembling the adult.

Copepoda. Amongst the free Copepoda the segmentation and formation of the layers have recently been investigated by Hoek (No. 512). He finds that there is, in both the fresh-water and marine forms studied by him, a centrolecithal segmentation similar to that of Palæmon and Pagurus (vide p. II2), which might from the surface be supposed to be 
complete and nearly regular. After the formation of the blastoderm an invagination of some of its cells takes place and is completed in about a quarter of an hour. The opening becomes closed. This invagination is compared by Hoek to the invagination in Astacus, and is believed by him to give rise to the mesenteron. Its point of closing corresponds with the hind end of the embryo. On the ventral surface there appear two transverse furrows dividing the embryo into three segments, and a median longitudinal furrow which does not extend to the front end of the foremost segment. The three pairs of Nauplius appendages and upper lip become subsequently formed as outgrowths from the sides of the ventral blastodermic thickening.

Amongst the parasitic Copepoda there are found two distinct types of segmentation, analogous to those in the Isopoda. In the case of Condracanthus the segmentation is somewhat irregular, but on the type of Eupagurus, etc. (vide p. I I2). In the other group (Anchorella, Clavella, Congericola, Caligus, Lerneopoda) the segmentation nearly resembles the ordinary meroblastic type (vide p. I20), and is to be explained in the same manner as in the cases of Oniscus and Cymothoa. The first blastodermic cells sometimes appear in a position corresponding with the head end of the embryo (Anchorella), at other times at the hind end (Clavella), and sometimes in the middle of the ventral surface. The dorsal surface of the yolk is always the latest to be inclosed by the blastoderm cells. A larval cuticle similar to that of the Isopoda is formed at the same time as the blastoderm. At the sides of the ventral thickening of the blastoderm there grow out the Nauplius appendages, of which only the first two appear in Anchorella. In Anchorella and Lerneopoda the embryos are not hatched at the Nauplius stage, but after the Nauplius appendages have been formed a fresh cuticle-the Nauplius cuticle--is shed, and within it the embryo develops till it reaches the so-called Cyclops stage (vide p. 490). The embryo within the egg has its abdomen curved dorsalwards as amongst the Isopoda.

Cirripedia. The segmentation of Balanus and Lepas commences by the segregation of the constituents of the egg into a more protoplasmic portion, and a portion formed mainly of food material. The former separates from the latter as a distinct segment, and then divides into two not quite equal portions. The division of the protoplasmic part of the embryo continues, and the resulting segments grow round the single yolk segment. The point where they finally enclose it is situated on the ventral surface (Lang) at about the position of the mouth (?).

After being enclosed by the protoplasmic cells the yolk divides, and gives rise to a number of cells, which probably supply the material for the walls of the mesenteron. The external layer of protoplasm forms the so-called blastoderm, and soon (Arnold, Lang) becomes thickened on the dorsal surface.

The embryo is next divided by two constrictions into three segments; and there are formed the three appendages corresponding to these, which are 
at first simple. The two posterior soon become biramous. The larva leaves the egg before any further appendages become formed.

\section{Comparative development of the organs.}

Central nervous system. The ventral nerve cord of the Crustacea develops as a thickening of the epiblast along the median ventral line; the differentiation of which commences in front, and thence extends backwards. The ventral cord is at first unsegmented. The supra-œsophageal ganglia originate as thickenings of the epiblast of the procephalic lobes.

The details of the above processes are still in most cases very imperfectly known. The fullest account we have is that of Reichenbach (No. 488) for Astacus. He finds that the supra-œsophageal ganglia and ventral cord arise as a continuous formation, and not independently as would seem to be the case in Chætopoda. The supra-œsophageal ganglia are formed from the procephalic lobes. The first trace of them is visible in the form of a pair of pits, one on each side of the middle line. These pits become in the Nauplius stage very deep, and their walls are then continued into two ridges where the epiblast is several cells deep, which pass backwards one on each side of the mouth. The walls of the pits are believed by Reichenbach to give rise to the optic portions of the supra-œsophageal ganglia, and the epiblastic ridges to the remainder of the ganglia and to the circum-œsophageal commissures. At a much later stage, when the ambulatory feet have become formed, a median involution of epiblast in front of the mouth and between the two epiblast ridges gives rise to a central part of the supraœsophageal ganglia. Five elements are thus believed by Reichenbach to be concerned in the formation of these ganglia, viz. two epiblast pits, two epiblast ridges, and an involution of epiblast between the latter. It should be noted however that the fate neither of the pair of pits, nor of the median involution, appears to have been satisfactorily worked out. The two epiblast ridges, which pass back from the supra-œsophageal ganglia on each side of the mouth, are continued as a pair of thickenings of the epiblast along the sides of a median ventral groove. This groove is deep in front and shallows out posteriorly. The thickenings on the sides of this groove no doubt give rise to the lateral halves of the ventral cord, and the cells of the groove itself are believed by Reichenbach, but it appears to me without sufficient evidence, to become invaginated also and to assist in forming the ventral cord. When the ventral cord becomes separated from the epiblast the two halves of it are united in the middle line, but it is markedly bilobed in section.

In the Isopoda it would appear both from Bobretzky's and Bullar's observations that the ventral nerve cord arises as an unpaired thickening of the epiblast in which there is no trace of anything like a median involution. After this thickening has become separated from the epiblast a slight 
median furrow indicates its constitution out of two lateral cords. The supra-œsophageal ganglia are stated to be developed quite simply as a pair of thickenings of the procephalic lobes, but whether they are from the first continuous with the ventral cord does not appear to have been determined.

The later stages in the differentiation of the ventral cord are, so far as is known, very similar throughout the Crustacea. The ventral cord is, as has been stated, at first unsegmented (fig. 24I A, r' $y^{\prime}$ ), but soon becomes divided by a series of constrictions into as many ganglia as there are pairs of appendages or segments (fig. 24I B, vg).

There appears either on the ventral side (Oniscus) or in the centre (Astacus, Palæmon) of the two halves of each segment or ganglion a space filled with finely punctuated material, which is the commencement of the commissural portion of the cords. The commissural tissue soon becomes continuous through the length of the ventral cord, and is also prolonged into the supraosophageal ganglia.

After the formation of the commissural tissue the remaining cells of the cord form the true ganglion cells. A gradual separation of the ganglia next takes place, and the cells become confined to the ganglia, which are finally only connected by a double band of commissural tissue. The commissural tissue not only gives rise to the longitudinal cords connecting the successive ganglia, but also to the transverse commissures which unite the two halves of the individual ganglia.

The ganglia usually, if not always, appear at first to correspond in number with the segments, and the smaller number so often present in the adult is due to the coalescence of originally distinct ganglia.

Organs of special sense. Comparatively little is known on this head. The compound eyes are developed from the coalescence of two structures, both however epiblastic, viz. (I) part of the superficial epiblast of the procephalic lobes; (2) part of the supra-œsophageal ganglia. The former gives rise to the corneal lenses, the crystalline cones, and the pigment surrounding them; the latter to the rhabdoms and the cells which encircle them. Between these two parts a mesoblastic pigment is interposed. 
Of the development of the auditory and olfactory organs almost nothing is known.

Dorsal organ. In a considerable number of the Malacostraca and Branchiopoda a peculiar organ is developed from the epiblast in the anterior dorsal region. This organ has been called the dorsal organ. It appears to be of a glandular nature, and is usually very large in the embryo or larva and disappears in the adult; but in some Branchiopoda it persists through life. In most cases it is unpaired, but in some instances a paired organ appears to take its place.

Various views as to its nature have been put forward. There is but little doubt of its being glandular, and it is possible that it is a provisional renal organ, though so far as I know concretions have not yet been found in it.

Its development has been most fully studied in the Isopoda.

In Cymothoa (Bullar, No. 499) there appears on the dorsal surface, in the region which afterwards becomes the first thoracic segment, an unpaired linear thickening of the blastoderm. This soon becomes a circular patch, the central part of which is invaginated so as to communicate with the exterior by a narrow opening only (fig. 242). It becomes at the same time attached to the inner egg membrane. It retains this condition till the close of larval life.

In Oniscus (Dohrn, No. 500 ; Bobretzky, No. 498) there appears very early a dorsal patch of thickened cells. These cells become attached at their edge to the inner egg membrane and gradually separated from the embryo, with which they finally only remain in connection by a hollow column of cells (fig. $24 \mathrm{I} \mathrm{A}, d o$ ).

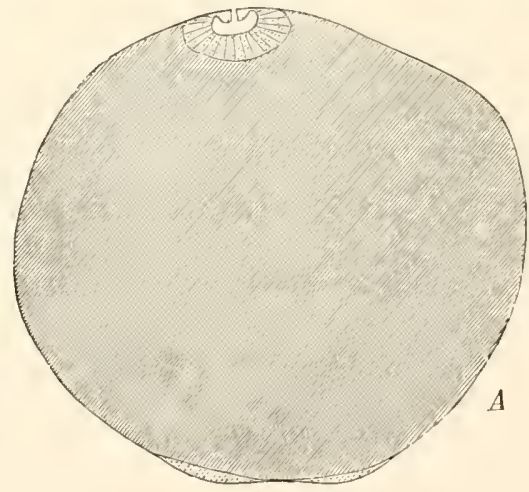

F1G. 2+2. Diagrammatic Section of CYMOTHOA SHEWING THE DORSAL ORGAN. (From Bullar.)

The original patch now gradually spreads over the inner egg membrane, and forms a transverse saddle-shaped band of flattened cells which engirths the embryo on all but the ventral side.

In the Amphipods the epiblast cells remain attached for a small area on the dorsal surface to the first larval skin, when this is formed. This patch of cells, often spoken of as a micropyle apparatus, forms a dorsal organ equivalent to that in Oniscus. A perforation is formed in it at a later 
period. A perhaps homologous structure is found in the embryos of Euphausia, Cuma, etc.

In many Branchiopoda a dorsal organ is found. lts development has been studied by Grobben in Moina. It persists in the adult in Branchipus, Limnadia, Estherea, etc.

In the Copepoda a dorsal organ is sometimes found in the embryo; Grobben at any rate believes that he has detected an organ of this nature in the embryo of Cyclops serrulatus.

A paired organ which appears to be of the same nature has been found in

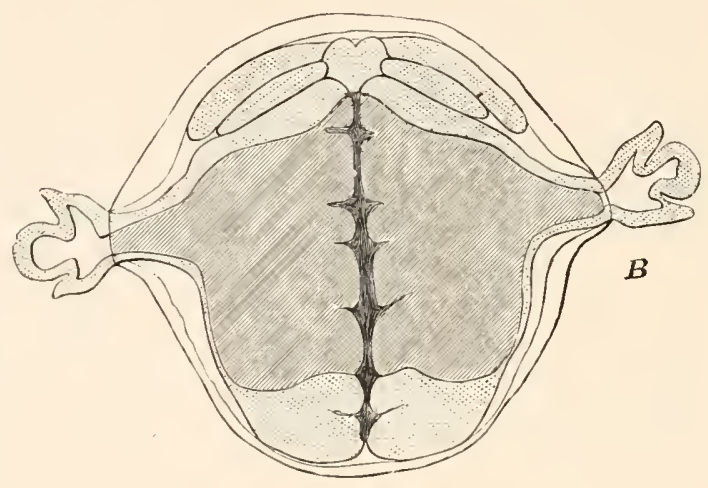

Fig. 243. DiAgramMATIC SECTION OF AN EMBRYO of Asellus åuaticus to SHew THE l'AlRED DORSAL ORGAN. (From Bullar; after E. van Beneden.) Asellus and Mysis.

In Asellus (Rathke (No. 501), Dohrn (No. 500), Van Beneden (No. 497)) this organ originates as two cellular masses at the sides of the body just behind the region of the procephalic lobes. Each of them becomes trifoliate and bends towards the ventral surface. In each of their lobes a cavity arises and finally the three cavities unite, forming a trilobed cavity open to the yolk. This organ eventually becomes so large that it breaks through the egg membranes and projects at the sides of the embryo (fig. 243. Though formed before the appendages it does not attain its full development till considerably after the latter have become well established.

In Mysis it appears during the Nauplius stage as a pair of cavities lined by columnar cells, which atrophy very early.

Various attempts have been made to identify organs in other Arthropod embryos with the dorsal organ of the Crustacea, but the only organ at all similar which has so far been described is one found in the embryo of Linguatula (vide Chapter XIX.), but there is no reason to think that this organ is really homologous with the dorsal organ of the Crustacea.

The mesoblast. The mesoblast in the types so far investigated arises from the same cells as the hypoblast, and appears as a somewhat irregular layer between the epiblast and the hypoblast. It gives rise to the same parts as in other forms, but it is remarkable that it does not, in most Decapods and Isopods 
(and so far we do not know about other forms), become divided into somites, at any rate with the same distinctness that is usual in Annelids and Arthropods. Not only so, but there is at first no marked division into a somatic and splanchnic layer with an intervening body cavity. Some of the cells become differentiated into the muscles of the body wall and limbs; and other cells, usually in the form of a very thin layer, into the muscles of the alimentary tract. In the tail of Palemon Bobretzky noticed that the cells about to form the muscles of the body were imperfectly divided into cubical masses corresponding with the segments; which however, in the absence of a central cavity, differed from typical mesoblastic somites. In Mysis Metschnikoff states that the mesoblast becomes broken up into distinct somites. Further investigations on this subject are required. The body cavity has the form of irregular blood sinuses amongst the internal organs.

Heart. The origin and development of the heart and vascular system are but very imperfectly known.

In Phyllopods (Branchipus) Claus (No. 454) has shewn that the heart is formed by the coalescence of the lateral parts of the mesoblast of the ventral plates. The chambers are formed successively as the segments to which they belong are established, and the anterior chambers are in full activity while the posterior are not yet formed.

In Astacus and Palæmon, Bobretzky finds that at the stage before the heart definitely appears there may be seen a solid mass of mesoblast cells in the position which it eventually occupies ${ }^{1}$; and considers it probable that the heart originates from this mass. At the time when the heart can first be made out and before it has begun to beat, it has the form of an oval sack with delicate walls separated from the mesenteron by a layer of splanchnic mesoblast. Its cavity is filled with a peculiar plasma which also fills up the various cavities in the mesoblast. Around it a pericardial sack is soon formed, and the walls of the heart become greatly thickened. Four bands pass off from the heart, two dorsalwards which become fixed to the integument, and two ventralwards. There is also a median band of cells connecting the heart with the dorsal integument. The main arteries arise as direct prolongations of the heart. Dohrn's observations on Asellus greatly strengthen the view that the heart originates from a solid mesoblastic mass, in that he was able to observe the hollowing out of the mass in

1 Reichenbach describes these cells, and states that there is a thickening of the epiblast adjoining them. In one place he states that the heart arises from this thickening of epiblast, and in another that it arises from the mesoblast. An epiblastic origin of the heart is extremely improbable. 
the living embryo ( $c f$. the development of the heart in Spiders). Some of the central cells (nuclei, Dohrn) becoine blood corpuscles. The formation of these is not, according to Dohrn, confined to the heart, but takes place in situ in all the parts of the body (antennæ, appendages, etc.). The corpuscles are formed as free nuclei and are primarily derived from the yolk, which at first freely communicates with the cavities of the appendages.

Alimentary tract. In Astacus the formation of the mesenteron by invagination, and the absorption of the yolk by the hypoblast cells, have already been described. On the absorption of the yolk the mesenteron has the form of a sack, the walls of which are formed of immensely long cellsthe yolk pyramids - at the base of which the nucleus is placed (fig. $238 \mathrm{~B}$ ). This sack gives rise both to the portion of the alimentary canal between the abdomen and the stomach and to the liver. The epithelial wall of both of these parts is formed by the outermost portions of the pyramids with the nuclei and protoplasm becoming separated off from the yolk as a layer of flat epithelial cells. The yolk then breaks up and forms a mass of nutritive material filling up the cavity of the mesenteron.

The differentiation both of the liver and alimentary tract proper first takes place on the ventral side, and commences close to the point where the proctodæum ends, and extends forward from this point. A layer of epithelial cells is thus formed on the ventral side of the mesenteron which very soon becomes raised into a series of longitudinal folds, one of which in the middle line is very conspicuous. The median fold eventually, by uniting with a corresponding fold on the dorsal side, gives rise to the true mesenteron; while the lateral folds form parallel hepatic cylinders, which in front are not constricted off from the alimentary tract. The lateral parts of the dorsal side of the mesenteron similarly give rise to hepatic cylinders. The yolk pyramids of the anterior part of the mesenteron, which projects forwards as a pair of diverticula on each side to the level of the stomach, are not converted into hepatic cylinders till after the larva is hatched.

The proctodæum very early opens into the mesenteron, but the stomodæum remains closed till the differentiation of the mid-gut is nearly completed. The proctodrum gives rise to the abdominal part of the intestine, and the stomodrum to the csophagus and stomach. The commencement of the masticatory apparatus in the latter appears very early as a dorsal thickening of the epithelium.

The primitive mesenteron in Palæmon differentiates itself into the permanent mid-gut and liver in a manner generally similar to that in Astacus, though the process is considerably less complicated. A distinct layer of cells separates itself from the outer part of the yolk pyramids, and gives rise to the glandular lining both of the mid-gut and of the liver. The differentiation of this layer commences behind, and the mid-gut very soon commiunicates freely with the proctodæum. The lateral parts of the primitive mesenteron become constricted into four wings, two directed forwards and two backwards; these, after the yolk in them has become absorbed, constitute the liver. The median part simply becomes the me- 
senteron. The stomachic end of the stomodæum lies in contact with the mesenteron close to the point where it is continued into the hepatic diverticula, and, though the partition-wall between the two becomes early very thin, a free communication is not established till the yolk has been completely absorbed.

The alimentary tract in the Isopoda is mainly if not entirely formed from the proctodæum and stomodæum, both of which arise before any other part of the alimentary system as epiblastic invaginations, and gradually grow inwards (fig. 244). In Oniscus the liver is formed as two discs at the surface of the yolk on each side of the anterior part of the body. Their walls are composed of cubical cells derived from the yolk cells, the

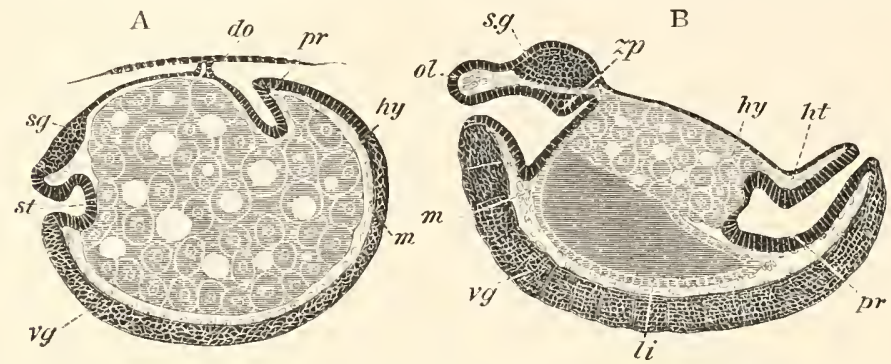

Fig. 244. Two Longitudinal sections through the eMrryo of Oniscus MURARiUs. (After Bobretzky.)

st. stomodæum; pr. proctodæum; hy. hypoblast formed of large nucleated cells imbedded in yolk ; $m$. mesoblast ; vg. ventral nerve cord ; $s g$. supra-œesophageal ganglion; li. liver; do. dorsal organ; $z p$. rudiment of masticatory apparatus.

origin of which was spoken of on p. 5i6. These two discs gradually take the form of sacks (fig. $244 \mathrm{~B}, \mathrm{li}$.) freely open on their inner side to the yolk. As these sacks continue to grow the stomodæum and proctodæum do not remain passive. The stomodæum, which gives rise to the œsophagus and stomach of the adult, soon exhibits a posterior dilatation destined to become the stomach, on the dorsal wall of which a well-marked prominence -the earliest trace of the future armature-is soon formed (fig. $244 \mathrm{~B}$, $z p$ ). The proctodæum ( $p r)$ grows with much greater rapidity than the stomodæum, and its end adjoining the yolk becomes extremely thin or even broken through. In the earliest stages it was surrounded by the yolk cells, but in its later growth the yolk cells become gradually reduced in number and appear to recede before it-so much so that one is led to conclude that the later growth of the proctodæum takes place at the expense of the yolk cells.

The liver sacks become filled with a granular material without a trace of cells; their posterior wall is continuous with the yolk cells, and their anterior lies close behind the stomach. The proctodæum continually grows forwards till it approaches close to the stomodæum, and the two 
liver sacks, now united into one at their base, become directly continuous with the proctodxum. By the stage when this junction is effected the yolk cells have completely disappeared. It seems then that in Oniscus the yolk cells (hypoblast) are nainly employed in giving rise to the walls of the liver; but that they probably also supply the material for the later growth of the apparent proctodxum. It becomes therefore necessary to conclude that the latter, which might seem, together with the stomodæum, to form the whole alimentary tract, does in reality correspond to the proctodæum and mesenteron together, though the digestive fluids are no doubt mainly secreted not in the mesenteron but in the hepatic diverticula. The proctodæum and stomodæum at first meet each other without communicating, but before long the partition between the two is broken through.

In Cymothoa (Bullar, No. 499) the proctodæum and stomodæum develop in the same manner as in Oniscus, but the hypoblast has quite a different form. The main mass of the yolk, which is much greater than in Oniscus, is not contained in definite yolk cells, but the hypoblast is represented by (1) two solid masses of cells, derived apparently from the inner layer of blastoderm cells, which give rise to the liver; and (2) by a membrane enclosing the yolk in which nuclei are present.

The two hepatic masses lie on the surface of the yolk, and each of them becomes divided into three short crecal tubes freely open to the yolk. The stomodxum soon reaches its full length, but the proctodæum grows forwards above the yolk till it meets the stomodrum. By the time this takes place the liver cæca have grown into three large tubes filled with fluid, and provided with a muscular wall. They now lie above the yolk, and no longer communicate directly with the cavity of the yolk sack, but open together with the yolk sack into the point of junction of the proctodxum and stomodxum. The yolk sack of Cymothoa no doubt represents part of the mesenteron, but there is no evidence in favour of any part of the apparent proctodæum representing it also, though it is quite possible that it may do so. The relations of the yolk sack and hepatic diverticula in Cymothoa appear to hold good for Asellus and probably for most Isopoda.

The differences between the Decapods and Isopods in the development of the mesenteron are not inconsiderable, but they are probably to be explained by the relatively larger amount of food yolk in the latter forms. The solid yolk in the Isopods on this view represents the primitive mesenteron of Decapods after the yolk has been absorbed by the hypoblast cells. Starting from this standpoint we find that in both groups the lateral parts of the mesenteron become the liver. In Decapods the middle part becomes directly converted into the mid-gut, the differentiation of it commencing behind and proceeding forwards. In the Isopods, owing to the mesenteron not having a distinct cavity, the differentiation of it, which proceeds forwards as in Decapods, appears simply like a prolongation forwards of the proctodrum, the cells for the prolongation being probably supplied from the yolk. In Cymothoa the food yolk is so bulky that a special yolk sack is developed 
for its retention, which is not completely absorbed till some time after the alimentary canal has the form of a continuous tube. The walls of this yolk sack are morphologically a specially developed part of the mesenteron.

\section{BIBLIOGRAPHY.}

\section{General Works.}

(447) C. Spence Bate. "Report on the present state of our knowledge of the Crustacea." Report of the British Association for 1878 .

(448) C. Claus. Untersuchungen zur Erforschung der genealogischen Grundlage des Crustaceen-Systems. Wien, 1876 .

(449) A. Dohrn. "Geschichte des Krebsstammes." Jenaische Zeitschrift, Vol. vi. 1871 .

(450) A. Gerstaecker. Bronn's Thierreich, Bd. v. Arthropoda, I866.

(451) Th. H. Huxley. The Anatomy of Invertebrated Animals. London, 1877 .

(452) Fritz Mïller. Fü̈ Darwin, 1864. Translation, Facts for Darwin. London, I 869 .

\section{Branchiopoda.}

(453) Brauer. "Vorläufige Mittheilung iiber die Entwicklung u. Lebensweise des Lepidurus (Apus) productus." Sitz. der Ak. d. Wiss. Wien, Vol. Lxıx., I874.

(454) C. Claus. "Zur Kenntniss d. Baues u. d. Entwicklung von Branchipus stagnalis u. Apus cancriformis." Abh. d. könig. Gesell, der VViss. Göttingen, Vol. xvi11. 1873 .

(455) C. Grobben. "Zur Entwicklungsgeschichte d. Moina rectirostris." Arbeit. a. d. zoologisch. Institute Wien, Vol. 11., 1879.

(456) E. Grube. "Bemerkungen über die Phyllopoden nebst einer Uebersicht etc." Archiv f. Naturgeschichte, Vol. xix., I853.

(457) N. Joly. "Histoire d'un petit Crustacé (Artemia salina, Leach) etc." Annales d. Sciences Natur., nd ser., Vol. Xı11., I 8 †०.

(458) N. Joly. "Recherches zoologiques anatomiques et physiologiques sur l'Isaura cycladoides (=Estheria) nouveau genre, etc." Annales $d$. Sciences Nat., and ser., Vol. xv11., I $84^{2}$.

(459) Lereboullet. "Observations sur la génération et le développement de la Limnadia de Hermann." Annales d. Sciences Natur., 5th ser., Vol. v., I 866.

(460) F. Leydig. "Ueber Artemia salina u. Branchipus stagnalis." Zeit. $f$. wiss. Zool., Vol. 111., $185 \mathrm{I}$.

(461) G. O. Sars. "Om en dimorph Udvikling samt Generationsvexel hos Leptodora." Vidensk. Selskab. Forhand, 1873 .

(462) G. Zaddach. De apodis cancreformis Schaeff. anatome et historia evolutionis. Dissertatzo inauguralis zootomica. Lionnæ, $\mathbf{1} 841$.

\section{Nebaliada.}

(463) C. Claus. "Ueber den Bau u. die systematische Stellung von Nebalia." Zeit.f. wiss. Zool., Bd. xxı1. I872.

(464) E. Metschnikoff. Development of Nebalia (Russian), i 868.

B. II. 


\section{Schizopoda.}

(465) E. van Beneden, “Recherches sur l'Embryogénie des Crustacés. II. Développement des Mysis." Bullet. de l'Académie roy. de Belgique, second series, Tom. XXvili. 1869 .

(466) C. Claus. "Ueber einige Schizopoden u. niedere Malakostraken." Zett. f. zeiss. Zoologie, Bd. XIII., 1863 .

(467) A. Dohrn. "Untersuchungen üb. Bau u. Entwicklung d. Arthropoden." Zeit.f. wiss. Zool., Bd. xxı., 1871, p. 375. Peneus zoæa (larva of Euphausia).

(468) E. Metschnikoff. "Ueber ein Larvenstadium von Euphausia." Zeit. fïr wiss. Zool., Bd. XIX., I869.

(469) E. Metschnikoff. "Ueber den Naupliuszustand von Euphausia." Zeit. für zeiss. Zool., Bd. Xxi., i $87 \mathrm{I}$.

\section{Decapoda.}

(470) Spence Bate. "On the development of Decapod Crustacea." Phil. Trans., 1858 .

(471) Spence Bate. "On the development of Pagurus." Ann. and Mag. Nat. History, Series 4, Vol. II., I 868.

(472) N. Bobretzky. Development of Astacus and Palamon. Kiew, 1873. (Russian.)

(473) C. Claus. "Zur Kenntniss d. Malakostrakenlarven." Wïrzb. natumw. Zeitschrift, I86 I.

(474) R. Q. Couch. "On the Metamorphosis of the Decapod Crustaceans." Report Cornwell Polyt. Society. 1848 .

(475) Du Cane. "On the Metamorphosis of Crustacea." Ann. and Mag. of Nat. History, 1839 .

(476) Walter Faxon. "On the development of Palæmonetes vulgaris." Bull. of the Mus. of Comp. Anat. Harvard, Cambridge, Mass., Vol. v., I879.

(477) A. Dohrn. "Untersuchungen üb. Bau u. Entwicklung d. Arthropoden." "Zur Entwicklungsgeschichte der Panzerkrebse. Scyllarus Palinurus." Zeit. f. zeiss. Zool., Bd. xx., 1870.

(478) A. Dohrn. "Untersuchungen üb. Bau u. Entwicklung d. Arthropoden. Erster Beitrag z. Kenntniss d. Malacostraken u. ihrer Larven Amphion Reynaudi, Lophogaster, Portunus, Porcellanus, Elaphocaris." Zeit. f. wiss. Zool., Bd. xx., 1870 .

(479) A. Dohrn. "Untersuchungen üb. Bau u. Entwicklung d. Arthropoden. Zweiter Beitrag, etc." Zeit.f. wiss. Zool., Bd. xxı., I8 8 I. 1843 .

(480) N. Joly. "Sur la Caridina Desmarestii." Ann. Scien. Nat., Tom. xix.,

(481) Lereboullet. "Recherches d. l'embryologie comparée surle développement du Brochet, de la Perche et de l'Écrevisse." Mém. Savans Étrang. Paris, Vol. xvir., I 862 .

(482) P. Mayer. "Zur Entwicklungsgeschichte d. Dekapoden." Fenaische Zeitschrift, Vol. xI., I877.

(483) Fritz Miiller. "Die Verwandlung der Porcellana." Archivf. Naturgeschichte, I862. 
(484) Fritz Müller. "Die Verwandlungen d. Garneelen," Archiv f. Naturgesch., Tom. xxix.

(485) Fritz M ïller. "Ueber die Naupliusbrut d. Garneelen." Zeit f. wiss. Zool., Bd. xxx., r878.

(486) T. J. Parker. "An account of Reichenbach's researches on the early development of the Fresh-water Crayfish." Quart. F. of M. Scicnce, Vol. xvili., I 878 .

(487) H. Rathke. Ueber die Bildung u. Entwickhnng d. Flusskrebses. Leipzig, 1829 .

(488) H. Reichenbach. "Die Embryoanlage u. erste Entwicklung d. Flusskrebses." Zeit. f. wiss. Zool., Vol, xxıx., i 877 .

(489) F. Richters. "Ein Beitrag zur Entwicklungsgeschichte d. Loricaten." Zcii.f. wiss. Zool., Bd. xxir., i 873 .

(490) G. O. Sars. "Om Hummers postembryonale Udvikling." Vidensk Selsk. Forh. Christiania, I874.

(491) Sidney J. Smith. "The early stages of the American Lobster." Trans. of the Connecticut Acad. of Arts and Sciences, Vol. II., Part 2, 1873.

(492) R. v. Willemoes Suhm. "Preliminary note on the development of some pelagic Decapoda." Proc. of Royal Society, i 876 .

\section{Stomatopoda.}

(493) W. K. Brooks. "On the larval stages of Squilla empusa." Chesapeake Zoological Laboratory, Scientific results of the Session of 1878 . Baltimore, 1879 .

(494) C. Claus. "Die Metamorphose der Squilliden." Abhand. der königl. Gesell. der Wiss. zu Göttingen, I8†1.

(495) Fr. M iiller. "Bruchstiick a. der Entwicklungsgeschichte d. Maulfuisser I. und ir." Archiv f. Naturgeschichte, Vol. xxvir., i862, and Vol. xxix., i863.

\section{Cumacea.}

(496) A. Dohrn. "Ueber den Bau u. Entwicklung d. Cumaceen." Fenaische Zeitschrift, Vol. v., i 8 ;o.

\section{Isopoda.}

(497) Ed. van Beneden. "Recherches sur l'Embryogénie des Crustacés. I. Asellus aquaticus." Bull. de l'Acad. roy Belsique, zme série, Tom. xxvili., No. 7, 1869 .

(498) N. Bobretzky. "Zur Embryologie des Oniscus murarius." Zeit. fïr ziss. Zool., Bd. xxiv., I8 84 .

(499) J. F. Bullar. "On the development of the parasitic Isopoda." Phil. Trans., Part II., 1878.

(500) A. Dohrn. "Die embryonale Entwicklung des Asellus aquaticus." Zeit. f. wiss. Zool., Vol. Xvir., I867.

(501) H. Rathke. Untersuchungen ïber die Bildung und Entwicklung der Wasser-Assel. Leipzig, 1832 .

(502) H. Rathke. Zur Morphologiv. Reisebemerkungen aus Taurien. Riga u. Leipzig. I $8_{37} \cdot$ (Bopyrus, Idothea, Ligia, Ianira.) 


\section{Amplipoda.}

(503) Ed. van Beneden and E. Bessels. "Mémoire sur la formation du blastoderme chez les Amphipodes, les Lernéens et les Copépodes." Classe des Sciences de 1 Acad. roy. de Belgique, Vol. xxxiv., i 868.

(504) De la Vallette St George. "Studien über die Entwicklung der Amphipoden." Abhand. d. naturfor. Gesell. zu Halle, Bd. v., I860.

\section{Copppoda.}

(505) E. van Beneden and E. Bessels. "Mémoire sur la formation du blastoderrne chez les Amphipodes, les Lernéens et Copépodes." Classe des Sciences de l'Acad. roy. de Belgique, Vol. xxxiv., i 868.

(506) E. van Ben eden. "Recherches sur l'Embryogénie des Crustacés Iv. Anchorella, Lerneopoda, Branchiella, Hessia." Bull. de l'Acad. roy. de Belgique, ame série, T. xxix., I 870 .

(507) C. Claus. Zur Anatomie u. Entwicklungsgeschichte d. Copepoden.

(508) C. Claus. "Untersuchungen über die Organisation u. Verwandschaft d. Copepoden." Wiirzburger naturviss. Zeitschrift, Bd. III., I862.

(509) C. Claus, "Ueber den Bau u. d. Entwicklung von Achtheres percarum." Zeit.f. wiss, Zool., Bd. XI., I862.

(510) C. Claus. Die freilebenden Copepoden mit besonderer Berïcksichtigung der Fanna Deutschlands, des Nordsee u. des Mittelmeeres. Leipzig, I863.

(511) C. Claus. "Ueber d. Entwicklung, Organisation u. systematische Stellung d. Argulidæ." Zeit. f. wiss. Zool., Bd. xxv., 1875 .

(512) P. P. C. Hoek. "Zur Entwicklungsgeschichte d. Entomostracen." Niederlïndisches Archiv, Vol. IV., I877.

(513) Nordmann. Mikrographische Beiträge zur Naturgeschichte der virbellosen 7'hiere. Zweites Heft. I832.

(514) Salensky. "Sphæronella Leuckartii." Archiv f. Naturgeschichte, I 868.

(515) F. Vejdovsky. "Untersuchungen iib. d. Anat. u. Metamorph. v. Tracheliastes polycolpus." Zeit.f. wiss. Zool., Vol. Xxıx., I877.

\section{Cirripedia.}

(516) C. Spence Bate. "On the development of the Cirripedia." Annals and Mag. of Natur. History. Second Series, Vili., I 8.5.

(517) E. van Beneden. "Développement des Sacculines." Bull. de l'Acad. roy. de Belg., 187 o.

(518) C. Claus. Die Cypris-ähnliche Larve der Cirripedien. Marburg, I869.

(519) Ch. Darwin. A monograph of the sub-class Cimpedia, 2 Vols., Ray Society, I $85 \mathrm{I}-4$.

(520) A. Dohrn. "Untersuchungen über Bau u. Entwicklung d. Arthropoden Ix. Eine neue Naupliusform (Archizoëa gigas)." Zeit. f. wiss. Zool., Bd. xx., 1870.

(521) P. P. C. Hoek. "Zur Entwicklungsgeschichte der Entomostraken I. Embryologie von Balanus." Niederländisches Archiv fïr Zoologie, Vol. 111., 1876-7.

(522) R. Kossmann. "Suctoria u. Lepadidx." Arbeiten a. d. zool.-zoot. Instiwite d. Univer. Würz., Vol. I., I873. 
(523) Aug. Krohn. "Beobachtungen über die Entwicklung der Cirripedien." Wiegmann's Archiv für Naturgesch., xxvi., I860.

(524) E. Metschnik off. Sitzungsberichted. Versammlung deutscher Naturforscher zu Hannover, I 865. (Balanus balanoides.)

(525) Fritz Müller. "Die Rhizocephalen." Archiv f. Naturgeschichte, $1862-3$.

(526) F. C. Noll. "Kochlorine hamata, ein bohrendes Cirriped." Zeit.f. wiss. Zool., Bd. xxv., 1875 .

(527) A. Pagenstecher. "Beiträge zur Anatomie und Entwicklungsgeschichte von Lepas pectinata." Zeit.f. wiss. Zool., Vol. xin., I 863 .

(528) J. V. Thompson. Zoological Researches and Ilinstrations, Vol. I., Part I. Memoir Iv. On the Cirripedes or Barnacles. 8vo. Cork, 1830.

(529) J. V. Thompson. "Discovery of the Metamorphosis in the second type of the Cirripedes, viz. the Lepades completing the natural history of these singular animals, and confirming their affinity with the Crustacea." Phil. Trans. I 835. Part II.

(530) R. von Willemoes Suhm. "On the development of Lepas fascicularis." Phil. Trans., Vol. 166, 1876.

\section{Ostracoda.}

(531) C. Claus. "Zur näheren Kenntniss der Jugendformen von Cypris ovum." Zeit.f. wiss. Zool., Bd. xv., I 865 .

(532) C. Claus. "Beiträge zur Kenntniss d. Ostracoden. Entwicklungsgeschichte von Cypris ovum." Schriften d. Gesell. zur Befördenung d. gesamm. Naturwiss. zu Marburg, Vol. IX., I 868. 


\section{CHAPTER XIX.}

\section{PCECILOPODA, PYCNOGONIDA, TARDIGRADA, AND LIN- GUATULIDA; AND COMPARATIVE SUMMARY OF ARTHROPODAN DEVELOPMEN'T.}

THE groups dealt with in the present Chapter undoubtedly belong to the Arthropoda. They are not closely related, and in the case of each group it is still uncertain with which of the main phyla they should be united. It is possible that they may all be offshoots from the Arachnidan phylum.

\section{PCECILOPODA.}

The development of Limulus has been studied by Dohrn (No. 533) and Packard (No. 534). The ova are laid in the sand near the spring-tide marks. They are enveloped in a thick chorion formed of several layers; and (during the later stages of development at any rate) there is a membrane within the chorion which exhibits clear indications of cell autlines ${ }^{1}$.

There is a centrolecithal segmentation, which ends in the formation of a blastoderm enclosing a central yolk mass. A ventral plate is then formed, which is thicker in the region where the abdomen is eventually developed. Six segments soon become faintly indicated in the cephalothoracic region, the ends of which grow out into prominent appendages (fig. $245 \mathrm{~A}$ ); of these there are six pairs, which increase in size from before backwards. A stomodæum $(m)$ is by this time established and is placed well in front of the foremost pair of appendages ${ }^{2}$.

In the course of the next few days the two first appendages of the abdominal region become formed (vide fig. $245 \mathrm{C}$ shewing those abdominal appendages at a later stage), and have a very different shape and direction to those of the cephalothorax. The appendages of the latter become

1 The nature of the inner membrane is obscure. It is believed by Packard to be moulted after the formation of the limbs, and to be equivalent to the amnion of Insects, while by Dohrn it is regarded as a product of the follicle cells.

2 Dohrn finds at first only five appendages, but thinks that the sixth (the anterior one) may have been present but invisible. 
flexed in the middle in such a way that their ends become directed towards the median line (fig. 245 B). The body of the embryo (fig. $245 \mathrm{~B}$ ) is now distinctly divided into two regions-the cephalothoracic in front, and the abdominal behind, both divided into segments.

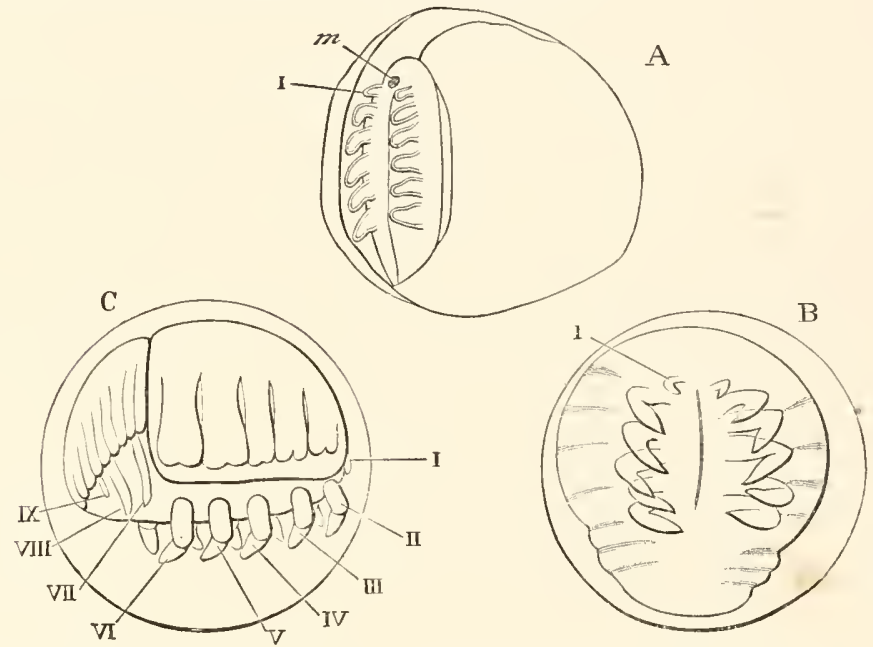

Fig. ${ }^{2}+5$. Three stages in the Development of Limulus polyphemus. (Somewhat modified from Packard.)

A. Embryo in which the thoracic limbs and mouth have become developed on the ventral plate. The outer line represents what Packard believes to be the amnion.

B. Later embryo from the ventral surface.

C. Later embryo, just before the splitting of the chorion from the side. The full number of segments of the abdomen, and three abdominal appendages, have become established; $m$. mouth; I-IX. appendages.

Round the edge of the ventral plate there is a distinct ridge-the rudiment of the cephalothoracic shield.

With the further growth of the embryo the chorion becomes split and cast off, the embryo being left enclosed within the inner membrane. The embryo has a decided ventral flexure, and the abdominal region grows greatly and forms a kind of cap at the hinder end, while its vaulted dorsal side becomes divided into segments (fig. $245 \mathrm{C}$ ). Of these there are according to Dohrn seven, but according to Packard nine, of which the last forms the rudiment of the caudal spine.

In the thoracic region the nervous system is by this stage formed as a ganglionated cord (Dohrn), with no resemblance to the peculiar œsophageal ring of the adult. The mouth is stated by Dohrn to lie between the second pair of limbs, so that, if the descriptions we have are correct, it must have by this stage changed its position with reference to the appendages. Between the thorax and abdomen two papiliae have arisen which form the 
so-called lower lip of the adult, but from their position and late development they can hardly be regarded as segmental appendages. In the course of further changes all the parts become more distinct, while the membrane in which the larva is placed becomes enormously distended (fig. $246 \mathrm{~A}$ ). The rudiments of the compound eyes are formed on the third (Packard) or fourth (Dohrn) segment of the cephalothorax, and the simple eyes near the median line in front. The rudiments of the inner process of the chelæ of the cephalothoracic appendages arise as buds. The abdominal appendages become more plate-like, and the rudiments of a third pair appear behind the two already present. The heart appears on the dorsal surface.

An ecdysis now takes place, and in the stage following the limbs have approached far more closely to their adult state (fig. $246 \mathrm{~A}$ ). The cephalothoracic appendages become fully jointed; the two anterior abdominal appendages (VII.) have approached, and begin to resemble the oper-
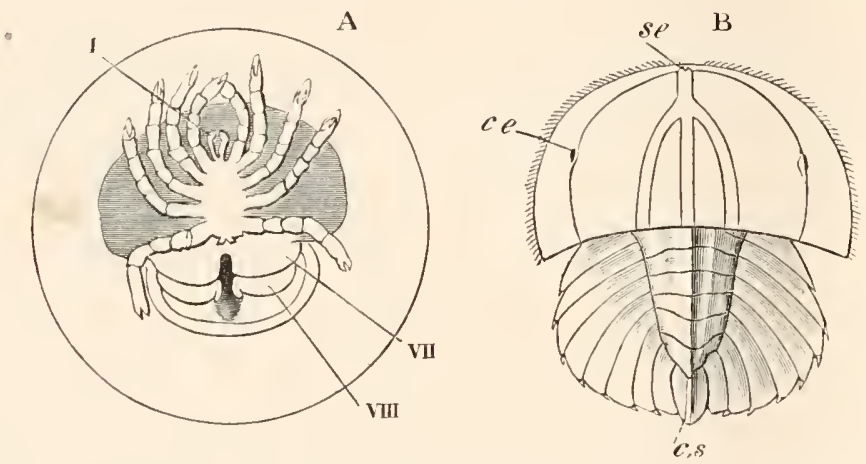

F1g. 24 6. Two stages in the develoiment of Linulus polyphemus.

(After Dohrn.)

A. An advanced embryo enveloped in the distended inner membrane shortly before hatching ; from the ventral side.

B. A later embryo at the Trilobite stage, from the dorsal side.

I., v11., v11. First, seventh, and eight appendages.

cs. caudal spine; se. simple eye ; cc. compound eye.

culum of the adult, and on the second pair is formed a small inner ramus. The segmentation of the now vaulted cephalothorax becomes less obvious, though still indicated by the arrangement of the yolk masses which form the future hepatic diverticula.

Shortly after this stage the embryo is hatched, and at about the time of hatching acquires a form (fig. $246 \mathrm{~B}$ ) in which it bears, as pointed out by Dohrn and Packard, the most striking resemblance to a Trilobite.

Viewed from the dorsal surface (fig. $246 \mathrm{~B}$ ) it is divided into two distinct regions, the cephalothoracic in front and the abdominal behind. The cephalothoracic has become much flatter and wider, has lost all trace of its previous segmentation, and has become distinctly trilobed. The 
central lobe forms a well-marked keel, and at the line of insertion of the rim-like edge of the lateral lobes are placed the two pairs of eyes (se and ce). The abdominal region is also distinctly trilobed and divided into nine segments; the last, which is merely formed of a median process, being the rudiment of the caudal spine. The edges of the second to the seventh are armed with a spine. The changes in the appendages are not very considerable. The anterior pair nearly meet in the middle line in front or the mouth; and the latter structure is completely covered by an upper lip. Each abdominal appendage of the second pair is provided with four gill-lamellæ, attached close to its base.

Three weeks after hatching an ecdysis takes place, and the larva passes from a trilobite into a limuloid form. The segmentation of the abdomen has become much less obvious, and this part of the embryo closely resembles its permanent form. The caudal spine is longer, but is still relatively short. A fourth pair of abdominal appendages is established, and the first pair have partially coalesced, while the second and third pairs have become jointed, their outer ramus containing four and their inner three joints. Additional gill-lamellæ attached to the two basal joints of the second and third abdominal appendages have appeared.

The further changes are not of great importance. They are effected in a series of successive moults. The young larve swim actively at the surface.

Our, in many respects, imperfect knowledge of the development of Limulus is not sufficient to shew whether it is more closely related to the Crustacea or to the Arachnida, or is an independent phylum.

The somewhat Crustacean character of biramous abdominal feet, etc. is not to be denied, but at the same time the characters of the embryo appear to me to be decidedly more arachnidan than crustacean. The embryo, when the appendages are first formed, has a decidedly arachnidan facies. It will be remembered that when the limbs are first formed they are all post-oral. They resemble in this respect the limbs of the Arachnida, and it seems to be probable that the anterior pair is equivalent to the cheliceræe of Arachnida, which, as shewn in a previous section, are really post-oral appendages in no way homologous with antennæ ${ }^{1}$.

The six thoracic appendages may thus be compared with the six Arachnidan appendages; which they resemble in their relation to the mouth, their basal cutting blades, etc.

The existence of abdominal appendages behind the six cephalothoracic does not militate against the Arachnidan affinities of Limulus, because in the Arachnida rudimentary abdominal appendages are always present in the embryo. The character of the abdominal appendages is probably

1 Dohrn believes that he has succeeded in shewing that the first pair of appendages of Limulus is innervated in the embryo from the supra-œesophageal ganglia. His observations do not appear to me conclusive, and, arguing from what we know of the development of the Arachnida, the innervation of these appendages in the adult can be of no morphological importance. 
secondarily adapted to an aquatic respiration, since it is likely (for the reasons already mentioned in connection with the Tracheata) that if Limulus has any affinities with the stock of the Tracheata it is descended from airbreathing forms, and has acquired its aquatic mode of respiration. The anastomosis of the two halves of the generative glands is an Arachnidan character, and the position of the generative openings in Limulus is more like that in the Scorpion than in Crustacea.

A fuller study of the development would be very likely to throw further light on the affinities of Limulus, and if Packard's view about the nature of the inner egg membrane were to be confirmed, strong evidence would thereby be produced in favour of the Arachnidan affinities.

(533) A. Dohrn. "Untersuch. üb. Bau u. Entwick. d. Arthropoden (Limulus polyphemus)." Fenaische Zeitschrift, Vol. vi., I 87 I.

(534) A. S. Packard. "The development of Limulus polyphemus." Mem. Boston Soc. Nat. History, Vol. II., I872.

\section{PYCNOGONIDA.}

The embryos, during the first phases of their development, are always carried by the male in sacks which are attached to a pair of appendages (the third) specially formed for this purpose. The segmentation of the ovum is complete, and there is in most forms developed within the eggshell a larva with three pairs of two-jointed appendages, and a rostrum placed between the front pair.

It will be convenient to take Achelia lævis, studied by Dohrn (No. 536), as type.

The larva of Achelia when hatched is provided with the typical three pairs of appendages. The foremost of them is chelate, and the two following pairs are each provided with a claw. Of the three pairs of larval appendages Dohrn states that he has satisfied himself that the anterior is innervated by the supra-œsophageal ganglion, and the two posterior by separate nerves coming from two imperfectly united ventral ganglia. The larva is provided with a median eye formed of two coalesced pigment spots, and with a simple stomach.

The gradual conversion of the larva into the adult takes place by the elongation of the posterior end of the body into a papilla, and the formation there, at a later period, of the anus; while at the two sides of the anal papilla rudiments of a fresh pair of appendages-the first pair of ambulatory limbs of the adult-make their appearance. The three remaining pairs of limbs become formed successively as lateral outgrowths, and their development is accomplished in a number of successive ecdyses. As they are formed cæca from the stomach become prolonged into them. For each of them there appears a special ganglion. While the above changes are taking place the three pairs of larval appendages undergo considerable reduction. The anterior pair singly becomes smaller, the second loses its claw, and the third becomes reduced to a mere stump. In the adult the 
second pair of appendages becomes enlarged again and forms the so-called palpi, while the third pair develops in the male into the egg-carrying appendages, but is aborted in the female. The first pair form appendages lying parallel to the rostrum, which are sometimes called pedipalpi and sometimes antennæe.

The anal papilla is a rudimentary abdomen, and, as Dohrn has shewn, contains rudiments of two pairs of ganglia.

The larvæ of Phoxichilidium are parasitic in various Hydrozoa (Hydractinia, etc.). After hatching they crawl into the Hydractinia stock. They are at first provided with the three normal pairs of larval appendages. The two hinder of these are soon thrown off, and the posterior part of the trunk, with the four ambulatory appendages belonging to it, becomes gradually developed in a series of moults. The legs, with the exception of the hindermost pair, are fully formed at the first ecdysis after the larva has become free. In the genus Pallene the metamorphosis is abbreviated, and the young are hatched with the full complement of appendages.

The position of the Pycnogonida is not as yet satisfactorily settled. The six-legged larva has none of the characteristic features of the Nauplius, except the possession of the same number of appendages.

The number of appendages (7) of the Pycnogonida does not coincide with that of the Arachnida. On the other hand, the presence of chelate appendages innervated in the adult by the supra-œsophageal ganglia rather points to a common phylum for the Pycnogonida and Arachnida; though as shewn above (p. 455) all the appendages in the embryo of true Arachnida are innervated by post-oral ganglia. The innervation of these appendages in the larvæ of Pycnogonida requires further investigation. Against such a relationship the extra pair of appendages in the Pycnogonida is no argument, since the embryos of most Arachnida are provided with four such extra pairs. The two groups must no doubt have diverged very early.

\section{BIBLIOGRAPHY.}

(535) G. Cavanna. "Studie e ricerche sui Picnogonidi." Pubblicasioni del $R$. Instituto di Studi superiori in Firenze, $187 \%$.

(536) An. Dohrn. "Ueber Entwicklung u. Bau d. Pycnogoniden." Fenaische Zeitschrift, Vol. v. 1870, and "Neue Untersuchungen iib. Pycnogoniden." Mittheil. a. d. zoologischen Station zu Neapel, Bd. I. I8 88 .

(537) G. Hodge. "Observations on a species of Pycnogon, etc." Annal. and Mag. of Nat. Hist. Vol. 1x. 1862.

(538) C. Semper. "Ueber Pycnogoniden u. ihre in Hydroiden schmarotzenden Larvenformen." Arbeiten a.d.zool.-zoot. Instit. Wiirzburg, Vol.1. $187+$.

\section{PEnTASTOMIDA.}

The development and metamorphosis of Pentastomum tænoides have been thoroughly worked out by Leuckart (No. 540) and will serve as type for the group. 
In the sexual state it inhabits the nasal cavities of the dog. The early embryonic development takes place as the ovum gradually passes down the uterus. The segmentation appears to be complete; and gives rise to an oval mass in which the separate cells can hardly be distinguished. This gradually differentiates itself into a characteristic embryo, divided into a tail and trunk. The tail is applied to the ventral surface of the trunk, and on the latter two pairs of stump-like unsegmented appendages arise, each provided with a pair of claws. At the anterior extremity of the body is formed the mouth, with a ventral spine and lateral hook, which are perhaps degenerated jaws. The spine functions as a boring apparatus, and an apparatus with a similar function is formed at the end of the tail. A larval cuticle now appears, which soon becomes detached from the embryo, except on the dorsal surface, where it remains firmly united to a peculiar papilla. This papilla becomes eventually divided into two parts, one of which remains attached to the cuticle, while the part connected with the embryo forms a raised cross placed in a cup-shaped groove. The whole structure has been compared, on insufficient grounds, to the dorsal organ of the Crustacea.

The eggs, containing the embryo in the condition above described, are eventually carried out with the nasal slime, and, if transported thence into the alimentary cavity of a rabbit or hare, the embryos become hatched by the action of the gastric juice. From the alimentary tract of their new host they make their way into the lungs or liver. They here become enveloped in a cyst, in the interior of which they undergo a very remarkable metamorphosis. They are, however, so minute and delicate that Leuckart was unable to elucidate their structure till eight weeks after they had been swallowed. At this period they are irregularly-shaped organisms, with a most distant resemblance to the earlier embryos. They are without their previous appendages, but the alimentary tract is now distinctly differentiated. The remains of two cuticles in the cyst seem to shew that the above changes are effected in two ecdyses.

In the course of a series of ecdyses the various organs of the larval form known as Pentastomum denticulatum continue to become differentiated. After the first (=third) ecdysis the œsophageal nerve-ring and sexually undifferentiated generative organs are developed. At the fourth (=sixth) ecdysis the two pairs of hooks of the adult are formed in pockets which appeared at a somewhat earlier stage; and the body acquires an annulated character. At a somewhat earlier period rudiments of the external generative organs indicate the sex of the larva.

After a number of further ecdyses, which are completed in about six months after the introduction of the embryos into the intermediate host, the larva attains its full development, and acquires a form in which it has long been known as Pentastomum denticulatum. It now leaves its cyst and begins to move about. It is in a state fit to be introduced into its final host ; but if it be not so introduced it may become encysted afresh.

If the part of a rabbit or hare infected by a Pentastomum denticulatum be eaten by a dog or wolf, the parasite passes into the nasal cavity of the 
latter, and after further changes of cuticle becomes a fully-developed sexual Pentastomum tænioides, which does not differ to any very marked extent from P. denticulatum.

In their general characters the larval migrations of Pentastomum are similar to those of the Cestodes.

The internal anatomy of the adult Pentastomum, as well as the characters of the larva with two pairs of clawed appendages, are perhaps sufficient to warrant us in placing it with the Arthropoda, though it would be difficult to shew that it ought not to be placed with such a form as Myzostomum (vide p. 369). There do not appear to be any sufficient grounds to justify its being placed with the Mites amongst the Arachnida. If indeed the rings of the body of the Pentastomida are to be taken as implying a true segmentation, it is clear that the Pentastomida cannot be associated with the Mites.

\section{BIBLIOGRAPHY.}

(539) P. J. van Beneden. " Recherches s. l'organisation et le développement d. Linguatules." Ann. d. Scien. Nat., 3 Ser., Vol. XI.

(540) R. Leuckart. "Bau u. Entwicklungsgeschichte d. Pentastomen." Leipzig and Heidelberg. 1860.

\section{TARDIGRADA.}

Very little is known with reference to the development of the Tardigrada. A complete and regular segmentation (von Siebold, Kaufmann, No. 54I) is followed by the appearance of a groove on the ventral side indicating a ventral flexure. At about the time of the appearance of the groove the cells become divided into an epiblastic investing layer and a central hypoblastic mass.

The armature of the pharynx is formed very early at the anterior extremity, and the limbs arise in succession from before backwards.

The above imperfect details throw no light on the systematic position of this group.

\section{Tardigrada.}

(541) J. Kaufmann. "Ueber die Entwicklung u. systematische Stellung d. Tardigraden." Zeit.f. wiss. Zool., Bd. III. $18_{5}$ I.

\section{Summary of Arthropodan Development.}

The numerous characters common to the whole of the Arthropoda led naturalists to unite them in a common phylum, but the later researches on the genealogy of the Tracheata and Crustacea tend to throw doubts on this conclusion, while there is not as yet sufficient evidence to assign with certainty a definite position in either of these classes to the smaller groups described in the present chapter. There seems to be but little 
doubt that the Tracheata are descended from a terrestrial Annelidan type related to Peripatus. The affinities of Peripatus to the Tracheata are, as pointed out in a previous chapter (p. 386), very clear, while at the same time it is not possible to regard Peripatus simply as a degraded Tracheate, owing to the fact that it is provided with such distinctly Annelidan organs as nephridia, and that its geographical distribution shews it to be a very ancient form.

The Crustacea on the other hand are clearly descended from a Phyllopod-like ancestor, which can be in no way related to Peripatus.

The somewhat unexpected conclusion that the Arthropoda have a double phylum is on the whole borne out by the anatomy of the two groups. Without attempting to prove this in detail, it may be pointed out that the Crustacean appendages are typically biramous, while those of the Tracheata are never at any stage of development biramous ${ }^{1}$; and the similarity between the appendages of some of the higher Crustacea and those of many Tracheata is an adaptive one, and could in no case be used as an argument for the affinity of the two groups.

The similarity of many organs is to be explained by both groups being descendants of Annelidan ancestors. The similarity of the compound eye in the two groups cannot however be explained in this way, and is one of the greatest difficulties of the above view. It is moreover remarkable that the eye of Peripatus $^{2}$ is formed on a different type to either the single or compound eyes of most Arthropoda.

The conclusion that the Crustacea and Tracheata belong to two distinct phyla is confirmed by a consideration of their development. They have no doubt in common a centrolecithal segmentation, but, as already insisted on, the segmentation is no safe guide to the affinities.

In the Tracheata the archenteron is never, so far as we know, formed by an invagination ${ }^{3}$, while in Crustacea the

1 The biflagellate antennæ of Pauropus amongst the Myriapods can hardly be considered as constituting an exception to this rule.

2 I hope to shew this in a paper I am preparing on the anatomy of Peripatus.

${ }^{3}$ Stecker's description of an invagination in the Chilognatha cannot be accepted without further confirmation; vide p. $3^{88}$. 
evidence is in favour of such an invagination being the usual, and, without doubt, the primitive, mode of origin.

The mesoblast in the Tracheata is formed in connection with a median thickening of the ventral plate. The unpaired plate of mesoblast so formed becomes divided into two bands, one on each side of the middle line.

In both Spiders and Myriopods, and probably Insects, the two plates of mesoblast are subsequently divided into somites, the lumen of which is continued into the limbs.

In Crustacea the mesoblast usually originates from the walls of the invagination, which gives rise to the mesenteron.

It does not become divided into two distinct bands, but forms a layer of scattered cells between the epiblast and hypoblast, and does not usually break up into somites; and though somites are stated in some cases to be found they do not resemble those in the Tracheata.

The proctodæum is usually formed in Crustacea before and rarely later ${ }^{1}$ than the stomodæum. The reverse is true for the Tracheata. In Crustacea the proctodæum and stomodæum, especially the former, are very long, and usually give rise to the greater part of the alimentary tract, while the mesenteron is usually short.

In the Tracheata the mesenteron is always considerable, and the proctodæum is always short. The derivation of the Malpighian bodies from the proctodæum is common to most Tracheata. Such diverticula of the proctodæum are not found in Crustacea.

1 This is stated to be the case in Moina (Grobben). 


\section{CHAPTER XX.}

\section{ECHINODERMATA ${ }^{1}$.}

THE development of the Echinodermata naturally falls into two sections:-

(I) The development of the germinal layers and of the systems of organs; (2) the development of the larval appendages and the metamorphosis.

The Development of the Germinal Layers and of the Systoms
of Organs.

The development of the systems of organs presents no very important variations within the limits of the group.

Holothuroidea. The Holothurians have been most fully studied (Selenka, No.563), and may be conveniently taken as type.

The segmentation is nearly regular, though towards its close, and in some instances still earlier, a difference becomes apparent between the upper and the lower poles.

At the close of segmentation (fig. 247 A) the egg has a nearly spherical form, and is constituted of a single layer of columnar cells enclosing a small segmentation cavity. The lower pole is slightly thickened, and the egg rotates by means of fine cilia.

An invagination now makes its appearance at the lower pole (fig. $247 \mathrm{~B}$ ), and simultaneously there become budded off from the cells undergoing the invagination amœboid cells, which

1 The following classification of the Echinodermata is employed in this chapter.
I. Holothuroidea.
IV. Echinoidea.
II. Asteroidea.
V. Crinoidea.

III. Ophiuroidea. 
eventually form the muscular system and the connective tissue. These cells very probably have a bilaterally symmetrical origin. This stage represents the gastrula stage which is common to all Echinoderms. The invaginated sack is the archenteron. As it grows larger one side of the embryo becomes flattened, and the other more convex. On the flattened side a fresh invagination

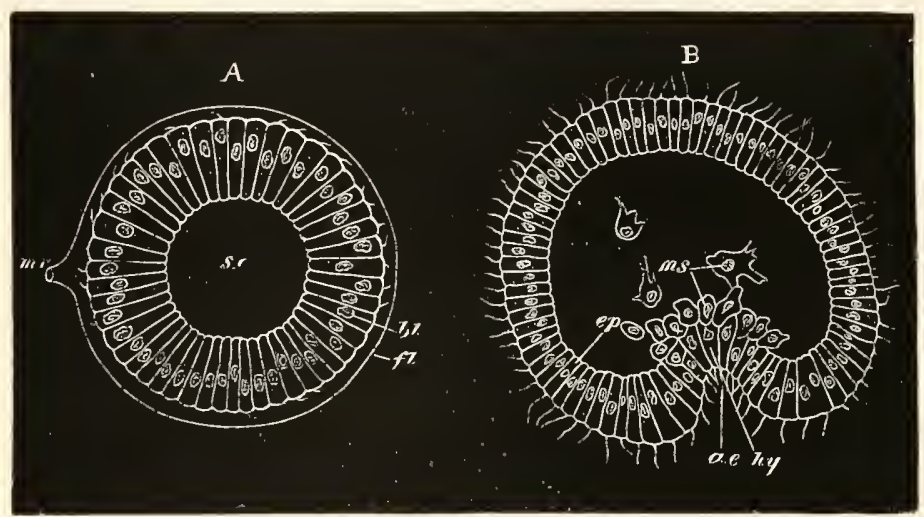

Fig. 247. Two stages in the development of Holothuria tubulosa VIEWED IN OPTICAL SECTION. (After Selenka.)

A. Blastosphere stage at the close of segmentation. B. Gastrula stage.

$m r$. micropyle; $f l$. chorion; s.c. segmentation cavity; $b l$. blastoderm; ep. epiblast ; hy. hypoblast; ms. amœboid cells derived from hypoblast; a.e. archenteron.

arises, the opening of which forms the permanent mouth, the opening of the first invagination remaining as the permanent anus (fig. $248 \mathrm{~A}$ ).

These changes give us the means of attaching definite names to the various parts of the embryo. It deserves to be noted in the first place that the embryo has assumed a distinctly bilateral form. There is present a more or less concave surface extending from the mouth to near the anus, which will be spoken of as the ventral surface. The anus is situated at the posterior extremity. The convex surface opposite the ventral surface forms the dorsal surface, which terminates anteriorly in a rounded præ-oral prominence.

It will be noticed in fig. $248 \mathrm{~A}$ that in addition to the primitive anal invagination there is present a vesicle (v.p.). This vesicle is directly formed by a constriction of the primitive

B. II. 
archenteron (fig. $249 V p v$.), and is called by Selenka the vasoperitoneal vesicle. It gives origin to the epithelioid lining of the body cavity and water-vascular system of the adult ${ }^{1}$. In the parts now developed we have the rudiments of all the adult organs.

The mouth and anal involutions (after the separation of the vaso-peritoneal vesicle) meet and unite, a constriction indicating their point of junction (fig. $248 \mathrm{~B}$ ). Eventually the former gives

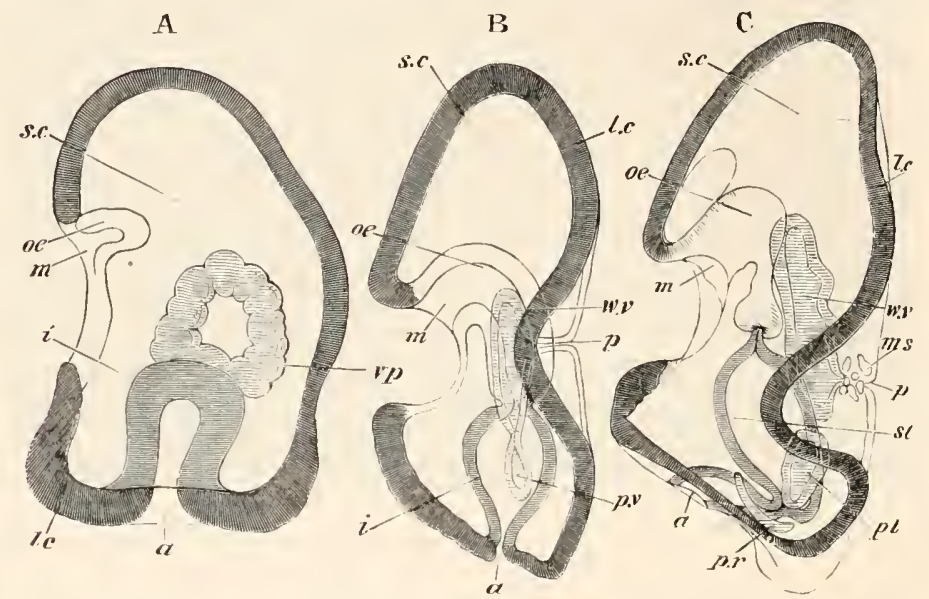

Fig. 24 8. Three stages in the development of Holothuria tubulosa Viewed from the side in optical section. (After Selenka.)

$m$. mouth ; oe. osophagus; st. stomach; $i$. intestine; $a$. anus; l.c. longitudinal ciliated band; v.p. vaso-peritoneal vesicle; $p . v$. peritoneal vesicle; $p . r$. right peritoneal vesicle; $p l$. left peritoneal vesicle; $w . \tau$. water-vascular vesicle; $p$. dorsal pore of water-vascular system; ms. muscle cells.

rise to the mouth and osophagus, and the latter to the remainder of the alimentary canal ${ }^{2}$.

The vaso-peritoneal vesicle undergoes a series of remarkable changes. After its separation from the archenteron it takes up a position on the left side of this, elongates in an anteroposterior direction, and from about its middle sends a narrow diverticulum towards the dorsal surface of the body, where an

1 The origin of the vaso-peritoneal vesicle is not quite the same in all the species. In Holothuria tubulosa it is separated from the creal end of the archenteron; the remainder of which then grows towards the oral invagination. In Cucumaria the archenteron forks (fig. 249); and one fork forms the vaso-peritoneal vesicle, and the other the major part of the mesenteron.

2 There appears to be some uncertainty as to how much of the larval œsophagus is derived from the stomodæal invagination. 
opening to the exterior becomes formed (fig. $248 \mathrm{~B}$, p.). The diverticulum becomes the madreporic canal, and the opening the dorsal pore.

The vaso-peritoneal vesicle next divides into two, an anterior vesicle (fig. $248 \mathrm{~B}, w . v$ ), from which is derived the epithelium of the water-vascular system, and a posterior (fig. $\left.248 \mathrm{~B}, p . \pi^{\prime}\right)$, which gives rise to the epithelioid lining of the body cavity. The anterior vesicle (fig. $248 \mathrm{C}, w . v$ ) becomes fivelobed, takes a horseshoe-shaped form, and grows round the œsophagus (fig. $256, v \cdot v \cdot r$ ). The five lobes form the rudiments of the water-vascular prolongations into the tentacles. The remaining parts of the water-vascular system are also developed as outgrowths of the original vesicle. Five of these, alternating with the original diverticula, form the five ambulacral canals, from which diverticula are produced into the ambulacral feet; a sixth gives rise to the Polian vesicle. The remaining parts of the original vesicle form the water-vascular ring.

We must suppose that eventually the madreporic canal loses its connection with the exterior so as to hang loosely in the interior, though the steps of this process do not appear to have been made out.

The original hinder peritoneal vesicle grows rapidly, and divides into two (fig. $248 \mathrm{C}$, $p l$. and $p r$.$) , which encircle the$ two sides of the alimentary canal, and meet above and below it. The outer wall of each of them attaches itself to the skin, and the inner one to the alimentary canal and watervascular system; in both cases the walls remain separated from the adjacent parts by a layer of the amœboid cells already spoken of. The cavity of the peritoneal vesicles becomes the permanent body cavity. Where the walls of

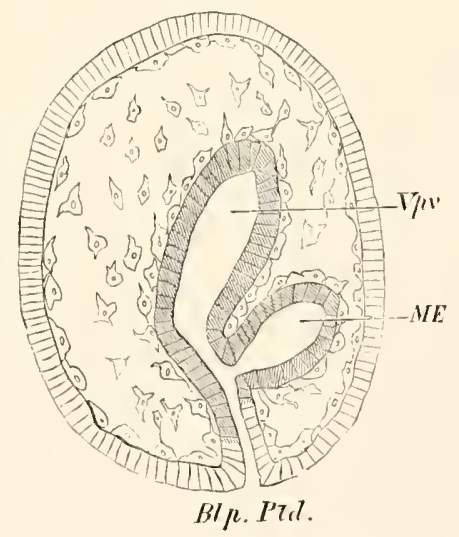

Fig, 249. LONGitudinal, SEction THROUGH AN EMBRYO OF CUCUMARIA DOLIOLUM AT THE END OF THE FOURTH DAY.

I pv. vaso-peritoneal vesicle; $M E$. mesenteron; Blp., Ptd. blastopore, proctodæum. 
the two vesicles meet on the dorsal side, a mesentery, suspending the alimentary canal and dividing the body cavity longitudinally, is often formed. In other parts the partition walls between the two sacks appear to be absorbed.

The amoboid cells, which were derived from the invaginated cells, arrange themselves as a layer round all the organs (fig. 249). Some of them remain amœboid, attach themselves to the skin, and form part of the cutis; and in these cells the calcareous spicula of the larva and adult are formed. Others form the musculature of the larval alimentary tract, while the remainder give rise to the musculature and connective tissue of the adult.

The development of the vascular system is not known, but the discovery of Kowalevsky, confirmed by Selenka, that from the walls of the watervascular system corpuscles are developed, identical with those in the bloodvessels, indicates that it probably develops in connection with the watervascular system. The observations of Hoffmann and Perrier on the communication of the two systems in the Echinoidea point to the same conclusion. Though nothing very definite is known with reference to the development of the nervous system, Metschnikoff suggests that it develops in connection with the thickened bands of epiblast which are formed by a metanorphosis of the ciliated bands of the embryo, and accompany the five radial tubes (vide p. 555). In any case its condition in the adult leaves no doubt of its being a derivative of the epiblast.

From the above description the following general conclusions may be drawn :-

(I) The blastosphere stage is followed by a gastrula stage.

(2) The gastrula opening forms the permanent anus, and the mouth is formed by a fresh invagination.

(3) The mesoblast arises entirely from the invaginated cells, but in two ways :-

(a) As scattered amœboid cells, which give origin to the muscles and connective tissue (including the cutis) of the body wall and alimentary tract.

(b) As a portion separated off from the archenteron, which gives rise both to the epithelioid lining of the body cavity, and of the water-vascular system.

(4) The œsophagus is derived from an invagination of the epiblast, and the remainder of the alimentary canal from the archenteron. 
(5) The embryonic systems of organs pass directly into those of the adult.

The development of Synapta diverges, as might be expected, to a very small extent from that of Holothuria.

Asteroidea. In Asterias the early stages of development conform to our type. There arise, however, two bilaterally symmetrical vaso-peritoneal diverticula from the archenteron. These diverticula give rise both to the lining of the body cavity and water-vascular system. With reference to the exact changes they undergo there is, however, some difference of opinion. Agassiz (543) maintains that both vesicles are concerned in the formation of the water-vascular system, while Metschnikoff (560) holds that the watervascular system is entirely derived from the anterior part of the larger left vesicle, while the right and remainder of the left vesicle form the body cavity. Metschnikoff's statements appear to be the most probable. The anterior part of the left vesicle, after separating from the posterior, grows into a five-lobed rosette (fig. $260, i$ ), and a madreporic canal $(h)$ with a dorsal pore opening to the exterior. The rosette appears not to grow round the œsophagus, as in the cases hitherto described. But the latter is stated to disappear, and a new œesophagus to be formed, which pierces the rasette, and places the old mouth in communication with the stomach. Except where the anus is absent in the adult, the larval anus probably persists.

Ophiuroidea. The early development of the Ophiuroidea is not so fully known as that of other types. Most species have a free-swimming larva, but some (Amphiura) are viviparous.

The early stages of the free-swimming larvæ have not been described, but I have myself observed in the case of Ophiothrix fragilis that the segmentation is uniform, and is followed by the normal invagination. The opening of this no doubt remains as the larval anus, and there are probably two outgrowths from this to form the vaso-peritoneal vesicles. Each of these divides into two parts, an anterior lying close to the œsophagus, and a posterior close to the stomach. The anterior on the right side aborts; that on the left side becomes the water-vascular vesicle, early opens to the exterior, and eventually grows round the oesophagus, which, as in Holothurians, becomes the œsophagus of the adult. The posterior vesicles give rise to the lining of the body cavity, but are stated by Metschnikoff to be at first solid, and only subsequently to acquire a cavity - the permanent body cavity. The anus naturally disappears, since it is absent in the adult. In the viviparous type the first stages are imperfectly known, but it appears that the blastopore vanishes before the appearance of the mouth. The development of the vaso-peritoneal bodies takes place as in the free-swimming larvæ.

Echinoidea. In the Echinoidea (Agassiz, No. 542, Selenka, No.564) there is a regular segmentation and the normal invagination (fig. 250 A). The amoboid mesoblast cells arise as two laterally placed masses, and give rise to the usual parts. The archenteron grows forward and bends towards 
the ventral side (fig. $250 \mathrm{~B}$ ). It becomes (fig. $250 \mathrm{C}$ ) divided into three chambers, of which the two hindermost $(d$ and $c)$ form the stomach and intestine; while the anterior forms the œsophagus, and gives rise to the

C

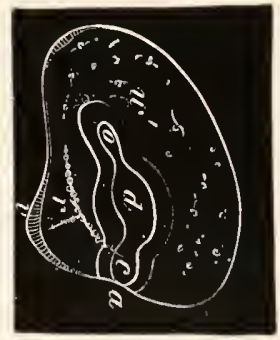

$\mathrm{B}$

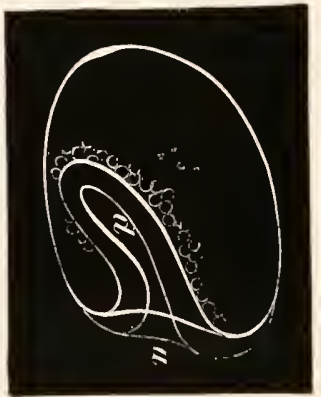

A

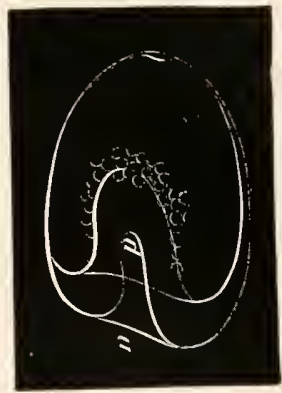

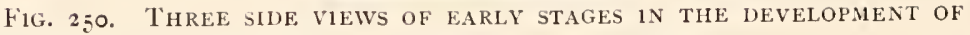
Strongylocentrus. (From Agassiz.)

$a$. anus (blastopore); $d$. stomach; o. esophagus; $c$. rectum; w. vaso-peritoneal vesicle; $v$. ciliated ridge; $r$. calcareous rod.

vaso-peritoneal vesicles. These latter appear as a pair of outgrowths (fig. 25I), but become constricted off as a single two-horned vesicle, which subsequently divides into two. The left of these is eventually divided, as in Asteroids, into a peritoneal and water-vascular sack, while the right forms the right peritoneal sack. An oral invagination on the flattened ventral side meets the mesenteron after its separation from the vaso-peritoneal vesicle. The larval anus persists, as also does the larval mouth, but owing to the manner in which the water-vascular rosette is established the larval œsophagus appears to be absorbed, and to be replaced by a fresh œsophagus.

Crinoidea. Antedon, the only Crinoid so far studied (Götte, No. 549), presents some not inconsiderable variations from the usual Echinoderm type. The blastopore is placed on the somewhat flattened side of the oval blastosphere, and not, as is usual, at the hinder end.

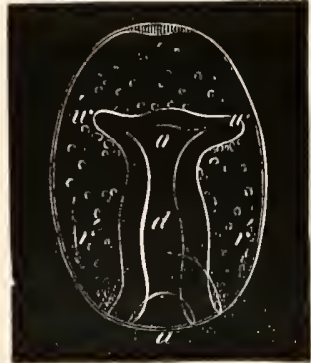

FIG. 25I. DORSO-VENTRAL VIEW OF AN EARLY LARVA OF STRONGYLOCENTRUS. (From Agassiz.)

a. anus; $d$. stomach ; 0 . œsophagus; $w$. vaso-peritoneal vesicle; $r$ calcareous rod.

The blastopore completely closes, and is not converted into the permanent anus. The archenteron gives rise to the epithelioid lining of both body cavity and water-vascular system. These parts do not, however, appear as a single or paired outgrowth from the archenteron, but as three distinct outgrowths which are not formed contemporaneously. Two of them are first 
formed, and become the future body cavity; but their lumens remain distinct. Originally appearing as lateral outgrowths, the right one assumes a dorsal position and sends a prolongation into the stalk (fig. $252 r p^{\prime}$ ), and the left one assumes first a ventral, and then an oral position (fig. $252(p)$.

The third outgrowth of the archenteron gives rise to the water-vascular vesicle. It first grows round the region of the future œsophagus and so forms the water-vascular ring. The wall of the ring then grows towards the body wall so as to divide the oral (left) peritoneal vesicle into two distinct vesicles, an anterior and a posterior, shewn in fig. $253, l p^{\prime}$ and $l p$. Before this division is completed, the water-vascular ring is produced in front into five processes - the future tentacles (fig. 252,w )-which project into the cavity of the oral vesicle $(l p)$. After the oral peritoneal space has become

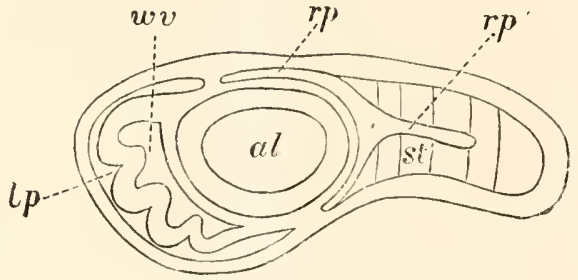

Fig. 252. LONGITUDINAL SECTION THROUGH an Antedon lakva. (From Carpenter; after Götte.)

al. mesenteron; wv. water-vascular ring ; lp. left (oral) peritoneal vesicle; rp. right peritoneal vesicle; $r p^{\prime}$. continuation of right vesicle into the stalk; st. stalk.

completely divided into two parts, the anterior dilates (fig. $253,\left(p^{\prime}\right)$ greatly, and forms a large vestibule at the anterior end of the body. This vestibule $\left(\not p^{\prime}\right)$ next acquires a communication with the mesenteron, shewn in fig. 253 at $m$. The anterior wall of this vestibule is finally broken through. By this rupture the mesenteron is placed in communication with the exterior by the opening at $m$, while at the same time the tentacles of the water-vascular ring $(t)$ project freely to the exterior. Such is Götte's account of the præ-oral body space, but, as he himself points out, it involves our believing that the lining of the diverticulum derived from the primitive alimentary vesicle becomes part of the external skin. This occurrence is so remarkable, that more evidence appears to me requisite before accepting it.

The formation of the anus occurs late. Its position appears to be the same as that of the blastopore, and is indicated by a papilla of the mesenteron attaching itself to the skin on the ventral side (fig. $253, a n$ ). It eventually becomes placed in an interradial space within the oral disc of the adult. The water-vascular ring has no direct communication with the exterior, but the place of the madreporic canal of other types appears to be taken in the larva by a single tube leading from the exterior into the body cavity, the external opening of which is placed on one of the oral plates (vide p. 57I) in the next interradial space to the right of the anus, and a corresponding diverticulum of the water-vascular ring opening into the body cavity. The line of junction between the left and right peritoneal vesicles forms in the larva a ring-like mesentery dividing the oral from the aboral part of the body 
cavity. In the adult ${ }^{1}$ the oral section of the larval body cavity becomes the ventral part of the circumvisceral division of the body cavity, and the subtentacular canals of the arms and disc; while the aboral section becomes the dorsal part of the circumvisceral division of the body cavity, the cœliac canals of the arms, and the cavity of the centro-dorsal piece. The primitive

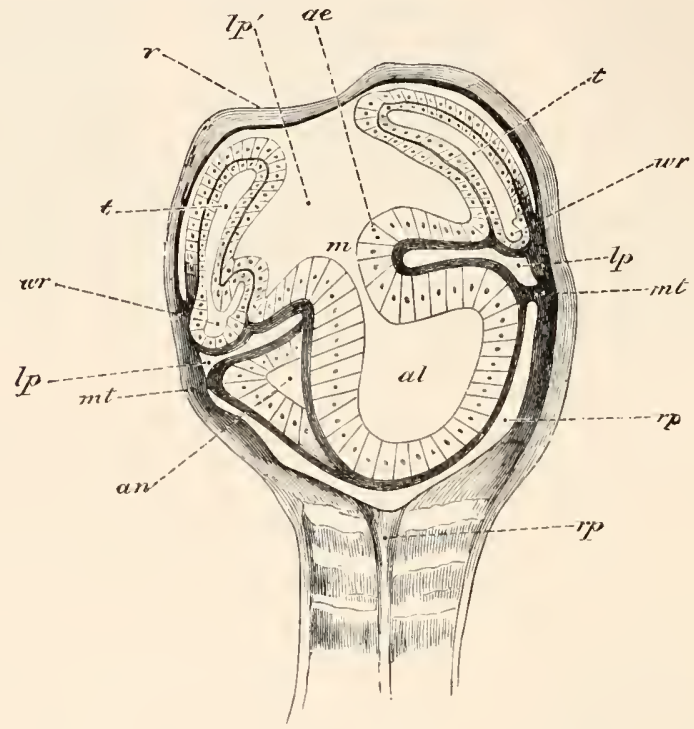

Fig. 253. Longitudinal Section through the Calyx of an advanced Pentracrinold ANTEdon larva iVITH Closed Vestibule.

(From Carpenter; after Götte.)

ae. epithelium of oral vestibule; $m$. mouth; al. mesenteron; an. rudiment of permanent anus; $l p$. posterior part of left (oral) peritoneal sack; $l p^{\prime}$. anterior part of left (oral) peritoneal sack; wr. water-vascular ring; $t$. tentacle; $m t$. mesentery; $r p$. right peritoneal sack; $r p^{\prime}$. continuation of right peritoneal sack into the stalk; $r$ roof of tentacular vestibule.

distinction between the sections of the larval body cavity becomes to a large extent obliterated, while the axial and intervisceral sections of the body cavity of the adult are late developments.

The more important points in the development indicated in the preceding pages are as follows:

(I) The blastosphere is usually elongated in the direction of the axis of invagination, but in Comatula it is elongated transversely to this axis.

1 Vide P. H. Carpenter, "On the genus Actinometra." Linnean Trans., 2nd Series, Zoology, Vol. II., Part I., I 879 . 
(2) The blastopore usually becomes the permanent anus, but it closes at the end of larval life (there being no anus in the adult) in Ophiuroids and some Asteroids, while in Comatula it closes very early, and a fresh anus is formed at the point where the blastopore was placed.

(3) The larval mouth always becomes the mouth of the adult.

(4) The archenteron always gives rise to outgrowths which form the peritoneal membrane and water-vascular systems. In Comatula there are three such outgrowths, two paired, which form the peritoneal vesicles, and one unpaired, which forms the water-vascular vesicle. In Asteroids and Ophiuroids there are two outgrowths. In Ophiuroids both of these are divided into a peritoneal and a water-vascular vesicle, but the right watervascular vesicle atrophies. In Asteroids only one water-vascular vesicle is formed, which is derived from the left peritoneal vesicle. In Echinoids and Holothuroids there is a single vaso-peritoneal vesicle.

(5) The water-vascular vesicle grows round the larval œsophagus in Holothuroids, Ophiuroids, and Comatula; in these cases the larval cesophagus is carried on into the adult. In other forms the water-vascular vesicle forms a ring which does not enclose the œsophagus (Asteroids and Echinoids); in such cases a new œesophagus is formed, which perforates this ring.

\section{Development of the larval appendages and metamorphosis.}

Holothuroidea. The young larva of Synapta, to which J. Miiller gave the name Auricularia (fig. 255), is in many respects the simplest form of Echinoderm larva. With a few exceptions the Auricularia type of larva is common to the Holothuria.

It is (fig. $254 \mathrm{~A}$ and fig. 255) bilaterally symmetrical, presenting a flattened ventral surface, and a convex dorsal one. The anus $(a n)$ is situated nearly at the hinder pole, and the mouth $(m)$ about the middle of the ventral surface. In front of the mouth is a considerable process, the præ-oral lobe. Between the mouth and anus is a space, more or less concave according to the age of the embryo, interrupted by a ciliated 
ridge a little in front of the anus. A similar ciliated ridge is present on the ventral surface of the præ-oral lobe immediately in front of the mouth. The anal and oral ridges are connected by two lateral ciliated bands, the whole forming a continuous band, which, since the mouth lies in the centre of it (fig. 255), may be regarded as a ring completely surrounding the body behind the mouth, or more naturally as a longitudinal ring.

The bilateral Auricularia is developed from a slightly elongated gastrula with an uniform covering of cilia. The gastrula becomes flattened on the oral side. At the same time the cilia become specially developed on the oral and anal ridges, and then on the remainder of the ciliated ring, while they are
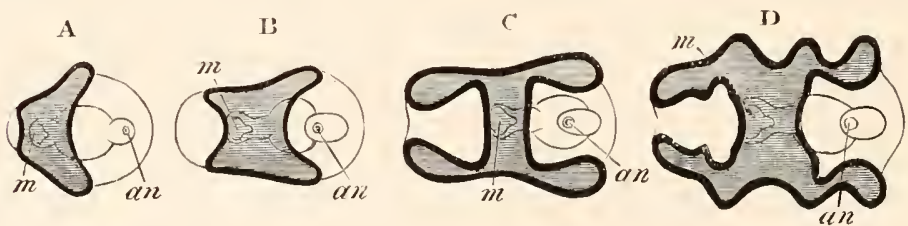

Fig. 255. DiagraMmatic Figures REPRESENTING THE EVOLUTiON OF AN Auricularia From the simplest Echinoderm larval form. (Copied from Miiller.)

The black line represents the ciliated ridge. The shaded part is the oral side of the ring, the clear part the aboral side.

m. mouth; an. anus.

simultaneously obliterated elsewhere; and so a complete Auricularia is developed. The water-vascular ring in the fully-developed larva has already considerably advanced in the growth round the œsophagus (fig. 256 wo.v.r).

Most Holothurian larvæ, in their transformation from the bilateral Auricularia form to the radial form of the adult, pass through a stage in which the cilia form a number of transverse 
rings, usually five in number, surrounding the body. The stages in this metamorphosis are shewn in figs. 256,257 , and 258.

The primitive ciliated band, at a certain stage of the metamorphosis, breaks up into a number of separate portions (fig. 256), the whole of which are placed on the ventral surface. Four of these (fig. $257 \mathrm{~A}$ and $\mathrm{B}$ ) arrange themselves in the form of an angular ring round the mouth, which at this period projects considerably. The remaining portions of the primitive band change their direction from a longitudinal one to a transverse (fig. $257 \mathrm{~B}$ ), and eventually grow into complete rings (fig. $257 \mathrm{C})$. Of these there are five. The middle one $(257 \mathrm{~B})$ is the first to develop, and is formed from the dorsal parts of the primitive ring. The two hinder rings develop next, and last of all the two anterior ones, one of

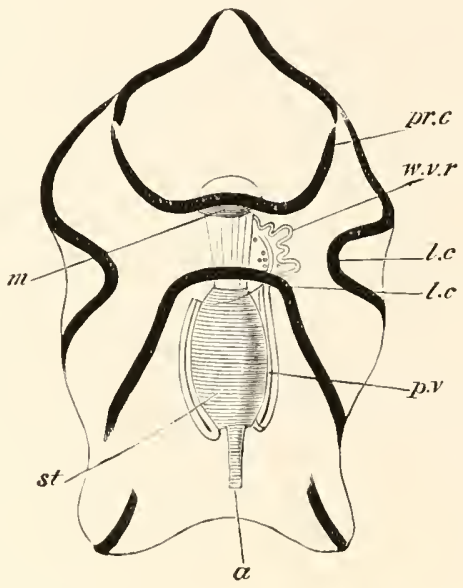

FIG. 256. FULL-GROWN LARVA OF Synapta. (After Metschnikoff.)

$m$. mouth ; st. stomach ; $a$. anus ; p.v. left division of perivisceral cavity, which is still connected with the watervascular system; w.x.r. water-vascular ring which has not yet completely encircled the osophagus; l.c. longitudinal part of ciliated band; pr.c. præ-oral part of ciliated band. which appears to be in front of the mouth (fig. $257 \mathrm{C}$ ).

The later development of the mouth, and of the ciliated ridge surrounding it, is involved in some obscurity. It appears from Metschnikoff (No. 560) that an invagination of the œsophagus takes place, carrying with it the ciliated ridge around the mouth. This ridge becomes eventually converted into the covering for the five tentacular outgrowths of the water-vascular ring (fig. 258), and possibly also forms the nervous system.

The opening of the œesophageal invagination is at first behind the foremost ciliated ring, but eventually comes to lie in front of it, and assumes a nearly terminal though slightly ventral position (fig. 258). No account has been given of the process by which this takes place, but the mouth is stated by Metschnikoff (though 
Müller differs from him on this point) to remain open throughout. The further changes in the metamorphosis are not considerable. The ciliated bands disappear, and a calcareous ring of ten pieces, five ambulacral and five interambulacral, is formed round the œsophagus. A provisional calcareous skeleton is also developed.

All the embryonic systems of organs pass in this case directly in to those of the adult.

The metamorphosis of most Holothuroidea is similar to that just described. In Cucumaria (Selenka) there is however no Auricularia stage, and the uniformly ciliated stage is succeeded by one with five transverse

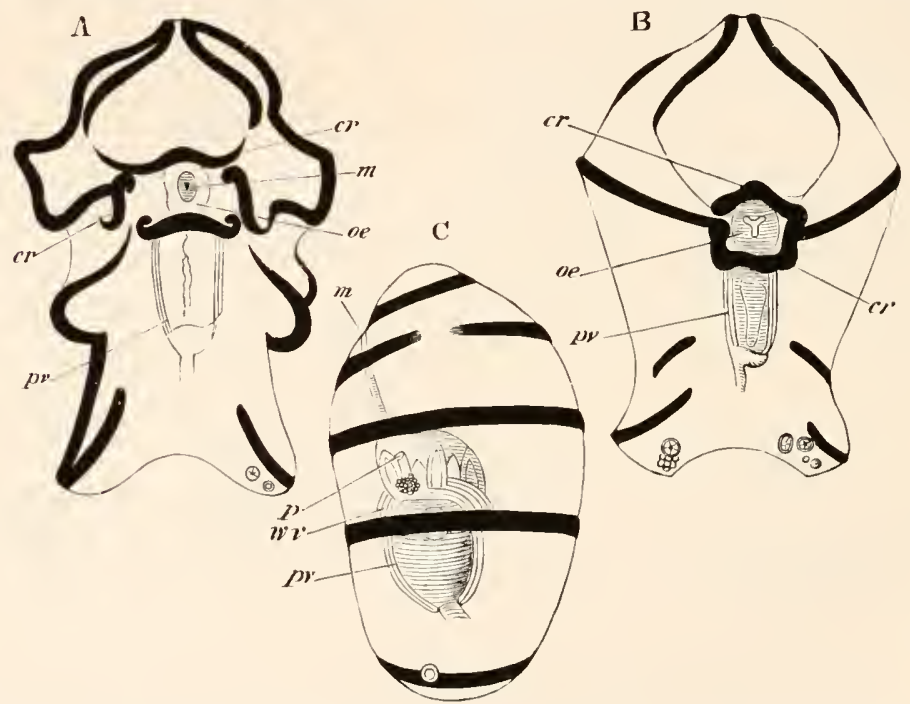

Fig. 257. Three stages in the Development Of Synapta. $\mathbf{A}$ and $\mathbf{B}$ are viewed from the ventral surface, and $\mathrm{C}$ from the side. (After Metschnikoff.)

$m$. mouth; $o e$. œsophagus; $p v$. walls of the perivisceral cavity; wr. longitudinal vessel of the water-vascular system; $p$. dorsal pore of water-vascular system; cr. ciliated ring formed round the mouth from parts of the primitive ciliated band.

bands of cilia, and a præ-oral and an anal ciliated cap. The mouth is at first situated ventrally behind the præ-oral cap of cilia, but the præ-oral cap becomes gradually absorbed, and the mouth assumes a terminal position.

In Psolinus (Kowalevsky) there is no embryonic ciliated stage, and the adult condition is attained without even a metamorphosis. There appear to 
be five plates surrounding the mouth, which are developed before any other part of the skeleton, and are regarded by $\mathrm{P}$. H. Carpenter (No. 548) as equivalent to the five oral plates of the Crinoidea. The larval condition with ciliated bands is often spoken of as the pupa stage, and during it the larvæ of Holothurians proper use their embryonic tube feet to creep about.

Asteroidea. The commonest and most thoroughly investigated form of Asteroid larva is a free swimming form known as Bipinnaria.

This form in passing from the spherical to the bilateral condition passes through at first almost identical changes to the Auricularian larva. The cilia become at an early period confined to an oral and anal ridge.

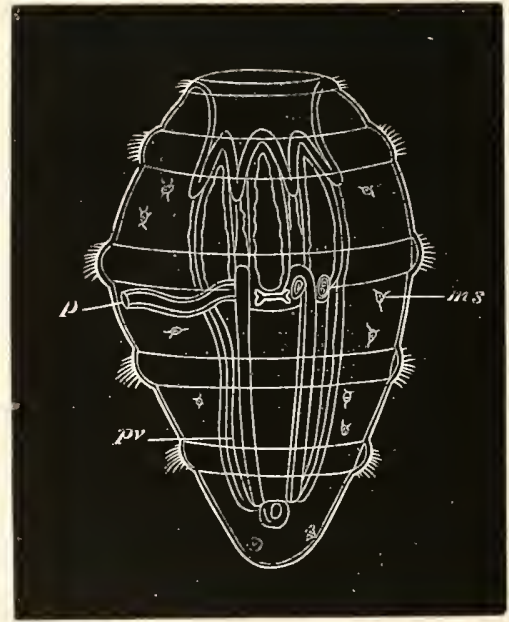

F1G. 2,8. A LATE STAGE 1N THE DEVELOPMENT OF SYNAPTA. (After Metschnikoff.)

The figure shews the vestibular cavity with retracted tentacles; the ciliated bands; the water-vascular system, etc.

$p$. dorsal pore of water-vascular system; $p v$. walls of perivisceral cavity; $m s$. amceboid cells.

The anal ridge gradually extends dorsalwards, and finally forms a complete longitudinal post-oral ring (fig. $259 \mathrm{~A}$ ); the oral ridge also extends dorsalwards, and forms a closed præ-oral ring (fig. $259 \mathrm{~A}$ ), the space within which is left unshaded in my figure.

The presence of two rings instead of one distinguishes the Bipinnaria from the Auricularia. The two larvæ are shewn side by side in fig. 254 , and it is obvious that the two bands of the Bipinnaria are (as pointed out by Gegenbaur) equivalent to the single band of the Auricularia divided into two. Ontologically, however, the two bands of Bipinnaria do not appear to arise from the division of a single band.

As the Bipinnaria grows older, a series of arms grows out along lines of the two ciliated bands (fig. 259 C) and, in many cases, three special arms are formed, not connected with the ciliated bands, and covered with warts. These latter arms are 
known as brachiolar arms, and the larvæ provided with them as Brachiolaria (fig. 259 D).

As a rule the following arms can be distinguished (fig. $259 \mathrm{C}$ and D), on the hinder ring (Agassiz' nomenclature) a median anal pair, a dorsal anal pair, and a ventral anal pair, a dorsal oral pair, and an unpaired anterior dorsal arm ; on the præ-oral ring a ventral oral pair, and sometimes (Müller) an unpaired anterior ventral arm.

The three brachiolar arms arise as processes from the base of the unpaired dorsal arm, and the two ventral oral arms. The extent of the development of the arms varies with the species.
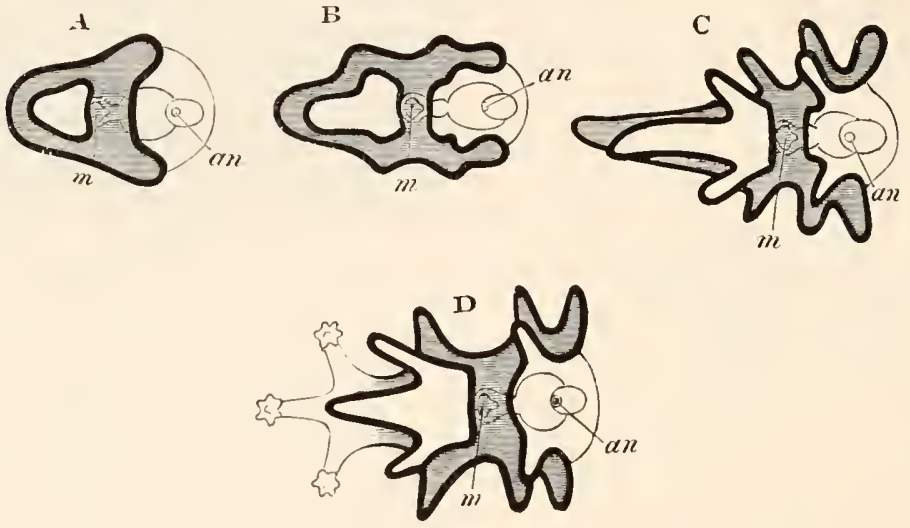

Fig. 259. Diagrammatic representation of Various forms of Asteroid larva. A, B, C, Bipinnaria; D, Brachiolaria. (Copied from Müller.)

The black lines represent the ciliated bands; and the shading the space between the pre-oral and the post-oral bands.

$m$. mouth; an. anus.

The changes by which the Bipinnaria or Brachiolaria becomes converted into the adult starfish are very much more complicated than those which take place in Holothurians. For an accurate knowledge of them we are largely indebted to Alex. Agassiz (No. 54:3). The development of the starfish takes place entirely at the posterior end of the larva close to the stomach.

On the right and dorsal side of the stomach, and externally to the right peritoneal space, are formed five radially situated calcareous rods arranged in the form of a somewhat irregular pentagon. The surface on which they are deposited has a spiral form, and constitutes together with its calcareous rods, the 
abactinal or dorsal surface of the future starfish. Close to its dorsal, i.e. embryonic dorsal, edge lies the dorsal pore of the water-vascular system (madreporic canal), and close to its ventral edge the anus. On the left and ventral side of the stomach is placed the water-vascular rosette, the development of which was described on p. 549. It is situated on the actinal or ventral surface of the future starfish, and is related to the left peritoneal vesicle.

Metschnikoff (No. 560) and Agassiz (No. 543) differ slightly as to the constitution of the water-vascular rosette. The former describes and figures it as a completely closed rosette, the latter states that 'it does not form a completely closed curve but is always open, forming a sort of twisted erescent-shaped arc.'

The water-vascular rosette is provided with five lobes, corresponding to which are folds in the larval skin, and each lobe corresponds to one of the calcareous plates developed on the abactinal disc. The plane of the actinal surface at first meets that of the abactinal at an acute or nearly right angle. The two surfaces are separated by the whole width of the stomach. The general appearance of the larva from the ventral surface after the development of the water-vascular rosette $(i)$ and abactinal $\operatorname{disc}(A)$ is shewn in fig. 260 .

As development proceeds the abactinal surface becomes a firm and definite disc, owing to the growth of the original calcareous spicules into more or less definite plates, and to the development of five fresh plates nearer the centre of the disc and interradial in position. Still later a central calcareous plate appears on the abactinal surface, which is thus formed of a central plate, surrounded by a ring of five interradial plates, and then again by a ring of five radial plates. The abactinal disc now also grows out into five short processes, separated by five shallow notches. These processes are the rudiments of the five arms, and each of them corresponds to one of the lobes of the water-vascular rosette. A calcareous deposit is formed round the opening of the water-vascular canal, which becomes the madreporic tubercle'. At about this stage the absorption of the larval appendages takes place. The whole anterior part of the

1 The exact position of the madreporic tubercle in relation to the abactinal plates does not seem to have been made out. It might have been anticipated that it would be placed in one of the primary interradial plates, but this does not seem to be the case. The position of the anus is also obscure. 
larva with the great præ-oral lobe has hitherto remained unchanged, but now it contracts and undergoes absorption, and becomes completely withdrawn into the disc of the future starfish. The larval mouth is transported into the centre of the actinal disc. In the larvæ observed by Agassiz and Metschnikoff nothing was cast off, but the whole absorbed.

According to Müller and Koren and Danielssen this is not the case in the larva observed by them, but part of the larva is thrown off, and lives for some time independently.

After the absorption of the larval appendages the actinal and abactinal surfaces of the young starfish approach each other, owing to the flattening of the stomach; at the same time they lose their spiral form, and become flat discs, which fit each other. Each of the lobes of the rosette of the watervascular system becomes one of the radial water-vascular canals. It first becomes five-lobed, each lobe forming a rudimentary tube foot, and on each side of the middle lobe two fresh ones

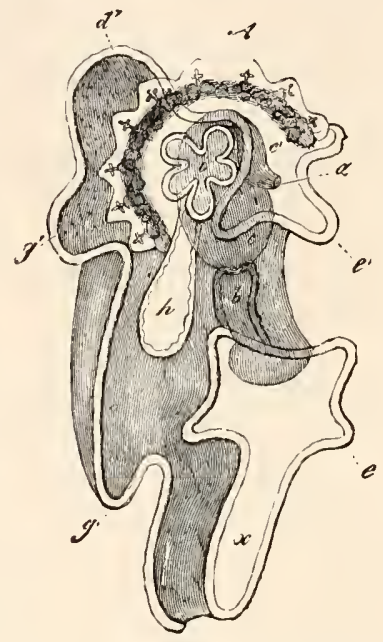

Fig. 260. BipinNaria larva of an Asteroin. (From Gegenbaur; after Miiller.)

$b$. mouth; $a$. anus; h. madreporic canal; $i$. ambulacral rosette; c. stomach; $d . g . c$. etc. arms of Bipinnaria; $A$. abactinal disc of young Asteroid. next spring out, and so on in succession. The terminal median lobe forms the tentacle at the end of the arm, and the cye is developed at its base. The growth of the water-vascular canals keeps pace with that of the arms, and the tube feet become supported at their base by an ingrowth of calcareous matter. The whole of the calcareous skeleton of the larva passes directly into that of the adult, and spines are very soon formed on the plates of the abactinal surface. The original radial plates, together with the spines which they have, are gradually pushed outwards with the growth of the arms by the continual addition of fresh rows of spines between the terminal plate and the plate next to it. It thus comes about that the original radial plates persist at the end of the arms, in connection with the unpaired 
tentacles which form the apex of the radial water-vascular tubes.

It has already been mentioned that according to Metschnikoff (No. 560) a new œesophagus is formed which perforates the water-vascular ring, and connects the original stomach with the original mouth. Agassiz (No. 543) maintains that the water-vascular ring grows round the primitive œesophagus. He says-" During the shrinking of the larva the long œesophagus becomes "shortened and contracted, bringing the opening of the mouth of the larva "to the level of the opening of the osophagus, which eventually becomes "the true mouth of the starfish." The primitive anus is believed by Metschnikoff to disappear, but by Agassiz to remain. This discrepancy very possibly depends upon these investigators having worked at different species.

There is no doubt that the whole of the larval organs, with the possible exception of the œsophagus, and anus (where absent in the adult), pass directly into the corresponding organs of the starfish-and that the præ-oral part of the body and arms of the larva are absorbed and not cast off.

In addition to the Bipinnarian type of Asteroid larva a series of other forms has been described by Müller (No. 561), Sars, Koren, and Danielssen (No. 554) and other investigators, which are however very imperfectly known. The best-known form is one first of all discovered by Sars in Echinaster Sarsii, and the more or less similar larvæ subsequently investigated by Agassiz, Busch, Müller, Wyville Thomson, etc. of another species of Echinaster and of Asteracanthion. These larvæ on leaving the egg have an oval form, and are uniformly covered by cilia. Four processes (or in Agassiz' type one process) grow out from the body; by these the larvæ fix themselves. In the case of Echinaster the larvæ are fixed in the ventral concavity of the disc of the mother, between the five arms, where a temporary brood-pouch is established. The main part of the body is converted directly into the disc of the young starfish, while the four processes come to spring from the ventral surface, and are attached to the water-vascular ring. Eventually they atrophy completely. Of the internal structure but little is known; till the permanent mouth is formed, after the development of the young starfish is pretty well advanced, the stomach has no communication with the exterior.

A second abnormal type of development is presented by the embryo of Pteraster miliaris, as described by Koren and Danielssen ${ }^{1}$. The larvæ to the number of eight to twenty develop in a peculiar pouch on the dorsal surface of the body. The early stages are not known, but in the later ones the whole body assumes a pentagonal appearance with a mouth at one edge

1 The following statements are taken from the abstract in Bronn's Thierreichs.

B. II. 
of the disc. At a later stage the anus is formed on the dorsal side of an arm opposite the mouth. The stomach is surrounded by a water-vascular ring, from which the madreporic canal passes to the dorsal surface, but does not open. At a later stage the embryonic mouth and anus vanish, to be replaced by a permanent mouth and anus in the normal positions.

A third, and in some respects very curious, form is a worm like larva of Müller, which is without bands of cilia. The dorsal surface of the youngest larva is divided by transverse constrictions into five segments. On the under side of the first of these is a five-lobed disc, each lobe being provided with a pair of tube feet.

At a later period only three segments are visible on the dorsal surface, but the ventral surface has assumed a pentagonal aspect. The later stages are not known.

Ophiuroidea. The full-grown larva of the Ophiuroids is known as a Pluteus. It commences with the usual more or less spherical form; from this it passes to a form closely resembling

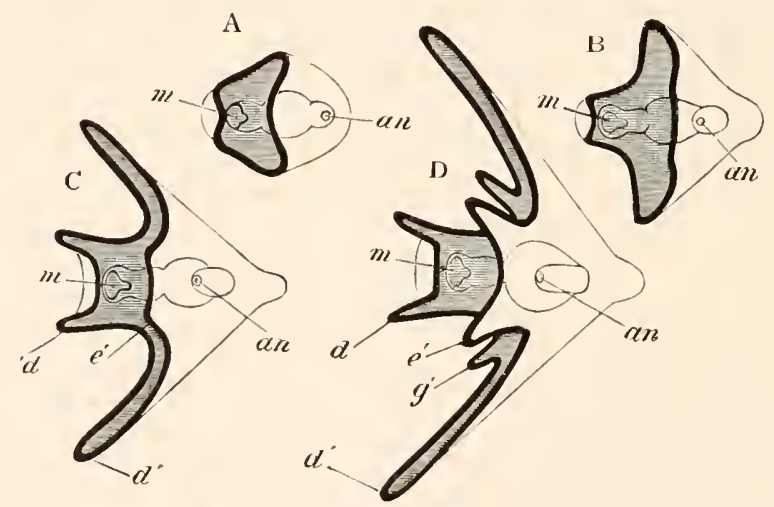

Fig. 26I. Diagramiatic Figures Shewing the evolution of an OphiUroid Pluteus from a simple Echinoderm larva. (Copied from Müller.) The calcareous skeleton is not represented.

$m$. mouth; $a n$. anus; $d$. anterior arms; $d^{\prime}$. lateral arms; $e^{\prime}$. posterior arms; $g^{\prime}$. anterolateral arms.

that of Auricularia with a rounded dorsal surface, and a flattened ventral one. Soon however it becomes distinguished by the growth of a post-anal lobe and the absence of a præ-oral lobe (fig. 26I B). The post-anal lobe forms the somewhat rounded apex of the body. In front of the mouth, and between the mouth and anus, arise the anal and oral ciliated ridges, which soon become continued into a single longitudinal ciliated ring. At the same time the body becomes prolonged into a series of 
processes along the ciliated band, which is continued to the extremity of each. The primitive ciliated ring never becomes broken up into two or more rings. A ciliated crown is usually developed at the extremity of the post-anal lobe. The arms are arranged in the form of a ring surrounding the mouth, and are all directed forwards.

The first arms to appear are two lateral ones, which usually remain the most conspicuous (fig. 26 $\mathrm{I} \mathrm{B}$ and $\mathrm{C}, d^{\prime}$ ). Next arises a pair on the sides of the mouth, which may be called the mouth or anterior arms $(\mathrm{C}, d)$. A pair ventral to and behind the lateral arms is then formed, constituting the posterior arms $\left(\mathrm{D}, e^{\prime}\right)$, and finally a pair between the lateral arms and the anterior, constituting the anterolateral arms $\left(\mathrm{D}, g^{\prime}\right)$.

The concave area between the arms forms the greater part of the ventral surface of the body. Even before the appearance of any of the arms, and before the formation of the mouth, two calcareous rods are formed, which meet behind at the apex of the post-anal lobe, and are continued as a central support into each of the arms as they are successively formed. These rods are shewn at their full development in fig. 262. The important points which distinguish a Pluteus larva from the Auricularia or Bipinnaria are the following :

(I) The presence of the postanal lobe at the hind end of the body. (2) The slight development of a præ-oral lobe. (3) The provisional calcareous skeleton in the larval arms.

Great variations are presented in the development of the arms and provisional skeleton. The presence of lateral arms is however a distinctive characteristic of the Ophiuroid Pluteus. The other arms may be quite absent, but the lateral arms never.

The formation of the permanent Ophiuroid takes place in

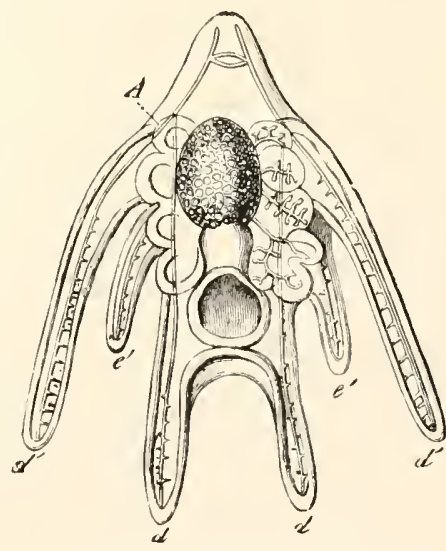

Fig. 262. PLUTEUS LARVA OF AN OpIIURoID. (From Gegenbaur; after Miiller.)

A. rudiment of young Ophiuroid; $d^{\prime}$. lateral arms; $d$. anterior arms; $e$. posterior arms. much the same way as in the Asteroidea. 
There is formed (fig. 262) on the right and dorsal side of stomach the abactinal disc supported by calcareous plates, at first only five in number and radial in position ${ }^{1}$. The disc is at first not symmetrical, but becomes so at the time of the resorption of the larval arms. It grows out into five processes - the five future rays. The original five radial plates remain as the terminal segments of the adult rays, and new plates are always added between the ultimate and penultimate plate (Müller), though it is probable that in the later stages fresh plates are added in the disc.

The ventral surface of the permanent Ophiuroid is formed by the concave surface between the mouth and anus. Between this and the stomach is
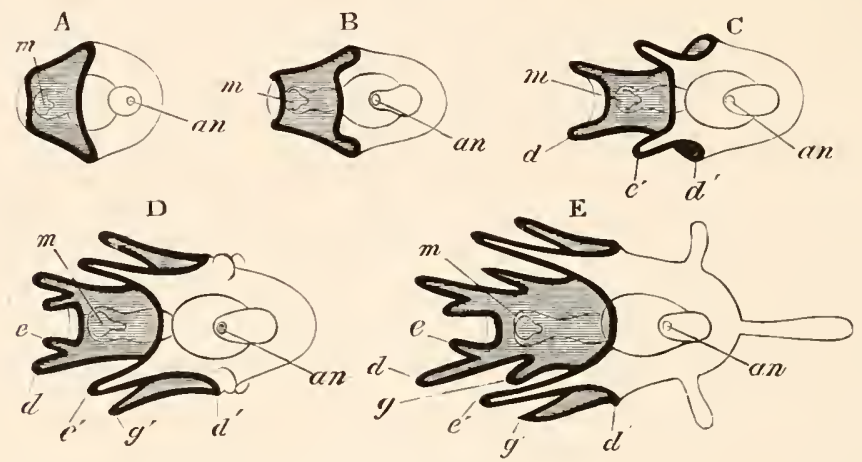

Fig. 263. Diagramiatic figures sheiving the evolution of Echinoid Plutei. (Copied from Miiller.) The calcareous skeleton is not represented. E. Pluteus of Spatangus.

$m$. mouth; an. anus; $d$. anterior arms; $d^{\prime}$. point where lateral arms arise in the Ophiuroid Pluteus; $e$. anterointernal arms; $e^{\prime}$. posterior arms; $g^{\prime}$. anterolateral arms; g. anteroexternal arms.

situated the water-vascular ring. It is at first not closed, but is horseshoeshaped, with five blind appendages (fig. 262). It eventually grows round the cesophagus, which, together with the larval mouth, is retained in the adult. The five blind appendages become themselves lobed in the same way as in Asterias, and grow out along the five arms of the disc and become the radial canals and tentacles. All these parts of the water-vascular system are of course covered by skin, and probably also surrounded by mesoblast cells, in which at a later period the calcareous plates which lie ventral to the radial canal are formed. The larval anus disappears. As long as the larval appendages are not absorbed the ventral and dorsal discs of the permanent Ophiuroid fit as little as in the case of the Brachiolaria, but at a certain period the appendages are absorbed. The calcareous rods of the larval arms

1 Whether interradial plates are developed as in Asterias is not clear. They seem to be found in Ophiopholis bellis, Agassiz, but have not been recognised in other forms (vide Carpenter, No. 548, p. 369). 
break up, the arms and anal lobe become absorbed, and the dorsal and ventral discs, with the intervening stomach and other organs, are alone left. After this the discs fit together, and there is thus formed a complete young Ophiuroid.

The whole of the internal organs of the larva (except the anus), including the mouth, œsophagus, the body cavity, etc. are carried on directly into the adult.

The larval skeleton is, as above stated, absorbed.

The viviparous larva of Amphiura squamata does not differ very greatly from the larvæ with very imperfect arms. It does not develop a distinct ciliated band, and the provisional skeleton is very imperfect. The absence of these parts, as well as of the anus, mentioned on p. 549, may probably be correlated with the viviparous habits of the larva. With reference to the passage of this larva into the adult there is practically nothing to add to what has just been stated. When the development of the adult is fairly advanced the part of the body with the provisional skeleton forms an elongated rod-like process attached to the developing disc. It becomes eventually absorbed.

Echinoidea. The Echinus larva (fig. 263) has a Pluteus form like that of the Ophiuroids, and in most points, such as the

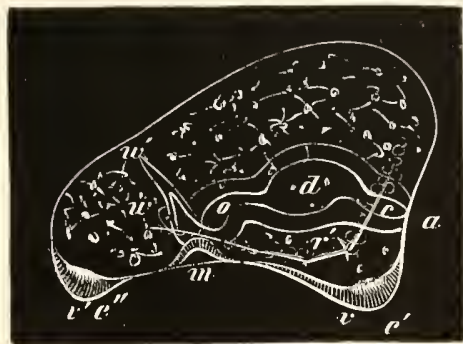

$A$

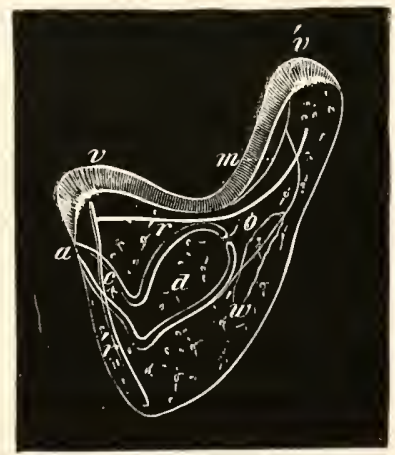

L

Fig. 264. Two larve of Strongylocentrus. (From Agassiz.)

$m$. mouth; $a$. anus; $o$. œsophagus; $d$. stomach ; $c$. intestine; $v^{\prime}$. and $v$. ciliated ridges ; $w$. water-vascular tube; $r$. calcareous rods.

presence of the anal lobe, the ciliated band, the provisional skeleton, etc., develops in the same manner. The chief difference between the two Pluteus forms concerns the development of the lateral arms. These, which form the most prominent arms in the Ophiuroid Pluteus, are entirely absent in the Echinoid 
Pluteus, which accordingly has, as a rule, a much narrower form than the Ophiuroid Pluteus.

A pair of ciliated epaulettes on each side of and behind the ciliated ring is very characteristic of some Echinoid larvæ. They are originally developed from the ciliated ring (fig. $266 \mathrm{~A}$

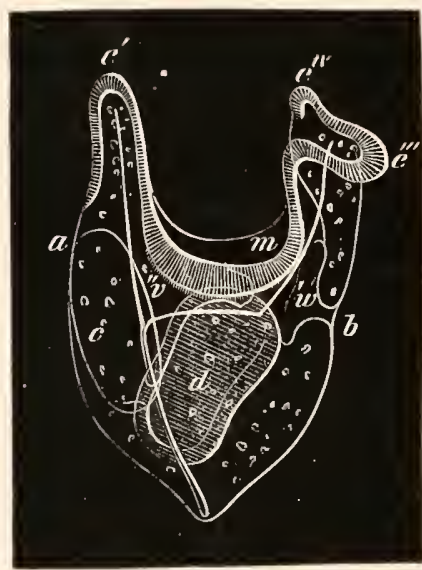

A

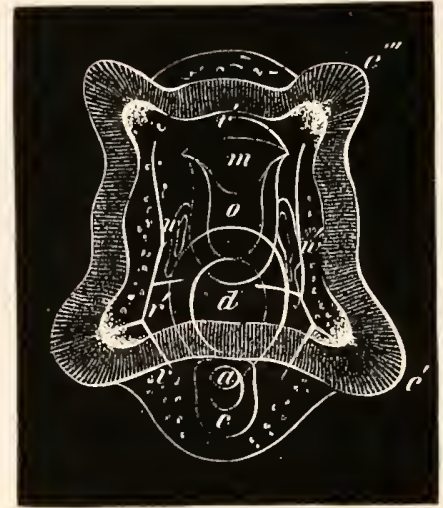

B

Fig. 265. LATERAL AND VEnTRAL VIEW OF A LARVA OF StrongYlocentrus. (From Agassiz.) General references as in fig. $26_{4}$.

$b$. dorsal opening of madreporic canal; $e^{\prime}$. posterior arms; $e^{\prime \prime \prime}$. anterior arms; $e^{\mathrm{IV}}$. anterointernal arms.

and $\left.\mathrm{B}, v^{\prime \prime}\right)$. The presence of three processes from the anal lobe supported by calcareous rods is characteristic of the Spatangoid Pluteus (fig. $263 \mathrm{E}$ ).

The first two pairs of arms to develop, employing the same names as in Ophiuroids, are the anterior attached to the oral process (fig. $263 \mathrm{C}, d$ ) and the posterior pair $\left(e^{\prime}\right)$. A pair of anterolateral arms next becomes developed $\left(g^{\prime}\right)$. A fourth pair (not represented in Ophiuroids) appears on the inner side of the anterior pair forming an anterointernal pair (e), and in the Spatangoid Pluteus a fifth pair may be added on the external side of the anterior pair forming an anteroexternal pair $(g)$.

Each of the first-formed paired calcareous rods is composed of three processes, two of which extend into the anterior and posterior arms; and the third and strongest passes into the anal lobe, and there meets its fellow (fig. 265). A transverse bar in front of the arms joins the rods of the two sides meeting them at the point where the three processes diverge. The process in the anterolateral arm (fig. $266 \mathrm{~B}$ ) is at first independent of this system of rods, but eventually unites with it. Although our knowledge of 
the Pluteus types in the different groups is not sufficient to generalise with great confidence, a few points seem to have beell fairly determined ${ }^{1}$. The Plutei of Strongylocentrus (figs. 266 and 267) and Echinus have eight arms and four ciliated epaulettes. The only Cidaris-like form, the Pluteus of which is known, is Arbacia: it presents certain peculiarities. The anal lobe derelops a pair of posterior (auricular) appendages, and the ciliated ring, besides growing out into the normal eight appendages, has a pair of short blunt anterior and posterior lobes. An extra pair of non-ciliated accessory mouth arms appears also to be developed. Ciliated epaulettes are not present. So far as is known the Clypeastroid larva is chiefly characterized by the round form of the anal lobe. The calcareous rods are latticed. In the Pluteus of Spatangoids there are (fig. 263) five pairs of arms around the mouth pointing forwards, and three arms developed from the anal lobe pointing backwards. One of these is unpaired, and starts from the apex of the anal lobe. All the arms have calcareous rods which, in the case of the posterior pair, the anterolateral pair, and the unpaired arm of the anal lobe, are latticed. Ciliated epaulettes are not developed.

Viviparous larvæ of Echinoids have been described by Agassiz $^{2}$.

The development of the permanent Echinus has been chiefly worked out by Agassiz and Metschnikoff.

In the Pluteus of Echinus lividus the first indication of the adult arises, when three pairs of arms are already developed, as an invagination of the skin on the left side, between the posterior and anterolateral arms, the bottom of which is placed close to the water-vascular vesicle (fig. $266 \mathrm{~B}, w w^{\prime}$ ). The base of this invagination becomes very thick, and forms the ventral disc of the future Echinus. The parts connecting this disc with the external skin become however thin, and, on the narrowing of the external aperture of invagination and the growth of the thickened disc, constitute a covering for the disc, called by Metschnikoff the amnion. The water-vascular vesicle adjoining this disc grows out into five processes, forming as many tube feet, which cause the surface of the involuted disc to be produced into the same number of processes. The external opening of the invagination of the disc never closes, and after the development of the tube feet begins to widen again, and the amnion to atrophy. Through the opening of the invagination the tube feet now project. The dorsal and right surface of the Pluteus, which extends so as to embrace the opening of the madreporic canal and the anus, forms the abactinal or dorsal surface of the future Echinus (fig. 267,a). This disc fits on to the actinal invaginated surface which arises on the left side of the Pluteus. On the right surface of the larva (dorsal of permanent Echinus) two pedicellariæ appear, and at a later period spines are formed, which are at first arranged in a ring-like form round the edge of the primitively flat test. While these changes are taking place, and the two surfaces of the future Echinus are gradually moulding themselves so as to

1 Vide especially Mïller, Agassiz, and Metschnikoff.

2 For viviparous Echini vide Agassiz, Proc. Amer. Acad. i $8 ; 6$. 
form what is obviously a young Echinus, the arms of the Pluteus with their contained skeleton have been gradually undergoing atrophy. They become irregular in form, their contained skeleton breaks up into small pieces, and they are gradually absorbed.

The water-vascular ring is from the first complete, so that, as in Asterias, it is perforated through the centre by a new œsophagus. According

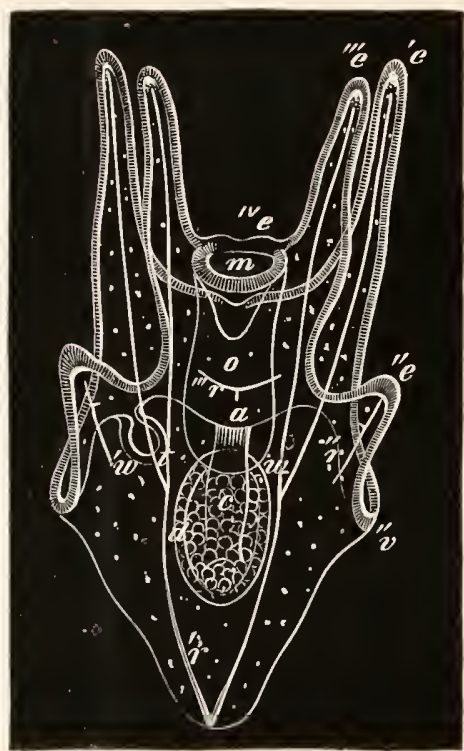

B

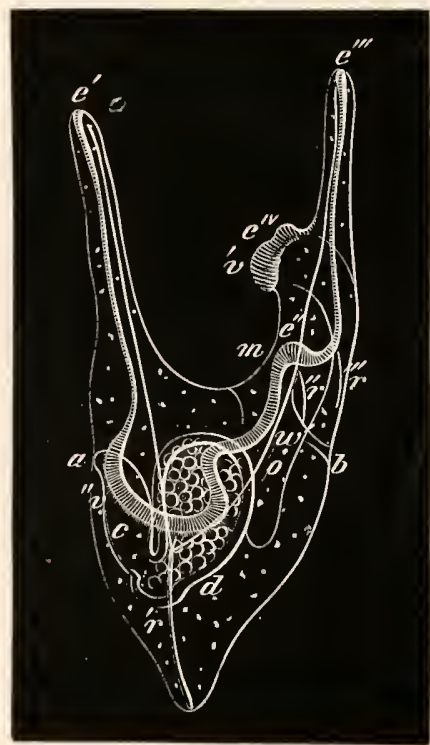

A

Fig. 266. Side and dorsal, View of a larva of Strongylocentrus.

(From Agassiz.) General reference letters as in figs. $26_{4}$ and $26_{5}$.

$e^{\prime \prime}$. anterolateral arms; $v^{\prime \prime}$. ciliated epaulettes; $u^{\prime}$. invagination to form the disc of Echinus.

to Agassiz the first five tentacles or tube feet grow into the radial canals, and form the odd terminal tentacles exactly as in Asterias ${ }^{1}$. Spatangus only differs in development from Echinus in the fact that the opening of the invagination to form the ventral disc becomes completely closed, and that the tube feet have eventually to force their way through the larval epidermis of the amnion, which is ruptured in the process and eventually thrown off.

Crinoidea. The larva of Antedon, while still within the egg-shell, assumes an oval form and uniform ciliation. Before it

1 Götte (No. 549) supported by Müller's and Krohn's older, and in some points extremely erroneous observations, has enunciated the view that the radial canals in Echinoids and Holothuroids have a different nature from those in Asteroids and Ophiuroids. 
becomes hatched the uniform layer of cilia is replaced by four transverse bands of cilia, and a tuft of cilia at the posterior extremity. In this condition it escapes from the egg-shell

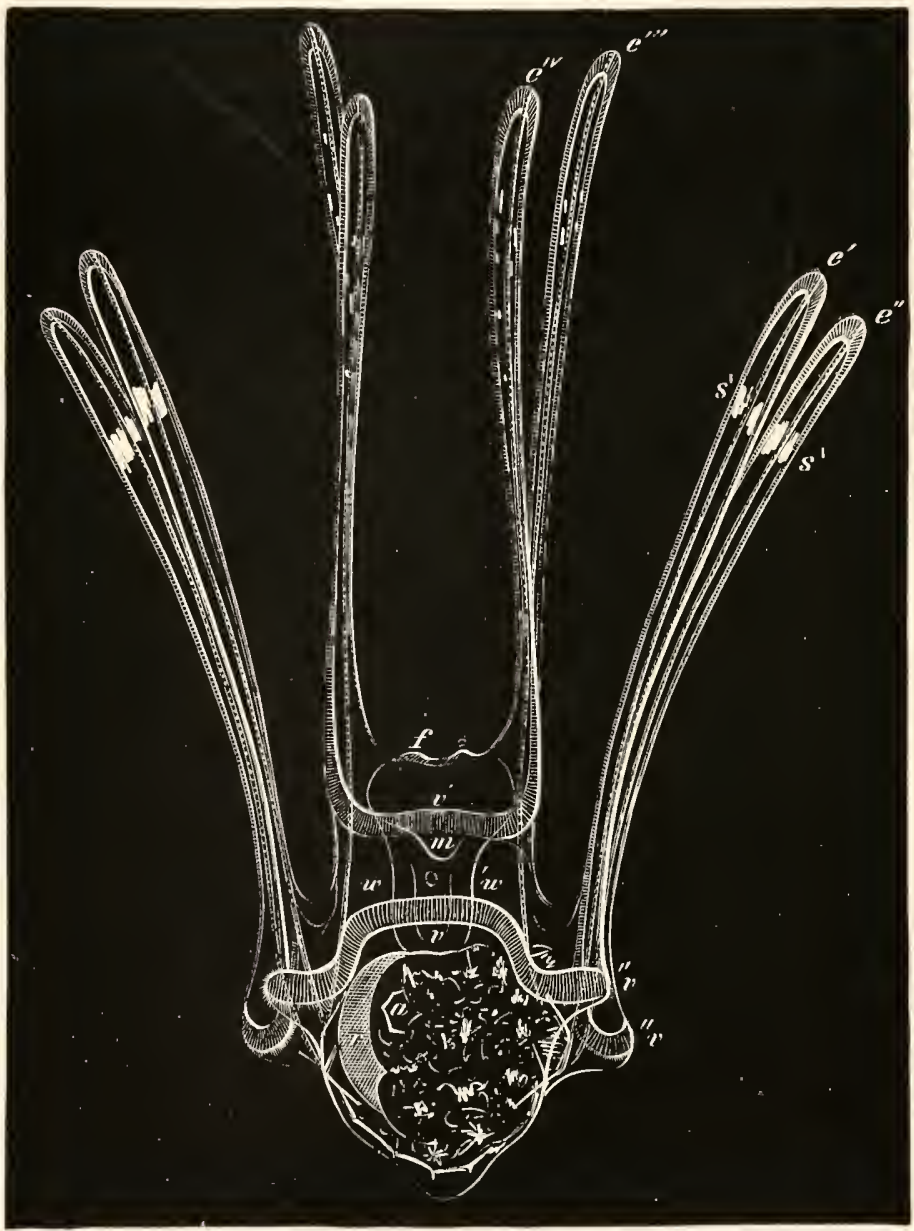

Fig. 267. Full-grown larva of Stroxiylocentrus. (From Agassiz.)

The figure shews the largely-developed abactinal disc of the young Echinus enclosing the larval stomach. Reference letters as in previous figs.

(fig. $268 \mathrm{~A}$ ), and becomes bilateral, owing to a flattening of the ventral surface. On the flattened surface appears a ciliated 
depression corresponding in position with the now closed blastopore (vide p. 550). The third ciliated band bends forward to pass in front of this (fig. 269). Behind the last ciliated band there is present a small depression of unknown function, also

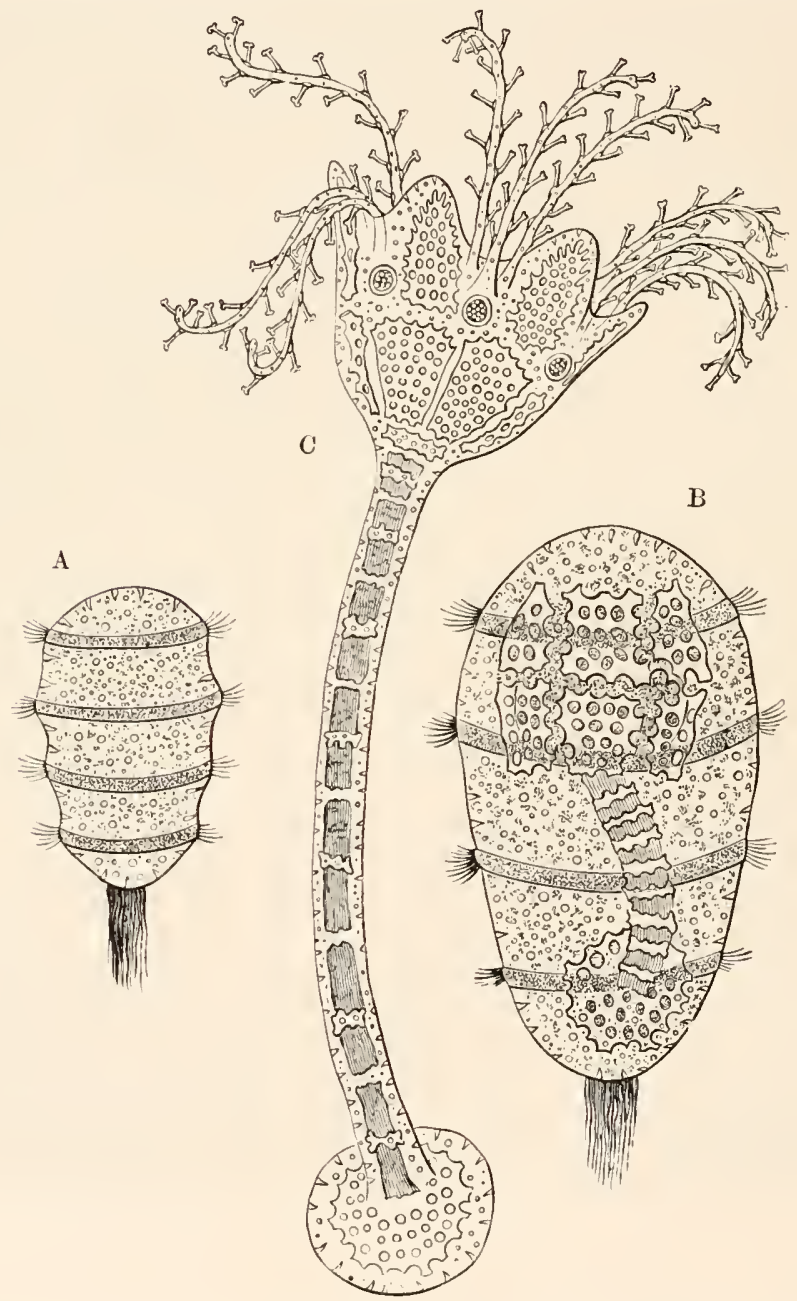

Fig. 268. Three stages in the development of Antedon (Comatula.) (From Lubbock; after Thomson.)

A. larva just hatched; B. larva with rudiment of the calcareous plates; C. Pentacrinoid larva. 
situated on the ventral surface. The posterior extremity of the embryo elongates to form the rudiment of the future stem, and a fresh depression, marking the position of the future mouth, makes its appearance on the anterior and ventral part.

While the ciliated bands are still at their full development, the calcareous skeleton of the future calyx makes its appearance in the form of two rows, each of five plates, formed of a network of spicula (figs. $268 \mathrm{~B}$ and 269). The plates of the anterior ring are known as the orals, those of the posterior as the basals. The former surround the left, i.e. anterior peritoneal sack; the latter the right, i.c. posterior peritoneal sack. The two rows of plates are at first not quite transverse, but form two oblique circles, the dorsal end being in advance of the ventral. The rows soon become transverse, while the originally somewhat ventral oral surface is carried into the centre of the area enclosed by the oral plates.

By the change in position of the original ventral surface relatively to the axis of the body, the bilateral symmetry of the larva passes into a radial symmetry. While the first skeletal elements of the calyx are being formed, the skeleton of the stem is also established. The terminal plate is first of all established, then the joints, eight at first, of the stem. The centro-dorsal plate is stated by Thomson to be formed as the

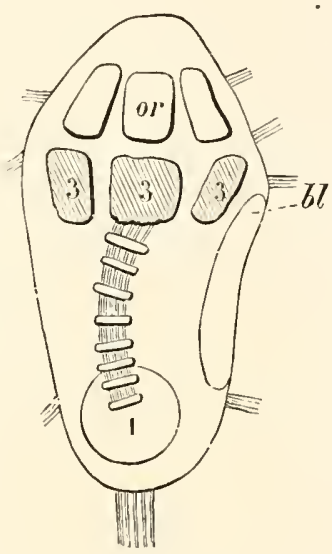

Fig. 269. LARVA OF ANTEDON WITH RUDIMENTS of CalCareous SKELETON. (From Carpenter; after Thomson.)

I. Terminal plate at the end of the stem ; 3. basals; $o r$. orals ; $b l$. position of blastopore. uppermost joint of the stem ${ }^{1}$. The larva, after the completion of the above changes, is shewn in fig. $268 \mathrm{~B}$, and somewhat more diagrammatically in fig. 269.

After the above elements of the skeleton have become established the ciliated bands undergo atrophy, and shortly after-

${ }^{1}$ Götte (No. 549) on the other hand holds that the centro-dorsal plate is developed by the coalescence of a series of at first independent rods, which originate simultaneously with, and close to, the lower edges of the basals, and that it is therefore similar in its origin to the basals. 
wards the larva becomes attached by the terminal plate of its stem. It then passes into the Pentacrinoid stage. The larva in this stage is shewn in fig. $268 \mathrm{C}$ and fig. 270 . New joints are added at the upper end of the stem next the calyx, and a new element-the radials-makes its appearance as a ring of five small plates, placed in the space between the basals and orals, and in the intervals alternating with them (fig. 270, 4). The roof of the oral vestibule (vide fig. 253 and p. $55 \mathrm{I}$ ) has in the meantime become ruptured; and the external opening of the mouth thus becomes established. Surrounding the mouth are five petal-like lobes, each of them supported by an oral plate (fig. $268 \mathrm{C})$. In the intervals between them five branched and highly contractile tentacles, which were previously enclosed within the vestibule, now sprout out: they mark the position of the future radial canals, and are outgrowths of the water-vascular ring. At the base of each of them a pair of additional tentacles is soon formed. Each primary tentacle corresponds to one of the radials. These latter are therefore, as their name implies, radial in position; while the basals and orals are interradial. In addition to the contractile radial tentacles ten non-contractile tentacles, also diverticula of the water-vascular ring, are soon formed, two for each interradius.

In the course of the further development the equatorial space between the orals and the basals enlarges, and gives rise to a wide oral disc, the sides of which are formed by the radials resting on the basals; while in the centre of it are

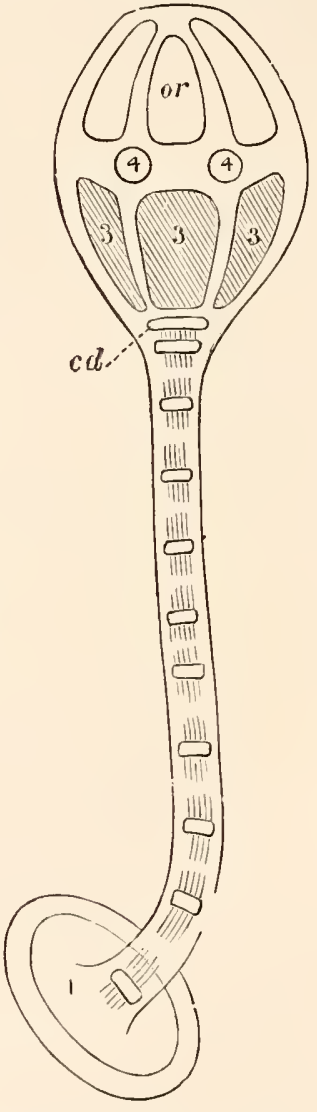

Fig. 270 . Young PeNTACRINOID LARVA OF ANTEDON. (From Carpenter; after Wyville Thomson.)

$\therefore$ terminal plate of stem; $c d$. centro-dorsal plate; 3 . basals; 4 . radials; or orals. placed the five orals, each with its special lobe.

The anus, which is formed on the ventral side in the position 
of the blastopore (p. 551), becomes surrounded by an anal plate, which is interradial in position, and lies on the surface of the oral disc between the orals and radials. On the oral plate in the next interradius is placed the opening of a single funnel leading into the body cavity, which Ludwig regards as equivalent to the opening of the madreporic canal (vide p. 55 I) ${ }^{1}$.

From the edge of the vestibule the arms grow out, carrying with them the tentacular prolongation of the water-vascular ring. Two additional rows of radials are soon added.

The stalked Pentacrinoid larva becomes converted, on the absorption of the stalk, into the adult Antedon. The stalk is functionally replaced by a number of short cirri springing from the centro-dorsal plate. The five basals coalesce into a single plate, known as the rosette, and the five orals disappear, though the lobes on which they were placed persist. In some stalked forms, e.g. Rhizocrinus Hyocrinus, the orals are permanently retained. The arms bifurcate at the end of the third radial, and the first radial becomes in Antedon rosacea (though not in all species of Antedon) concealed from the surface by the growth of the centro-dorsal plate. An immense number of funnels, leading into the body cavity, are formed in addition to the single one present in the young larva. These are regarded by Ludwig as equivalent to so many openings of the madreporic canal; and there are developed, in correspondence with them, diverticula of the water-vascular ring.

\section{Comparison of Echinoderm Larve and General Conchusions.}

In any comparison of the various types of Echinoderm larva it is necessary to distinguish between the free-swimming forms, and the viviparous or fixed forms. A very superficial examination suffices to shew that the free-swimming forms agree very much more closely amongst themselves than the viviparous

1 I have made no attempt to discuss the homologies of the plates of the larval Echinodermata because the criteria for such a discussion are still in dispute. The suggestive memoirs of P. H. Carpenter (No. 548) on this subject may be consulted by the reader. Carpenter attempts to found his homologies on the relation of the plates to the primitive peritoneal vesicles, and I am inclined to believe that this method of dealing with these homologies is the right one. Ludwig (No. 559) by regarding the opening of the madreporic canal as a fixed point has arrived at very different results. 
forms. We are therefore justified in concluding that in the viviparous forms the development is abbreviated and modified.

All the free forms are nearly alike in their earliest stage after the formation of the archenteron. The surface between the anus and the future mouth becomes flattened, and (except in Antedon, Cucumaria, Psolinus, etc. which practically have an abbreviated development like that of the viviparous forms) a ridge of cilia becomes established in front of the mouth, and a second ridge between the mouth and the anus. This larval form, which is shewn in fig. $264 \mathrm{~A}$, is the type from which the various forms of Echinoderm larvæ start.

In all cases, except in Bipinnaria, the two ciliated ridges soon become united, and constitute a single longitudinal postoral ciliated ring.

The larvæ in their further growth undergo various changes, and in the later stages they may be divided into two groups:

(I) The Pluteus larva of Echinoids and Ophiuroids.

(2) The Auricularia (Holothuroids) and Bipinnaria (Asteroids) type.

The first group is characterized by the growth of a number of arms more or less surrounding the mouth, and supported by calcareous rods. The ciliated band retains its primitive condition as a simple longitudinal band throughout larval life. There is a very small præ-oral lobe, while an anal lobe is very largely developed.

The Auricularia and $\mathrm{Bi}$ pinnaria resemble each other in shape, in the development of a large præ-oral lobe, and in the absence of provisional calcareous rods; but differ in the fact that the ciliated band is single in Auricularia (fig 27 I A), and is double in Bipinnaria (fig. 27 I B).

The Bipinnarialarva shews a great tendency to develop soft arms; while in the Auricularia the longitudinal ciliat-
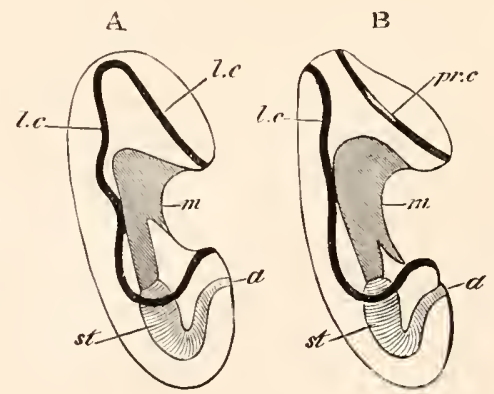

Fig. 27 I. A. The larva of a HoloTHUROId. B. The larva OF aN ASTERIAS.

m. mouth; st. stomach; $a$. anus; l.c. primitive longitudinal ciliated band; pr.c. præ-oral ciliated band. 
ed band breaks up into a number of transverse ciliated bands. This condition is in some instances reached directly, and such larvæ undoubtedly approximate to the larvæ of Antedon, in which the uniformly ciliated condition is succeeded by one with four transverse bands, of which one is pre-oral.

All or nearly all Echinoderm larvæ are bilaterally symmetrical, and since all Echinodermata eventually attain a radial symmetry, a change necessarily takes place from the bilateral to the radial type.

In the case of the Holothurians and Antedon, and generally in the viviparous types, this change is more or less completely effected in the embryonic condition; but in the Bipinnaria and Pluteus types a radial symmetry does not become apparent till after the absorption of the larval appendages. It is a remarkable fact, which seems to hold for the Asteroids, Ophiuroids, Echinoids, and Crinoids, that the dorsal side of the larva is not directly converted into the dorsal disc of the adult; but the dorsal and right side becomes the adult dorsal or abactinal surface, while the ventral and left becomes the actinal or ventral surface.

It is interesting to note with reference to the larva of the Echinodermata that the various existing types of larvæ must have been formed after the differentiation of the existing groups of the Echinodermata ; otherwise it would be necessary to adopt the impossible position that the different groups of Echinodermata were severally descended from the different types of larvæ. The various special appendages, etc. of the different larvæ have therefore a purely secondary significance; and their atrophy at the time of the passage of the larva into the adult, which is nothing else but a complicated metamorphosis, is easily explained.

Originally, no doubt, the transition from the larva to the adult was very simple, as it is at present in most Holothurians; but as the larvæ developed various provisional appendages, it became necessary that these should be absorbed in the passage to the adult state.

It would obviously be advantageous that their absorption should be as rapid as possible, since the larva in a state of transition to the adult would be in a very disadvantageous 
position. The rapid metamorphosis, which we find in Asteroids, Ophiuroids, and Echinoids in the passage from the larval to the adult state, has no doubt arisen for this reason.

In spite of the varying provisional appendages possessed by Echinoderm larvæ it is possible, as stated above (p. 574), to recognise a type of larva, of which all the existing Echinoderm larval forms are modifications. This type does not appear to me to be closely related to that of the larvæ of any group described in the preceding pages. It has no doubt certain resemblances to the trochosphere larva of Chætopoda, Mollusca, etc., but the differences between the two types are more striking than the resemblances. It firstly differs from the trochosphere larva in the character of the ciliation. Both larvæ start from the uniformly ciliated condition, but while the præ-oral ring is almost invariable, and a peri-anal ring very common in the trochosphere; in the Echinoderm larva such rings are rarely found; and even when present, i.e. the præ-oral ring of Bipinnaria and the terminal though hardly peri-anal patch of Antedon, do not resemble closely the more or less similar structures of the trochosphere. The two ciliated ridges (fig. 264 A) common to all the Echinoderm larvx, and subsequently continued into a longitudinal ring, have not yet been found in any trochosphere. The transverse ciliated rings of the Holothurian and Crinoid larvæ are of no importance in the comparison between the trochosphere larvæ and the larvæ of Echinodermata, since such rings are frequently secondarily developed. Cf. Pneumodermon and Dentalium amongst Mollusca.

In the character of the præ-oral lobe the two types again differ. Though the præ-oral lobe is often found in Echinoderm larvæ it is never the seat of an important (supra-œesophageal) ganglion and organs of special sense, as it invariably is in the trochosphere.

Nothing like the vaso-peritoneal vesicles of the Echinoderm larvæ has been found in the trochosphere; nor have the characteristic trochosphere excretory organs been found in the Echinoderm larvæ.

The larva which most nearly approaches those of the Echinodermata is the larva of Balanoglossus described in the next chapter. 


\section{BIBLIOGRAPHY.}

(542) Alex. Agassiz. Revision of the Echini. Cambridge, U.S. I872-74.

(543) Alex. Agassiz. "North American Starfishes." Memoirs of the Mnzsum of Comparative Anatomy and Zoology at Harvard College, Vol. V., No. I. I877 (originally published in 1864 ).

(544) J. Barrois. "Embryogénie de l'Asteriscus verruculatus." Foumal de l'Anat. et Phys. I 879 .

(545) A. Baur. Beiträge zur Naturgeschichte d. Synapta digitata. Dresden, I 864 .

(546) H. G. Bronn. Klassen u. Ordnungen etc. Strahlenthicre, Vol. II. r 86o.

(547) W. B. Carpenter. "Researches on the structure, physiology and development of Antedon." Phil. Trans. CLvi. I866, and Procedings of the Roy. Soc., No. I66. I 876 .

(548) P. H. Carpenter. "On the oral and apical systems of the Echinoderms." Qnart. F. of Micr. Science, Vol. xvin. and xix. $1878-9$.

(549) A. Götte. "Vergleichende Entwicklungsgeschichte d. Comatula mediterranea." Arch. fïr micr. Anat., Vol. xil. I876.

(550) R. Greeff. "Ueber die Entwicklung des Asteracanthion rubens vom Ei bis zur Bipinnaria u. Brachiolaria." Schriften d. Gesellschaft zur Beförderung $d$. gesammten Naturwissenschaften zu Marburg, Bd. XiI. I876.

(551) R. Greeff. "Ueber den Bau u. die Entwicklungd. Echinodermen," Sitz. d. Gesell. z. Beförderung d. gesam. Naturziss, zu Marburg, No. 4. I879.

(552) T. H. Huxley. "Report upon the researches of Miiller into the anat. and devel. of the Echinoderms." Ann. and Mag. of Nat. Hist., and Ser., Vol. viII. $185 \mathrm{I}$.

(553) Koren and Danielssen. "Observations sur la lipinnaria asterigera. Ann. Scien. Nat., Ser. III., Vol. vil. $18_{4}$.

(554) Koren and Danielssen. "Observations on the development of the Starfishes." Ann. and Mag. of Nat. Hist., Vol. xx. I857.

(555) A. Kowa levsky. "Entwicklungsgeschichte d. IIolothurien." Mím. Ac. Pítersbourg, Ser. viI., Tom. xi., No. 6.

(556) A. Krohn. "Beobacht. a. d. Entwick. d. Holothurien u. Seeigel." Mïller's Archiv, $185 \mathrm{I}$.

(557) A. Krohn. "Ueb. d. Entwick. d. Seesterne u. Holothurien." Miiller's Archiv, 1853 .

(558) A. Krohn. "Heobacht. üb. Echinodermenlarven." Mïller's Archiv', $1854^{\circ}$

(559) II. Ludwig. "Ueb. d. primar. Steinkanal d. Crinoideen, nebst vergl. anat. Bemerk. üb. d. Echinodermen." Zeit.f. wiss. Zool., Vol. xxxıv. Is\&o.

(560) E. Metschnikoff. "Studien iib. d. Entwick. d. Echinodermen u. Nemertinen." Mém. Ac. Pítersbourg, Series viI., Tom. xiv., No. 8. I869.

$(561)^{1}$ J oh. M ïller. "Ueb. d. Larven u. d. Metamorphose d. Echinodermen." Abhandlungen d. Berlin. Akad. (Five Menioirs), I $8+8,49,50,52$ (two Memoirs).

(562) Joh. Miiller. "Allgemeiner Plan d. Entwicklung d. Echinodermen." Abhandl. d. Berlin. Aliad., I853.

1 The dates in this reference are the dates of publication.

B. II. 
(563) E. Selenka. "Zur Entwicklung d. Holothurien." Zeit. f. wiss. Z.ool., Bd. XxviI. I 876 .

(564) E. Selenka. "Keimblätter u. Organanlage bei Echiniden." Zeit.f. wiss. Zool., Vol. xxxiII. I879.

(565) Sir Wyville Thomson. "On the Embryology of the Echinodermata." Natural History Review, $\mathrm{IS6}_{4}$.

(566) Sir Wyville Thomson. "On the Embryogeny of Antedon rosaccus." Ihil. Trans. 1865 . 


\title{
CHAPTER XXI.
}

\author{
ENTEROPNEUSTA.
}

TrE larva of Balanoglossus is known as Tornaria. The pralarval development is not known, and the youngest stage (fig. 272) so far described (Götte, No. 569) has many remarkable points of resemblance to a young Bipinnaria.

A mouth ( $m$ ), situated on the ventral surface, leads into an alimentary canal with a terminal anus $(a n)$. A pre-oral lobe is well developed, as in Bipinnaria, but there is no post-anal lobe. The bands of cilia have the same general form as in Bipinnaria. There is a pre-oral band, and a longitudinal post-oral band; and the two bands nearly meet at the apex of the præoral lobe (fig. 273). A contractile band passes from the œesophagus to the apex of

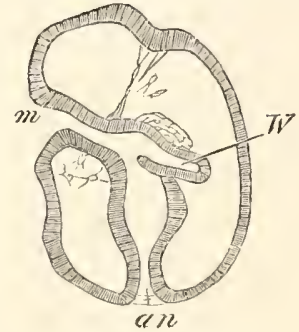

FIG, 272. EARLX STAGE IN THE DEVELOPMENT OF TORNARIA. (After Götte.)

$I V$. so-called watervascular vesicle developing as an outgrowth of the mesenteron; $m$. mouth; an. anus. the præ-oral lobe, and a diverticulum (fig. $272, W$ ) from the alimentary tract, directed towards the dorsal surface, is present. Contractile cells are scattered in the space between the body wall and the gut.

In the following stage (fig. $274 \mathrm{~A}$ ) a conspicuous transverse post-oral band of a single row of long cilia is formed, and the original bands become more sinuous. The alimentary diverticulum of the last stage becomes an independent vesicle opening by a pore on the dorsal surface (fig. $274 \mathrm{~A}, w$ ). The contractile cord is now inserted on this vesicle. Where this cord joins the apex of the pre-oral lobe between the two anterior bands of cilia a thickening of the epiblast (? a ganglion) has become 
established, and on it are placed two eye-spots (fig. $273 o c$, and fig. 274 A). A deep bay is formed on the ventral surface of the larva.

As the larva grows older the original bands of cilia become more sinuous, and a second transverse band with small cilia is formed (in the Mediterranean larva) between the previous transverse band and the anus. The water-vascular vesicle is prolonged into two spurs, one on each side of the stomach. A pulsating vesicle or heart is

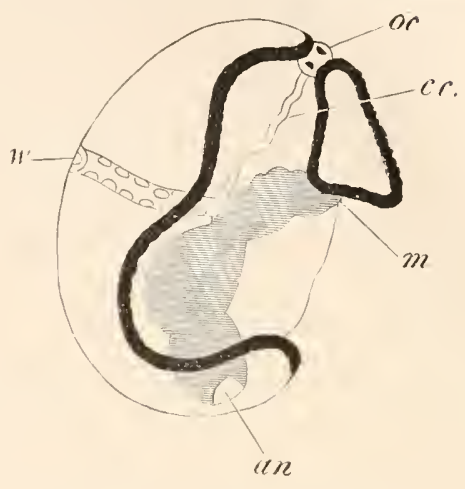

Fig. 273. YOUNG TORNARIA. (After Müller.)

m. mouth; an. anus; $i$. watervascular vesicle; oc. eye-spots; c.c. contractile cord. also formed (fig. $274 \mathrm{~B}, h t$ ), and arises, according to Spengel (No. 572), as a thickening of the epidermis. It subsequently becomes enveloped in a pericardium, and is placed in a depression in the water-vascular vesicle. Two pairs of diverticula, one behind the other, grow out (Agassiz, No. 568) from the gastric region of the alimentary canal. The two parts of each pair form flattened compartments, which together give rise to a complete investment of the adjoining parts of the alimentary tract. The two parts of each coalesce, and thus form
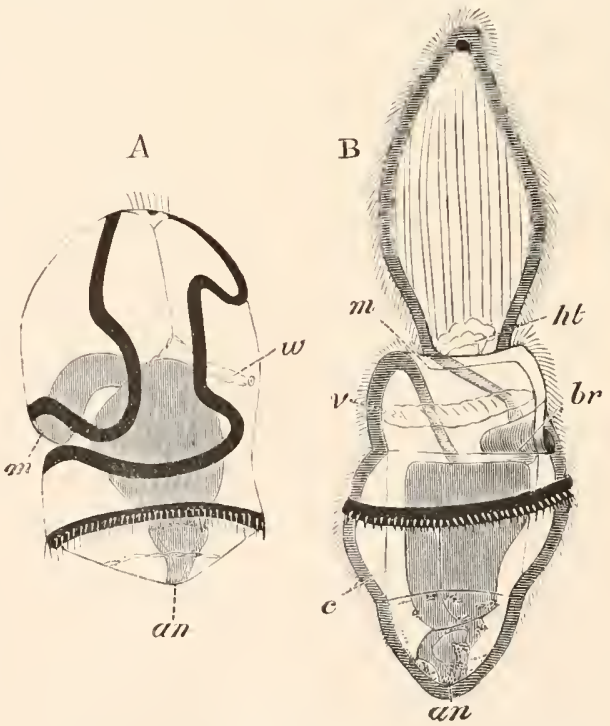

Fig. 274. Two STAGES IN THE UeVelopment of Tornaria. (After Metschnikoff.)

The black lines represent the ciliated bands.

$m$. mouth; an. anus; br. branchial cleft; $h t$. heart; $c$. body cavity between splanchnic and somatic mesoblast layers; $2 \omega$. water-vascular vesicle; ข. circular blood-vessel. 
a double-walled cylinder round the alimentary tract, but their cavities remain separated by a dorsal and ventral septum.

Eventually (Spengel) the cavity of the anterior cylinder forms the section of the body cavity in the collar of the adult, and that of the posterior (fig. $27+\mathrm{B}, c$ ) the remainder of the body cavity. The septa, separating the two halves of each, remain as dorsal and ventral mesenteries.

The conversion of Tornaria (fig. $274 \mathrm{~A}$ ) into Balanoglossus (fig. $274 \mathrm{~B}$ ) is effected in a few hours, and consists mainly in certain changes in configuration, and in the disappearance of the longitudinal ciliated band.

The body of the young Balanoglossus (fig. $274 \mathrm{~B}$ ) is divided into three regions (I) the proboscidian region, (2) the collar, (3) the trunk proper. The proboscidian region is formed by the elongation of the præ-oral lobe into an oval body with the eyespots at its extremity, and provided with strong longitudinal muscles. The heart (ht) and water-vascular vesicle lie near its base, but the contractile cord connected with the latter is no longer present. The mouth is placed on the ventral side at the base of the præ-oral lobe, and inmediately behind it is the collar. The remainder of the body is more or less conical, and is still girt with the larval transverse ciliated band, which lies in the middle of the gastric region in the Mediterranean species, but in the oesophageal region in the American one.

The whole of the body, including the proboscis, becomes richly ciliated.

One of the most important characters of the adult Balanoglossus consists in the presence of respiratory structures comparable with the

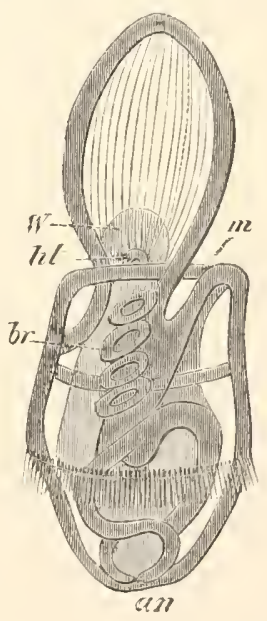

Fig. 275 . LATE STAGE iN TIE DEVElopMENT OF BALANOGlosSUS WITH FOUR BRANCHIAI. CLEFTs. (After Alex. Agassiz.)

m. mouth; $a n$. anus; br. branchial cleft; ht. heart; $W$. watervascular vesicle. vertebrate gill slits. The earliest traces of these structures are distinctly formed while the larva is still in the Tornaria 
condition, as one pair of pouches from the osophagus in the Mediterranean species, and four pairs in the American one (fig. 275, br).

In the Mediterranean Tornaria the two pouches meet the skin dorsally, and in the young Balanoglossus (fig. $274 \mathrm{~B}, \mathrm{br}$ ) acquire an external opening on the dorsal side. In the American species the first four pouches are without external openings till additional pouches have been formed. Fresh gill pouches continue to be formed both in the American and probably the Mediterranean species, but the conversion of the simple pouches into the complicated gill structure of the adult has only been studied by Agassiz (No. 568) in the American species. It would seem in the first place that the structure of the adult gill slits is much less complicated in the American than in the Mediterranean species. The simple pouches of the young become fairly numerous. They are at first circular; they then become elliptical, and the dorsal wall of each slit becomes folded; subsequently fresh folds are formed which greatly increase the complexity of the gills. The external openings are not acquired till comparatively late.

Our knowledge of the development of the internal organs, mainly derived from Agassiz, is still imperfect. The vascular system appears early in the form of a dorsal and a ventral vessel, both pointed, and apparently ending blindly at their two extremities. The two spurs of the water-vascular vesicle, which in the Tornaria stage rested upon the stomach, now grow round the œesophagus, and form an anterior vascular ring, which Agassiz describes as becoming connected with the heart, though it still communicates with the exterior by the dorsal pore and seems to become connected with the remainder of the vascular system. According to Spengel (No. 572) the dorsal vessel becomes connected with the heart, which remains through life in the proboscis: the cavity of the water-vascular vesicle forms the cavity of the proboscis in the adult, and its pore remains as a dorsal (not, as usually stated, ventral) pore leading to the exterior.

The eye-spots disappear.

Tornaria is a very interesting larval form, since it is intermediate in structure between the larva of an Echinoderm and trochosphere type common to the Mollusca, Chætopoda, etc. The shape of the body especially the form of the ventral depression, the character of the longitudinal ciliated band, the structure and derivation of the water-vascular vesicle, and the 
formation of the walls of the body cavity as gastric diverticula, are all characters which point to a connection with Echinoderm larvæ.

On the other hand the eye-spots at the end of the præ-oral lobe ${ }^{1}$, the contractile band passing from the œesophagus to the eye-spots (fig. 273), the two posterior bands of cilia, and the terminal anus are all trochosphere characters.

The persistence of the præ-oral lobe as the proboscis is interesting, as tending to shew that Balanoglossus is the surviving representative of a primitive group.

\section{BIBLIOGRAPIIY.}

(567) A. Agassiz. "Tornaria." Ann. Lyceum Nat. Hist. vıl. New York, 1866.

(568) A. Agassiz. "The History of Balanoglossus and Tornaria." Mem. Amer. Acad. of Arts and Scien., Vol. IX. I $\&_{73}$.

(569) A. Götte. "Entwicklangsgeschichte d. Comatula Mediterranea." Archiv fiir mikr. Anat., Bd. xil., I876, p. 64 I.

(570) E. Metschnikoff. "Untersuchungen iü d. Metamorphose, etc. (Tornaria)." Zeit. fiir wiss. Zool., Bd. xx. 1870.

(571) J. Müller. "Ueb. d. Larven u. Metamor. d. Echinodermen." Berlin Akad., $18+9$ and $\mathrm{i} 850$.

(572) J. W. Spengel. "Bau u. Entwicklung von Balanoglossus. Tagebl. d. Naturf. Vers. Mïnchen, 1877 .

1 It would be interesting to have further information about the fitte of the thickening of epiblast in the vicinity of the eye-spots. The thickening should by rights be the supra-œsophageal ganglion, and it does not seem absolutely impossible that it may give rise to the dorso-median cord in the region of the collar, which constitutes, according to Spengel, the main ganglion of the adult. 



\section{INDEX.}

Abdominalia, $459,493,499$

Acanthocephala, 379

Acanthosoma, $473,474, \pm 75$

Acarina, $4+4,+54$

Accipenser, $\mathrm{IO}_{2}$

Achieta, 319

Achelia, 538

Achtheres percarum, 490

Acineta, 7,8

Acraspeda, $152,165,167,178,179,182$, I 85, I 86

Actinia, I69, I 7 I, I 79

Actinophrys, 9

Actinotrocha, $3 \mathbf{I}_{5}, 3 \mathbf{I} 8,363,36_{4}$

Actinozoa, 26, 102, I52, $166,170,171$, I $72,176,178,179$, I 81, I 82,186

Actinula, 155

Aculeata, 42 I

Egineta flavescens, I, 8

Eginidx, I 56, I $5 \mathrm{~S}$

Eginopsis Mediterranea, $\mathrm{I}_{5}^{8}$

Equorea Mitrocoma, IS2

Agalma, I63

Agelena, $+36,+50$

Agelena labyrinthica, I I 9,438

Alciope, $7+$

Alcippidre, 499

Alcyonaria, I52

Alcyonidxe, I67, I68

Alcyonidium mytili, 297, 300, 302

Alcyonium palmatum, I 19, I $48,167,182$

Alima, ${ }_{4} S_{4},{ }_{4} 86$

Amœba, 19, 20

Amphibia, 22, 54, 56, 59, 60, 63, 66, 74, 83,102

Amphilina, 218

Amphioxus, 54, 56, 59, 6I , 66, 93, +26

Amphipoda, 5 I 8

Amphiporus lactifloreus, 202

Amphistomum, 3I

Amphitrochx, 330

subclavatum, 205

Amphiura squamata, 565
Anchorella, 108, 492, 520

Anelasma squalicola, 499

Anguillulidie, 37 I

Annelida, 14, 25, 98, 503, 525

Anodon, 37, 38, 39, 100, 107, 259, 260, $265,266,268$

Anopla, I S9, 202

Anura, 5

Antedon, 568, 573, 57t

Aphides, $15,16,76,79,116,+28,+29$

Aphrodite, $4^{2}$

Apis, 402, to7, to8, +12, 413

Aplysia, 99, 226, 238, 252, 253

Aplysinidre, $I_{4} 6$

Apoda, 459,493

Aptera, 395, +20

Apus, $16,79,460,{ }_{4}^{63}$

Arachnida, 22, I I $4,119,413,+3 \mathrm{I}, 435$, $4+4,454,455,458,537,539$

Arachnitis, $17 \mathrm{I}$

Araneina, 50, 5I, 436

Arbacia, 567

Arca, $3^{8}$

Archigetes, 2 I 8

Archizorea gigas, $49+$

Arenicola, $4^{2}$

Argiope, 3I I, 3 I 2,3 I $_{5}, 3$ I $_{7}$

Argonauta, 247,248

Argulus, +92

Armata, 355

Arthropoda, 1 2, 16, 1 8, 22, 75, 77,79,83, $108,110,221,3^{82}, 3^{83}, 43+, 44^{8,503}$, $525,53 t, 5 t^{\mathrm{I}}, 5 t^{2}$

Articulata, 3I I, 313, 3I6, 3 I $7_{7}$

Ascaridixe, 371

Ascaris nigrovenosa, 16,82 , lumbricoides, 375

Ascetta, I 44

Ascidia canina, 53

Ascidians, 74, 102, 208, 426

Asellus aquaticus, I I 2, I 20,516

Astacus, 66, $465,477,511,512,513$, 525 
Asteracanthion, 69, 70, 561

Asterias, 20, 68, 69, 71, $78,80,84,549$, $5^{6} 4$

Asteroidea, 35, 36, 54t, 549, 557, 563, $57^{6}$

Astræa, I69

Astroides, I 69

Atax Bonzi, +45

Atlanta, 231, 240

Atroche, 330

Aurelia, 167

Auricularia, 553, 554, 562, 57t

Autolytus cornutus, 3 I $9,3+3$

Aves, 56, 59, 6I, 64, I07. I09

Axolotl, I6

Balanoglossus, 576, 579, 58 I

Balanus balanoides, 75,493

Belemnites, 252, 253

Bipinnaria, $557,563,57+, 576,579$

Blatta, 374,395

Bojanus, organ of, 264,282

Bonellia, 20, $43,4+, 98,324,355,358$, 359

Bothriocephalus salmonis, 2 II

Brachiella, 492

proboscideus, 2 I 2

Brachiolaria, 558, 564

Brachiopoda, 3II , 3I7, $3 \mathbf{I} 8$

Brachyura, $466,480,4^{8} 3$

Branchiobdella, $+2,+3,346$

Branchiogasteropoda, 272

liranchiopoda, $79,459,523,524$

Branchipus, 463,524

Branchiura, 459,492

Branchionus urceolaris, 22 I

Braula, 396

Buccinum, 237, 280

Bullimus citrinus, 229

Bunodes, I69, I $7 \mathbf{I}$

Buthus, +3 I

Calcispongiae, $\mathrm{I}_{3} 8, \mathrm{I}_{4} \mathrm{~S}$

Calopteryx, +02

Calycophoridæ, 152, 159

Calyptoblastic Hydroids, I 84, I 85

Calyptraea, 223, 280

Campanularidæe, $\mathrm{I}_{3}, \mathrm{I}_{4}$

Capitella, 330, $33^{2}$

Carabidæ, 476

Carcinus Mcenas, $+81,+83$

Cardium, 260, 262

$$
\text { ,, pygmæum, } 262
$$

Carinaria, 240

Caryophyllium, 168,171

Cassiopea, 165,167

Cecidomyia, ${ }_{5} 5,79,+16,+17,+29$

Cephalopoda, 20, 40, 4I, 102, 108, I09,

$135,225,240,242,244,250,252,253$,

$270,271,272,274,279,282,287$

Cephalothrix galatheae, 202

Ceratospongia, ${ }_{4}{ }^{6}$
Cercariae, 207, 208, 209

Cerianthus, I68, I 7 I

Cestodes, I 4, 29, 3I, 32, 33, 189, 2 Iо, 2 I 2,2 I 8,3 I $3,425,54$ I

Chretogaster, 342

Chrotopoda, 5, IS, 23, +I, 43, 44, 54, $67,209,2$ I $5,270,275,307,3 \mathbf{I} 2,3 \mathbf{I} 7$, 3 г 8,3 I $9,320,326,334,338,3+2,3+6$, $349,350,351,3^{6}+369,3^{8} 3,386,+08$, $44^{8}, 457,458,52 \mathrm{I}, 576,582$

Chrtopteride, 333

Chretosomoidea, $37 \mathbf{I}$

Chelifer, $434,+36,+4^{2}, 44^{6}, 454$

Chermes, I5, +29

Chilognatha, 113, 387, 389, 391, 393, 395

Chilopoda, 387, 392, 394

Chilostomata, 292, 297, 298, 304, 305

Chironomus, 15,378 , tOI, +02, +15, +16, $+29$

Chiton, $254,256,257,273$

Chordata, 5

Chrysaora, 165

Chthonius, +36

Cicada, 395

Cirripedia, $459,492,496,503,509,520$

Cladocera, $459,+64,519$

Clausilia, 239

Clavella, 520

Clavularia crassa, 167

Cleodora, $24 \mathrm{I}$

Clepsine, $73,34^{6}, 347,349,35 \mathrm{I}, 35^{2}$, 353,354

Clio, 242,278

Clubione, 436

Clupeidx, 64

Cobitis barbatula, 378

Coccidæ, 429

Coccus, 50

Coelebogyne, 79

Collenterata, $3,5, \mathbf{1} 3, \mathbf{1} 8,26,27,28,35$, $74,93,94,126,148,170, I_{78,1} 79,180$, I 8 I, I9I, 342

Cœenurus cerebralis, 2 I3, 2 I 4

Colcochrete, I I

Coleoptera, 396, 402, 409, +12, +20, +21, $+25$

Collembola, $395,+26$

Comatula, 5, 552, 553

Condracanthus, III, I 20, 520

Conochilus volvox, $22 \mathrm{I}$

Convoluta, 32

Copepoda, ro9, I20, $459,+60,487,489$, $493,496,503,509,519$

Coralliun rubrum, I68, 182

Corethra, $+22,+23,4^{2}+$

Crangoninæ, $47^{6}$

Craniadæ, 3 I I

Craniata, 5, 6, I9, 20, 54, 56, 59, 6I 62 , $64,74,102$

Crinoidea, $35,36,544,550,568,576$

Criodilus, $32 \mathrm{I}, 324,328,34^{1}$ 
Crisia, $30_{4}$

Crocodilia, 63

Crustacea, 5, 6, I8, 5 I, 66, I02, I09, I 20, $45^{8}, 4^{6} 5,4^{87}, 502,52 \mathrm{I}, 524,537,54 \mathrm{I}$

Cryptophialus, 499, 509

Crystalloides, 163

Ctenophora, 26,93 , I02, $152,173,175$, 177, I 78, I79, I80, I8I, I 82

Ctenostomata, 292, 297, 298, 304, 305

Cucullanus elegans, $46,75,82,371,376$

Cucumaria, 546, 556, 574

Cumaceæ, $459,465,486,506$

Curculio, $42 \mathrm{I}$

Cyclas, 259, 260, 261, 265

Cyclops, $376,377,+18,+89,503$

Cyclostomata, 102, 292, 304

Cymbulia, 24I, 242

Cymothoa, $516,517,519,520,52+, 528$

Cynipidx, I $5,42 \mathrm{I}, 428$

Cyphonautes, 297, 301, 304, 306, 308

Cypridina, 500,502

Cysticercus cellulosie, 2 I 4, 2 I 7

$$
\begin{aligned}
& , \quad \text { fasciolaris, } 2 \text { I6 } \\
& , \quad \text { limacis, 213 }
\end{aligned}
$$

Daphnia, 79,464

Dasychone, $33^{1}, 336$

Decapoda, 66, $248,459,465,469,504$, 5 I I

Dendroccela, 32, 33, I89, 195, 196

Dentalium, 258,576

Dcsmacidon, $\mathrm{I}+7$

Desor, type of, 196, 197, 201, 202, 204, 2 I $2, t^{2} t$

Diastopora, $30_{4}$

Dibranchiata, 225, 253

Dicyema, 9, I 31,134, I 35, I 36

Dimya, 225

Diphyes, I 59

Diplozoon, I I, 209, 210

Diporpa, 2 Io

Diptera, 49, I94, 204, 396, 40I, 402, 407, 409, $412,+16,+20,+29$

Discina radiata, $3 \mathbf{I} 7$

Discinidæe, 3 I I

Discophora, $\mathbf{I} 8,+2, \mathbf{I} 65,34^{6}, 3^{8} 3$

Distomee, I89, 205, 425

Distomum, 3 I

$$
\begin{array}{ll}
, & \text { cygnoides, 209 } \\
, & \text { globiparum, 207 } \\
,, & \text { lanceolatum, 205 }
\end{array}
$$

Dochmius duodcnale, 375

$$
\text { , trigonocephalus, } 375
$$

Donacia, toI

Dracunculus, 376,377

Echinaster fallax, 23

$$
\text { ,, Sarsii, I02, 56 } 1
$$

Echinodermata, 5, I8, 24, 35, 74, 102, $325,+2+, 544,573,57+, 576,582$

Echinoidea, $35,36,544,549,565,576$

Echinorhyucus, 379,380
Echinus lividus, $8_{3}, 8_{4}, 88$

Echiurus, $44,357,35^{8}$

Ectoprocta, 297, 306

Edriophthalmata, 459,465

Elaphocaris, 473

Elasmobranchii, $23,56,59,61,62,64$, $67,105,106.107,108,109$

Enopla, 189, 202

Entoconcha mirabilis, 237

Entomophaga, +2 I

Entoprocta, 292, 298, 300, 302, 304, 306 Epeira, $43^{6}$

Epheniera, 395, 409, 420, 422

Ephyra, I86

Epibulia aurantiaca, I59, I65

Erichthus, 48, 507

Errantia, 3 I9, 336

Esperia, I 47

Estheria, $4^{6} 3,4^{6} 4$

Euaxes, IOI, 322, $32+, 341,34^{6}, 3+9$

Eucharis, 178 ,, multicornis, 178

Eucopepoda, +59

Eucope polystyla, 23, I5t

Eunice sanguinea, 3 I9

Eupagurus prideauxii, I I 2, I I 3, I I 5, 5 I I , 520

Euphausia, 465, 468, 504, 505, 518, 523

Eurostomaia, 176

Eurylepta auriculata, 192

Eurynome, $4^{83}$

Euspongia, $\mathbf{I}_{4} 6, \mathrm{I}_{+7}$

Filaria, 377

Filarida, $37 \mathbf{I}$

Firoloidea, 240

Flagellata, 7,8

Flustrclla, 30I, 30.3

Formica, 396

Fungia, I82, I86

Fusus, $275,280,284,288$

Gammarus, I 22, 518

$$
\text { ,, fluviatilis, } \mathbf{I}_{\mathbf{7}}
$$

, locusta, I Io, II 2

Garoids, 54 , 102

Gasteropoda, 39, 41, 98, 225, 226, 229, $230,232,23.3,240,258,260,261,270$, $272,275,279,283,324$

Giasterosteus, 64, 2 Io

Gastrotricha, 370

Gasterotrochxe, 330, 333

Gccarcinus, $4^{6} 5$

Geophilus, 392, 393

Gephyrea, 5, 18, 24, 4t, 54, 67, 162, $3^{18}, 320,325,355,357,3^{61}, 364$

Germogen, I34

Gcryonia hastata, I 56

Geryonida, 156

Glochidlia, 267,268

Gnathobdellida', 346,349

Gordiacea, $9+$ 
Gordioidea, 37 I, 374,378

Gorgonia, I68

Gorgonidæ, 181

Gorgoninæ, I 8 I

Gregarinidxe, 8

Gryllotalpa, 40 I, 4 I 2, 4 I 3

Gummineæ, $\mathbf{I}_{4} 7$, I 48

Gymnoblastic Hydroids, I 84 , I 85

Gymnolæemata, 292

Gymnosomata, 225, 240, 2.4 I, 242, 270

Gyrodactylus, 2 Io

Ialichondria, $\mathbf{I}_{47}$

Halisarca, 22, 66, I 45

I Ialistemma, I65

Helicidæ, 238

Helioporidæ, I8 2

Helix, 67, 229

Hemiptera, $395,402,403,409,420,42$ I

Hessia, I08, 492

Heterakis vermicularis, 374

Ieteronereis, $3+3$

Heteropoda, $7 \mathbf{I}, 7 \mathbf{7}, \mathbf{2 2 5}, \mathbf{2 2 6}, \mathbf{2 3} \mathbf{I}, 27 \mathrm{~S}$

Hexacoralla, 152 , I $79, \mathbf{I} 82$

Hippopodius gleba, 27,159

Il irudinea, $74,8_{4}$

Hirudo, 350, 351, 352, 353, 35t

Holometabola, $420,+22$

Holostomum, 205

Holothuria, I9, 25, 35, 549, 558, 576

Holothuroidea, $35,5+4,553,556$

Homarus, 477

Hyaleacea, 273,275

Hyaleidæ, $2+$ I

Hydra, 2 I, 22, 26, 28, 29, 34, I 52, I 54, $155,179,183$

Hydractinia, 539

Hydrocoralla, I52, I8I, I85

Hydroidea, I 52

Hydromedusx, I 52, I $79, \mathbf{I} 8_{2}, \mathbf{I} 8_{3}, \mathbf{I} 8_{4}$, I 85, I 86, I 87

Hydrophilus, $374,396,400,401,402$, $40_{4}, 408,409$

Hydrozoa, I4, I 9, 26, 27, 67, $1_{2} 2, I_{52}$, I 55, I 65, I 79 , I So, I \& I, I \&2, 539

Hymenoptera, 396, 40I, 402, $4_{12}, 420$, $42 \mathrm{I}, 4^{25}$

Ichneumon, 396

Inarticulata, $3 \mathbf{I}$ I, 3 I6

Inermia, 355

Infusoria, 7,8

Insecta, 5, I 5, I 8, I 9, $25,46,395,396$, $425,455,+58$

Intoshia gigas, I 36

Isidinæe, 18 I

Isodyctia, I 47

Isopoda, I09, 5I 5, 519, 52 I, 523, 527

Julus Moneletei, $3^{87}, 3^{88}, 3^{89}$

Kochlorine, 499
Lacertilia, 64

Lacinularia, 22 I, 223

,$\quad$ socialis, 75

Lamellibranchiata, $\mathbf{2 3}, \mathbf{2 5}, \mathbf{3 7}, 39,98$, $225,24 \mathrm{I}, 257,258,259,269,270,271$, $273,274,288$

Lepadidxe, $49^{8}$

Lepas fascicularis, $224,493,494,495$

Lepidoptera, 79, 396, 402, 407, 408, $4^{12}$, $4^{13}, 4^{15}, 4^{I} 7,4^{20},+2 \mathrm{I}, 4^{23},+25,+26$, 455

Leptodora, I6, 51

Leptoplana, 74, 189, 192, 193

Lernæopoda, $490,492,520$

Leucifer, 507

Libellulidx, $402,403,409,420$

Limax, 229, 232, 239, 278, 280

Limnadia, 79,524

Limulus, 534

Lina, 402

Lingulidæe, 3 I I, 316

Lithobius, 393

Lobatre, 178

Loligo, $2+2,243,244,247,253$

Loricata, 507,514

Lota, 105

Loxosoma, 292, 294, 296, 306, 307

Lucernaria, I85

Lumbricus, $34^{1}, 3^{68}$

$$
\begin{array}{ll}
, & \text { agricola, } 32 \text { I } \\
,, & \text { rubellus, } 324 \\
,, & \text { trapezoides, } 13,321,323
\end{array}
$$

Lumbriconereis, 334

Lymnxus, 82, 98, 226, 227, 232, 238 , $28 I$

Lycosa, +36

Macrostomum, 32, 34

Macrura, $47^{6}$

Malacobdella, 203

Malacodermata, I 71

Malacostraca, 66, 459, 462, $465,50_{4}$, $505,506,51 \mathrm{I}, 523$

Mammalia, $56,58,59,64,66$

Marsipobranchii, 59

Mastigopus, 473,474

Medusæ, $27,154,157,158,163,164,176$, I 78, I 8 I, I $82,183,184$, I 85,186

Megalopa, ${ }_{4} 8_{2}, 48_{3},{ }_{4} 8_{4}$

Melolontha, 402, 42 I

Membranipora, 297, 303

Mermithida, $37 \mathbf{I}$

Mesotrochæ, 330

Metachætæ, 335

Metazoa, 9, 10, 1 2, 67, 86, 125, 1 35, 1 49, I 50,179

Millepora, 152, I8I

Mitraria, 308, 337

Molgula, 102

Mollusca, 5, I $8,24,66,74,8_{4}, 99,225$, $2+7,248,251,256,257,262,27 \mathrm{I}, 285$, $288,307,3^{2} 5,333,352,576,5^{82}$ 
Monomya, 225

Monostomum capitellum, 205

Monotrochre, $33^{\circ}$ mutabile, 205, 206

Iontacuta, 260, 262

Musca, 396

Muscid $x, 420,423$

Myobia, $4+4,4+5$

Myrianida, $3+3$

Myriapoda, 2 2, 1 I r, I 1 3, 387, 394, 395, $+13,+58$

Myriothela, I55

Myrmeleon, $39^{6}$

Mysis, $120,469,472,486,504 \cdot 509,525$

Mytilus, 260, 26 I

Myxinoids, 5

Myxispongiae, 145

Myzostomea, 369

Nais, $34^{2}$

Nassa mutabilis, Io I, 226, 227, 23.3, 262, $278,279,288,324$

Natantia, $4^{87}$

Natica, 237,283

Nauplius, 5, I6, $460,+61,4^{6} 3_{3}+{ }^{6} 5,466$, $469,+73,+90,+9 r,+93,+97$

Nautilus pompilius, $253,2,6$

Nebaliadie, $459,4^{65}, 486$

Nematoda, 45, 46, 50, 66. 74, 75, 37 I, $373,37+, 376$

Nematogens, I 3 I

Nematoidea, I8, $84,94,37$ I, $37+$

Nematus ventricosus, $I_{3},+27$

Nemertea, 94, I89, 196, 202, 20.4

Nemertines, 30, 31, 33, 93, I 36, I95, $202,328,333,+24$

Nephelis, 82, 346, 349, 350, $35 \mathbf{I}, 352$, 354

Nereis, $3+3$

, diversicolor, $3 \mathbf{1 9}$

, Dumerilii, 343

Neritina, 229, 237

Neuroptera, $396,+401,+20,+21$

Neuroterus ventricularis, $t^{28}$

Notonecta, 395

Nototrochx, 330,353

Nudibranchiata, 229, $24 \mathrm{I}$

Ocellata, $\mathbf{1} 84$

Octocoralla, I 52, I 79

Octopus, $2+8$

Odontophora, 225, 257, $27 \mathrm{I}$

Odontosyllis, 333

Oedogonium, I I

Oligochreta, 42, 319, 32 I , 325, 330, 338, $3+6,352$

Olynthus, I $4+$

Oniscus murarius, $107, \mathbf{1 0 8 ,} \mathbf{1 0 9 ,} \mathbf{1} 20$, $516,520,528$

Opercula, $3 \mathbf{I}$

Ophiothryx, 36, 549

Ophidia, 64
Ophiuroidea, I $36,544,553,562,565$, 576

Ophryotrochre puerilis, 333

Opisthobranchiata, 225, 232, 2.37

Ornithodelphia, Iog

Orthonectidæe, $\mathbf{I}_{3} 6$

Orthoptera, $395,+14,420,42 I+425,+26$

Ostracoda, $459,500,5$ IO

Ostrea, 259, 260, 262

Oxyuridæe, $46,373,37+$

Oxyurus ambigua, $37+$

, vermicularis, 375

Precilopoda, 534

Paguridae, +77

Palæmon, I Io

Palæmonetes, 476

Palæmoninx, 476,5 I I, 5 I 2

Palinurus, $478,4^{80}$

Paludina, 66, 227, 229, $235,270,278$, 280

,$\quad$ costata, 229

, vivipara, 226

Pandorina, I I

Parasita, $+^{89}$

Pedalion, 22 I

Pedicellina, 98, 292, 296, 299, 307

Pelagia, 167 , I85

Penæin $x, 476$

Penreus, I Io, I I $3,+65,469,+73,+7+$, $504, \div$ I 8

Pennatulidæ, I8 I

Pentacrinus,

Pentastomida, $539,5+0$

Pentastomum denticulatum, $5+0,5+\mathrm{I}$

Percidae, 64

tanoides, 539, 540, 54 I

Perennichietæ, 335

Peripatus, 5, 386, 4 I I , + I 2, 4 I $3,5+2$

Petromyzon, 6I, 63, 64, 74, 83

Phalangella, $30_{4}$

Phalangidæ, +36

Phallusia, 83

Phascolosoma, $44,355,356,36$ I

Pholcus, $436,4+2$

Phoronis, 3 I $5,35.5,363,364$

Phoxinus levis, 378

Phryganea, 396, 40I, 409

Phylactolæmata, 292, 294, 297, 305, 306

Phyllobothrium, 2 I8

Phyllodoce, 329

Phyllopoda, I6, $459,46 \mathrm{r}, 505$

Phyllosoma, 479,480

Phylloxera, +29

Physophoridie, I52, 162, $16_{4}$

Pilidium, type of, 196, 200, 201, 202, 204, $42+$

Pisces, 5

Piscicola, 20, 43

Pisidium, 259, 260, 262, 264

Planaria Neapolitana, I93

Planorbis, 273, 281, 325 
Platyelminthes, I $8,20,24,221,+24$

Platygaster, $39^{6}, 4$ I 6,4 I 7 , I 8, + I 9

I'leurobrachia, I $76,177,238$

Pneumodermon, $24^{2}, 576$

Podostomata, 292

Poduridie, foI, 405

Polychreta, 42, 3I 9, 325, 338

P'olydesmus complanatus, $3^{8} 7,3^{88}$

Polygordius, 3 I9, $325,326,327,328$, $332,357,386$

Polynœ, 42,33 I

Polyophthalmus, 328

Polyplacophora, 225, 254, 270, 27 I, 288

Polystomeæ, I89, 205, 209

Polystomum, 200

Polytrochre, 330, 333

Polyxenia leucostyla, I $5^{8}$

Polyxenus lagurus, $3^{87}$

Polyzoa, 98, .303, 305, .306, .308, .3 I 5, 3I6

Porcellana, $48_{3}$

Porifera, $\mathbf{I}_{2}, \mathbf{I}_{3} 8, \mathbf{I}_{4} 8$

Porthesia, I I 5

Prorhyncus, 32, 34

Prosobranchiata, 225, 237, $28 \mathrm{I}$

Prostomum, 32, 34, .38, I96

Protozoa, 8, 9, Io, I I, 86, I 35 , I +9

Protozoaea, 47

Protula Dysteri, $34^{2}$

Pseudoneuroptera, +26

Pseudoscorpionidae, 4.34

Psolinus, 556, 574

l'sychidre, i 6

Pteraster miliaris, ;6I

Pteropoda, 98, 225, 226, 229, 230, 232, $240,258,270,272,279,283$

Pterotrachaea, 7 I, 229, 240

Pulex, 396

Pulmonata, 39, 225, 232, 238, 28I, 282

Purpura lapillus, $7 \mathrm{~S}$

Pycnosonida, 538

Pyrosoma, I 3, 53, Io9

Rana temporaria, 2 Io

Raspailia, $\mathbf{I}_{47}$

Redia, 206, 207, 208, 209

Reniera, I 47

Reptilia, 56, 59, 60, 6I, 62, 64, I09

Rhabditis dolichura, 82

Rhabdocœla, 32, 33, I 89, I96

Rhabdopleura, 294, 306

Rhizocephala, $459,493,499,500$

Rhizocrinus, 5

Rhizostoma, $\mathbf{1}_{7}$

Rhombogens, I 3I, I 34

Rhynchonellidæe, 3I I

Rhyncobdellidre, $34^{6}$

Rotifera, 5, I 2, I8, 75, 76, 77, 79, 83, I02, $22 \mathrm{I}, 308,325$

Saccocirrus, $328,329,332,3+0$

Sacculina, 500
Sagartia, I 69, I 7 I

Sagitta, $23,74,94,130,366,367,3^{68}$

Salmonidre, $6+$

Salpa, Iо2

Sarcia, I64

Scaphopoda, 225, 257, 270, 27I

Schistocephalus, 2 I 1

Schizopoda, $459,4^{6},+66$

Scolopendra, 392

Scorpio, I $20,+3 \mathrm{I}, 4+6,+54,+55,+57$

Scrobicularia, 38, 39

Scyllarus, +77

Scyphistoma, I 79, I85, I86

Sedentaria, 3 I $9,33^{6}$

Sepia, $20,40,4 \mathrm{r}, 24^{2}, 243,2+4,245$, $247,249,253$

Sergestidx, $473,50 \%$

Serpula, $3 \mathbf{I} 9,325,33 \mathbf{I}$

Sertularia, I 52, I $83,18+$

Silicispongize, $\mathbf{I}+7$

Simulia, $40 \mathrm{I}$, + I 5

Siphonophora, I3, 27, 152, 159, 163, I 65,179, I $80,182, I 85$

Sipunculida, 24

Sipunculus, t+

Sirex, 396

Sitaris, 42 I

Spathegaster baccarum, 428

Spio, +2, 332, 333

Spiroptera obtusa, 376

Spirorbis Pagenstecheri, 3 I9 , spirillum, $3 \mathbf{1 9}, 336$

Spirula, 252

Spirulirostra, 252

Spongelia, I $77_{7}$

Spongida, $\mathbf{1}^{8} 8, \mathbf{I}_{44}, \mathbf{1}_{4} 8, \mathbf{1}_{4} 9$

Spongilla, $\mathbf{r}_{47}$, I 50

Sporocysts, 206, 207, 208, 209

Squilla, 66, 504, 507

Stephanomia pictum, I 62, I 65

Stomatopoda, $459,+^{6} 5,4^{S_{4}}$

Stomodreum, + I 3

Strongylidae, 37 I, 375

Strongylocentrus, 567

Strongysoloma Guerinii, 387, 388, 390

Stylasteridre, 152, I SI

Styliolidx, 24 I

Stylochopsis ponticus, I 93

Sycandra, 93, I $38, I_{44}, I_{45}, I_{47}$, I so

Syllis, $3+3$ raphanus, 138 , I $7+$

,, vivipara, $3 \mathbf{I} 9$

Sympodium coralloides, I 68

Treniatæe, $\mathbf{I}_{7} 8$

Tardigrada, $5+\mathbf{I}$

Tegenaria, +36

Teleostei, I $8, \mathbf{2 5}, \mathbf{5 6}, 59,64$, г 7 , 109

Telotrochi, $33^{\circ}$

Tendra, 300

Tenthreds, $39^{6}$

Terebella conchilega, $33^{2}, 333,337$ 
Terebella nebulosa, 332, 333

Terebratula, 3I I , 3 I 5

Terebratulina, 3 I I, 3 I 5,3 I 6

Teptentrionalis, $3 \mathbf{I} 5,3 \mathbf{I} 6$

Tergipes, 232, 238

, Edwardsii, 2.38

, lacinulatus, 238

Tethya, I 47

Tetrabranchiata, 225

Tetranychus telarius, I I6

Tetrastemma varicolor, 20.3

Thalassema, 4t, 355, 357

Thalassinidx, +77

Thallophytes, I I

Thecidium, $3 \mathbf{I} \mathbf{I}, 3 \mathbf{I} 2,3 \mathbf{I} 5,3 \mathbf{I} 6$

Thecosomata, 225

Thoracica, 459, 493, 499, 500

Thysanozoon, 192, 193

Thysanura, $395,408,425,458$

Tichogonia, 39

Tipula, 396

Tipulidæe, 420, 42 I

Toenia coenurus, $2 \mathrm{I}_{4}$

,, echinococcus, 2 I 5,2 I 7

, solium, 2 I 7

Tornaria, 579, $58 \mathrm{I}$

Toxopneustes, 22, 24, 35, 85, 88, 89

Tracheata, $385,426,43^{2}, 44^{8}, 455,457$, $458,538,54$ I

Trachymedusx, I 53, I $56, \mathbf{I}_{79}, \mathbf{I}_{5}$

Trematodes, I4, I6, 29, 30, $31,32,3.3$, $+6,94$, I $89,205,208,210,2$ I 2,216
Trichina, 377,378

Trichinidæ, 37 I

Trichocephalus affinis, 374

Trochosphæra xquatorialis, 22 I

Tubiporidæ, $\mathbf{I} 82$

Tubularia, 34, 38, I 52, I 54, I58

Tubularidæ, 29, I79, I83

Tunicata, 5, I4, 53

Turbellaria, 5, 30, 3I, 33, 74, 98, IO2, I 36, I 79, I 89, I 93,333

Tyroglyphus, 445

Unio, $37,3^{8}, 39,100$, го I, $259,260,265$, $266,4+5$

Vaginulus luzonicus, 229

Vermes, 5, 74, I02, 22.3, 324, 3.52

Verongia rosea, $\mathbf{I}_{4} 6$

Vertebrata, 14, I8, 19, 24, 59, 64, 8,3 , $272,349,397,426$

Vesiculata, i $8_{4}$

Vitrina, 229

Vorticella, 8, 9, ro

Wilsia, $6_{4}$

Xiphoteuthis, 252

Zoantharia, $152,168,160$

Zora, $4^{65}, 4^{68}, 47 \mathrm{r},+74,4^{82}, 4^{8} 3,4^{8}$, 486,504 



\title{
BIBLIOGRAPHY.
}

\author{
The Ovum.
}

General Works.

(1) Ed. van Beneden. "Recherches sur la composition et la signification de l'œuf," etc. Mém. cour. d. I'Acad. roy. des Sciences de Belgique, Vol. xxxiv. i 870.

(2) R. Leuckart. Artikel "Zeugung," R. Wagner's Handwörterbuch d. Physioloyie, Vol. IV, I8 83 .

(3) Fr. Leydig. "Die Dotterfurchung nach ihrem Vorkommen in d. Thierwelt u. n. ihrer Bedeutung." Oken. Isis, $\mathrm{I}_{4} 8$.

(4) Ludwig. "Ueber d. Eibildung im Thierreiche." Arbeiten a. d. zool.-zoot. Institut. WVïrzburg, Vol. I. $1874^{1}$.

(5) Allen Thomson. Article "Ovum" in Todd's Cyclopadia of Anatomy and Phy'siology, Vol. v. I 859 .

(6) W. Waldeyer. Eicrstock $u$ Ei. Leipzig, I87o.

THE OIUM OF COLENTERATA.

(7) Ed. van Beneden. "De la distinction originelle d. testicule et de l'ovaire." Bull. Acall. roy. Belgique, 3 e série, Vol. xxxvir. i ${ }_{74}$.

(8) R. and O. Hertwig. Der Organismus d. Medusen. Jena, 1878 .

(9) N. Kleinenberg. Hydra. Leipzig, 1872.

\section{THE OVUM OF PLATYELAINTHES.} 1879.

(10) P. Hallez. Contributions à l'Histoire naturelle des Turbellariés. Lille,

(11) S. Max Schultze. Beiträge z. Naturgeschichte d. Turbellarien. Greifswald, $185 \mathrm{I}$. IS 36.

(12) C. Th. von Siebold. "Melminthologische Beiträge." Müller's Archiv',

(13) C. Th. von Siebold. Lehrbuch d. vergleich. Anat. d. wirbellosen Thiere. Berlin, 1848 .

(1.) E. Zeller. "Weitere Beiträge z. Kenntniss d. Polystomen." Zcit. f. wiss. Zool., Bd. Xxvir. I 876 .

[Vide also Ed. van Beneden (No. I).]

\section{THE OVUM OF ECHINODERMATA.}

(15) C. K. Hoffmann. "Zur Anatomie d. Echiniden u. Spatangen." Niederlündisch. Archio f. Zoologie, Vol. I. I871.

(16) C. K. Hof fmann. "Zur Anatomie d. Asteriden. Niederländisch. Archiv" f. Zoologic, Vol. II. I873.

(17) H. Ludwig. "Beiträge zur Anat. d. Crinoiden." Zeit. f. wiss. Zool., Vol. xxvili. I 877 .

(18) Joh. Müller. "Ueber d. Canal in d. Eiern d. Holothurien." Miiller's Archiv, I854.

(19) C. Semper. Holothurion. Leipzig, i 868.

(20) E. Selenka. Befruchtungd. Eies v. Toxopncustes varicgatus, i 878 . [Vide also Ludwig (No. 4 ), etc.]

1 A very complete and critical account of the literature is contained in this paper.

B. II. 
THE OVUM OF MOLLUSCA.

\section{Lamellibranchiata.}

(21) II. Lacaze-Duthiers. "Organes génitaux des Acéphales Lamellibranches." Ann. Sci. Nat., $4^{\text {me }}$ série, Vol. II. I854.

(22) W. Flemming. "Ueb, d. er. Entwick. am Ei d. Teichmuschel." Archiv f. mikr. Anat., Vol. x. I874.

(23) W. Flemming. "Studien iib. d. Entwick. d. Najaden." Sitz. d. k. Akad. Wiss. Wien, Vol, Lxxi. 1875 .

(24) Th. von Itessling. "Einige Bemerkungen, etc." Zeit. f. wiss. Zool., Bd. v. 1854 .

(25) H. von Jhering. "Zur Kenntniss d. Eibildung bei d. Muscheln." Zeit. f. wiss. Zool., Vol. Xxix. 1877 .

(26) Keber. De Introitu Spermatozoorum in ovula, etc. Königsberg, 1853 .

(27) Fr. Leydig. "Kleinere Mittheilung etc." Muiller's Archiv, I 854.

\section{Gasteropoda.}

(28) C. Semper. "Beiträge z. Anat. u. Physiol, d. Pulmonaten." Zcit. f. ziss. Zool., Vol. vili. 1857.

(29) H. Eisig. "Beitrïge z. Anat. u. Entwick. d. Pulmonaten." Zeit.f. ariss. Zool., Vol. xix. 1869 .

(30) Fr. Leydig. "Ueb. Paludina vivipara." Zeit. f. wiss. Zool., Vol. II. 1850.

\section{Cephalopoda.}

(31) Al. Kölliker. Entwicklungsgeschichted. Ccphalopoden. Zürich, I844.

(32) E. R. Lankester. "On the Developmental History of the Mollusca." Phil. Trans., I 875 .

\section{THE OVUM OF THE CHETOPODA.}

(33) Ed. Claparède. "Les Annelides Chæetopodes d. Golfe de Naples." Mím. d. l. Sociét. phys. et d'hist. nat. de Genìve, 1868-9 and 1870.

(34) E. Ehlers. Die Borstcnwiormer nach system. und anat. Untersuchungen. Leipzig, $186_{4}-68$.

(35) E. Selenka. "Das Gefäss-System d. Aphrodite aculenta." Niederländisches Archiv f. Zool., Vol. II. 1873.

\section{THE OVUM OF DISCOPHORA.}

(36) II. Dorner. "Ueber d. Gattung Branchiobdella." Zit.f. wiss. Zool., Vol. xV. I 865.

(37) R. Leuckart. Die menschlichen Parasiten.

(38) Fr. Leydig. "Zur Anatomie v. Piscicola geometrica, etc." Zeit. f. wiss. Zool., Vol. I. I 849 .

(39) C. O. Whitman. "Embryology of Clepsine." Quart. F. of Micr. Sci., Vol. xviı. I878.

\section{THE OVUM OF GEPHYREA.}

(40) Keferstein u. Ehlers. Zoologische Beiträge. Leipzig, I86ı.

(41) C. Semper. Holothuricn, I868, p. 145.

(42) J. IV. Spengel. "Beiträge z. Kenntniss d Gephyreen." Beitrügc $a$. $d$. zool. Station z. Neapel, Vol. I. I 879 .

(43) J. W. Spengel. “Anatomische Mittheilungen iib. Gephyreen." Tagebl. d. Naturf. Vers. München, 1877 .

\section{THE OVUM OF NEMATODA.}

(44) Ed. Claparède. De la formation et de la fécondation des aufs chcz les Vers Nématodes. Genève, I 859 .

(45) R. Leuckart. Die menschlichen Parasiten. 
(46) H. Munk. "Ueb. Ei- u. Samenbildung u. Befruchtung b. d. Nematoden." Zeit. f. wiss. Zool., Vol. Ix. 1858 .

(17) H. Nelson. "On the reproduction of Ascaris mystax, etc." Phil. Trans. 1852.

(48) A. Schneider. Monographie d. Nematoden. Berlin, I866.

\section{THE OVUN OF INSECTA.}

(19) A. Brandt. Ueber das Ei u. seine Bildungsstätte. Leipzig, 1878.

(50) T. I. Huxley. "On the agamic reproduction and morphology of Aphis." Linnean Trans., Vol. xxir. i 858. Vide also Manual of Invertebrated Animals, 1877.

(51) R. Leuckart. "Ueber die Micropyle u. den feinern Bau d. Schalenhaut bei den Insecteneiern." Miiller's Archiv, i 855 .

(52) Fr. Leydig. Der Eierstock u. dic Samentasche d. Insecten. Dresten, i 866.

(53) Lubbock. "The ova and pseudova of Insects." Phil. Trans. i859.

(54) Stein. Die weiblichen Geschlechtsorganed. Käfer. Berlin, $18_{4} 7$.

[Conf. also Claus, Landois, Weismann, Ludwig (No. 4).]

\section{TIIE OVUM OF ARANEINA.}

(55) Vict or Carus. "Ueb. d. Entwick. d. Spinneneies." Zeit. f. ziss. Zool., Vol. II. I 8 亏0.

(56) v. Wittich. "Die Entstehung d. Arachnideneies im Eierstock, etc." Miiller's Archir; $\mathbf{1} 8+9$.

[Conf. Leydig, Balbiani, Ludwig (No. 4 ), etc.]

THE OVUM OF CRUSTACEA.

(57) Aug. Weismann. "Ueb. d. Bildung von Wintereiern bei Leptodora hyalina." Zeit.f. wiss. Zool., Vol. xxviı. 1876.

[For general literature vide Ludwig, No. 4 , and Ed. van Beneden, No. ז.]

\section{THE OVUM OF CHORDATA.}

\section{Urochorda (Tunicata).}

(58) A. Kowa levsky. "Weitere Studien ï. d. Entwicklung d. Ascidien." Archiv f. micr. Anat., Vol. viI. I87I.

(59) A. Kowalevsky. "Ueber Entwicklungsgeschichte d. Pyrosoma." Arch. f. micr. Anat., Vol. XI. 1875 .

(60) Kupffer. "Stammverwandtschaft zwischen Ascidien u. Wirbelthieren." Arch. f. micr. Anat., Vol. vi. is 70.

(61) Giard. "Etudes critiques des travaux, etc." Archives Zool. expériment., Vol. I. 1872 .

(62) C. Semper. "Ueber die Entstehung, etc." Arbeiten a. d. zool.zoot. Institut IVïraburg, Bd. II. I 875 .

\section{Cephalochorda.}

(63) P. Langerhans. "Z. Anatomie d. Amphioxus lanceolatus," pp. 330-3. Archiv f. mikr. Anat., Vol. xiI. I876.

\section{Craniata.}

(64) F. M. Balfour. "On the structure and development of the Vertebrate Ovary." Quart. F. of Micr. Science, Vol. xviII. I 878 .

(65) Th. Eimer. "Untersuchungen ü. d. Eier d. Reptilien." Archiv f. mikr. Anat., Vol. viII. I872.

(66) Pfluger. Die Eierstöcke d. Säugethiere u. d. Menschen. Leipzig, I 863.

(67) J. Foulis. "On the development of the ova and structure of the ovary in Man and other Mammalia." Quart. F. of Nicr. Science, Vol. Xvi. i 876 .

(68) J. Foulis. "The development of the ova, etc." Fournal of Anat. and Phys., Vol. xiIr. 1878-9. 
(69) C. Gegenbaur. "Ueb. d. Bau u. d. Entwicklung d. Wirbelthiereier mit partieller Dottertheilung." Miiller's Archiv, i 86 I.

(70) Alex. Götte. Entricklungsgeschichte d. Unke. Leipzig, 1875.

(71) W. His. Untersuchungen iib. d. Ei u.d. Eientwicklung bei Kinochenfischen. Leipzig, I 873 .

(72) A. Kölliker. Entwicklungsgeschichte d. Menschen w. höherer Thiere. Leipzig, 1878 .

(73) J. Müiller. "Ueber d. zahlreichen Porenkanäle in d. Eikapsel d. Fische." Miller's Archiv, I $8_{54}$.

(74) W. H. Ransom. "On the impregnation of the ovum in the Stickleback." Pro. R. Society, Vol. vir. i 854 .

(75) C. Semper. "Das Urogenitalsystem d. Plagiostomen etc." Arbeiten a. d. zool.-zoot. Instit. Wiirzburg, Vol. I1. I 875 .

[Cf. Ludwig, No. 4 , Ed. van Beneden, No. 1, Waldeyer, No. 6, etc.]

\section{MAturation AND IMPREgNATION OF THE OVUM.}

(76) A uerbach. Organologische Studien, Heft 2. Breslau, 1874.

(77) Bambeke. "Recherches s. Embryologie des Batraciens." Bull. de l'Acad. royale de Belgriguc, sme sér., T. Lxi. I8;6.

(78) E. van Beneden. "La Maturation de l'CEuf des Mammifères." Bull. de l'Acad. royale de Belgique, 2 me sér., T. xL. No. I $2,1875$.

(79) I d em. "Contributions à l'Histoire de la Vésicule Germinative, \&c." Bull. le l'Acad. royale de Belgique, sme sér., T. xLI. No. I, I 876 .

(80) O. Bïtschli. Eizelle, Zellthcilung, und Conjugation der Infusorien. Frankfurt, $18 ; 6$.

(81) F. M. Balfour. "On the Phenomena accompanying the Maturation and Impregnation of the Osum." Quart. F. of Micros. Science, Vol. XviII. 1878.

(82) Calberla. "Iiefruchtungsvorgang beim Ei von Petromyzon Planeri." Zeit. f. wiss. Zool., Vol. xxx.

(83) W. Flem ming. "Studien in d. Entwickelungsgeschichte der Najaden." Sitz. d. k. Akad. Wien, B. Lxxi. 1875 .

(84) H. Fol. "Die erste Entwickelung des Geryonideneies." Fenaische Zeitschrift, Vol. vin. 1873 .

(85) Idem. "Sur le Développement des Ptéropodes." Archives de Zoologie' Expérimentale et Gínirale, Vol. Iv. and v. 1875-6.

(86) Idem. "Sur le Commencement de l'Hénogénie." Archives des Scienees Physiques et Naturelles. Genève, i 877 .

(87) I dem. Recherches s.l. Fécondation ctl.commen. d.l'Hinogínie. Genève, I 879 .

(88) R. Greeff. " "Ueb. d. Bau u. d. Entwickelung d. Echinodermen." Sitzun. der Gesellschaft z. Beförderung d. gesammten Natumoiss. z. Marburs, No. 5, is 8 .

(89) Oscar Hertwig. "Beit. z. Kenntniss d. Bildung, \&c., d. thier. Eies." Morphologisches Fahrbuch, Vol. I. i 876.

(90) I dem. Ibid. Morphologisches Fahrbuch, Vol. IIJ. Heft 1, I 877.

(91) I dem. "Weitere Beiträge, \&c." Morphologisches Fahrbuch, Vol. III. I 877.

(92) I dem. "Beit. z. Kenntniss, \&c." Morphologisches Fahrbuch, Vol. Iv. Heft I and 2. 1878 .

(93) N. Kleinenberg. Hytra. Leipzig, is 72 .

(94) C. Ku pffer u. B. Benecke. Der Vorgang d. Befruchtung am Eie d. Neunaugen. Königsberg, 1878.

(95) J. Oella cher. "Beiträge zur Geschichte des Keimbläschens im Wirbelthiereie." Archiv f. micr. Anat., Bd. vili. i 872 .

(96) W. Salensky. "Befruchtung u. Furchung d. Sterlets-Eies." Zoologischer Anzeiger, No. I I, I 878 . 1878 .

(97) E. Selenka. Befruchtung les Eies von Toxopneustes variegatus. Leipzig,

(98) Strasburger. Ucber Zellbildung u. Zelltheilung. Jena, i 876.

(99) I dem. Ueber Befruchtung u. Zelltheilung. Jena, is 8 .

(100) C. O. Whitman. "The Embryology of Clepsine." Quart. F. of Nirr. Science, Vol. xirll. 1878 . 


\section{Division OF Nucleus.}

(101) IV. F Iemming. "Beiträge z. Kenntniss d. Zelle u. ihrer Lebenserscheinungen." Archiv f. mikr. Anat., Vol. Xvi. 1878 .

(102) E. Klein. "Observations on the glandular cpithelium and division of nuclei in the skin of the Newt." Quart. F. of Mifr. Science, Vol. xix. I879.

(103) Peremeschko. "Ueber d. Theilung d. thierischen Zellen." Archiz $f$. mikr. Anat., Vol. xvi. 1878.

(104) E. Strasburger. "Ucber ein z. Demonstration geeignetes ZelltheilungsObject." Sitz.d. Fenaischen Gesell.f. Med. u. Naturwiss., July I 8, 1879.

\section{SEGMENTATION.}

(105) E. II aeckel. "Die Gastrula u. Eifurchung." Fenaische Zeitschrift, Vol. IX. $\quad{ }_{1877}$.

(106) Fr. Leydig. "Die Dotterfurchung nach ilrem Vorkommen in d. Thierwelt u. n. ihrer Bedeutung." Oken. Isis, is $8_{4}$.

\section{General Works on EMBryology.}

(107) K. E. von Baer. "Ueb. Entwicklungsgeschichte d. Thiere." Königsberg, $1828-37$.

(108) C. Claus. Grundzïge d. Zoologie. Marburg und Leipzig, 1879.

(109) C. Gegenbaur. Grundriss d. vergleichenden Anatomie. Leipzig, is78. Vide also Translation. Elements of Comparative Anutomy. Macmillan and Co., 1878 .

(110) E. Haeckel. Studien z. Gastraa-Theorie. Jena, 1877, and also Fenaische Zeitschrift, Vols. VIII. and $\mathrm{Ix}$.

(111) E. Haeckel. Schöpfungsgeschichte. Leipzig. Vide also Translation. The History of Creation. King and Co., London, 1876.

(112) E. Haeckel. Anthropogenie. Leipzig. Vile also Translation. Anthropogeny (Translation). Kegan Paul and Co., London, 1878 .

(113) Th. H. Huxley. The Anatomy of Invertebrated Animals. Churchill,

(114) E. R. Lankester. "Notes on Embryology and Classification." Quart. 7. of Aicr. Science, Vol. xvir. 1877 .

(115) A. S. P. Packard. Life Histories of Animals, including Man, or Outlines of Comparative Embryology. Holt and Co., New York, 1876.

(116) H. Rathke. Abhandlungen z. Bildung-und Entwicklungsgesch. d. Menschen u.d. Thiere. Leipzig, 1833 .

\section{DICYEMIDE.}

(117) E. van Beneden. "Recherches sur les Dicyemides." Bull. d. IAcadimie roy. de Belgrique, $2^{\mathrm{e}}$ sér. T. XLI. No. 6 and T. XlII. No. $7,18_{7} 6$. Vidé this paper for a full account of the literature.

(118) A. Kölliker. Ueber Dicyema paradoxum den Schmarotzer der Veninanhinge der Cephalopoden.

(119) Aug. Krohn. "Ueb. d. Vorkommen von Entozoen, etc." Froriep Notizen, vil. I839.

\section{ORTHONECTIDA.}

(120) Alf. Giard. "Les Orthonectida classe nouv. d. Phylum des Vers." Fournal de 'A nat. et de la Physiol., Vol. xv. 1879.

(121) El. Metschnikoff. "Zur Naturgeschichte d. Orthonectida." Zoologischer Anseiger, No. $40-43,1879$.

\section{PORIFERA.}

'(122) C. Barrois. "Embryologie de quelques éponges de la Manche." Annales des Sc. Nat. Zool., vi. ser., Vol. III. 1876.

(123) Carter. "Development of the marine Sponges." Annals and Mag. of Nat. Hist., th series, Vol. xıv. IS 7 . 
(121) Ganin ${ }^{1}$ " "Zur Entwicklung d. Spongilla fluviatilis." Zoologischer Anseiger, Vol. I. No. 9, 1878 .

(125) Robert Grant. "Observations and Experiments on the Structure and Functions of the Sponge." Edinburgh Phil. F., Vol. XIII. and Xiv., 1825, 1826.

(126) E. Haeckel. Die Kalkschrü̈mme, I872.

(127) E. Haeckel. Studicn zur Gastraa-Theorie. Jena, I877.

(128) C. Keller. Untersuchungen über Anatomie und Entwicklungsgeschichte ciniger Spongien. Basel, i 876.

(129) C. Keller. "Studien üb. Organisation u. Entwick. d. Chalineen." Zeit. f. wiss. Zool., Bd. XxviII. I879. 1856.

(130) Lieberkühn. "Beitr. z. Entwick. d. Spongillen." Müller's Archiv,

(131) Lieberkiihn. "Neue Beiträge zırr Anatomie der Spongien." Müller's Archiv, 1859 .

(132) El. Metschnik off. "Zur Entwicklungsgeschichte der Kalkschwämme." Zeit.f. weiss. Zool., Bd. XxIV. I874.

(133) El. Metschnik off. "Beiträge zur Morphologie der Spongien." Zeit. f. wiss. Zool., Bd. Xxviı. I 876 .

(134) El. Metschnikoff. "Spongcologische Studien." Zeit. f. wiss. Zool., Bd. XXXII. I879.

(135) Miklucho Maklay. "Beiträge zur Kenntniss der Spongien." Fenaische Zeitschrift, Bd. IV. I868.

(136) O. Schmidt. "Zur Orientirung iiber die Entwicklung der Schwämmc." Zeit.f. worss. Zool., Bd. xxv. 1875 .

(137) O. Schmidt. "Nochmals die Gastrula der Kalkschwämme." Archiv für mikrosk. Anat., Bd. XII. 1876 .

(138) O. Schmidt. "Das Larvenstadium von Ascetta primordialis und Asc. clathrus." Archiv fïr mikrosk. Anatomic, Bd. xıv. 1877 .

(139) F. E. Schulze. "Ueber den Bau und die Entwicklung von Sycandra raphanus." Zeit. f. wiss. Zool., Bd. xxv. 1875 .

(140) F. E. Schulze. "Zur Entwicklungsgeschichte von Sycandra." Zeit. $f$. wiss. Zool., Bd. Xxvir. 1876.

(141) F. E. Schulze. "Untersuchung üb. d. Bau, etc. Die Gattung Halisarca." Zit. f. wiss. Zool., Bd. xxvin. 1877 .

(142) F. E. Schulze. "Untersuchungen üb. d. Bau, etc. Die Metamorphose von Sycandra raphanus." Zeit.f. wiss. Zool., Bd. xxxı. 1878.

-(143) F. E. Schulze. "Untersuchungen ï. d. Bau, etc. Die Familie Aplysinidie." Zeit.f. wiss. Zool., Bd. xxx. 1878 .

(144) F. E. Schulze. "Untersuchungen ï. d. Bau, ctc. Die Gattung Spongclia." Zcit.f. wiss. Zool., Bd. Xxxi1. i 878 .

\section{CELENTERATA. \\ General.}

(145) Alex. Agassiz. Illustrated Catalogue of the Museum of Comparative Anatomy at IHarvard College, No. II. American Acalephæ. Cambridge, U. S., I865.

(146) O. and R. Hertwig. Der Organismus d. Meduse u, seine Stellungz. Keimblattertheorie. Jena, 1878 .

(147) A. Kowalevsky. "Untersuchungen üb. d. Entwicklung d. Coelentcratell." Nachrichton d. kaiscr. Gesell. d. Freunde d. Naturerkenntniss d. Anthropologie u. Ethnographie. Moskau, I873. (Rinssian). For abstract vide Gahresberichte d. Anat. u. Phys. (Hoffman u. Schwalbe), 1873 .

\section{Hydrozoa.}

(148) L. Agassiz. Contributions to the Natural History of the Unital States of America. Boston, 1862 . Vol. IV.

(149) G. J. Allman. A Monograph of the Gymnoblastic or Tubularian Hydroids. Ray Society, I87I-2.

1 There is a Russian paper by the same anthor, containing a full account, with clear illustrations, of his observations. 
(150) G. J. Allman. "On the structure and development of Myriothela." Phit. Trans., Vol. ClXv. p. 2.

(151) P. J. van Beneden. "Mém. sur les Campanulaires de la Côte d'Ostende considérés sous le rapport physiologique, embryogénique, et zoologique." Nouv. Mlém. de 'Acad. de Brux., Tom. xvil. $18+4$.

(152) P. J. van Beneden. "Recherches sur l'Embryogénie des Tubulaires et l'histoire naturelle des différents genres de cette famille qui habitent la Côte d'Óstende." Nouv. Arém. de l'Acad. de Brux., Tom. xvil. $18+4$.

(153) C. Claus. "Polypen u. Quallen d. Adria." Denk. d. math.-natumiss. Classe d. k. k. Akad. d. Wiss. Wien, Vol. xxxvin. I877. $18+7$.

(154) J. G. Dalyell. Rare and Remarkable Animats of Scotland. London,

(155) H. Fol. "Die erste Entwicklung d. Geryonideneies." Fenaische Zeitschrift, Vol. vil. 1873.

(156) Carl Gegenbaur. Zur Lehre vom Generationswechsel und der Fortpflanzung bei Medusen und Polypen. Würzburg, 1854.

(157) Thomas Hincks. "On the development of the Ilydroid Polypes, Clavatella and Stauridia; with remarks on the relation between the Polype and the Medusoid, and between the Polype and the Medusa." Brit. Assoc. Kep., i I86r. I 869 .

(158) E. Haeckel. Zur Entwicklungsgeschichte d. Siphonophoren. Utrecht,

(159) Th. H. Huxley. Oceanic Hydrozaa. Ray Society, 1858.

(160) Geo. Johnston. A History of British Zoophytes. Edin. 1838. and Edition, $18+7$.

(161) N. Kle in enberg. Hydra, eine anatomisch-entwicklnngsgeschichtliche Untersuchung. Leipzig, i 872.

(162) El. Metschnikoff. "Ueber die Entwicklung einiger Colenteraten." Bull. de l'Acad. de St Pítersbourg, xv. 1870.

(163) El. Metschnikoff. "Studien über Entwicklungsgeschichte d. Medusen u. Siphonophoren." Zeit.f. wiss. Zool., Bd. xxiv. 1874 .

(164) H. N. Moseley. "On the structure of the Stylasteridæ." Phit. Trants., 1878 .

(165) F. E. SchuIze. Uiber den Bau und die Entwicklung von Cordylophora tacustris. Leipzig, 1871 .

\section{Actinozoa.}

(166) Al. Agassiz. "Arachnitis (Edwarsia) brachiolata." Proc. Boston Nat. Hist. Society, 1860 . 1878

(167) Koch. "Das Skelet d. Alcyonarien." Morphotog. Fahrbuch, Bd. Iv.

(168) A. Kowalevsky. "Z. Entwicklung d. Alcyoniden, Sympodium coralloides und Clavularia crassa." Zootogischer Anzeiger, No. $38,1879$.

(169) H. Lacaze Duthiers. Histoire nat. du Corait. Paris, 1864.

(170) H. Lacaze Duthiers. "Développement des Coralliaires." Archive's de Zoologie expérimentale et générate, Vol. I. I872 and Vol. II. 1873.

(171) C. Semper. "Ueber Generationswechsel bei Steinkorallen etc." Zeit.f. wiss. Zool., Bd. Xxi1. 1872 .

\section{Ctenophora.}

(172) Alex. Agassiz. "Embryology of the Ctenophorx." Mem. of the Amer. Acad. of Arts and Sciences, Vol. x. No. I11. $187+$.

(173) G. J. Allman. "Contributions to our knowledge of the structure and development of the Beroidæ." Proc. Roy. Soc. Edinburgh, Vol. Iv. 1862.

(171) C. Chun. "Das Nervensystem u. die Musculatur d. Rippenquallen." Abhand. d. Senkenberg. Geseltsch., B. XI. 1879.

(175) C. Claus. "Bemerkungen ii. Ctenophoren u. Medusen." Zeit. f. wiss. Zool., XIv. 1864 .

(176) II. Fol. Ein Beitragz. Anat. u. Entwickl. einiger Kippenquallen. is69.

(177) C. Gegenbaur. "Studien ü. Organis. u. System d. Ctenophoren." Archiv f. Naturgesch., xxiI. I 856 .

(178) A. Kowalevsky. "Entwicklungsgeschichte d. Rippenquallen." Ním. Acad. St Pétersbours, viı. série, Tom. x. No.+. 1866. 

1846 .

(179) J. Price. "Embryology of Ciliogrades." Proceed of British Assoc.,

(180) C. Semper. "Entwicklung d. Eucharis multicornis." Zeit. f. wiss. Zool., Vol. IX. 1858 .

\section{Platyelminthes.}

\section{Tutrbellaria.}

(181) Alex. Agassiz. "On the young stages of a few Amnelids" (Planaria angulata). Annals Lyceum Nat. Hist. of New York, Vol. viII. 1866.

(182) Dalyell. "Powers of the Creator."

(183) C. Girard. "Embryonic development of Planocera elliptica." Four. of Acad. of Nat. Sci., Philadelphia. New Series, Vol. II. $185+$.

(184) Alex. Götte. "Zur Entwicklungsgeschichte d. Seeplanarien." Zoologischer Anzeiger, No. 4,1878 .

(185) P. 11allez. Contributions à l'histoire naturelle des Turbellariés. Thésis à la faculté des Sciences p. le grade d. Docteur ès-sciences naturelles. Lille, 1879.

(186) Knappert. "Bijdragen tot de Ontwikkelings-Geschiedenis der Zoetwater-Planarien." Provinciaal Utrechtsch Genootschap van Küunsten en IVetenschappen. Utrecht, i 865 .

(187) W. Keferstein. "Beiträge z. Anat. u. Entwick. ein. Seeplanarien von St. Malo." Abh. d. könig. Gesell. d. IViss, zu Göttingen. Bd. XIv. 1868.

(188) El. Metschnik off. "Untersuchungen üb. d. Ent wicklung d. Planarien." Notizen d. neurussischen Gesellschaft d. Naturforscher. Odessa, Bd. v. I877. Vide Hoffman and Schwalbe's Bericht for 1878 .

(189) H. N. Moseley. "On Stylochus pelagicus and a new species of pelagic Planarian, with notes on other pelagic species, on the larval forms of Thysanozoon, etc." Quart. Fourn. of Micr. Science, Vol. XVII. 1877 .

(190) J. Miiller. "Ueber eine eigenthimliche Wurmlarva a. d. Classe d. Turbellarien, etc." Miiller's Archivf. Anat. u. Phys. I850.

(191) J. Muiller. "Ueber verschiedene Formen von Seethieren." Müller's Archiv f. Anat. und Phys. 1854.

\section{Nemertea.}

(192) J. Barrois. "L'Embryologie des Némertes." An. Sci. Nat., Vol. vi. 1877 .

(193) O. Bütschli. Archiv f. Naturgeschichte, i 873 .

(194) A. Krohn. "Ueb. Pilidium n. Actinotrocha." Müller's Archiv, i 858.

(195) E. Desor. "Embryology of Nemertes." Procedings of the Boston Nat. History Socicty, Vol. vi. 1848 .

(196) G. Dieck. "Entwicklungsgeschichte d. Nemertinen." Fonaische Zeitschrift, Vol. vili. $187+$.

(197) C. Gegen baur. "Bemerkungen üb. l'ilidium gyrans, etc." Zeitschrift fiir wiss. Zool., Bd. v. $185+$.

(198) C. K. II offman. "Entwicklungsgeschichte von Tetrastemma tricolor." Niederländisches Archiv, Vol. III. 18;6, 18;7.

(199) C. K. Hoffman. "Zur Anatomie und Ontogenie von Malacobdella." Niederländisches Archiv, Vol. IV. I877.

(200) W. C. Mc Intosh. British Annelids. The Nemerteans. Ray Society, $1873-4$.

(201) Leuckart u. Pagenstecher. "Untersuchungen üb. niedere Seethiere." Miiller's Archiv, i 858 .

(202) E. Metschnikoff. "Studien üb. die Entwicklung d. Echinodermen u. Nemertinen." Mém. Acad. imp. Pétersbourg, vir. Ser., Tom. xiv. No. 8, i 869.

\section{Trematoda.}

(203) T. S. Cobbold. Entozoa. Groombridge and Son, 1864.

(204) T.S. Cobbold. Parasites; a Treatise on the Entozoa, etc. Churchill, 1879 .

(205) Filippi. "Mém. p. servir à l'histoire génétique des Trématodes." Ann.

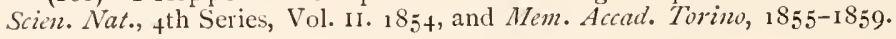


(206) R. Leuckart. Dic menschlichen Parasiten, Vol. I. I $86_{3}$, p. $4_{5} \mathrm{~S}_{5}$ et seq.

(207) H. A. Pagenstecher. Trematoden u. Trematodenlarvin. IPeidelberg, 1857 .

(208) C. Th. von Siebold. Lehrbuch d. vergleich. Anat. wirbelloser Thiere. berlin, $\mathbf{I} s_{4} 8$.

(209) J. J. S. Steenstrup. Generationswechsel. I $8+2$.

(210) R. v. Willemoes-Suhm. "Zur Naturgeschichte d. Polystomum integerrimum, etc." Zeit.f. wiss. Zool., Vol. xxiı. I872.

(211) R. v. Willemoes-Suhm. "Helminthologische Notizen III." Zeit. $f$. wiss. Zool., Vol. xxiII. I873. Vide this paper for a summary of known observations and literature.

(212) G. R. IVagener. Beiträge zur Entwicklungsgeschichte d. Eingezueideziörmer. Haarlem, ${ }_{1} S_{55}$.

(213) G. R. Wagener. "Helminthologische Bemerkungen, etc." Zeit.f.wiss. Zool., Vol. Ix. I 850 .

(214) G. R. Wagener. "Ueb. Gyrodactylus elegans." Archiv f. Anat. u. Phys. I 860.

(2L5) E. Zeller. "Untersuchungen ïb. d. Entwicklung d. Diplozoon paradoxum." Zeit.f. wiss. Zool., Vol. xxis. is72.

(216) E. Zeller. "Untersuchungen ï. d. Entwick. u. Bau d. Polystomum integerrimum." Ziit.f. wiss. Zool., Vol. xxiI. I872.

(217) E. Zeller. "Weitere Beiträge z. Kenntniss d. Polystomen." Zeit. f. wiss. Zool., Vol. xxvin. I 876.

\section{Cestoda.}

(218) Ed. van beneden. "Recherches sur la composition et la signification d. l'œuf." Mém. cour. Acad. roy. Belgique. Vol. xxxiv. is68.

(219) P. J. van Beneden. "Les vers Cestoïdes considérés sous le rapport physiologique embryogénique, etc." Bull. Acall. Scien. Bruxelles. Vol. Xvil. I 850 .

(220) T. S. Cobbold. Entozoa. Groombridge and Son, I 864.

(221) T. S. Cobbold. Parasites; a treatise on the Entozoa, etc. Churchill, I 879 .

(222) Th. H. Huxley. "On the Anatomy and Development of Echinococcus veterinorum." Proc. Zool. Soc. Vol. xx. I852.

(203) J. K noch. "Die Naturgesch. d. breiten Bandwürmer." Mém. Acad. Imp. Pétersbourg, Vol. v. Ser. 7, 1863.

(224) F. K ïchenmeister. "Ueber d. Umwandlung d. Finnen Cysticerci in Bandwiimer (Tænien)." Prag. Vierteljahrsschr. $\mathbf{I}_{5} \mathbf{5 2}$.

(225) F. Küchenmeister. "Experimente ïb. d. Entstehung d. Cestoden. 2 "Stufe zunächst d. Conurus cerebralis." Günsburg, Zcitsch. klin. Mled. I v. I 853.

(226) R. Leuckart. Die menschlichen Parasiten, Vol. I. Leipzig, 1863. Vide also additions at the end of the ist and 2 nd volume.

(227) R. Leuckart. "Archigetes Sieboldii, eine geschlechtsreife Cestodenamme." Zeit. f. wiss. Zool., Vol. xxx. Supplement, I8 78.

(228) El. Metschnik off. "Observations sur le développement de quelques animaux (Bothriocephalus proboscideus)." Bull. Acal. Imp. St Pitersbourg, Vol. XIII. 1869 .

(229) IV. Salensky. "Ueb. d. Bau u. d. Entwicklungsgeschichte d. Amphilina." Zeit. f. wiss. Zool., Vol. xxiv. $187+$.

(230) Von Siebold. Burdach's Physiologie.

(231) R. von Willemoes-Suhm. "Helminthologische Notizen." Zeit. f. wiss. Zool., Vol. XIx. Xx. Xxi1. 1869, 70 and 73 .

\section{ROTIFERA.}

(232) F. Cohn. "Ueb. d. Fortpflanzung von Räderthiere." Zeit. f. wiss. Zool., Vol. vil. 1856 .

(233) F. Cohn. "Bemerkungen ü. Räderthiere." Zeit.f. wiss. Zool., Vol. Ix. 1858 , and Vol. xiI. I $86_{2}$.

(234) T. I. II xley. "Lacinularia socialis." Trans. of the Microscopical Socicty, 1853 . 
(235) Fr. Leydig. "Ueb. d. Bau u. d. systematische Stellung d. Räderthiere." Zeit. f. wiss. Zool., Vol. vi. I854.

(236) W. Salensky. "Beit. z. Entwick. von Brachionus urceolaris." Zeit. f. wiss. Zool., Vol. xxi1. I 872.

(237) C. Semper. "Zoologische Aphorismen. Trochosphæra æquatorialis." Zeit.f. zeiss. Zool., Vol. xxi1. 1872 .

\section{Mollusca. \\ General.}

(238) T. H. Huxley. "On the Morphol. of the Cephal. Mollusca." Phit. Trans., 1853.

(239) E. R. Lankester. "On the developmental history of the Mollusca." Phil. Trans., 1875 .

(240) II. G. Bronn and W. Keferstein. Die Klassen u. Ordnungen $d$. Thierreichs, Vol. III. 1862-1866.

\section{Gasteropoda att Pteropoda.}

(241) J. Alder and A. Hancock. "Devel. of Nudibr." Ann. and Magas. Nat. Ilist., Vol. xir. I $8+3$.

(242) N. Bobretzky. "Studien über die embryonale Entwicklung d. Gasteropoden." Archivf. micr. Anat., Vol. xill.

(243) W. K. Brooks. "Preliminary Observations on the Development of Marine Gasteropods." Chesapeake Zoological Laboratory, Session of i878. Baltimore, 1879 .

(244) O. Bütschli. "Entwicklungsgeschichtliche Beiträge (Paludina vivipara)." Zeit. f. wiss. Zool., Vol. xxix. I877.

( 45$)$ W. Carpenter. "On the devel. of the embr. of Purpura lapillus." Trans. Micros. Soc., $2^{d}$ series, Vol. III. 1855.

(246) W. Carpenter. "On the devel. of the Purpura." Ann. and Mag. of Nat. Hist., $2^{d}$ series, Vol. xx. 1857 .

(247) E. Claparède. "Anatomie u. Entwickl. der Neritina fluviatilis." Muiller's Archiv, I857.

(248) H. Eisig. "Beitr. z. Anat. u. Entwickl. der Geschlechtsorg. von Lymnæus." Zeitschr. f. wiss. Zool., Vol. xIx. i 869.

(249) H. Fol. "Sur le développement des Ptéropodes." Archives de Zool. expérim. et générale, Vol. IV. I875.

(250) H. Fol. "Sur le développement des Gastéropodes pulmonés." Compt. rend., $1875, \mathrm{pp} .523-526$.

(251) H. Fol. "Sur le développement des Hétéropodes." Archives de Zool. expérim. et génírale, Vol. v. 1876 .

(252) C. Gegen baur. "Beit. z. Entwicklungsgesch. der Landgasteropoden." Zeitschr.f. w. Zool., Vol. III. I 85 I. I 855 .

(253) C. Gegenbaur. Untersuch. ïb. Pteropoden u. Heteropoden. Leipzig,

(251) H. von Jhering. "Entwicklungsgeschichte von Helix." Finaische Zeitschrift, Vol. IX. 1875 .

(255) W. Keferstein and E. Ehlers. "Beob. üb. d. Entwick. v. Eolis peregr." Zool. Beitr., I86ı.

(256) J. Koren and D. C. Danielssen. "Bemærk. til Mollusk. Udvikling." Nyt Mag. f. Naturvidensk., Vol. v. I 847 . Isis, p. 202. I848.

(257) J. Koren and D. C. Danielssen. Bidrag til Pectinibr. Udvikl. Bergen, I 85 I (supplement, 1852). Ann. and Mag. Nat. Hist., I857.

(258) A. Krohn. "Beobacht. aus d. Entwickl. der Pteropoden u. Heterop." Miiller's Archiv, 1856 and $185 i$.

(259) A. Krohn. Beitr. zur Entwickl. der Pteropoden u. Heteropoden. Leipzig, I 860.

(260) Ir. de Lacaze-Duthiers. "Mém. sur l'anat. et l'embryog. des Vermets." $2^{\mathrm{e}}$ partie. Ann. sc. nat., $t^{\mathrm{e}}$ série, T. XIII. I 860.

(261) P. Langerhans. "Zur Entwickl. der Gasterop. Opisthobr." Zeitschr. f. w. Zool., Vol. Xxin. $18_{73}$. 
(262) E. R. Lankester. "On the development of the Pond-Snail." Quart. F. of Micr. Scie., Vol. XIv. is 7 .

(263) E. R. Lankester. "On the coincidence of the blastopore and anus in Paludina vivipara." Quart. F. of Micr. Scie., Vol. xvi. i 876. 1850 .

(264) F. Leydig. "Ueber Paludina vivipara." Zeitschr. f. zu. Zool., Vol. II.

(265) J. Miiller. Veber Synapta dig. u. ̈̈b. d. Erzeng. v. Schnecken in Holoth., 1852 .

(266) J. Müller. "Bemerk. aus d. Entwickl. der Pteropoden." Monatsber. Berl. Akad., I 857 .

(267) C. Rabl. "Die Ontogenie d. Süsswasser-Pulmonaten." Fenaische Zeitschrift, Vol. Ix. 1875 .

(268) C. Rabl. "Ueb. d. Entwick. d. Tellerschnecke (Planorbis)." Morph. Fahrbuch, Vol. v. is 79 .

(269) IV. Salensky. "Beitr. zur Entwickl. d. Prosobr." Zeitschr. f. w. Zool., Vol. xxis. is 82 . 1851 .

(270) O. S'chmidt. "Ueb. Entwick. von Limax agrestis." Muiller's Archiv,

(271) Max S. Sclultze. "Ueler d. Entwick. des Tergipes lacinulatus." Arch. f. Naturg., Jahrg. xv. I $8+9$.

(272) E. Selenka. "Entwick. von Tergipes claviger." Niederl. Arch.f. Zool, Vol. I. I $8 ;$ I.

(273) E. Selenka. "Die Anlage d. Keimbl. bei l'urpura lapillus." Nicderl. Arch.f. Zool., Vol. I. 1872 .

(274) C. Semper. "Entwickl. der Ampullaria polita, etc." Natuurk. Verhandl. Utrechts Genootsch., 1862.

(275) An. Stecker. "Furchung u. Keimblatterbiklung bei Calyptraa." Morphol. Fahrbuch, Vol. II. 1876 .

(276) A. Stuart. "Ueb. d. Entwickl. einiger Opisthol,r." Zeitschr. f. w. Zool., Vol. xv. I 865 .

(277) N. A. Warneck. "Ueber d. Bild. u. Entwick. d. Embryos bei Gasterop." Bullet. Soc. natural. de Moscou, T. xxiII. 1850.

\section{Cephalopoda.}

(278) P. J. van Beneden. "Recherches sur l'Embryogénie des Sépioles." Nouv. Mćm. Acall Roy. de Bruxelles, Vol. xiv. $18_{t 1}$.

(279) N. Bobretzky. Observation on the levelopment of the Cephalopoda (Russian). Nachrichten d. kaiserlichen Gesell. d. Freunde der Naturwiss. Anthropolog. Ethnogr. bei d. Universität Moskau.

(280) H. Grenacher. "Zur Entwicklungsgeschichte d. Cephalopoden." Zit. f. wiss. Zool., Bd. xxiv. I874.

(281) A. Kölliker. Entwicklungsgeschichted. Cephalopoden. Zürich, 184 .

(282) E. R. Lankester. "Observations on the development of the Cephalopoda." Quart. F. of Micr. Science, Vol. Xv. 1875 .

(283) E. Metschnikoff. "Le développement des Sépioles." Archives a. Sc. phys. et nat., Vol. xxx. Genève, I867.

\section{Polyplacophora.}

(284) A. Kowalevsky. "Ueb. d. Entwick. d. Chitonen." Zoologischer Anseiger, No. 37. 1879 .

(2๑5) S. L. Lovén. "Om utvecklingen hos slägtet Chiton." Stockholm öfuersigt, xir. is 55. [Vile also Ann. and Mag. of Nat. Mist., Vol. XviI. $18_{56} 6$, and Archiof. Naturgeschichte, is $\mathbf{5}^{6}$.]

\section{Scaphopoda.}

(286) H. Lacaze-Duthiers. "Développement du Dentale." Ann. d. Sci. Nat., Series IV. Vol. viI. 1857 .

\section{Lamellibranchiata.}

(287) M. Braun. "Postcmbryonale Entwicklung d. Süsswasser-Muscheln." Zoologischer Garten. 
(288) C. G. Carus. "Neue Untersuch. ib. d. Entwickl. unserer Flussmuschel." Verh. Leop.-Car. Akad., Vol. xvi. I 832 .

(289) W. Flemming. "Studien in d. Entwicklungsgeschichte der Najaden." Sitz. d. k. Akad. Wiss. Wien, Vol. Lxxi. 1875 .

(290) F. Leydig. " Ueber Cyclas Cornea." Mïller's Archiv, I85.

(291) S. L. Lovén. "Bidrag til Känned. om Utveckl. af Moll. Acephala Lamellibr." Vetensk. Akad. Handi., I $8_{4}$ 8. [Vide also Arch. f. Naturg., 1849.]

(292) C. Rabl. "Ueber d. Entwicklungsgeschichte d. Malermuschel." Fenaische Zeitschrift, Vol. x. 1876 .

(293) W. Salensky. " Bemerkungen iiber Haeckels Gastræa-Theorie (Ostrea)." Arch. f. Naturg., I87t.

(294) O. Schmidt. "Ueb. d. Entwick. von Cyclas calyculata." Müller's Arch., 1854 .

(295) O. Schmidt. "Zur Entwickl, der Najaden." Wien. Sitzungsber. math.-nat. C $\%$., Vol. xix. I $8_{5} 6$.

(296) I?. Stepan off. "Ueber die Geschlechtsorgane u. die Entwicklung von Cyclas." Archiv f. Naturgeschichte, $186_{5}$.

(297) H. Lacaze-Duthiers. "Uéveloppement d. branchies d. Mollusques Acéphales." An. Sc. Nat., Sèr. Iv. Vol. v. I856.

\section{POLYZOA.}

\section{General.}

(298) J. Barrois. Recherches sur l'mbryologie des Bryozoaires. Lille, 1877.

\section{Entoprocta.}

(299) B. Hatschek. "Embryonalentwicklung u. Knospung d. Pedicellina echinata." Zeitschrift fïr wiss. Zool., Bd. xxix. I877.

(300) M. Salensky. "Etudes sur les Bryozoaires entoproctes." Ann. Scien. Nat., Ser. vi. Tom. v. i 877 .

(301) O. Schmidt. "Die Gattung Loxosoma." Archiv f. mik. Anat., Bd. xir. 1876 .

(302) C. Vogt. "Sur le Loxosome des Phascolosomes." Archives de Zool. expir. et génér., To.n. v. I 876 .

(303) C. Vogt. "Bemerkungen zu Dr llatschek's Aufsatz üb. Embryonalentwicklung u. Knospung von Pedicellina echinata." Zeit. f. wiss. Zool., Bd. xxx. 1878 .

\section{Ectoprocta.}

(304) G. J. Allman. Monograph of fresh water Polyzoa. Ray Society.

(305) G. J. Allman. "On the structure of Cyphonautes." Quart. F. of Micr. Scie., Vol. XII. I872.

(306) G. J. Allman. "On the structure and development of the Phylactolxmatous Polyzoa." Foumal of the Linnean Society, Vol. Xiv. No. 77. I878.

(307) J. Barrois. "Le développement d. Bryozoaires Chilostomes." Comptes rendus, Sept. $23,{ }_{1} 8_{7} 8$.

(308) E. Claparède. "Beiträge zur Anatomie u. Entwicklungsgeschichte d. Seebryozoen." Zeit. für wiss. Zool., Bd. XxI. I871.

(309) E. Claparède. "Cyphonautes." Anat. u. Entzuick. wirbell. Thiere. Leipzig, $186+$.

(310) R. E. Grant. "Observations on the structure and nature of Flustrx." Edinburgh New Philosoph. Fournal, i827.

(311) B. Hatschek. "Embryonalentwicklung u. Knospung d. Pedicellina echinata" (Description of Cyphonautes). Zeit. f. wiss. Zool., Bd. xxIx. I877.

(312) T. H. Huxley. "Note on the reproductive organs of the Cheilostome Polyzoa." Quart. Four. of Micr. Science, Vol. IV. 1856.

(313) L. Joliet. “Contributions à l'histoire naturelle des Bryozoaires des côtes de France." Archives le Zoologie Expérimentale, Vol. vi. 1877.

(314) E. Metschnikoff. "Ueber d. Metamorphose einiger Seethiere." Göttingische Nachrichten, I 869 . 
(315) E. Metschnikoff. Bull. de I'Acad. de St Pitersbourg, xv. I87 i, p. 507.

(316) H. Nitsche. "Beiträge zur Kenntniss d. Bryozoen." Zeit. f. wiss. Zool., Bd. xx. 1870 .

(317) IV. Repiachoff. "Zur Naturgeschichte d. chilostomen Seebryozoen." Zit.f. wiss. Zool., Bd. xxvi. г 876 .

(318) W. Repiachoff. "Ueber die ersten Entwicklungsvorgänge bei Tendra zostericola." Zeit.f. wiss. Zool., Bd. xxx. I878. Supplement.

(319) W. Repiachoff. "Zur Kenntniss der Bryozoen." Zoologischer Anzeiger, No. io, Vol. I. I $8 ; 8$.

(320) W. Repiachoff. " Bemerkungen üb. Cyphonautes." Zoologischer Anzeiger, Vol. II. I879.

(321) M. Salensky. "Untersuchung an Seebryozoen." Zit. fïr wiss. Zool., Bd. xxiv. I 874 .

(322) A. Schneidcr. "Die Entwicklung u. syst. Stellung d. Bryozoen u. Gephyreen." Archiv f. mikr. Anat., Vol. v. 1869.

(323) S mitt. "Om Hafsbryozoernas utveckling och fettkroppar." Aftryck ur öfuers. af hong. Vet. Akad. Förh. Stockholm, r 865.

(324) T. Hincks. British Marine Polyzoa. Van Voorst, r 880.

[Conf. also works by Farre, Hincks, Van Beneden, Dalyell, Nordmann.]

\section{BRACHIOPODA.}

(325) W. K. Brooks. "Development of Lingula." Chesapeake Zoological Laboratory, Scientific Results of the Session of 1878 . Baltimore, J. Murphy and Co.

(326) A. Kowalevsky. "Development of the Brachiopoda." Protocol of the First Session of the Cnited Sections of Anatomy', Physiology, and Comparative Anatomy at the Meeting of Russian Naturalists in Kasun, 187.3. (Russian.)

(327) II. Lacaze-Duthiers. "Histoire de la Thécidie." Ann. Scien. Nat. ctc. Ser. 4, Vol. xv. I86I.

( 328$)$ Morse. "On the Early Stages of Terebratulina septentrionalis." Mim. Boston Soc. Nat. History, Vol. II. I 869 , also Amm. So Mag. of Nat. Hist. Series 4 , Vol. ViII, I $87 \mathbf{I}$.

(329) Morse. "On the Embryology of Terebratulina." Mem. Boston Soc. Nat. History, Vol. IIt. I 873 .

(330) Morse. "On the Systematic Position of the Brachiopoda." Procedings of the Boston Soc. of Nat. Hist., I87.,.

(331) Fritz Miiller. "Beschreibung einer Brachiopoden-Larve." Miiller's Archiv, is6o.

\section{CHATOPODA.}

(332) Alex. Agassiz. "On the young stages of a few Annelids." Annals Lyceum Nat. IIist. of New York, Vol. vili. is 866.

(333) Alex. Agassiz. "On the embryology of Autolytus cornutus and alternations of generations, etc." Boston Foumal of Nat. History. Vol. vir. i859-63.

(334) IV. Busch. Beobachtungen ï. Anat. u. Entwick. cinger wirleiloser Secthiere, I $85 \mathrm{I}$.

(335) Ed. Claparède. Beobachtungen ü. Anat. u. Entwich. wirbelloser Thiere an ¿l. Küste von Normandie. Leipzig, 1863.

(336) Ed. Claparède u. E. Iletschnikoff. "Reiträge z. Kenntniss üb. Entwicklungsgeschichte d. Chretopoden." Zit.f. wiss. Zool., Vol. Xix. I869.

(337) E. Grube. Untersuchungen üb. Entwicklungd. Anneliden. Königsberg, I $84+$.

(338) B. Hatschek. "Beiträge z. Entwick. u. Morphol. d. Anneliden." Sitz. d. k. Akal. Itriss. Wien, Vol. Lxxiv, 1876.

(339) B. Hatschek. "Studien ïber Entwicklungsgeschichte der Anneliden." Arbitin aus $d$. zoologischen Institute d. Universitüt ITicn. Von C. Claus. Heft III. 1878 .

(340) Th. H. Huxley. "On hermaphrodite and fissiparous spccies of tubicolar Annelide (P'rotula)." Edinburgh New Phil. Fournal, Vol. I. 1855.

(341) N. Kleinenberg. "The development of the earthworm Lumbricus

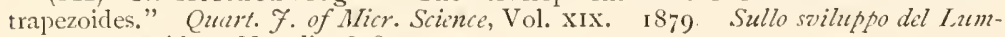
bricus trapesoides. Napoli, I878. 
(342) A. Kowalevsky. "Embryologische Studien an Wïrmern u. Arthropoden." Mém. Acad. Pétersbourg, Series viI. Vol. xvi. i 87 r.

(313) A. Krohn. "Ueber die Erscheinungen bei d. Fortpflanzung von Syllis prolifera u. Autolytus prolifer." Archiv f. Naturgesch. I852.

(344) R. Leuckart. "Ueb. d. Jugendzustände ein. Anneliden, etc." Archiv f. Naturgesch. 1855 .

(345) S. Lovén. "Beobachtungen ii. die Metamorphose von Anneliden." Wiegmann's Archiv, I8 42 .

(346) E. Metschnikoff. "Ueber die Metamorphose einiger Seethierc (Mitraria)." Zeit.f. wiss. Zool., Vol. xxi. $187 \mathrm{I}$.

(317) M. Milne-Edwards. "Rechcrches zoologiques, etc." Ann. Scie. Natur. III. Série, Vol. III. I8+5.

(348) J. Müller. "Ueb. d. Jugendzustände einiger Secthiere." Monats. d. k. Akad. Wiss. Berlin, $185 \mathrm{I}$.

(349) Max M ïller. "Ucber d. weit. Entwick. von Mesotrocha sexoculata." Müller's Archiv, i 855 .

(350) Quatrefages. "Mémoire s. l'embryogénie des Annelides." Ann. Scie. Natur. III. Série, Vol. x. I $8_{4} 8$.

(351) M. Sars. "Zur Entwicklung d. Anneliden." Archiv f. Naturgeschichte, Vol. XI. 1845 .

(352) A. Schneider. "Ueber Bau u. Ent wicklung von Polygordius." Müller's Archiv, $\mathbf{1} 868$.

(353) A. Schneidcr. "Entwicklung u. system. Stcll. d. Bryozocn u. Gephyrcen (Mitraria)." Archivf. mikr. Anat. Vol. v. 1869.

(354) M. Schultze. Ueb. die Entwicklung z'on Arenicola piscatorum u. andere Kiemenwïmer. Halle, is 56 .

(355) C. Semper. "Die Verwandschaftbeziehungen d. gegliederten Thiere." Arbeiten a. d. zool.-zoot. Instit. Wiirzburg, Vol. III. 1876-7.

(356) C. Semper. "Beiträge z. Biologic d. Oligochæten." Arbeiten a. d. zool.-zoot. Instit. Würzlurg, Vol. IV. I $877-8$.

(357) M. Stossich." "Teiträge zur Entwicklung d. Chrtopoden." Sitz. d.k. k. Akad. Wiss. Wien, B. Lxxvir. I878.

(358) R. v. Willemoes-Suhm. "Biologische Beobachtungen ii. nicdrige Meeresthiere." Zeit.f. wiss. Zool. Bd. xxi. I87i.

\section{DISCOPHORA.}

(359) O. Bütschli. "Entwicklıngsgeschichtliche Beiträge (Nephelis)." Zeit. f. voiss. Zool. Vol. XXIX, 1877 .

(360) E. Grube. Untersuchungen ïb. d. Entwicklung d. Anneliden. Königsberg, is $8+4$.

(361) C. K. Hoffmann. "Zur Entwicklungsgeschichte d. Clepsineen." Niederländ. Archiv f. Zool. Vol. Iv. I877.

(362) R. Leuckart. Die menschlichen Parasiten (Hirudo), Vol. I. p. 686, et seq.

(363) H. Rathke. Beit. z. Entwicklungsgesch. d. Hirudineen. Leipzig, I 862.

(364) Ch. Robin. Mém. sur le Déreloppement embryogénique des Hirudinées. Paris, 1875 .

(365) C. O. Whitman. "Embryology of Clepsine." Quart. F. of Micro. Science, Vol. Xvili. 1878 . tions.]

[Vide also C. Semper (No. 355) and Kowalevsky (No. 342) for isolated observa-

\section{GEPHYREA.}

\section{Geplyyea nuda.}

(366) A. Kowalevsky. Sitz. d. zool. Abth. d. III. Versam. muss. Naturf (Thalassema). Zeit.f. wiss. Zool. Vol. xxir. I872, p. 284.

(367) A. Krohn. "Ueb. d. Larve d. Sipunculus nudus nebst Bemerkungen, ' etc. Miiller's Archiv, 1857 . 
(368) M. Salensky. "Ueber die Metamorphose d. Echiurus." Morphologisches Fahrbuch, Bd. II.

(369) E. Selenka. "Eifurchung u. Larvenbildung von Phascolosoma elongatum." Zeit.f. wiss. Zool. I875, Bd. xxv. p. I.

(370) J. W. Spengel. "Beiträge z. Kenntniss d. Gephyreen (Bonellia)." Nittheil. a. d. zool. Station z. Neapel, Vol. I. 1879.

\section{Gephyrea tubicola (Actinotrocha).}

(371) A. Krohn. "Ueb. Pilidium u. Actinotrocha." Miiller's Archiv, r858.

(:372) A. Kowalevsky. "On anatomy and development of Phoronis," P'etcrsburg, 1867. 2 Pl. Russian. Vide Leuckart's Bericht, I 866-7.

(373) E. Metschnikoff. "Ucber d. Metamorphose einigcr Secthiere (Actinotrocha)." Zeit.f. wiss. Zool. Bd. XXI. I87ı. 1846.

(37.1) J. Mi iller. "Tericht ïb. ein. Thierformen d. Nordsee." Miiller's Archiv,

(375) An. Schneider. "Ueb. d. Metamorphose d. Actinotrocha branchiata." Miiller's Arch. I 862.

\section{Chatognatha.}

(376) O. Bütschli. "Zur Entwicklungsgeschichte der Sagitta." Zeitschrift f. wiss. Zool, Vol. Xxirl. 1873 .

(377) C. Gegenbaur. "Ueber die Entwicklung der Sagitta." Abhanl. $d$. naturforschenden Gesellschaft in Halle, 1857 .

(378) A. Kowalevsky. "Embryologische Studien an Wiirmern u. Arthropodcn." Mém. Acad. Pítersbourg, vir. sér., Tom. xvi., No. I2. I87r.

\section{Myzostomen.}

(379) L. Graff. Das Genus Myzostoma. Leipzig, 1877.

(380) E. Metschnikoff. "Zur Entwicklungsgeschichte d. Myzostomum." Zeit. f. zoiss. Zool., Vol. xvi. I 866.

(381) C. Semper. "Z. Anat. u. Entwick. d. Gat. Myzostomum." Zeit. f. wiss. Zool., Vol. Ix. 1858 .

\section{GASTROTRICHA.}

(382) H. Ludwig. "Ucber die Ordnung Gastrotricha Metschn." Zit.f. wiss. Zool., Vol. xxvi. 1876 .

\section{NemATELmintiles.}

(383) O. Bütschli. "Entwicklungsgeschichte d. Cucullanus elegans." Zcit. f. wiss. Zool., B. Xxvi. i 876 .

(38t) T. S. Cobbold. Entozoa. Groombridge and Son, i864.

(385) T. S. Cobbold. Parasites; a Treatise on the Entozoa of Man and Animals. Churchill, 1879.

(386) O. Galeb. "Organisation et développement des Oxyuridés," etc. Archives de Zool. expér. et gínér., Vol. vil. i 878. 1866 .

(387) R. Lcuckart. Untersuchungen üb. Trichina spiralis. 2nd ed. Leipzig,

(388) R. Leuckart. Die menschlichen Parasiten, Bd. II. 1876.

(389) I. A. Pagenstecher. Die Trichinen nach Versuchen dargestellt. I.cipzig, 1865 .

(390) A. Schneider. Monographic d. Nematoden. Ierlin, I866.

(391) A. Villot. "Monographie des Dragoneaux" (Gordioidea). Archives de Zool. expér. et génér., Vol. III. 1874.

\section{ACANTHOCEPHALA.}

(392) R. Greeff. "Untersuchungen ï. d. Bau u. Entwicklung des Echin. miliarius." Archio f. Naturgesch. I864.

(393) R. Leuckart. Die menschlichen Parasiten. Vol. II. p Bor ct scq. r 876. 
(394) An. Schneider. "Ueb. d. Bau d. Acanthocephalen." Archiv f. Anat. u. Phys. is68.

(395) G. R. Wagener. Beiträge z. Entwicklungsgeschichte d. Eingerveidewïrmer. Haarlem, i 865 .

\section{TRACHEATA.}

\section{PROTOTRACHEATA.}

(396) H. N. Moseley. "On the Structure and Development of Peripatus capensis." Phil. Trans. Vol. 164, I874.

\section{MYRIAPODA.}

(397) G. Newport. "On the Organs of Reproduction and Development of the Myriapoda." Philosophical Transactions, 18+1.

(398) E. Metschnikoff. "Embryologie der doppeltfuissigen Myriapoden (Chilognatha)." Zeit.f. witss. Zool., Vol. Xxiv. i874.

(399) E. Metschnik off. "Embryologisches iiber Geophilus." Zcit. f. wiss. Zool., Vol. xxv. i 875 .

(400) Anton Stecker. "Die Anlage d. Keimblatter bei den Diplopoden." Archivf. mik. Anatomie, Bd. xIv. I877.

\section{INSECTA.}

(401) M Balbiani. "Observations s. la reproduction d. Phylloxera du Chêne." An. Sc. Nat. Ser. v. Vol. XIX. I874.

(402) E. Bessels. "Studien ii. d. Entwicklung d. Sexualdriisen bei den Lepidoptera." Zeit.f. wiss. Zool. Bd. xviI. I867.

(403) Alex. B randt. "Beiträge zur Entwicklungsgeschichte d. Libellulida u. Hemiptera, mit besonderer Berïcksichtigung d. Embryonalhitilen derselben." Mím. Ac. Pétersbourg, Ser. viI. Vol. xiII. 1869.

(404) Alex. Brandt. Ueber das Ei u. seine Bildungsstätte. Leipzig, r878.

(405) O. Biitschli. "Zur Entwicklungsgeschichte d. Biene." Zeit. f. wiss. Zool. Bd. Xx. I 870 .

(406) H. Dewitz. "Bau u. Entwicklung d. Stachels, etc." Zeit.f. wiss. Zool. Vols. xxv. and xxvir. 1875 and 1877 .

(407) H. Dewitz. "Beiträge zur Kenntniss d. Postembryonalentwicklung d. Gliedmassen bei den Insecten." Zeit. f. wiss. Zool. xxx. Supplement. 1878.

(408) A. Dohrn. "Notizen zur Kenntniss d. Insectenentwicklung." Zeitschrift f. wiss. Zool. Bd. Xxvi. I 876 .

(409) M. Fabre. "L'hypermétamorphose et les mœurs des Méloïdes." $A n$. Sci. Nat. Series IV. Vol. vil. I 857 .

(410) Ganin. "Beiträge zur Erkenntniss d. Entwicklungsgeschichte d. Insecten." Zeit.f. wiss. Zool. 1Bd. xix. I869.

(411) V. Graber. Die Insecten. München, 1877 .

(412) V. Graber. "Vorläuf. Ergeb. iib. vergl. Embryologie d. Insecten." Archiv f. mikr. Anat. Vol. xv. is 8 s.

(413) O. v. Grimm. "Ungeschlechtliche Fortpflanzung einer Chironomus-Art u. deren Entwicklung aus dem unbefruchteten Ei." Mím. Acad. Pétersbourgo. I 870.

(414) B. Hatschek. "Beiträge zur Entwicklung d. Lepidopteren." Fenaische Zeitschrift, Bd. XI.

(415) A. Kölliker. "Observationes de primâ insectorum genese, etc." Ann. Sc. Nat. Vol. xx. I $8+3$.

(416) A. Kowalevsky. "Embryologische Studien an Würmern u. Arthropoden." Mém. Ac. imp. Pitersbourg, Ser. viI. Vol. xvi. I87I.

(417) C. Kraepelin. "Untersuchungen iib. d. Bau, Mechanismus u. d. Entwick. des Stachels d. bienartigen Thiere." Zeit. f. wiss. Zool. Vol. XxiII. I873;

(418) C. Kupffer. "Faltenblatt an d. Embryonen d. Gattung Chironomus." Arch.f. mikr. Anat. Vol. II. I866.

(419) R. Leuckart. Zur Kénntniss d. Gencrationswechsels u. d. Parthenogenese b. d. Insecten. Frankfurt, 1858 . 
(420) Lubbock. Origin and Iletamorphosis of Linsects. 1874 . 1873 .

(421) Lubbock. Nonograph on Collembola and Thysanura. Ray Society,

(422) Melnikow. "Peiträge z. Embryonalentwicklung d. Insecten." Archiv f. Naturgeschichte, Bd. xxiv. 1859 .

(42:3) E. Metschnikuff. "Embryologische Studien an Insecten." Zeit. $f$. wiss. Zool. Bd. XVI. I 866.

(424) P. Neyer. "Ontogenie und Phylogenie d. Insecten." Fenaische Zeitschrift, Vol. x. $18,6$.

(425) Fritz Miller. "Beiträge 2. Kenntniss d. Termiten." Fenaische Zeitschrift, Vol. IX. 1875 .

(426) A. S. Packard. "Embryological Studies on Diplex, Perithemis, and the Thysanurous genus Isotoma." Alem. Peabody Acad. Science, I. 2. is 87 I.

(427) Suckow. "Geschlechtsorgane d. Insecten." II eusinger's Zeitschrift f. organ. Physik, Bd. II. 18s\$.

(428) Tichomiroff. "Ueber die Entwicklungsgeschichte des Seidenwïrms." Zoologischer Anzeiger, II. Jahr. No. 20 (Preliminary Nitice).

(429) Aug. Weismann. "Zur Embryologie d. Insecten." Archio f. Anat. und Phys. 1864 .

(430) Aug. Weismann. "Entwicklung d. Dipteren." Zcit. f. wiss. Zool. Vols. XII. and XIV. Leipzig, $1863-+$.

(431) A ug. Weisman 11. " Die Metamorphose d. Corethra plumicornis." Zeit. f. zeriss. Zool. Vol. XVI. I 866.

(432) N. Wagner. "Beitrag z. Lehre d. Fortpflanzung d. Insectenlarven." Zeit.f. wiss. Zool. Vol. xil. 1860.

(433) Zaddach. Untersuchussen ïh. d. Bau u. d. Entricklung d. Gliederthiere. lierlin, $185_{4}$.

\section{IR.ACHNIDA.}

\section{Scorpionide.}

(434) El. Mletschnikoff. "Embryologie des Scorpions." Zit.f. wilss. Zcol. 13l. XXI. Is;o.

(130) H. Rathke. Reisebemerbungen aus Taurien (Scorpio), Leiprig, 1837.

\section{Pscutoscorpionide.}

(436) El. Metschnikoff. "Entwicklungsgeschichte d. Chelifer." Zeit.f. wiss. Zool. Bd. xxi. is;o.

(437) A. Stecker. "Entwicklung der Chthonius-Eier im Mutterleibe und oie Bildung des Blastoderms." Sitzung. königl. böhmisch. Gesellschaft IVissenseh., i 876 , 3. Heft, and Annal. and Mag. Nat. History', I876, xvili. 197.

\section{Phalangide.}

(438) M. Balbiani. "Mémoire sur le développement des Phalangides." Ann. Scien. Nat. Series v. Vol. xvi, 1872.

\section{Arancina.}

(439) M. Balbiani. "Mémoire sur le développement des Aranéides." Ann. Scion. Nat. Series v. Vol. xvir. 1873.

(440) F. M. Balfour. "Notes on the development of the Araneina." Quart. Fourn. of Nicr. Science, Vol. xx. I880.

(441) J. Barrois. "Recherches s. 1. développement des Araignées." Fournal de l'A nat. et de la Physiol. 1878 .

(442) E. Claparède. Recherches s. Thócolution des Araignées. Utrecht, I862.

(443) Herold. De generatione Aranconm in Ovo. Marburg, I824.

(44) H. Ludwig. "Ueber die Bildung des Blastoderns bei den Spinnen." Zicit. f. zuiss. Zool. Vol. xxvi. $18-6$.

B. II. 


\section{Acarina.}

(445) P. van Beneden. "Développement de l'Atax ypsilophora." Acad. Bruxelles, t. xxiv.

(446) Ed. Claparède. "Studien über Acarinen." Zeit. f. wiss. Zool., Bd. XVIII. I 868 .

\section{CrustaceA.}

\section{General Works.}

(447) C. Spence Bate. "Report on the present state of our knowledge of the Crustacea." Report of the British Association for 1878 .

(448) C. Claus. Untersuchungen zur Erforschung der genealogischen Grundlage des Crustaccon. Systems. Wien, 1876 .

(449) A. Dohrn. "Geschichte des Krebsstammes." Jenaische Zcitschrift, Vol. VI. I 8 ; .

(450) A. Gerstaecker. Bronn's Thierrcich, Bd. v. Arthropoda, I 866.

(451) Th. II. Iuxley. The Anatomy of Invertcbrated Animals. London, 1877 .

(452) Fritz Miiller. Für Darwin, i864. Translation, Facts for Damuin. London, I869.

\section{Branchiopoda.}

(453) Brauer. "Vorläufige Mittheilung ïber die Entwicklung u. Lebensweise des Lepidurus (Apus) productus." Sitz. der Ak. d. Wiss. Wien, Vol. Lxix., I87+.

(454) C. Claus. "Zur Kenntniss d. Baues u. d. Entwicklung von Branchipus stagnalis u. A pus cancriformis." Abh. d. könig. Gesell, der IViss. Göttingen, Vol. xvi1l. 1873 .

(455) C. Grobben. "Zur Entwicklungsgeschichte d. Moina rectirostris." Arbeit. a. d. zoologisch. Institute Wien, Vol. 11., is 79.

(456) E. Grube. "Bemerkungen über die Phyllopoden nelst einer Uebersicht etc." Archiv f. Naturgeschichte, Vol. xix., I853.

(457) N. Joly. "IIistoire d'un petit Crustacé (Artemia salina, Leach) etc." An. nales $d$. Scienccs Natur., and ser., Vol. XiIr., I 840.

(458) N. Joly. "Recherches zoologiques anatomiques et physiologiques sur l'Isaura cycladoides (= Estheria) nouveau genre, etc." Annales $d$. Scienies Nat., and ser., Vol. XviI., $18+2$.

(459) Lereboullet. "Observations sur la génération et le développement de la Limnadia de Ilermann." Annales $d$. Sciences Natur., sth ser., Vol. v., 1866.

(460) F. Leydig. "Ueber Artemia salina u. Branchipus stagnalis." Zeit. f. wiss. Zool., Vol. III., I85 I.

(461) G. O. Sars." "Om en dimorph Udvikling samt Generationsvexel hos Leptodora." Vidensk. Selskab. Forhand, is 73 .

(462) G. Zaddach. De apodis cancreformis Schaeff. anatome ct historia evolutionis. Dissertatno manguralis zootomica. Bonne, $18+\mathrm{I}$.

\section{Ncbaliade.}

(463) C. Claus. "Ueber den Bau u. die systematische Stellung von Nebalia." Zeit.f. wiss. Zool., Bd. Xxil. 1872 .

(464) E. Metschnik off. Development of Ncbalia (Russian), I 868.

\section{Schizopoda.}

(465) E. van Beneden. "Recherches sur l'Embryogénie des Crustacés. II. Développement des Mysis." Bullet. de l'Académie roy. de Belgique, second series, Tom. XXviII. I869.

(466) C. Claus. "Ueber einige Schizopoden u. niedere Malakostraken." Zcit. f. zeiss. Zoologie, Bd. XIII., IS63. 
(467) A. Dohrn. "Untersuchungen ïb. Bau u. Entwicklung d. Arthropoden." Zeit. f. wiss. Zool., Bd. xxi., 1871, p. 375. Peneus zorea (larva of Euphausia).

(468) E. Metschnikoff. "Ueber ein Larvenstadium von Euphausia." Zeit. für zeiss. Zool., Bd. XIX., I860.

(469) E. Metschnikoff. "Ueber den Naupliuszustand von Euphausia." Zeit. für wiss. Zool., Bd. xxi., 1871 .

\section{Decorpodit.}

(470) Spence Bate. "On the development of Decapod Crustacea." Phil. Trans., 1853 .

(471) Spence Bate. "On the development of Pagurus." Ann. and Mag. Nat. History, Series +, Vol. I1., 1868 .

(472) N. Bobretzky. Development of Astacus and Palemon. Kiew, 1873. (Russian.)

(473) C. Cla us. "Zur Kenntniss d. Malakostrakenlarven." Würzb. naturw. Zeitschrift, I861.

(474) R. O. Couch. "On the Metamorphosis of the I lecapod Crustaceans." Report Comawall Polyt. Socicty, $18_{4} 8$.

(475) Du Cane. "On the Metamorphosis of Crustacea." Ann. and Mug. of Nat. Kistory, 1839.

(476) Walter Faxon. "On the development of Palæmonetes vulgaris." Bull. of the Mus. of Comp. Anat. Harvard, Cambridge, Mizs., Vol. v., 1879.

(477) A. Dohrn. "Untersuchungen ïb. Bau u. Entwicklung d. Arthropoden." "Zur Entwicklungsgeschichte der Panzerkrebse. Scyllarus Palimums." Zeit. f. wiss. Zool., Bd. xix., 1870.

(478) A. Dohrn. "Untersuchungen ïb. Bau u. Entwicklung d. Arthropoden. Erster Beitrag z. Kenntniss d. Nalacostraken u. ilırer Larven Amphion Reynaudi, Lophogaster, Portunus, Porcellanus, Elaphocaris." Ziit. f. wiss. Zool., Bd. xx., 1870.

(479) A. Dohrn. "Untersuchungen iib. Bau u. Entwicklung d. Arthropoden. Zweiter Beitrag, etc." Zeit. f. wiss. Zool., Bd. XxI., 1871 .

(450) N. Joly. "Sur la Caridina Desmarestii." Ann. Scicn. Nat., Tom. Nix., $18+3$.

(\$81) Lereboullet. "Recherches d. l'embryologie comparée sur le développement du Brochet, de la Perche et de l'Ecrevisse." Mim. Sazuns Étrang. Paris, Vol. XVII., I\$6z.

(482) P. Mayer. "Zur Entwicklungsgeschichte d. Dekapoden." Foncische Zeitschrift, Vol. xi., $18 ; 7$.

(483) Fritz Müller. "Die Verwandlung der Porcellana." Archiof. Naturgeschichte, 1862.

(48t) Fritz Miiller. "Die Verwandlungen d. Garneelen." Archiv f. Luturgesch., Tom. xxix.

(485) Fritz N üller. "Ueber die Naupliusbrut d. Garneelen." Zeit. f. wiss. Zool., Bd. xxx., 1878 .

(486) T. J. Parker. "An account of Reichenlach's researchen on the early development of the Fresh-water Crayfish." Quart. F. of M. Science, Vol. Xvin., 1878 .

(487) II. Rathke. Uebor die Bildung u. Entwicklung d. Flusskrelses. Leipzig, 1829 .

(48s) II. Reichenbach. "Die Embryoanlage u. erste Entwicklung d. Flusskrebses." Ziit.f. wiss. Zool., Vol. xxix., $187 \%$.

(48.) F. Richters. "Ein Beitrag zur Entwicklungsgeschichte d. Loricaten." Zeit.f. wiss. Zool., Bd. Xxin., I873.

(490) G. O. Sars. "Om Hummers postembryonale Udvikling." Vidcnsk Selsk. Forh. Christiania, $187+$.

(491) Sidney J. Smith. "The early stages of the American Lobster." Trans. of the Connecticut Acad. of Arts and Sciences, Vol. II., Part 2, i873.

(492) R. v. Willemoes Suhm. "Preliminary note on the development of some pelagic Decapoda." Proc of Royal Society', is 76. 


\section{Stomatopoda.}

(493) W. K. Brooks. "On the larval stages of Squilla empusa." Chesapeake Zoological Laboratory, Scientific results of the Session of 1878. Baltimore, 1879.

(494) C. Claus. "Die Metamorphose der Squilliden." Abhand. dir königl. Gesell. elcr Wiss. zu Göttingen, I87'.

(495) Fr. Mïller. "Bruchstiick a. der Entwicklungsgeschichte d. Maulfüsser I. und 11." Archivf. Naturgeschichte, Vol. Xxirin., I862, and Tol. Xxix., 1863.

\section{Cintacer.}

(496) A. Dohrn. "Ueber den Bau u. Entwicklung d. Cumaceen." Fenaische Zeitschrift, Vol. V., $18 \% 0$.

\section{Isopoda.}

(497) Ed. van Beneden. "Recherches sur l’Embryogénie des Crustacés. I. Asellus aquaticus." Bull. de l'Acal. roy. Belsique, sme série, Tom. xxvili., No. 7 , 1860 .

(498) N. Bobretzky. "Zur Embryologie des Oniscus murarius." Zit. fïr wiss. Zool., lid. Xxiv., $187+$.

(499) J. F. Bullar. "On the development of the parasitic lsopoda." Phil. Trans., Part II., 1878.

(500) A. Dohrn. "Die embryonale Entwicklung des Asellus aquaticus." Zeit. f. wiss. Zool., Vol. xril., I86\%.

(501) H. Rathke. Untersuchungen über die Bilaung und Entwicklung der Hasser-Assel. Leipzig, 1832 .

(5.2) H. Rathke. Zur Murphologie. Reisebemerkungen aus Taurien. Riga u. Leipzig, 1837. (Bopyrus, Idothea, Ligia, Ianira.)

\section{Antplipoda.}

(503) Ed. van Beneden and E. Bessels. "Mémoire sur la formation du blastoderme chez les Amphipodes, les Lernéens et les Copépodes." C'lasse des Siciences de PAcad. roy. de Belgique, Vol. xxxiv., i 868 .

(504) De la Valette St George. "Studien iber die Entwicklung der Amphipoden." Abhand. d. naturfor. Gesell. zu Halle, Bd. V., i $\$ 60$.

\section{Copcpode.}

(505) E. van Beneden and E. Bessels. "Mémoire sur la formation du blastoderme chez les Amphipodes, les Leméens et Copépodes." Classe des Scicnces de 'Acad. roy. de Belgique, Iol. Xxxiv., r 868.

(506) E. va u Beneden. "Recherches sur l'Embryogénie des Crustacés Iv. Anchorella, Lemeopoda, Branchiella, Hessia." Bull. de l'Acad. roy. de bilgrique, zme série, T. xхाх., 18 ;o.

(507) C. Claus. Zur Anatonie u. Entrivckungsgeschichted. Copepoden.

(508) C. Claus. "Untersuchungen über die Organisation u. Verwandschaft d. Copepoden." IVürburser naturwiss. Zeitschrift, Bi. III., I862.

(509) C. Claus. "Ueber den Bau u. d. Entwicklung von Achtheres percarum." Zeit.f. wiss. Zool., Bd. Xı., I862.

(510) C. Claus. Die freilebenden Copefoden mit besonderer Beriücksichtignng der

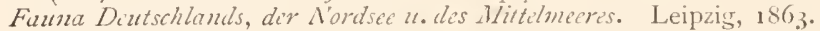

(511) C. Claus. "Ueber d. Entwicklung, Organisation u. systematische Stellung d. Argulida." Zeit.f. wiss. Zool., Hd. xxr., is 75.

(51) I. P. C. Hoek. "Zur Entwicklungsgeschichte d. Entomostracen." Niederlänlisches Archiv, Vol. IV.. I877.

(513) Nordmann. Nikrographische Beiträge zur Naturgeschichte der wirbellosen 7hiere. Zweites Heft. 18,32.

(511) Salensky. "Spharonella Leuckartii." Archio f. Naturgeschichte, i 868.

(515) F. Vejdovsky. "Untersuchungen iih. d. Anat. u. Metamorph. v. Tracheliastes polycolpus." Zit.f. i'iss. Zool., Vol. xixix., 1877 . 


\section{Cirripedia.}

(516) C. Spence Bate. "On the development of the Cirripedia." Annals and Mag. of Natur. History. Second Series, vin., I855.

(j17) E. van Beneden. "Développement des Sacculines." Bull. de l'Acad. roy. de Belg., i8 8 o.

(518) C. Claus. Die Cypris-ähnliche Larate der Cirripedien. Marburg, i869.

(519) Ch. Darwin. A monograph of the sub-class Cirripedia, 2 Vols., Ray Society, I $8,1-4$.

(520) A. Dohrn. "Untersuchungen über Bau u. Entwicklung d. Arthropoden Ix. Eine ncue Naupliusform (Archizoëa gigas)." Zeit. f. wiss. Zool., Bd. xx., 1870.

(521) P. P. C. Hoek. "Zur EntwickIungsgeschichte der Entomostraken I. Embryologie von Balanus." Niederlïndische's Archiv für Zoolosie, Vol. III., I8;6-7.

(522) R. Kossmann. "Suctoria u. Lepadidæe." Arbeiten a. d. zool.-zoot. Institu:te d. Cniver. Wuirz., Vol, I., I873.

(523) A ug. Krohn. "Beobachtungen über die Entwicklung der Cirripedien." Wiegmanis Archiv fiir Naturgesch., Xxvi., I 860.

(524) E. Metschnikoff. Sitzungsberichted. Versammlung deutscher Naturforscher zu Hannozer, i 865 . (Balanus balanoides.)

(525) Fritz Miller. "Die Rhizocephalen." Archiv f. Naturgeschichte, $1862-3$.

(520) F. C. Noll. "Kochlorine hamata, ein bohrendes Cirriped." Zeit. f. wiss. Zool., Bd. xxv., 1875 .

(527) A. Pagenstecher. "Beiträge zur Anatomie und Entwicklungsgeschichte von Lepas pectinata." Zeit.f. wiss. Zool., Vol, xill., I 863.

(528) J. V. Thompson. Zoological hesearches and lilustrations, Vol. I., Part I. Memoir iv. On the Cirripedes or Barnacles. 8vo. Cork, is 8 o.

(529) J. V. Thompson. "Discovery of the Mctamorphosis in the second type of the Cirripedes, viz. the Lepades completing the natural history of these singular animals, and confirming their affinity with the Crustacea." Phil. Trans. I835. Part I I.

(530) R. von Willemoes Suhm. "On the development of Lepas fascicularis." Phil. Trans., Vol. I66, I876.

\section{Ostracoda.}

(531) C. Claus. "Zur näheren Kicnntniss der Jugendformen von Cypris ovum." Zeit. f. wiss. Zool., Bd. Xv., i $\mathrm{S}_{5}$.

(532) C. Claus. "Beiträge zur Kenntniss d. Ostracoden. Entwicklungsgeschichte von Cypris ovum." Schriften d. Gesell. zur Beförderung d. gesamm. Naturwiss. zu Marburs, Vol. IX., I 868.

\section{PECILOPODA.}

(533) A. Dohrn. "Untersuch. uib. Bau u. Entwick. d. Arthropoden (Limulus polyphemus)." Fenaische Zeitschrift, Vol. vi., 18 ; r.

(534) A. S. Packard. "The development of Limulus polyphemus." Mem. Boston Soi. Nat. History', Vol. 11., I8;2.

\section{PYCNOGONIDA.}

(535) G. Cavanna. "Studie e ricerche sui Picnogonidi." Pubblicazioni del $R$. fustituto di Studi suferiori in Firenae, 1877.

(536) A n. Dohrn. "Ueber Entwicklung u. Bau d. Pycnogoniden.", Fenaische Zeitschrift, Vol. v. I8;o, and "Neue Untersuchungen üb. Pycnogoniden." Mittheil. a. d. zooloxischen Station zu Niapel, Ba. I. Is;8.

(537) G. Hodge. "Olservations on a species of Pycnogon, etc." Annal. and Mag. of Nat. Hist. Vol. IX. I 862 .

(538) C. Semper. "Ueber Pycnogoniden u. ihre in Hydroiden schmarotzenden Larvenformen." Arbeiten a. d.zool.-zoot. Instit. M"ürzburg. Vol. I. $18 i_{+}$. 


\section{Pentastomida.}

(539) P. J. van Beneden. "Recherches s. l'organisation et le développement d. Linguatules." Ann. d. Scicn. Nat., 3 Ser., Vol. xi.

(510) R. Leuckart. "Bau u. Entwicklungsgeschichte d. Pentastomen." Leipzig and Heidelberg. 1860.

\section{TARDIGRADA.}

(541) J. Kaufmann. "Ueber die Entwicklung u. systematische Stellung d. Tardigraden." Zeit. f. wiss. Zool., Bd. III. I $85 \mathrm{I}$.

\section{ECHINODERMATA.}

(542) Alex. Agassiz. Revision of the Echini. Cambridge, U.S. $1872-74$.

(543) Alex. Agassiz. "North American Starfishes." Memoirs of the Muscum of Comparative Anatomy and Zoology at Harvard College, Vol. v., No. I. is77 (originally published in $\mathbf{I} 86_{+}$).

(514) J. Barrois. "Embryogénie de l'Asteriscus verruculatus" Fournal de l'Anat. et Phys. I87\%. I $86+$.

(545) A. Baur. Beiträge zur Vaturgeschichte d. Symapta digitata. Dresden,

(546) H. G. Bronn. Klassen u. Ordnungen etc. Strahlenthiere, Vol. II. I860.

(547) W. B. Carpenter. "Researches on the structure, physiology and development of Antedon." Phil. Trans. CLVI, I 866, and Procedings of the Roy. Soc., No. 166. I $8 ; 6$.

(548) P. H. Carpcnter. "On the oral and apical systems of the Echinoderms." Quart. $\widetilde{y}$. of Micr. Science, Vol. xvil. and Xix. is-8-9.

(549) A. Götte. "Vergleichende Entwicklungsgeschichte d. Comatula mediterranen." Arch. fïr micr. Anat., Vol. Xil. is-6.

(550) R. Greeff. "Ueber die Entwicklung des Astcracanthior rubens vom Ei bis zur Bipinnaria u. Brachiolaria." Schriflen d. Gesellschafi zur Beforderning d. gesammten Naturaissenschaften zu Marburg, Bd. Xir. I8-6.

(551) R. Greeff. "Ueber den Bau u. die Entwicklung d. Echinodermen." Sitz. d. Geselt. z. Beförderung d. gesam. Naturwiss. zu Marburg, No. +. I879.

(552) T. H. Huxley. "Report upon the researches of Miller into the anat. and devel. of the Echinoderms." Ann. and Mag. of $\mathrm{Nat}$. Hist., and Ser., Vol. VIIr. $18=\mathbf{I}$.

(553) Koren and Danielssen. "Observations sur la Bipinnaria asterigera." Ann. Scien. Nat., Ser. III., Vol. VII. I8+7.

(5.54) Koren and Danielssen. "Observations on the development of the Starfishes." Ann. and Mag. of Nat. Hist., Vol. Xx. 1857.

(555) A. Kowa levsky. "Entwicklungsgeschichte d. Holothurien." Mém. Ac. Pétersbourg, Ser. vil., Ton. xi., No. 6.

(556) A. Krohn. "Beobacht. a. d. Entwick. d. Holothurien u. Secigel." Muller's Archiv, I $85 \mathbf{I}$.

(5.57) A. Krohn. "Ueb. d. Entwick. d. Seesterne u. Holothurien." Müller's Archiz', I 853 .

(55s) A. Krohn. "Peobacht. iib. Echinodermenlarven." Müller's Archiv, I 8 氵4.

(559) H. Ludwig. "Ueb. d. primar. Steinkanal d. Crinoideen, nebst vergl. anat. Bemerk. üb. d. Echinodermen." Zeit.f. quiss. Zool., Vol. xxxıv. I880.

(560) E. Meischnik off. "Studien iib. d. Entwick. d. Echinodermen u. Nemertinen." Mém. Ac. Pítersbourg, Series vis., Tom. xiv., No. 8. I869.

$(561)^{l}$ Joh. Müller. 'U Ueb. d. Larven u. d. Metamorphose d. Fchinodermen.' A thandlungen d. Berlin. Akad. (Five Menioirs), i $848,49,50,52$ (two Memoirs).

(562) Joh. Mïller. "Allgemeiner Plan d. Entwicklung d. Echinodermen. Abhandl. d. Borlin. Akad., I 853 .

1 The dates in this reference are the dates of pul,lication. 
(563) E. Selenka. "Zur Entwicklung d. Holothurien." Zeit. f. wiss. Z.ool., Bd. xxvil. $18 ; 6$.

(564) E. Selenka. "Keimblätter u. Organanlage bei Echiniden." Zeit.f. wiss. Zool., Vol. xxxirI. 1879 .

(565) Sir Wyville Thomson. "On the Embryology of the Echinodermata." Natural History Reviezu, r864.

(566) Sir Wyville Thomson. "On the Embryogeny of Antedon rosaceus." Phil. Trans. I 865 .

\section{ENTEROPNEUSTA.} I 866.

(567) A. Agassiz. "Tornaria." Ann. Lyceum Nat. Hist. vin. New York.

(568) A. Agassiz. "The History of Balanoglossus and Tornaria." Mem. Amer. Acad. of Arts and Scien., Vol. Ix. 1873 .

(569) A. Götte. "Entwicklungsgeschichte d. Comatula Mediterranea." Archiv fïr mikr. Anat., Bd. xiI., 18,6, p. $6+1$.

(570) E. Metschnikoff. "Untersuchungen ïb. d. Metamorphose, etc. (Tornaria)." Zeit. fïr wiss. Zool., Bd. xx. 1870.

(571) J. Mi iiller. "Ueb. d. Larven u. Metamor. d. Echinodermen." Berlin. Akad., I 849 and 1850 .

(572) J. W. Spengel. "Bau u. Entwicklung von Balanoglossus." Tagebl. d. Naturf. Vers. Miunchen, I877. 



\section{Alemorial Exítion}

\section{THE WORKS}

FRANCIS MAITLAND BALFOUR

VOL. II.

A TREATISE ON COMPARATIVE EMBRYOLOGY.

Vol. I. Invertebrata.

\section{Fontrout :}

MACMILLAN AND CO. 1885 



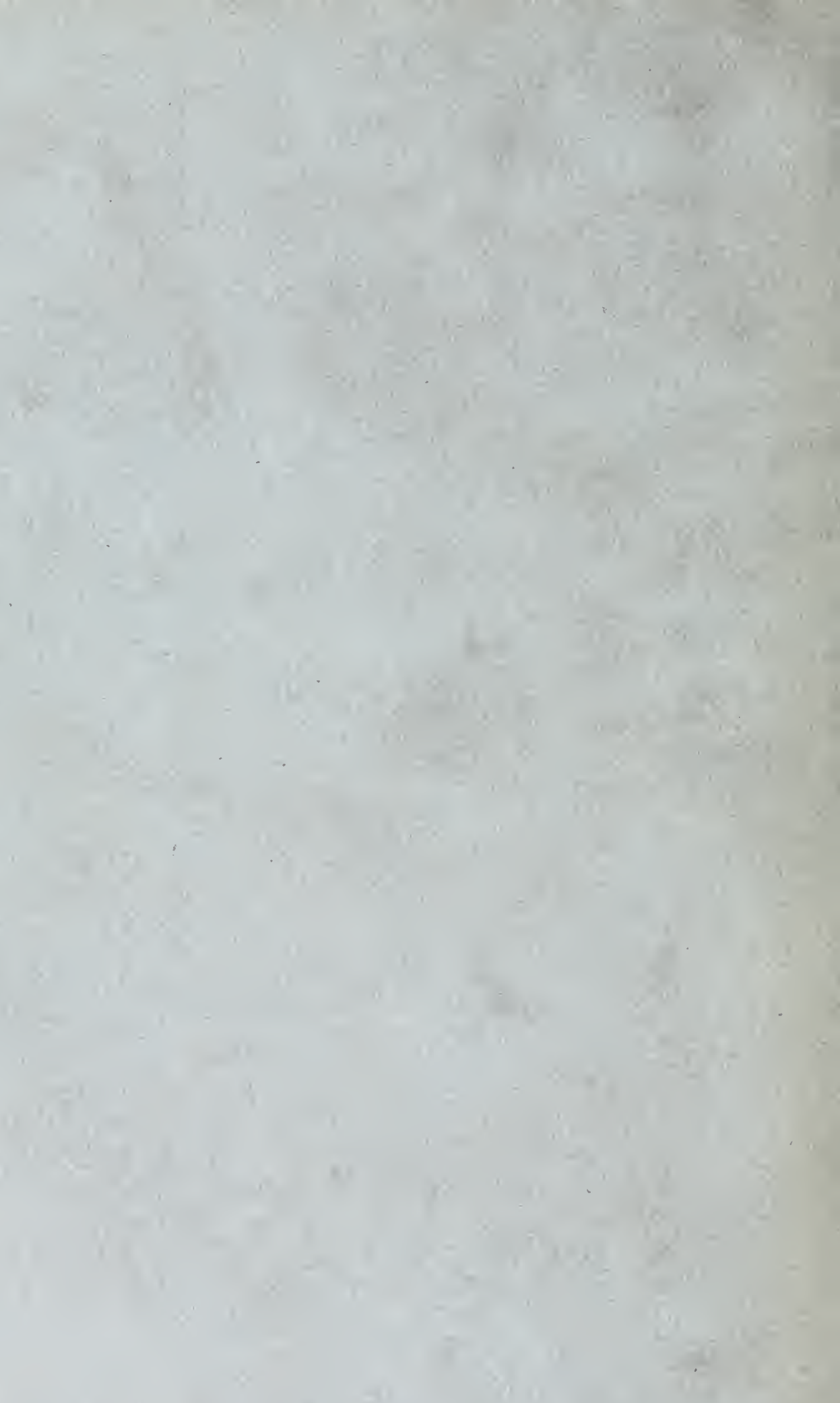







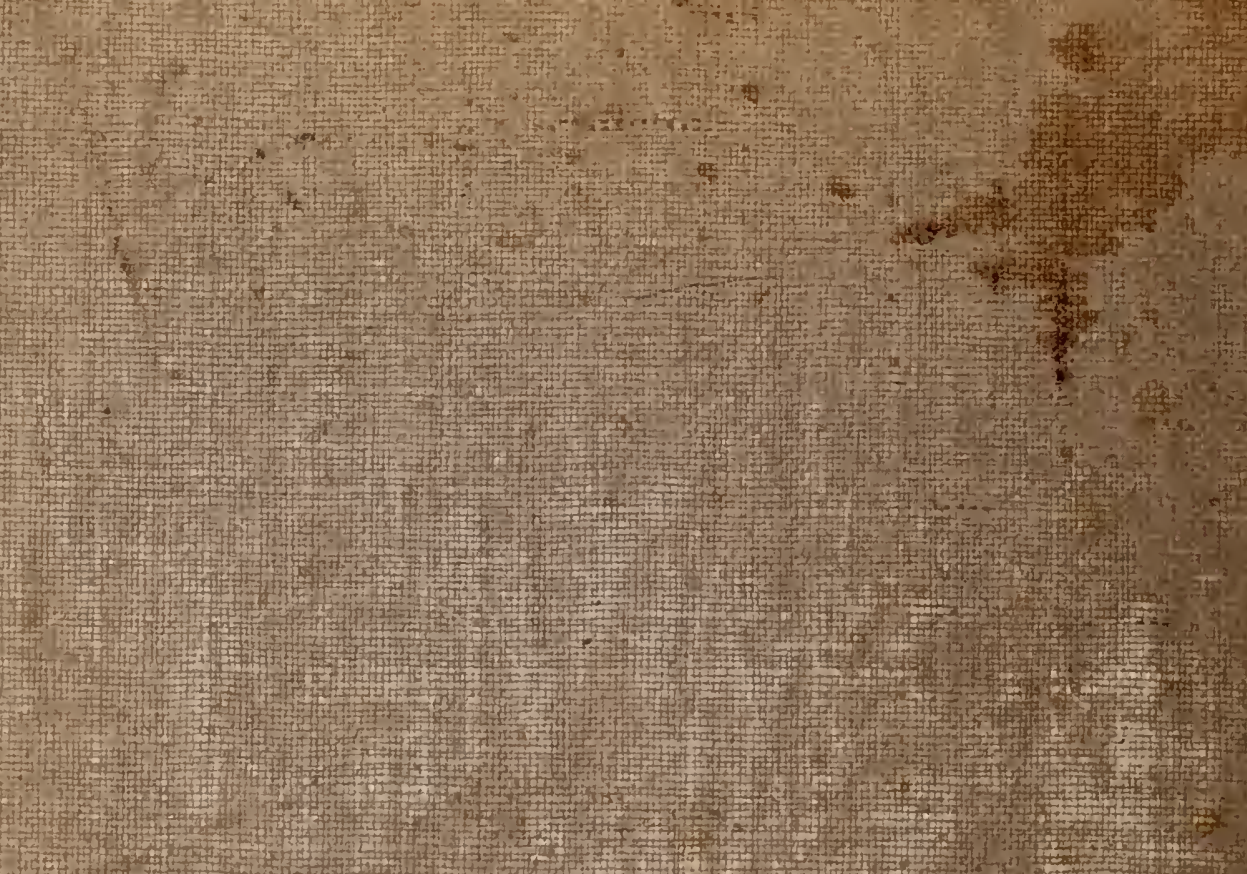

(1) 4.7. 10.

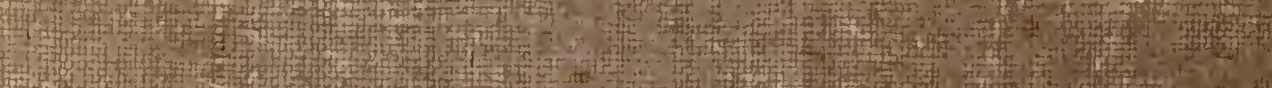
Fin P. (1)

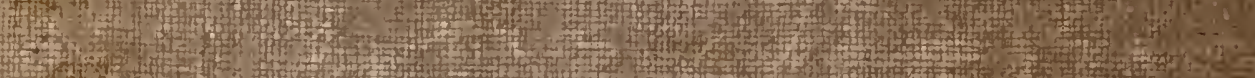
4 (2)

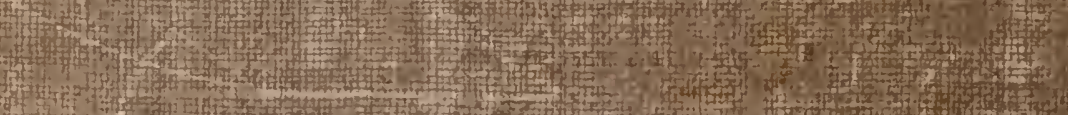
F.t.

If

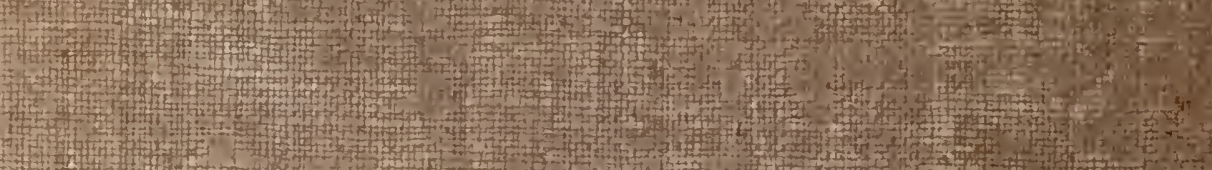
1.

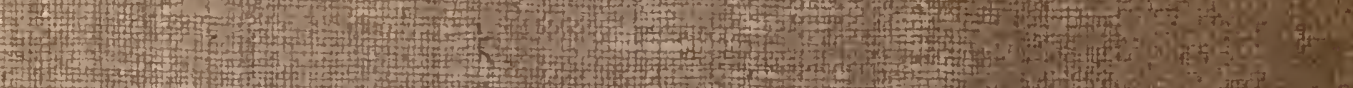

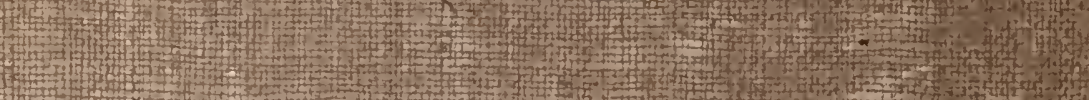

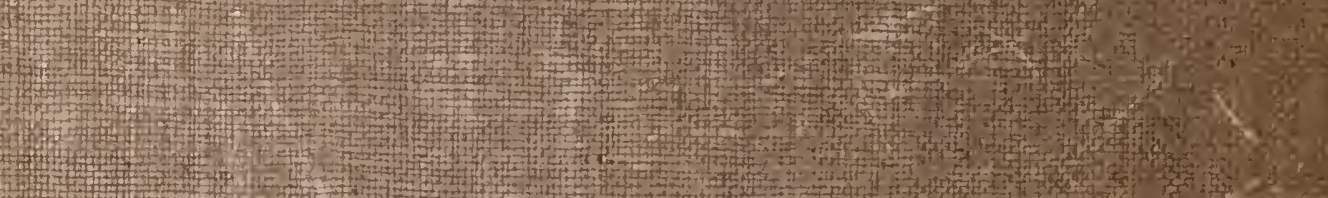
(1)

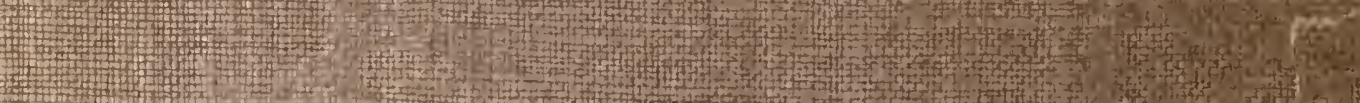

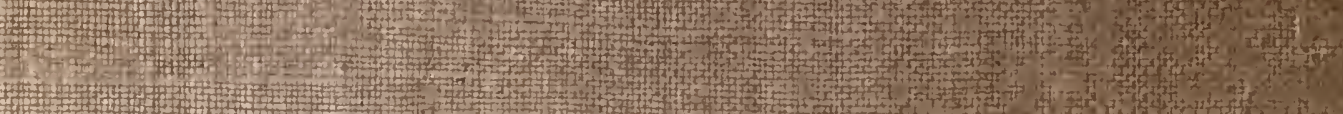

